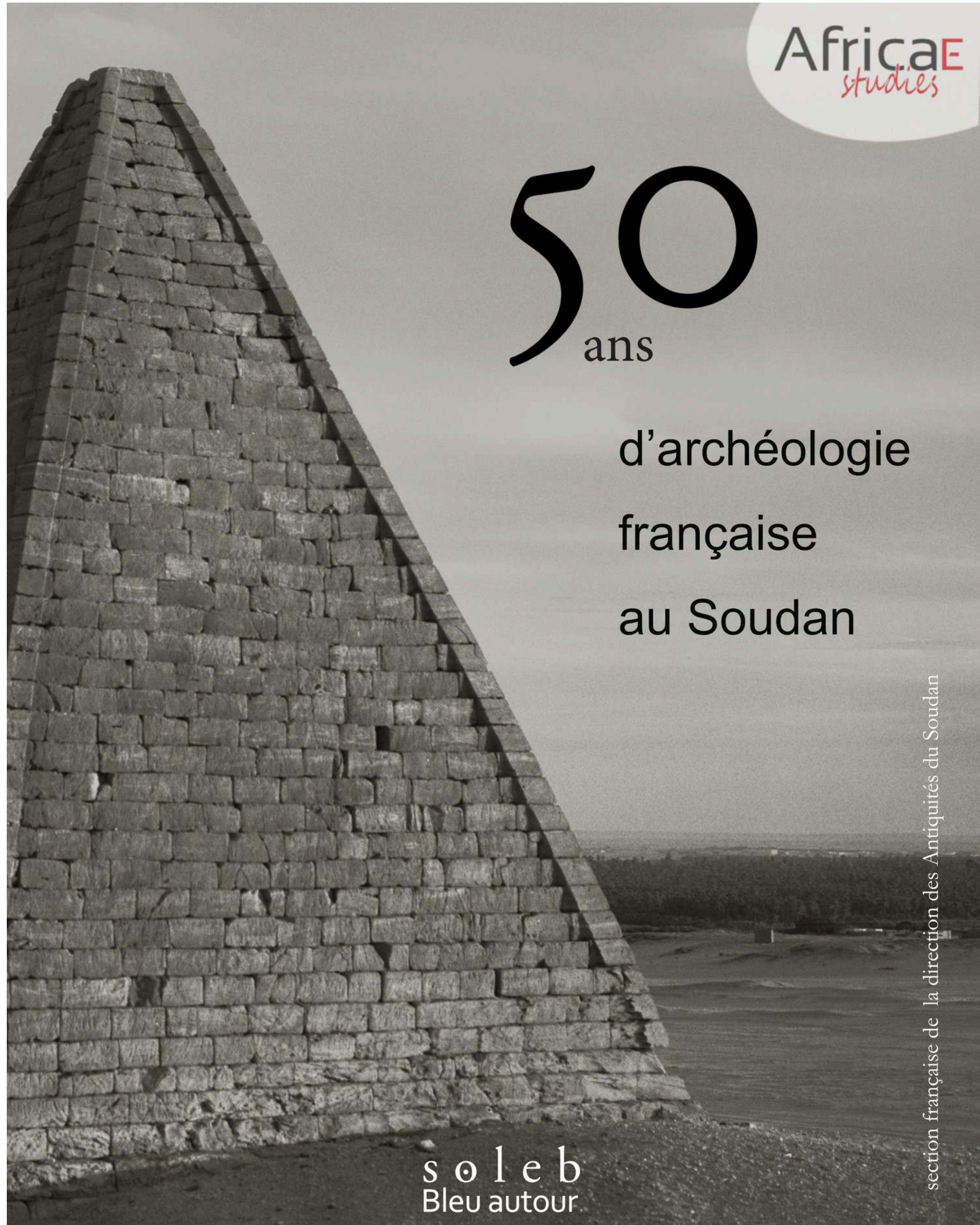




\section{Africae Africae}

\section{0 ans d'archéologie française au Soudan}

\section{Marc Maillot (dir.)}

DOI : 10.4000/books.africae. 3042

Éditeur : Africae, Soleb, Bleu autour

Lieu d'édition : Nairobi

Année d'édition : 2020

Date de mise en ligne : 17 janvier 2022

Collection : Africae Studies

EAN électronique : 9782493207081

\section{OpenEdition \\ Books}

https://books.openedition.org

Édition imprimée

EAN (Édition imprimée) : 9782358481847

Nombre de pages : 287

\section{Référence électronique}

MAILLOT, Marc (dir.). 50 ans d'archéologie française au Soudan. Nouvelle édition [en ligne]. Paris,

Khartoum : Africae, 2020 (généré le 28 janvier 2022). Disponible sur Internet : <http://

books.openedition.org/africae/3042>. ISBN : 9782493207081. DOI : https://doi.org/10.4000/

books.africae.3042.

(C) Africae, 2020

Conditions d'utilisation

http://www.openedition.org/6540 


\section{RÉSUMÉS}

Le Soudan est une passion française. Ses vestiges archéologiques, d'une beauté intemporelle, nourrissent en France une fascination de plus de deux siècles. Elle s'exprime par une étroite coopération dont le maître d'œuvre est depuis 1969 la Section française de la direction des Antiquités du Soudan (SFDAS).

Préfacé par Nicolas Grimal, professeur au Collège de France et membre de l'Institut, l'ouvrage retrace, en même temps que l'histoire du Soudan, ces cinquante années de recherches, de découvertes, de préservation et de valorisation d'un précieux patrimoine. Dû aux meilleurs spécialistes et riche de nombreuses cartes, d'illustrations rares et de photographies saisissantes de Claude Iverné, il présente les fouilles les plus édifiantes. Il est une somme, et un carnet de voyage aussi savant que plaisant.

\section{MARC MAILLOT (DIR.)}

Marc Maillot est chercheur-pensionnaire à la SFDAS, spécialiste de l'architecture et de l'urbanisme antique, rattaché au CNRS, à la Sorbonne et à l'Université centrale de Floride.

\section{NOTE DE L'ÉDITEUR}

Ce livre, coédité par Soleb et Bleu autour avec le soutien de la SFDAS, a paru originellement en 2021 en format imprimé et en PDF et epub interactif, dans la collection « Études d'égyptologie » dirigée par Nicolas Grimal, professeur au Collège de France. 

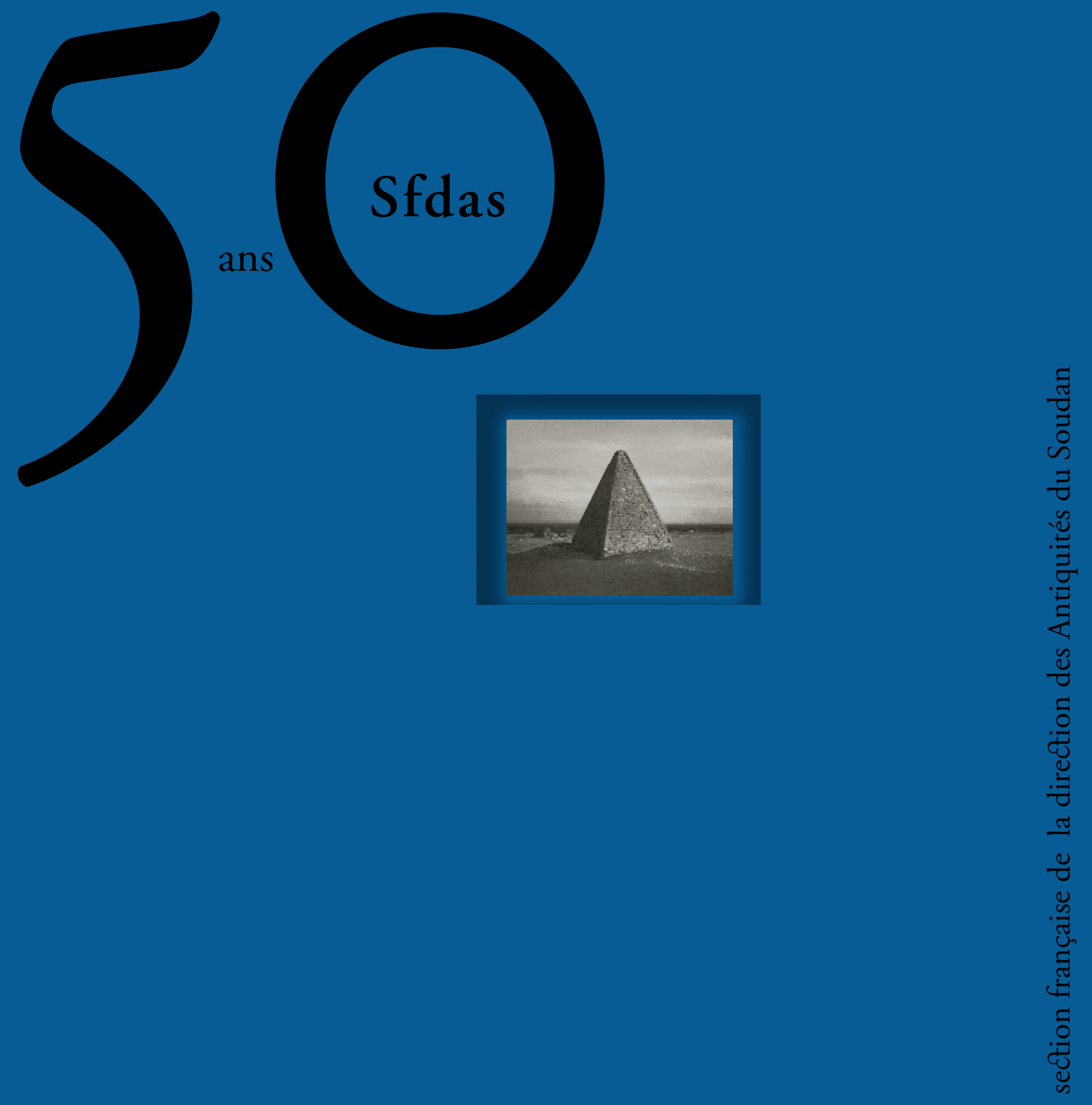

$\mathrm{s} \odot \mathrm{l} \mathrm{e} \mathrm{b}$ 
Ce fichier numérique est interactif: la table des matières, les appels de figures et le numéro placé au début de la légende de ces mêmes figures, les appels et les références des notes de fin de chapitre, les mentions des institutions et les différents logotypes peuvent être cliqués, de même que les éléments de la couverture, les titres de chapitre, etc. Les têtes de pages renvoient au sommaire et les pieds à la page précédemment vue. 



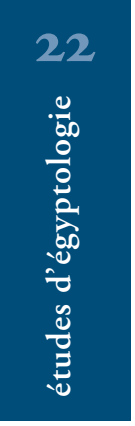

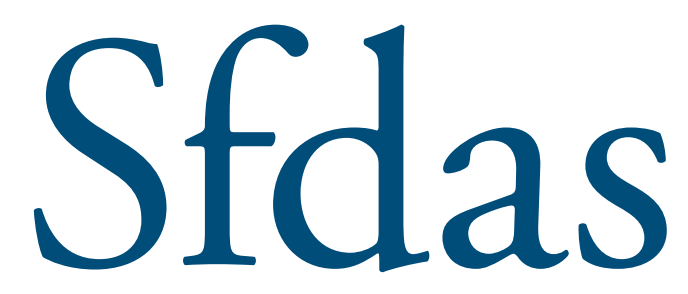

22 décembre

section française de la direction des Antiquités du Soudan

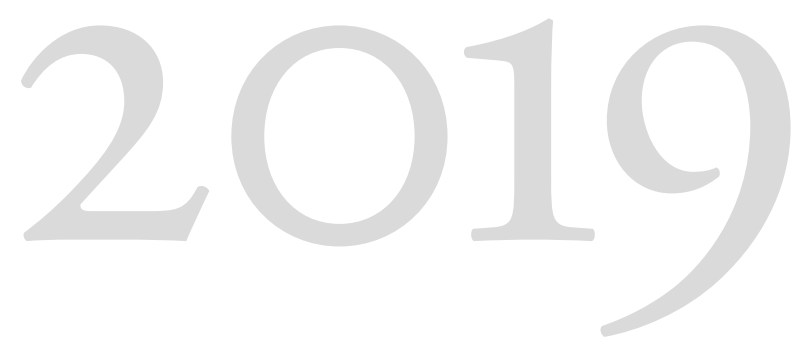

$s \odot \mathrm{leb}$

Bleu autour 


\section{In memoriam Jacques Reinold}

(Mâcon, 10 décembre 1944-Hourgada, 23 juin 2020)

El-Kadada, dans la région de Shendi, et Kadrouka, dans le district de Dongola, sont les deux toponymes du Néolithique de la vallée du Nil moyen auxquels Jacques Reinold, qui vient de nous quitter, aura attaché son nom de façon indélébile. Formé à l'archéologie préhistorique à Pincevent par André Leroi-Gourhan, à l'archéologie de sauvetage en Allemagne sur le plateau d'Aldenhoven et en Suisse dans la baie d'Auvernier, dans les équipes de Jens Lüning et de Michel Egloff, à la prospection archéologique enfin par André Vila dans le début des années 1970 et ses travaux au sud de la cataracte de Dal, Jacques Reinold était prêt et armé pour prendre la direction de la section française, qu'il occupa de 1984 à 2000 pour un mandat dont la durée et l'éclat sont encore dans les mémoires.

Longues campagnes, dans un Soudan qui n'était pas celui que nous connaissons aujourd'hui, régime spartiate que partageait sa femme Ulla et qu'ils adaptaient à tous leurs terrains, qu'il s'agisse des fouilles programmées néolithiques, de la reconnaissance de la région de la quatrième cataracte menacée par le projet d'un barrage désormais construit ou encore des prospections dans la concession des mines d'or de la compagnie Ariab...

Jacques Reinold fait incontestablement partie de ces savants de terrain dont l'action et la carrière auront profondément marqué un champ disciplinaire — le Néolithique nilotique lui doit beaucoup - mais également le pays dans lequel ils ont vécu $\square \mathrm{V}$. R.

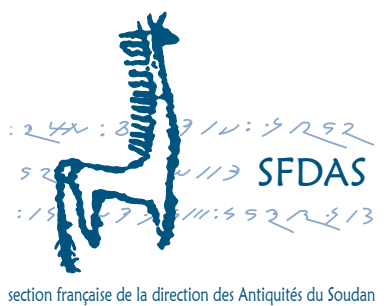



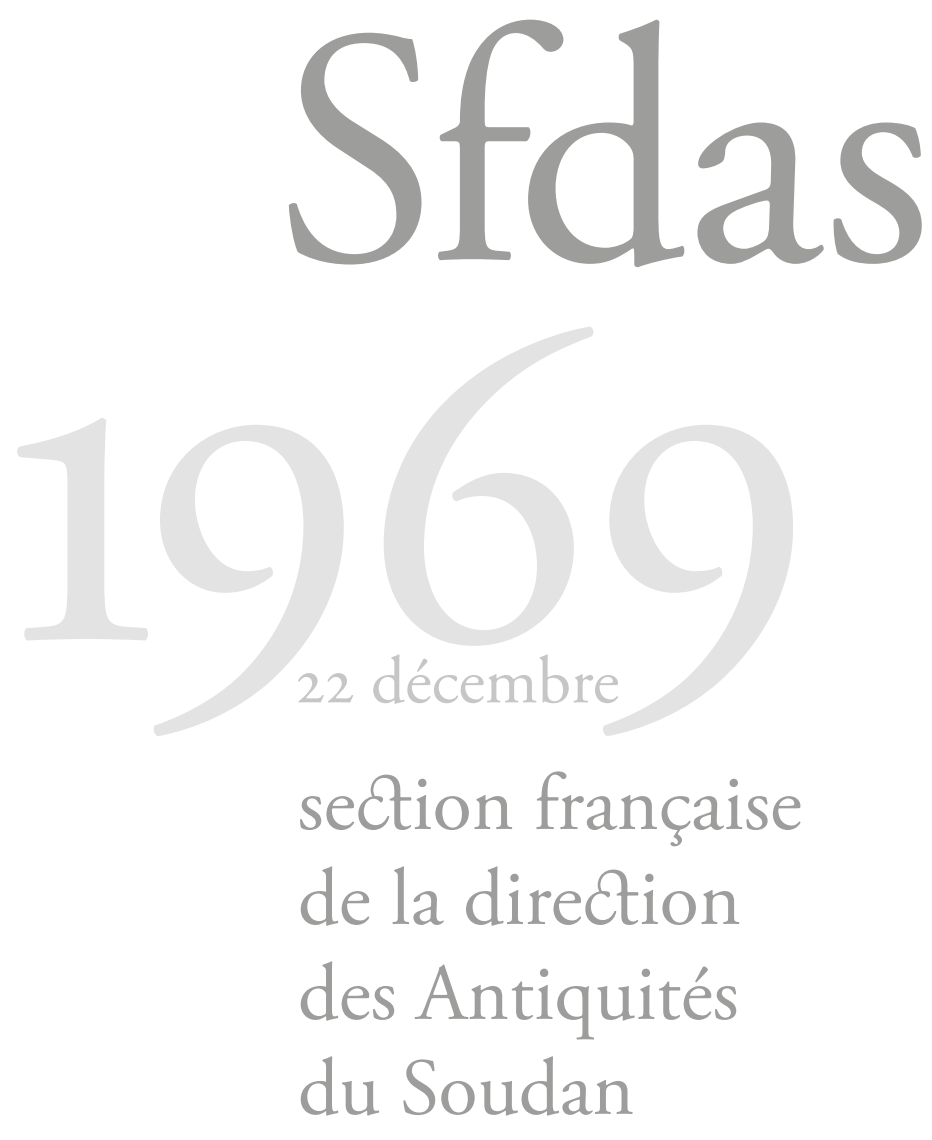

sous la direction

de Marc Maillot

Charles Bonnet

Philippe Chambon

Romain David

Faïza Drici

Hatim el-Nour Ogeil

Vincent Francigny

Nicolas Grimal

Claude Iverné

Elsa Jadot

Olivier Langlois

Séverine Marchi

Giorgio Nogara

Claude Rilly

Vincent Rondot

Manon Routhiau

Pascal Sellier

Joanna Then-Obłuska Gilles Tiberghien

Dominique Valbelle 
cinquante années de coopération exemplaire

Hatim el-Nour Ogeil

bien plus qu'une coopération archéologique et patrimoniale

Nicolas Grimal

\section{cartes}

carte générale du Soudan

22

de la préhistoire au royaume de Kerma

de la colonisation égyptienne à la fin de Méroé

24

de la chute de Méroé au royaume Fung

la mission archéologique française de Sedeinga

Claude Rilly

Saï, aux origines de l'archéologie franco-soudanaise 
Charles Bonnet, Séverine Marchi, Dominique Valbelle

trente-cinq ans d'archéologie préhistorique à Kadrouka

cimetières et habitats néolithiques dans une concession menacée

Olivier Langlois, Philippe Chambon, Pascal Sellier

el-Hassa 2000-2020

Vincent Rondot, Giorgio Nogara, Faïza Drici

un siècle de fouilles archéologiques au Soudan

Marc Maillot

Gereif Est et le Méroïtique méridional

Romain David, Elsa Jadot,

Manon Routhiau, Joanna Then-Obłuska

dans les ruines nubiennes du désert argentique

Gilles Tiberghien

photographies de Claude Iverné 



\section{cinquante années de coopération exemplaire}

Hatim el-Nour Ogeil 
La National Corporation for Antiquities and Museums a été créée dès 1905 et était alors placée sous l'égide du ministère de l'Éducation. En 1971, concomitamment à l'inauguration du musée national du Soudan, ses statuts ont changé. Désormais sous l'autorité du ministère de la Culture, la NCAM, riche d'une longue et féconde histoire, est responsable de l'archéologie et des musées du Soudan.

\section{une triple mission}

cinquantenaire

8

de la section

française

de la direction

des Antiquités

du Soudan

La NCAM a une triple mission et comprend autant de départements spécialisés. La première de ces missions concerne les activités de terrain: les surveys et les missions archéologiques; la supervision des fouilles entreprises par les missions soudanaises ou étrangères; la garde et la protection des sites sur lesquels se trouvent des vestiges archéologiques remarquables et de ceux sur lesquels des fouilles sont entreprises.

Cette mission est accomplie sous la direction des officiers et des inspecteurs des antiquités. Les sites sont surveillés par des gardes salariés par la NCAM et par la police des antiquités et du tourisme. (Citons, parmi les nombreux chantiers de fouilles en activité, Kerma-Doukki Gel, Saï, Sedeinga, el-Hassa, el-Kadada, Kadrouka... et, parmi les vestiges archéologiques remarquables, outre ceux déjà cités, Méroé dont les pyramides sont un des symboles du Soudan, Soleb, Kerma, Moussawarat es-Soufra, le Gébel Barkal, Nouri, Kourrou...)

La seconde mission a trait, notamment, au musée national du Soudan, qui est une structure intégrée à la NCAM. Les objets provenant des fouilles et entrant dans ses collections permanentes sont, le plus souvent, conservés pour étude dans les réserves; dès lors qu'ils sont particulièrement remarquables, ils peuvent être exposés de manière permanente ou présentés lors d'expositions temporaires; ils sont, enfin, susceptibles d'être mis en dépôt dans les différents musées régionaux ou d'être prêtés à l'étranger pour des expositions prestigieuses.

Cette mission englobe également l'administration des musées régionaux et la création de nouveaux musées dans toutes les provinces soudanaises. Ces créations visent à unifier les collections nationales et régionales en un seul "contexte», de manière à en assurer la cohérence sociale et à promouvoir, sous l'égide de la NCAM, un tourisme «responsable». Ces musées ont vocation à être spécialisés, par discipline: musée de la Monnaie, musée de l'Agriculture... La NCAM administre actuellement treize musées. Parmi les principaux, citons:

— Le musée d'Ethnographie, ouvert en 1956 dans les anciens locaux du club de l'armée britannique, sur la rue al-Gama’a, à Khartoum; 
— Le musée du Khalifa, créé en 1928, à Omdurman, dans la maison occupée par Abdullahi, successeur du Mahdi, non loin de l'emplacement de la tombe de ce dernier;

— Le musée de Sheikan, ouvert en 1965 à el-Obeid, au Kordofan, pour commémorer la bataille remportée en 1883 par les troupes du Mahdi sur celles du colonel britannique William Hicks, passé à la postérité sous le nom de Hicks Pacha;

— Le palais du sultan Ali Dinar, dernier souverain du Darfour, à el-Fashir, devenu résidence des gouverneurs britanniques puis transféré à la NCAM en 1971;

— Le musée de Kerma, inauguré en 2008, à la suite des fouilles de Charles Bonnet et qui présente un panorama de l'archéologie régionale depuis les premières occupations humaines jusqu’à la période actuelle.

La troisième mission de la NCAM concerne la conservation et la restauration des antiquités et des ouvres d'art. Le département des Restaurations travaille avec les missions archéologiques pour assurer la préservation des objets mis au jour et est engagé dans un contrôle et une remise en état permanents des sites et des monuments.

Ce département agit également en lien avec celui du musée national et assure la surveillance des objets conservés dans les réserves ou présentés de manière permanente. Il assure également, à la demande, la restauration des œuvres. Il travaille, de plus, en liaison étroite et fréquente avec de nombreuses institutions scientifiques étrangères dont il reçoit souvent les membres venus en mission d'étude.

\section{l'archéologie au Soudan}

La NCAM est, également, l'héritière d'une longue et riche histoire «archéologique», parfois mouvementée. "Monopolisées» dans les premiers temps par les égyptologues, les «études nubiennes» ont, à la suite des fouilles de sauvetage rendues nécessaires par la création du lac Nasser, connu un développement considérable et sont désormais une discipline à part entière de l'histoire et de l'archéologie.

Après James Bruce, «inventeur» des sources du Nil en 1772, et Burckhardt, venu en 1814, le Français Frédéric Cailliaud accompagne, entre 1820 et 1822, Ismail Pacha, "général des armées de son père Méhémet Ali». (Admirateur de Bonaparte, le vice-roi souhaite, comme celui-ci, donner une sorte de justification scientifique à son expédition coloniale en s'entourant de savants, le plus souvent français et parfois anglais.)

Il est presque immédiatement suivi par Linant de Bellefonds, qui s'est joint à l'expédition anglaise de Bankes. À Moussawarat es-Soufra, derrière la grande terrasse, sur le mur nord du complexe central, deux inscriptions 
en français et quasi identiques, perdues au milieu de la savane soudanaise, montrent bien la rivalité entre les deux savants: Louis Linant de Bellefonds, premier des deux explorateurs à avoir visité le site, se dit «mandé par l'Angleterre» et Frédéric Cailliaud, dont l'ironie est perceptible, déclare, lui, avoir été «mandé de la France».

Quelques années plus tard, vient le temps des aventuriers indépendants, dont le plus connu est un médecin italien: Giuseppe Ferlini. Venu en 1830 comme chirurgien-major de l'armée, mais bien décidé à trouver des trésors et à faire fortune, il déserte. À Méroé, il fait exploser sans scrupule certaines des pyramides avec de la poudre à canon. Dans la tombe de la reine Amanishakhéto, il trouve un petit chaudron rempli de bijoux qu'il vendra avec beaucoup de mal. Ces bijoux sont, en effet, très étranges aux yeux des spécialistes de l'art égyptien. Il faudra que l'égyptologue allemand Lepsius, de retour du Soudan, prouve qu'il s'agit bien de trésors méroïtiques et non de faux grossiers. Ces magnifiques bijoux sont alors achetés pour moitié par le roi de Prusse et pour moitié par le roi de Bavière et sont donc, aujourd'hui, répartis entre les musées de Berlin et de Munich.

En 1842, une expédition est placée par Frédéric-Guillaume IV, roi de Prusse, sous la direction de Carl Richard Lepsius, un des meilleurs égyptologues de son temps, parfois présenté comme le successeur de Champollion. Lepsius parcourt la vallée du Nil en Égypte et il remonte le fleuve jusqu'au cœur du Soudan, allant jusqu’à Méroé, et même un peu au-delà. (Champollion était venu de 1828 à 1829 à la tête d'une expédition envoyée par Charles X,

de la section

française

de la direction des Antiquités du Soudan roi de France, mais il s'était arrêté à la seconde cataracte.) Lepsius collecte un nombre impressionnant d'objets, ce qui explique que le musée de Berlin soit le plus riche d'Europe en antiquités soudanaises.

En 1846, avec l'accord de Méhémet Ali, vice-roi d'Égypte, un bâtiment revient chargé de 249 caisses contenant 1500 objets. La publication, entre 1849 et 1859, des douze volumes des Denkmäler aus Aegypten und Nubien («Monuments d'Égypte et de Nubie») va permettre aux savants de redécouvrir la région en présentant quantité de textes et de dessins beaucoup plus précis que ceux publiés auparavant. (Cailliaud en effet ne connaissait pas l'égyptien, alors que Lepsius était excellent égyptologue, d'où de meilleurs fac-similés.) Avec ces fameux Denkmäler, les savants disposent véritablement d'un matériel de grande qualité scientifique.

L'administration coloniale est soutenue par les Occidentaux, avec l'aide d'administrateurs souvent chrétiens, venus notamment du Liban ou de Syrie, mais également de Grande-Bretagne. Le poids des impôts levés sur le pays et l'occidentalisation croissante des Turcs explique la réaction des Soudanais contre ce gouvernement et l'établissement d'un pouvoir islamique pendant une douzaine d'années. 
Muhammad Ahmad ibn Abd Allah Al-Mahdi se révolte en 1881 et prend Khartoum le 26 janvier 1885, malgré la défense acharnée de Charles Gordon (qui est tué durant le combat). Le Mahdi meurt le 22 juin 1885 et son bras droit, Abdullahi, lui succède. Pendant la Mahdiyya (1885-1898), l'archéologie se trouve évidemment au point mort et toutes les missions scientifiques sont interrompues.

En 1884-1885, Horatio Herbert Kitchener avait fait partie de l'expédition qui avait échoué à sauver le général Charles Gordon. Sous sa direction, entre 1896 et 1898 , les Anglais s'emparent progressivement du Soudan et parachèvent leur conquête lors de la bataille d'Omdourman, au cours de laquelle plus de 15000 mahdistes, dans leur grande majorité équipés de lances, sont tués.

Kitchener met dès lors en place un nouveau pouvoir colonial, le "condominium anglo-égyptien", associant les deux pays. Les archéologues commencent à revenir. Ils sont essentiellement britanniques dans un premier temps, puis allemands. Les Français, quant à eux, se sont passionnés pour l'Égypte à la suite des découvertes de Champollion et sont en lutte avec les Anglais pour la constitution d'un Empire colonial: il faudra attendre longtemps pour qu'ils s'intéressent au Soudan. Tout cela explique que le British Museum possède des collections d'antiquités soudanaises importantes, mais pas le musée du Louvre.

Entre 1898 et 1956, l'administration britannique est la première à développer la gestion du patrimoine archéologique soudanais. Les Britanniques mettent également en œuvre, dès 1905, la première législation sur les antiquités, à la base de la loi actuelle, et, la même année, la National Corporation for Antiquities and Museums voit le jour. En 1939, enfin, un poste spécifique est créé, celui de Commissioner for Archaeology, assuré en premier lieu par Anthony John Arkell.

\section{des années de coopération scientifique}

Peu après la proclamation de l'indépendance, le 19 décembre 1955, les autorités soudanaises confient à un Français, Jean Vercoutter, la direction de la gestion des antiquités. C'est lui qui assurera la transition menant, en 1971, à l'occasion de l'inauguration du musée national du Soudan, à la redéfinition des missions de la National Corporation for Antiquities and Museums. Homme d'expérience au Soudan, il fouille dès 1953 la ville fortifiée de Kor, en Basse Nubie, datant du Moyen Empire, et lance en 1954 les premiers travaux sur l'île de Saï. Il est également très impliqué dans le sauvetage des antiquités menacées par le haut barrage d'Assouan. (Annoncé en 1954 par Gamal Abdel Nasser et mis en eau en 1973, ce barrage a amené 
la création du lac Nasser qui a noyé une large partie de la Nubie, forçant les populations à l'exil et entraînant la disparition d'un vaste patrimoine archéologique.)

Jean Vercoutter supervise plusieurs missions de prospection des zones en danger, la couverture photographique associée, et fait appel à la communauté internationale pour intégrer le Soudan à la grande campagne de l'Unesco. Nommé professeur à l'université Charles-de-Gaulle-Lille 3 en 1961, il engage l'institution dans la campagne de sauvetage des monuments de la Nubie. À l'époque, cette implication fait de l'université le centre névralgique de la recherche française en archéologie soudanaise, via l'association d'une unité du CNRs à l'institution et au lancement de deux fouilles archéologiques sur les sites d'Akcha et de Mirgissa. En 1969, la fin de la campagne de Nubie permet à Jean Vercoutter de concentrer ses travaux à Saï, mission qu'il dirigera jusqu'en 1981.

Dans le même temps, la section française de la direction des Antiquités du Soudan (Sfdas) est fondée en 1967, toujours à l'initiative de Jean Vercoutter. Régie par «l'Accord de coopération culturelle et technique entre le gouvernement de la République démocratique du Soudan et le gouvernement de la République française", signé à Khartoum le 22 décembre 1969, il y a cinquante ans, la Sfdas assure la coopération de la France et du Soudan, tant dans le domaine des fouilles que dans celui de leur publication. La muséographie, la conservation du patrimoine et l'élaboration de rapports d'activité font également partie de ses missions.

de la section

française

de la direction des Antiquités du Soudan

La Sfdas est, depuis la signature de cet accord, intégrée à la National Corporation for Antiquities and Museums - au sein, plus exactement, du musée national du Soudan. Cette position privilégiée lui permet d'apporter un soutien aux missions françaises et étrangères travaillant au Soudan et de développer des partenariats scientifiques et muséologiques. La Sfdas, étant le plus ancien et le plus important institut archéologique permanent au Soudan, occupe dès lors une position de fer de lance de la recherche scientifique française dans le pays. Au partenariat naturel avec la NCAM s'ajoutent des coopérations variées avec les établissements scientifiques français et les universités tant soudanaises qu'européennes. Avec l'appui de l'ambassade de France à Khartoum, elle permet à la diplomatie française d'entretenir durablement ses relations avec le Soudan.

Depuis cinquante ans, la Sfdas a été dirigée successivement par André Vila (1969-1975), Francis Geus (1975-1984), Jacques Reinold (19842000), Francis Geus (2000-2004), Vincent Rondot (2005-2009), Claude Rilly (2009-2014) et Vincent Francigny (2014-2019); depuis avril 2019 elle l'est par Marc Maillot qui y fut, auparavant, chercheur. C'est donc cinquante années de travail en commun et d'intégration fructueuse 
de la Sfdas au sein de la NCAM que nous célébrons cette année; cinquante années de relations fécondes et amicales; cinquante années au cours desquelles de nombreuses découvertes ont été effectuées et ont complété, ou remis en question, nos connaissances dans les domaines de l'archéologie et de l'histoire.

Je suis heureux qu'à l'occasion de ce cinquantenaire sorte le présent ouvrage qui manifeste de manière éclatante l'apport de la Sfdas à l'archéologie du Soudan et la coopération exemplaire entre nos deux pays. Je suis également heureux de rappeler qu'à cette même occasion est parue la version numérique - diffusée gratuitement à travers le monde d'Histoire et civilisations du Soudan, de la Préhistoire à nos jours, ouvrage publié en 2017 avec l'appui de la Ncam et de la Sfdas et qui a fait date. Je ne doute pas que réussiront à en être publiées, un jour prochain, les traductions en arabe et en anglais que le Soudan et la communauté scientifique internationale appellent de leurs vœux 



\section{bien plus}

qu'une coopération

archéologique

et patrimoniale

Nicolas Grimal 
cinquantenaire

\section{6}

de la section

française

de la direction

des Antiquités

du Soudan
La coopération archéologique et patrimoniale développée par la France au Soudan est, à plus d'un égard, exemplaire. Elle a su, depuis l'indépendance du pays déclarée fin 1955, prendre sans à-coups le relais de l'administration britannique - qui avait créé, un demi-siècle plus tôt, les cadres généraux, non seulement de l'archéologie, mais, plus généralement, de la gestion du patrimoine historique du pays.

Le début des années cinquante marque un tournant dans l'étude et la protection des civilisations antiques de la vallée du Nil. Au Soudan, le départ de l'administration britannique provoque un mouvement comparable à celui qui porta les Français à administrer les antiquités d'Égypte dans le dernier quart du $\mathrm{xIX}^{\mathrm{e}}$ siècle, un peu pour la même raison. S’y ajoutait, pour l'Égypte, naturellement, l'antériorité de la découverte de Champollion et des travaux qui s'ensuivirent, dans la lignée de l'expédition de Bonaparte. Cette suprématie française dans la gestion des antiquités et du patrimoine ne survécut pas longtemps à la révolution nassérienne et laissa la place à une gestion purement nationale au cours de ces mêmes années cinquante, ramenant les Français au même niveau que les autres nationalités intervenant en Égypte.

Sans qu'il y ait eu de remplacement de l'un des terrains par l'autre, ce sont essentiellement des égyptologues qui se sont tournés vers le Soudan, apportant les stratégies et les problématiques de recherches qu'ils mettaient déjà en œuvre au nord de la première cataracte. L'archéologie du Soudan a donc été, dans les premiers temps, très semblable à celle d'Égypte, s'attachant de préférence aux sites monumentaux et aux nécropoles contemporaines des pharaons. Mais la réalité de la longue histoire du pays s'est imposée rapidement: les méthodes d'investigation des préhistoriens, associées aux techniques de laboratoire, ont permis une évaluation plus fine des sociétés réellement autochtones, des plus hautes origines aux riches témoignages chrétiens et médiévaux.

Dans ce curieux chassé-croisé, c'est, dans les deux cas, la personnalité d'un homme qui a permis d'ancrer ce choix politique dans la réalité. En Égypte, ce fut Auguste Mariette; au Soudan, Jean Vercoutter. L'un comme l'autre créèrent le service des Antiquités et surent l'asseoir sur des bases scientifiques et humaines profitables aux deux parties.

Pour ce qui est du Soudan, enfin, un autre événement fut déterminant: la décision prise par Gamal Abdel Nasser en 1954 de faire construire le haut barrage d'Assouan, qui devait, vingt ans plus tard, amener les eaux du Nil à noyer toute la Basse Nubie. Fort de son expérience du terrain et des contacts qu'il avait noués avec ses collègues d'autres pays, Jean Vercoutter sut concentrer les énergies sur les objectifs de la campagne de sauvetage des monuments de Nubie menée par l'Unesco: il permit de 
réaliser, en particulier, des surveys, moins spectaculaires peut-être que les démontages et déplacements des grands temples, mais tout aussi fondamentaux. Au cours de ces vingt années, le réseau scientifique se resserra ainsi, et le nombre de missions archéologiques augmenta, si bien qu'en 1967 la section française de la direction des Antiquités du Soudan fut créée; son existence fut ratifiée, deux ans plus tard, dans le cadre de l'accord de coopération entre la France et le Soudan, signé en décembre 1969.

Partie prenante de la National Corporation for Antiquities and Museums, elle joue depuis un rôle central dans toutes les activités archéologiques et patrimoniales du pays, mais également dans la publication des divers travaux réalisés. Bien souvent intermédiaire avec les missions étrangères, forte de la confiance toujours renouvelée des autorités soudanaises, elle joue pleinement son rôle de recherche et de formation, en coordination avec les services culturels et de coopération de l'ambassade de France à Khartoum et forte de l'appui de la direction des Sciences humaines et sociales du ministère de l'Europe et des Affaires étrangères.

La Sfdas, en effet, fait partie aujourd'hui du réseau des vingtsept Instituts français de recherche à l'étranger (Umifre), placés sous la tutelle du ministère de l'Europe et des Affaires étrangères et du Centre national de la recherche scientifique. Ses liens étroits avec le monde universitaire, jusque récemment plus particulièrement avecl'universitéLille-III-Charles-de-Gaulle (où avait été créée pour Jean Vercoutter en 1961 une chaire d'égyptologie et de papyrologie), mais également son orientation vers l'archéologie soudanaise — aujourd'hui avec l'UMR 8167 "Orient \& Méditerranée», basée à la Sorbonne -, lui permettent une action continue entre coopération et formation, et ce dans tous ses domaines d'activité.

Vincent Francigny, directeur de la Sfdas de 2014 à 2018 et désormais rattaché à cette équipe, a repris la direction des fouilles de Saï en 2015, avec l'appui de la Commission consultative des fouilles française à l'étranger du ministère de l'Europe et des Affaires étrangères. Celle-ci s'implique également directement dans d'autres missions, qui travaillent en relation avec la Sfdas: la mission archéologique de Sedeinga, dirigée par Claude Rilly, lui aussi directeur de la Sfdas de 2009 à 2014, également la mission de Kerma/Doukki Gel, fondée par Charles Bonnet, membre de l'Institut, et dirigée aujourd'hui sur le terrain par Séverine Marchi. — Tout cela sans compter la mission du Louvre sur les sites de Mouweiss puis d'el-Hassa ou les activités de l'antenne de Khartoum du Cedej, qui travaille sur le monde contemporain en étroite collaboration avec la Sfdas.

Le but de cette courte évocation n'est pas de retracer l'histoire de la Sfdas, présentée dans cet ouvrage par Hatim el-Nour Ogeil, mais plus de tenter de mettre en lumière son rôle dans l'action diplomatique d'influence 
cinquantenaire

\section{8}

de la section

française

de la direction des Antiquités du Soudan de notre pays. Le Soudan a été pendant longtemps tenu à l'écart de la scène politique internationale: à cause de son histoire récente et des conflits qu'elle a générés, jusqu'à la partition du pays en deux, mais également à cause des liens établis par ses gouvernements successifs, volontairement ou non, avec l'islam le plus radical. C'est ainsi que de grands États, au premier rang desquels les États-Unis d'Amérique, mais suivis par de nombreux autres, l'ont mis au ban des relations internationales et coupé, en particulier, de certains programmes d'aide humanitaire, culturelle et sociale. Une fois de plus, la population civile a eu à souffrir des choix politiques de ses dirigeants. La révolution commencée en décembre 2018 semble avoir inauguré une nouvelle ère - en tout cas, elle permet au moins à la société civile d'exister dans le système politique. Ces mouvements, nés avec les "printemps arabes", de 2010 à 2012, ont connu des succès divers, même si la révolution naissante au Liban montre clairement qu'il y a des limites au soutenable...

Face à de telles situations, les exhortations politiques sont certainement de moindre poids que l'aide apportée aux pays pour comprendre, protéger et valoriser ce qui les définit bien mieux que les théories politiques: leur patrimoine historique et culturel, bien plus profondément enraciné que les idéologies. En cela aussi et surtout, la coopération que notre pays mène à travers son réseau scientifique est exemplaire: la Sfdas y joue avec brio son rôle dans cette partie du monde où les tensions sont si fortes et la solidarité internationale bien rare 
L'édition du cinquantenaire de la Sfdas est la conclusion naturelle d'une semaine de célébrations qui se sont tenues du 15 au 19 septembre 2019, au Musée national du Soudan et à l'institut français: exposition des photographies de la série «archéologique» de Claude Iverné, cycle de conférences des anciens directeurs de la Sfdas, conférence de presse au Musée national à l'occasion de la remise officielle aux autorités soudanaises du panneau de Soleb, de la stèle de la dame Ataqelula de Sedeinga et du relief de la candace du temple à Amon d'el-Hassa, qui ont bénéficié tous trois de programmes de restauration.

La Sfdas souhaite remercier l'ensemble des contributeurs de ce volume, tant pour leur expertise et leur ténacité sur le terrain de la vallée du Nil Moyen, que pour leur disponibilité à toute épreuve quant aux différents travaux de la Sfdas au sein desquels ils sont impliqués. Cet ouvrage, qui vient couronner un demi-siècle de coopération scientifique entre la France et le Soudan, repose sur leur action et sur leur dévouement, dont la Sfdas se veut être à la fois l'écrin et l'avant-poste. Il a été rendu possible grâce à des contributions cruciales, en premier lieu desquelles la fondation Michela-Schiff-Giorgini, la section française de la direction des Antiquités du Soudan (Sfdas), et l'UsR 3336 Afrique du CNRs. Il convient de rappeler à cette occasion le rôle fondamental joué par les Umifre, les Instituts français de recherche à l'Étranger : naviguant au plus près des communautés scientifiques internationales, ils sont les fers de lance de la recherche française dans leurs zones géographiques respectives.

Louvrage jubilaire de la Sfdas a également reçu le soutien du ministère de l'Europe et des Affaires étrangères, de la National Corporation for Antiquities and Museums (NCAM) et du musée national du Soudan, du Collège de France, du musée du Louvre, de l'Université centrale de Floride, de l'Ambassade de France à Khartoum et de l'Institut français du Soudan, et a été publié avec le concours de l'Institut français d'Archéologie orientale (Ifao) et du Centre national de la Recherche scientifique (CNRs), laboratoire UMR 8167, Orient et Méditerranée.

Enfin, la Sfdas remercie chaleureusement Abdelrahman Ali et Hatim el-Nour Ogeil, respectivement ancien et nouveau directeurs de la NCAM, pour leur appui constant et leur aide précieuse au sein de l'administration soudanaise. Ce goût du temps long et de la mémoire partagée donne souffle et chair à cette édition du cinquantenaire de la Sfdas, dont j'ai l'honneur d'être le gouvernail temporaire en cette période toute particulière

Marc Maillot directeur de la Sfdas Khartoum, 16 août 2020 

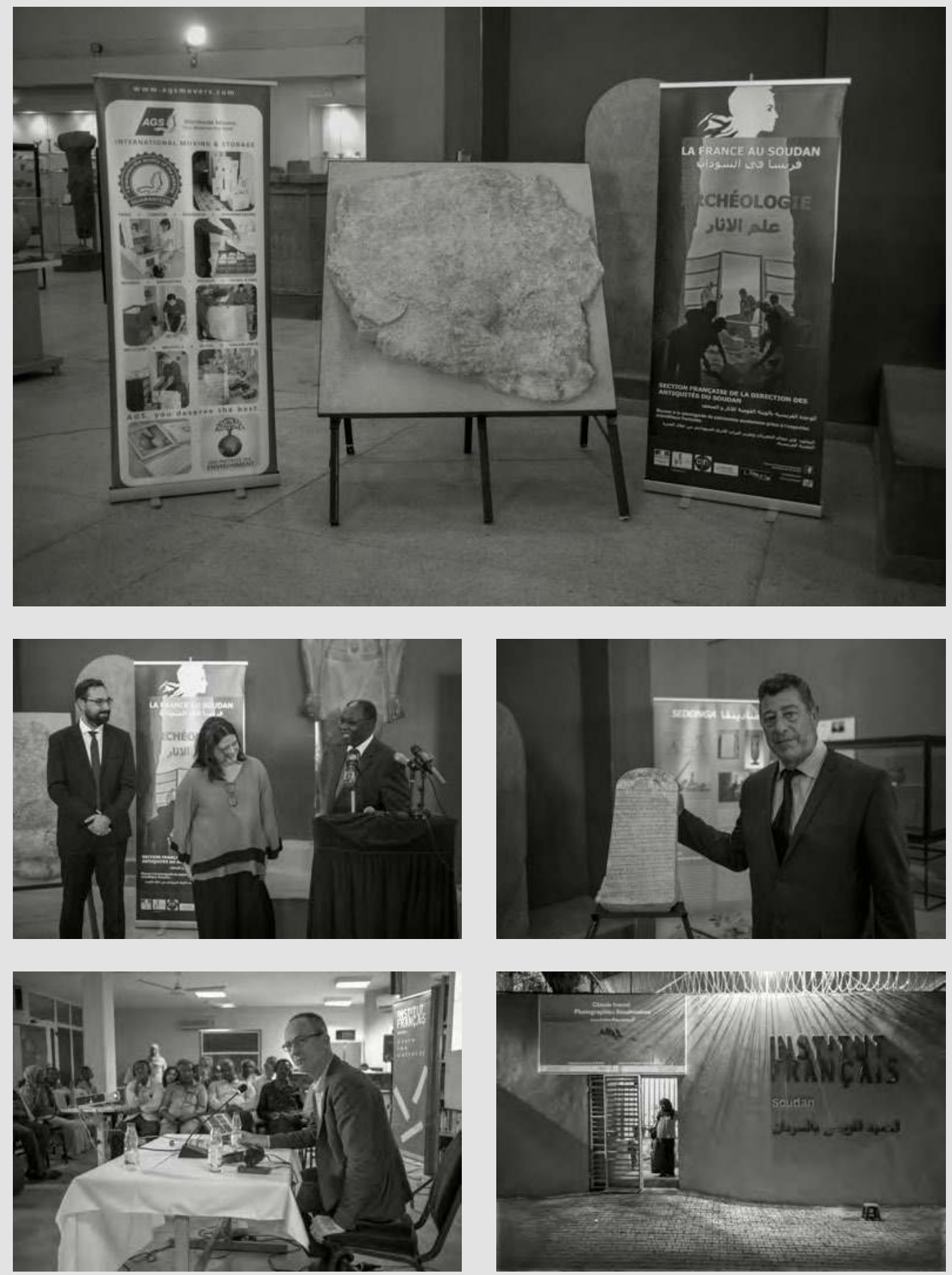

Du 15 au 19 septembre 2019, au Musée national du Soudan et à l'Institut français: remise officielle aux autorités soudanaises du panneau de Soleb, de la stèle de la dame Ataqelula de Sedeinga et du relief de la candace du temple à Amon d'el-Hassa, qui ont bénéficié de programmes de restauration en France; cycle de conférences des anciens directeurs de la Sfdas et exposition de la série «archéologique » de Claude Iverné. 


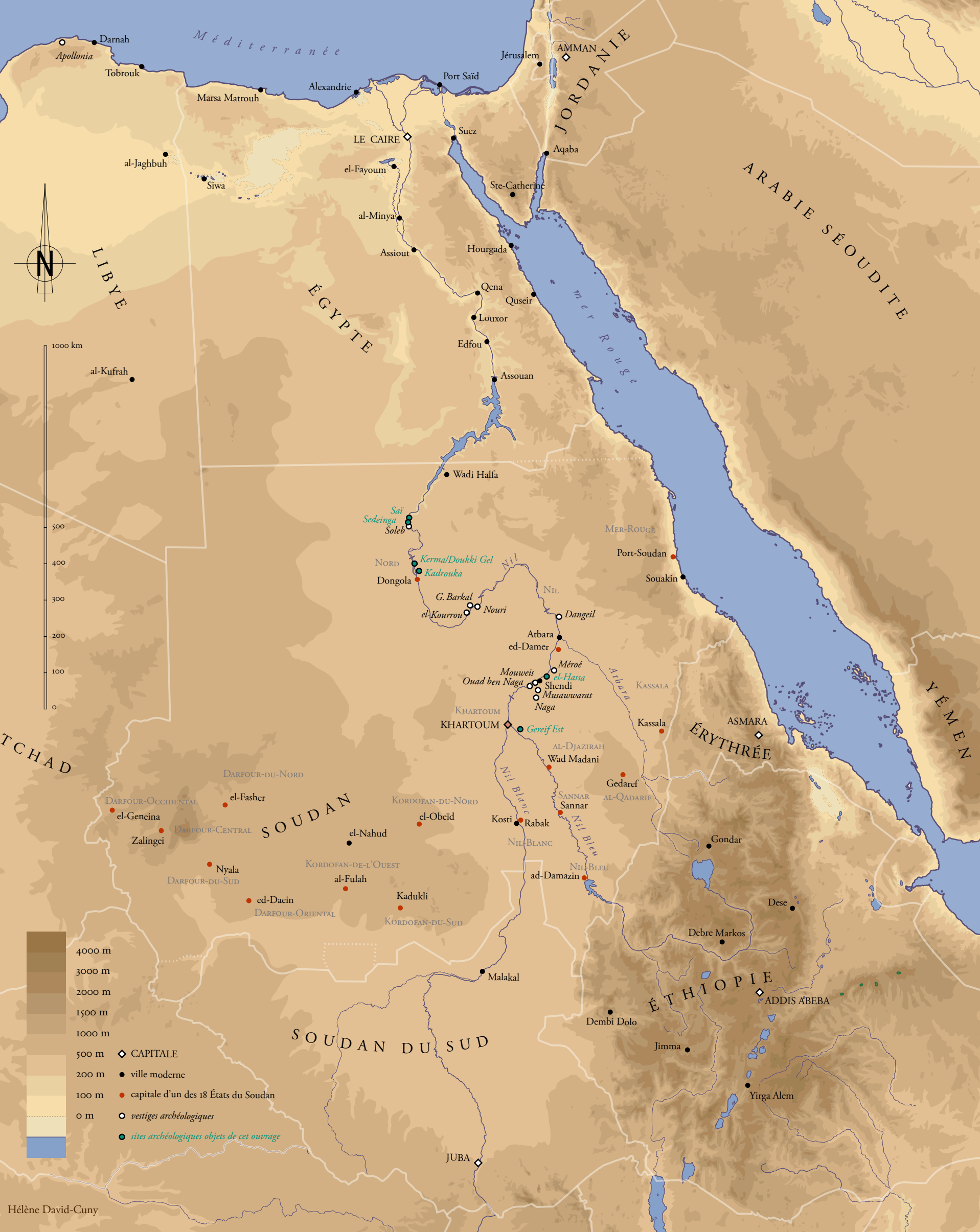




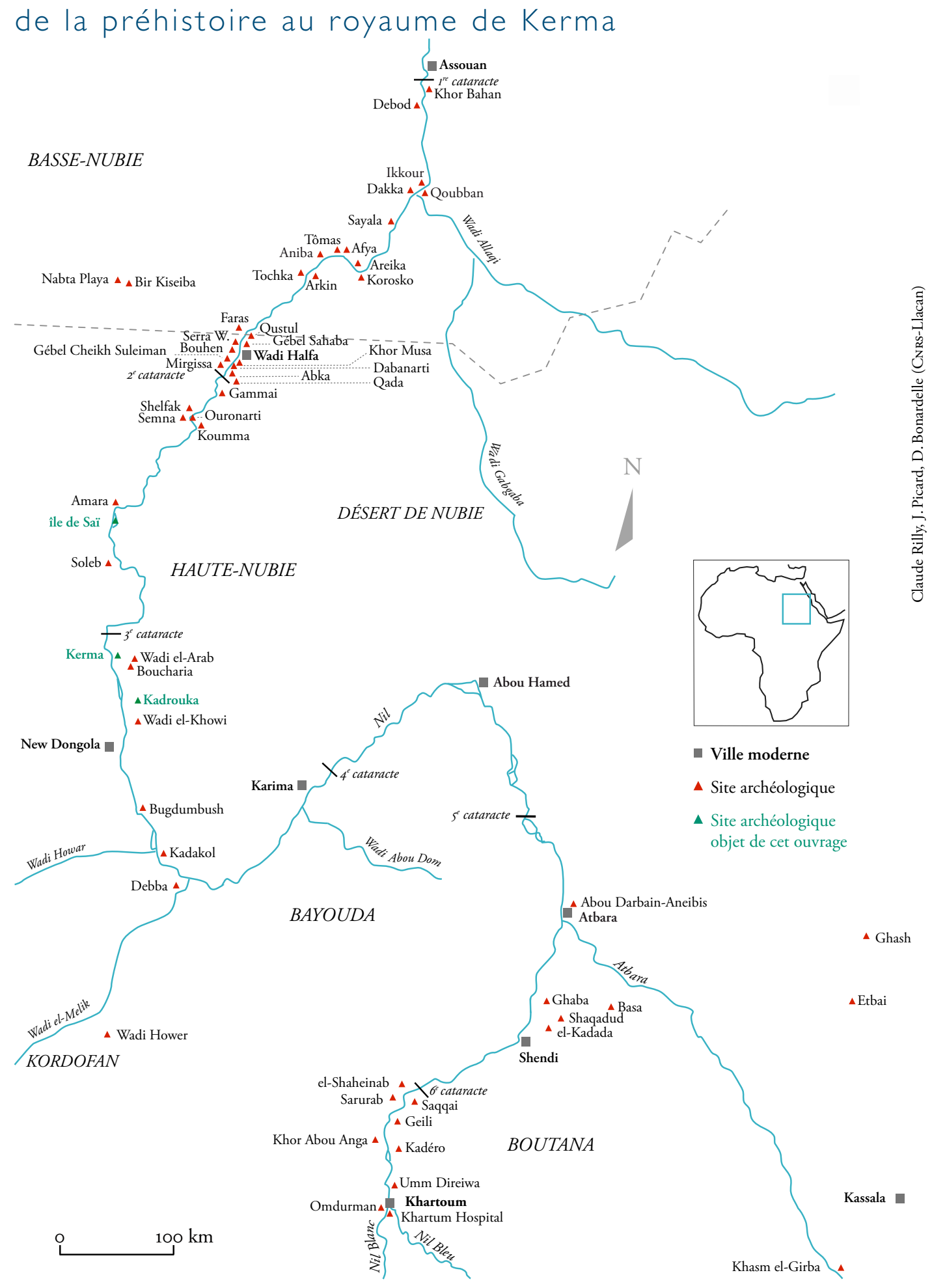




\section{de la colonisation égyptienne à la fin de Méroé}

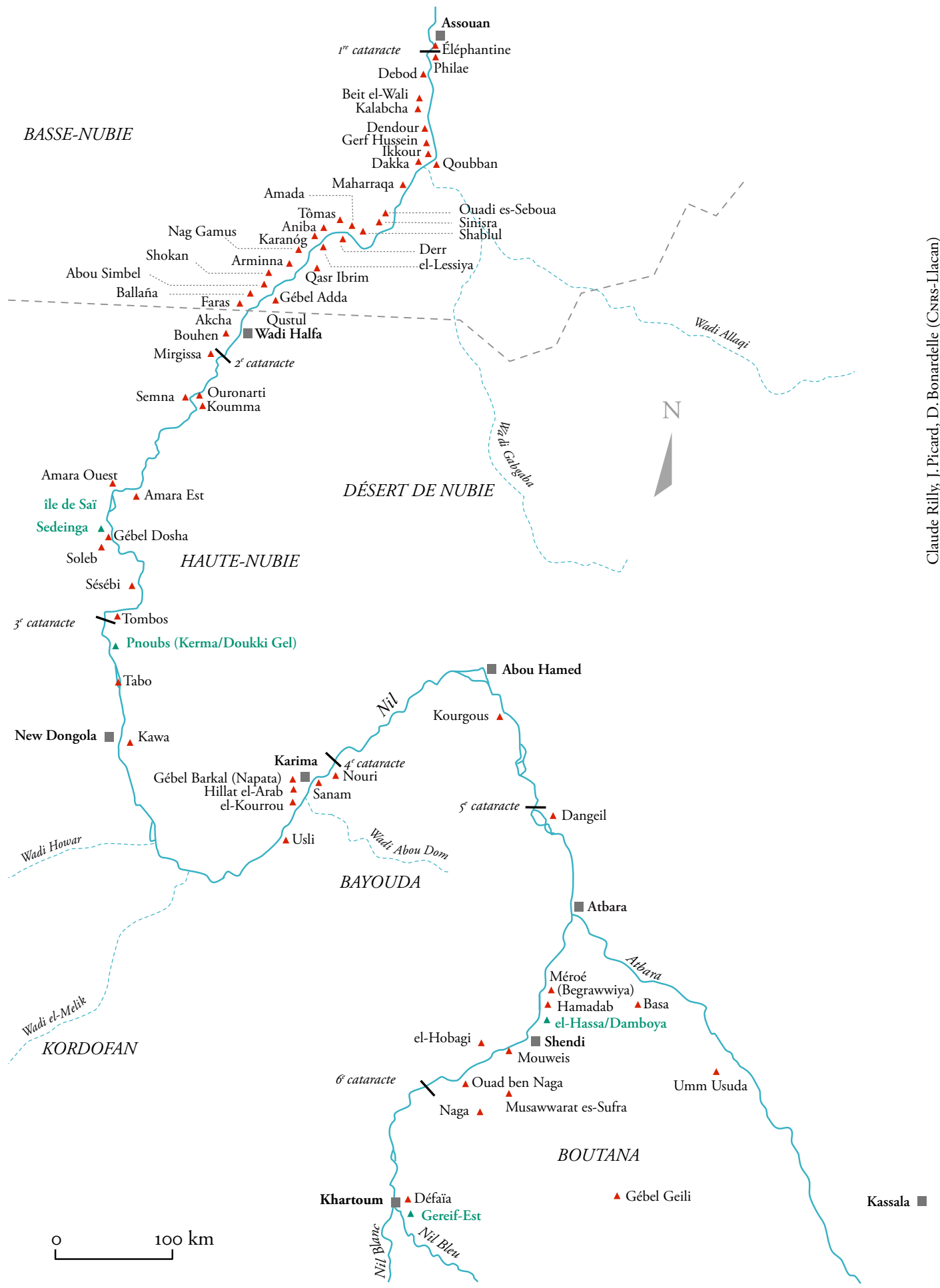




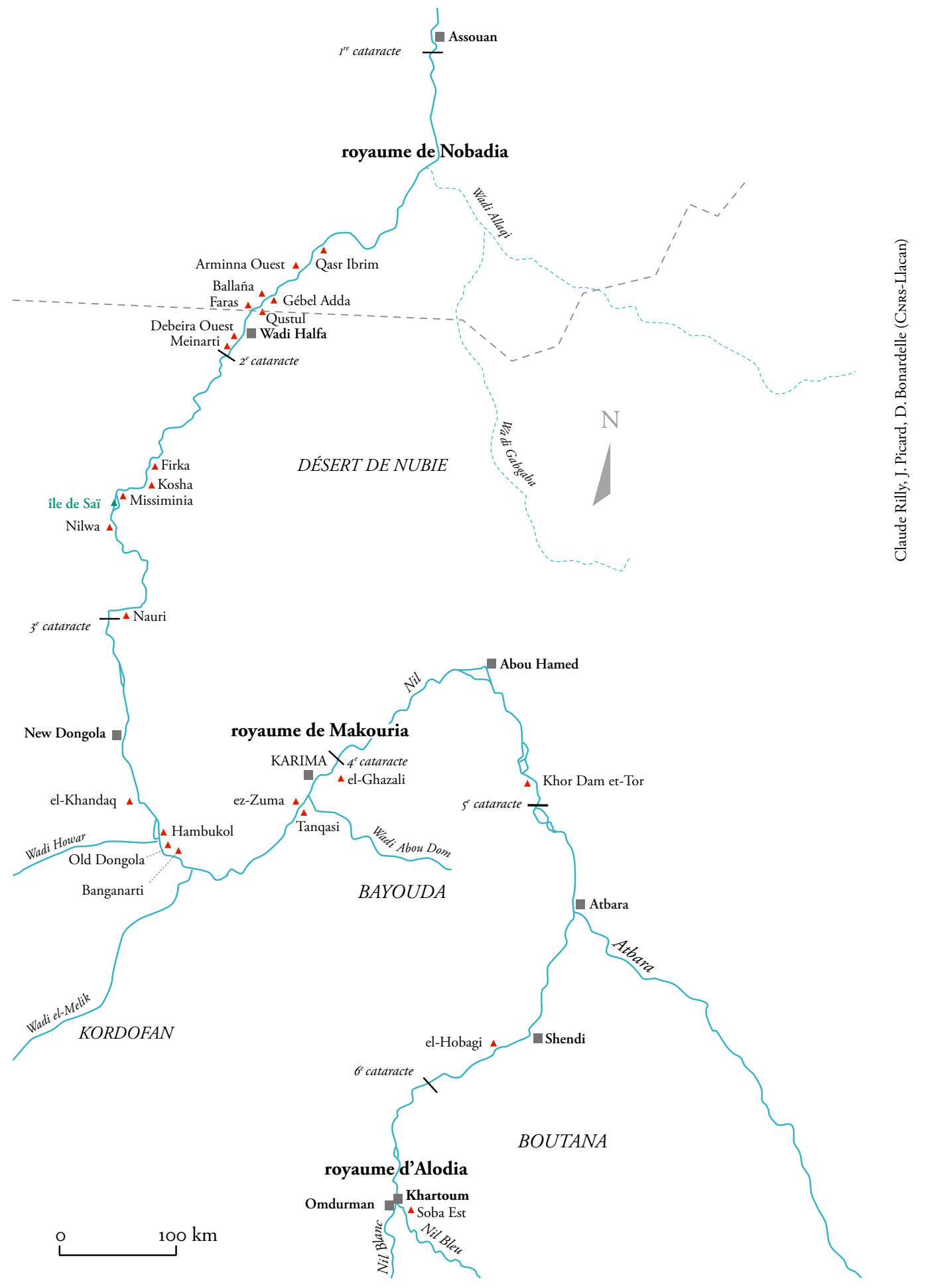



la mission

archéologique

française

de la reine Tiyi aux dames de Nubie

de Sedeinga

Claude Rilly 


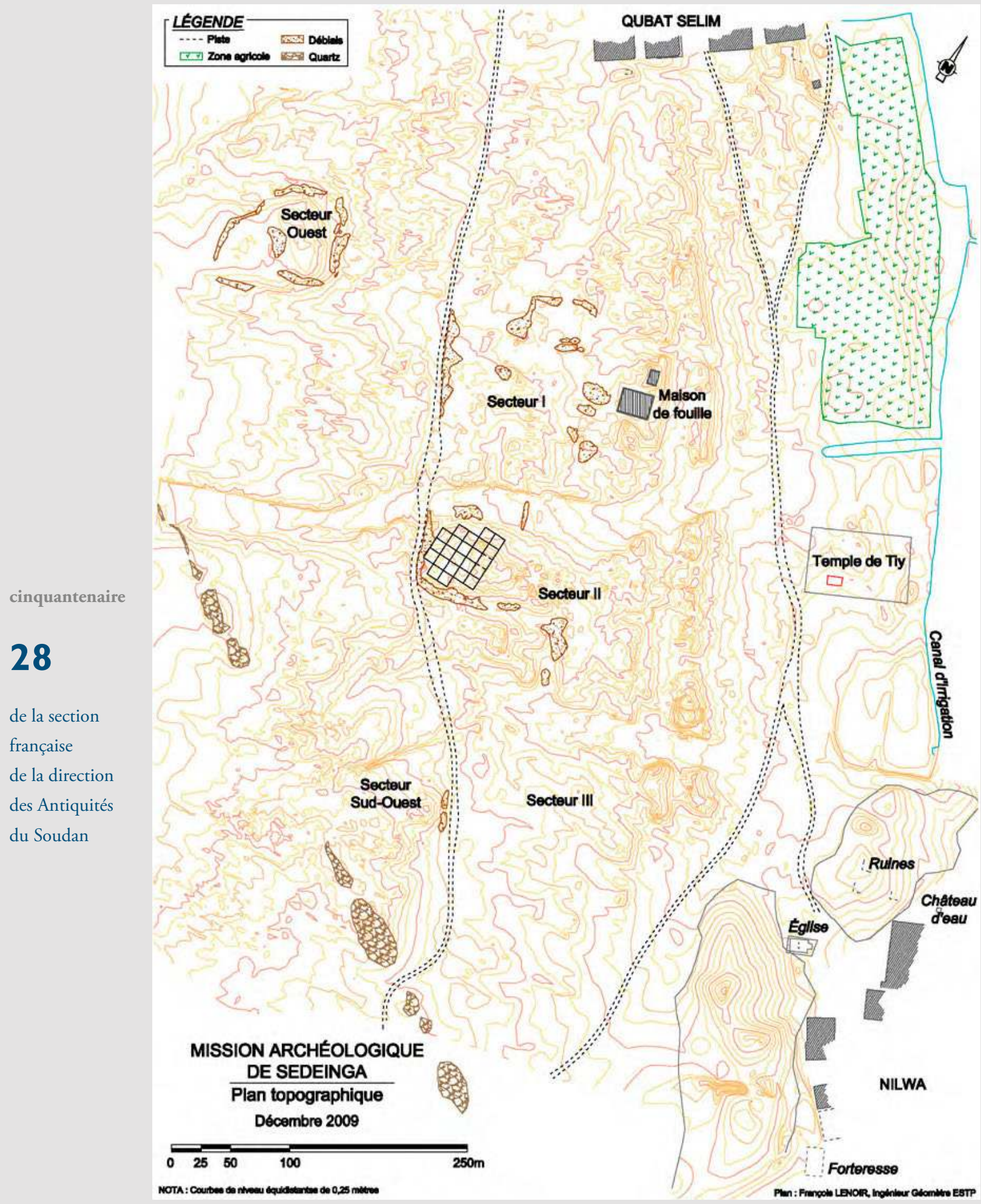

1. Carte topographique du site archéologique (SEDAu/Fr. Lenoir). 
La mission française de Sedeinga figure parmi les plus anciens chantiers archéologiques en activité au Soudan, puisque les fouilles y ont commencé il y plus de cinquante ans, en 1963. Trente-neuf campagnes y ont été menées depuis lors, dont trente-quatre sur la nécropole napatoméroïtique et récemment cinq sur le temple égyptien de la reine Tiyi. Bien qu'elle n'ait appartenu aux fouilles programmées de la Sfdas qu'épisodiquement, lors de la vacance de la mission néolithique de Kadrouka de 2009 à 2013, elle a continué par la suite à bénéficier d'un soutien logistique régulier de notre institut archéologique à Khartoum, qui vient de fêter son cinquantenaire. À cette occasion, je voudrais remercier les directeurs de la Sfdas qui m’ont précédé ou succédé, MM. †Jacques Reinold, †Francis Geus, Vincent Rondot, Vincent Francigny et Marc Maillot pour l'aide précieuse qu'ils ont apportée à la mission de Sedeinga.

Sedeinga n'a certes été qu'une petite fondation égyptienne sous la $\mathrm{XVIII}^{\mathrm{e}}$ dynastie et, plus tard, une capitale régionale du royaume koushite, mais ses vestiges occupent une place de premier plan dans l'histoire ancienne de la vallée du Nil. Les reliefs du temple égyptien de la reine Tiyi, si érodés soient-ils, apportent avec ceux de Soleb un éclairage de grand intérêt sur les prémices d'une nouvelle théologie royale. Elle aboutira lors du règne suivant à la révolution religieuse d'Akhénaton. Quant à la nécropole de l'époque napato-méroïtique, elle constitue le lieu d'inhumation le plus riche d'enseignements sur cette période, depuis que le barrage d'Assouan, en 1964, a ennoyé les cimetières de Karanóg et de Faras. Malgré les pillages répétés dont elle a été la victime, elle recèle encore un extraordinaire mobilier funéraire - stèles et tables d'offrandes inscrites, éléments de chapelles décorés, statues-ba, couronnements de pyramides, céramiques peintes ou estampées, vaisselles d'apparat et bijoux d'importation —, qui n'a pas d'équivalent ailleurs au Soudan. Elle présente également des structures architecturales bien conservées et inédites qui posent de nombreuses questions mais apportent aussi des données nouvelles sur les croyances funéraires des habitants de la Nubie antique.

\section{Historique des fouilles de Sedeinga}

Sedeinga est située en Nubie soudanaise, à $200 \mathrm{~km}$ au sud de la frontière égyptienne et $700 \mathrm{~km}$ au nord de Khartoum, entre les villages de Qubbat Selim au nord et de Nilwa au sud. Le site archéologique (fig.1) est coupé par deux pistes parallèles au Nil, la piste haute étant celle par où transitaient jusque récemment les caravanes de dromadaires. Entre ces pistes s'étend l'immense nécropole napato-méroïtique, sur près de 25 ha. Elle est traversée d'ouest en est par deux oueds asséchés perpendiculaires au Nil, qui isolent 
trois zones, dénommées du nord au sud secteurs I, II et III. À l'ouest du secteur I, de l'autre côté de la piste haute, s'élève une petite butte, dite "secteur ouest", qui a accueilli les sépultures des princes locaux à l'époque méroïtique. À l'opposé, vers le Nil, de l'autre côté de la piste basse, s'élèvent les ruines du temple de la reine Tiyi.

À $14 \mathrm{~km}$ au sud se trouve le temple de Soleb, bâti sous Amenhotep III, l'époux de Tiyi. Les deux monuments avaient été décrits par les voyageurs occidentaux depuis Frédéric Cailliaud et étudiés en détail par l'égyptologue C. R. Lepsius dans ses Denkmäler aus Ägypten und Äthiopien. Mais, jusqu'en 1957, ils étaient restés vierges de toute opération archéologique. Cette année-là, une jeune Italienne issue d'une riche famille pisane, Michela Schiff-Giorgini, en obtint la concession de la part du service des Antiquités du Soudan (Ncam) nouvellement créé. Tombée amoureuse de la Nubie lors d'un séjour thérapeutique en Égypte, elle consacra une partie de sa fortune et vingt ans de sa vie à documenter, fouiller et restaurer le temple de Soleb. Elle s'entoura de spécialistes français, l'archéologue Clément Robichon et l'égyptologue Jean Leclant. Lorsque les deux premiers volumes de la publication de Soleb furent achevés, en 1963, l'équipe divisa son travail entre Soleb et Sedeinga.

\section{0}

de la section

française

de la direction des Antiquités du Soudan

Le temple de Tiyi, qui n'était plus qu'un amas de ruines surmonté d'une unique colonne encore debout (fig. 2), fit l'objet de quelques relevés et d'une consolidation du chapiteau. L'intérêt se porta plutôt sur les vestiges de la nécropole méroïtique, dont des éléments de grès affleuraient çà et là. Les premières missions, en 1963-1965 et en 1970, se concentrèrent sur le secteur ouest, où furent exhumées douze pyramides ayant appartenu aux princes de la cité. Malgré les pillages répétés, un très beau matériel fut découvert. Réparti aujourd'hui entre le musée de l'université de Pise et le musée national du Soudan, il comprenait notamment de très belles verreries alexandrines, des bagues-cachets et des inscriptions méroïtiques. En 1976, les travaux de Soleb étant terminés, $M^{\text {me }}$ Schiff-Giorgini accepta que les fouilles de Sedeinga fussent reprises par Jean Leclant au sein d'une mission française. Elle-même s'éteignit prématurément en 1977. En 19791980, le travail archéologique reprit et une maison de fouilles fut construite. Les travaux se concentrèrent sur le secteur I. En 1991, l'architecte et égyptologue Audran Labrousse reprit officiellement la direction de la mission, à laquelle il participait depuis longtemps. Les fouilles se déplacèrent sur le secteur II, la partie centrale de la nécropole, où de nouvelles pyramides furent dégagées. En 1994, Catherine Berger-El Naggar remplaça Audran Labrousse à la tête de la mission. Elle continua les travaux sur le secteur II de la nécropole jusqu'au début des années 2000, puis sur le secteur ouest et, en parallèle, diligenta deux sondages aux abords du temple. 


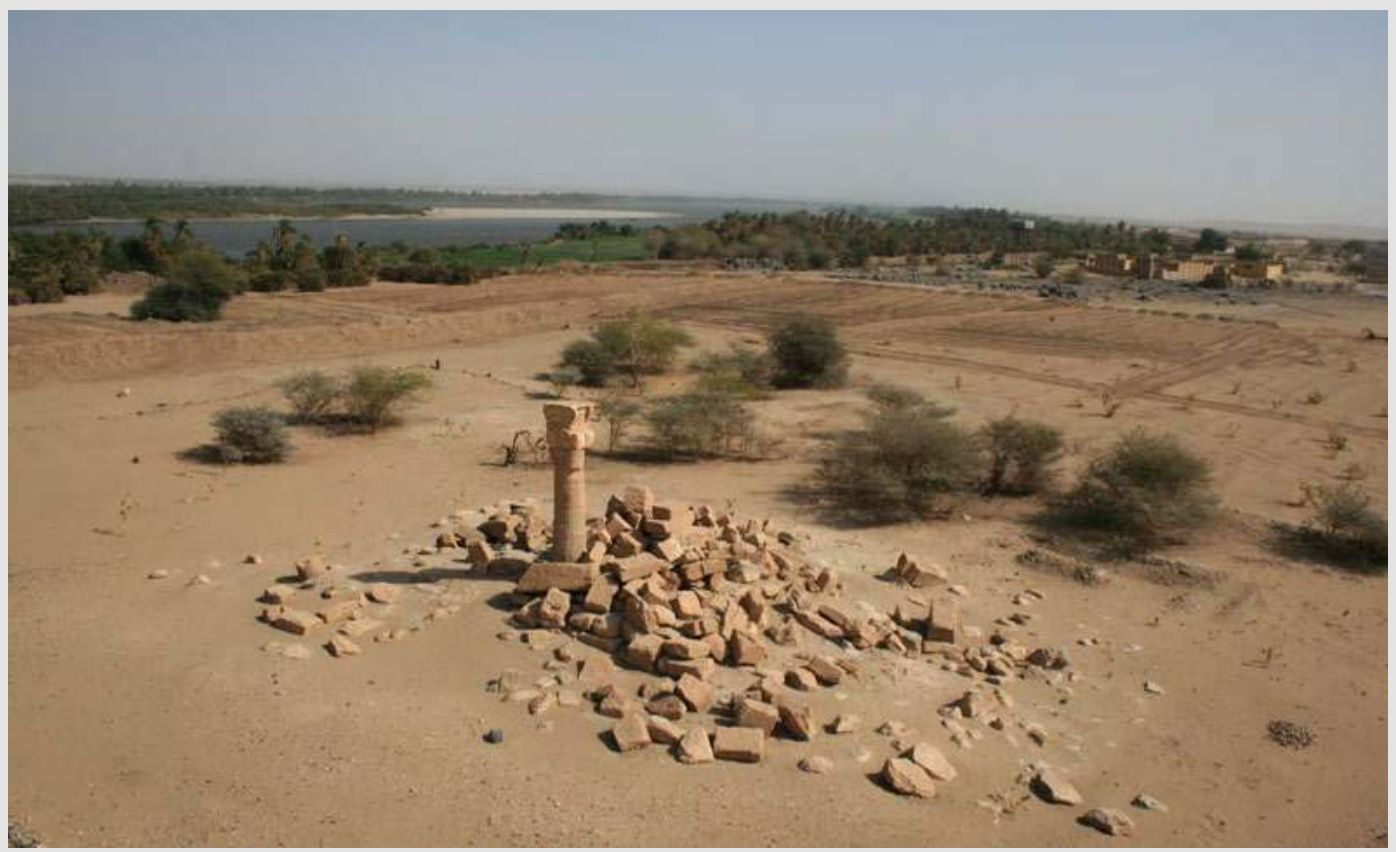

2. Les ruines du temple de la reine Tiyi en 2012 (photo B.-N. Chagny).

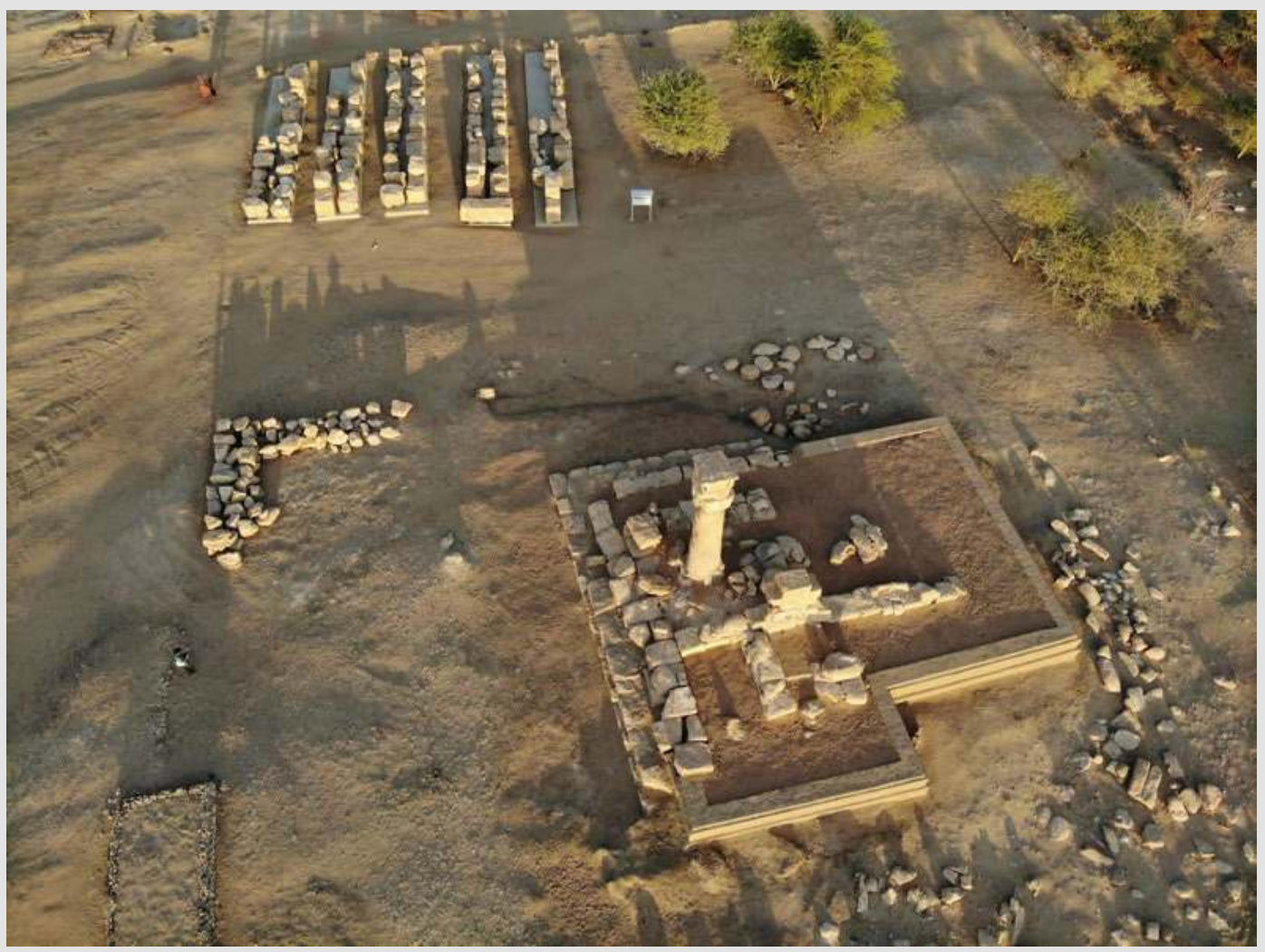

la mission archéologique française de Sedeinga

3. Le temple de la reine Tiyi après fouille et restauration en 2019 (SEDAu/A. Chen). 
cinquantenaire

\section{2}

de la section

française

de la direction

des Antiquités

du Soudan
En 2009, en tandem avec Vincent Francigny ${ }^{1}$, nous reprîmes la fouille à la demande de $\mathrm{M}$. Leclant et $\mathrm{M}^{\mathrm{me}}$ Berger-El Naggar. Les travaux continuèrent sur la partie ouest du secteur II où avaient été mis au jour une vingtaine de monuments. De 2009 à 2019, plus de soixante-dix pyramides et deux cents tombes associées furent dégagées, puis fouillées. En 2017 fut ouvert en parallèle un second chantier sur le secteur II, à l'est de la zone explorée par Audran Labrousse, avec l'espoir de découvrir les tombes les plus anciennes de la nécropole. Trois programmes quadriennaux ont été jusqu’à présent menés avec le soutien de la Commission des Fouilles du ministère des Affaires étrangères sur les thèmes suivants: (1) Chronologie générale de la nécropole de Sedeinga; (2) Transition entre le napatéen et le mérö̈tique;

(3) Recherche des origines de la nécropole.

Comme la plupart des missions locales ou étrangères opérant au Soudan, Sedeinga a bénéficié d'un mécénat du Qatar-Sudan Archaeological Project (QsaP), une organisation réunissant l'autorité des musées du Qatar et l'archéologie soudanaise autour de la mise en valeur du patrimoine soudanais. Le projet a été mis en ouvre de 2015 à 2019 avec la coopération de l'UmR 8167 du CNRS «Orient et Méditerranée», composante «Mondes pharaoniques", dirigée par Pierre Tallet ${ }^{2}$. Il a ainsi été possible de réaliser le démontage de la ruine du temple de Tiyi, une opération difficile et coûteuse qui n’avait pu être menée, faute de moyens, de logistique adéquate et de spécialistes, depuis les débuts de la mission, il y a cinquante ans (fig. 3). La fouille du temple, effectuée sous la direction de Nadia Licitra
1 Les autres membres de la mission sur la nécropole étaient Agathe Chen (anthropologue, HADEs), Vincent Colard (directeur des fouilles), Romain David (céramologue), Juliette Larroye (céramologue, 2015), Sandra Porez (dessinatrice), Simone Nannucci (archéologue), Marzia archéologue, doctorante à Paris-IV Sorbonne), Belsam Abdelhamid (2013), Ayman Eltaieb (2014) and Huyam Khalid (2015-2017) (inspecteurs de la NCAM). L'équipe des ouvriers était dirigée par notre rais Abdelrahman Fadl.

2 La mission sur le temple comprenait également Claire Somaglino (épigraphiste, Paris IV), Nadia Licitra (archéologue), Romain David (céramologue), Damien Laisney (topographe), Vincent Cabrol (tailleur de pierre), Jean-Pierre Peulvast (géomorphologue, Paris IV), Hassan Mohammed (restaurateur, IfaO), Jean-François Gout (photographe), Vincent Colard (topographe et logisticien), Giorgio Nogara (enregistrement du site au cadastre), Yassine Mohamed (enregistrement du site au cadastre, NCAM), Robert Ryndziewicz (spécialiste de magnétométrie), Karen Henderson et Antoine Langanay (étudiants en égyptologie à Paris IV-Sorbonne), Dany Joly (encadrement médical). Le service des Antiquités soudanais (NCAM) était représenté par l'inspecteur Ayman Eltaieb en 2015 et l'inspectrice Huyam Khalid en 2016-2018. 
en 2016 et 2017, a permis de préciser l'architecture du monument, mais n'a malheureusement pas mis au jour de matériel important, qui avait disparu depuis longtemps. En revanche, tous les blocs décorés ou épigraphiés, après la restauration des plus abîmés, ont pu être extraits et installés en une exposition de plein air sur des banquettes maçonnées. La plupart d'entre eux étaient invisibles jusqu'ici (fig. 4). L'ensemble du site de Sedeinga a été pourvu de cinq panneaux explicatifs en anglais et en arabe à l'intention des visiteurs. Enfin, deux prospections géomagnétiques ont été réalisées en 2018-2019 par l'équipe polonaise de Tomasz Herbich sur 20 ha au nord, au sud et à l'est du temple, dans le but de repérer les vestiges de la cité, qui n’ont jamais été localisés. Malheureusement, cette opération n’a pas permis de les découvrir, si bien que nous en sommes réduits à des hypothèses improbables, comme une destruction complète des bâtiments ou la submersion des vestiges suite à une avancée vers l'ouest du cours du Nil, voire la présence de la ville sur l'autre rive.

\section{Sedeinga, considérations géographiques et économiques}

Sedeinga appartenait originellement à la série des «menenou» de Moyenne Nubie, des établissements égyptiens fortifiés bâtis autour d'un complexe religieux après la conquête de Koush : Amara Est, Saï, Soleb, Sésébi, KermaDoukki Gel, Napata. En Moyenne Nubie, les cités pharaoniques de la rive droite ont été désertées à l'époque méroïtique au profit des agglomérations situées sur la rive droite du fleuve, Amara Ouest, Kedurma, KermaDoukki Gel, Kawa, ou sur les îles, comme Saï et Tabo. Seule Sedeinga est restée habitée sur la rive occidentale. Il est difficile de ne pas y voir une conséquence de la pression croissante des tribus qui nomadisaient à l'ouest du Soudan et notamment ceux qu'en leur langue les Méroïtes appelaient «Noubas» $(N o b)$, un terme péjoratif signifiant "esclaves» (Rilly 2008, p. 215-219). Cette ethnie apparaît dans les chroniques napatéennes ${ }^{1}$. Ce sont alors des peuples lointains, situés probablement au Darfour et au nord du Kordofan, qui constituent pour les rois koushites des réservoirs d'esclaves et de bétail à razzier au terme d'expéditions à longue distance. Au début de l'époque méroïtique, ils sont mieux organisés et se sont rapprochés du Nil: ils sont décrits par le géographe grec Ératosthène comme un "grand peuple», divisé en plusieurs royaumes. À partir du $\mathrm{III}^{\mathrm{e}}$ siècle

1 Les textes napatéens les désignent sous le nom de $M b$. Transcrit plus tard Mho en méroïtique et prononcé/max ${ }^{\mathrm{w} u} / \mathrm{ou} / \mathrm{maj}^{\mathrm{w}} \mathrm{u} /$, ce terme est probablement une adaptation de l'auto-désignation des Nubiens, qui peut être reconstruite *magur ou *magi : cf. Rilly 2010, p. 11761179. 
cinquantenaire

\section{4}

de la section

française

de la direction des Antiquités du Soudan

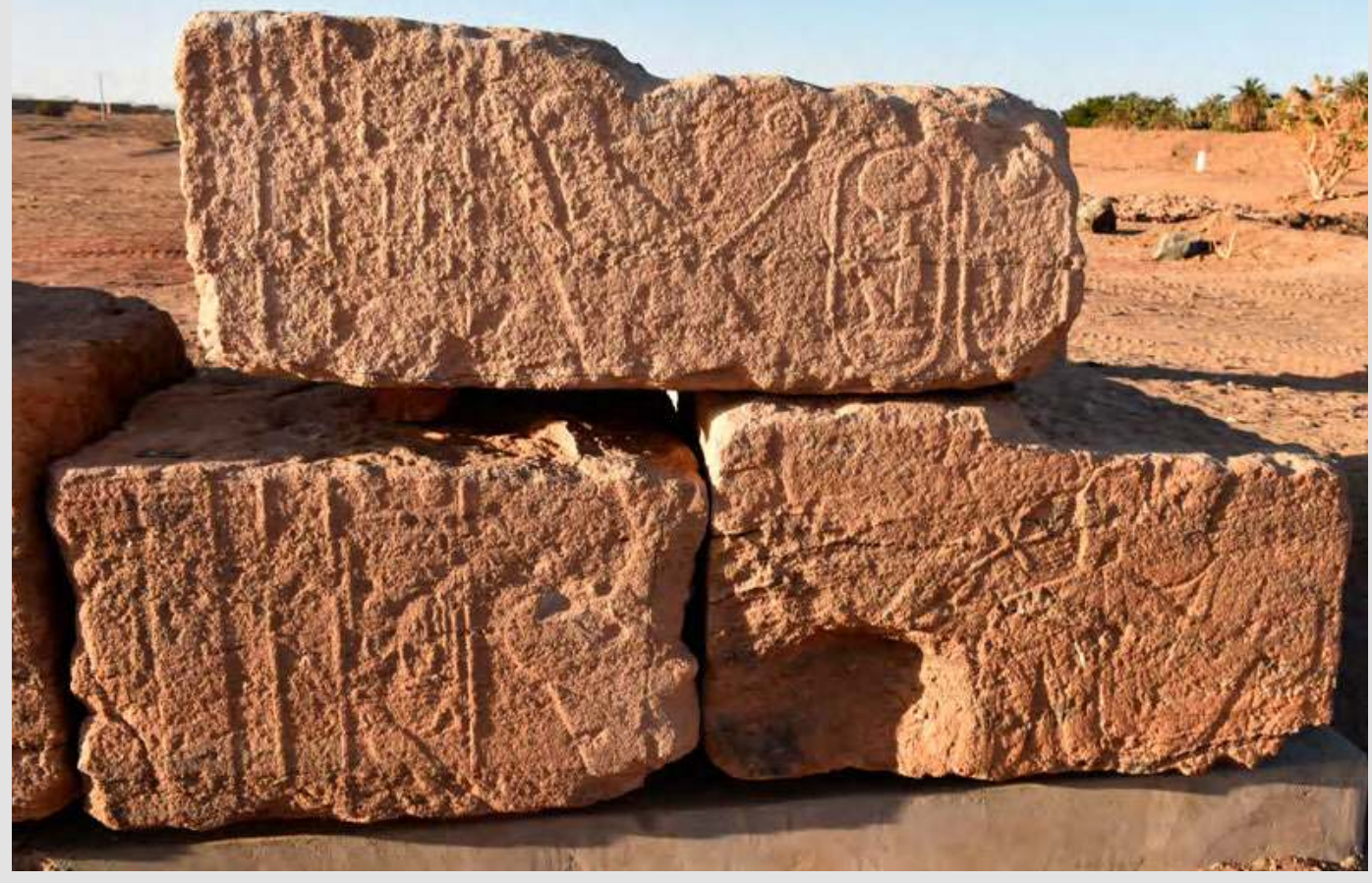

4. Relief du temple de Sedeinga: le dieu Atoum tend le signe de vie à Amenhotep III (SEDAu/Cl. Rilly).

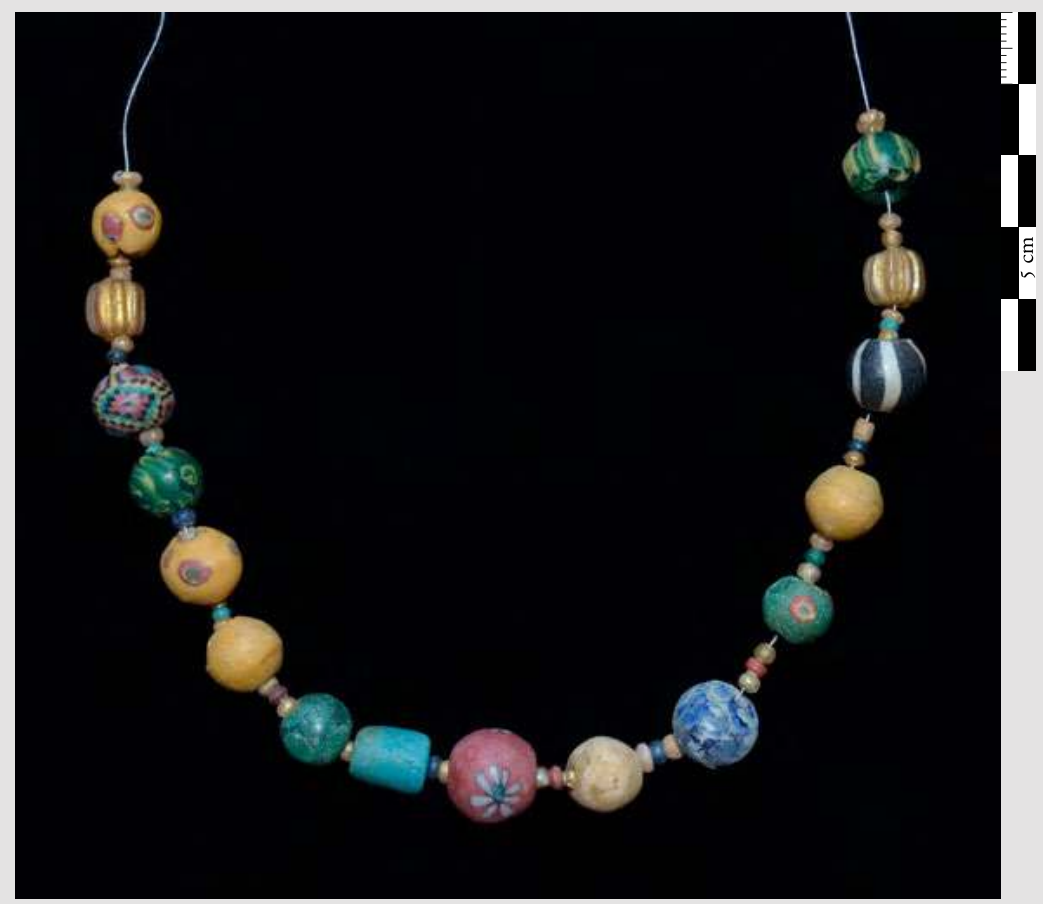

5. Collier de perles millefiori importé d'un atelier méditerranéen (Sedau/ V. Francigny). 
de notre ère, de fréquents combats sont cités dans les textes méroïtiques. Vers 270, le vice-roi de Basse-Nubie Abratoyé est contraint d'intervenir bien loin de son fief, à l'ouest de Sedeinga, pour les repousser, ainsi qu'il est relaté dans sa stèle funéraire ${ }^{1}$. L'absence de vestiges du méroïtique final et du post-méroïtique sur le site laisse d'ailleurs supposer que la contre-offensive du vice-roi n'empêcha pas, quelques années plus tard, la destruction de la cité. Une simple bourgade est connue plus tard à Nilwa, où est construite aux $\mathrm{VI}^{\mathrm{e}}-\mathrm{VII}^{\mathrm{e}}$ siècles une église de dimensions modestes, puisqu'à l'époque chrétienne Sedeinga a perdu son statut de capitale régionale au profit de l'évêché de Saï.

Cette localisation au débouché des pistes de l'ouest du Soudan sur le Nil, qui a causé sans doute la perte de Sedeinga, est aussi ce qui a fait sa richesse. L'endroit est en effet une des branches de la «Piste des quarante jours» (Darb al-arba'in) qu'empruntaient jusqu'à ces dernières années les caravanes qui circulaient entre l'ouest du Soudan et l'Égypte ${ }^{2}$. Cette route du désert, longue de $1800 \mathrm{~km}$, qui reliait Kobbé, près d'el-Fasher, capitale du Darfour, à Assiout, en Égypte, permettait d'acheminer, notamment durant la domination ottomane, les produits des régions sahéliennes jusqu'au Nil. Benoît de Maillet, consul de France en Égypte sous le règne de Louis XIV, en donne une liste non exhaustive: poudre d'or, défenses d'éléphants, ébène, civette, gomme arabique, plumes d'autruche, mais surtout des milliers d'esclaves enlevés au Darfour par des tribus arabisées. ${ }^{3}$ La plupart de ces marchandises, essentiellement constituées de matières premières qui étaient ensuite manufacturées en Égypte, sont les mêmes que celles que les anciens Égyptiens importaient du Soudan depuis l'Ancien Empire (Rilly 2017, p. 72-73).

À l'époque moderne, cette piste est toujours parcourue par des caravanes de dromadaires venus du Darfour, qui sont désormais destinés aux boucheries du Caire. Jusqu'en 2018, il n'était pas rare de voir des troupeaux de plusieurs centaines de têtes traverser le site de la nécropole de Sedeinga, mais ils sont désormais chargés sur des camions depuis la halte vétérinaire de Dongola et gagnent l'Égypte la route asphaltée récemment tracée et achevée sur la rive gauche. Le tracé principal de la Piste des quarante jours ne rejoignait le Nil qu'à son point d'arrivée à Assiout et les caravanes souvent se contentaient de l'eau médiocre des oasis de Laqiya Arba'in

1 Rem 1333, lignes 22-24, voir Carrier 2001, p. 25 et 31.

Le nom méroïtique de Sedeinga (Atiye), suivi de teneke-le "l'ouest»

y est associé avec la mention de chefs ennemis tués et de butin saisi.

2 Voir Shaw 1929, Ducène 2007, Iverné 2007, Riemer et Förster 2013,

p. 52-53.

3 Ducène 2007, p. 250. 
cinquantenaire

\section{6}

de la section

française

de la direction

des Antiquités

du Soudan et Sélima, mais il arrivait assez souvent qu'elles fassent un détour jusqu'aux rives du fleuve pour mieux abreuver et reposer les bêtes (Shaw 1929, p. 67). Le Nil était alors atteint aux deux endroits les plus proches de la piste, à savoir la $3^{\mathrm{e}}$ cataracte ou la boucle où se trouvent Soleb et Sedeinga.

Bien que les premières mentions connues de la Piste des quarante jours ne remontent qu'au $\mathrm{x}^{\mathrm{e}}$ siècle de notre ère, il est vraisemblable qu'elle existait déjà à l'époque napato-méroïtique, puisque le climat dans la région était le même qu'aujourd'hui et que, bien sûr, la position des montagnes et des oueds n'a pas changé en deux mille cinq cents ans, une bien petite tranche de temps à l'échelle géologique. Les caravanes étaient alors constituées d'ânes et non de dromadaires, qui ne seront utilisés systématiquement qu'à la fin de l'Antiquité. Toutefois, la moindre résistance à la soif de ces équidés obligeait à se rapprocher du Nil avant la traversée du désert Libyque. L'escale dans la boucle de Sedeinga, qui était, nous l'avons vu, facultative à l'époque ottomane, était alors une nécessité.

Les produits bruts importés du Sahel n'ont évidemment pas laissé de traces certaines en Nubie, car on ne peut deviner la provenance des matériaux à partir desquels ont été réalisés les rares bijoux en or, objets en ébène ou en ivoire qui ont échappé aux pillages et ont été découverts dans les fouilles de la nécropole de Sedeinga. En revanche, de nombreux objets manufacturés venus des ateliers alexandrins et d'autres régions méditerranéennes y ont été retrouvés ${ }^{1}$. On connaît notamment les verreries magnifiques exhumées dans les tombes princières du cimetière Ouest, au début des fouilles sur le site (Leclant 1975), mais depuis lors sont venues s'ajouter d'autres importations comme un collier de perles millefiori de toute beauté (fig. 5). Ce somptueux bijou a pourtant été retrouvé en place au cou d'un petit enfant curieusement inhumé dans la grande carrière de sable qui coupe en deux la zone excavée, ce qui l'a protégé des pilleurs.
1 Pour la céramique importée, notamment des amphores de région méditerranéenne (Alexandrie, Bétique, Gaule, Grèce), voir David et Francigny 2018. Les auteurs, tout en insistant toutefois sur la faible quantité de céramiques importées, soit près de $3 \%$ du matériel retrouvé, estiment (p. 262) que: "L'inventaire réalisé [...] est tout de même révélateur de la capacité de l'élite de Sedeinga à se procurer des marchandises habituellement rencontrées dans les tombes royales et princières, ou dans les grands centres de Basse Nubie que sont Faras et Karanog. L'importance politique de Sedeinga permet en effet à ses notables d'accéder à des denrées rares, dont le contenu pourrait avoir voyagé sur plusieurs milliers de kilomètres. Le conditionnel est toutefois nécessaire car la question légitime du réemploi du mobilier amphorique dans un relai tel que l'Égypte demeure sans réponse définitive.» 
Selon toute vraisemblance, c'est au commerce transfrontalier que les élites de Sedeinga ont dû leur richesse. La région n'offre en effet aucun potentiel agricole, le ruban de terre arable étant réduit à quelques centaines de mètres sur chaque rive, à la différence des larges étendues fertiles autour de Kerma et de Dongola. Comme tout le nord du Soudan, le désert autour de Sedeinga est riche en or, notamment à l'ouest du village moderne de Hamid, face à l'île de Saï. Mais l'exploitation de ces gisements locaux n'est devenue rentable que grâce à l'outillage moderne et il ne semble pas qu'elle ait existé de manière intensive dans l'Antiquité, où l'essentiel de l'or venait des mines situées dans le désert Arabique, à l'est de la Basse-Nubie.

Il faut donc supposer que ce sont les transactions avec les caravanes et les taxes prélevées en nature ${ }^{1}$ sur les marchandises qui ont enrichi les habitants de Sedeinga. L'une des fonctions administratives les plus fréquemment citées dans les textes funéraires de la nécropole est celle d'aribet. Une variante de ce mot, arebetke, connue par deux inscriptions de Basse$\mathrm{Nubie}^{2}$, est transcrite zrbtng'y dans un graffito démotique du temple d'Isis à Philae et décrite comme le travail d'un contrôleur des dîmes et revenus en nature perçus par le clergé de la déesse ${ }^{3}$. La fonction d'aribet est attestée en relation avec des unités territoriales, villes (Sedeinga) ou nomes (Tawete). Elle figure en position intermédiaire dans le cursus honorum des plus hauts dignitaires de Basse et Moyenne Nubie ${ }^{4}$ et elle est fréquemment attestée comme fonction des membres importants de la famille cités dans les mentions généalogiques des défunts ${ }^{5}$. Une traduction «directeur des taxes»

1 On rappelle que les royaumes soudanais n'utiliseront la monnaie qu'à partir de la conquête musulmane.

2 Rem 0292 (Karanog): arebetke: Simlo-te-l-o-wi «il était contrôleur des taxes à Karanog"; ReM 1020 (El-Malki) : arbetke peseto-li-se-l-o-wi "il était contrôleur des taxes du vice-roi».

3 Ph. 417, proscynème de Tami, cf. FHN III, p. 1011-1016: "J'ai passé dix ans comme arebetanke, à mesurer pour le temple d'Isis à l'aide du grand medja (récipient pour mesurer) et je n'ai pas triché sur la mesure."

4 Le prince de Sedeinga Natemakhora, à la fin du $\mathrm{II}^{\mathrm{e}}$ siècle de notre ère, est aribet Atiye-te-l "directeur des taxes à Sedeinga (REM 1090 et 1091, cf. Rilly 2013, p. 23), tandis que le vice-roi Abratoye, vers 270, a été aribet Twete-li-se-l «directeur des taxes du (nome de) Tawete" (REM 1088 et 1333, cf. Carrier 2001, p. 35. Le nome de Tawete (< ég. ts $w$ s d ) correspondait vraisemblablement à la région située en face de Sedeinga sur la rive droite, voir argumentation dans Rilly 2013, p. 106.

5 Voir Rem 1281 (époux de la défunte), textes de Sedeinga II T $286 \mathrm{~d} 1$ et II T 302 d1, ainsi que REM 1292 (oncle maternel), textes de Sedeinga II S o22 et II T 319d1 (père de la défunte), cf. Rilly et Francigny 2011, p. 78. 
semble plus adaptée au statut de ces deux notables, tandis que le dérivé arebetke désignerait un "contrôleur des taxes", à un échelon inférieur dans la comptabilité administrative.

\section{Le temple de la reine Tiyi}

Le site de Sedeinga fut occupé sporadiquement entre la fin du néolithique et le Nouvel Empire. Un cimetière d'élite datant de la fin du néolithique, vers 3900 av. J.-C., a été retrouvé lors des premières fouilles du secteur ouest sous la pyramide $\mathrm{W}_{\mathrm{T} 1}$, dont la base enclot délibérément l'ensemble des tombes. Un peu plus tard, encore plus à l'ouest, des fosses-silos ont été creusées pour accueillir des greniers pré-Kerma. De la poterie d'importation égyptienne Nagada III et des analyses ${ }^{14} \mathrm{C}$ sur des coquilles d'autruche ont permis de dater cette installation autour de 3100 . Aucun vestige significatif de la période Kerma n'a été retrouvé jusqu'ici. Il semble donc que le premier établissement historique ait été fondé par les Égyptiens.

C'est sous le règne de Thoutmosis III, vers 1470 , que la colonisation égyptienne s'organise durablement en Nubie. Dans la région de Sedeinga, un petit temple fut alors creusé dans le roc au-dessus de la passe

cinquantenaire

\section{8}

de la section

française

de la direction

des Antiquités

du Soudan du Gébel Dosha qui surplombe le Nil. Ce lieu, riche en grès blanc et rose, fut choisi comme carrière cent ans plus tard, et deux temples équidistants furent bâtis par Amenhotep III, l'un, Soleb, à $7 \mathrm{~km}$ au sud, l'autre, Sedeinga, à $7 \mathrm{~km}$ au nord. Le temple de Soleb, le plus vaste sanctuaire égyptien édifié sur le sol du Soudan, accueillit le culte d'Amon et de Nebmaâtrê, la figure divinisée d'Amenhotep III. Par la suite, le monument fut en partie décoré à neuf pour commémorer le jubilé des trente années de règne du pharaon. Le temple de Sedeinga est la contrepartie féminine de Soleb. La grande épouse royale Tiyi y était assimilée à la déesse Hathor et lui prête ses traits sur les chapiteaux de la salle hypostyle qui constitue le cœur du monument. Bien que de taille modeste, avec une emprise au sol de 17,65 × 26,47 m, le bâtiment revêt une grande importance théologique, puisque il est le premier temple jamais édifié pour une reine divinisée de son vivant. Il ne sera imité que par Ramsès II, qui, un siècle plus tard, fera creuser, dans la falaise d'Abou Simbel, le temple de la reine Néfertari à côté du sien. Cette nouvelle image d'un couple royal - et non plus seulement d'un roi — ainsi divinisé préfigurait l'idéologie du règne suivant, où Akhenaton et Néfertiti seront représentés sur un pied d'égalité.

Le temple de Sedeinga (fig.6) comportait une salle hypostyle de plan rectangulaire, soutenue par huit colonnes hathoriques dont les abaques étaient gravés au nom de la reine Tiyi, entouré par les deux cartouches de son époux, Nebmaâtrê et Amenhotep. Le long de leurs fûts 


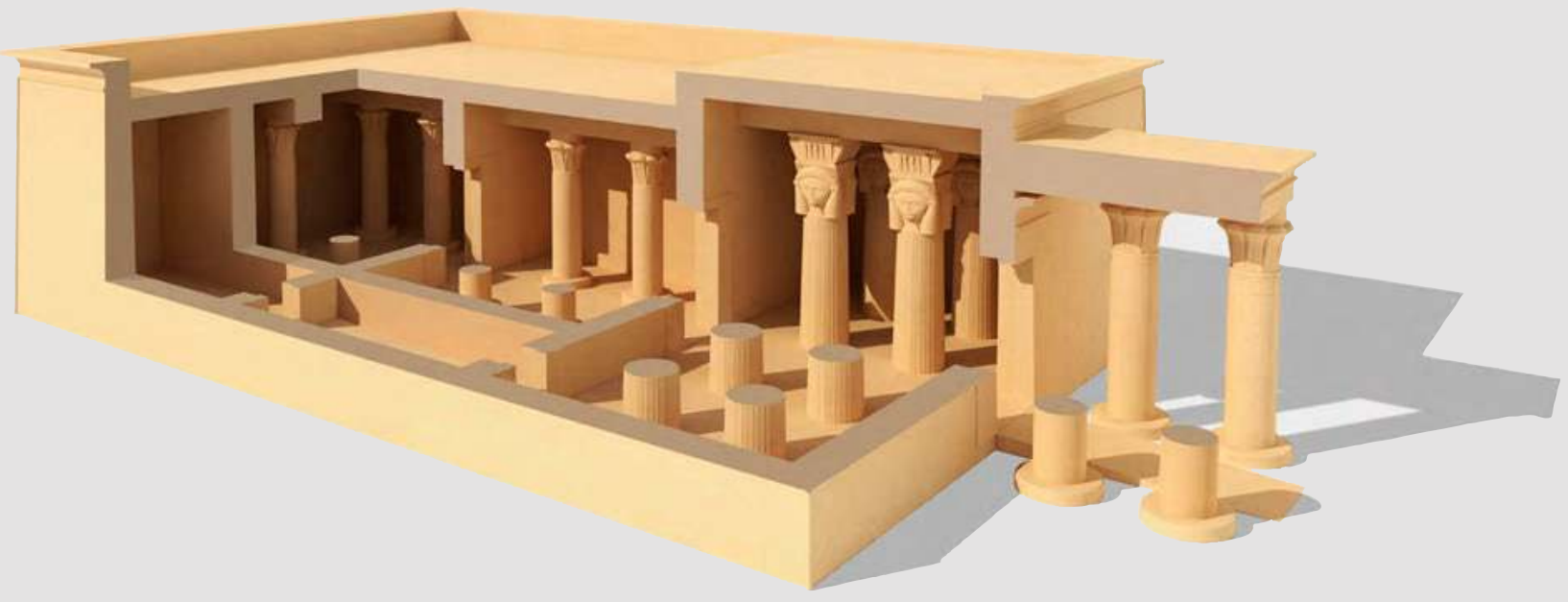

6. Reconstruction ${ }_{3} \mathrm{D}$ du temple de Tiyi (Sedau/M. Fraisse).

la mission

archéologique

française

de Sedeinga 
cinquantenaire

\section{0}

de la section

française

de la direction

des Antiquités

du Soudan cannelés est inscrite la dédicace du temple, stipulant que le roi «a fait son monument pour la grande épouse royale, la noble, la grande de louanges, Tiyi». Quatorze énormes architraves, du même module que celles de Soleb, soutenaient les dalles du plafond. Elles portaient les titres et les noms du roi en gigantesques hiéroglyphes. Lors de la campagne de martelage du nom d'Amon sous le règne d'Akhenaton, le cartouche d'Amenhotep fut maladroitement retaillé pour y inscrire une seconde fois le praenomen du roi, Nebmâtrê. La salle hypostyle était percée à l'ouest d'une large ouverture, qu'une inscription désignait comme «la grande porte de la grande épouse royale Tiyi, douée de vie». Elle était surmontée d'un linteau monumental représentant d'un côté la course du roi devant le dieu Amon, de l'autre la reine figurée en sphinge. Deux statues de gabbro de la reine et probablement du roi, plus grandes que nature, se tenaient de part et d'autre de la baie. Seuls le socle et les jambes de la statue de Tiyi ont été retrouvés. La porte s'ouvrait sur un naos flanqué de deux chapelles, sans doute prolongé à l'ouest par trois magasins.

Après l'épisode des martelages à l'époque amarnienne, les noms et la figure d'Amon furent restaurés à Soleb sous le règne de Toutânkhamon, comme l'indique une inscription gravée sur les fameux lions transportés au British Museum par Lord Prudhoe. À Sedeinga, en revanche, on a peu de traces de restauration. Soleb devint le siège du "délégué de Koush ", représentant du vice-roi de Nubie dans le sud de la colonie égyptienne. Les deux temples restèrent en activité jusqu'à la fin de la $\mathrm{xx}^{\mathrm{e}}$ dynastie. Il semble qu’avec le retrait des Égyptiens qui suivit, les édifices ne furent plus guère entretenus. Sous le règne du roi koushite Piânkhy, vers 740, Soleb fut dépouillé de ses statues de bélier et de lions, transportées devant le temple d'Amon de Napata au Gébel Barkal. C'est quelques décennies plus tard que son fils, le roi Taharqo, fit bâtir une colonnade devant l'entrée du temple de Sedeinga, qui fut probablement restauré pour l'occasion. Toutefois, dans le siècle qui suivit, le monument s'écroula. Il avait été bâti sur une élévation naturelle de terre avec des fondations peu profondes et il aura suffi sans doute d'un léger séisme pour l'abattre, et non, comme on l'a suggéré, d'une inondation centennale dont nous n'avons pas retrouvé de traces.

\section{La nécropole napato-méroïtique}

Même ruiné, le temple de Tiyi, réinterprété comme un sanctuaire d'Isis, garda une place centrale à l'époque napato-méroïtique. Une tombe royale du $\mathrm{II}^{\mathrm{e}}$ siècle av. J.-C., située à $1,5 \mathrm{~km}$ à l'ouest et orientée au degré près sur le monument de la reine égyptienne, a été découverte en 2012. Restée inachevée, elle laisse penser qu'une femme de la famille régnante avait envisagé 
d'installer sa sépulture sous la protection de la déesse. La ville de Sedeinga, nommée Atiye en méroïtique, déformation de l'égyptien ḩw.t Tjy «temple de Tiyi», devint le chef-lieu de la région, sans doute après la remise en activité du temple sous Taharqo. Elle constituait un nome à part entière du royaume de Koush. Vers la fin du II $^{\mathrm{e}}$ siècle, la cité est administrée par un prince local appelé Natemakhora. Ses inscriptions funéraires ${ }^{1}$, mises au jour dans le secteur Ouest, le présentent comme chef de district (sleqene) de Sedeinga, stratège (pelmos), c'est-à-dire gouverneur de ce nome et de celui de Tawete, situé de l'autre côté du Nil. Il exerce aussi, comme nous l'avons vu précédemment (cf. n. 4, p. 37), la fonction de directeur des taxes (aribet), si importante dans cette étape caravanière. Tout cela faisait de lui l'homme le plus puissant sur le territoire compris entre la Basse-Nubie, administrée par le vice-roi (peseto), et la cité de Pnoubs, l'actuelle Kerma.

L'importance de la cité durant près d'un millénaire explique la taille et la richesse de sa nécropole située à l'ouest du temple. Sans doute a-t-elle été inaugurée sous le Nouvel Empire et a-t-elle accueilli les sépultures égyptiennes des desservants du culte de Tiyi, mais on n'en a pas trouvé trace jusqu'à présent. Les plus anciennes tombes que l'on ait pu dater sont situées à l'est du secteur II et remontent au début de l'époque napatéenne, voire à la $\mathrm{xxv}^{\mathrm{e}}$ dynastie ${ }^{2}$. Un série de petites fosses coiffées de tumuli de pierres, fouillées en 1998-1998 dans la partie sud-ouest de la nécropole, ont également livré du matériel napatéen ancien, mais aucune date précise n’a pu être avancée. Il en va de même des grandes structures du secteur I, qui ont été systématiquement pillées et réutilisées à l'époque méroïtique pour des enterrements collectifs. Elles correspondaient peut-être aux inhumations de l'élite égyptianisée, alors que les tumuli auraient accueilli de plus modestes occupants. Entre le ve siècle et la fin du Ive siècle, deux grands ensembles funéraires sont construits dans la partie ouest du secteur II, en bordure de la piste chamelière. Une centaine de pyramides de taille variée, de 0,8 à $5 \mathrm{~m}$ d'arête, y sont édifiées. Elles scellent des substructures souvent soignées. Les descenderies, dont les plus grandes sont équipées de marches, débouchent sur des caveaux régulièrement taillés dans le sédiment schisteux.

Une caractéristique originale de ces pyramides est la proportion non négligeable de monuments incluant une coupole interne (fig. 7), le plus souvent reliée aux angles de la structure par des demi-croisillons. Les fouilles effectuées jusqu’à présent ont mis au jour huit pyramides de ce type, alors

1 Voir l'analyse de ces textes dans Rilly 2013.

2 La substructure de la tombe II T 413 est datée de Cal. 781 -511 av. J.-C. (probabilité 95,4\%) à partir de sédiments végétaux extraits des briques (Laboratoire CDRC- Lyon, 2018). 


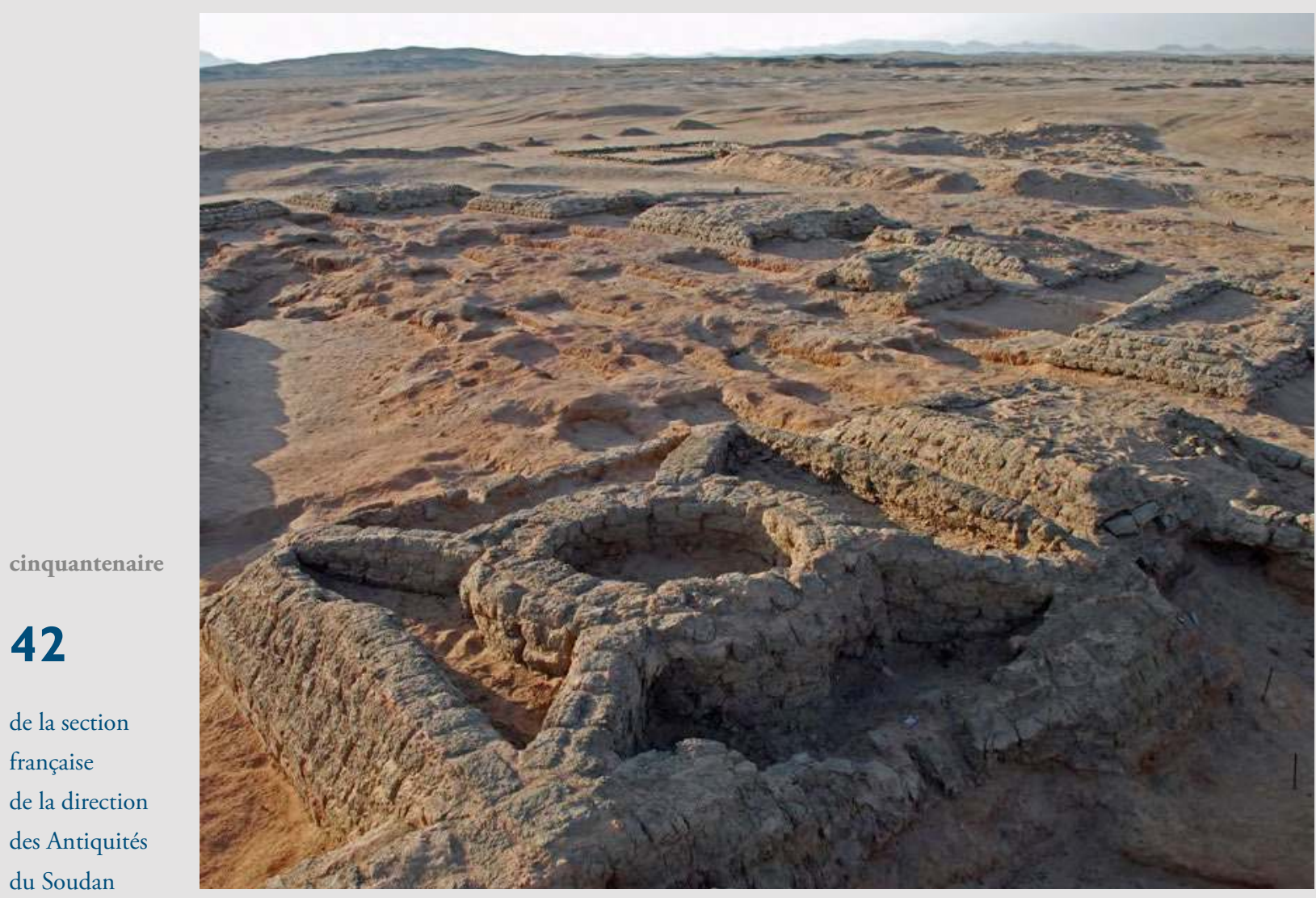

7. Pyramide II 232 à coupole interne (SEDAU/ V. Francigny). 
qu'une seule est connue en dehors de ce site, dans la nécropole princière de Méroé (Beg. W. 2). Ces coupoles, dans un cas (II T 169) minuscule et ajoutée sans fondement sur la base du monument, n'ont pas de fonction architecturale. L'hypothèse qu'elle ait correspondu à une fusion entre le tumulus traditionnel et la pyramide d'importation égyptienne a été confirmée par la découverte en 2012 et 2013 de deux tumuli de briques (II T 235 ET 297) qui abritaient les sépultures inviolées de deux enfants napatéens. Le mélange assumé des deux traditions, égyptienne et soudanaise, est un des traits les plus remarquables de la civilisation koushite et se trouve parfaitement illustré ici.

La persistance, jusqu’à des époques tardives, de traditions égyptiennes incorporées dans la culture méroïtique est aussi démontrée par la découverte récente d'une statue exceptionnelle. En 2016 avait été trouvée en surface de la tombe II $\mathrm{T} 361$ une stèle de grès très abîmée au nom d'un certain Pawarite-wada. En 2018, la substructure fut fouillée et une tête d'oiseau-ba bien conservée fut trouvée dans la descenderie. Enfin, en 2019, le corps de la statue fut retrouvé dans une petite tombe au sud (II T 354), où il avait manifestement été jeté par les pilleurs après que la tête, sans doute par superstition, en eut été détachée. Une fois reconstitué, cette statue-ba de grande taille $(70 \mathrm{~cm}$ de hauteur) montrait un homme jeune portant un tablier historié et, surtout, une peau de léopard ajustée sur les épaules (fig. 8). Cet habillement est caractéristique des prêtres-sem, chargés des cérémonies funéraires et notamment de l'ouverture de la bouche sur les momies, symboliquement effectuée en effleurant les lèvres du défunt du doigt puis de divers instruments. Le plus étonnant est le nom de cet officiant. Pawaritewada (pwrite-wd) signifie "celui qui dispense la force vitale " 1 , ce qui est rien moins qu'une définition du rôle du prêtre-sem. Nous connaissons dans les textes méroïtiques plusieurs exemples de personnes qui ont changé de nom au cours de leur vie, notamment en raison de leur position familiale ou de leur fonction sociale. C'est ce nouveau nom, et non celui qu'on leur a donné à leur naissance, qui sera inscrit dans leur épitaphe ${ }^{2}$.

Toutes les tombes napatéennes de Sedeinga, à l'exception de quelques sépultures d'immatures, ont été pillées peu de temps après les inhumations. La plupart d'entre elles ont été réutilisées à l'époque méroïtique. Dans cette partie ouest du secteur II, beaucoup de ces enterrements secon-

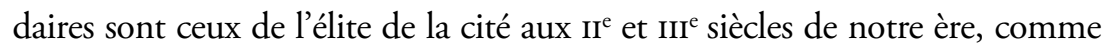

1 Pour pwrite "force vitale», voir Rilly 2010, p. 136 et 363; Rilly 2017, p. 237. Le dérivé verbal $w d$ doit vraisemblablement se rattacher au nubien (nobiin) $u d$-ir «placer, mettre, verser».

2 Voir Rilly et Francigny 2012, p. 68. On connaît autre autres «Grand-mère» $(A b l)$, Grande Sour (Kditelhl), Grand-prêtre (Beloloqe) et Envoyé (Apoteye). 
cinquantenaire

\section{4}

de la section

française

de la direction

des Antiquités

du Soudan le prouve la découverte en ce lieu d'une trentaine de tables d'offrandes et surtout de stèles inscrites en cursive méroïtique. La réutilisation des anciennes tombes napatéennes par ces familles opulentes ne peut s'expliquer simplement par une attitude opportuniste, encore moins par souci d'économie, comme le montre la construction, à peine plus tôt, de grandes pyramides dans le secteur Ouest pour les nomarques méroïtiques de Sedeinga. En réaménageant et en réoccupant des sépultures napatéennes antérieures de six ou sept siècles, on cherche plutôt à créer un lien avec de lointains ancêtres, peut-être considérés comme des intercesseurs privilégiés avec les divinités de l'au-delà ${ }^{1}$.

Sur les structures anciennes, on reconstruit des pyramides et des chapelles funéraires. Des stèles de grès inscrites, plus rarement des tables d'offrandes, y ont installées pour commémorer le défunt. Les textes funéraires, qui ont le plus souvent été produits pour les femmes de riches familles de notables, détaillent leurs liens familiaux avec l'élite, non seulement de Sedeinga mais aussi d'autres cités du royaume de Méroé. Une stèle retrouvée en II T 410 en 2017 (fig. 9) décrit par exemple une défunte, appelée Maliwaras, comme fille d'un gouverneur, sœur de deux grands-prêtres dans le temple proche d'Amara et mère d'un gouverneur de la ville de Faras, chef-lieu de Basse-Nubie. Une autre stèle, retrouvée en très bon état avec ses pigments bien conservés dans la tombe II T 355, appartenait à une dame de Sedeinga, nommée Ataqeloula (fig. 10). Fille d'un prêtre du temple de Pnoubs (Kerma), elle comptait dans sa lignée maternelle un prince de la famille royale, un prêtre d'Amon et des membres du clergé d'Isis et d'Horus. Ces inscriptions funéraires, qui constituent pour la compréhension du site des sources d'information irremplaçables et qu'aucune autre des nécropoles actuellement fouillées au Soudan n’a livré en aussi grand nombre, montrent qu'en dépit des distances les différentes provinces du royaume de Koush échangent et communiquent fréquemment, que ce soit pour des raisons politiques, religieuses ou matrimoniales.

Bien que pillé pendant des millénaires, bien que fouillé depuis plus de cinquante ans, le site de Sedeinga continue à livrer à chaque campagne archéologique des informations capitales sur le royaume napato-méroïtique et à fournir un matériel funéraire inestimable. Il reste encore beaucoup à fouiller et on peut supposer que seule une moitié des vestiges a été mise au jour. Sur l'immense secteur III par exemple, le plus au sud, une seule tombe, d'époque chrétienne, a été dégagée. Des fragments de tables d'offrandes en céramique, typiques de l'époque napatéenne, y affleurent, montrant que plusieurs époques doivent y être représentées. Cinquante nouvelles années ne seront pas de trop pour exploiter l'ensemble du site 


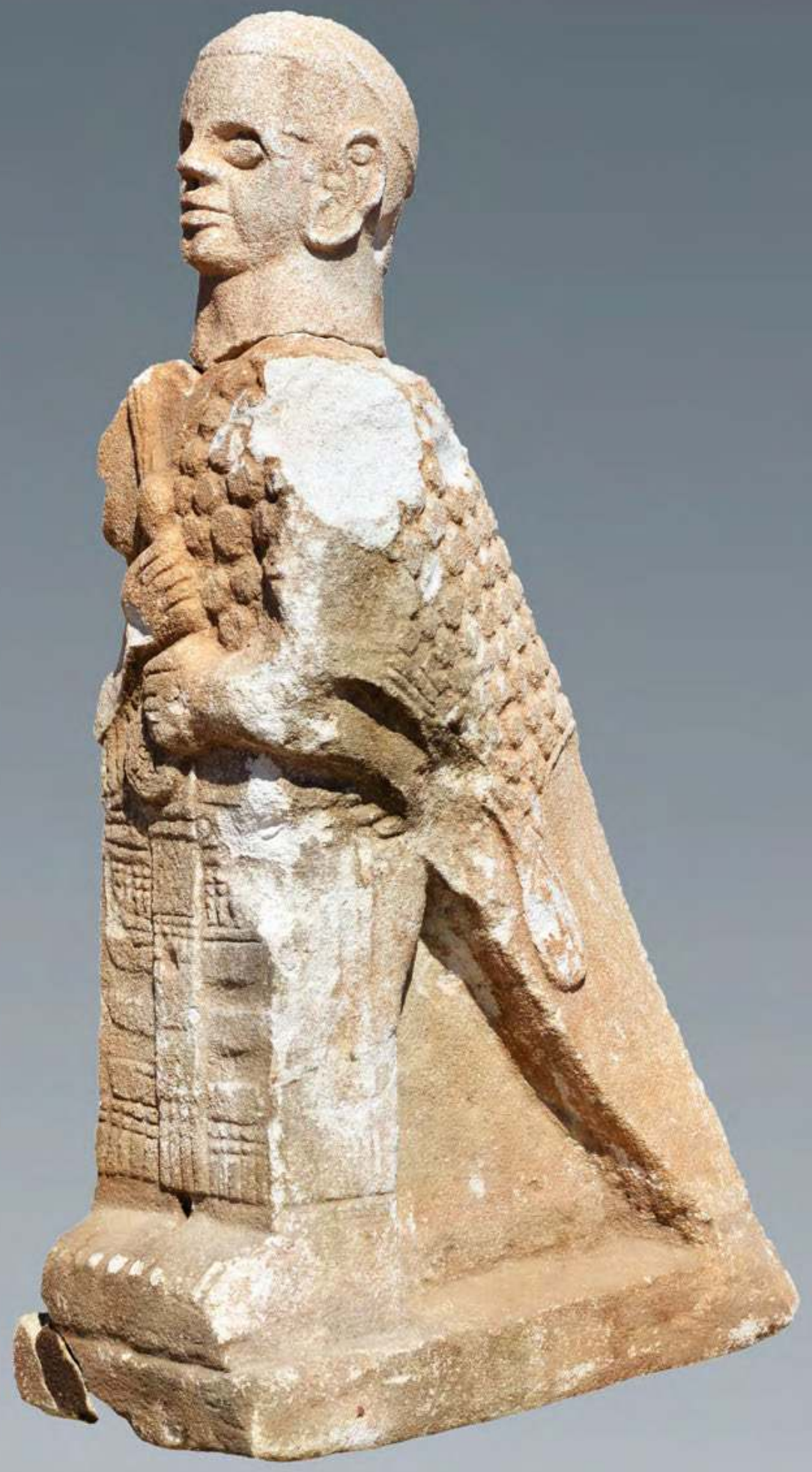

8. Statue-ba d'un prêtre-sem, nécropole méroïtique de Sedeinga (SEDAU/ V. Francigny). 


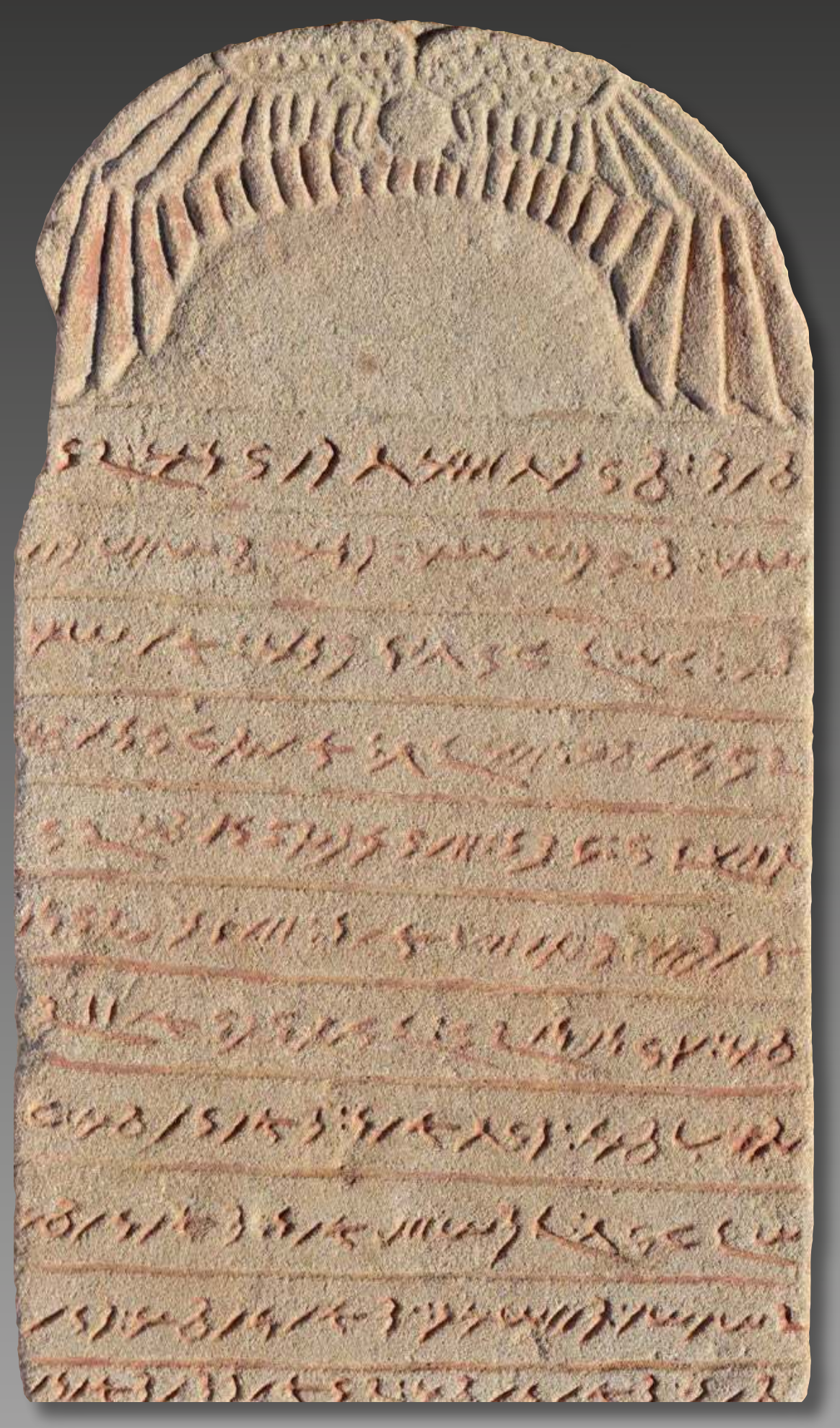




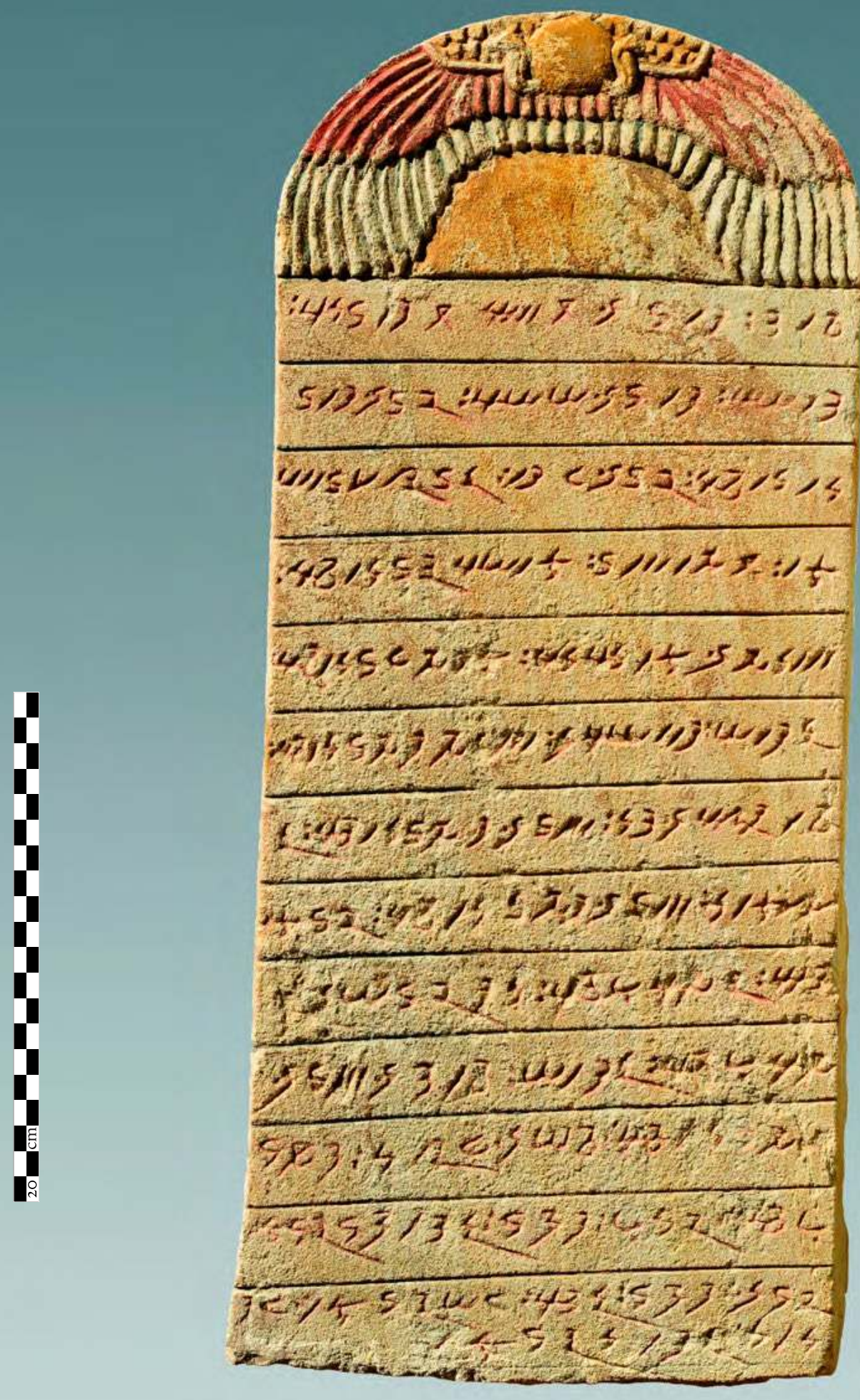




\section{bibliographie}

cinquantenaire

48

de la section

française

de la direction

des Antiquités

du Soudan

Cailliaud, Fr. 1826 - Voyage à Méroé, au Fleuve Blanc, au-delà de Fâzoql, dans le Midi du Royaume de Sennâr, à Syouah et dans cinq autres oasis fait dans les années 1819, 1820, 1821 et 1822, 3 vol., Paris.

Carrier, Cl. 2001 - «La stèle méroïtique d'Abratoye. Caire Je n ${ }^{\circ}$ 90008». Meroitic Newsletters 28, p. 21-53.

David, R. et Francigny V. $\quad 2018$ — «Les céramiques importées à Sedeinga et la question des "échanges à longue distance" dans le royaume de Méroé», dans David, R. (éd.), Céramiques égyptiennes au Soudan ancien, Cahiers de la Céramique Égyptienne 11, Le Caire, p. 255-278.

Ducène, J.-Ch. 2007 - «Le Darb el-Arba în à l'époque musulmane», dans Bruwier, M.-C. (éd.) Pharaons noirs. Sur la Piste des Quarante Jours, Musée royal de Mariemont, p. 245-252.

Frv III = Eide, T., Hägg, T., Pierce, et R. H., Török, L. 1998 - Fontes Historiae Nubiorum. Textual Sources for the History of the Middle Nile Region between the Eighth Century BC and the Sixth Century $A D$. Vol. III. Bergen.

Iverné, C. 2007 - "Quelques voyageurs occidentaux au Soudan oriental du $16^{\mathrm{e}}$ au $19^{\mathrm{e}}$ siècle», dans Bruwier, M.-C. (éd.), Pharaons noirs. Sur la Piste des Quarante Jours, Musée royal de Mariemont, p. $245-252$.

Leclant, J. 1975 - «Les verreries de la nécropole méroïtique de l'Ouest à Sedeinga (Nubie soudanaise)", dans K. Michalowski (éd.), Nubia-Récentes Recherches. Actes du colloque nubiologique international au musée de Varsovie, 19-22 juin 1972, p. 85-87.

Lepsius, C.R. 1849-1859 - Denkmäler aus Aegypten und Aethiopien, 12 vol., Berlin,

Riemer, H. et F. Förster 2013 - «Ancient desert roads: Towards establishing a new field of archaeological research", dans H. Riemer, H. et F. Förster (éds), Desert Road Archaeology in Ancient Egypt and Beyond., Cologne, p. 19-58.

Rilly, Cl. 2008 - «Enemy Brothers. Kinship and Relationship Between Meroites and Nubians (Noba)", dans Godlewski W. et A. Łajtar, Between the Cataracts. Proceedings of the 1oth Conference of Nubian Studies, Warsaw, 27 August-2 September 2006, Part. I. Mains Papers, Varsovie, p. 211-225. 2010 - Le méroïtique et sa famille linguistique, Paris. 
2013 - «Sur les traces de Jean Leclant à Sedeinga: les textes méroïtiques du prince Natemakhora", ArchéoNil 23, p. 91-110. 2017 — «Histoire du Soudan, des origines à la chute du sultanat Fun", dans O. Cabon (éd.), Histoire et Civilisations du Soudan, Paris, p. 25-445.

Rilly, C. et Francigny, V. 2011 - "The Late Meroitic Cemetery at Sedeinga. Campaign 2010», Sudan \& Nubia 15, p. 72-79 2012 - "Excavations of the French Archaeological Mission in Sedeinga, Campaign 2011", Sudan \& Nubia 16, p. 60-71. 2018 - "Closer to the Ancestors. Excavations of the French Mission in Sedeinga 2013-2017", Sudan \& Nubia 22, p. 65-74.

Shaw, W.B.K. 1929 - "Darb El Arba in. The Forty Days' Road». Sudan Notes and Records 12, p. 63-71. 



\section{Saï, aux origines \\ de l'archéologie \\ franco-soudanaise}

Vincent Francigny 
cinquantenaire

\section{2}

de la section

française

de la direction

des Antiquités

du Soudan
À l'origine de la collaboration archéologique entre la France et le Soudan, que reflète la grande longévité du centre permanent de recherche établi à Khartoum en 1969 , on trouve un certain nombre d'initiatives dont la plus ancienne est celle de la mission archéologique de l'île de Saï, fondée en 1954. Bien qu'elle n'ait fonctionné que de manière intermittente, c'est cette mission qui permit à la France, plus d'un siècle après les exploits de Cailliaud et Linant de Bellefonds, de proposer aux autorités soudanaises, engagées sur la voie de l'indépendance, de miser sur un savoir-faire indiscutable en matière de patrimoine et de recherche archéologique. Le cinquantenaire de la Sfdas, qui met à l'honneur un dispositif unique dans le pays, est l'occasion de revenir sur toutes ces initiatives et de rendre hommage à leurs inventeurs, à leur détermination et à leur courage.

\section{J'y vis les ruines d'un petit temple égyptien...}

C'est avec ces mots que Frédéric Cailliaud (1826) décrivit son arrivée sur la ville antique de Saï, après avoir franchi le fleuve et fait escale à la petite église médiévale située au nord de l'île. Les choses n'étaient pourtant pas gagnées d'avance car Cailliaud, comme tous les voyageurs qui l'avaient précédé dans la région en ce début de XIX ${ }^{e}$ siècle, ne trouva guère d'embarcation pour se rendre sur place. Convaincu de l'intérêt que pouvait avoir une île aussi grande en plein cœur de la Nubie, il ne dut sa réussite qu’à son équipe qui lui fabriqua un radeau de fortune avec des branches de palmiers dattiers et de roseaux. Après vingt minutes de laborieuse traversée, Cailliaud devint ainsi le premier Européen à fouler le sol de Saï et à en décrire les quelques vestiges qui s’offraient à lui.

Près d'un siècle et demi auparavant, un voyageur turc ottoman nommé Evliya Çelebi s'était déjà rendu à Saï. Parcourant et décrivant les territoires conquis par la Sublime Porte, périple qu'il compila dans les dix volumes de son «Livre des voyages», il y fit halte en 1673, Saï étant alors la forteresse la plus au sud de l'Empire. Cependant, comme il ne décrivit pas le patrimoine ancien de l'île, c'est bien à Cailliaud qu'on attribua l'invention du site.

Cette prouesse du Français, qui n'occupe pourtant que quelques pages dans sa publication, eut un impact important sur l'histoire de la recherche archéologique dans la région. En associant l'île à la présence égyptienne durant l'Antiquité, elle plaça Saï sur la liste des lieux à visiter pour la plupart des expéditions qui s'aventureraient dès lors en Nubie. Parmi elles, celle dirigée par Karl Richard Lepsius marqua un tournant. Conçue sur le plan scientifique et documentaire à la manière de l'expédition napoléonienne en Égypte, elle fut la première à prélever des pièces archéologiques à Saï, dont une inscription méroïtique, et à en livrer une description circonstanciée. 
De toutes les descriptions qui s'égrenèrent ainsi jusqu'au début du $\mathrm{xx}^{\mathrm{e}}$ siècle, il faut mentionner celle du prolifique égyptologue Sir Wallis Budge (1907), qui travaillait alors pour le British Museum, et dont les interprétations malheureusement erronées influencèrent longtemps les débats sur la datation des vestiges de Saï. En attribuant la première fortification du site à Sésostris III, puis la construction d'une importante forteresse à Amenhotep III, il véhicula l'idée que Saï avait été conquise par les Égyptiens dès le Moyen Empire, une erreur qui s'inscrira dans le temps et que l'on retrouvera pendant des décennies jusque dans l'ouvrage de référence Porter-Moss (1952). Ses conclusions engendrèrent aussi une confusion sur la nature des fortifications visibles à l'époque en surface, dont on sait qu'elles ne sont pas égyptiennes mais correspondent à un édifice militaire fondé au XVI siècle par les Ottomans.

Fort heureusement, l'année où parut The Egyptian Sudan (Budge 1907) fut aussi celle où le premier égyptologue américain, James Henry Breasted, mit les pieds à Saï. Sa visite et surtout les photos qu'il prit sur place permirent de rétablir en partie la vérité sur la datation en apportant la preuve d'une importante activité de construction sous le règne de Thoutmosis III. Breasted s'arrêta en particulier sur un détail d'un pilier de temple gisant au sol dans les décombres de la forteresse et sur lequel on pouvait voir, sous l'iconographie officielle du roi Thoutmosis III accueilli par Amon, une petite inscription ajoutée après coup au nom du vice-roi de Nubie Nehy. Le texte, précédé d'une représentation de Nehy agenouillé les mains levées en signe d'adoration (fig. 1), détaille l'ordre donné par le roi durant la $25^{\mathrm{e}}$ année de son règne de reconstruire en pierre le temple à Amon jusque-là érigé en briques. Breasted livra aussi quelques éléments d'une autre inscription remontant cette fois à Thoutmosis I, qu'il vit en contrebas du temple sur un rocher au bord du Nil. Il n'existe malheureusement aucun fac-similé de cette inscription aujourd'hui disparue, l'important n'étant pas là mais dans les conclusions qu'elle apporte en faisant remonter la présence égyptienne à Saï au début de la XviII ${ }^{\mathrm{e}}$ dynastie.

Dans les premières décennies du $\mathrm{xx}^{\mathrm{e}}$ siècle, l'exploration pionnière de la Nubie céda progressivement la place à des missions de fouilles ciblant les grands sites royaux et provinciaux du Nord du Soudan. Depuis ces missions, il n'était pas rare que les équipes étendent leurs recherches dans la région avoisinante, soit de manière systématique, soit au gré de visites effectuées durant les jours de repos. C'est ainsi que l'anglais Herbert Walter Fairman, qui travaillait non loin sur le site d'Amara Ouest, découvrit lors d'une excursion à Saï les restes d'une statue royale représentant le souverain Ahmosis; statue complétée quelques années plus tard par des villageois qui en exhumèrent la tête. 


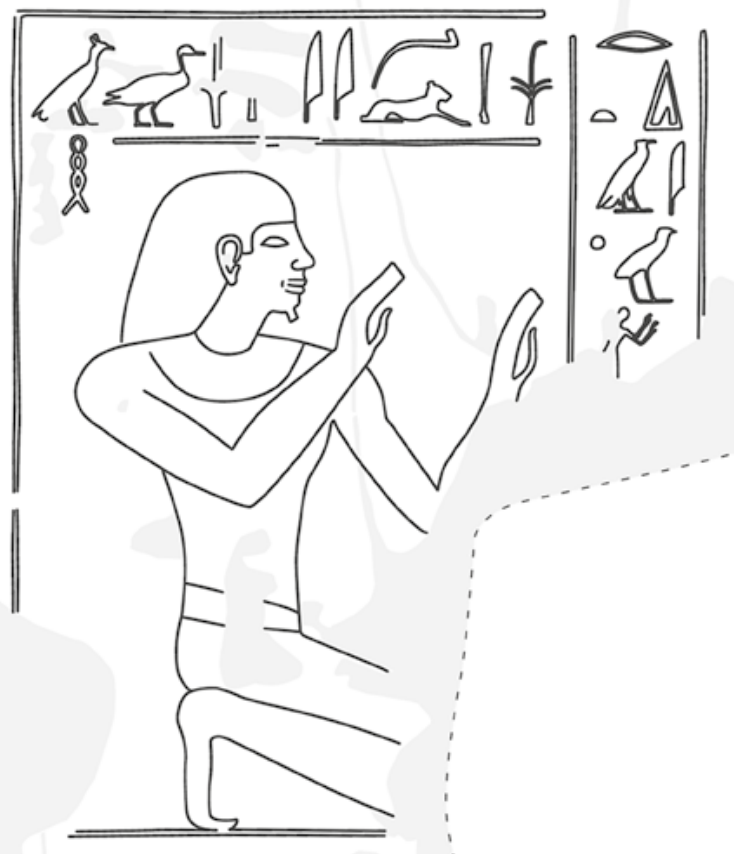

cinquantenaire

1. Représentation du vice-roi Nehy (fac-similé A. Guillou).

54

de la section

française

de la direction des Antiquités du Soudan

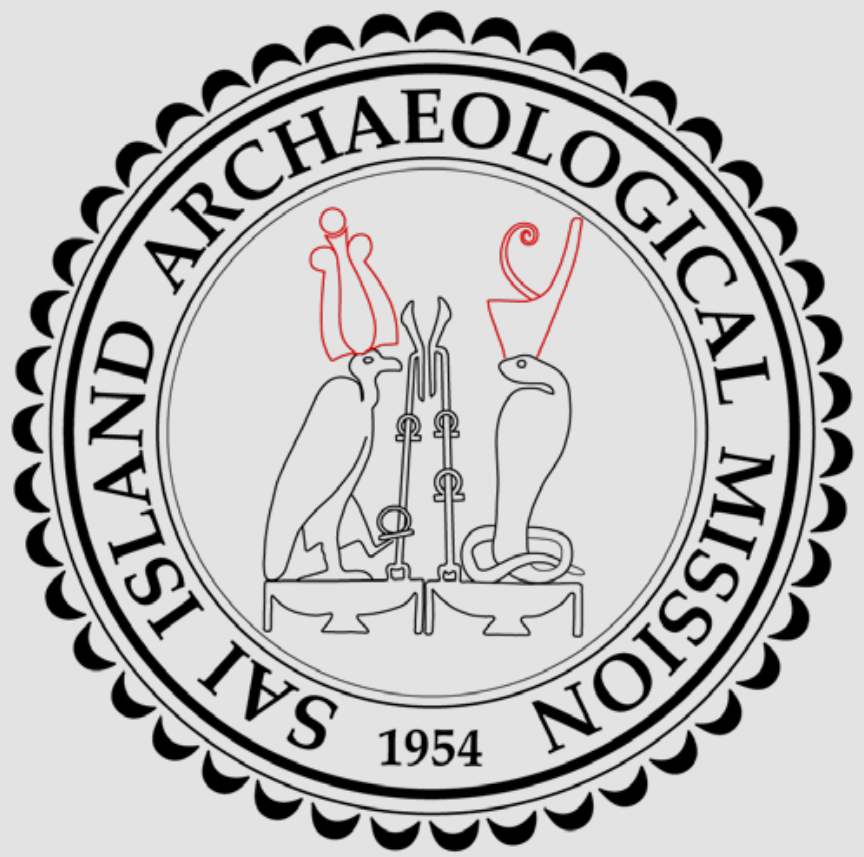

2. Logo de la mission (dessin V. Francigny). 
Une seconde statue relativement similaire, mais à l'effigie d'Amenhotep I ${ }^{\text {er }}$, fut découverte un peu plus tard. L'ensemble ainsi composé rouvrit le débat sur la fondation de la ville égyptienne au Nouvel Empire. Pour un certain nombre de chercheurs, dont Vivian Davies (2017), il ne fait aucun doute que ces statues, bien que partageant de nombreux traits communs, ont été réalisées à des époques différentes. Parmi les arguments avancés, on évoque notamment leuts proportions légèrement différentes. Aussi le fait que l'inscription de la statue d'Ahmosis comporte uniquement une dédicace à Amon-Rê, alors que celle d'Amenhotep I ${ }^{\text {er }}$ en possède une seconde à Dedoun. En d'autres termes, l'établissement de Saï aurait été fondé sous Ahmosis, il aurait disposé d'un temple ou d'une chapelle dans lequel un culte lui aurait été rendu et, plus tard, lors du règne de son fils et successeur Amenhotep I ${ }^{\text {er }}$, on aurait sculpté la seconde statue dans le style de la première par souci de continuité ou en guise d'hommage.

Pour d'autres, dont Luc Gabolde (2012) qui a pu récemment réétudier un grand nombre de documents épigraphiques sur place, tout laisse croire que ces deux statues sont contemporaines. Les arguments pour soutenir cette thèse, nombreux et convaincants, portent sur l'analyse de la pierre, un grès fin moucheté assez singulier et parfaitement similaire sur les deux entités, et sur des considérations esthétiques et épigraphiques. On note, par exemple, le même caractère frustre de la sculpture et une composition identique pour chaque statue. Le port de la robe jubilaire par chacun des souverains, vêtement plutôt rare dans la tradition statuaire au Nouvel Empire, est un autre facteur qui invite à penser que les deux pièces furent réalisées de concert. Enfin, la composition des textes, relativement identique, suggère également une gravure commune ${ }^{1}$.

Un autre ensemble d'inscriptions semble corroborer cette chronologie. Sur deux linteaux polychromes en pierre mis au jour dans les fondations $\mathrm{du}$ temple d'Amon, on voit le cartouche du roi Thoutmosis III entouré des noms d'Amenhotep Ir (Amnehotep à gauche et Djeserkarê à droite). Le choix du souverain de se placer sous la protection du pharaon Amenhotep Ir pourrait en effet indiquer que ce dernier est à la fois considéré comme l'ancêtre protecteur du sanctuaire et le probable fondateur de la ville. Jusqu'à présent, aucune autre découverte archéologique n'est venue contredire ce scénario, le matériel céramique trouvé à Saï et datant du début de la XviII ${ }^{\mathrm{e}}$ dynastie pouvant aussi bien correspondre à l'un ou l'autre règne.

1 Luc Gabolde (2012) avance l'hypothèse du caractère posthume de la statue d'Ahmosis en raison de l'absence de l'épithète di-anx dans l'inscription, alors qu'elle est présente sur l'inscription dédiée à Amenhotep I ${ }^{\text {er. }}$. 
Depuis la première description de ses vestiges égyptiens par Cailliaud, Saï est devenue un site majeur de la recherche archéologique visant à comprendre comment la Nubie fut annexée puis administrée par les Égyptiens. Premier établissement fondé lors de la conquête, qui fut lente et connut de nombreux revers, le site archéologique de la ville, qui fait à nouveau l'objet d'un programme de fouilles depuis 2017, devrait permettre de répondre à de nombreuses questions encore en suspens sur les règles appliquées par les belligérants envers les populations nubiennes et leur culture.

\section{Une île sur le Nil}

cinquantenaire

\section{6}

de la section

française

de la direction

des Antiquités

du Soudan

Dans une région aussi désertique que la Nubie, l'implantation des communautés a souvent été guidée par les contraintes environnementales. Dans un contexte majoritairement hostile, les rives du Nil sont bien entendu en première ligne et les îles, d'incontournables sources de terres arables pour l'agriculture. Sur le plan militaire, lorsqu'une île dispose d'une taille suffisante pour abriter un établissement et que sa topographie assure un contrôle du trafic fluvial, elle devient un enjeu stratégique de premier ordre. C'est ce qui arriva à Saï qui, dès l'époque Kerma, devint le principal foyer de population dans la région et par conséquent le premier rempart face au voisin du nord. Lorsque les Égyptiens décidèrent d'envahir la Nubie et de lancer leurs armées vers la capitale du royaume de Kerma, la prise de Saï devint naturellement une priorité, tant pour le symbole de victoire face à une importante implantation ennemie, que pour les aspects logistiques, l'île pouvant servir de tête de pont à l'armée pour la suite de la conquête.

Cette histoire orageuse contraste avec le calme apparent de Saï aujourd'hui, où la richesse des témoignages du passé s'efface derrière le quotidien des communautés villageoises d'agriculteurs qui y résident. Saï n'est plus un atout stratégique, sauf pour les archéologues. Car une île, même sur un fleuve, est un terrain de recherche privilégié en ce sens qu'il génère de facto une forme de conservatisme favorable à la préservation du passé. Au sein du règne végétal ou animal, on se mélange moins et on développe une plus grande homogénéité biologique sur un territoire tant soit peu isolé. C'est une aubaine pour toutes les études cherchant à déceler des anomalies pouvant indiquer l'origine allochtone d'un individu ou d'un objet, par exemple dans le cadre de l'analyse des corps ou du mobilier retrouvés dans les tombes de Saï. On en tire des outils de recherche particulièrement précieux pour aborder les questions de la colonisation d'un territoire, du remplacement éventuel de ses élites et des transmissions culturelles qui se sont opérées. 
De façon plus empirique, une île comme Saï, c'est aussi l'assurance de travailler dans un conservatoire naturel qui a moins souffert des affres du développement. De par ses petites dimensions $(4 \mathrm{~km}$ de large, environ $10 \mathrm{~km}$ de long), et faute de pont et d'une population suffisamment dense qui aient pu justifier des opérations d'envergure, on a moins eu tendance à y développer des infrastructures durant le $x^{\mathrm{e}}$ siècle. Ainsi, l'île n'a été raccordée au réseau électrique qu'en 2018. Les projets d'agriculture y demeurent aussi moins prégnants, ce qui prolonge un peu le sursis des sites ne faisant pas l'objet d'un programme de fouille ou de mesures de protection particulières.

Dans le passé, Saï joua un double rôle stratégique. L'île permettait de contrôler le fleuve et occupait une position charnière entre deux mondes: la puissance égyptienne au nord, portée aux époques tardives par les grands empires méditerranéens, et les divers royaumes nubiens au sud. Les eaux du lac Nasser ayant désormais recouvert la plupart des sites de Basse Nubie, Saï est aussi devenue l'un des rares lieux où l'enquête sur les métissages culturels et les syncrétismes religieux engendrés par la conquête égyptienne peut encore être poursuivie.

Un autre élément clef pour comprendre l'importance du site est son rôle joué dans l'économie de l'or qui gravitait autour du territoire nubien. Dès le Moyen Empire, les Égyptiens avaient cadenassé le nord de la Nubie par un réseau d'imposantes forteresses régulant l'accès aux pistes menant vers les mines et les régions auriferes, en particulier celles du Wadi Allaqi et du Wadi Gabgaba. Une fois le territoire pacifié et un réseau de villes nouvelles créé dans les provinces de Wawat et de Kush, le périmètre d'extraction fut élargi à un plus grand territoire; de même, le tribut nubien annuel, qui comprenait également de l'or, dût forcément transiter par des relais sécurisés. La récente découverte à Saï de la tombe d'un chef des orfevres (Budka 2017) est significative de cette dynamique, cruciale pour la royauté pharaonique.

\section{Du site au projet scientifique}

C'est en ayant toutes ces considérations historiques et environnementales à l'esprit que Jean Vercoutter décida en 1954 d'établir une mission archéologique sur l'île de Saï. Le logo de la nouvelle mission réalisé en 2019 (fig. 2) rappelle cette date fondatrice qui fit naître entre la France et le Soudan une relation privilégiée de confiance et de coopération en matière de patrimoine. Jean Vercoutter fut la véritable cheville ouvrière de cette relation en acceptant de devenir, à la suite d'illustres prédécesseurs britanniques, le nouveau Commissioner for Archaeology du service des Antiquités du Soudan; un service qu'il guidera sur la voie de l'indépendance en formant un successeur soudanais, Thabit Hassan Thabit. 
cinquantenaire

\section{8}

de la section

française

de la direction

des Antiquités

du Soudan
Convaincu par le potentiel que représentait une ville égyptienne entière à fouiller, avec son sanctuaire et ses nécropoles, Jean Vercoutter souhaitait développer à Saï un projet ambitieux et une infrastructure pérenne. Dès le début, il dota la mission de moyens d'envergure, installant notamment un système Decauville sur rail pour évacuer les déblais de la partie sud de la ville recouverte par une forteresse ottomane. Mais à peine s'était-il lancé dans ces travaux que fut prise la décision de rehausser significativement le barrage d'Assouan, condamnant les grands sites de Basse Nubie dont la forteresse de Mirgissa où Jean Vercoutter dut intervenir. Dès 1959, sous l'égide de l'Unesco, ce qui resta dans les mémoires comme «la campagne de Nubie» devint mondiale et couvrit toute la région.

Jean Vercoutter ne put reprendre les travaux à Saï qu'en 1969, pour une dizaine de saisons marquées par plusieurs interruptions. Accompagnée par l'architecte Michel Azim, la fouille des quartiers sud de la ville prit en quelques années une ampleur sans précédent. Les niveaux égyptiens souvent enfouis sous plusieurs mètres de déblais furent atteints rapidement. Cette stratégie foudroyante eut pour corollaires la maigreur de la collecte de données concernant la période médiévale et la faiblesse de l'interprétation des stratigraphies complexes encore visibles aujourd'hui sur le site.

Dans les quartiers sud mis au jour, deux types de bâtiments furent fouillés. Les premiers correspondent à des séries de magasins rectangulaires de grande taille et pour la plupart voûtés. Disposés le long de rues parfois très larges, ils sont le fruit d'une profonde réorganisation du tissu urbain réalisée par-dessus une ancienne zone de stockage dont il reste quelques traces de silos circulaires. Des aménagements tardifs y ont été retrouvés, divisant certains espaces en de plus petites structures. Ces bâtiments jouxtent un quartier résidentiel marqué par la présence de petites maisons faisant face à un imposant édifice palatial que les fouilleurs attribuèrent à la présence d'un gouverneur sur l'île (fig. 3).

L'exploration de ces secteurs permit la découverte d'un important mobilier usuel et de nombreux blocs de pierre en place ou en position secondaire de remploi. Parmi eux, beaucoup étaient décorés ou portaient des restes d'inscriptions hiéroglyphiques, laissant penser un temps à Jean Vercoutter qu'il pouvait y avoir eu plusieurs sanctuaires au sein de la ville.

Ces fructueuses recherches connurent cependant quelques interruptions en raison du manque d'ouvriers. Dans les années soixante-dix, la région de Saï, comme une grande partie de la Nubie, subit en effet un exode rural qui laissa les villages exsangues. Ce fut un bien pour un mal: lorsqu'il dut abandonner ces fouilles d'envergure, Jean Vercoutter entreprit un travail d'exploration plus fin qui permit la découverte sur l'île de nombreux sites importants jusqu'alors inconnus. 


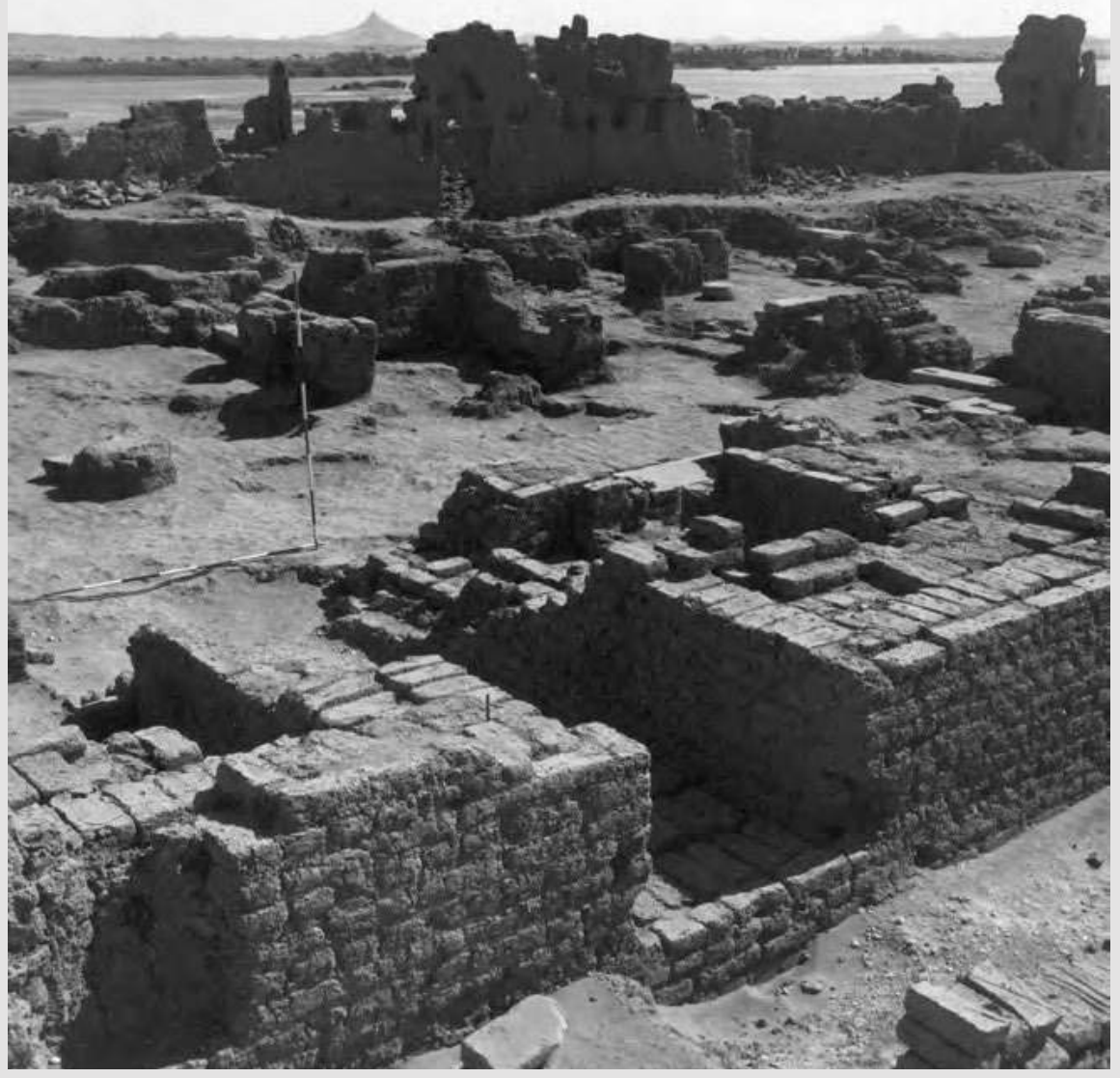

59

3. Anciennes fouilles sur la ville (archives Jean Vercoutter).

Saï,

aux origines

de l'archéologie

franco-

soudanaise

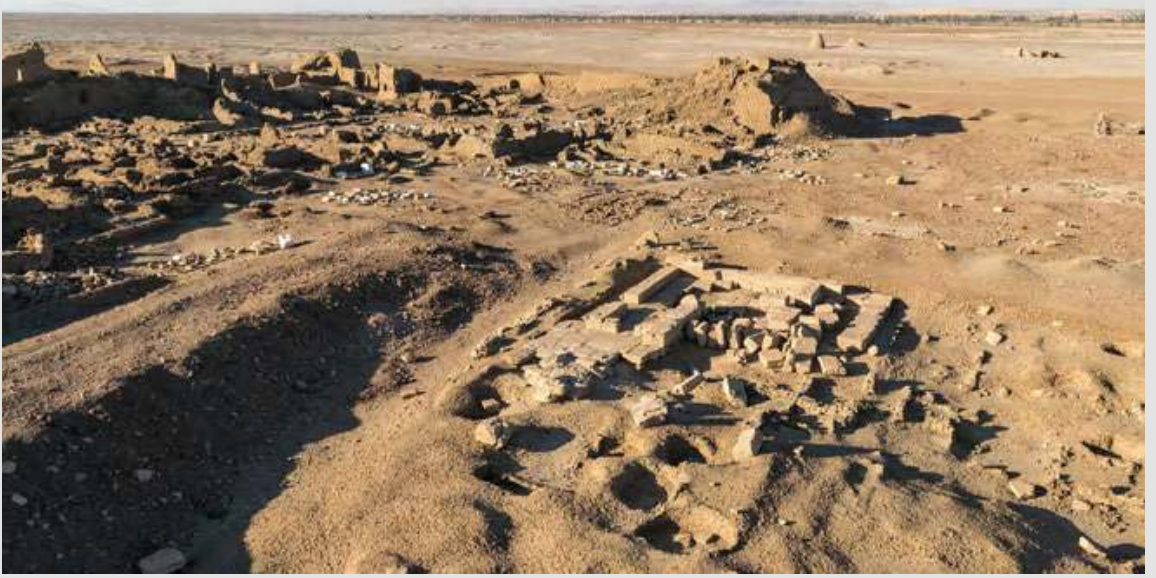

4. Ruines du temple d'Amon (photo Olivier Cabon). 


\section{Un temple aux origines incertaines}

Malgré ces aléas, la priorité absolue, qui était de dégager les restes du temple localisé au sud-est, fut maintenue, le travail étant facilité par la faible conservation des vestiges (fig. 4). Démonté durant l'antiquité tardive et la période médiévale, mais aussi endommagé par les effondrements de la falaise sur laquelle il était perché, il ne subsistait en effet de ce sanctuaire jadis dédié à Amon que quelques arases de pierre dans sa partie occidentale. Malgré ces apparences peu encourageantes, les fouilleurs y découvrirent pas moins de huit dépôts de fondations richement dotés (Thill 1994). Ces derniers, typiques de la XviII ${ }^{\mathrm{e}}$ dynastie, comprenaient surtout de la vaisselle céramique ainsi que des modèles d'instruments et d'outils rappelant la cérémonie de fondation et la future construction de l'édifice: houes, meules, mortiers et moules à briques miniaturisés en terre cuite, parfois associés à des amulettes et plaquettes votives en faïence.

Orienté selon un axe est-ouest avec une porte aujourd'hui disparue qui devait faire face au Nil et au soleil levant, le sanctuaire devait rivaliser de hauteur avec l'enceinte de la ville. On estime souvent à propos de ses fondations, comme pour celles d'autres bâtiments, qu'elles reposaient

cinquantenaire

\section{0}

de la section

française

de la direction

des Antiquités

du Soudan sur une terrasse artificielle faite de petits galets. Cependant, la nature parfaitement homogène de cette couche constituée de galets roulés et de sable de rivière, qui plus est dénuée de restes anthropiques et se rencontrant à de nombreux endroits du site, renvoie plutôt à un dépôt naturel ayant éventuellement fait l'objet d'un terrassement.

Le temple, lorsqu'il était debout, comportait un sanctuaire axial classique, doté d'une antichambre encadrée par des salles latérales. Un portique devait s'élever au-devant ou au sein d'une cour intérieure, comme l'attestent les imposants piliers à section carrée que Breasted photographia en 1907. La construction de cette adjonction a sûrement accompagné un changement majeur de l'antichambre, divisée en deux, créant ainsi une sorte de vestibule rayonnant sur des salles latérales, elles aussi divisées en deux. De nombreuses phases d'agrandissement ou de rénovation semblent avoir eu lieu, mais leur séquençage et leur chronologie restent incertains, tant les vestiges in situ sont fragmentaires.

En se basant sur les archives de la mission, une récente étude s'est focalisée sur les structures antérieures recouvertes par le temple (Azim et Carlotti 2012) dont les dépôts assurent une fondation sous Thoutmosis III. Ces vestiges, qui s'assimilent à de l'habitat composé de plusieurs maisons distinctes, furent datés de l'époque Kerma sur la base de fortes concentrations céramiques affiliées à cette culture et de parallèles architecturaux avec l'habitat rural découvert notamment sur le site de Gism el-Arba. 
Pourtant, tout porte à croire que ces maisons sont égyptiennes et correspondent en fait aux premières phases de l'établissement égyptien, avant qu'il ne fût en grande partie modifié sous Thoutmosis III qui le dota d'une enceinte. Le fait que du mobilier Kerma ait été retrouvé dans ces niveaux traduit plus la dépendance des premiers habitants à la production des marchés locaux, que l'existence d'une ville nubienne antérieure. Pour que la culture matérielle locale se soit égyptianisée, il eût en effet fallu que des processus longs et profonds se soient mis en place, bien au-delà des premiers temps de la colonisation.

En surface, le démantèlement du temple et la réutilisation massive de ses blocs ont paradoxalement permis de préserver quelques éléments clefs de son histoire. Le plus ancien exemple de ces démolitions est d'ailleurs d'époque pharaonique, puisqu'il tient à l'injonction faite à Nehy de remplacer le temple en terre crue par un édifice en pierre. C'est en effet dans les soubassements du temple de Thoutmosis III qu'on été retrouvés des linteaux également inscrits à son nom.

Ici, deux interprétations s'offrent à nous: soit, durant les différentes phases d'expansion du temple, une porte monumentale a été démontée et enfouie sous le nouveau bâtiment; soit ces éléments de porte proviennent d'un édifice qui se trouvait ailleurs et dont la démolition se serait terminée par la consécration d'une partie de ses pièces architecturales, en particulier celles inscrites au nom du roi et enterrées sous le nouveau sanctuaire. Rappelons en effet que des dépôts votifs accompagnaient certaines de ces pièces, elles-mêmes volontairement positionnées avec leurs inscriptions face contre terre, ce qui renforçait le caractère sacré de leur enfouissement.

Pour le reste des blocs issus du temple et retrouvés à Saï, ils connurent des fortunes diverses. Certains servirent de montant ou de seuil dans des bâtiments médiévaux, quand on ne tailla pas directement un escalier en leur sein. Leur recensement et leur étude, placés sous la direction de Luc Gabolde et Jean-François Carlotti, permettent de distinguer plusieurs jalons chronologiques de la vie du temple, jusqu'aux ramessides, et les spécificités des cultes qui y étaient rendus. Le corpus ainsi constitué et relativement figé depuis les années soixante-dix commence à nouveau à s'enrichir via de nouveaux programmes développés sur place. C'est ainsi, par exemple, qu'un linteau de Thoutmosis III fut découvert lors de la reprise des fouilles sur la nécropole d'élite méroïtique adjacente à la ville (fig.5). Servant de porte pour la chambre funéraire collective située au centre du cimetière, le bloc avait été savamment retaillé de manière à préserver les noms du roi et portait encore les stigmates d'une chute et des réparations au plâtre auxquelles on avait procédé. 


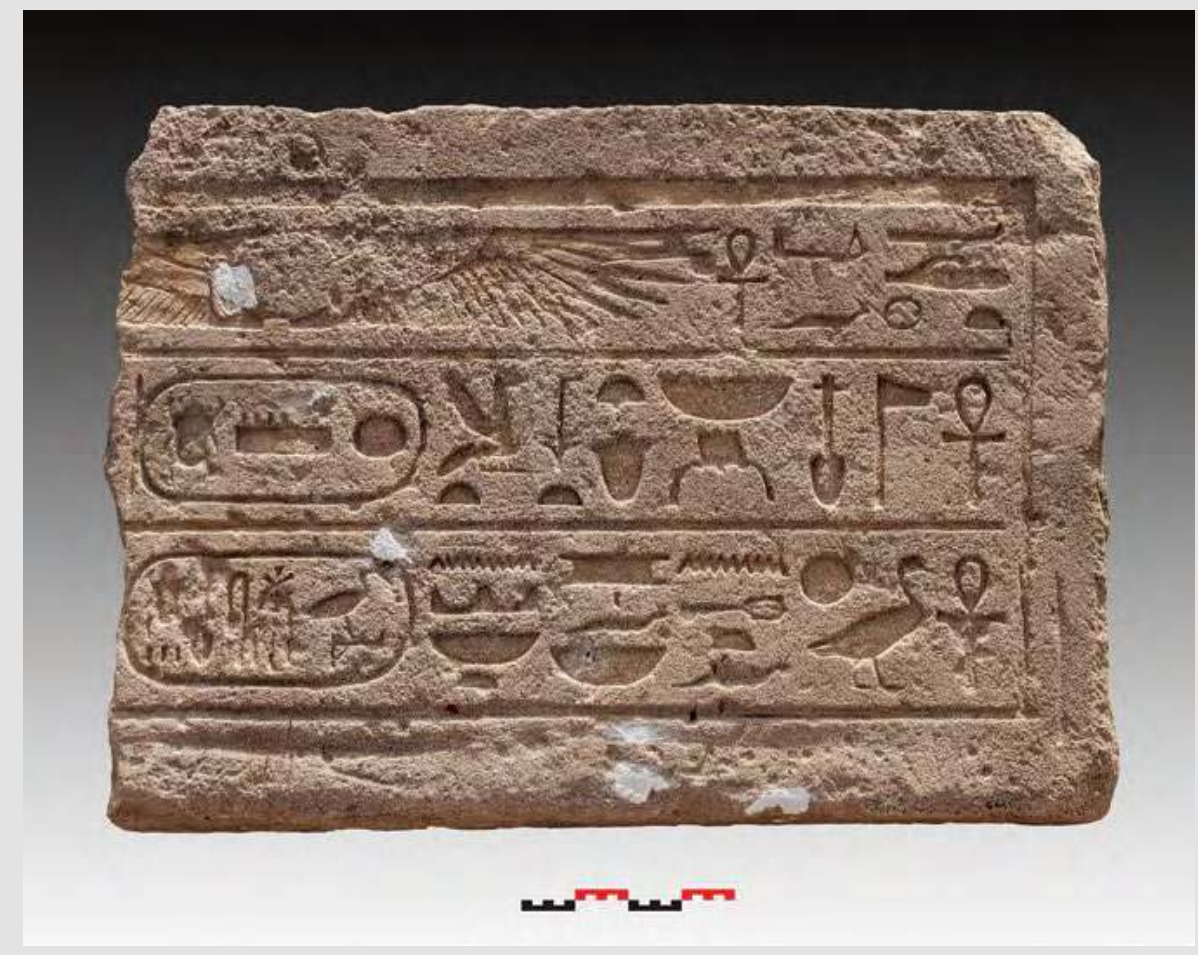

\section{2}

de la section

française

de la direction des Antiquités du Soudan

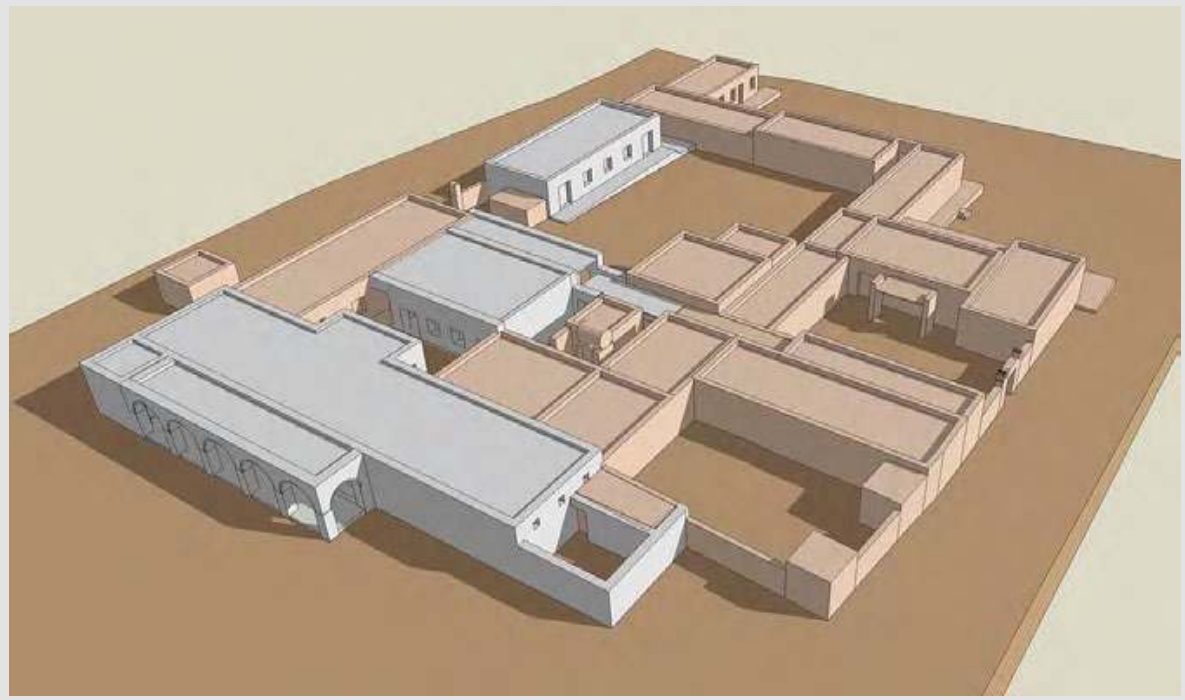

6. Projet de musée adjoint à la maison de fouille. 


\section{Un nouveau programme de recherche}

Mise en veille pendant une quinzaine d'années, la mission de Saï fut ressuscitée au milieu des années quatre-vingt-dix par Francis Geus, maître de conférences à Lille qui avait déjà travaillé sur le site et fut un élève de Jean Vercoutter. Durant plus d'une décennie, F. Geus remit à flot une infrastructure et développa des collaborations internationales qui étendirent grandement le champ de nos connaissances sur place, surtout dans le domaine de la Préhistoire. À sa mort, le chantier connut plusieurs programmes à court terme, dont l'un prévoyait justement la reprise des fouilles sur la ville pharaonique, délaissée depuis le début des années quatre-vingt. C’est dans la continuité de ce projet qu'en 2015 la mission fut confiée à Vincent Francigny, sous l'égide de la Sfdas et de la commission des fouilles du ministère des Affaires étrangères. Depuis 2019, la mission fait désormais partie des projets portés par l'UmR 8167-Orient et Méditerranée du CNRs et de la Sorbonne.

Débuté alors que la mission bénéficiait depuis plusieurs années d'un important soutien du Qatar Sudan Archaeological Project (QsaP), le nouveau projet mis en place à Saï allie à la fois recherches et questions patrimoniales. Ces dernières se traduisent par la mise en place d'un plan de gestion des zones archéologiques qu'accompagne la création d'un musée de site visant à les présenter au public (fig. 6). Sur un territoire aussi vaste, recouvert en partie par quatre villages distincts dotés de terres agricoles, il s'agit là d'un projet fédérateur autour d'un patrimoine commun que le récent développement de l'orpaillage menace.

Le premier dossier de recherche auquel s'est attelée la mission concerne les deux nécropoles kouchites qui avaient été découvertes par Francis Geus aux abords de la ville antique et dont la fouille avait été abandonnée suite à sa soudaine disparition. Affublés des matricules 8-B-5.A et 8-B-52.B issus des subdivisions géographiques proposées par la carte archéologique du Soudan de Friedrich Hinkel, il faut reconnaître derrière ces dénominations cryptiques la présence de deux cimetières élitaires de la période méroïtique. Dotés chacun de moins d'une centaine de tombes, ils ont colonisé deux petites éminences naturelles, selon une tradition bien établie en Nubie, qui leur font dominer symboliquement le reste des terres dédiées à l'enterrement des communautés locales. La scission en deux groupes d'élite, inhabituelle pour l'époque, s'expliquerait par la volonté des premiers de s'établir non loin du site de la ville où devait se trouver un sanctuaire kouchite, comme le confirme la découverte récente de blocs inscrits (Francigny 2015) aux noms du couple royal Natakamani et Amanitore (milieu du I ${ }^{\text {er }}$ siècle de notre ère). Le second groupe serait, quant à lui, enterré de façon plus traditionnelle en marge de la nécropole commune. 
Les premiers enseignements à tirer de cette recherche toujours en cours concernent l'apparente puissance de cette petite communauté provinciale pourtant installée loin des cercles de pouvoir de Napata et Méroé. La relation privilégiée à l'Égypte romaine se fait en particulier sentir à travers un mobilier funéraire compilant les exemples de produits et objets issus ou inspirés par les grands empires méditerranéens. La présence de pièces romaines, alors que Méroé dispose d'une économie non-monétaire, et d'autres artefacts rares en Nubie (fig. 7) laisse penser que ces contacts se faisaient non seulement via le commerce à longue distance mais aussi via des ambassades ou des pèlerinages de l'autre côté de la frontière. La découverte exceptionnelle de décrets amulétiques oraculaires inscrits sur des pièces de cuir va dans ce sens (Rilly 2008).

Sur le plan de l'organisation spatiale, les deux nécropoles se présentent sous la forme classique de regroupements de petites pyramides en briques crues qui imitent à moindre échelle les tombeaux royaux. Sous ces structures, des accès creusés en pente et parfois garnis de marches permettent de descendre vers la chambre funéraire qui, selon sa taille, était prévue pour un ou plusieurs enterrements. Quels que soient les cas de figure, la réutilisation de tombes anciennes était monnaie courante chez les Méroïtes, qu'elles aient été pillées ou nettoyées pour l'occasion.

La conservation exceptionnelle de certains corps et matières

64

de la section

française

de la direction

des Antiquités

du Soudan organiques, en particulier sur le site $8-B-52 . B$ où le substrat particulier semble avoir asséché l'atmosphère des tombes et maintenu une hygrométrie relativement stable, permet des observations anthropologiques d'une rare précision pour cette période. La présence systématique de nombreuses sépultures d'enfants dans les murs des pyramides et en surface (fig. 8) permet aussi de restituer une image plus fidèle de la population et des conditions de vie de l'époque, ces données faisant généralement défaut dans la plupart des publications anciennes de cimetières méroïtiques.

Le second dossier de recherche développé à Saï, qui s’inscrit dans une perspective de plus long terme, concerne la ville antique et médiévale en partie fouillée par Jean Vercoutter. C'est aussi le plus ardu dans la mesure où, pour le traiter, il faut obligatoirement revenir sur les conclusions déjà proposées il y a près de quarante ans et revoir la documentation à la lumière de nos connaissances actuelles et des nouvelles technologies mises à notre disposition. Afin d'appréhender l'infinie complexité d'un site urbain dont la longue occupation induit nécessairement de nombreuses phases de reconstructions et de changements, la décision fut prise dès la première saison, en 2017 , de commencer par dégager de grands espaces en surface afin de faire apparaitre des éléments d'organisation spatiale permettant d'orienter la poursuite des fouilles (fig. 9). 


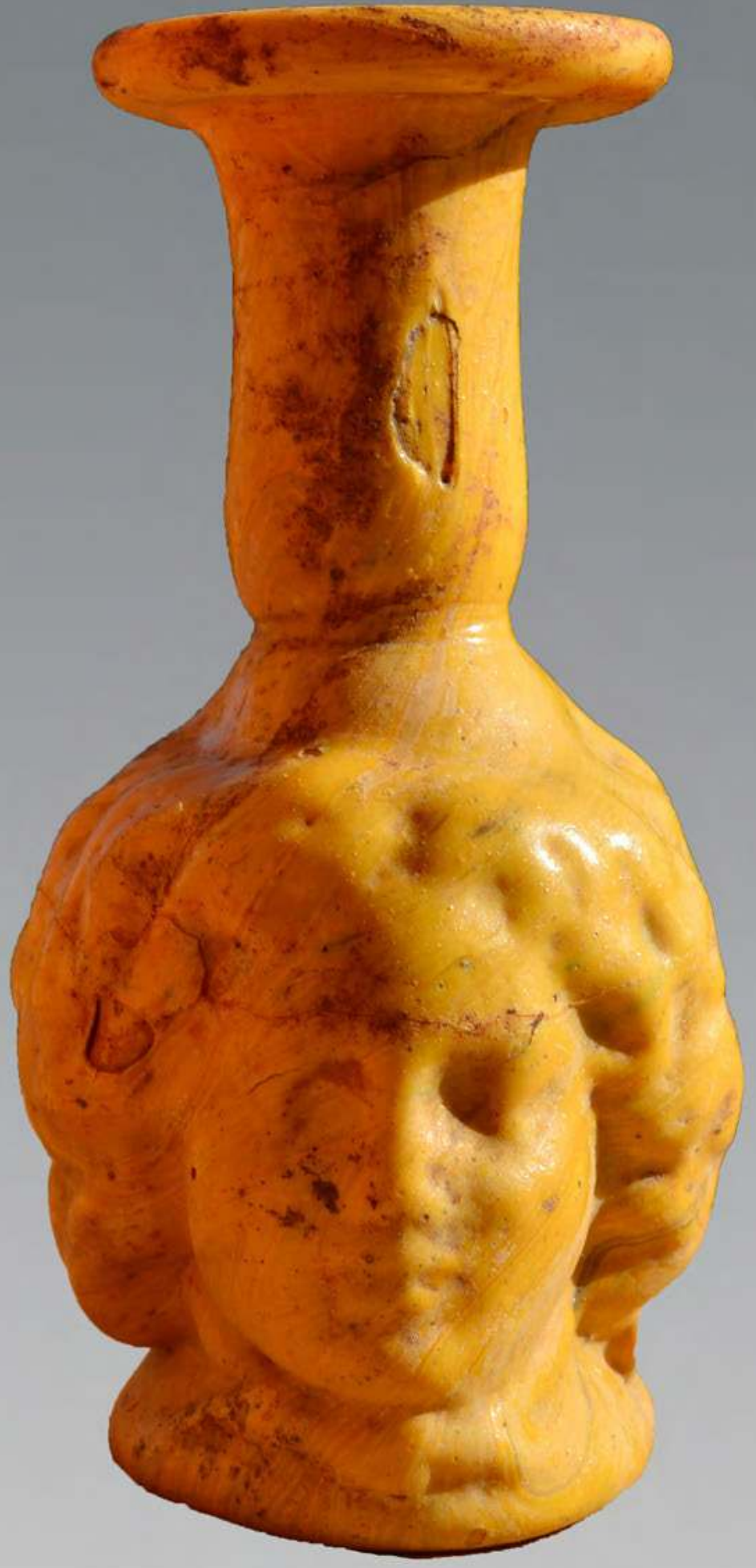

7. Flacon janiforme en verre moulé d'époque romaine (photo Vincent Francigny). 


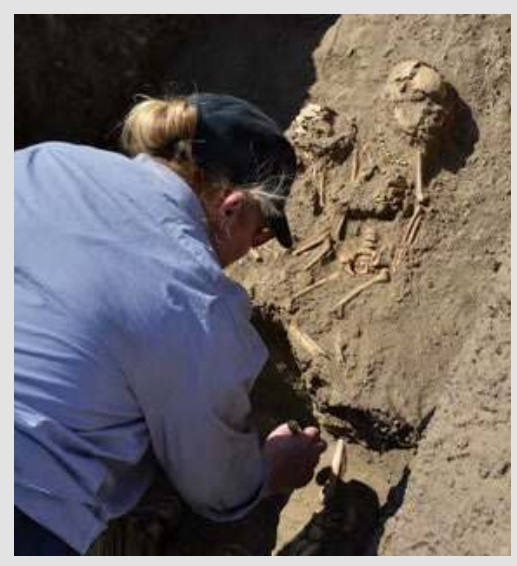

8. L'anthropologue Tosha Dupras fouillant des sépultures d'enfants (photo Vincent Francigny).

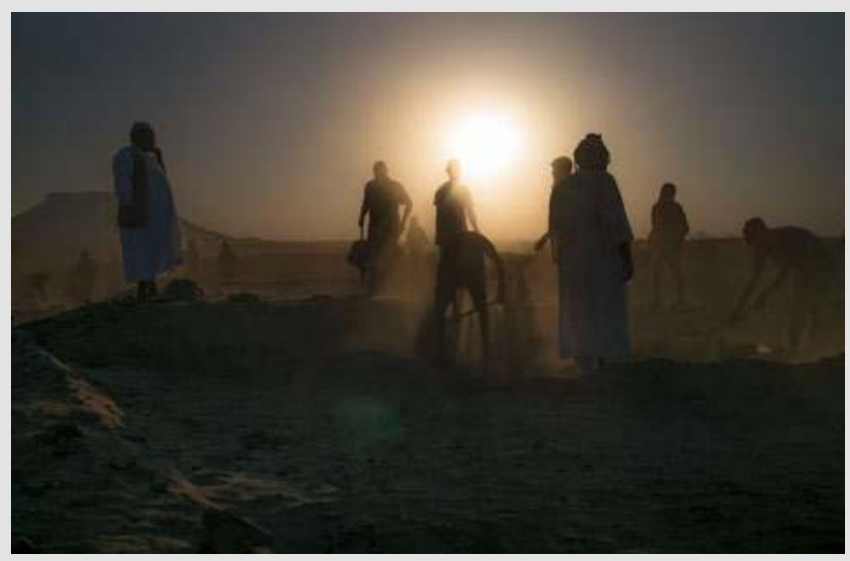

9. Ouvriers sur le chantier de fouille de la ville (photo Olivier Cabon).

cinquantenaire

\section{6}

de la section

française

de la direction des Antiquités du Soudan

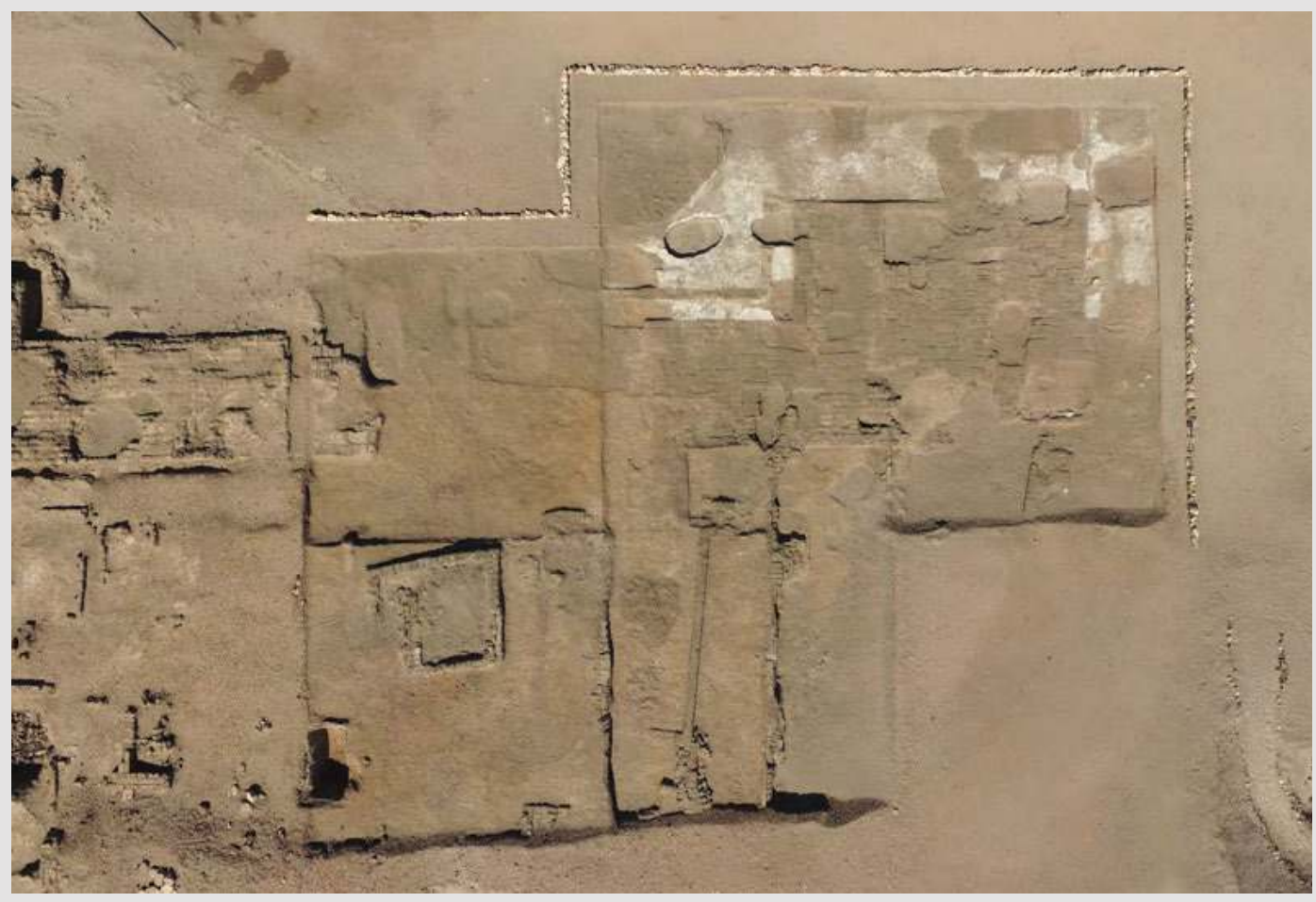

10. Angle Nord-Est de la fortification égyptienne

(photo Vincent Francigny). 
Cette stratégie fut payante puisqu'elle nous permit dès les premières semaines de repérer l'emplacement exact de l'angle Nord-Est de la fortification de la ville égyptienne qui avait échappé aux fouilles les plus récentes menées sur place. La découverte, d'importance, permit de placer correctement le mur d'enceinte Est de la ville et de définir avec précision la taille réelle de la ville, ce qui allait à l'encontre des nombreuses propositions existantes (Azim 1975; Adenstedt 2016, Budka 2018). Comme on pouvait s'y attendre, étant donné la position stratégique de l'établissement sur une falaise dominant le Nil, l'angle était pourvu d'un bastion quadrangulaire de grande taille qui permettait de surveiller le trafic fluvial en aval du fleuve (fig. 10).

Malgré les nombreuses perturbations tardives, fosses et destructions, la fouille a révélé une installation complexe et de grande qualité dotée d'un mur défensif de plus de $4 \mathrm{~m}$ d'épaisseur, lui-même doublé au nord (où l'exposition au vent et à l'érosion est la plus forte) d'un remblai de grès complété par un petit muret en briques crues. Le comblement, à l'époque médiévale, du fossé qui complétait ce dispositif militaire marque la fin de l'utilisation de celui-ci. C'est en effet durant l'ère chrétienne, qui débute $\mathrm{au}$ milieu du $\mathrm{VI}^{\mathrm{e}}$ siècle de notre ère, que les installations pharaoniques rendues caduques subirent de fortes transformations. Quand elles ne furent pas tout simplement supprimées sous l'effet de terrassements divers ou du remploi de ses matériaux de construction, elles servirent d'assise ou de base à de nouveaux bâtiments en briques crues. On constate ainsi que, dans ce qu'il restait de l'enceinte, des petites pièces furent creusées dans son massif, et que de nouveaux axes de circulation la traversèrent, étendant l'emprise urbaine au-delà des limites anciennes de la ville. De nouveaux murs épais apparurent aussi sur les bords extérieurs, indiquant qu'une infrastructure défensive plus légère avait été mise en place près du fleuve. La véritable surprise vint cependant de l'angle Nord-Ouest où les dégagements de surface mirent au jour un système défensif inédit, lui aussi d'époque médiévale, qui s'apparente plutôt à celui d'une forteresse. Un mur courbe au parement de pierre et doté d'un important bastion y fut dégagé, indiquant la possible présence dans le quart Nord-Ouest de la ville d'une place fortifiée inconnue jusqu'à ce jour.

Depuis le début de son exploitation dans les années cinquante et soixante-dix, le site était réputé avoir conservé les traces d'une occupation continue depuis l'Antiquité jusqu'à la fin de la période ottomane. Une série de vérifications fut donc entreprise pour confirmer ou infirmer cette chronologie, à commencer par des sondages au-dessous des niveaux égyptiens. Que ce soit dans le secteur sud ou au centre de la ville, ces derniers tombèrent sur un substrat naturel homogène concluant à l'absence d'habitat 
antérieur à cette phase. D'autres sondages et observations sur le bâti confirmèrent l'important bouleversement consécutif à la construction de l'enceinte, probablement au moment de la reconstruction du temple sous Thoutmosis III, la contrainte d'une aire désormais confinée entraînant une rationalisation de l'espace et la destruction, par exemple, des constructions circulaires de type silos.

En définitif, la séquence kouchite (napatéenne et méroïtique) attendue n'apparaît pas dans les couches récemment dégagées et semble aussi discutable sur les zones anciennement fouillées. À l'exception des restes d'un temple érigé au milieu du I $^{\text {er }}$ siècle de notre ère par Natakamani et Amanitore, les indices d'une ville datant de l'Antiquité Tardive font défaut. Il est vraisemblable qu'à cette époque, comme ce fut le cas durant l'âge de bronze avec des traces d'habitat Kerma retrouvés plus au sud de l'île, les communautés locales aient préféré installer leurs villages en bordure des terres cultivables plutôt que sur un plateau rocheux et stérile. La quantité importante de blocs architecturaux et de vestiges de bâtiments d'époque médiévale mis au jour sur la ville indique cependant que ce lieu stratégique fut à nouveau prisé durant l'ère chrétienne. L'étude d'une église, cernée d'une multitude d'édifices que marquent des kôms couverts de céramique et de briques cuites, pourra à l'avenir nous renseigner sur les raisons de ce regain d'intérêt pour Saï, qui devint alors le siège d'un évêché

\section{8}

de la section française de la direction des Antiquités du Soudan
Asdenstedt, I. 2016 - Reconstructing Pharaonic Architecture in Nubia: The Case Study of SAV 1, Sai Island, CAEN 3, Vienne.

Azim, M. $\quad 1975$ - «Quatre campagnes de fouilles sur la forteresse de Saï, 1970-1973", CRIPEL 3, Lille, p. 91-125.

Azim, M. et J.-F. Carlotti 2012 — «Le Temple A de l'île de Saï et ses abords", dans F. Doyen et D. Devauchelle (éds), Fouilles sur lîle de Saï (Soudan) 2005-2010, CRIPEL 29, Lille, p. 11-65.

Budge, E. W. 1907 - The Egyptian Sudan, Its History and Monuments, Londres. 
Budka, J. 2017 - «Pyramid cemetery SAC 5, Sai island, Northern Sudan an update based on fieldwork from 2015-2017", Egypt and the Levant 27, Vienne, p. 107-130.

2018 - "Acrossborders. Five seasons of work in the Pharaonic town, Sai Island», dans J. Budka et J. Auenmüller (éds), From Microcosm to Macrocosm. Individuals households and cities in Ancient Egypt and Nubia, Leiden, p. 113-126.

Cailliaud, F. 1826-1827 - Voyages à Méroé, au Fleuve Blanc au-delà du Fazoql, dans le midi du royaume de Sennâr, à Syouah, et dans cinq autres oasis, fait dans les années 1819, 1820, 1821 et 1822, Paris.

Davies, V. W. 2017 - «A statue-cache from Sai: Putting the pieces together", dans N. Spencer, A. Stevens et M. Binder (éds), Nubia in the New Kingdom, BMPES 3, Louvain, p. 133-148.

Francigny, V. 2015 - "The Meroitic Temple at Sai Island", dans M. Zach (éd.), The Kushite World. Proceedings of the $11^{\text {th }}$ International Conference of Meroitic Studies, Vienne, p. 201-211.

Gabolde, L. 2012 — «Réexamen des jalons de la présence de la XVIII ${ }^{\mathrm{e}}$ dynastie naissante à Saï", dans F. Doyen et D. Devauchelle (éds), Fouilles sur l'île de Sä̈ (Soudan) 2005-2010, CRIPEL 29, Lille, p. 115-137.

Porter, B. et R. L. B. Moss 1952 - Topographical Bibliography of Ancient Egyptian Hieroglyphic Texts, Reliefs and Paintings vol. 7, Oxford.

Rilly, C. 2012 — «Les textes méroïtiques de l'île de Saï», KUSH 19, Le Caire, p. 139-177.

Thill, F. 1994 - "Les dépôts de fondation du temple de Saï», La Nubie, Les Dossiers d'Archéologie 196, Paris, p. 32-33. 



\section{les sites de Kerma et de Doukki Gel}

Charles Bonnet

Séverine Marchi

Dominique Valbelle 
Depuis près de cinquante ans, une mission archéologique suisse, puis suisse-franco-soudanaise, poursuit ses recherches sur deux sites qui permettent de remonter aux origines de l'histoire du Soudan. Dès le début de nos travaux, nous avons bénéficié de l'expérience acquise par les fondateurs de la Sfdas, qui sont intervenus sur l'île de Saï où les vestiges pré-Kerma et les époques Kerma ont apporté des informations significatives sur la chronologie des céramiques et la typologie des tombes des différents cimetières.

D'autre part, la base logistique créée à Khartoum offrait des facilités dont a profité notre mission durant ces dernières décennies. Grâce à cette collaboration, nous pouvons présenter ici des résultats importants obtenus durant une très longue période. Des amitiés ont été nouées très tôt et d'utiles discussions scientifiques nous ont aidés à élaborer nos interprétations.

\section{L'établissement pré-Kerma}

cinquantenaire

\section{2}

de la section

française

de la direction

des Antiquités

du Soudan

Les cultures Kerma se sont développées en un premier ensemble vers 3000 avant J.-C., avec un établissement fortifié caractérisé par une puissante enceinte de terre et des poteaux de bois (fig.1). Plusieurs quartiers de huttes circulaires et des bâtiments quadrangulaires permettent de définir une topographie complexe comprenant de vastes surfaces réservées au stockage de plusieurs produits placés dans des jarres ou directement en sous-sol dans des fosses-silos.

Aujourd'hui situé à plusieurs kilomètres du cours du Nil, l'établissement était proche de bras du fleuve qui se sont peu à peu asséchés. L'agglomération pré-Kerma n'est que partiellement reconnue. Elle occupait une large bande de terrain, bientôt réutilisée par une vaste nécropole des troisième et deuxième millénaires avant J.-C. Cette dernière peut être rattachée aux phases culturelles d'un royaume indigène qui s'est étendu sur un immense territoire entre l'Égypte et l'Afrique centrale.

\section{La ville de Kerma}

De manière surprenante, la capitale de ce royaume était distante de quelque $700 \mathrm{~m}$ d'une seconde métropole antique aux proportions considérables. Ainsi, sans doute à la même époque, deux villes coexistaient sur un emplacement unifié en continuité d'une grande île limitée par les eaux du Nil. À Kerma, se sont multipliés les échanges avec l'Égypte et le bassin méditerranéen, comme nous avons pu le constater par la présence de milliers de sceaux et d'empreintes de sceaux préservés dans certaines habitations ou sur les places du noyau urbain. D'ailleurs, les contacts avec 


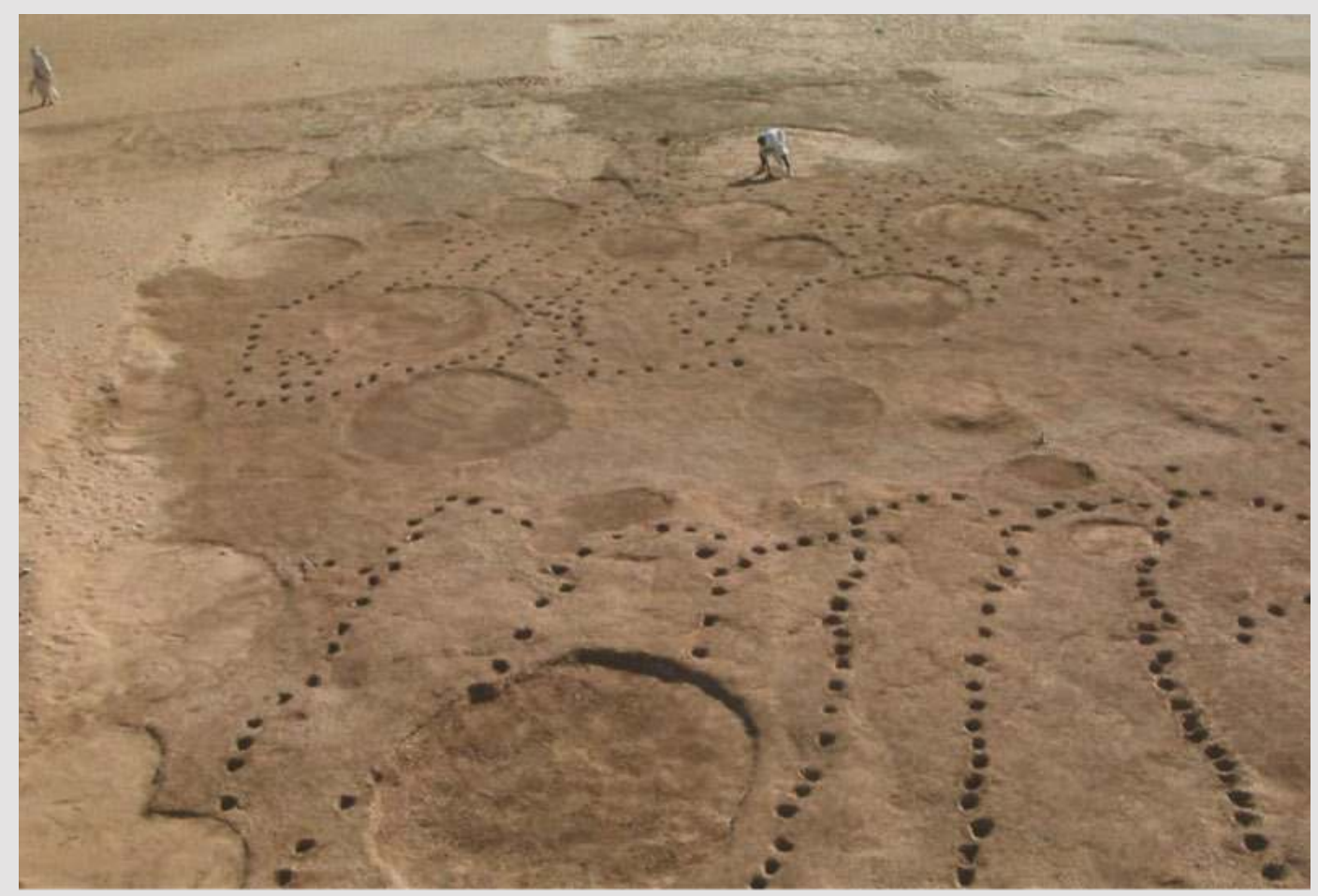

1. Vue de l'agglomération pré-Kerma (copyright de toutes les illustrations de cet article:

Mission archéologique suisse-franco-soudanaise de Kerma/Doukki Gel).

\section{3}

les sites

de Kerma

et de

Doukki Gel 
cinquantenaire

74

de la section

française

de la direction

des Antiquités

du Soudan

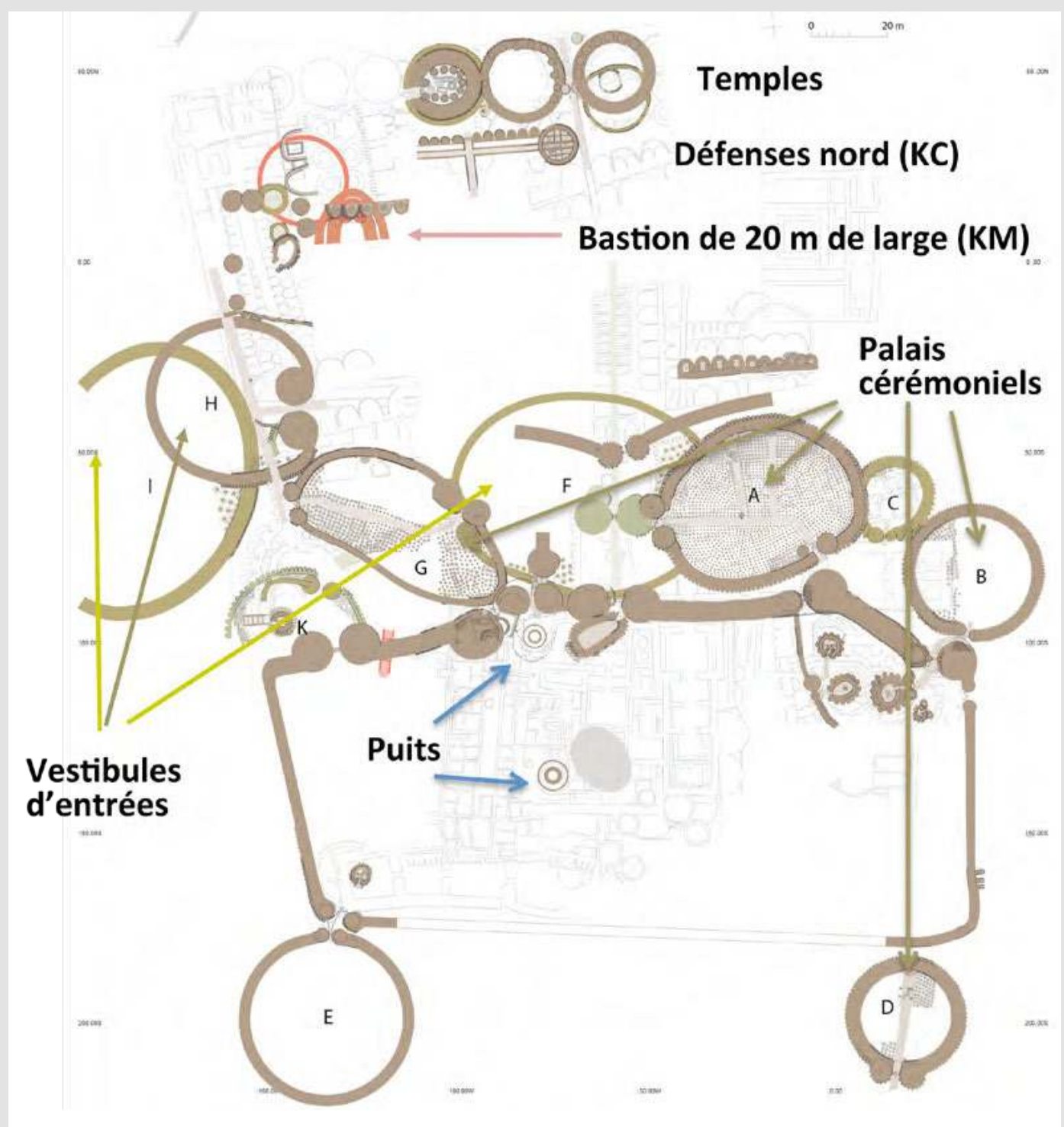

2. Plan schématique de la ville indigène de Doukki Gel. 
l'Égypte ont favorisé l'organisation de la ville où plusieurs institutions paraissent copier celles de l'État voisin. C'est aussi le cas pour l'architecture quadrangulaire des bâtiments de culte et des maisons. Il en va tout autrement de Doukki Gel où les constructions sont toujours de plans ovales ou circulaires et où nous avons pu étudier un mode de construction encore inconnu.

\section{Une deuxième ville sur le site de Doukki Gel}

Cette agglomération contemporaine de Kerma (fig. 2) est d'une interprétation délicate car nous ne pouvons pas utiliser une méthode comparative. Létrangeté des grands monuments d'un diamètre pouvant atteindre jusqu'à $70 \mathrm{~m}$ témoigne d'une influence méridionale. On a en effet l'impression que c'est en Afrique centrale que l'on devrait retrouver des exemples de ce type de constructions. La voie de pénétration nord-sud qui suit le Nil doit être comprise avec un axe est-ouest allant de la mer Rouge vers l'ouest en passant par Kassala, le Kordofan et le Darfour.

Malheureusement, nous ne savons presque rien sur l'occupation ancienne du Soudan central et, dans l'attente de nouveaux résultats archéologiques, nous devons essayer de comprendre une architecture étonnante, très différente des exemples récents du XviII ${ }^{e}$ siècle ou postérieurs. C'est vraisemblablement déjà vers 2000 avant J.-C. que cette influence africaine permet à des coalitions militaires de s'opposer à l'avance des troupes pharaoniques, sous l'impulsion du roi de Kerma. Les textes égyptiens font la preuve de la présence de chefs de guerre provenant des pays méridionaux à la tête des troupes rebelles. La ville de Doukki Gel, la Panébès antique, représente apparemment le point de rencontre où se retrouvaient les coalitions défendant le verrou de Kerma (fig. 3).

En réexaminant les hypothèses présentées par George Reisner il y a 100 ans, après trois saisons de fouilles seulement sur les sites de la ville de Kerma et de sa nécropole orientale, nous avons systématiquement étudié les ensembles urbains et funéraires. Il est apparu que, contrairement à une première évaluation, les grands édifices en briques crues qui avaient impressionné les premiers voyageurs du début du XIX siècle n'avaient pas été conçus par des architectes égyptiens. Ces deffufa, d'un nom local signifiant "une construction faite par l'homme, se détachant sur l'horizon", étaient en fait des bâtiments de culte souvent reconstruits, et cela par une population nubienne ayant des traditions qui se distinguaient nettement de celles des voisins du nord. La deffufa occidentale entourée par un quartier de chapelles était le temple principal marquant le centre d'une grande cité indigène devenue capitale d'un royaume. 


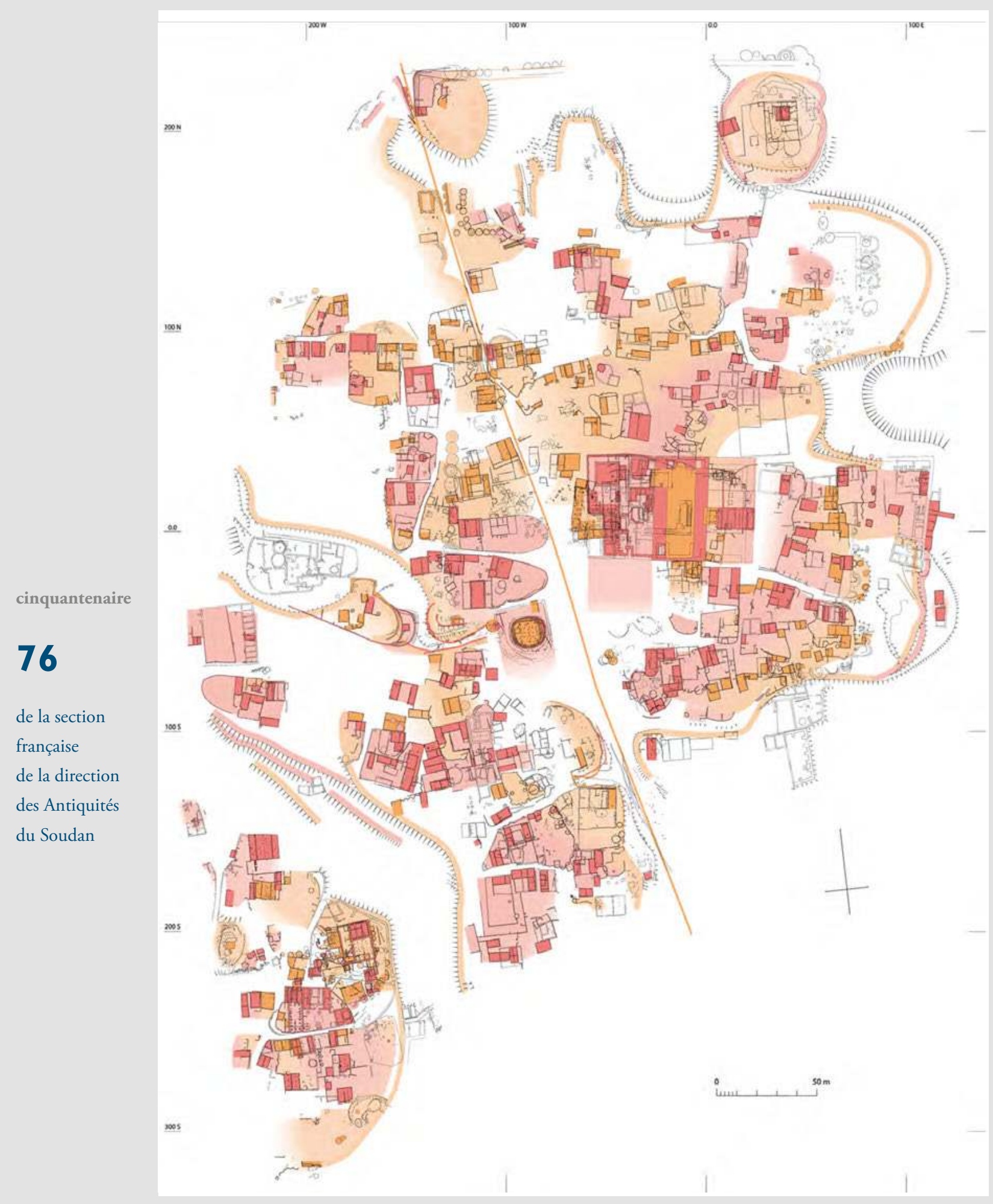

3. Plan schématique de la ville de Kerma au Kerma Moyen. 


\section{Les textes égyptiens}

Durant la fouille de la ville de Kerma, peu de témoignages épigraphiques égyptiens ont été recueillis. Une petite stèle assez fruste a été mise au jour dans les fondations d'une chapelle du Kerma Moyen proche de la deffufa (fig. 4). Elle portait deux inscriptions verticales en hiéroglyphes cursifs, qui nommaient le capitaine de bateau Iyméri et le capitaine de bateau Méréri, et commémore la venue à Kerma, vers la fin de l'Ancien Empire, de ces deux responsables égyptiens qui ont tenu à laisser un témoignage de leur passage à l'intérieur du téménos. Il a par ailleurs, a été découvert, dans une tombe du Kerma Ancien de la nécropole, un miroir gravé au nom de «la dame noble, la fille royale, l'ornement unique du roi la maîtresse de vénération à l'égard de son père, mise au monde par Sénetites, Sénetites». L'objet devait être remployé puisque la sépulture où il était déposé était occupée par un homme. Rappelons que les Kouchites ne semblent pas avoir pratiqué l'écriture, à l'exception des personnes qui connaissaient l'égyptien.

\section{La ville secondaire}

Il a alors été possible de reconnaître au sud-ouest du site de Kerma les monuments commémoratifs d'un complexe religieux constitué par plusieurs chapelles sans doute consacrées à des cultes prévus pour des rois défunts, probablement inspiré du modèle de la hout-ka égyptienne (fig. 5). L'ensemble était doté de grands ateliers où des pains d'offrandes étaient préparés. D'autres artisans devaient fabriquer des objets pour le mobilier de certaines tombes de la nécropole orientale. Ainsi, des haches en pierre verte polie ont été inventoriées avec des pièces de bronze. L'établi d'un orfêvre avait conservé un petit lingot d'or dans une cavité. C'est une véritable ville secondaire qui a été aménagée pour l'institution que défendait un canal profond de $7 \mathrm{~m}$ et bordé de murs dotés de bastions. Une habitation imposante, peut-être réservée au roi, et de nombreuses annexes complétaient cette fondation.

\section{L'urbanisme de la ville de Kerma}

Dans la partie principale de la ville (fig.6) ont été mis au jour deux palais résidentiels qui, par leurs proportions, se distinguaient des autres habitations. L'un, plus ancien, se présentait dans une double enceinte arrondie, plusieurs salles étant destinées à divers usages; elles sont rectangulaires en plan et quelquefois une rangée de supports légers en bois soutenait une toiture confectionnée avec des branches et des fibres de palmiers. 


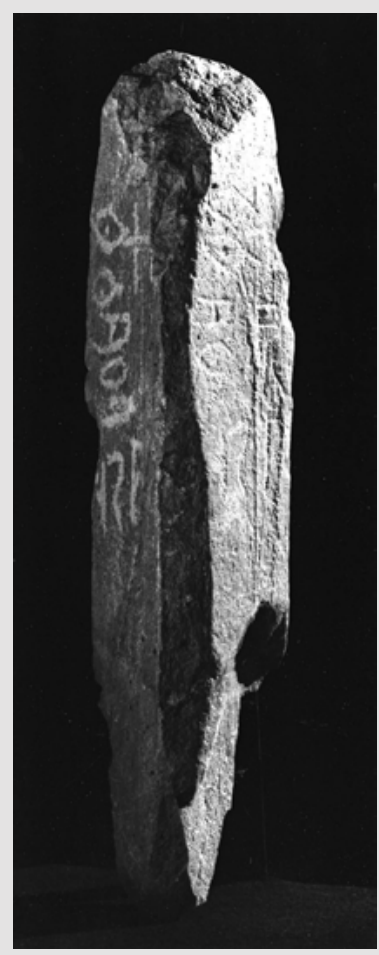

cinquantenaire

\section{8}

de la section française de la direction des Antiquités du Soudan
4. Stèle des capitaines

de bateau Iyméri et Méréri.

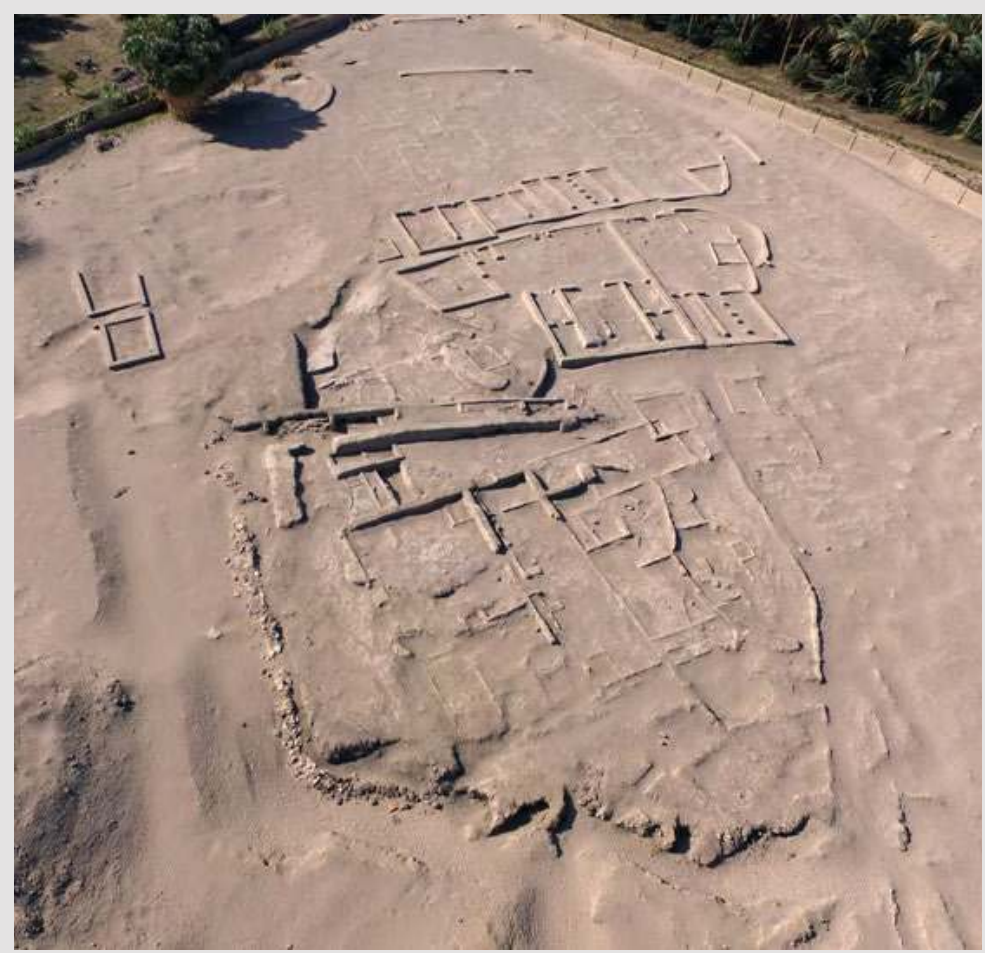

5. Vue aérienne de la ville secondaire de Kerma.

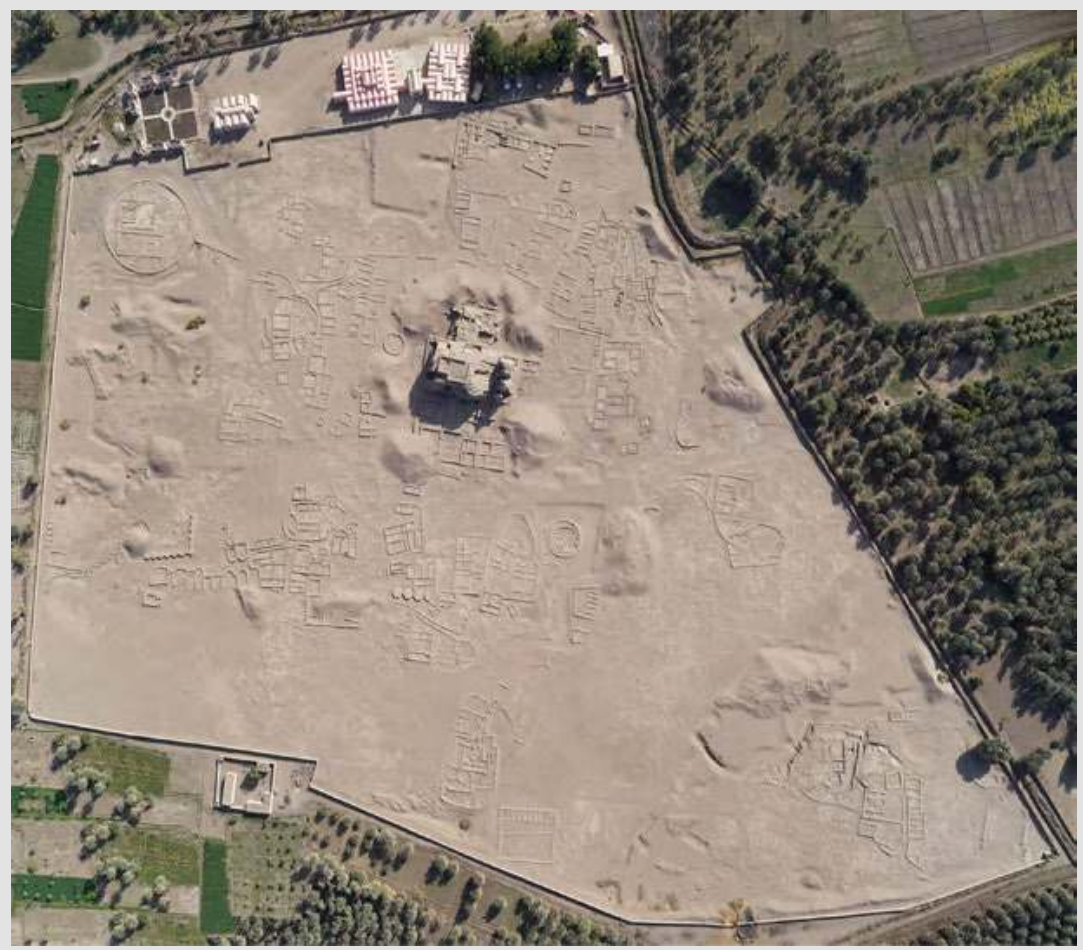

6. Vue aérienne

de la ville de Kerma. 
Un palais de la fin du Kerma Classique comportait en son centre une salle de réception royale et son trône. Dans l'entrée se trouvait un local d'archives où des rouleaux de terre fine étaient façonnés avant le scellement de produits ou de messages. Deux silos imposants étaient réservés au stockage des céréales. Dans le quartier religieux, devant la deffufa, un palais cérémoniel et son emplacement pour les scellements montrent que le souverain avait une fonction religieuse aussi bien que monarchique. Une salle d'audience arrondie semble se rattacher à un autre type d'architecture.

L'étude de la topographie urbaine a permis de comprendre la hiérarchisation de certaines habitations qui, plus grandes que d'autres maisons, étaient placées le long des principaux accès, de manière à surveiller le trafic des marchandises. Des bâtiments plus simples donnent une première idée de la densité de la population. On doit pourtant ajouter que des milliers de trous de poteaux restituent la présence de centaines de huttes de plus de $4 \mathrm{~m}$ de diamètre. Il est vraisemblable qu'elles étaient occupées par des populations différentes au service des habitants des grandes demeures. Les systèmes de défense le long des fossés qui entouraient la ville sont particulièrement développés. On découvre ainsi des éléments de murs à redans en pierre ou des enceintes bastionnées en briques crues. La troupe disposait de casernements dispersés.

\section{La ville de Panébès, “Le-jujubier »}

À Doukki Gel, il faudra une très longue période de recherche, puisque les rares sondages en profondeur que nous avons pratiqués font apparaître les couches superposées de très nombreux niveaux de construction. Tous les et de 0,20 m ont été mises en évidence les traces de nouvelles structures arasées, ce qui signifie que la ville a bien souvent changé de plan. Les fortifications ont sans cesse été modifiées par l'adjonction de nouvelles enceintes épaulées par des bastions gigantesques et des murs puissants retrouvés jusqu'à $3 \mathrm{~m}$ de profondeur. Les Nubiens et les forces africaines coalisées répondaient aux installations militaires que les Égyptiens avaient élevées sur la deuxième cataracte au Moyen Empire. La ville que découvre Thoutmosis ${ }^{\text {er }}$ lors de sa conquête du territoire est immense et nous n'en connaissons qu'une infime partie (fig. 7).

Si le centre fortifié avec ses deux puits a été bouleversé par les programmes architecturaux postérieurs, on doit pourtant noter qu'un atelier de bronzier était installé près des lieux de culte les plus anciens. D’énormes tuyères permettent d'en évoquer la technologie sophistiquée, comme pour le four mis au jour devant la deffufa occidentale. Deux temples ovales et un petit palais cérémoniel ont également laissé des traces claires avec leurs 


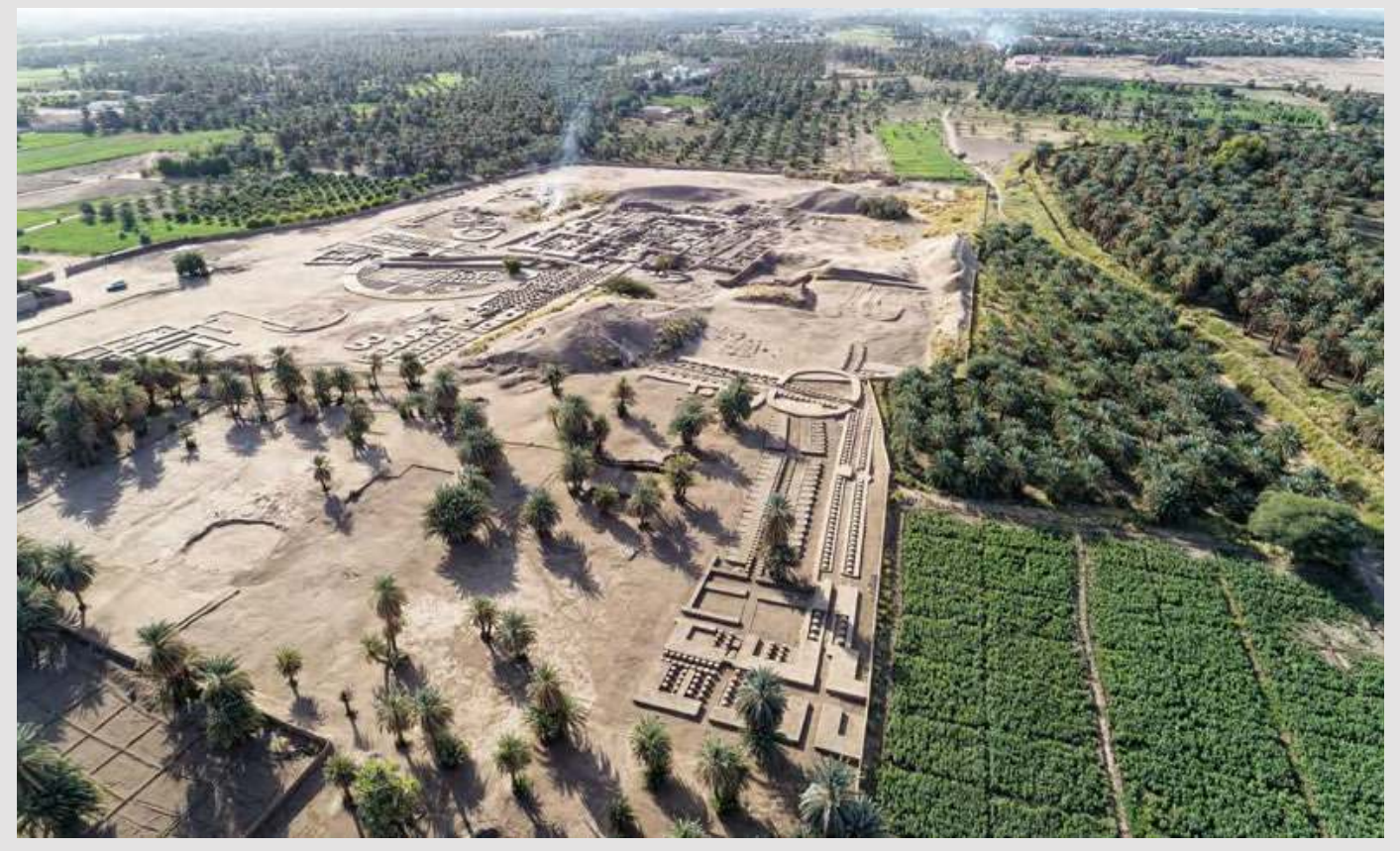

7. Vue aérienne de la ville de Panébès sur le site de Doukki Gel.

cinquantenaire

\section{0}

de la section

française

de la direction

des Antiquités

du Soudan

\section{W}

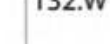

16.N

11. N

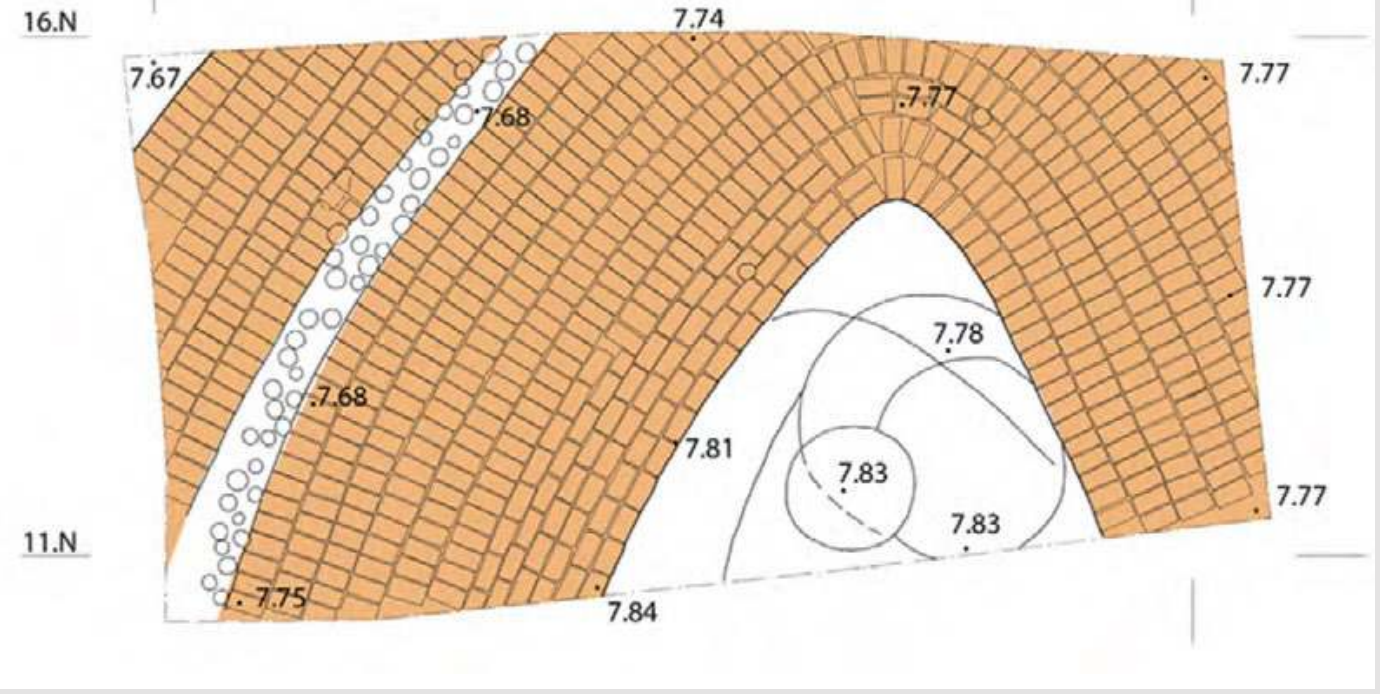

122.W

8. Plan détaillé d'un bastion de $18 \mathrm{~m}$ de large visible dans un sondage

du nord du site de Doukki Gel. 
grands contreforts permettant de voûter une salle unique disposant d'un autel quadrangulaire surmonté d'un socle circulaire. Ces sanctuaires se sont maintenus lors de la conquête égyptienne du Nouvel Empire. Ils ont alors été restaurés et agrandis. À la périphérie de la métropole, les restes de nombreux temples ont été découverts. Ces impressionnants monuments circulaires devaient représenter une défense symbolique pour les habitants. Ils ont été transformés souvent par des agrandissements ou par une diminution de leurs proportions. Eux aussi ont subsisté durant l'occupation égyptienne, les dieux nubiens étant respectés par les envahisseurs.

Ce sont naturellement les fronts fortifiés qui ont demandé un effort soutenu (fig. 8) car, dès l'Ancien Empire, les pharaons rêvent de contrôler cette région d'où proviennent des marchandises recherchées (or, ivoire, bois d'ébène...) ou la main-d'œuvre. Plusieurs enceintes aux bastions accolés semblent être privilégiées, alors que de vastes vestibules d'entrée étaient prévus pour les visiteurs en attente d'une audience et pour ceux qui apportaient certains produits recherchés. Mais d'autres bâtiments de grande ampleur entourent le noyau urbain. Ils se caractérisent par la présence de plusieurs trônes accessibles par des allées pavées de briques. Des colonnes très rapprochées occupent le reste de l'espace intérieur de ces installations sans doute réservées aux rois ou à des chefs de guerre. On peut considérer que ces édifices étaient prévus pour des rencontres entre hauts dignitaires et qu'en fait il s'agissait de palais cérémoniels.

\section{Le ménénou de Thoutmosis Jer}

La ville de Doukki Gel est partiellement arasée lors de la fondation d'un ménénou par Thoutmosis I ${ }^{\text {er }}$. La deffufa est incendiée et la ville de Kerma est abandonnée. Ce ménénou (fig. 9), une institution pharaonique fortifiée en terre conquise, va renfermer un ensemble religieux égyptien classique, avec trois temples juxtaposés. Le temple occidental et le temple central font partie d'un premier programme architectural, auquel est ajouté ultérieurement le temple oriental. Entièrement construits en briques crues, ces bâtiments renferment des informations précieuses sur l'architecture de terre à cette époque, ces bâtiments ayant été le plus souvent remplacés ultérieurement en Égypte par des constructions en pierre. On notera en particulier l'importance accordée aux salles hypostyles - introductives au temple central et intérieures aux trois temples - et aux portiques périptères qui sont connus un peu plus tard en Égypte même.

Deux palais cérémoniels sont bâtis respectivement au nord-est et au sud. Le premier conserve les vestiges d'une salle du trône conçue sur le modèle des dispositifs indigènes. Un plan régulateur est fixé par des allées monumentales 
tracées depuis des avant-portes aux entrées principales. Les architectes égyptiens cherchent à conduire vers le temple central dédié à l'Amon de Karnak et à l'Amon nubien, tandis que le temple occidental est consacré à l'Amon de Panébès. Des réserves alimentaires sont stockées dans vingt silos de belles proportions, alors que des troupeaux de bovinés sont parqués sous la protection des murs d'enceinte de la ville. Un atelier de potiers dispose de fours dans le ménénou où sa production est largement diffusée. Un palais résidentiel doit exister à l'ouest; il est en cours de dégagement.

La ville de Panébès sera bien souvent reconstruite durant le Nouvel Empire. Après une révolte qui se produit à la charnière du règne de Thoutmosis Ir et de Thoutmosis II et durant laquelle le ménénou est détruit, il est reconstruit sous les règnes de Thoutmosis II et d'Hatchepsout sur un plan très proche de celui de Thoutmosis I ${ }^{\text {er }}$ (fig. 10). Le temple occidental, au plan original, mérite une description détaillée de ses dispositifs cultuels originaux. Un escalier ouvert dans l'angle sud-ouest de la salle hypostyle conduit par un souterrain vers le bas du puits sud. Cet accès unique à l'eau de la nappe phréatique depuis l'intérieur du temple implique une importance particulière accordée aux rites de l'eau. Le temple étant majoritairement en briques crues, son sanctuaire avait un sol simplement blanchi à la chaux, mais un naos fragmentaire en grès y était déposé. La disparition rapide de ce monument a permis la conservation d'une grande partie de son mobilier cultuel.

Thoutmosis III, à son tour, rase les temples élevés par sa tante,

de la section

française

de la direction

des Antiquités

du Soudan

\section{2}




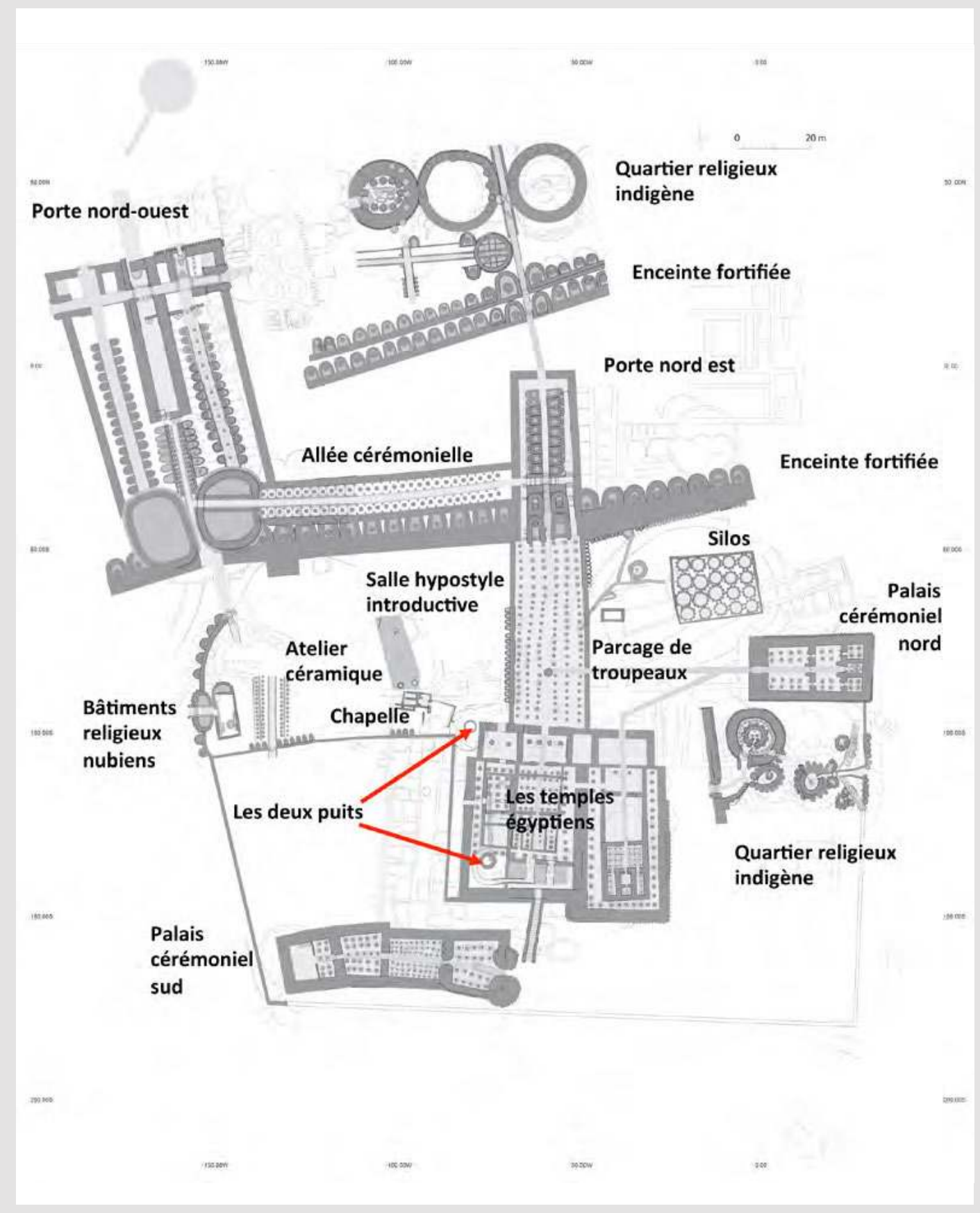

9. Plan schématique du ménénou de Thoutmosis Ir 


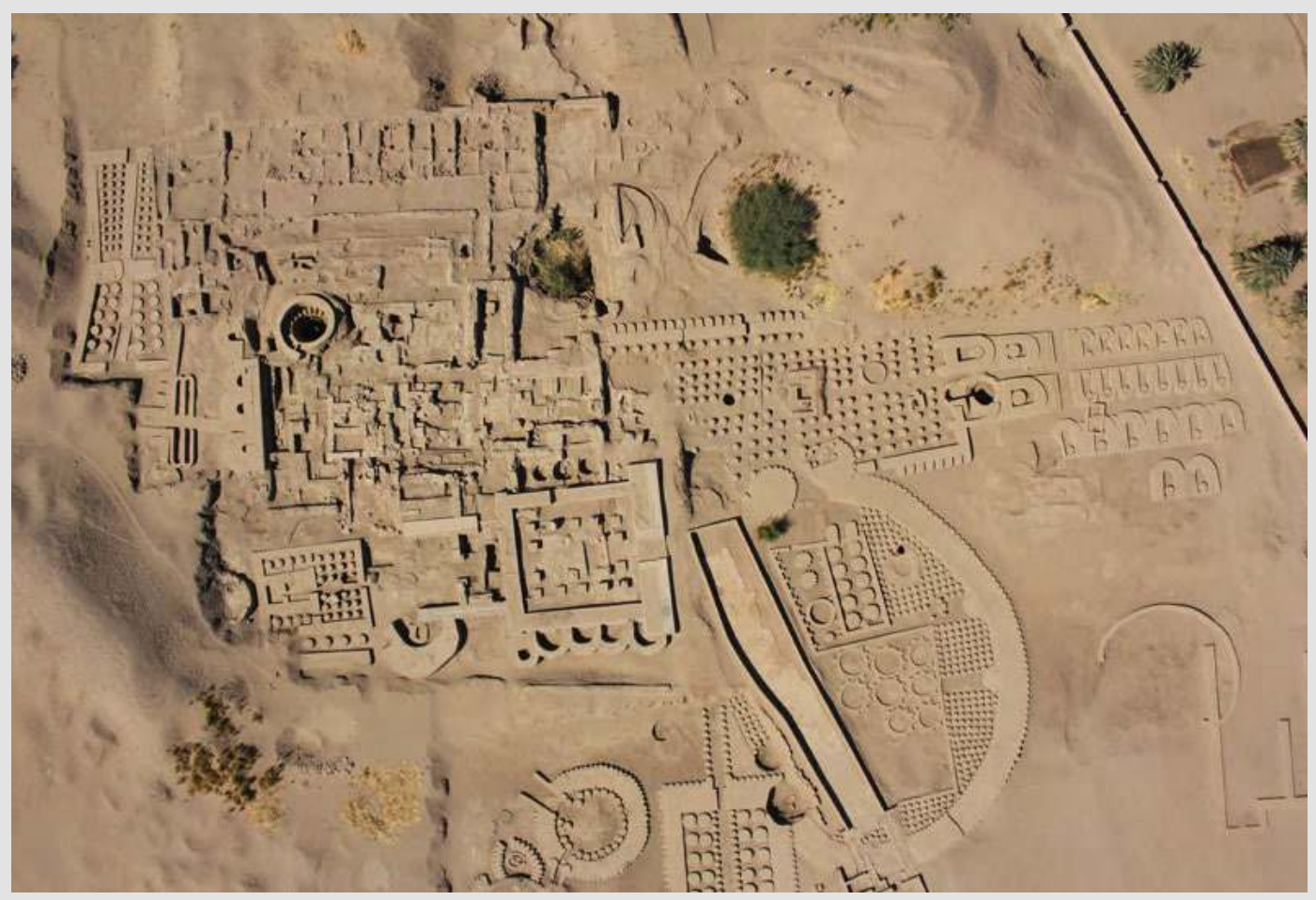

cinquantenaire

10. Vue aérienne des temples égyptiens de Panébès.

\section{4}

de la section

française

de la direction

des Antiquités

du Soudan

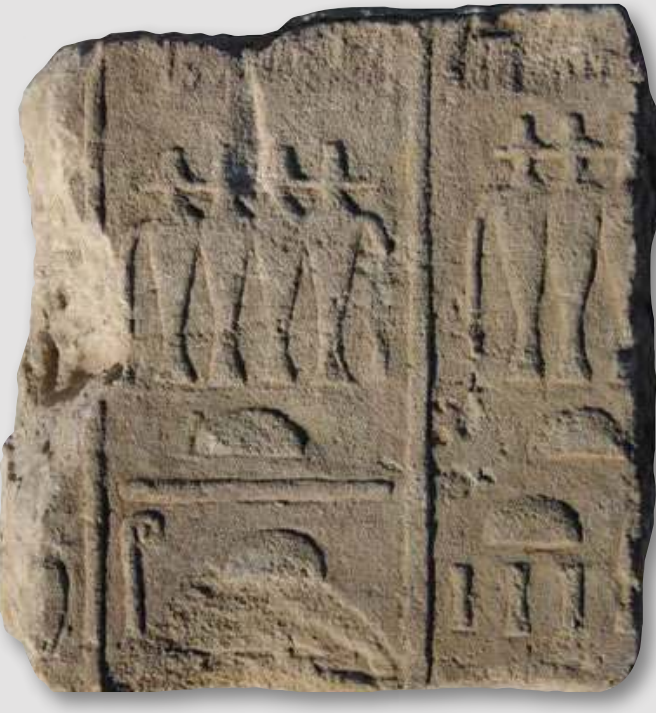

11. Bloc du fond du sanctuaire du temple central

nommant l'Amon de Nubie et l'Amon de Karnak.
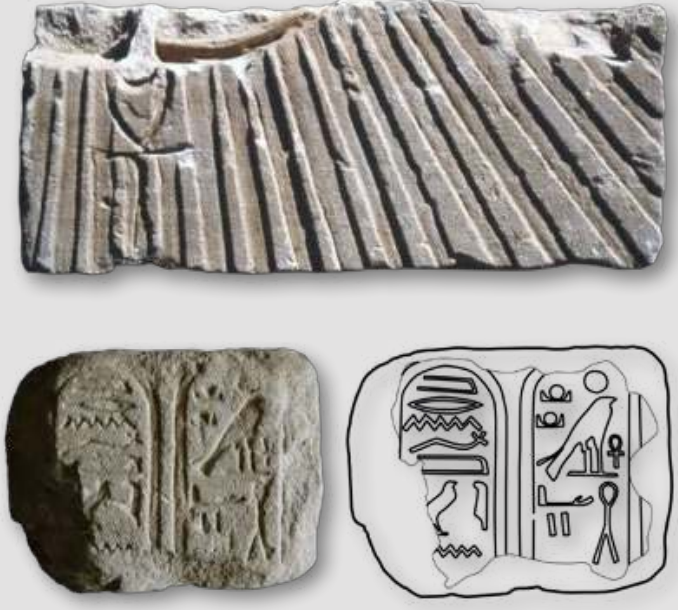

12. Deux talatates, l'une figurant le disque solaire Aton,

l'autre portant les cartouches du dieu. 
d'Amon sur tous les décors visibles et sur les statues. Puis les monuments de ses prédécesseurs servent de carrière pour tailler les talatates d'un nouveau temple qu'il fait ériger sur les fondations du temple central (fig. 12). Le décor consistait en un grand registre où figuraient les traditionnelles scènes d'offrandes à Aton par la famille royale que l'on connaît essentiellement par les tombes et les stèles d'Amarna. Ayant sans doute épuisé les ressources en pierre des bâtiments existant sur le site, c'est en briques crues qu'il fait reconstruire le temple de l'est.

Les activités architecturales ralentissent sous les Ramessides. Les vestiges attribuables à Séthi $I^{\text {er }}$ sont peu nombreux. Cependant, la découverte d'une empreinte au nom du temple d'Abydos estampillée sur une anse de jarre - à une faible distance du décret de Nauri destiné à protéger les biens et les personnes de la fondation du temple funéraire du roi montre le dynamisme des activités économiques dans la région, comme l'avait suggéré, sous Amenhotep II, la découverte d'un grand nombre d'empreintes de sceaux au nom de ce dernier et du linteau d'une annexe vraisemblablement dévolue à la gestion des biens correspondants. En revanche, du règne de Ramsès II, seule une stèle fragmentaire sur laquelle le roi offre des bouquets à l'Amon de Panébès a été retrouvée dans une fosse. Deux talatates regravées sous Ramsès III indiquent que le temple amarnien, où les noms et les visages des souverains avaient cependant été à leur tour martelés, était toujours debout à l'époque.

\section{Les inscriptions égyptiennes}

Si les habitants de Kerma ne semblent pas avoir eu d'écriture, les Égyptiens qui ont occupé le ménénou de Panébès durant la majeure partie du Nouvel Empire ont laissé de multiples monuments inscrits. Outre le décor des temples successifs, de nombreuses stèles royales ou de particuliers et plusieurs statues épigraphiées commentent événements et pratiques religieuses ou funéraires et révèlent l'identité, les titres et les dévotions des hommes qui ont séjourné dans cette base égyptienne conçue pour gérer le territoire environnant et diffuser l'idéologie monarchique à une population progressivement acculturée.

C'est sur plusieurs stèles de particuliers mises au jour dans le sanctuaire abandonné du temple occidental de Thoutmosis II et Hatchepsout qu'apparaissent les mentions les plus anciennes de Panébès «Le-jujubier» sous la forme d'une épithète du dieu Amon: Amon de Panébès (fig. 13). Le toponyme se retrouve sur des monuments de toutes les époques. Il sera réinterprété graphiquement par les Égyptiens comme Pernébès «La-maison-du-jujubier» lors de la campagne militaire de Psammétique II, 


\section{Panébès sous la $\mathbf{x x v}$ dynastie}

La XXve dynastie verra le renouveau de cette ville avec des remaniements de prestige. Deux souverains de cette dynastie construisent ou transforment les temples du Nouvel Empire qui tombaient sans doute en ruine: Chabaka et Taharqa. Le nom du premier, qui résidait à Memphis et a surtout développé un vaste programme architectural en Égypte, est néanmoins conservé sur plusieurs blocs découverts sur le site de Doukki Gel.

De multiples éléments de décor des constructions du second ont également été mis au jour. Une statue de Taharqa (fig. 14) et deux de Tanoutamon étaient dressées dans le temple central, désormais dédié à l'Amon local. Elles témoignent de l'intérêt que les monuments nubiens, et ceux de ce site, conservent ou acquièrent lorsque ces souverains sont chassés d'Égypte par les Assyriens.

\section{Le début de la dynastie napatéenne à Doukki Gel}

de la section

française

de la direction

des Antiquités

du Soudan
Cet intérêt ne se démentit pas sous les premiers rois de la nouvelle dynastie napatéenne. Si nous n'avons pas retrouvé de témoignage in situ du règne d'Atlanersa, la figuration de l'Amon de Panébès au revers du pylône du temple B 700 qu'il fait édifier au Gébel Barkal suggère que le couronnement était peut-être déjà confirmé dans les quatre grands sanctuaires d'Amon — Gébel Barkal, Sanam, Kawa et Doukki Gel. Le dieu connaît à cette époque une variante iconographique qui n'est pas attestée au Nouvel Empire: il est représenté sous la forme d'un criosphinx couché sur un socle, à l'ombre d'un jujubier. Deux statues de Senkamanisken - l'une coiffée du pschent, l'autre de la couronne kouchite séden - et une statue d'Anlamani viennent s'ajouter à celles des derniers souverains de la $x^{\prime} v^{e}$ dynastie dans le temple central de Doukki Gel.

Sur cette dernière, Anlamani arbore le pschent sur les deux côtés duquel sont fixées les cornes de béliers d'Amon (fig.15), exemple unique à ce jour en ronde-bosse de cet attribut divin déjà présent dans les représentations de l'image d'Amenhotep III divinisé, à Louqsor et à Soleb par exemple. Par ailleurs, sur la stèle de Kawa qui commémore son couronnement, Anlamani confère à chacune de ses quatre sœurs la fonction 


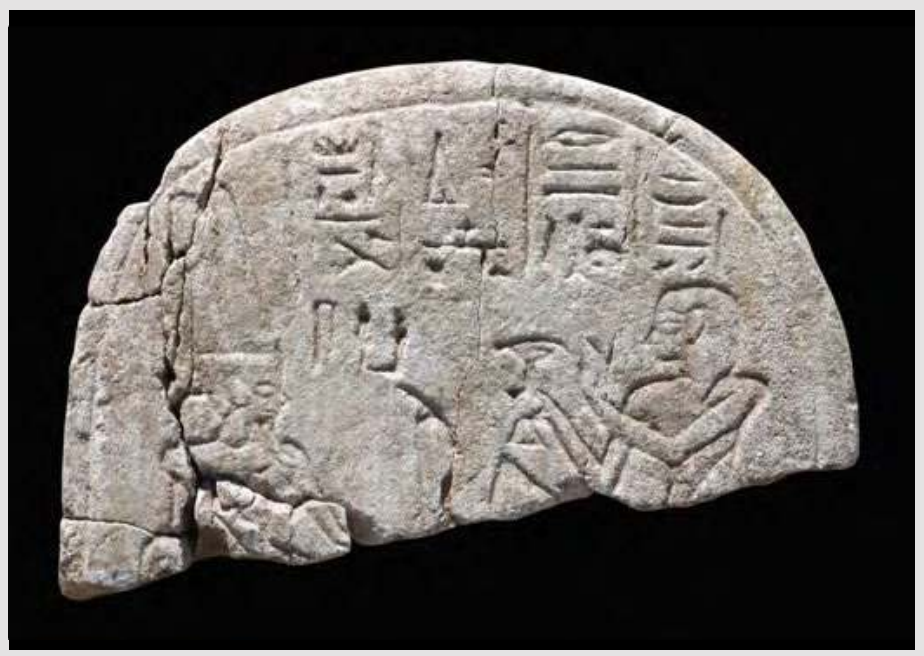

13. Stèle d'un directeur de la cavalerie, comportant

la plus ancienne figuration de l'Amon de Panébès.

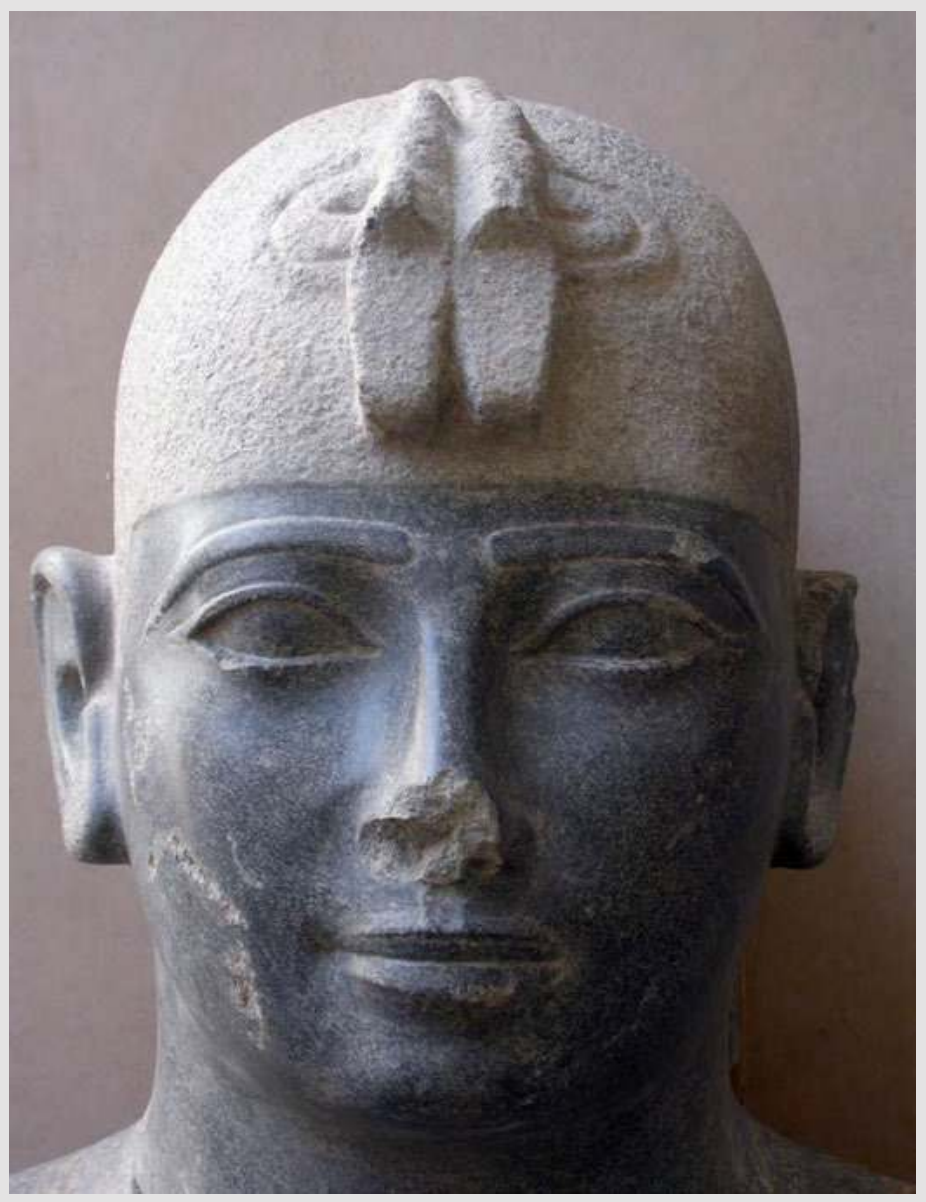

les sites

de Kerma

et de

Doukki Gel

14. Tête de la statue de Taharqa provenant de la cachette de Doukki Gel. 


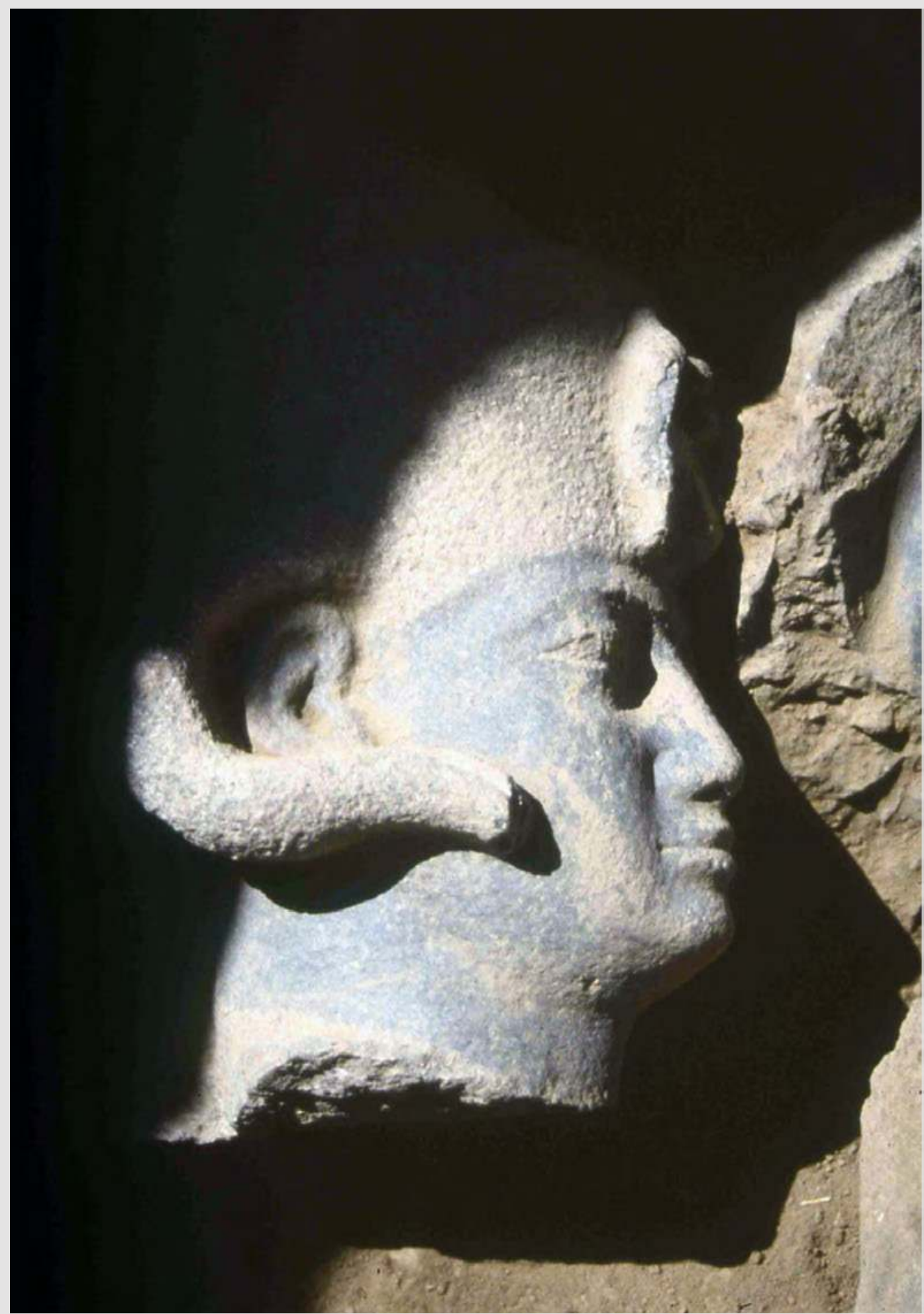

15. Tête de la statue d'Anlamani dans la cachette. 
de joueuse de sistre d'Amon dans les quatre grands sanctuaires du dieu. La dernière statue, placée auprès des autres à Doukki Gel, est celle de son successeur, Aspelta, encore très jeune.

\section{La campagne militaire de Psammétique II}

Une étape historique nous paraît cependant de grande importance pour les développements urbains. Il s'agit de l'expédition militaire de Psammétique II, connue par trois stèles égyptiennes, par des graffiti grecs, cariens et phéniciens, ainsi que par Hérodote. Elle bouleversa l'ensemble bâti en provoquant la dispersion des quartiers et la réhabilitation des monuments officiels. À cette occasion, les sept statues monumentales érigées à la fin de la $\mathrm{Xxv}^{\mathrm{e}}$ dynastie et au début de la période napatéenne sont brisées à Doukki Gel, comme celles du Gébel Barkal et de Dangeil. C'est le roi napatéen Aspelta qui, après s'être réfugié avec son armée au sud du pays plus difficile d'accès, va reconstruire les temples et les habitations de l'élite. Des tours de défense vont s'aligner en double rangée pour protéger le flanc nord.

\section{La cachette}

Les quarante fragments des statues royales monumentales de granit noir brisées par les Égyptiens sont placés, une fois recueillis, dans une cachette qui constitue un aménagement sacré permettant de perpétuer le culte des rois ancêtres. Ces très belles pièces de l'art de la $\mathrm{XXV}^{\mathrm{e}}$ dynastie et du royaume napatéen témoignent de la qualité de la statuaire des $\mathrm{VII}^{\mathrm{e}}-\mathrm{VI}^{\mathrm{e}}$ siècles avant J.-C., révélant un style original qui n'est pas attesté par ailleurs, comme on peut le découvrir notamment sur les sculptures de Tanoutamon ou d'Anlamani. L'inventaire du matériel archéologique complète l'image des objets contemporains manufacturés dans un atelier destiné à préparer de belles appliques de faïence. D'un naos fragmentaire subsiste également une corniche à gorge en bronze décorée de plaques en lapis-lazuli. Le meuble en bois était recouvert d'un stuc doré à la feuille.

\section{La stèle de l'an 3 d'Aspelta}

Sept fragments d'une stèle de granodiorite datée de l'an 3 d'Aspelta nous est parvenue incomplète. Gravée le douzième jour du premier mois de l'hiver, soit moins d'un mois après celle que le roi laissa à Sanam, elle commémore l'envoi que ce dernier fait à Doukki Gel d'une délégation de notables, partiellement similaire à celle qu'il avait dépêchée au temple d'Amon taureau de la Nubie, à Sanam, pour annoncer aux prêtres la nomination 
de son épouse, Madiqen, comme joueuse de sistre, en remplacement de Nasalsa désignée précédemment par Anlamani. La nature des dispositions que cette délégation devait transmettre aux prêtres du temple d'Amon de Panébès n'est pas conservée, mais elles concernaient naturellement le personnel et les offrandes accordées au dieu. Ces ordres royaux interviennent sans doute peu de temps après le départ des troupes de Psammétique II et l'aménagement de la cachette (fig. 16).

\section{Les derniers rois de la dynastie napatéenne à Doukki Gel}

cinquantenaire

\section{0}

de la section française de la direction des Antiquités du Soudan

Si nous n'avons pas conservé d'inscription historique des successeurs d'Aspelta, la stèle d'Amannoté-ériké, qui évoque la confirmation du couronnement royal par l'Amon de Gematon et celui de Panébès à qui il consacre une grande offrande, affecte du personnel et divers cadeaux, suggère que ces pratiques rituelles s'étaient maintenues. Or, c'est précisément des blocs et fragments du décor d'un temple de ce roi qui sont les premiers, postérieurs au règne d'Aspelta, découverts à Doukki Gel. On notera qu'il a curieusement choisi comme nom de couronnement celui que portait Psammétique II. À leur tour, Harsiotef, Natasen et Sabrakamani, qui inscriront des décrets similaires incluant le temple d'Amon de Panébès, perpétuent cette tradition monarchique jusqu'à la fin de la dynastie napatéenne. Le nom de ce dernier roi est également gravé sur un tambour de colonne du temple, à côté de l'image du dieu sous sa forme criocéphale (fig. 17).

\section{Doukki Gel sous la dynastie méroittique}

La période méroïtique apporte aussi des témoins du développement urbain. Ainsi, l'un des plus grands temples du Soudan s'élève à l'est du site où l'on construit également un vaste palais résidentiel. Les deux puits sont transformés. Celui du sud présente une réalisation architecturale extraordinaire avec son escalier hélicoïdal à l'intérieur se terminant au niveau de la nappe phréatique par la figuration d'un pied royal écrasant des prisonniers. Le puits nord était surmonté d'un côté par une plateforme servant aux cérémonies en rapport avec l'eau: dans l'espace aménagé a été retrouvé un splendide support de bronze qui devait servir à maintenir un flambeau.

Rappelons que l'un des plus anciens exemples de méroïtique cursif, datant des environs de 220 avant J.-C., se trouve sur la façade du temple napatéen oriental. S’il est difficile, sur le site, de reconnaître des édifices datables du début de cette période, on peut avancer sans crainte d'erreur que le temple de l'est a fait l'objet d'un important programme architectural sous Amanitore et Natakamani (fig. 18), comme de nombreux autres sites 


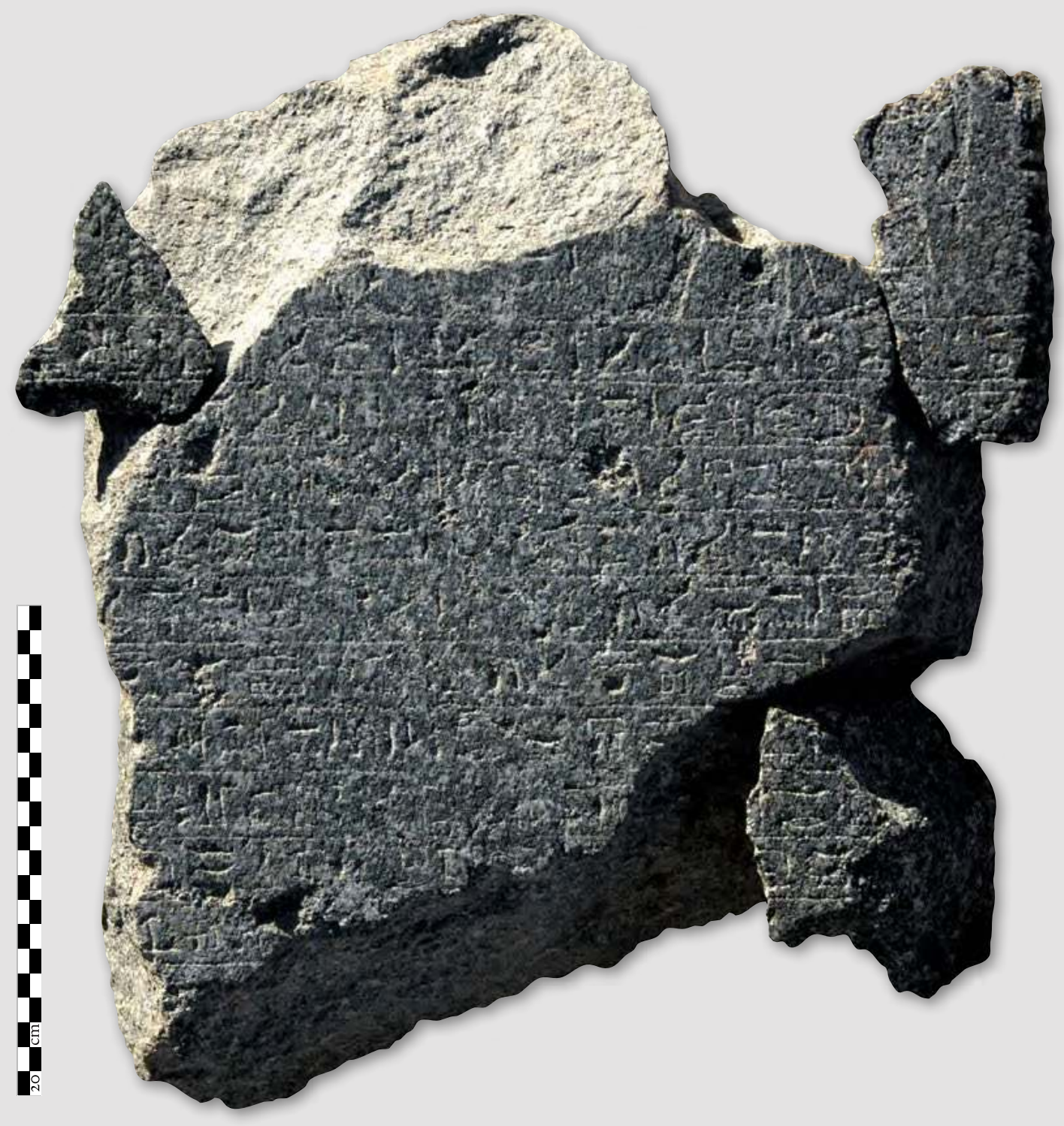

et de

Doukki Gel

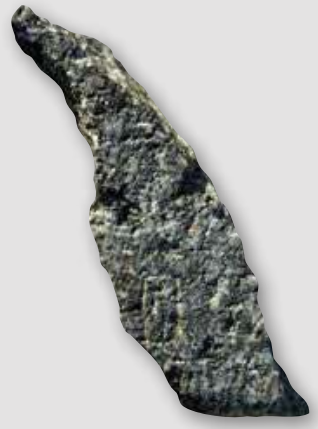

16. Les fragments de la stèle de l'an 3 d'Aspelta recueillis à Doukki Gel. 


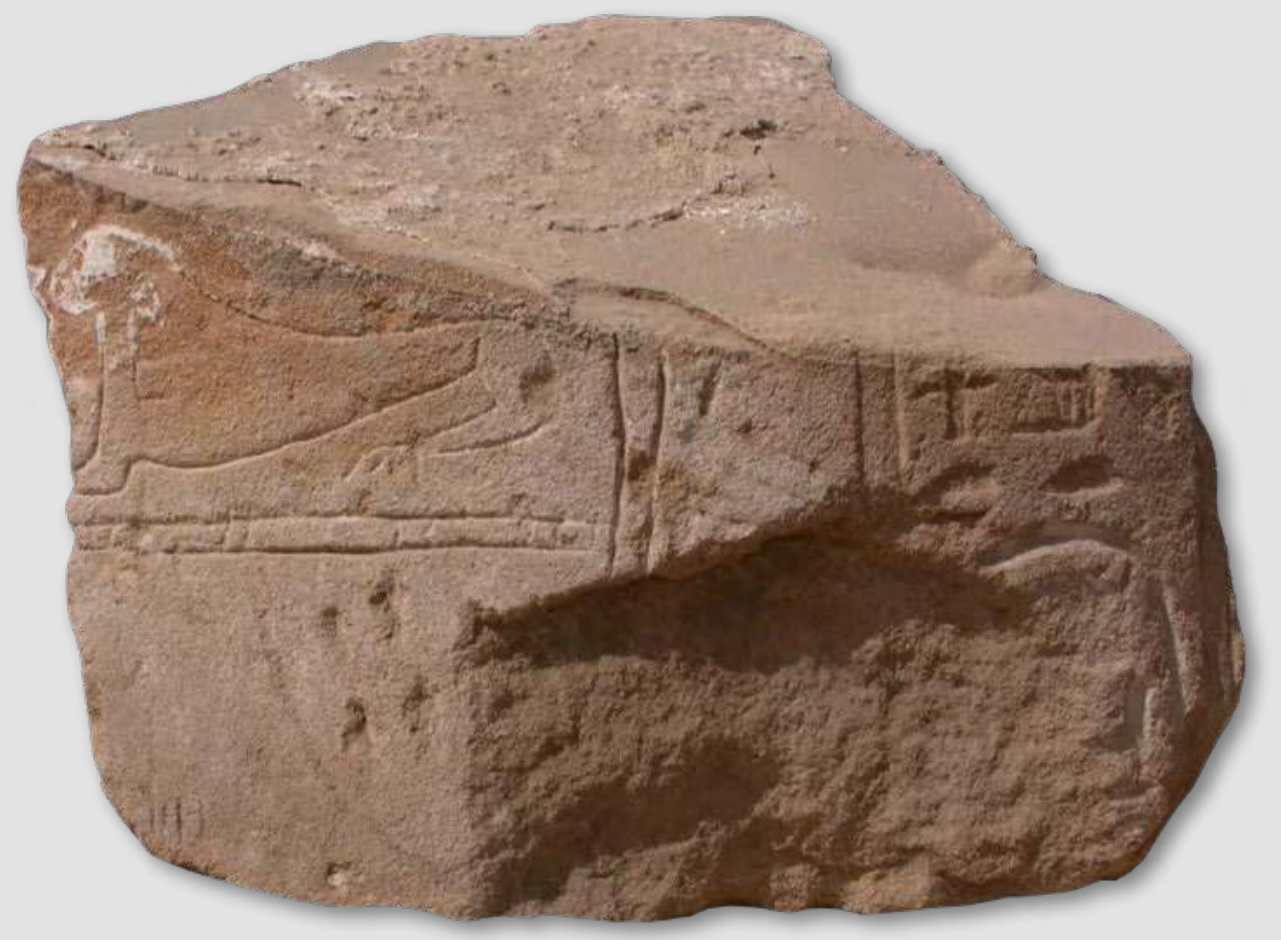

cinquantenaire 17. Tambour de colonne portant la figuration de l'Amon de Panébès et les cartouches de Sabrakamani.

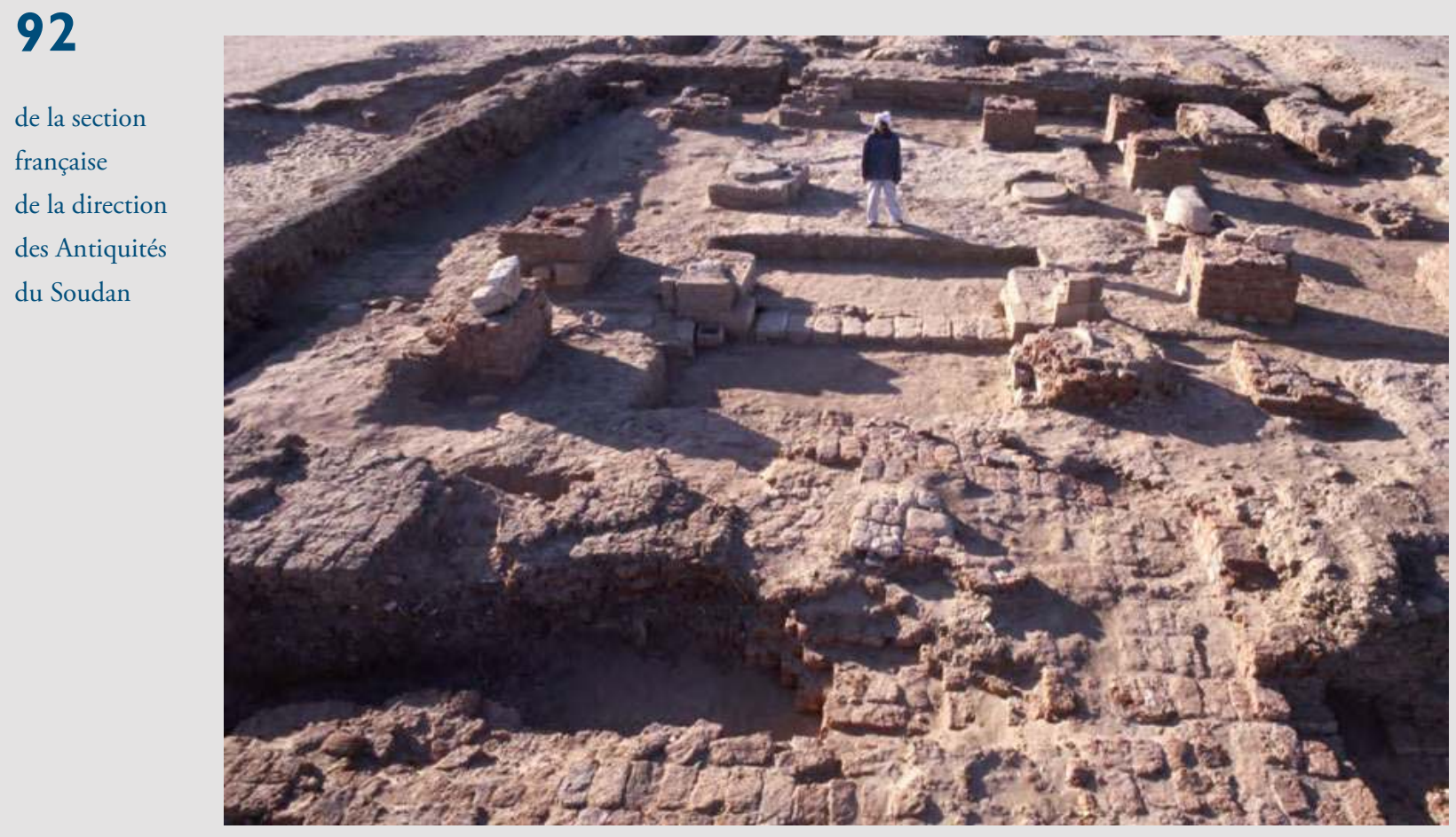

18. Le temple méroïtique oriental. 
de l'empire méroïtique. Un petit monument fragmentaire de l'un de leurs successeurs, Amanakharéquérem montrant le souverain en train d'offrir son nom «Nebmaâtrê» à Amon, a été recueilli dans la salle hypostyle du temple central. De nombreux blocs et fragments attribuables à la période méroïtique témoignent des nombreux remaniements qu’a connus ce temple.

Les deux villes de Kerma et de Panébès, par leur continuité d'occupation, nous donnent une idée d'un des lieux d'échanges ayant joué un rôle considérable entre l'Afrique centrale et l'Égypte. Grâce aux résultats archéologiques, il devient possible de combler l'absence d'informations sur les débuts de l'histoire africaine. Toutefois, il faudra encore beaucoup de temps et de recherches pour découvrir la richesse de ce patrimoine

\section{bibliographie}

\section{Ouvrages}

Ahmed S. El-Din M. 1992 - L'agglomération napatéenne de Kerma.

Enquête archéologique et ethnographique en milieu urbain, éd. ERC, Paris.

Bonnet Ch. 1986 - Kerma, Territoire et métropole. Quatre leçons au Collège de France, Bibliothèque générale 9, Ifao, Le Caire.

Bonnet Ch. (éd.) 1990 - Kerma, royaume de Nubie, Genève.

Bonnet Ch. 2019 - The Black Kingdom of the Nile, Harvard University Press, Cambridge Mass.

Bonnet Ch., Valbelle D. et al. 2000 - Edifices et rites funéraires à Kerma, Paris, éd. Errance.

Bonnet Ch., Valbelle D. 2004 - Le temple principal de la ville de Kerma et son quartier religieux, éd. Errance, Paris.

2005 - Des pharaons venus d'Afrique, éd. Citadelles et Mazenod, Paris.

2014 - La ville de Kerma: une capitale nubienne au sud de l'Égypte, éd. Favre, Lausanne.

2018 - Les temples égyptiens de Panébès «le jujubier»à Doukki Gel (Soudan), Paris.

Valbelle D. 2012 - Les stèles de l'an 3 d'Aspelta (avec une annexe de Cl. Rilly), $B d E$ 154, Ifao, Le Caire.

Valbelle D. et Yoyotte J.-M. (éds) 2011 - Statues égyptiennes et kouchites démembrées et reconstituées, Pups, Paris. 


\section{Rapports de fouilles}

Bonnet Ch. et al., "Kerma», Genava ns XXvi, 1978, p. 107-134; XXVIII, 1980,

p. 31-72; XXX, 1982, p. 29-70; XXXII, 1984, p. 5-42; XXXIV, 1986. p. 5-45; XXXVI, 1988, p. 5-35; XXXIX, 1991, p. 5-41; XLI, 1993, p. 1-35; XLIII, 1995, p. 31-64; XLV, 1997, p. 97-123; XLVII, 1999, p. 57-86; XLIX, 2001, p. 197-234; LI, 2003, p. 257-300; LIII, 2005, p. 223-270; LV, 2007, p. 183-246; LVII, 2009, p. 135-165; LIX, 2011, p. 1-10.

Bonnet Ch. 2015 — «Une ville cérémonielle africaine du début du Nouvel

\section{Articles} Empire égyptien", Bifao 115, p. 1-14.

Bonnet Ch. 1995 - «Nouvelles données sur les peintures murales de la chapelle K XI à Kerma, Note d'information », CRAI, avril-juin 1995, p. 643-650.

1999 — "The funerary traditions of Middle Nubia», dans: D. Welsby (éd.), Recent Research in Kushite History and Archaeology. Proceedings of the 8th Conference for Meroitic Studies, British Museum Occasional Paper 131, Londres.

2013 - Découverte d'une nouvelle ville cérémonielle nubienne et le menenou de Thoutmosis I ${ }^{\text {er }}$ (Doukki Gel, Soudan), Hommage à Jean Leclant", CRAI avril-juin 2013, p. 807-823. 2017 - «Doukki Gel, une ville africaine aux frontières de l'Égypte», CRAI, nov.déc. 2017, Paris, p. 1347-1366. 2019a — «The religious architecture of Kerma and Dokki Gel from

de la section française de la direction des Antiquités du Soudan the $3^{\text {rd }}$ to the $1^{\text {st }}$ millenium BC», Nubian Handbook, dans D. Raue (dir.), De Gruyter Inc, Boston, p. 413-432. 2019b — «La porte nord-ouest de la ville de Doukki Gel», Bifao 119, p. 37-49.

Bonnet Ch., Valbelle D. 2003 — «Un dépôt de statues royales du début du vI siècle av. J.-C. à Kerma » CRAI, mai 2003, p. 749-771. 1980 - Un prêtre d'Amon de Pnoubs enterré à Kerma», Bifao 8o, p. 1-12. 2007 - «Black Pharaohs: A Cachette of Statues from Kerma, Sudan", Discovery, Unearthing the New Treasures of Archaeology, Thames \& Hudson, London, p. 120-121. 2019 - «The cache of Dukki Gel (Pa-nebes)» dans D. Raue (éd.), Handbook of Ancient Nubia, De Gruyter Inc, Boston, p. 667-674.

Bonnet C., Valbelle D. et Ahmed S. El-Din M. 2000, «Les sanctuaires de Kerma du Nouvel Empire à l'époque méroïtique", CRAI juillet-octobre 2000, p. 1099-1120.

Marchi S. 2017 - «Le royaume de Kerma à la fin du Moyen Empire», dans G. Andreu-Lanoë et Fl. Morfoisse (éd.), Sésostris III et la fin du Moyen Empire, Cripel 31, p. 85-102. 
2000 — «Entre arrière-pays et capitale, l'approvisionnement et le stockage des céréales dans le royaume de Kerma (Soudan) ", dans A. Bats (éd.), Les céréales dans le monde antique, NeHet 5 , p. 197-216.

2018 - «Découvertes récentes sur le site de Doukki Gel : les fortifications de la période Kerma», dans M. Maillot (éd.), Actualité de la recherche archéologique française au Soudan, Les routes de l'Orient ancien. Hors Série 3, p. 31-45. À paraitre — «Water for Temples and Palaces: the Wells of Dukki Gel during the Napatan and Meroitic Periods", Proceedings of the 12th International Conference for Meroitic Studies, 5-9 septembre 2016, Prague-Musée National (sous presse).

Meyrat P., 2020, "Catching the King's eye - New joins for two statues from the Dokki Gel cache», Sudan and Nubia 23.

Valbelle D., 1990 - «L'égyptien à Kerma sous l'Ancien Empire» dans:

Ch. Bonnet (éd.), Kerma, royaume de Nubie, Genève, p. 95-97. 2003 - «L'Amon de Pnoubs», RdE 54, p. 191-211. 2007 — «Penrê et les directeurs des pays étrangers méridionaux dans la première moitié de la XVIII ${ }^{\mathrm{e}}$ dynastie ", $R d E$ 58, p. 157-175 et pl. XIX-XXIII.

2012 - "Comment les Égyptiens du début de la XviII ${ }^{e}$ dynastie désignaient les Kouchites et leurs alliés», Bifao 112, p. 447-464. 2014 - «Le jujubier dans la toponymie nilotique», dans: E. M. Ciampini, F. Contardi et G. Rosati (éds.), Egyptological Studies offered to Alessandro Roccati by some of his colleagues, Orientalia 83/1, p. 106-122.

2015 - «Où et comment les Égyptiens ont-ils commémoré leurs campagnes militaires contre Kerma?», Bifao 115, p. 471-486. 2018 - «Egyptian practice of Nubian toponyms: Iam, Kush and Pnubs", HonoraryVolume Dedicated to Professor László Török, Institute of Archaeology, Research Centre for the Humanities, the Hungerian Academy of Science and Museum of Fine Arts, Budapest, p. 445-453.

2019 - «Inbt, snbt et mnnw: des dispositifs défensifs particuliers aux frontières de l'Égypte», dans: S. Vuilleumier et P. Meyrat (éds.), Sur les pistes du désert, Mélanges offerts à Michel Valloggia, éd. Infolio, Gollion, p. 243-253.

À paraître - «Sièges nominatifs et chapelles "de confréries"”, Bifao 120, Le Caire, (sous presse).

Valbelle D. et Marchi S., 2017, «Dokki Gel: et møde mellem ægyptisk og afrikansk arkitektur ", Papyrus 37/1, p. 4-13. 

trente-cing ans

d'archéologie

cimetières et habitats néolithiques

préhistorique

dans une concession menacée

à Kadrouka

Olivier Langlois

Philippe Chambon

Pascal Sellier 
II y a tout juste trente-cinq ans, Jacques Reinold, alors directeur de la SFDAs, engageait les premiers travaux archéologiques sur la concession de Kadrouka (ou Kadruka , Kudruka). Les différents cimetières fouillés dans cet espace qu'il qualifia de « réserve archéologique exceptionnelle» (Reinold 2004b: 162) ont livré un mobilier d'une grande richesse, dont quelques objets emblématiques [notamment deux superbes figurines féminines en grès (fig.1)] furent présentés au public dans le cadre de plusieurs expositions, au Soudan et en Europe. Ces découvertes ont assuré la notoriété de Kadrouka, qui est rapidement devenue un haut-lieu du Néolithique soudanais. En 2014, après une longue interruption des activités archéologiques, une nouvelle équipe a repris l'exploitation de la concession, grâce au financement du Qatar Sudan Archaeological Project (QsAP). Les travaux initialement prévus, qui se rapportaient aux seuls sites funéraires, s'inscrivaient dans la continuité de ceux réalisés précédemment. Mais nous avons rapidement décidé d'étendre l'étude aux sites d'habitats qui, contrairement à ce qui était affirmé, n'étaient pas totalement détruits. Malheureusement, durant la quinzaine d'années d'interruption des travaux archéologiques sur la concession, les dépôts fertiles du wadi el-Khowi, où se concentrait l'essentiel des occupations néolithiques, avaient été l'objet d'une exploitation agricole intensive. À la reprise des recherches, les champs couvraient déjà une grande partie du tracé de cet ancien réseau hydrographique qui, au

de la section

française

de la direction des Antiquités du Soudan rythme des nouvelles mises en culture, ne tarderait pas à être intégralement exploité (fig.2). Et si les cimetières ne semblaient pas menacés par l'extension des cultures, on pouvait craindre que les derniers sites d'habitats soient détruits par les tracteurs à brève échéance.

Les recherches et les évolutions dont il vient d'être question seront au cœur de ce texte consacré à une concession dont le potentiel, autrefois exceptionnel, s'est vu considérablement amoindri par plusieurs décennies d'expansion agricole. Après avoir présenté les caractéristiques essentielles de la concession, puis fait un bref historique des recherches qui y ont été menées, nous décrirons chacune d'elles, en précisant les perspectives qui les ont sous-tendues.

\section{La concession}

La concession de Kadrouka occupe une bande de terre qui s'étend sur plus d'une vingtaine de kilomètres sur la rive droite du Nil, à une quarantaine de kilomètres au sud de la $3^{\mathrm{e}}$ cataracte, dans une région de Haute Nubie connue sous le nom de Northern Dongola Reach (fig.3). Comme les concessions mitoyennes de Kawa (au sud) et de Kerma (au nord), elle est traversée par le wadi el-Khowi, un ancien bras du Nil qui formait un réseau 


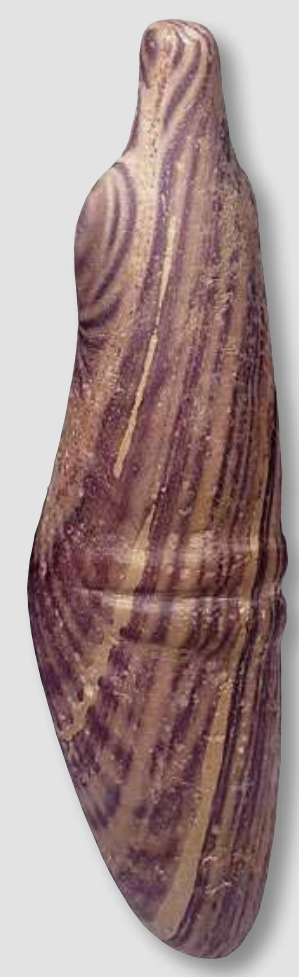

1. KDK21 - Figurine en grès (d'après J. Reinold 2000).

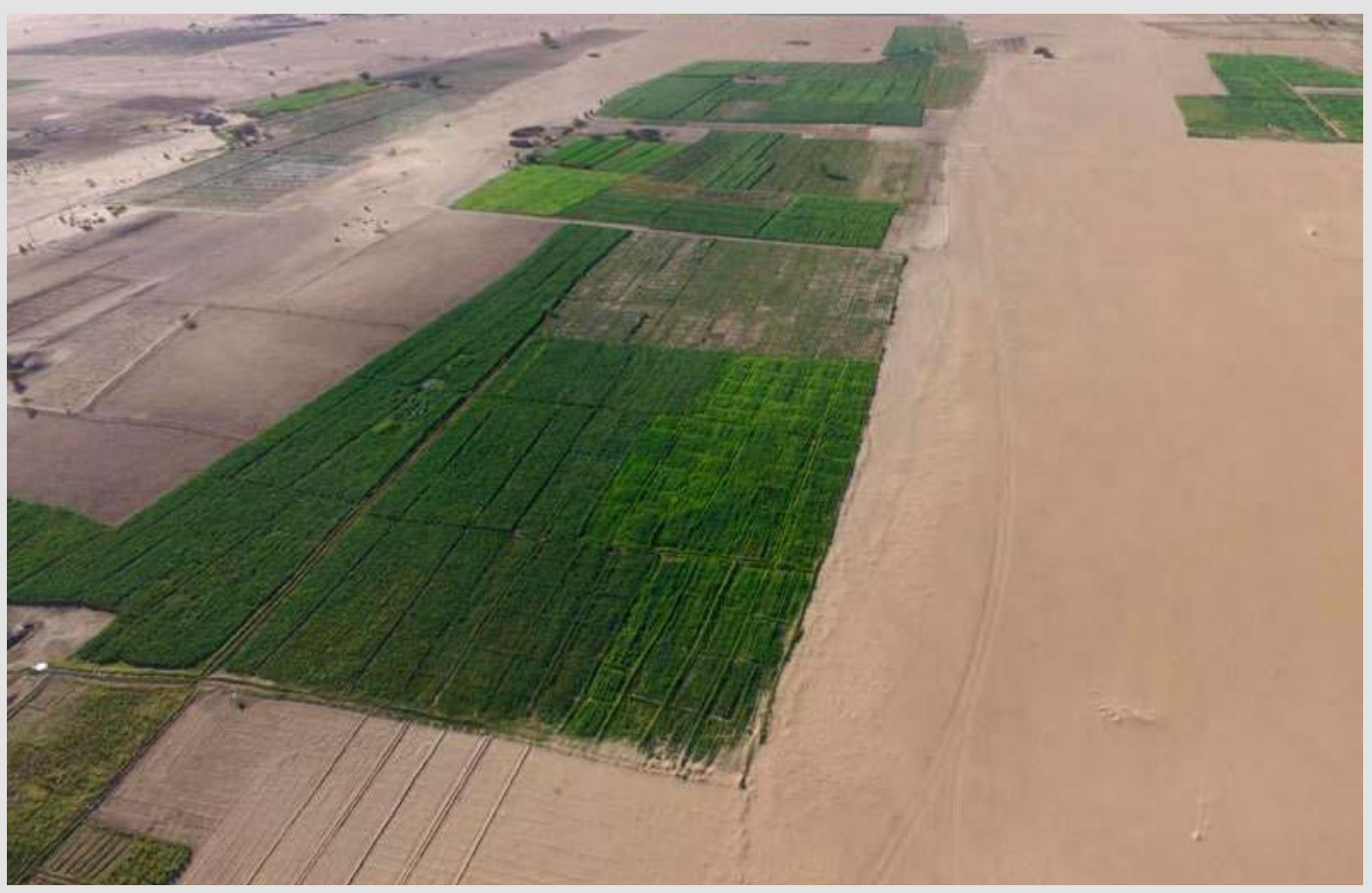

99

trente-cinq ans

d'archéologie préhistorique

à Kadrouka

2. Vue du cours du wadi el-Khowi (cliché: Y. Bière, 2016). 
cinquantenaire

\section{0}

de la section

française

de la direction

des Antiquités

du Soudan

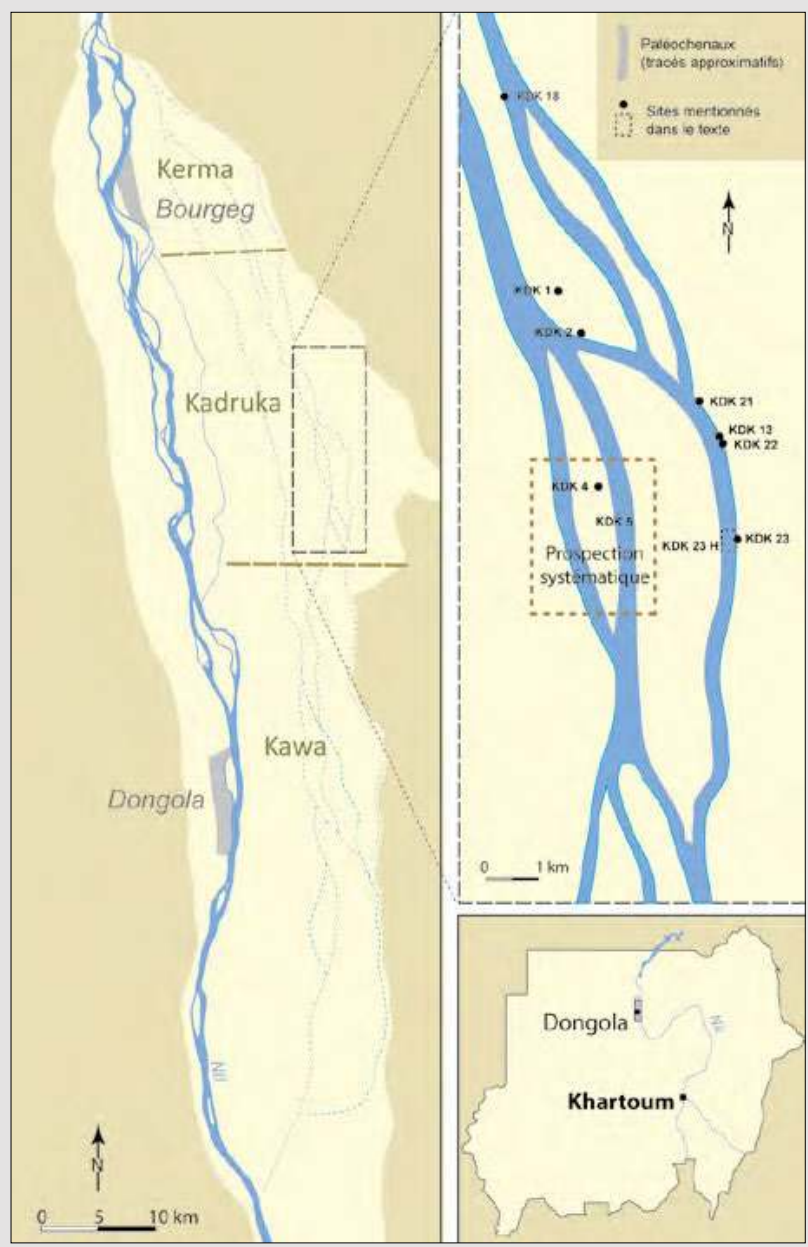

3. Localisation de la concession et des sites mentionnés dans le texte, tracé du wadi el-Khowi.

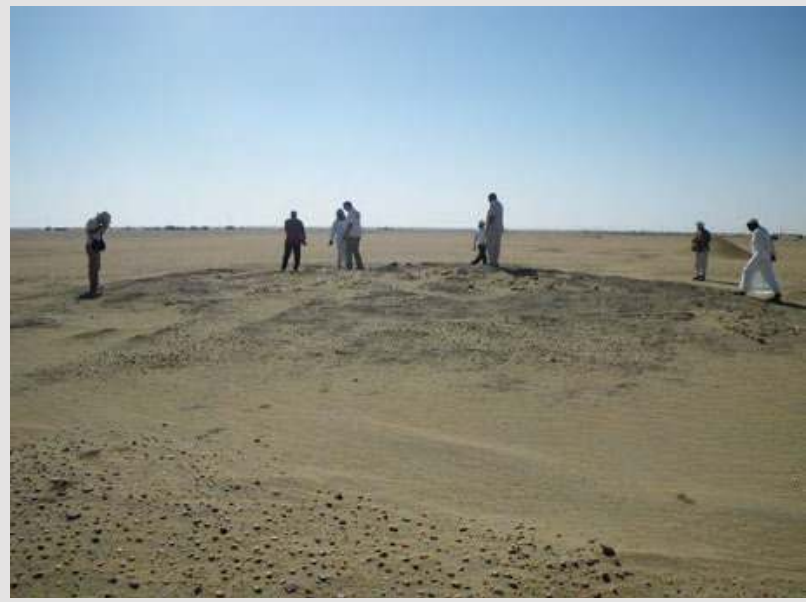

4. La butte funéraire KDK30 (cliché: mission Kadruka, 2013). 
anastomosé de chenaux durant la Préhistoire récente. L'espace couvert par la concession comprend ainsi trois milieux distincts, formant autant de bandes longitudinales: le bassin de Kerma à l'ouest, le désert à l'est et le cours du wadi el-Khowi (qui occupe la bordure orientale du bassin) dans la partie centrale.

À l'échelle des trois concessions traversées par le wadi el-Khowi, les sites se rattachent à des périodes d'autant plus anciennes que l'on s'éloigne de l'actuel cours du Nil en direction de l'est. Cette distribution correspond au déplacement du Nil, depuis le wadi el-Khowi, son ancien cours, jusqu'à son cours actuel, à une dizaine de kilomètres plus à l'ouest. Elle montre que les populations régionales ont affectionné les zones humides bien avant que l'assèchement du climat ne réduise les possibilités d'occupation à ce type de milieux.

Lorsque les recherches ont débuté, au milieu des années 1980, la concession comprenait différentes catégories de sites, de toutes époques, depuis la Préhistoire récente jusqu’à la période islamique (cf. infra). Mais les gisements les plus occidentaux, Kerma ou plus récents, avaient déjà souffert de l'expansion de l'agriculture et de la progression du bâti, si bien que l'intérêt de la concession portait déjà davantage sur les occupations néolithiques et pré-kerma que sur les occupations plus récentes. On ne s'étonnera donc pas que la concession doive sa célébrité à ses gisements néolithiques, et plus particulièrement aux cimetières de cette période. $\mathrm{Au}$ nombre d'une quinzaine, ces cimetières néolithiques ont été repérés

par J. Reinold sur le cours du wadi el-Khowi. La plupart se présentent sous la forme de buttes circulaires ou ovalaires peu élevées (moins de $2 \mathrm{~m}$ ) de quelques dizaines de mètres de diamètre, vestiges d'anciens îlots qui ponctuaient autrefois le réseau hydrographique (fig.4) ${ }^{1}$. Mais, comme nous le verrons, dans les années 1980-1990, ces buttes funéraires ne représentaient qu'une infime partie des gisements préhistoriques qui se distribuaient tout au long des branches de cet ancien Nil.

\section{Un bref historique des recherches}

On peut faire remonter à décembre 1985 l'histoire de cette concession. À cette date, Charles Bonnet, le directeur de la mission archéologique de Kerma, se rendit à Tambo Est (ancienne appellation du secteur de Kadrouka) où plusieurs sites menacés de destruction lui avaient été signalés. Ayant pris la mesure de l'intérêt exceptionnel de cet espace et de la grande

1 Selon J. Reinold (2004b: 163), contrairement aux autres buttes funéraires, KDK21 aurait une origine anthropique. 
cinquantenaire

\section{2}

de la section

française

de la direction

des Antiquités

du Soudan vulnérabilité de ce dernier face au processus d'extension des cultures qui s'engageait, il contacta Negm el-Den Mohamed Sherif, le directeur du service des Antiquités et des Musées nationaux, ainsi que Jacques Reinold, alors directeur de la SFDAs, pour les informer de cette situation préoccupante et les engager à entreprendre au plus vite une étude archéologique de la zone située à l'est de la localité de Kadrouka. Parmi les sites signalés, Charles Bonnet mentionnait un établissement rural remontant à l'époque Kerma classique et d'impressionnants ensembles d'époque néolithique. Durant la campagne 1985-1986, l'équipe de l'université de Genève (dir.: Ch. Bonnet) entrepris de sonder deux sites Kerma particulièrement menacés: l'établissement rural susmentionné (KDK6) et un cimetière remontant au Kerma ancien (KDK3), où six tombes furent fouillées.

Dès janvier 1986, J. Reinold (1987) effectua une première reconnaissance de la concession qui révéla une quinzaine de sites et procéda aux premiers sondages exploratoires au sein de plusieurs cimetières néolithiques (fig.3). Il initia également la fouille de KDK1, l'une des buttes funéraires signalées par Charles Bonnet. Trois autres campagnes seront nécessaires pour achever l'exploration de ce gisement, révélant le potentiel de la concession, ainsi que la richesse considérable de certains dépôts funéraires. Selon J. Reinold (2000 : 78), la fouille de KDK1 a livré 142 tombes, rattachées pour les deux tiers à la période néolithique et, pour le tiers restant, à la période Kerma ${ }^{1}$. À peine la fouille de KDK1 achevée, un autre cimetière, KDK18, fut investigué, révélant 124 tombes. Il faudra trois campagnes pour en venir à bout, la dernière (intervenue en 1991-1992) s'étant étendue sur trois mois. Suivit la fouille de quatre autres cimetières: de KDK13 en 1994 et 1995 (une trentaine de tombes fouillées), de KDK21 entre 1994 et 1998 (243 tombes fouillées), de KDK2 à la fin des années 1980, puis en 1997 (113 tombes fouillées sur un total estimé à un millier) et de KDK22 en 1988/89, puis entre 1997 et 1999 (une trentaine de tombes fouillées sur un total évalué à 150). Plus de 700 tombes, en comptant celles rencontrées lors des "sondages-tests" réalisés sur la quasi-totalité des cimetières, furent ainsi mises au jour. Parallèlement aux fouilles, J. Reinold entreprit une prospection sur l'ensemble de la concession. Aux sites préalablement découverts au nord de la concession, pour la plupart protohistoriques et historiques, se sont ajoutés de nombreux autres, relevant du Néolithique

1 Ces chiffres sont ceux fournis par J. Reinold. Dans la pratique,

l'établissement d'un chiffre précis est largement artificiel.

C'est ainsi que les études menées récemment par E. Maines (2019) sur le matériel osseux de KDK1 ont abouti à des résultats légèrement différents. 
jusqu'aux périodes les plus récentes. Ces différents travaux se sont arrêtés en 1999, ouvrant sur une quinzaine d'années d'interruption des recherches sur l'emprise de la concession.

En 2009, Vincent Rondot, directeur en titre de la SFDas, inscrivit la concession dans un vaste projet pluri-régional (étendu à la Nubie et au Soudan central), intitulé Archaeological Project Proposal in El-Kadada, El-Ghaba and El-Kadrouka et porté par J. Reinold, qui sera soumis dans le cadre d'un appel à proposition lancé par le Qsap (Qatar Sudan Archaeological Project). Concernant la concession de Kadrouka, ce projet ambitionnait la publication de deux cimetières (KDK1 et KDK18), ainsi que la fouille d'un troisième et la conduite de nouvelles prospections. Mais, alors que le QsaP se préparait, J. Reinold connu des problèmes de santé l'empêchant de mettre en œuvre son projet. Claude Rilly, le nouveau directeur de la SFDAS, proposa alors à deux des responsables de l'équipe actuelle (O. Langlois et P. Chambon) de le mener à bien.

Le projet fut toutefois redimensionné et limité à la concession de Kadrouka, avec comme objectifs initiaux la fouille d'un nouveau cimetière et l'étude d'une partie des données et assemblages issus des fouilles antérieures, en commençant par celles conduites à KDK1. Peu d'archéologues soudanais ou d'équipes internationales travaillant aujourd'hui sur le Néolithique de Nubie, la reprise de l'étude de la concession de Kadrouka fut d'emblée perçue comme l'occasion de construire une équipe pérenne dédiée à ce domaine de recherche. Le potentiel révélé par les travaux de J. Reinold étant énorme, et des matériaux nombreux et diversifiés devant être traités, poursuivre l'exploitation de la concession ne pouvait que s'envisager sur le long terme, en mobilisant un large panel de spécialistes. L'engagement de jeunes chercheurs, au côté de chercheurs séniors, semblait aussi une condition nécessaire pour imprimer une nouvelle dynamique aux études engagées plusieurs décennies auparavant par la SfDAs sur le Néolithique du Soudan. Dans sa configuration actuelle, cette équipe est composée de spécialistes, chercheurs, enseignantschercheurs et étudiants, qui se rattachent pour la plupart à deux unités de recherche: l'UmR 7264 (Серам), à Nice, et l'UmR 7206 (équipe Archéologie-biologique et bio-archéologie), à Paris.

Depuis 2014, cette nouvelle équipe, co-dirigée par les trois auteurs du présent texte, a donc repris les recherches archéologiques dans l'emprise de la concession. Dans la continuité des travaux précédents, l'étude des pratiques funéraires, pour elles-mêmes et pour ce qu'elles nous apprennent des sociétés qui les ont mises en œuvre, demeure un objectif majeur. La fouille d'un nouveau cimetière (KDK23) ainsi que les études nécessaires à la publication de KDK1 ont été prévues dès la conception du programme 


\section{Les travaux conduits dans les années 1980-1990 par Jacques Reinold}

Grâce aux travaux d'Antony J. Arkell, le Néolithique du Soudan occupe depuis bien longtemps une place de choix dans les chapitres consacrés à la Préhistoire récente de l'Afrique. Toutefois, jusque dans les années 1980, les sociétés néolithiques de la moyenne vallée du Nil étaient surtout connues à travers les recherches menées au Soudan central et en Basse-Nubie. Ainsi, lorsque J. Reinold commença à travailler dans le Northern Dongola Reach, le Néolithique de Haute Nubie était à peine connu. Les travaux qu'il effectua à Kadrouka présentent donc indéniablement un caractère pionnier.

Nous avons vu que, dès la première campagne de terrain, intervenue début 1986, J. Reinold avait mené deux activités en parallèle, la prospection de la concession et la fouille de cimetières, qui se sont étendues sur plusieurs campagnes. Les prospections ont cessé en 1994, alors que les fouilles se sont poursuivies jusqu'à la toute fin des années 1990.

Les prospections ont largement reposé sur les indications fournies par un réseau d'informateurs locaux. Elles ont permis de repérer quelque

de la section

française

de la direction des Antiquités du Soudan cent soixante sites, tous types et périodes confondus, qui figurent dans les archives de la concession. Parmi ceux-ci, peu sont précisément documentés, certains n'étant même plus localisables. C'est en particulier le cas des sites qui, ayant été repérés lors des premières campagnes, avant que J. Reinold ne dispose d'un GPs, ont été positionnés par triangulation à partir de repères aujourd'hui disparus.

Bien que non systématique, la prospection a mis en évidence le schéma général de l'occupation de cette section de la vallée du Nil, à savoir la distribution chrono-spatiale des implantations qui se sont succédé tout au long des périodes préhistoriques, protohistoriques et historiques (Reinold 1987: 44-45, 2000 : 45-46; $2001:$ ). Cette distribution singulière, due, comme nous l'avons vu, à une modification du cours du Nil, fut ensuite confirmée, plus au sud et au nord, dans les périmètres des concessions de Kawa (Welsby 2000, 2001) et de Kerma (Honegger 2001, 2005, 2007). Elle sera un élément structurant des recherches sur les sociétés anciennes de cette partie de la vallée du Nil. Concernant plus particulièrement la partie orientale de la concession, traversée par le cours du wadi el-Khowi, J. Reinold fait mention d'une vingtaine de sites localisés au voisinage immédiat 
de cet ancien cours d'eau: une quinzaine de buttes funéraires et une demidouzaine «d'épandages de matériel» qui se rapportent non seulement au Néolithique mais aussi à la période Pré-Kerma.

Si les prospections ont été étendues aux différentes catégories de sites, toutes périodes confondues, les fouilles ont presque exclusivement porté sur des cimetières néolithiques. Comme précédemment à Kadada (Soudan central) où il avait fouillé plusieurs nécropoles, J. Reinold a privilégié l'étude des contextes funéraires.

Trente ans après leur achèvement, les premières fouilles réalisées par J. Reinold à Kadrouka témoignent encore de la maîtrise de leur auteur dans l'approche archéologique des sépultures. Préhistorien issu de la génération Pincevent, familiarisé avec le dégagement des vestiges in situ, J. Reinold appliqua aux sépultures de KDK1 des méthodes encore peu courantes au milieu des années quatre-vingts: fouille en place, relevé sur papier millimétré (au $1 / 5^{\mathrm{e}}$ ), usage non compté des photographies et prélèvement exhaustif du matériel et des ossements caractérisent la méthode employée. Il en résulte une documentation que bien des fouilles contemporaines, même conduites dans le contexte plus favorable du territoire français, pourraient lui envier. Mais le prélèvement exhaustif du matériel et des ossements ne sera répété qu’à KDK18.

Car pour KDK21, J. Reinold choisit de mettre au jour, sans procéder à leur démontage, le plus grand nombre possible de sépultures de manière à obtenir, au final, une photographie globale du cimetière (cf. par ex. Reinold 2004a: 42 et 2004b: 164). Le mobilier fut récupéré (hormis certaines palettes et du matériel de mouture), mais les squelettes ne furent que partiellement démontés, les prélèvements opérés se limitant le plus souvent à un os coxal et une demi-arcade dentaire. Une nouvelle étape fut franchie avec la fouille partielle menée à KDK2. Là, comme à KDK21, l'essentiel des ossements fut laissé sur place, de même qu'une grande partie du mobilier. Une méthode de fouille plus habituelle, "consistant à araser progressivement le kôm par passes d'une vingtaine de centimètres ", sera enfin adoptée pour fouiller le cimetière KDK22 (Leclant et Minault-Gout $2000: 150)$.

À ce jour, aucun des cimetières de Kadrouka n'a encore fait l'objet d'une publication monographique, si bien que les travaux qui y ont été menés et l'information qui y a été collectée ne sont connus qu'à travers une série de textes, pour la plupart destinés à un large public. Si quelques tombes particulières y ont été décrites, l'information délivrée y est synthétique. Les données issues des cimetières fouillés exhaustivement (KDK1, KDK18 et KDK21) ont surtout donné lieu à une lecture sociale, une série de facteurs, tels la distribution des sépultures, leur richesse différentielle, 
cinquantenaire

\section{6}

de la section

française

de la direction

des Antiquités

du Soudan

la présence de certains éléments mobiliers et le sexe des sujets inhumés ayant été associés dans la perspective de préciser l'organisation des communautés concernées. Les observations et les conclusions formulées pour chacun de ces trois cimetières peuvent être résumées comme suit:

KDK21 est le seul tertre fouillé qui aurait une origine anthropique. Il aurait servi de lieu de sépulture durant la première moitié du $5^{\mathrm{e}}$ millénaire ${ }^{1}$. Bien que son occupation semble globalement remonter au Néolithique moyen A, elle pourrait se diviser en deux phases. Au sujet de l'une d'elle, J. Reinold fait état d'une «sépulture principale» (Reinold 2004b: 165), entourée d'une série de tombes d'enfants, qui contenait deux individus: une femme considérée comme le sujet principal et un homme qui serait le sujet secondaire. Cette tombe et l'association aux sujets féminins des vases caliciformes, une catégorie de poterie à caractère cérémoniel, témoigneraient du statut élevé des femmes.

Le cimetière KDK18 fut occupé, probablement brièvement, durant le troisième quart du $5^{\mathrm{e}}$ millénaire ${ }^{2}$. Le concernant, J. Reinold envisage aussi une évolution en deux temps. Durant les premiers temps de l'occupation, les tombes se distribuaient de part et d'autre d'une sorte d'allée menant au sommet de la butte, tandis que le versant opposé était occupé par un autre groupe de tombes. La partie centrale du cimetière, alors exempte de creusement, pourrait avoir accueilli un bâtiment. Dans un second temps, cet espace central aurait reçu la dépouille d'une femme, accompagnée d'un riche matériel, dont un objet en grès de forme phallique. Une demi-douzaine d'autres sépultures auraient ensuite environné cette tombe, avant que le cimetière ne cesse d'être utilisé. Comme à KDK21, seules les femmes semblent avoir été inhumées avec certaines catégories d'objets (vases caliciformes, palettes à fard), marquant, là encore, l'importance de leur statut. La richesse différentielle des dépôts serait un autre témoignage de la «diversification sociale» qui caractérisait ces communautés (Reinold 2004b: 68).

Au regard des datations radiométriques et de l'homogénéité du mobilier, l'occupation néolithique du cimetière KDK1, centrée sur la fin du $5^{\mathrm{e}}$ millénaire (Néolithique moyen $\mathrm{B}$ ), fut à la fois particulièrement brève et récente ${ }^{3}$. J. Reinold a envisagé une organisation concentrique de la partie

$15850 \pm 70 \mathrm{BP} ; 5875 \pm 110 \mathrm{BP} ; 5890 \pm 60 \mathrm{BP}$; $5910 \pm 60$ Bp (Reinold 2004b: 172).

2 Les cinq datations obtenues se situent entre $5470 \pm 70 \mathrm{BP}$ et $5580 \pm 70 \mathrm{Bp}$ (Reinold 2004b: 167).

3 La butte fut réutilisée comme espace funéraire à la période Kerma. Les trois datations radiométriques qui concernent la période néolithique ont donné les résultats suivants: $5290 \pm 60 \mathrm{BP}$; 
sommitale du cimetière (fig.5). Celui-ci se serait développé à partir d'une tombe fondatrice particulièrement riche, située au sommet de la butte: la fameuse sépulture 131, dite "du chef», qui se singularise par ailleurs par sa grande profondeur et par le côté (droit) sur lequel reposait le sujet (masculin) inhumé. Les riches sépultures qui occupent la partie médiane de ce tertre auraient d'ailleurs surtout renfermé des sujets masculins, contrairement aux tombes périphériques, de moindre richesse, qui seraient plutôt féminines (Reinold 2000 : 78 ; 2004b : 170).

Selon J. Reinold (2004b : 171), les données issues de la fouille des cimetières témoigneraient finalement d'une hiérarchisation croissante de sociétés aux structures diverses, déjà organisées en "véritables chefferies " (fig.6). De manière explicite, cette évolution est comprise comme participant du processus qui, un millénaire et demi plus tard, aboutira au royaume de Kerma. Elle en serait en quelque sorte le prélude. L'absence d'une étude biologique exhaustive, comme l'amélioration logique des outils anthropologiques pour les diagnostics de sexes et d'âge, conduisent aujourd'hui à considérer avec prudence les hypothèses formulées. En outre, l'état actuel des squelettes n'autorise plus qu'une révision partielle.

Si cette lecture sociale de l'abondante information collectée est parfaitement légitime, elle n'a pas reposé sur une analyse quantifiée des données disponibles. Une telle analyse aurait considérablement accru notre connaissance des pratiques funéraires en présence qui, au regard de l'information délivrée, reste sommaire. De plus, certaines découvertes réalisées dans ces cimetières auraient pu ouvrir sur d'autres questions que la question sociale. On pense en particulier aux modes de vie et de subsistance de ces populations néolithiques, encore souvent considérées comme pastorales et nomades. La présence dans plusieurs tombes de KDK1 de restes d'orge (qui comptent parmi les plus anciens témoins de la présence de cette céréale proche-orientale dans la vallée du Nil), associée à la fréquence des vestiges d'habitats, avait bien conduit J. Reinold à considérer que les populations inhumées dans les cimetières de Kadrouka étaient possiblement des agropasteurs qui occupaient les rives du wadi el-Khowi tout ou partie de l'année.

Mais, faute d'avoir été suffisamment documentée et publiée, cette hypothèse n'a pas suscité l'intérêt qu'elle méritait. Les résidus d'orge découverts à KDK1 furent finalement négligés, laissant tout au plus envisager

$5360 \pm 70 \mathrm{BP} ; 5590 \pm 60 \mathrm{Bp}$ (Reinold 2004b: 172).

Ces datations couvrent une grande partie de la seconde moitié $\mathrm{du} 5^{\mathrm{e}}$ millénaire, mais J. Reinold a considéré la datation la plus ancienne comme divergente. 
5. KDK1 - Plan

général (d'après

J. Reinold, 2004a). cinquantenaire

\section{8}

de la section

française

de la direction

des Antiquités

du Soudan
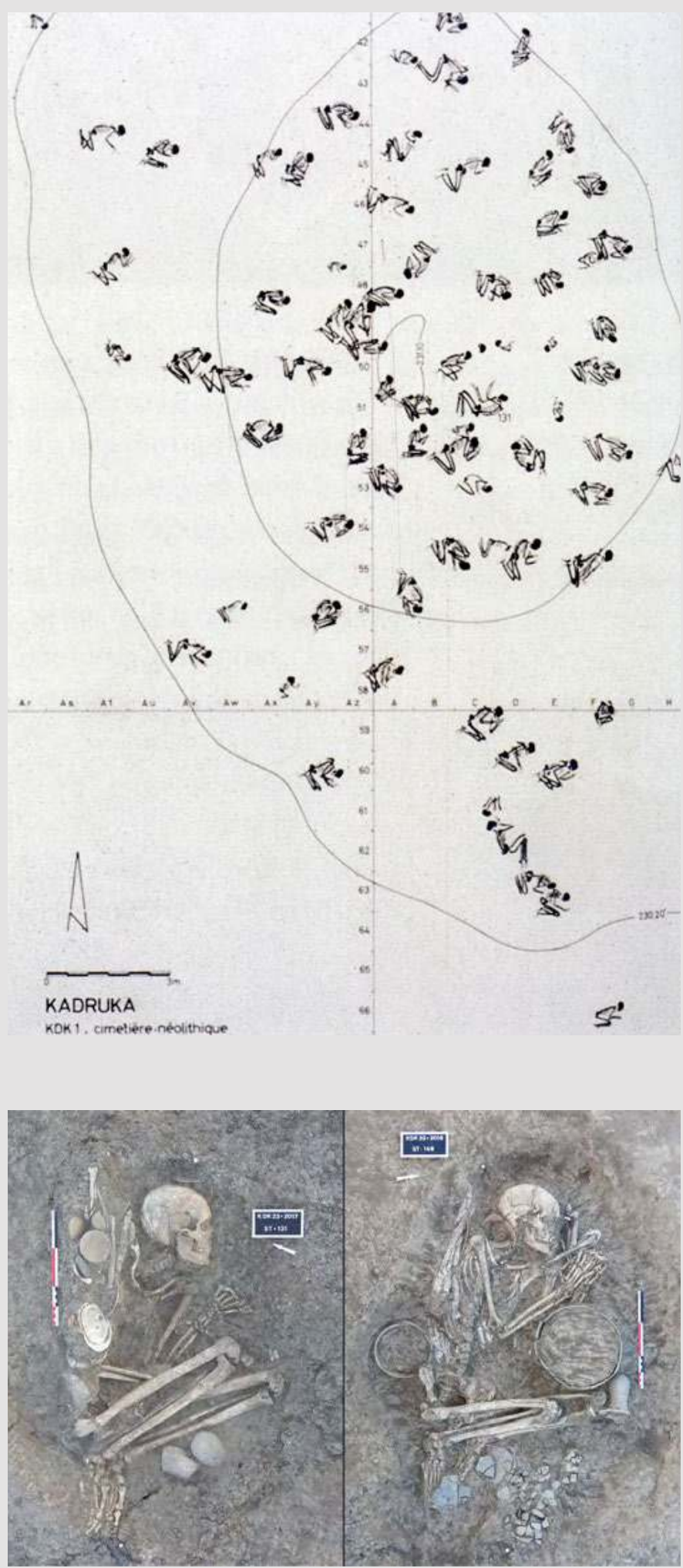

6. KDK23 - Deux "riches " tombes néolithiques (cliché: mission Kadruka, 2017 et 2018). La quantité de mobilier est le principal critère retenu pour qualifier ainsi les sépultures, avec quelquefois des objets rares, sinon uniques: une demi-défense d'éléphant (débitée dans la longueur) est ainsi associée au sujet 141 . En revanche, les dispositifs sépulcraux ne distinguent nullement ces individus. Les fosses non apprêtées ont les mêmes dimensions étriquées, et l'hypothèse d'une simple couverture ou d'une peau repliée sur le cadavre est également privilégiée. 
la possibilité d'une agriculture d'appoint, pratiquée dans le cadre d'une économie fondamentalement pastorale, quand ils ne furent pas considérés comme des denrées de prestige importées depuis ou via la basse vallée du Nil (Hildebrand et Schilling 2016: 85; Hildebrand et al. 2018: 231). Il fallut ainsi attendre ces dernières années et la découverte d'autres indices de consommation de céréales pour que le pastoralisme nomade de ces populations soit explicitement remis en question (Madella et al. 2014; Out et al. 2016; Salvatori et Usai 2019).

Pour la suite du propos, il est important de remarquer qu'en plus des fouilles menées dans les cimetières J. Reinold a entrepris des travaux limités sur certains des "épandages de matériel » repérés sur le cours du wadi el-Khowi, des sites qu'il considéra comme d'anciens habitats néolithiques déflatés qui s'étendaient le long des chenaux. Ce fut en particulier le cas à KDK29 où J. Reinold entreprit de dégager le sable superficiel pour accéder au limon sous-jacent. Ce faisant, il mit au jour de très nombreux trous de poteaux (Leclant et Clerc 1991: 258, fig.93). Malgré la découverte de traces qui démontraient leur relative préservation, les habitats néolithiques et Pré-Kerma qui se concentraient au voisinage du wadi el-Khowi, et qui se présentaient sous la forme "d'épandages de matériel», furent considérés comme de simples palimpsestes, résultat d'une érosion qui, à l'échelle de la concession, aurait évacué entre $40 \mathrm{~cm}$ et $80 \mathrm{~cm}$ de sédiments (Reinold 1994 : 72). La reprise des investigations sur la concession a conduit à réviser fondamentalement ces considérations.

\section{Les travaux en cours depuis 2014}

Début 2014, après un premier repérage, les travaux ont repris sur la concession de Kadrouka grâce au financement alloué par le QatarSudan Archaeological Project (QsaP). Si, au regard de l'information alors disponible, nous avons tout d'abord axé notre problématique sur le domaine funéraire, le réexamen du potentiel de la concession nous a rapidement conduits à élargir notre recherche à tous les aspects de la vie (et donc de la mort) des populations néolithiques.

\section{KDK23}

Lors de la reprise du projet Qsap, trois critères ont guidé le choix du cimetière à fouiller: une certaine distance par rapport aux champs les plus proches, une faible érosion du kôm en surface et une extension raisonnable (fig.7 et fig.8). Un potentiel d'une centaine de sépultures 
cinquantenaire

\section{0}

de la section

française

de la direction

des Antiquités

du Soudan paraissait satisfaisant ${ }^{1}$, à comparer à la poignée de tombes de KDK13 et aux plus de 800 estimées de KDK2. Sur cette base, nous avons donc retenu KDK23.

Le choix était la fouille exhaustive du cimetière, nécessaire pour avoir une perception complète de la population inhumée, de la durée de son utilisation et de sa topographie. Sans écarter la lecture sociale, nous souhaitions avant tout retrouver la chaîne opératoire funéraire, c'est-àdire décrypter les gestes depuis la mort de l'individu jusqu'à l'oubli de sa tombe. Ce décryptage était notamment nécessaire pour mettre en examen l'image selon laquelle les pratiques funéraires du Néolithique soudanais seraient d'une grande stabilité, quelques traits, tel que l'emploi d'une peau pour recouvrir le cadavre, la présence presque systématique de céramique ou le rôle des massacres de bœuf, se prolongeant même jusqu'à la période Kerma. Une telle ambition requerrait l'enregistrement précis des témoins archéologiques afin, dans un premier temps, de recréer l'image de la tombe et, dans un second, de mettre en séquence les éléments observés et interprétés. L'enregistrement devait être optimal, conjuguant plans et photographies (fig.9). L'électrification du secteur rendant aisée l'impression d'images numériques, nous avons opté pour des photographies verticales comme base des plans de démontage, gagnant ainsi du temps sur le terrain. Les plans millimétrés ont été conservés pour les cas où la fouille nécessitait de prélever prématurément certains vestiges, ou lorsqu'il s'agissait d'ossements épars dans un comblement.

La butte correspondant à KDK23 atteint une quarantaine de mètres de diamètre, pour une hauteur d'environ 1,50 m au-dessus de la plaine. Comme dans les autres cimetières identifiés, J. Reinold y avait pratiqué un sondage, en janvier 1989, sous la forme habituelle d'un décapage en "q" de sa surface: soit une fenêtre de 4 × $6 \mathrm{~m}$ au sommet de la butte, et un segment de $2 \mathrm{~m}$ de large de sa base au sommet sur son flanc sud. Ce sondage avait mis au jour deux sépultures de très jeunes sujets (de moins de $1 \mathrm{an}$ ) et permis d'entrevoir trois squelettes à différentes hauteurs dans une fosse test située au point le plus haut de la butte. La fouille, entamée en 2014, a d'abord retrouvé les contours de ces sondages, avant d'attaquer le décapage systématique du kôm. La première campagne a permis de définir les protocoles de prises d'information.

1 L'évaluation ne pouvait être qu'un pari reposant sur la taille de la butte et l'extension des vestiges en surface. Elle s'est avérée erronée. Au vu de la densité et des tombes déjà fouillées, l'effectif sera bien supérieur à 200 . 


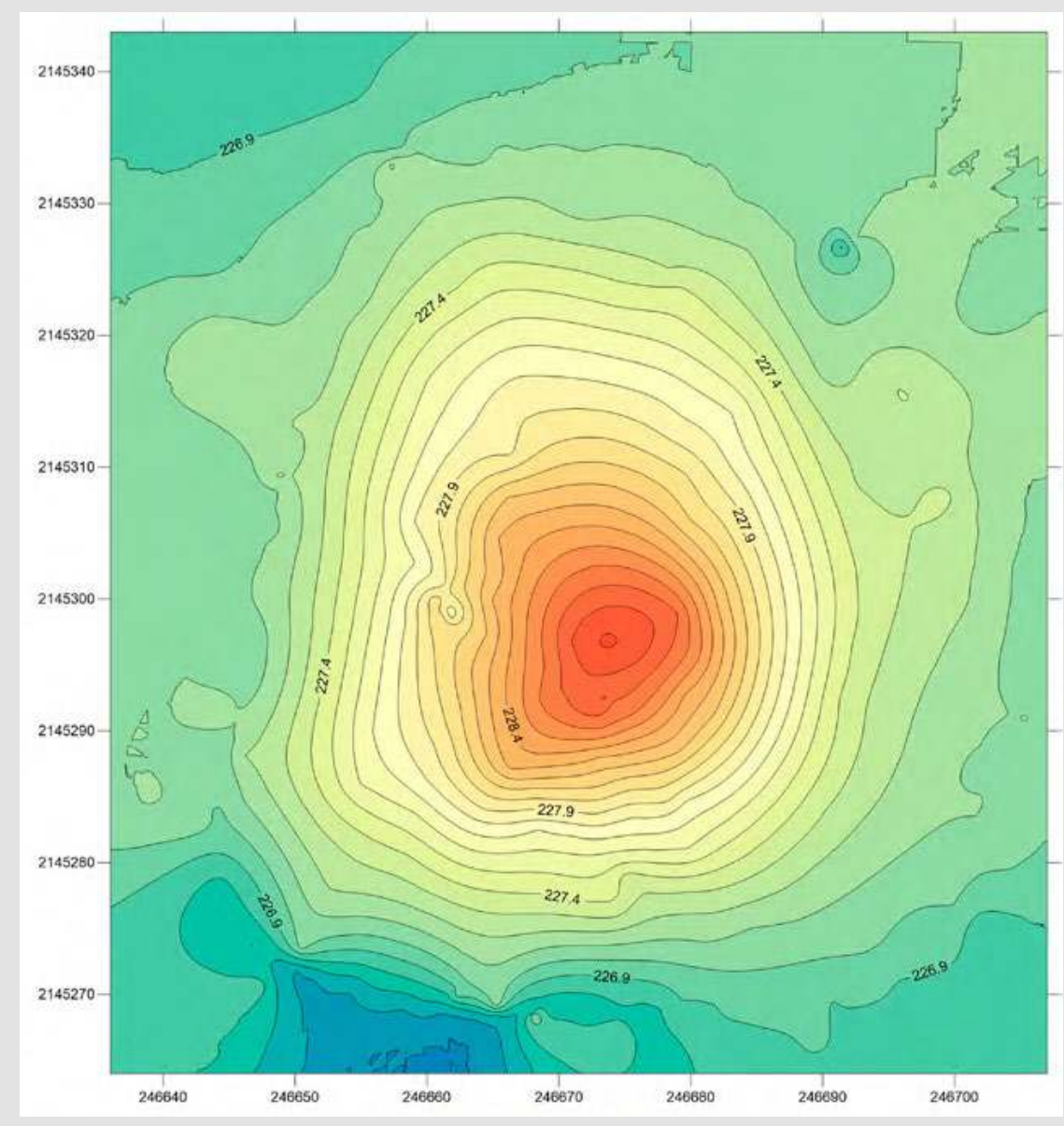

7. KDK23 - Isoplèthes d'altitude (réalisation: G. Davtian, 2014).

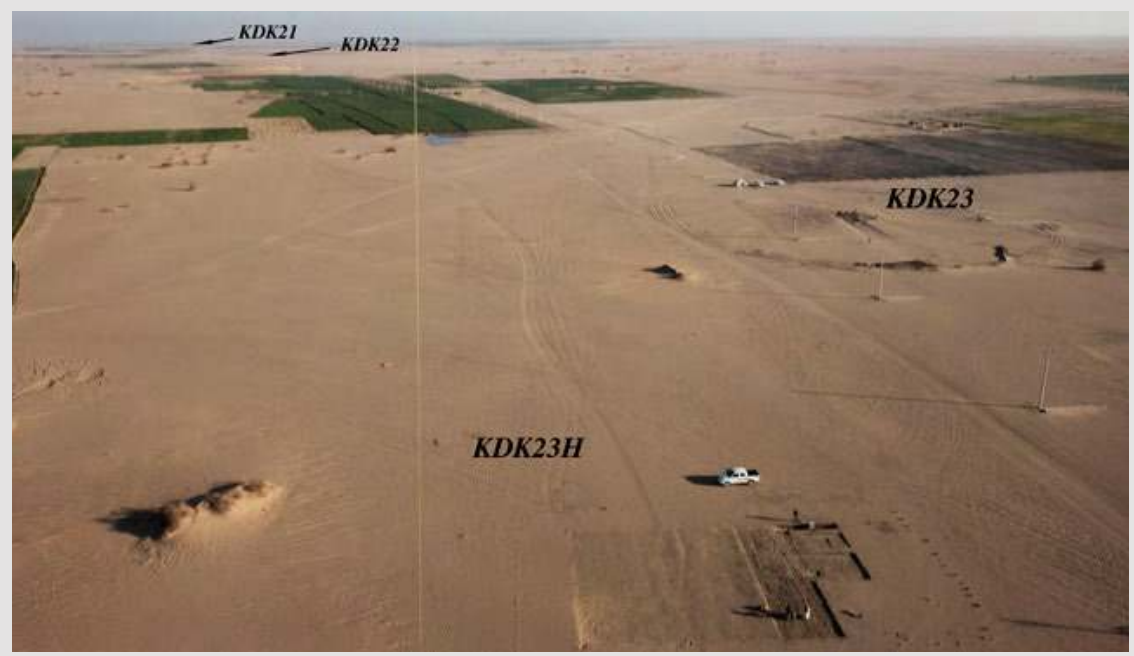

8. KDK23 et KDK23H - Vue aérienne (cliché: Y. Guichard, 2016).

\section{1}

trente-cinq ans

d'archéologie préhistorique à Kadrouka 


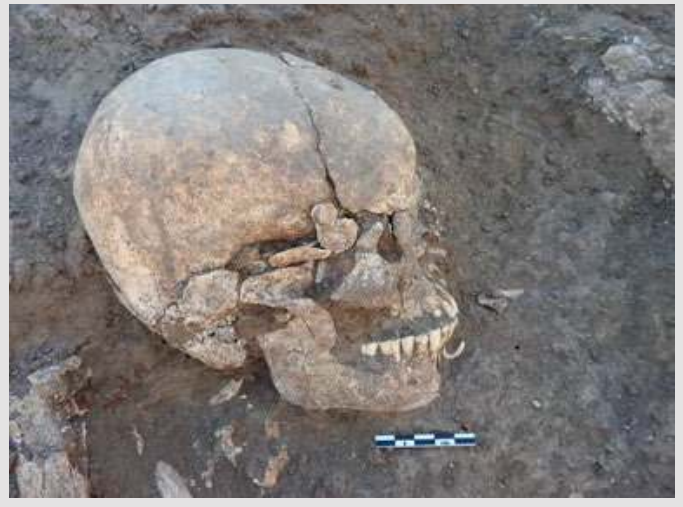

9. KDK23 - Un labret dégagé en place juste au-dessus du menton du sujet de la sépulture 135 (cliché: mission Kadruka, 2017).

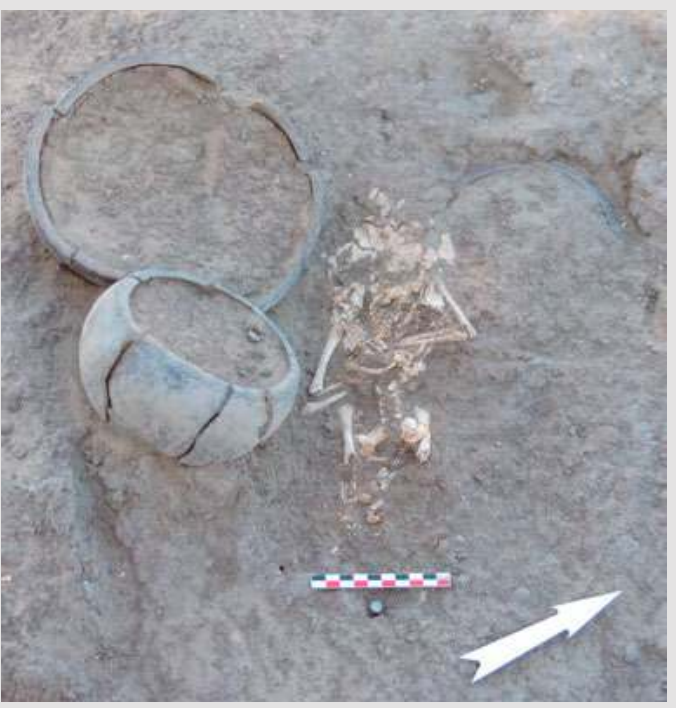

11. KDK23 - Sépulture 25. Un sujet périnatal en position ventrale, face vers le sol, les membres inférieurs hyperfléchis sous le tronc. La position est vraisemblablement liée à l'emploi d'un panier ou d'un couffin (cliché: mission Kadruka, 2014).

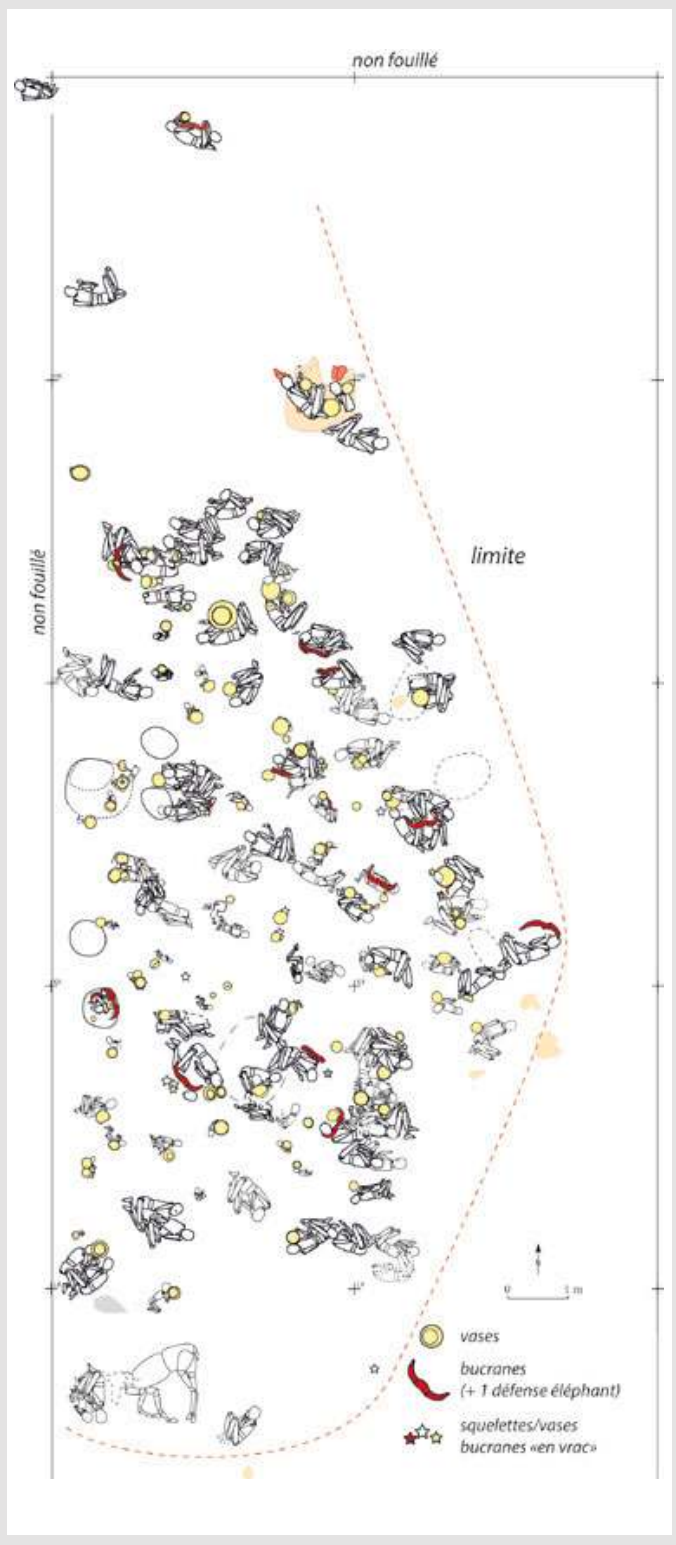

10. KDK23 - Plan général du cimetière à l'issue de la campagne 2019.

La densité globale dépasse 1 sépulture par $\mathrm{m}^{2}$. Les limites sud et est sont reconnues. Les sépultures les plus profondes ne sont pas encore fouillées, singulièrement dans la partie nord du secteur ouvert. 

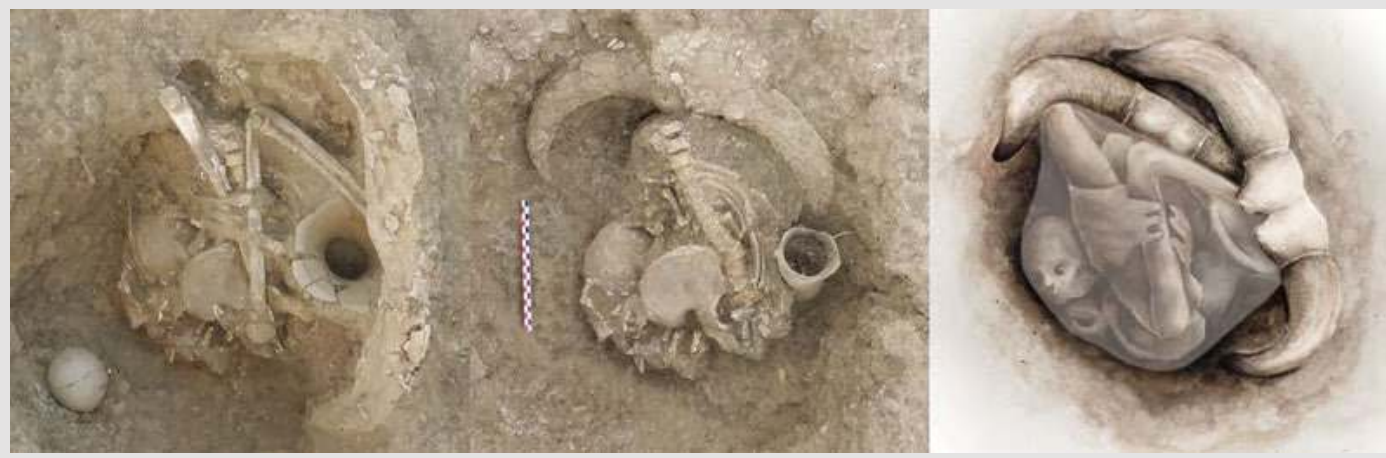

12. KDK23 - Sépulture 89. Une inhumation secondaire avec démembrement partiel. Le bilan des articulations en connexion ou disloquées correspond à une décomposition en ordre paradoxal, donc à un probable dessèchement, sinon à une momification de la dépouille avant son dépôt. En outre, des manipulations sont encore indiquées par quelques traces de découpe (clichés: mission Kadruka, 2016; dessin C. Martha).

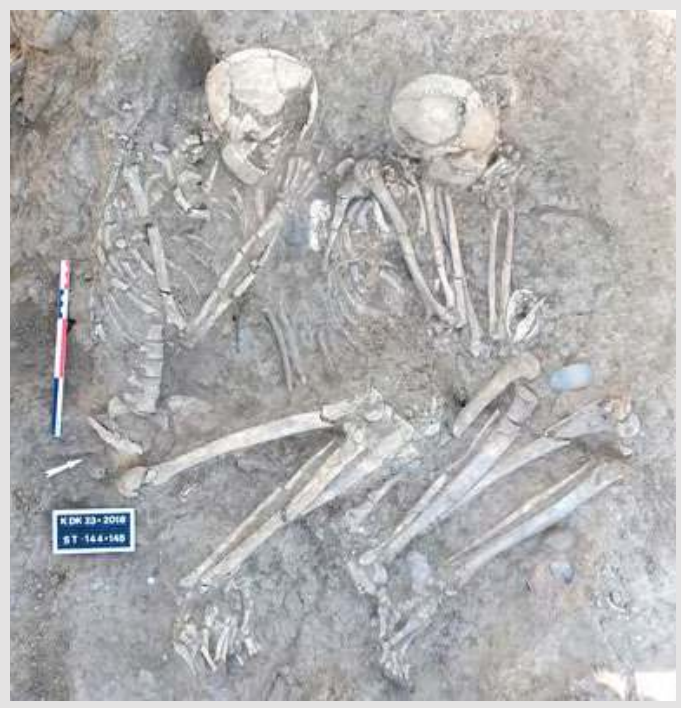

13. KDK23 - Sépulture double $144 / 145$. Aucune différence dans le traitement des cadavres n'indique la primauté de l'un sur l'autre: les deux sujets dans la même position occupent un espace équivalent (cliché: mission Kadruka, 2018).

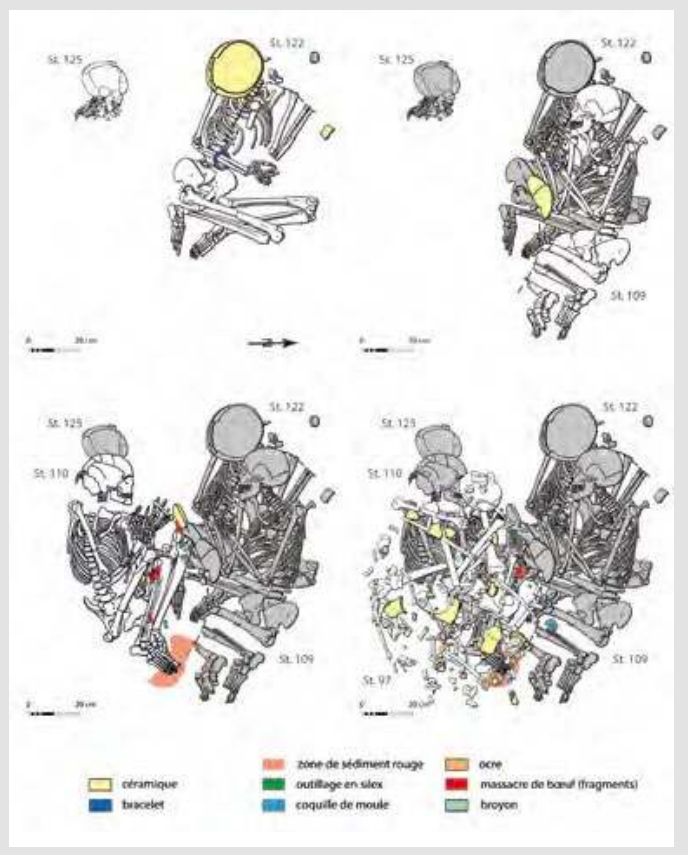

113

trente-cinq ans d'archéologie préhistorique à Kadrouka
14. KDK23 - Succession de sépultures au même emplacement.

Les sujets 109 et 110 sont situés à la même profondeur,

en vis-à-vis, et les têtes au même niveau. Le recoupement entre les deux sujets indique pourtant la postériorité du sujet 110. Enfin, la quasi-totalité du squelette 97, dont la tombe devait précéder 110, gît dans le comblement de celle-ci. 
cinquantenaire

\section{4}

de la section

française

de la direction

des Antiquités

du Soudan
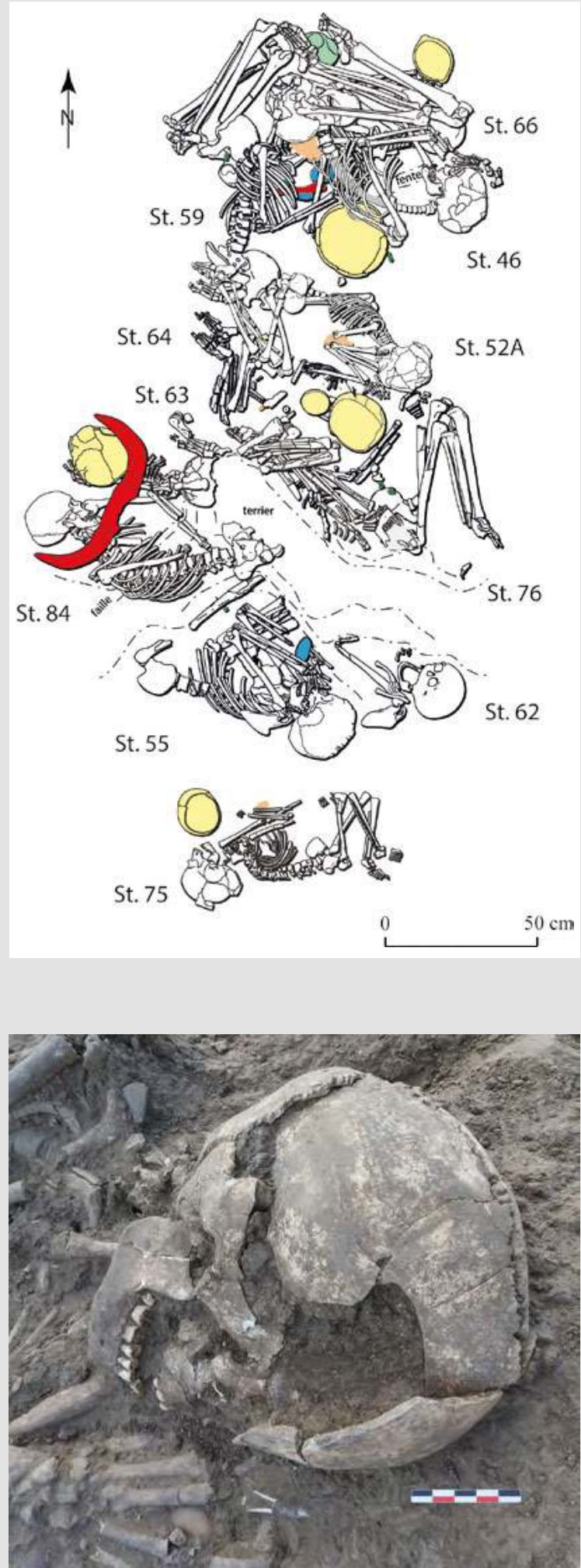

15. KDK23 - Regroupement de sépultures sous forme de petite rangée. En dehors du sujet 84 , qui dépasse vers l'ouest, tous s'inscrivent dans un grand rectangle de $3 \times 1 \mathrm{~m}$.

16. KDK23 - Bloc crâniofacial du sujet 144 portant la trace de l'impact d'un instrument contondant en limite de l'os pariétal droit et de l'os frontal. Si elle fut infligée au sujet vivant, cette blessure perimortem a assurément été fatale (cliché: mission Kadruka, 2018). 
Face à la fragmentation des ossements, et donc à l'impossibilité de les prélever dans de bonnes conditions, les données métriques ou morphologiques ont essentiellement été cotées lors du prélèvement du squelette, et ce, dès 2015.

La surface de la butte est presque uniformément couverte, à l'image de la plaine, par un niveau de sable grossier. Malgré l'instabilité de ce sédiment, il peut contenir des vestiges en place: une petite série de sépultures sont ainsi apparues quelques centimètres sous le sol actuel. Ce premier horizon sableux, grossier et jaune, laisse la place, après $5 \mathrm{~cm}$, à une strate de sable et de limon mélangés, donc moins grossiers et de couleur marbrée à grise, mais encore très "léger» à la fouille. En revanche, le passage au limon sous-jacent marque un changement complet. Dense et sec, il a une consistance extrêmement dure. Il en résulte une difficulté réelle à dégager soigneusement les vestiges. Le caractère très homogène du limon ne permet pas de distinguer les creusements. Les cisaillements de la butte, entaillée de failles dues à la rétraction du sédiment, crée régulièrement de faux effets de limite. Enfin, la densité des sépultures est telle que, dans la partie supérieure de la butte, tout le sédiment correspond peu ou prou à un comblement. La conséquence logique de cette absence de lisibilité a été de procéder au décapage successif de toute la hauteur de la butte à l'emplacement du cimetière, des squelettes les plus superficiels aux plus profonds.

À l'issue de la $7^{\mathrm{e}}$ campagne, fin 2019, la fouille de KDK23 n'est pas encore achevée. 143 sépultures, pour un total de 147 individus ${ }^{1}$, ont été mises au jour, sur près de $125 \mathrm{~m}^{2}$, soit près des deux tiers de la surface estimée du cimetière (fig.10). S'il n'entre pas en contradiction évidente avec le panorama produit par J. Reinold, le tableau actuel des pratiques funéraires présente davantage de diversité et de complexité. Parmi les acquis, il faut d'abord mentionner une plus grande diversité des modes de dépôts. Ainsi, l'usage de véritables contenants, paniers ou couffins, est suspecté pour les plus jeunes sujets (fig.11). Concernant les adultes, on note quelques dépôts différés, avec dessèchement (ou momification) possible de la dépouille, suivi dans un cas du démembrement du sujet avant l'inhumation secondaire (fig.12). Plusieurs sépultures doubles ont été rencontrées, sans montrer une hiérarchie entre les sujets associés (fig.13). Le regroupement de défunts intervient également dans le cas de tombes successives: il existe de véritables petits locus d'inhumation, concentration extrême de sujets en un même point (fig.14). La gestion des restes antérieurs peut varier du désintérêt total à la réduction de corps, en passant par la réintroduction des ossements dans le comblement

1 Les nombreux restes épars retrouvés en surface ou dans les comblements n'apparaissent pas dans ce total. En l'état, ils doivent correspondre à une dizaine de sujets supplémentaires. 
de la sépulture plus récente. En tout état de cause, il n'existait aucune gêne à manipuler les ossements. À côté de ces locus, la topographie du cimetière fait apparaître des rangées de sépultures, donc bordées par des espaces vides relatifs, possibles couloirs de circulation dans le cimetière (fig.15). Signalons encore que les plus jeunes sujets, dont la représentation apparaît conforme à la démographie supposée d'une telle population, ne sont présents que dans la partie la plus haute du cimetière. Enfin, et même si cela ne concerne pas directement les pratiques funéraires, les stigmates de violence interpersonnelle s'accumulent au fil des campagnes (fig.16).

\section{Les habitats}

Alors que nous débutions la fouille du cimetière KDK23, nous avons constaté qu'il était bordé, sur son versant ouest, par une de ces vastes étendues parsemées d'éclats évoquées par J. Reinold (fig. 8). Nous avons alors décidé de nous assurer que cette étendue, que nous avons nommée $\mathrm{KDK}_{23} \mathrm{H}$, n'était rien de plus qu'un palimpseste d'anciens niveaux d'occupation déflatés par l'érosion, un état qui, selon une idée largement admise, serait celui de la quasi-totalité des habitats néolithiques régionaux.

Le premier travail a consisté à décompter les différents vestiges

de la section

française

de la direction

des Antiquités

du Soudan représentés à la surface de plus de 200 parcelles de $4 \mathrm{~m}^{2}$. Ce décompte a permis d'établir une carte de densité, révélant ainsi deux zones de fortes concentrations du mobilier, ainsi qu'une organisation en bandes (fig.17). Associée à d'autres indices, notamment la présence d'une ligne de «structures de combustion ", un phénomène souvent considéré comme témoignant d'anciennes ripisylves, cette organisation semblait montrer que l'espace avait été traversé par un chenal. Nous avons alors choisi de localiser un sondage sur le secteur qui avait révélé une densité maximale d'artefacts. Après avoir dégagé le sable superficiel sur près de $45 \mathrm{om}^{2}$, nous avons découvert un grand nombre de trous de poteaux, très majoritairement situés sur la partie orientale de l'espace ouvert (fig. 18). Une tranchée fut creusée à l'angle nord-est de cet espace, révélant effectivement la présence d'un chenal dont le remplissage était ponctué de trous de poteaux, ainsi que deux fosses (St. 29 et St. 193) contenant de la faune domestique (fig.19 et fig.20). Ces fosses, ainsi que le comblement final du chenal, furent datés de la seconde moitié du $5^{\mathrm{e}}$ millénaire entre 4450 et 3800 cal. Bc, la plupart des datations se rapportant au dernier tiers du millénaire. Plus à l'ouest, dans une zone beaucoup plus pauvre en trous de poteaux, un foyer en cuvette (St. 416) daté de 4690-4464 cal. Bc fut repéré et fouillé (fig.21). Ses environs étaient parsemés d'éclats lithiques et de fragments osseux. Le remontage des éclats et esquilles a permis de reconstituer plusieurs galets (fig.22). 


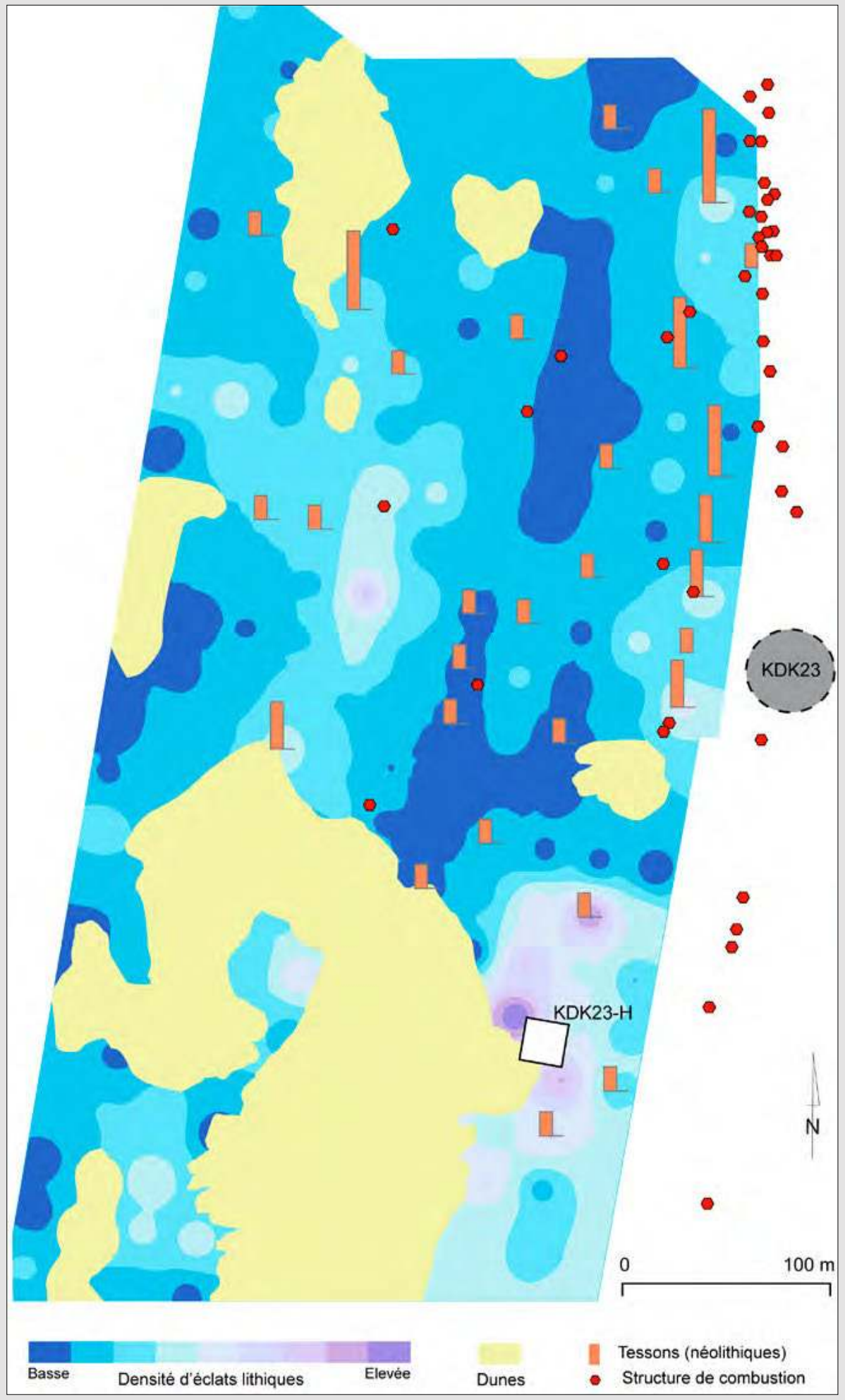

trente-cinq ans

d'archéologie préhistorique à Kadrouka 17. КDK23H - Carte de densité (réalisation: G. Davtian, 2014). 


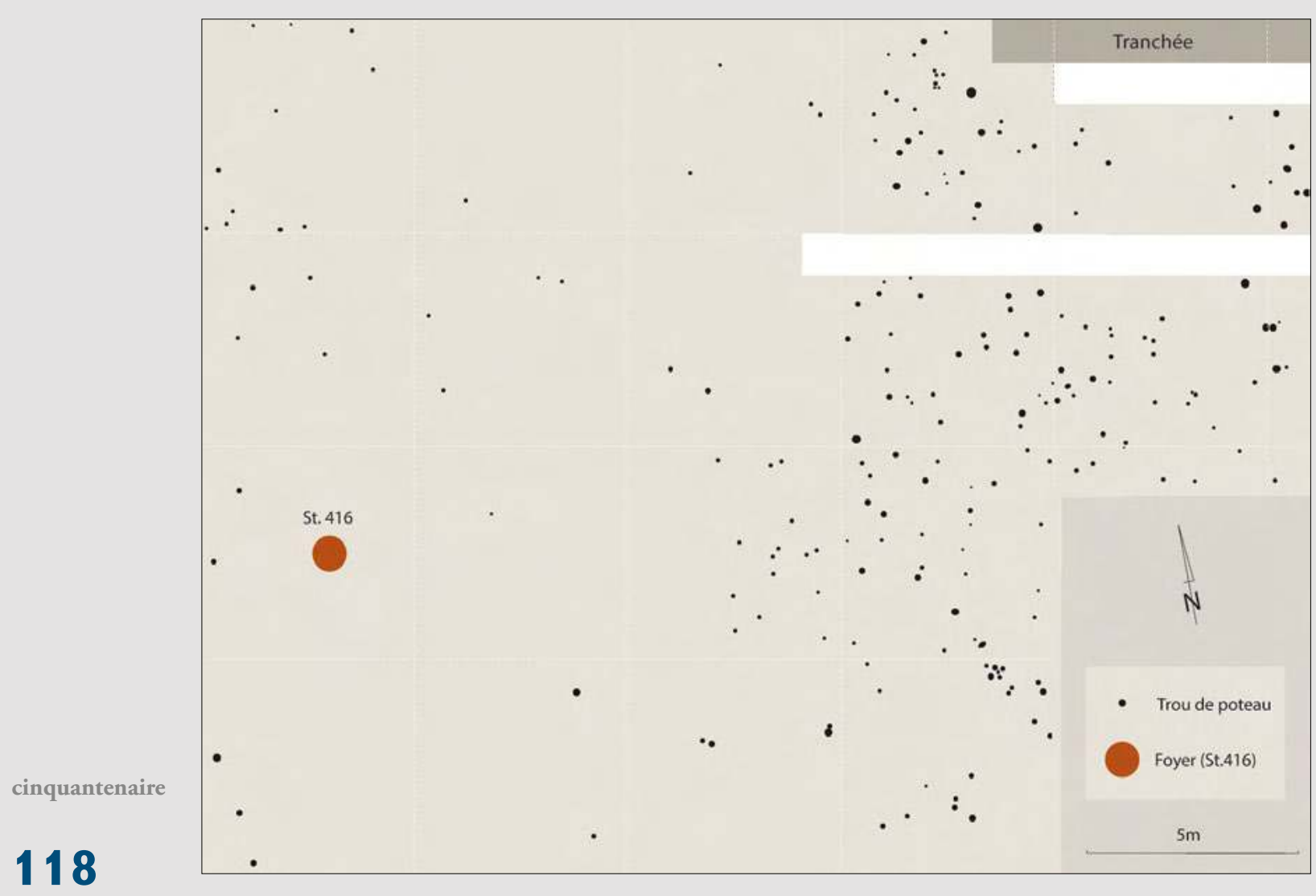

18. KDK23 H - Plan général de l'espace fouillé.

de la section

française

de la direction des Antiquités du Soudan

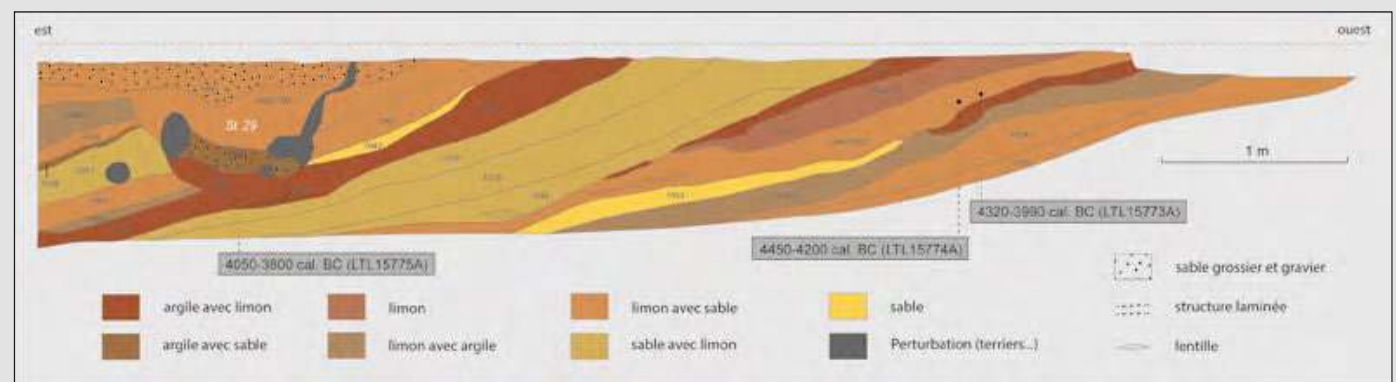

19. KDK23 $\mathrm{H}$ - Coupe de la tranchée entaillant le paléochenal. 


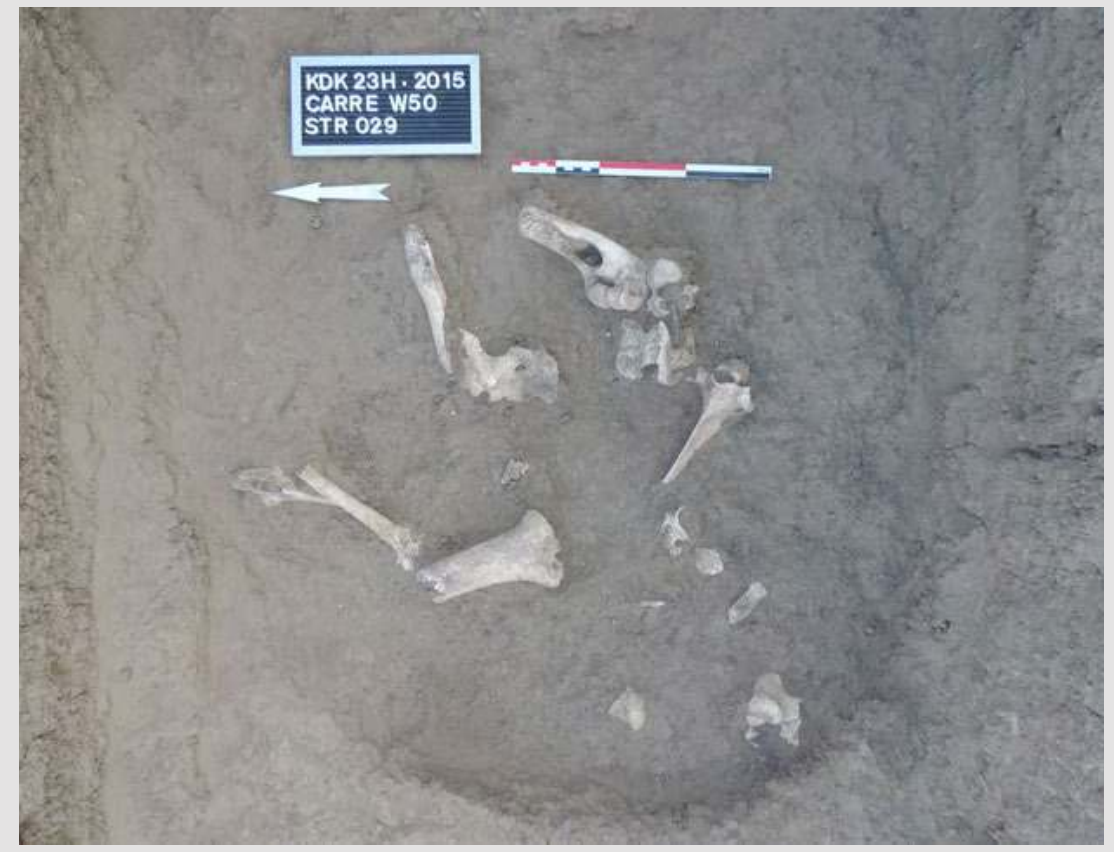

20. KDK23 H - Fosse St. 29 creusée dans le remplissage du paléochenal (cliché:

mission Kadruka, 2015).

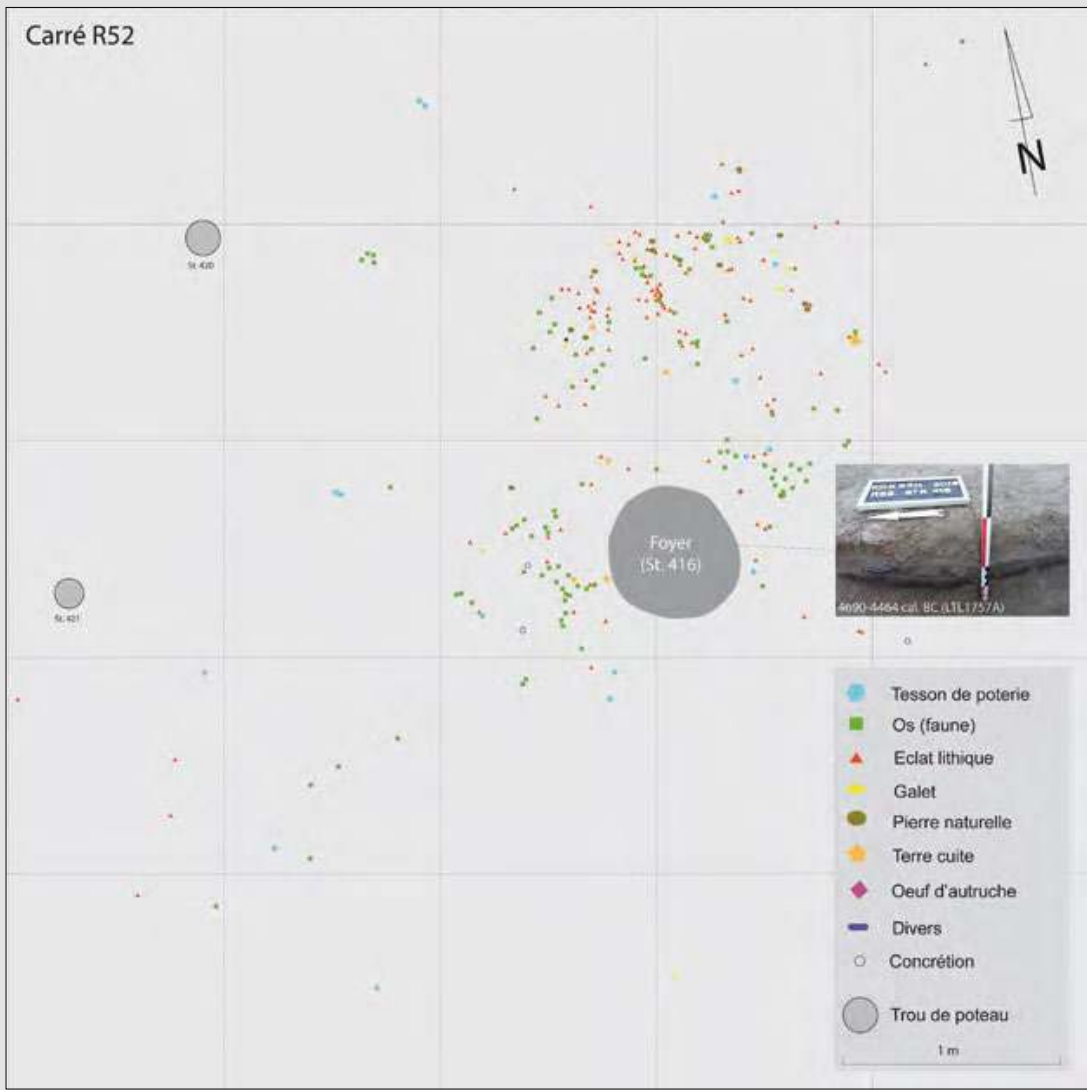

21. KDK23 $\mathrm{H}$ - Distribution

des artefacts et écofacts aux environs du foyer St.416.

trente-cinq ans

d'archéologie préhistorique à Kadrouka 
cinquantenaire

\section{0}

de la section française de la direction des Antiquités du Soudan

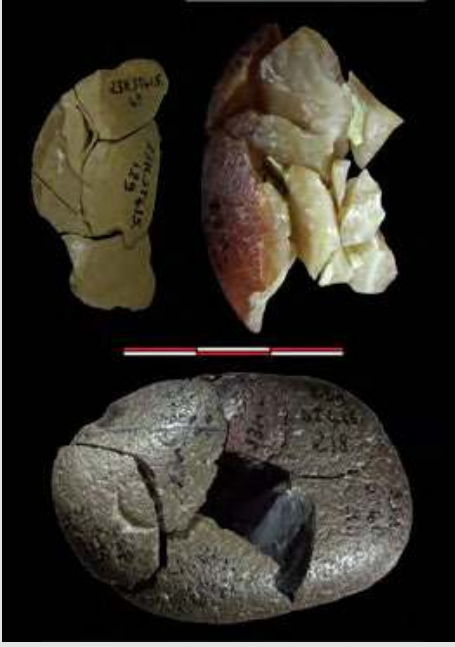

22. KDк23 $\mathrm{H}$ - Deux galets remontés (éclats issus des environ du foyer St.416; clichés L. Khalidi \& C. Pruvost, 2018).

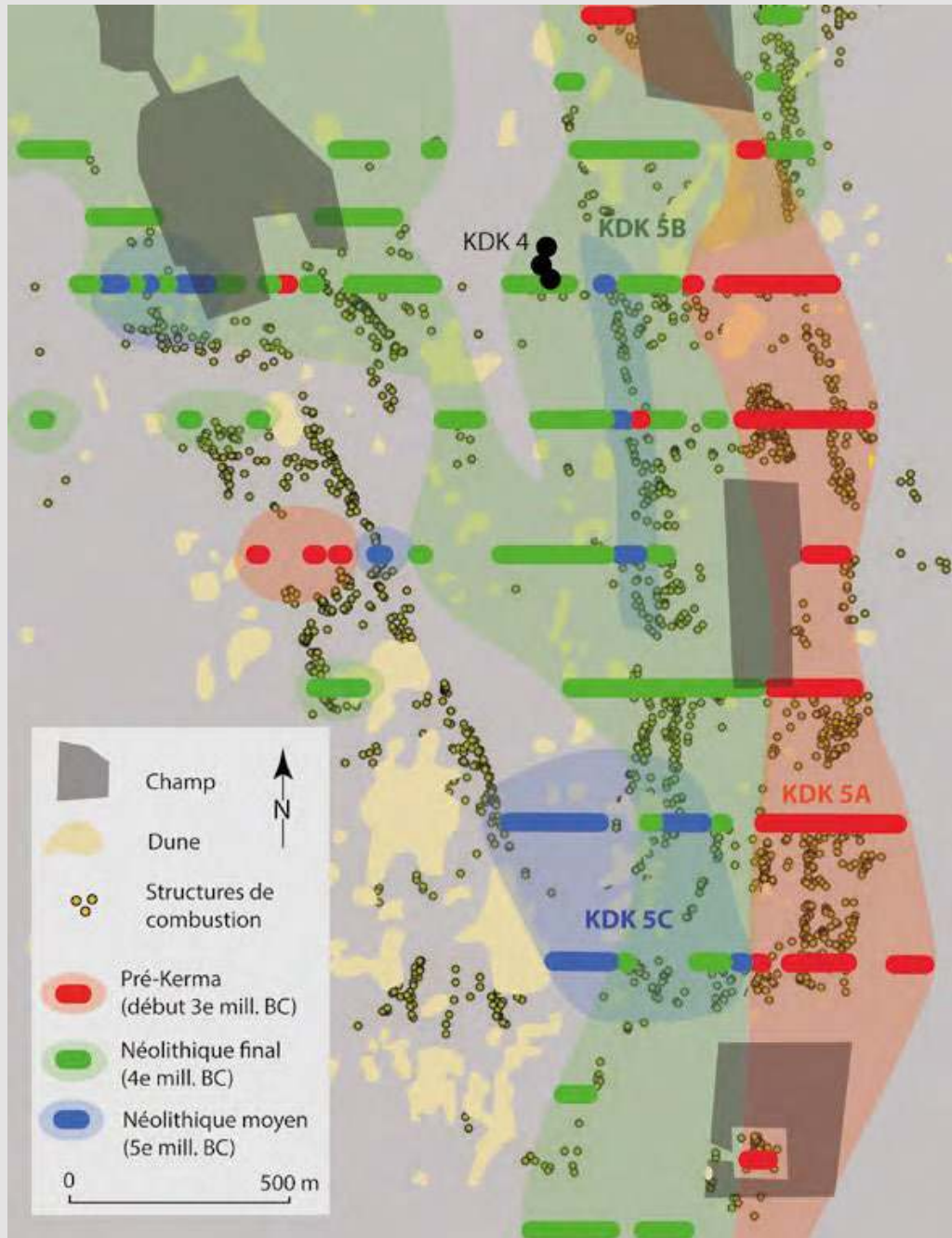

23. KDK5-Zone ayant fait l'objet d'une prospection systématique par transects transversaux aux paléochenaux.

Extension des occupations néolithiques (KDK5 $\mathrm{C}$ et $\left.\mathrm{KDK}_{5} \mathrm{~B}\right)$ et prékerma (KDKsA) telles qu'elles apparaissent en surface. 
Bien qu'ils n'aient pas permis de définir d'indiscutables alignements, les trous de poteaux, particulièrement nombreux à l'est de l'espace étudié, montraient que le lit et la rive ouest de ce chenal avaient accueilli des structures bâties alors même que le cours d'eau était encore actif. Le foyer et le remontage du mobilier découvert à sa proximité démontraient quant à eux le caractère parfaitement in situ du secteur.

Il fut décidé d'étudier d'autres espaces de ce type. Notre choix s'est porté sur l'une des dernières «fenêtres» relativement épargnées par les cultures, située à environ $2 \mathrm{~km}$ à l'est de $\mathrm{KDK}_{23} / 23 \mathrm{H}$, où J. Reinold avait repéré un vaste «épandage de matériel» de forme linéaire, dénommé KDK5 (fig.3). Une première prospection révéla la présence de deux occupations manifestement diachrones (KDK5A et KDK5B), formant deux bandes parallèles bordées ou traversées par des alignements de structures de combustion (fig.23). Un sondage test fut réalisé dans chacune d'elles, révélant une stratification comparable à celle reconnue dans le chenal de $\mathrm{KDK}_{23} \mathrm{H}$ et permettant de les rapporter, respectivement, à la charnière des $4^{\mathrm{e}}$ et $3^{\mathrm{e}}$ millénaires (KDK5A: Pré-Kerma) et au milieu du $4^{\mathrm{e}}$ millénaire (KDK5 B: Néolithique final) ${ }^{1}$. L'année suivante, une surface de $150 \mathrm{~m}^{2}$ fut ouverte, révélant là encore de nombreux trous de poteaux et plusieurs foyers. Une nouvelle datation confirma globalement l'ancienneté de l'occupation $\mathrm{KDK}_{5} \mathrm{~B}^{2}$. Une prospection systématique (par transects transversaux aux chenaux) fut ensuite entreprise sur l'ensemble de la zone, permettant de préciser l'extension des deux occupations mentionnées et d'une troisième remontant probablement au milieu du $5^{\mathrm{e}}$ millénaire $\left(\mathrm{KDK}_{5 \mathrm{~S}} \mathrm{C}\right)$. À la faveur des décapages occasionnés par le vent, cette prospection a révélé un grand nombre d'endroits parsemés de trous de poteaux. L'année passée, la recherche de la limite méridionale de l'occupation $\operatorname{KDK}_{5} \mathrm{~B}$ nous a conduits à sonder un secteur particulièrement bien préservé: quelques $\mathrm{m}^{2}$ ont ainsi livré plus de 500 artefacts (des éclats «frais» et des tessons) et écofacts (des fragments d'os brûlés). Le mobilier reste à remonter, mais sa fraicheur ne laisse aucun doute sur l'excellent état de préservation du niveau archéologique.

Des recherches menées sur plusieurs "épandages de matériel", il ressort donc que ces anciens habitats sont très loin d'être intégralement détruits. Les traces qu'ils portent, ou, pour la plupart, qu'ils portaient, témoignent de l'intérêt marqué des populations néolithiques et Pré-Kerma pour les milieux hydromorphes qui composaient alors le cours et les abords du wadi el-Khowi. Il est encore difficile d'évaluer la densité et de préciser

1 KDK5A a été daté de $4388 \pm 45$ Br (LtL17576A) et KDK5 B de $4767 \pm 45 \mathrm{BP}(\mathrm{LrL17577A})$

$24863 \pm 40 \mathrm{BP}$ (LTL18421A). 
la saisonnalité de ces occupations qui, avant l'expansion de l'agriculture, s'étendaient sur des dizaines de kilomètres, tout au long des branches du wadi el-Khowi. Même si elles se rapportent à une séquence longue, de deux millénaires, la multitude de trous de poteaux que l'on peut observer le long de ces branches est peu compatible avec une fréquentation ponctuelle des milieux inondables par des pasteurs nomades. Il nous semble plus raisonnable d'y voir les traces de communautés qui séjournaient durablement en ces lieux. On peut alors se demander ce qui amenait ces groupes humains à séjourner ainsi dans des zones humides, boueuses et instables. Considérant la présence de résidus d'orge dans certaines tombes de KDK1 et celle de concentrations de phytolithes de céréales en $\mathrm{C}_{3}$ sous les crânes d'individus inhumés dans le cimetière R12 (Madella et al. 2014; Out et al. 2016), peutêtre faut-il envisager qu'ils y pratiquaient une agriculture de décrue.

\section{conclusion}

cinquantenaire

\section{2}

de la section

française

de la direction

des Antiquités

du Soudan

Depuis quelques années, après une longue période d'interruption des activités, les recherches ont repris sur la concession de Kadrouka. Cette reprise a supposé d'établir un bilan des recherches déjà effectuées localement et de leurs résultats, un préalable nécessaire à l'élaboration de nouvelles stratégies capables d'accroître notre connaissance des sociétés investiguées.

Les travaux menés dans les années 1980-1990 par J. Reinold sur plusieurs cimetières de Kadrouka avaient assuré la célébrité de cette concession, considérée depuis comme un haut lieu du Néolithique soudanais. De la fouille de ces cimetières n'avait pourtant résulté aucune publication monographique, le matériel restant à étudier et les données collectées à analyser. Les questions d'ordre social avaient été privilégiées dans quelques articles synthétiques. Or, il est évident qu'une analyse plus approfondie sera nécessaire pour caractériser les pratiques et des gestes funéraires consignés dans les tombes de chacun des cimetières. Une telle analyse permettra non seulement d'approfondir la lecture sociale mais aussi d'aborder bien d'autres questions essentielles. Beaucoup reste donc à faire pour exploiter l'extraordinaire documentation amassée par notre prédécesseur. Ainsi, différentes études convergent actuellement pour aboutir à une publication détaillée des travaux réalisés à KDK1. Mais, avec le temps, comme trop souvent en archéologie, l'absence d'élaboration et d'exploitation de la documentation primaire a conduit à des pertes irrémédiables.

Les recherches de terrain en cours concernent deux types de sites: les cimetières et les habitats. La fouille de la butte funéraire KDK23 s'inscrit dans la continuité des travaux précédents, mais notre objectif premier est de caractériser aussi finement que possible les pratiques et les gestes 
funéraires des populations qui ont inhumé leurs morts dans ce cimetière, ce qui a supposé de mobiliser les méthodes de fouilles, de relevé et d'analyse permettant d'accéder à cette finesse d'information. Dans cette perspective, les autres questions accessibles à travers la fouille d'un cimetière ne sont envisagées qu’à titre complémentaire.

Les travaux menés sur les habitats marquent en revanche un renouvellement dans la manière d'envisager l'exploitation de la concession. C'est en cherchant à nous assurer que les habitats n'étaient rien de plus que de simples palimpsestes, impropres à la fouille, et après avoir finalement constaté qu'il n'en était rien, que nous avons ouvert un nouveau champ d'investigation. Tout porte à croire que, dans les années 1980-1990, le cours du wadi el-Khowi était couvert de dizaines de kilomètres d'habitats pour partie conservés. Mais, depuis lors, il a été la cible principale d'une expansion agricole de grande ampleur, amenée à s'étendre sur les dernières sections de chenaux encore relativement épargnées. Alors que la découverte tardive de ces derniers habitats ouvrait une fenêtre inespérée sur le monde des vivants, il était évident que celle-ci ne tarderait pas à se refermer. Parvenir à une compréhension générale de ces habitats, à travers la fouille de certains d'entre eux, n'est pas seulement urgent, en raison de la menace qui pèse sur eux, mais apparaît aussi comme essentiel. De fait, ces sites étant méconnus, ils ont aussi été négligés, ce qui a conduit à mécomprendre le mode de vie des populations néolithiques régionales (cf. Langlois et al. 2020). Ainsi, bien que J. Reinold n'ait pas fait mystère de l'abondance des traces d'habitats, celles-ci ont parfois été jugées trop discrètes (cf. Wengrow et al. 2014: 104; Hildebrand et Schilling 2016: 85) pour que l'on puisse admettre qu'au Néolithique les abords du wadi el-Khowi étaient occupés par des populations possiblement nombreuses, qui y séjournaient durablement. Ces habitats apparaissent ainsi comme des pièces importantes à verser au dossier qui, depuis quelques années (cf. Madella et al., 2014; Out et al. 2016; Salvatori et Usai 2019), jette le doute sur les caractères pastoral et nomade des populations néolithiques qui ont laissé leurs traces aux abords du wadi el-Khowi

\section{remerciements}

Nous tenons en premier lieu à exprimer notre gratitude au personnel de la National Corporation for Antiquities and Museums (Ncam). Nous pensons en particulier à son directeur, Hatim el-Nour, qui nous a autorisés à reprendre l'étude de la concession, ainsi qu'à nos collègues inspecteurs qui nous ont apporté une aide très précieuse durant les différentes campagnes: 
Amgad Bashir Ali (1985-2014), Abdelhay Abdelsawy, Mohammed Saad Abdalla et Alsalmani Ezaeldeen Kara. La reprise des travaux, en 2014, et leur poursuite n'ont été possibles que grâce au financement du QSAP (Qatar Sudan Archaeological Project) et au soutien du personnel de la SFDAS, en particulier de ses directeurs successifs: Claude Rilly, Vincent Francigny et Marc Maillot. Nous nous sentons très redevables envers ces institutions et leurs représentants. Les chercheurs et étudiants qui ont participé aux campagnes de terrain sont beaucoup trop nombreux pour être remerciés individuellement. Nous tenons tout de même à mentionner ici les personnes qui ont contribué de manière particulièrement substantielle à l'acquisition des données présentées dans le texte: Hala Alarashi (Cepam, Nice); Louiza Aoudia (Laboratoire d'anthropologie du CNRPAH, Alger; Éco-anthropologie, Paris); Lucie Cez (ArScAn, Nanterre); Gourgen Davtian (Cepam, Nice); Hélène Delattre (Orient \& Méditerranée, Lyon); Gilles Durrenmath (Cepam, Nice); Lionel Gourichon (Cepam, Nice); Sambo Hassimi (univ. de Yaoundé 1, Cameroun); Hisham Khidir Karrar (Khartoum State Antiquities, Soudan); Lamya Khalidi (Cepam, Nice); Emma Maines (Écoanthropologie, Paris); Charlotte Pruvost (univ. de Toulouse II).

cinquantenaire

\section{4}

de la section

française

de la direction des Antiquités du Soudan

\section{bibliographie}

Hildebrand, E. and Schilling, T. 2016 - «Storage amidst early agriculture along the Nile: Perspectives from Sai Island», Sudan, Quaternary International, 412 (B), p. 81-95.

Hildebrand, E., Garcea, E., Florenzano, A. and Mercuri, A. M. 2018 - «Multiscalar perspectives on Holocene climatic and environmental changes in the Sahara and Nile corridor, with special consideration of Archaeological sites on Sai Island, Sudan ", dans M. Mercuri, C. D'Andrea, R. Fornaciari, and A. Höhn, ed, Plants and peoples in the African past. Progress in African archaeobotany, Cham: Springer, p. 215-245.

Honegger, M., 2001 - "Fouilles préhistoriques et prospection dans la région de Kerma», Genava, 49, p. 221-228.

2005 - «Kerma et les débuts du Néolithique africain», Geneva, 53, p. 239-249.

2007 - «Aux origines de Kerma», Genava, 55, p. 201-212.

Langlois, O., Durrenmath, G., Khalidi, L., Khiddir Ahmed Karrar, H., Cez, L., Gourichon, L., Sambo, H., and Pruvost, C. 2020 - «Chronicle of a destruction foretold: a belated reassessment of the conservation status of Neolithic habitation sites in the Kadruka concession (Northern Dongola Reach, Sudan)», Sudan \& Nubia, 23, p. 61-67. 
Leclant, J. and Clerc, G. 1991 - «Fouilles et travaux en Égypte et au Soudan », 1989-1990, Orientalia, 6o, p. 159-273.

Leclant, J. and Minault-Gout, A. 2000 - "Fouilles et travaux en Égypte et au Soudan», 1997-1998, seconde partie, Orientalia, 69, p. 141-181.

Madella, M., Garcia-Granero J. J., Out W., Ryan P. and Usai D. 2014 - «Microbotanical evidence of domestic cereals in Africa 7000 years ago ", Plos one, 9 (10), p. 1-9.

Maines, E., 2019 - Diversité biologique et archéologie de la mort: une approche populationnelle et culturelle du Néolithique soudanais (Haute Nubie), thèse de l'Université de Paris 1.

Out, W., Ryan, P., Garcia-Granero, J. J., Barastegui, J., Maritan, L., Madella, M. and Usai D. 2016 - «Plant Exploitation in Neolithic Sudan; A review in the light of new data from cemeteries R12 and Ghaba", Quaternary International, 412 (B), p. 36-53.

Reinold, J. $\quad 1987$ — «Les fouilles pré- et protohistoriques de la Section Française de la Direction des Antiquités du Soudan : les campagnes 1984-85 et 1985-86». Archéologie du Nil Moyen, 2, p. 17-6o.

1994 - "Kadruka», dans B. Gratien and F. Le Saoult (éds), Nubie, les cultures antiques $d u$ Soudan, à travers les explorations et les fouilles françaises et franco-soudanaises, Lilles: Université Charles De GaulleLille III, p. 71-86. 2000 - Archéologie au Soudan. Les civilisations de Nubie, Paris: Errance, $144 \mathrm{p}$. 2001 - "Kadruka and the Neolithic in the Northern Dongola Reach", Sudan and Nubia, 5, p. 2-14. 2004a - «Kadruka», dans D. Welsby, and J. Anderson, (éds), Sudan, ancien treasures, Londres, British Museum Press, p. 42-48. 2004b - «Le Néolithique soudanais: funéraire et structures sociales», dans J. Guilaine, dir., Aux marges des grands foyers du Néolithique. Périphéries débitrices ou créatrices?, Paris, Errance, p. 151-174.

Salvatori, S. and Usai, D. 2019 - "The Neolithic and 'pastoralism' along the Nile: a dissenting view", Journal of Word Prehistory, 32 (3), p. 251-285.

Welsby, D. 2000 — -South from Kadruka: the Neolithic in the Northern Dongola Reach. Recent Research Into the Stone Age of Northeastern Africa", Studies in African Archaeology, 7, 129-136. 2001 - Life on the Desert Edge. Seven thousand years of settlement in the Northern Dongola Reach, Sudan, BAR International Series/SARS publications, Oxford: Archeopress, 2 vol., 640 p.

Wengrow, D., Dee, M., Foster, S., Stevenson, A., Bronk Ramsey, C. 2014 - "Cultural convergence in the Neolithic of the Nile Valley: a prehistoric perspective on Egypt's place in Africa", Antiquity, 88, p. 95-111. 



\section{el-Hassa 2000-2020}

À Jacques Reinold, compagnon du choix du site

Vincent Rondot

Giorgio Nogara

Faïza Drici 
C'est en 1999, à l'initiative de l'Académie des inscriptions et belleslettres, que fut lancée l'idée d'engager la fouille programmée d'un établissement urbain méroïtique dans la région de la capitale de ce royaume. Dans les objectifs du projet, il s'agissait alors pour ses initiateurs, Jean Leclant et Charles Bonnet, de réinvestir la section française de la direction des Antiquités du Soudan dans les études de terrain non loin de Khartoum et de donner ainsi à ses recherches une visibilité plus grande, à un moment où plusieurs programmes de fouille venaient d'être engagés dans la région par différentes institutions européennes.

Choisir d'étudier el-Hassa, un site urbain encore peu connu mais réputé potentiellement riche, permettrait de mieux comprendre les conditions selon lesquelles s'était organisé le maillage des établissements urbains en périphérie de la capitale d'une part, ainsi que les raisons de la prolifération des sanctuaires dédiés au culte du dieu Amon de l'autre, et de relativiser l'importance prise dans notre représentation des choses par les deux sites les plus connus que sont Naga et Mousawwarat es-Soufra.

Il faut rappeler que le royaume - ou l'empire, la question ne peut encore être définitivement tranchée - méroïtique (III siècleav.IV $V^{\mathrm{e}}$ siècleapr. J.-C.) est l'héritier des états qui se sont développés entre la première et la sixième cataracte et que l'on a pris désormais l'habitude de regrouper, selon le nom qu'ils se donnaient et qu'on leur donnait alors, sous

de la section

française

de la direction

des Antiquités

du Soudan le terme générique de "Kouch». Nommés d'après leurs capitales successives, les royaumes de Kerma (2500-1500 av. J.-C.) et de Napata (vIII ${ }^{\mathrm{e}}-\mathrm{IV}^{\mathrm{e}}$ siècle av. J.-C.) furent très tôt et très profondément marqués par l'influence de leur voisin égyptien, tour à tour partenaire commercial en Nubie, conquérant, puissance occupante puis voisin. Avant l'avènement des royaumes chrétiens de Nubie, les contacts avec l'Égypte ptolémaïque puis romaine permirent à l'hellénisme de venir influencer à son tour cette culture antique.

Dans une région comprise entre le Nil et l'Atbara appelée par les géographes classiques "île de Méroé», le centre de l'état méroïtique est organisé autour d'un ensemble d'établissements royaux centralisant les fonctions politiques, religieuses et économiques. Au sud de la capitale Méroé et en rive droite du Nil, les "villes» d'Hamadab, el-Hassa, Mouweis et Ouad ben Naga, situées à des distances relativement égales les unes des autres, paraissent constituer, selon l'hypothèse de Friedrich Hinkel, autant d'étapes de caravane (fig. 1).

En arabe, has signifie "galets, petits cailloux, gravier» et el-Hassa pourrait ainsi être traduit en français par «La Gravelière». Le site, à $25 \mathrm{~km}$ au sud des pyramides de Méroé et à $180 \mathrm{~km}$ au nord de Khartoum, fait partie de ces complexes étatiques ayant joué un rôle important dans le maillage urbain organisé par le pouvoir méroïtique. Il fut brièvement visité et décrit 


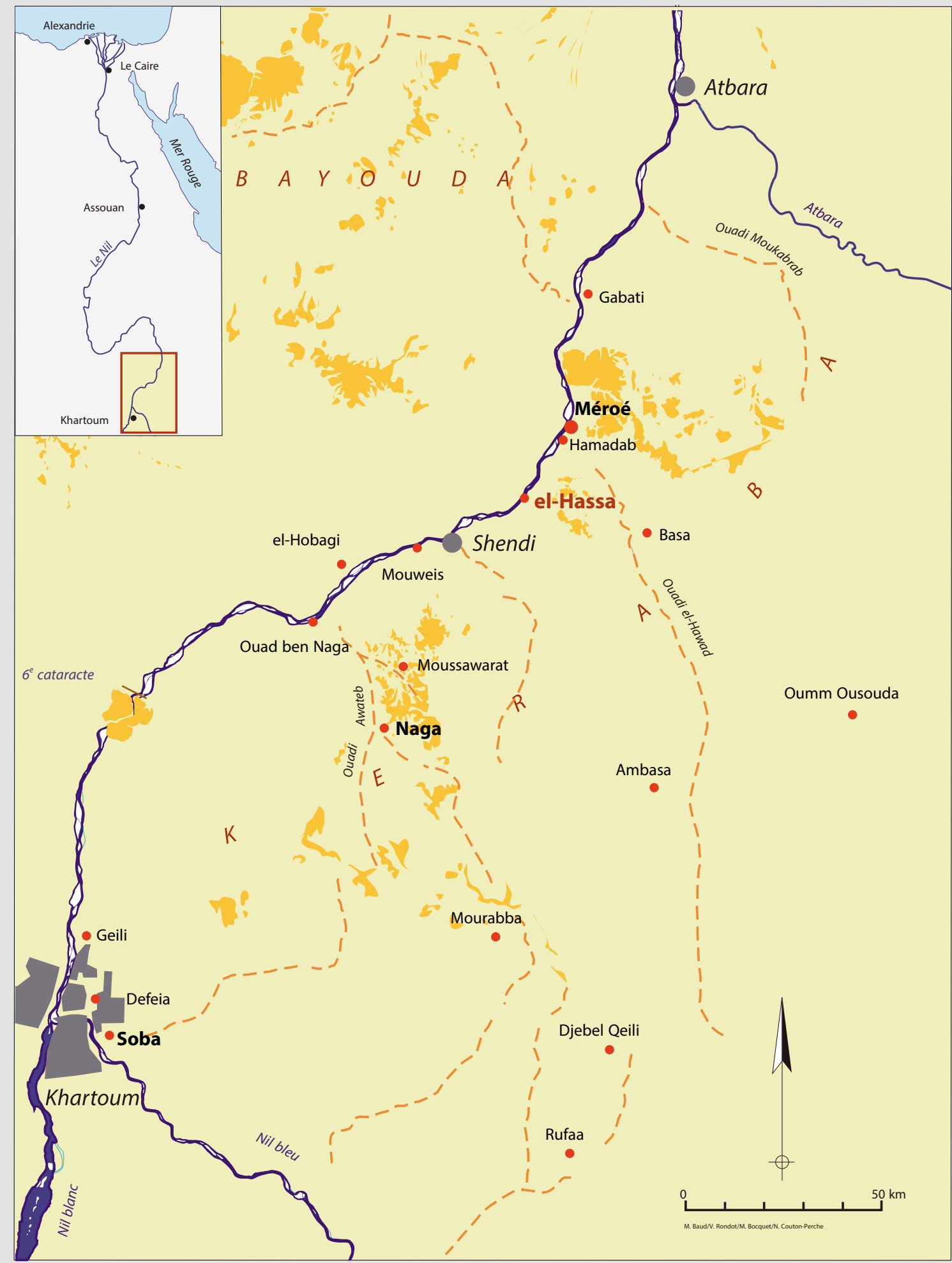

129

el-Hassa

$2000-2020$

1. Plan de localisation des établissements royaux de l'île de Méroé. 
par trois voyageurs du XIX ${ }^{\mathrm{e}}$ siècle grâce auxquels l'Europe a découvert le patrimoine archéologique du Soudan. En mai 1814, Johann Ludwig Burckhardt, alias Cheikh Ibrahim, l'un des premiers à dépasser Abou Simbel: "The ruins seemed to consist of small insulated oblong squares irregularly dispersed among the trees». En mars 1822, Linant de Bellefonds: "parmi de grands arbres, sur le bord du Nil, il y a une quantité de décombres de briques crues et cuites et de pierres, et les restes d'un temple dont on voit seulement quelques pierres et un sphinx qui est enterré». En avril 1822, soit quelques jours après Linant, Frédéric Cailliaud: "parmi les monceaux de débris de grès et de briques cuites, l'emplacement d'un temple, quelques pierres de taille en grès et la tête mutilée d'un sphinx bélier, aussi en grès, et de style égyptien ». En 1975, la statue d'un bélier au nom du qore Amanakhareqerema fut découverte lorsque les agriculteurs entreprirent le creusement d'un canal à travers le site (fig. 2 et 3 ). La présence de cette statue, associée à l'évocation des ruines d'un temple par nos trois voyageurs, confirma la présence d'un sanctuaire à Amon puisque le bélier, au Soudan plus encore qu'en Égypte, est l'animal dans lequel s'incarne le dieu. C'est l'ensemble de ces informations qui nous engagea à vouloir en savoir plus sur ce temple à Amon, de façon à mieux comprendre comment s'était développé son culte dans une région où demande à être mieux comprise la question de la présence napatéenne avant l'expansion du royaume méroïtique. Ce sont désormais six statues de béliers qui ont été mises au jour sur le site.

Une première campagne de reconnaissance du terrain fut engagée

de la section

française

de la direction

des Antiquités

du Soudan

en 2000 par la section française de la direction des Antiquités du Soudan à Khartoum (Sfdas), en partenariat avec la National Corporation for Antiquities and Museums (NCAM), l'université de Lille (Halma) et l'université de Shendi. L'objectif était la réalisation du plan topographique du site, d'une superficie de 21 hectares (fig. 4), et la localisation du temple à Amon, aujourd'hui ensablé. Un volet important de ce nouveau chantier de fouille était de répondre à la demande de formation aux techniques de la fouille programmée. La NCAM ainsi que les universités de Shendi et de Khartoum y participèrent en déléguant leurs Antiquities Officers et leurs maîtres de conférences.

Les ruines du complexe religieux avaient été recouvertes par le sable éolien, au point de faire disparaître les structures décrites par les voyageurs. Dès les premières campagnes, il fallut admettre que le bâtiment était très détruit. Comme la plupart des monuments officiels méroïtiques, le temple à Amon d'el-Hassa fut édifié en grosses briques cuites liées au mortier de limon et donc facilement réutilisables. Ainsi, dans les années 1970, ses ruines furent exploitées au point que plusieurs murs du temple ont été complètement vidés de leurs briques. Cette circonstance, qui nous a obligés à étudier les murs en allant souvent les «chercher» jusqu’à la base de leurs 


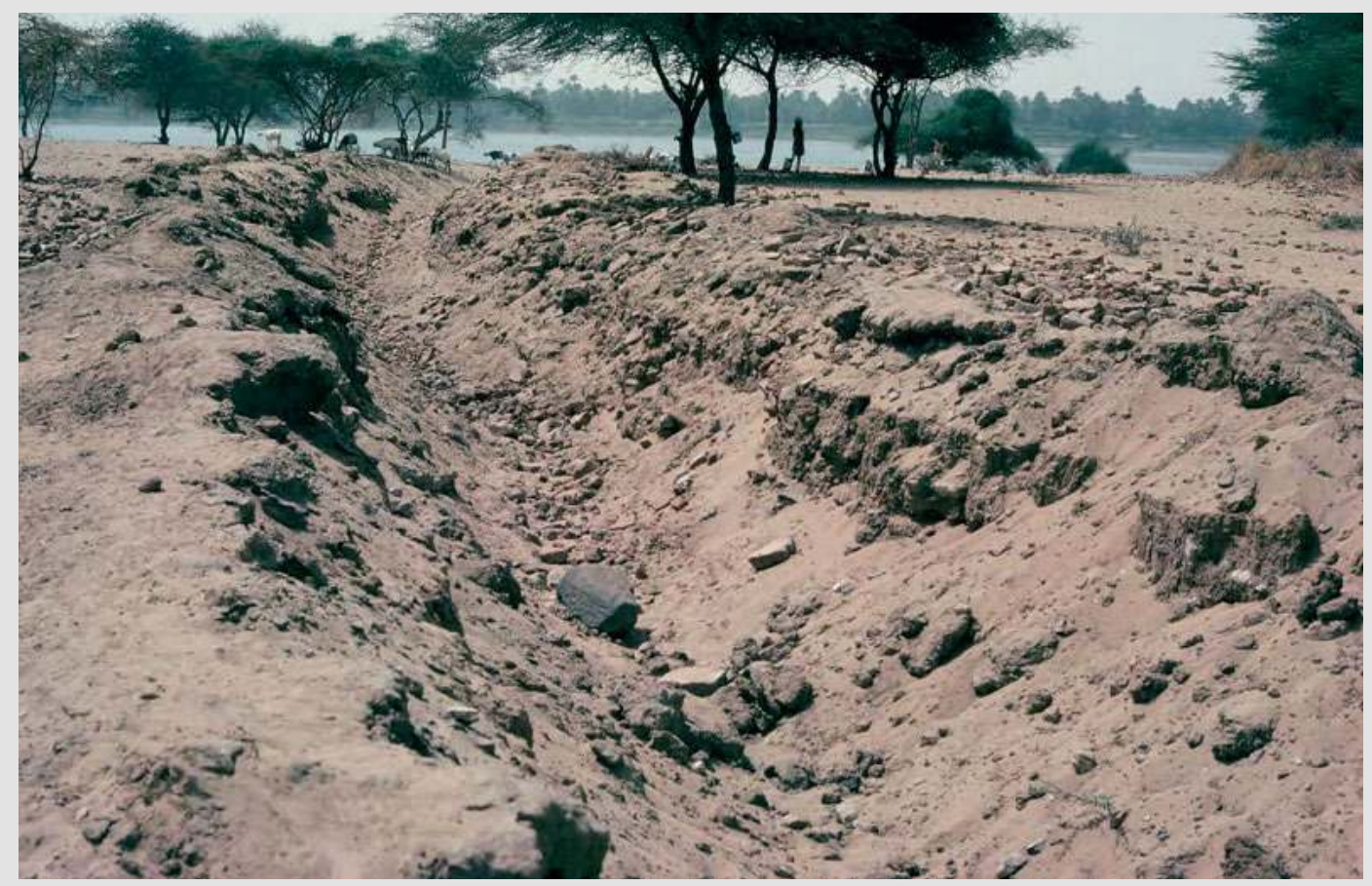

2. Vue partielle du canal creusé en 1975. (C) Fr. Geus/Sfdas.

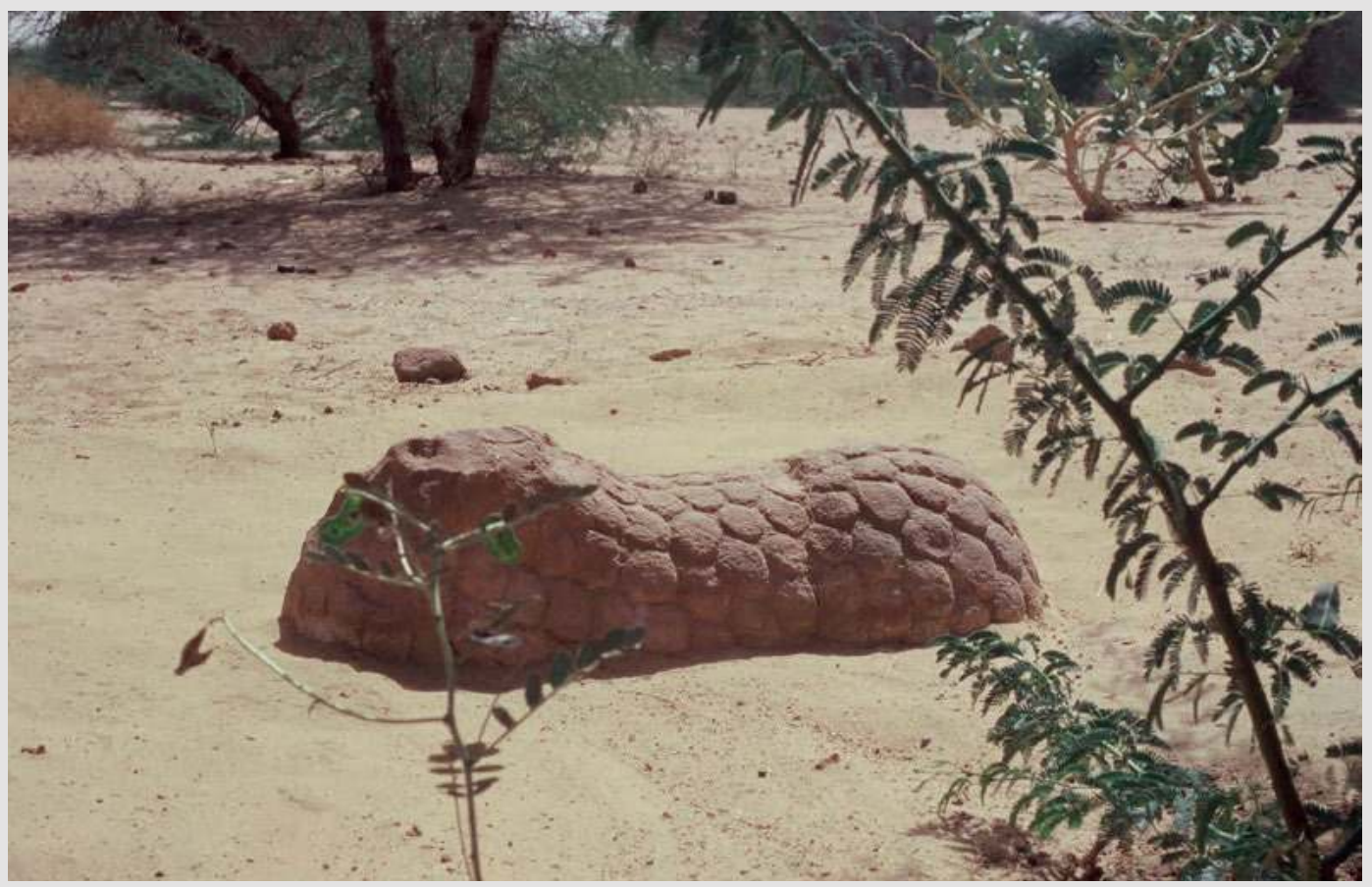

3. Statue de bélier ( $7 \mathrm{~N}$ sur le plan) retrouvée en 1975 lors du creusement du canal (Rem 1151). (C) 2000 V. Rondot, el-Hassa/Sfdas. 


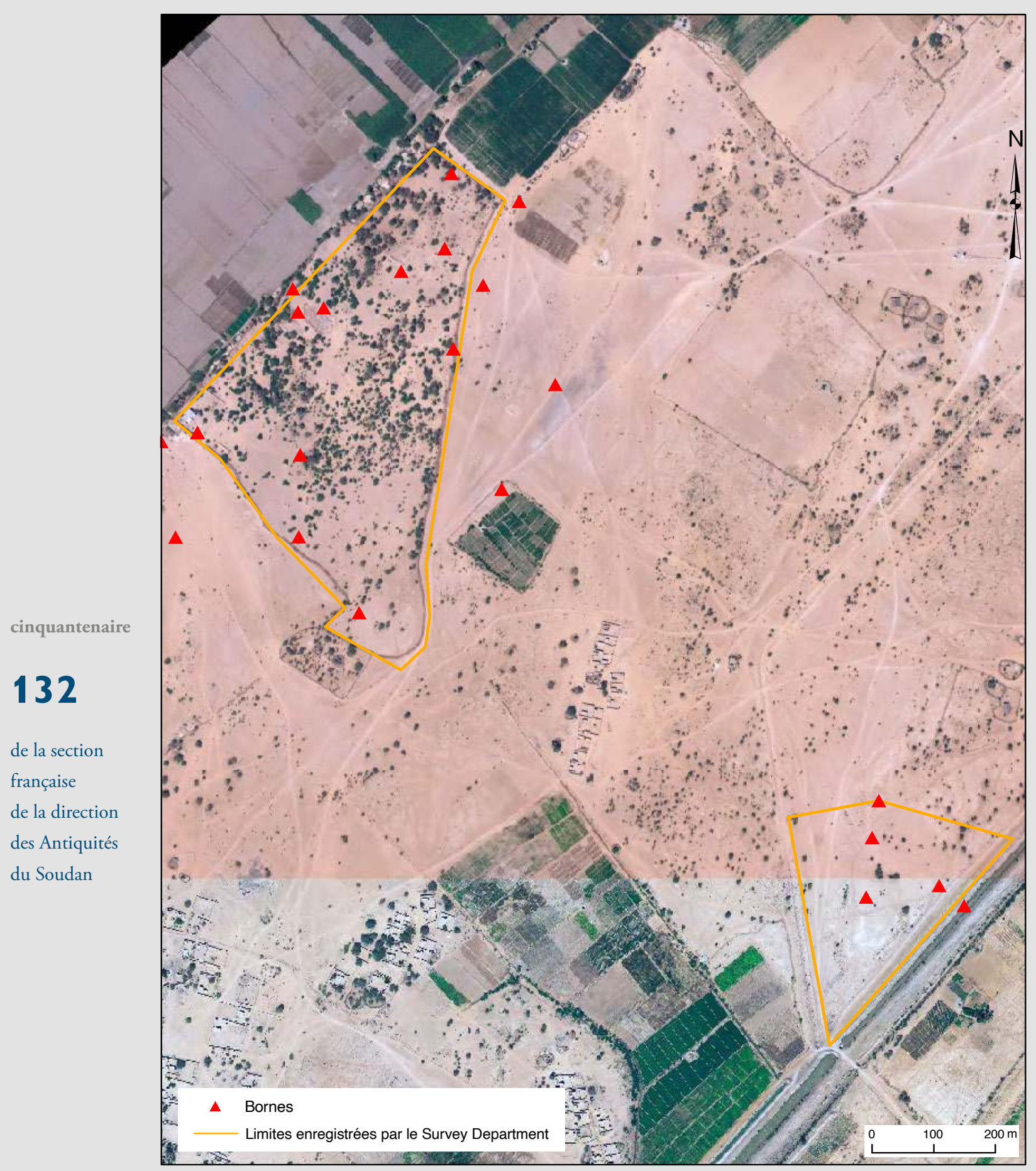

4. Orthophotographie des sites d'el-Hassa et de Damboya en 2007 ,

avec indication des limites des terrains archéologiques. @ 2007 IGN, el-Hassa/Sfdas. 


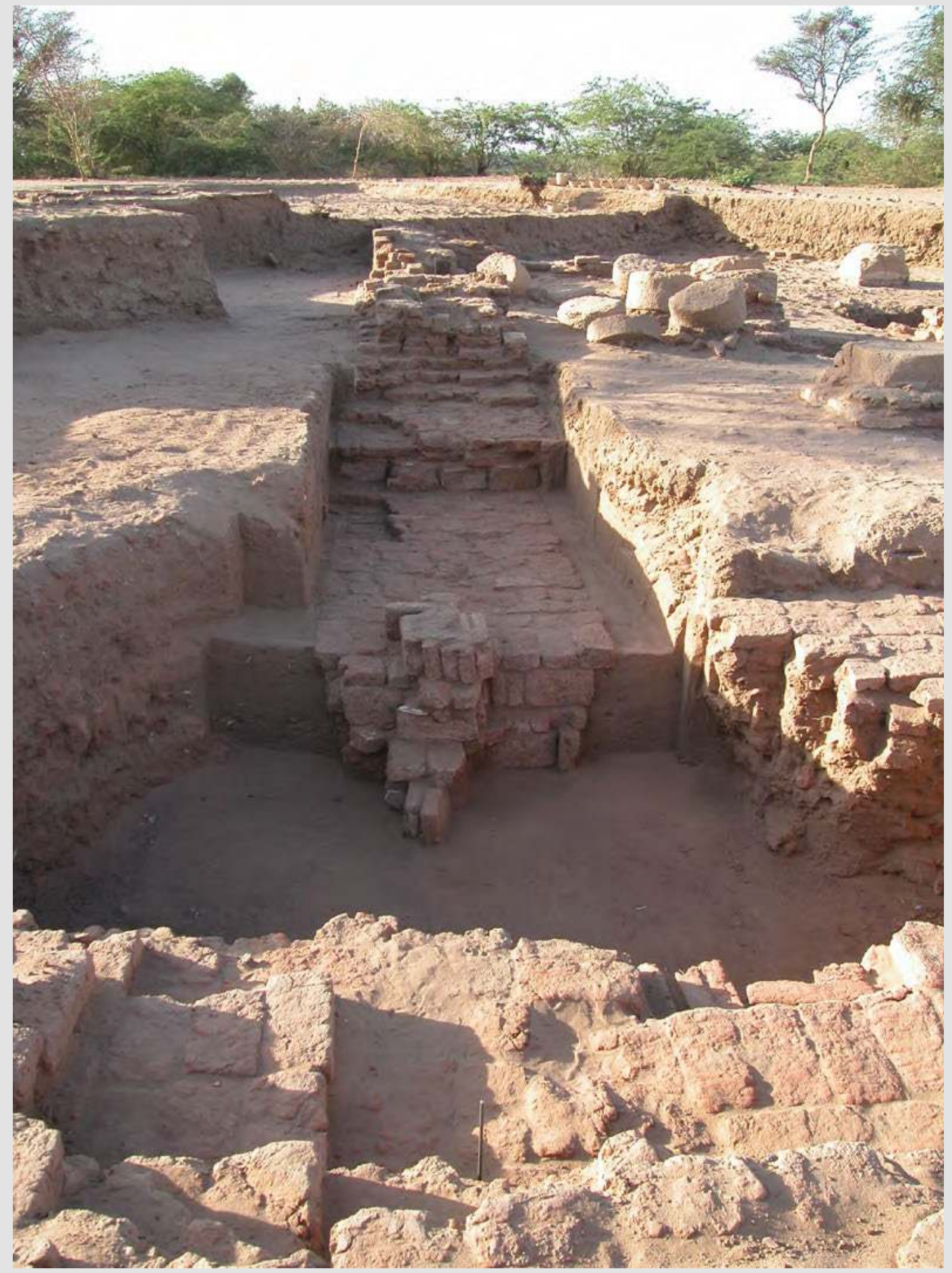

133

el-Hassa

$2000-2020$

5. Vue des fondations du môle sud du pylône ainsi que du mur sud du temple

(vers l'ouest). (C) 2004 G. Nogara, el-Hassa/Sfdas. 
cinquantenaire

\section{4}

de la section

française

de la direction

des Antiquités

du Soudan
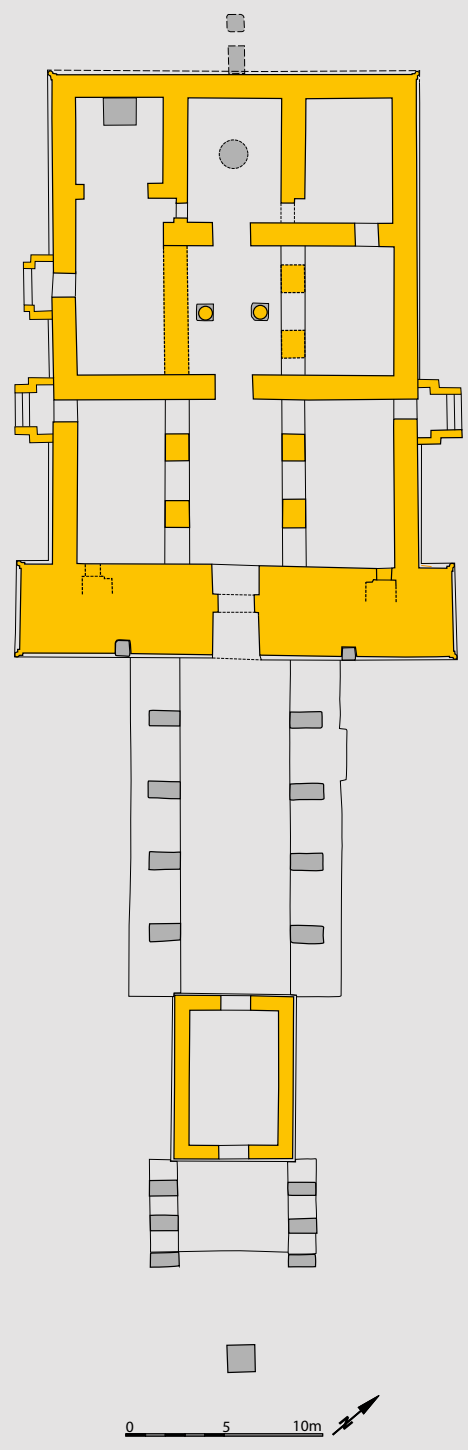

PHASE 1 


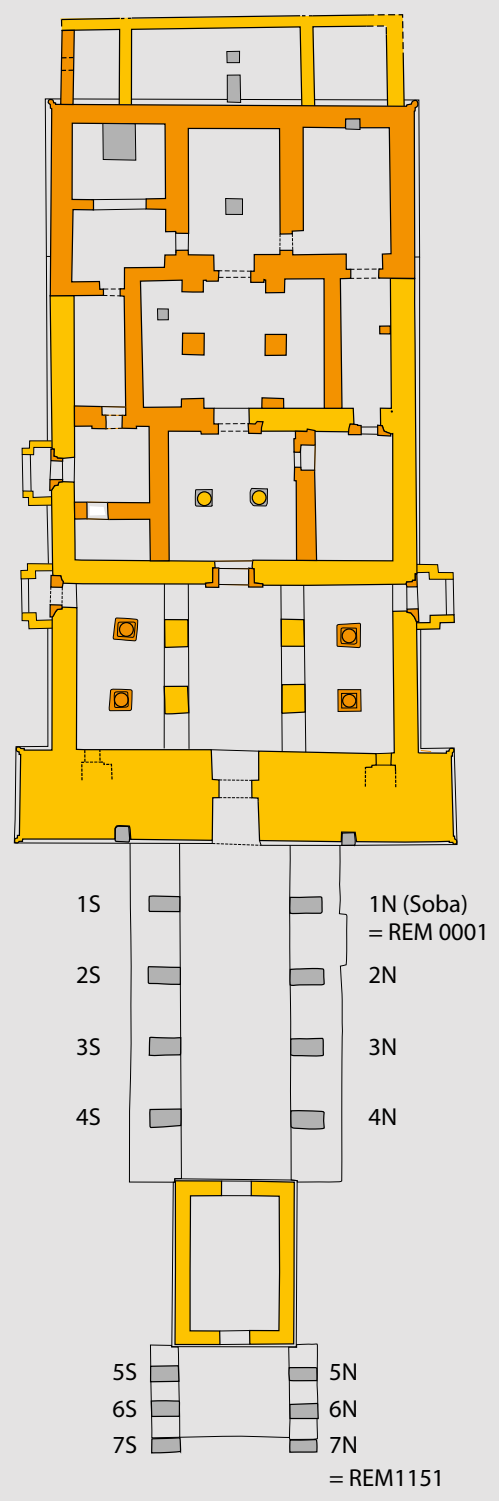

\section{5 \\ el-Hassa \\ 2000-2020}

7. Temple à Amon, phase 2, échelle 1:500.

(C) 2019 G. Nogara, el-Hassa/Sfdas.

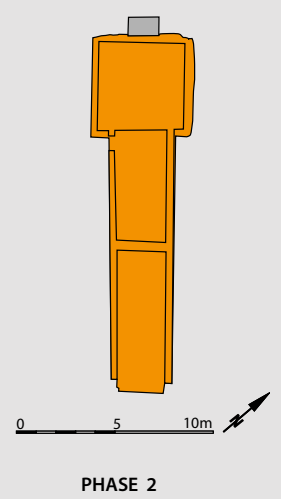


fondations (fig. 5), a permis de faire quantité d'observations sur les techniques de construction, d'analyser et de comprendre toute une série de profondes modifications qui avaient été apportées au projet d'origine, conférant ainsi une dimension historique inattendue à cette étude architecturale.

\section{Les trois phases du temple}

cinquantenaire

\section{6}

de la section

française

de la direction

des Antiquités

du Soudan

Dans la première phase (fig. 6), le plan du temple se constitue d'un pylône suivi par trois rangées de salles; la première rangée, où se trouve l'entrée, est occupée par une salle hypostyle tripartite avec axe bordé de piliers. L'accès au sanctuaire se fait par l'espace central de la rangée médiane, une salle hypostyle à deux colonnes, ouverte au nord sur une salle latérale et vraisemblablement séparée par un mur de l'espace latéral sud. C'est dans cette dernière rangée qu'est installé le sanctuaire, dans lequel le naos - il faut insister sur ce point - reposait sur une base de plan circulaire connue grâce à ses fondations. Sur son côté sud, figure bien une chapelle avec autel monumental ouvrant à l'est, par une large baie, sur la cour à ciel ouvert de la deuxième rangée, selon le dispositif des chapelles de Nouvel An propres aux temples à Amon kouchites. Vers l'est, le pylône est précédé par un dromos bordé de statues de bélier, introduit par un petit autel situé sur son axe et interrompu par un kiosque, tandis qu'à l'arrière du temple la présence de briques alignées sur l'axe du bâtiment laisse supposer l'existence d'une chapelle adossée abritant une statue de bélier posée sur un socle, selon le même principe qu'au temple à Amon de Naga. Il est ainsi avéré que, dès sa première phase de construction, le temple d'el-Hassa était dédié au dieu Amon. Pour une raison ou pour une autre, ce premier bâtiment ne correspondit plus au sanctuaire voulu et, après une très courte période d'utilisation, il fut profondément modifié dans son plan.

Le temple fut agrandi vers l'ouest par l'édification d'une quatrième rangée de salles (fig. 7), dans laquelle ont été déplacés le sanctuaire et la chapelle du Nouvel An avec sa cour à ciel ouvert, tandis que l'ancienne troisième rangée fut profondément transformée par la construction d'une salle hypostyle tripartite à piliers et pilastres abritant un reposoir dans la travée sud et flanquée, de part et d'autre, de deux couloirs. Une nouvelle chapelle adossée fut construite à l'arrière du temple, réutilisant partiellement un bâtiment carré à cour centrale préexistant. À la différence notable de ce qui prévalait dans sa première phase, toutes les portes du temple présentent désormais des modénatures. Sur le dromos, l'ancien autel de plan carré fut remplacé par un autel monumental surélevé, légèrement décalé sur le côté nord de l'axe, et auquel on accédait par une rampe (fig. 8). Ainsi le plan de cette deuxième phase présentet-il la même distribution des espaces que dans les temples à Amon classiques: 
autel monumental à l'entrée et légèrement déporté par rapport à l'axe de la voie processionnelle, dromos flanqué de statues de bélier et interrompu par un kiosque et temple avec chapelle adossée à l'arrière du sanctuaire.

Ces modifications ne sont pas, à l'évidence, dues à des contraintes d'ordre technique: le premier temple avait été profondément fondé et bien construit. Les raisons ne peuvent être que d'ordre théologique: le nouveau plan obtenu est beaucoup plus «égyptien» que ne l'était celui du premier temple et respecte mieux les volumes et les modénatures du style pharaonique. La transformation du temple à Amon d'el-Hassa serait alors un nouvel exemple des résultats que pouvaient avoir, à l'époque méroïtique, les recherches du clergé sur les modèles à appliquer et à respecter lorsque la construction d'un nouveau lieu de culte au dieu Amon était décidée. Qu'il s'agisse de reproduire le plan d'un monument déjà présent sur le territoire ou de tenir compte de nouveaux modèles dont on avait connaissance par les contacts entre les deux royaumes, des sources canoniques à reproduire étaient nécessaires.

De nombreux indices prouvent que le temple a connu une période d'abandon significative, avant d'être reconstruit à une période déjà tardive. D'importantes réparations sur l'ensemble du temple sont la preuve d'une reconstruction à grande échelle, sinon presque totale, du complexe cultuel. Il s'agit ici de la troisième et dernière phase de son existence. La profondeur et l'étendue des réparations font que l'on ne peut retenir l'hypothèse d'une destruction volontaire et penser beaucoup plus - sans pour autant la privilégier - à celle d'un écroulement provoqué par un tremblement de terre. L'absence quasi-totale de céramique bien ancrée dans le deuxième siècle de notre ère suggère qu'une période d'abandon a fait suite à cet écroulement généralisé. Par ailleurs, la présence d'une sépulture, installée dans une des salles de la phase 2 alors abandonnée, confirme bien un arrêt de l'activité religieuse entre les phases 2 et 3 du temple. Le caractère très médiocre de la reconstruction en phase 3 , qui n'utilise que des matériaux de récupération pauvrement mis en œuvre, parât être le signe incontestable d'une période de déclin. L'ancienne chapelle adossée n’a plus été reconstruite et fut matérialisée par un simple enclos. Côté dromos, on observe la reconstruction du kiosque et de l'autel monumental, ainsi que de nouveaux aménagements sur les deux trottoirs de l'allée processionnelle.

\section{Le relief à la candace}

Pendant la campagne de fouille de 2006, lors du dégagement de l'extrémité est de la cour sud du temple, a été mis au jour un gros bloc, encore en connexion, de maçonnerie en briques cuites, dont la face parementée (sud) était recouverte d'une forte épaisseur de mortier façonné en bas-relief 
et peint. Le bloc, tronçon du môle sud du pylône, était enfoncé verticalement dans le sol de la cour au sud du temple. Un sondage, pratiqué le long du bloc de maçonnerie dans le remplissage sableux du canal creusé en 1975, permit de mettre au jour la totalité de sa face modelée, laquelle, conservée sur une hauteur de 1,30 m, s'est avérée correspondre à un gros fragment de personnage dans lequel on reconnaît sans difficulté le large bassin d'une candace (fig. 9). La moitié inférieure du bras gauche de la reine-mère était aussi conservée le long de sa cuisse, avec dans la main l'objet rituel dans lequel on s'accorde généralement à reconnaître un épi de sorgho. Si ce fragment modelé trouve un parallèle dans la scène du temple du Lion à Naga représentant les souverains en offrande devant Apédémak, il restera à comprendre la place exacte donnée à cette candace dans le programme décoratif du mur extérieur sud du temple, sachant qu'elle décorait, seule selon toute probabilité, le mur sud du môle sud. Les travaux de restauration du relief (fig. 10 et 11), menés à bien par la société berlinoise Restaurierung am Oberbaum, ont permis de détecter deux états différents de la représentation de la reine: le premier avec une robe à bandes bleues, le deuxième avec une robe jaune à écailles rouges. Cette observation est d'importance car le passage à un décor plus classique ou "égyptien" pour la robe de la candace semblerait bien s'accompagner de la transformation du temple en phase 2 , qui - comme nous l'avons mentionné plus haut - se conforme de façon délibérée aux canons classiques de l'architecture pharaonique.

de la section

française

de la direction

des Antiquités

du Soudan

\section{Le "trésor " dans le sanctuaire}

Lors de la campagne de 2005 , le sanctuaire du temple fut atteint. L'écroulement du plafond voûté de la salle avait scellé le matériel archéologique en place, devant le socle du naos. Tout un ensemble d'objets cultuels étaient encore en place pour un dernier rituel: un bol en céramique posé sur une pierre taillée en fer à cheval (fig. 12), une table à libation en forme de croix-ânkh, une hache en pierre polie et une tête de massue néolithiques ainsi que plusieurs cailloux choisis pour leurs formes remarquables.

Plus loin, le long d'un mur, furent retrouvés trois bronzes: un pommeau de canne en forme de buste d'une reine méroïtique (fig. 13), un Osiris et le cylindre d'un autel à feu portatif hellénistique. Sous leur gangue de concrétions et de sédiments, les trois bronzes étaient dans un très bon état de conservation. Leur restauration, dans les laboratoires Valectra grâce à un mécénat accordé par EDF en 2007, a permis de démontrer qu'il s'agissait bien de bronze, c'est-à-dire d'un mélange de cuivre et d'étain, fondu à la cire perdue en y ajoutant du plomb pour en faciliter la coulée. Le buste de la reine est certainement l'œuvre d'art la plus originale de l'ensemble. 

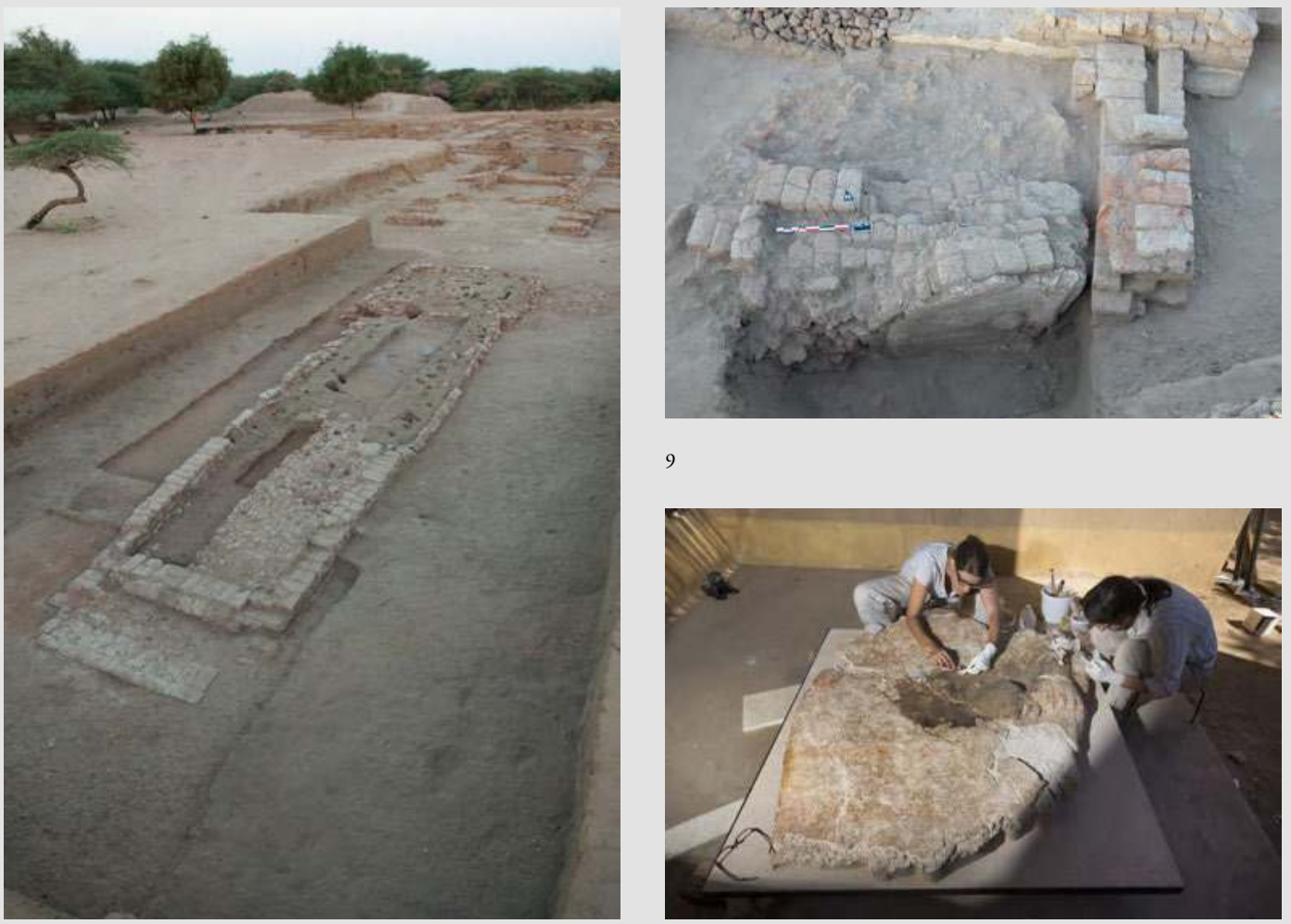

8

10

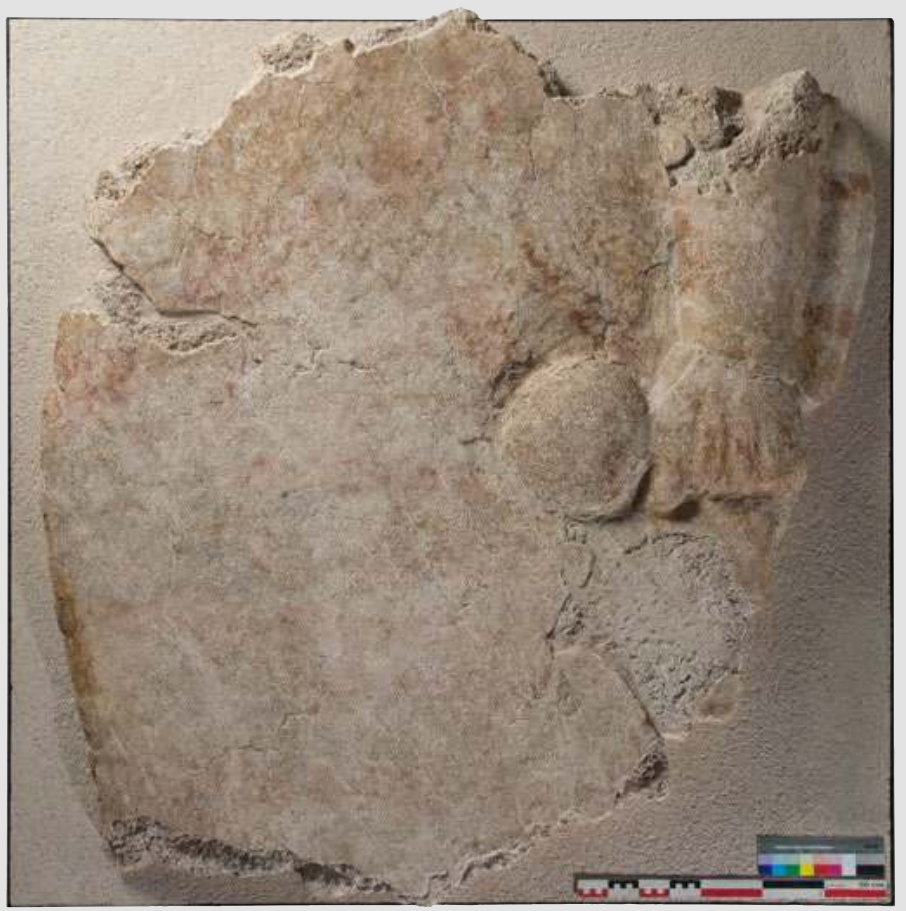

8. Vue générale de l'autel monumental construit en phase 2 (vers l'ouest).

(C) 2012 J.-Fr. Gout, el-Hassa/Sfdas.

9. Découverte du bloc de maçonnerie portant le reste de décor en relief de mortier sculpté et figurant le bassin de la candace. Vue vers le Nord. Le bloc de maçonnerie appartenait au môle sud du pylône. (C) 2012 J.-Fr. Gout, el-Hassa/Sfdas.

10. Le relief en cours de restauration par Maria Fasshauer et Dunja Rütt (Restaurierung am Oberbaum).

(C) 2014 J.-Fr. Gout, el-Hassa/Sfdas.

11. Bas-relief restauré, remis au musée national du Soudan le 19 septembre 2019 et prêt à présentation muséale. (C) 2014 J.-Fr. Gout, el-Hassa/Sfdas. 
cinquantenaire

\section{0}

de la section

française

de la direction des Antiquités du Soudan
12. Bloc de grès taillé en fer à cheval et placé, pour un dernier rituel, sur le sol du sanctuaire devant le socle du naos. (C) 2005 G. Nogara, el-Hassa/Sfdas.

13. Pommeau de canne cérémonielle (?) en bronze,

h. 8,6 cm. SNM 31689 (Has 197); buste d'une reine méroïtique.

Restauration Manuel Leroux, mécénat Valectra.

(C) 2009 Musée du Louvre/Chr. Décamps.

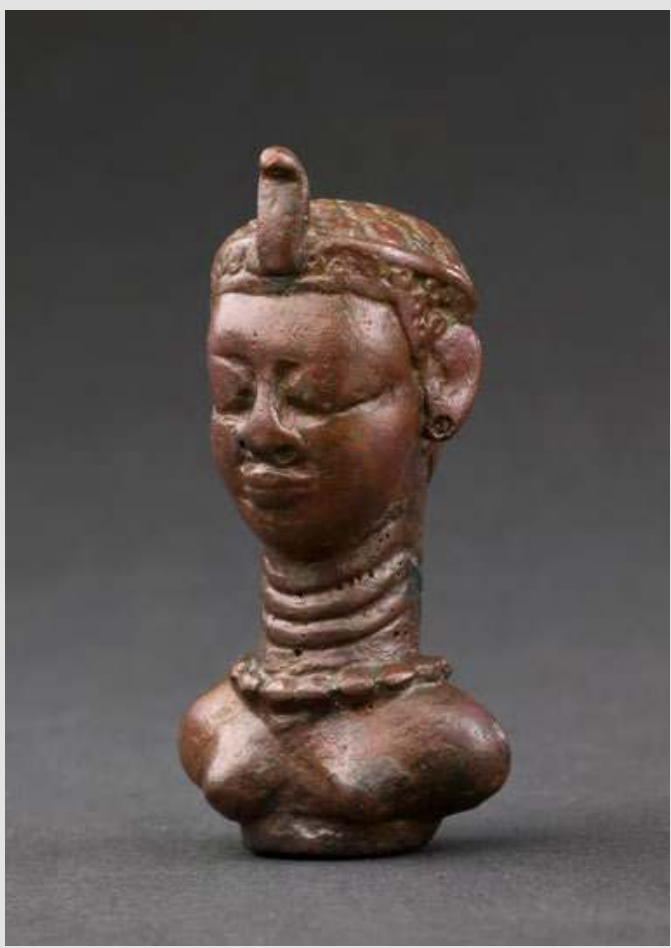

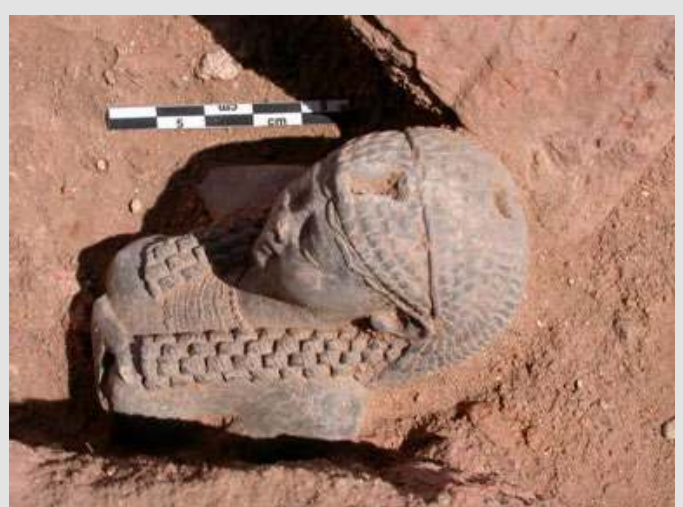

14. Buste d'une statuette d'Isis lactans au moment de sa découverte. Serpentinite (?), h. 9,2 cm. SNM 35115 (Has 150). (C) 2010 Musée du Louvre/Chr. Décamps.
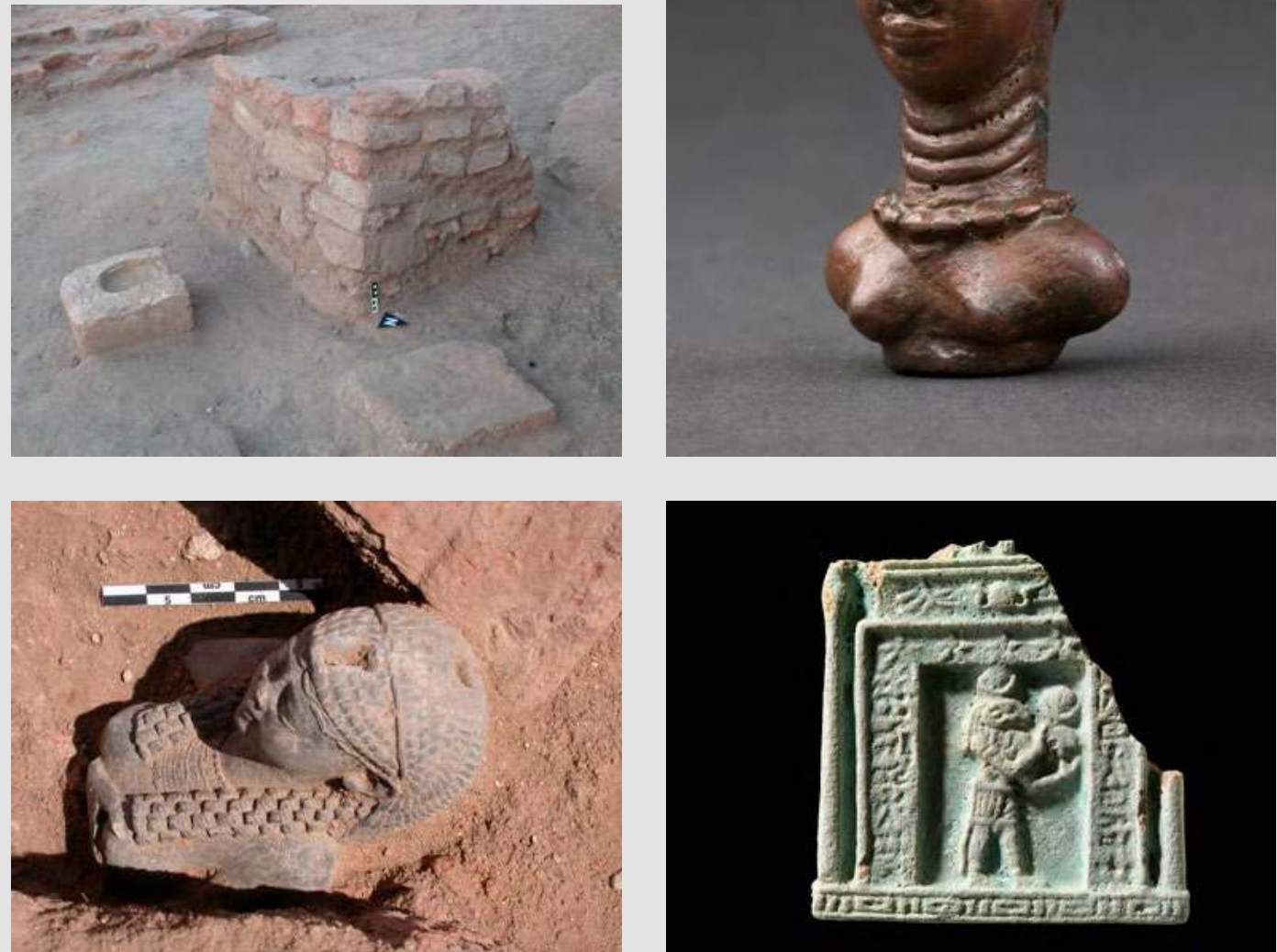

15. Pectoral en forme de naos représentant un Amon lunaire.

Faïence siliceuse, h. $9,7 \mathrm{~cm}$. SNM 35130 (HAS 208).

(C) 2010 Musée du Louvre/G. Poncet. 
Tel qu'il est, l'objet est complet et représente le buste d'une femme que le cobra dressé au front désigne comme une reine, peut-être une candace. Les plis sur l'avant et l'arrière du cou correspondent à des "plis de Vénus" et indiquent l'opulence qui caractérise les reines-mères de la famille royale méroïtique, les candaces. Les bras sont tronqués, les seins petits et hauts, et les lobes d'oreilles percés (pour des boucles d'oreilles que l'on imagine en or). Si le cou est démesurément allongé, c'est pour permettre l'emmanchement de l'objet: en effet, la partie creuse dans sa base prouve qu'il s'insérait sur une tige, au sommet d'un sceptre ou d'une canne cérémonielle.

Enfin, une cache ménagée à l'intérieur de la maçonnerie du socle du naos livrait également tout un matériel de petite statuaire et des faïences regroupé dans une coupe elle-même en faïence: buste d'Isis lactans (fig. 14), scarabée ailé et criocéphale en pierre jaune. On retiendra en tout cas que sont regroupés dans ce dépôt des objets de facture méroïtique, des objets d'importation égyptienne, des armes votives néolithiques récupérées par les Mérö̈tes dans des tombes de leurs lointains ancêtres et, enfin, des jeux de la nature. Avec un petit vase décoré de deux vautours aux ailes éployées, le pectoral est l'une des faïences les plus remarquables retrouvées dans la cache du sanctuaire. Il représente en effet une forme lunaire du dieu Amon figuré à l'intérieur de son temple (fig. 15): c'est l'astre lunaire qui coiffe le dieu bélier à la manière d'une couronne, et le dieu est représenté offrant — au roi sans aucun doute - une coiffe elle-même sommée d'un disque lunaire. Rien ne permet, dans l'état de notre documentation, de proposer ni même de penser qu'il puisse s'agir de la forme particulière du dieu Amon d'el-Hassa. Ce sera cependant un point qui restera à vérifier et à démontrer ultérieurement grâce au concours d'arguments complémentaires qui pour le moment font défaut. Le torse de déesse comme le scarabée ailé à tête de bélier sont tous deux de fabrication et donc d'importation égyptienne. Le geste que fait la déesse de porter la main à son sein montre qu'il s'agit d'une statuette d'Isis allaitant l'enfant divin Horus, exemplaire supplémentaire de la riche iconographie d'Isis lactans à Méroé. Sur des critères stylistiques, on peut comprendre qu'au moment où il est enfoui dans la base du socle du naos, ce fragment de statuette est déjà vieux de près de trois cents ans. Cette antiquité le rendait-elle précieux aux yeux des prêtres qui l'ont ajouté au «trésor » du temple? Ces deux objets, quoi qu'il en soit, sont deux témoins supplémentaires des contacts intellectuels entre les deux royaumes, entretenus notamment par les milieux sacerdotaux, d'une part, et du rôle que jouaient les sanctuaires dans le maintien des traditions théologiques, d'autre part. La découverte de cette cache pose sans doute plus de questions qu'elle n'apporte de réponses: pour quelle raison ces objets ont-ils 
été «enfouis» ainsi dans la maçonnerie du socle du naos? S'agissait-il d'objets cultuels déclassés ou avaient-ils à jouer un rôle particulier à un endroit aussi important que celui-là?

La présence d'armes d'apparat néolithiques dans des contextes cultuels méroïtiques - funéraires surtout, il est vrai — est déjà connue, et cet exemple nettement caractérisé est le bienvenu pour démontrer qu'il s'agit d'une pratique courante. Il en va de même des jeux de la nature désormais de mieux en mieux documentés, que l'on pense aux découvertes récentes de Naga ou du Gébel Barkal.

\section{Le palais cérémoniel}

cinquantenaire

\section{2}

de la section

française

de la direction

des Antiquités

du Soudan

La fouille a progressivement révélé la présence, immédiatement au sud du temple à Amon, d'un grand bâtiment de plan carré qui assez rapidement a pu être interprété comme un palais royal et, dans un deuxième temps, comme un palais cérémoniel fonctionnellement et rituellement lié au temple et dépendant de lui (fig. 16). Tout indique en effet que ce bâtiment royal était directement lié aux rituels qui se déroulaient dans le temple et permettait au souverain de jouer le rôle théologique attendu de lui. L'argument définitif qui permet de proposer aujourd'hui une telle analyse est le fait que, dans la phase 1 , le temple, le palais cérémoniel ainsi que le bâtiment à cour centrale mentionné ci-dessus et situé sur le côté ouest du temple font partie à l'évidence du même programme architectural: les dimensions respectives des trois bâtiments et l'organisation générale de l'espace (qui suggèrent également la présence - récemment vérifiée par un sondage — d'un quatrième bâtiment à l'ouest du palais cérémoniel) prouvent que nous sommes en présence d'un seul et unique projet architectural dès l'origine. Très peu d'exemples de l'association de ces deux typologies de bâtiment sont connus. Le temple et le palais cérémoniel sont parallèles et alignés sur leur façade. Dans leur phase 1, les deux édifices présentent les mêmes dimensions, en longueur comme en largeur. D'un plan classique, le palais se présente comme un édifice à cour centrale et de plan sensiblement carré, auquel on accédait par des escaliers sur les quatre façades. Les restes d'un escalier à l'intérieur de la construction indiquent la présence d'un étage. Les deux bâtiments sont reliés entre eux par un espace ouvert, long et étroit, une sorte de cour que délimitent deux murs à l'ouest et à l'est, cour sur laquelle donnent les deux portes latérales du temple, d'une part, et la porte nord du palais, d'autre part. On accédait à cette dernière depuis la cour par un escalier à double volée; les trois autres entrées sont également accessibles par des escaliers monumentaux. L'entrée principale se trouvait sur la façade orientale, dans l'alignement du pylône, et protégée par un parvis délimité par un muret. 


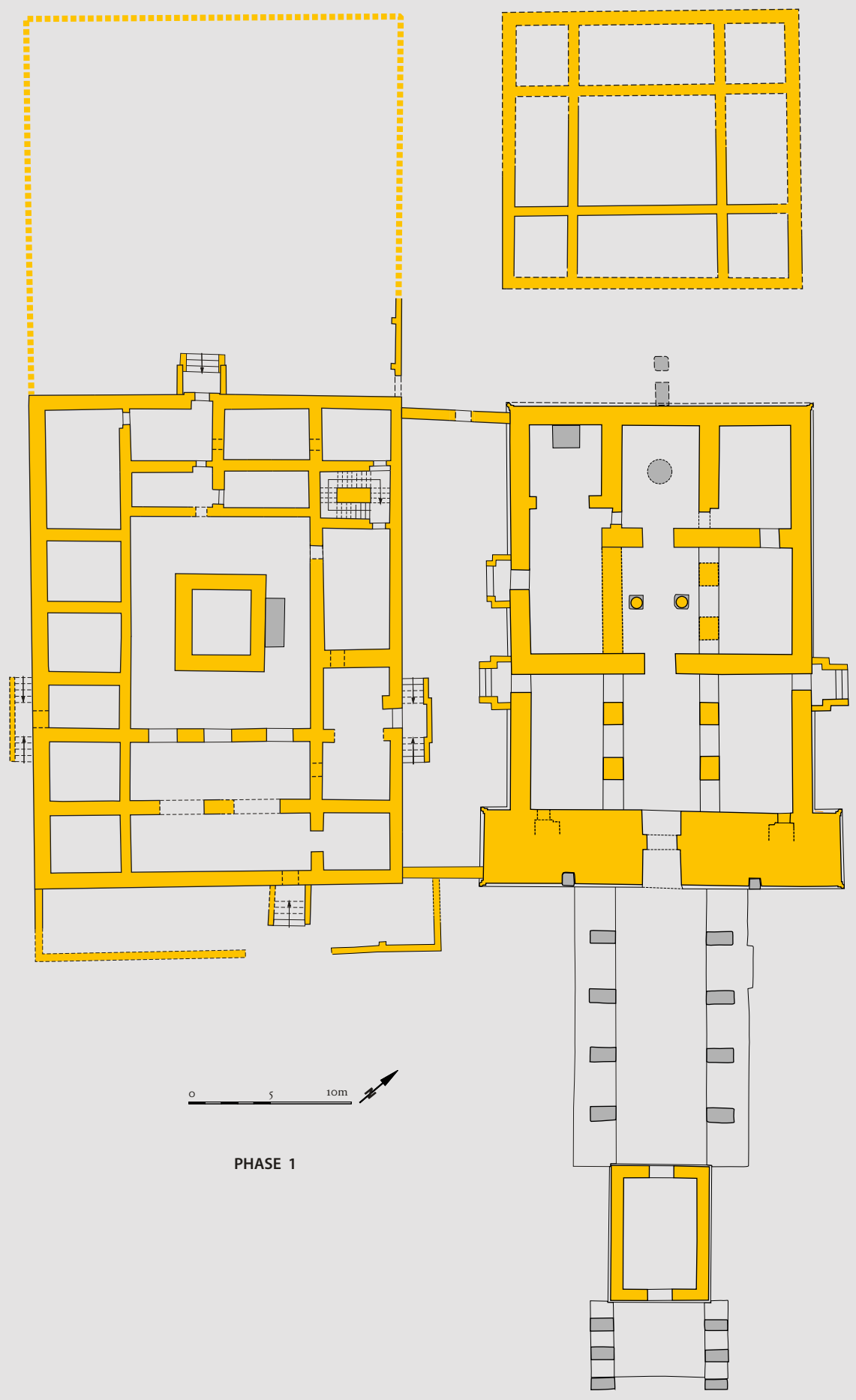

143

el-Hassa

$2000-2020$ 

un étage selon toute probabilité; sa partie centrale était occupée par un déambulatoire organisé autour d'un puits de lumière carré. Les vestiges d'une sorte de "podium » avec décor géométrique polychrome sont conservés dans la travée nord du déambulatoire (fig.17). Élément central du palais, à n'en pas douter, ce "podium» — on souhaiterait pouvoir mieux caractériser ce détail architectural — jouait certainement un rôle crucial dans la liturgie en lien avec le temple, peut-être celui d'une estrade pour un trône. Depuis l'entrée principale sur le côté est, on y accédait par une succession de deux salles scandées par des baies de plus en plus étroites. Les vastes dimensions du déambulatoire et des salles, sur les côtés nord et est, paraissent confirmer le caractère représentatif et officiel de l'édifice. Un escalier, situé vers l'angle nord-ouest, amenait à une partie de fonction vraisemblablement plus privée. Comme le temple, le palais cérémoniel a connu des modifications dans son plan, principalement par des changements dans la circulation entre les différentes salles. La modification la plus importante consiste en l'édification de deux cloisons de part et d'autre du "podium», cloisons qui empêchaient qu'il soit visible directement et qui faisaient qu'on n'y accédait plus désormais que par deux passages étroits. Ainsi faut-il comprendre que les rituels dont ce podium était le lieu, déjà protégés par la position de ce dernier au centre du palais en phase 1, ont été rendus encore plus secrets (?) en phase 2.

Une fois écroulé, le palais cérémoniel a été abandonné et sa ruine de la section

française

de la direction des Antiquités du Soudan

\section{4} fut exploitée pour ses matériaux lors de la reconstruction en phase 3, désormais séparée du temple par un mur-écran réduisant l'emprise de la cour sud. Les ruines du palais cérémoniel abritèrent par la suite une longue occupation profane, constatée sur plusieurs niveaux et caractérisée par la présence de foyers, de réservoirs d'eau et de braseros scellés dans les sols.

\section{Les béliers de Nebmaâtrê Amanakhareqerema}

On accède au temple à Amon d'el-Hassa par une voie processionnelle dont l'allée est classiquement rythmée par une rampe et un kiosque, et flanquée de paires de statues de béliers. Le dromos d'el-Hassa présente l'originalité, non expliquée encore, d'être asymétrique et de compter quatre paires de bélier de grosse taille à l'ouest du kiosque et trois paires de taille plus petite installées sur la rampe, du côté est. Cette asymétrie du plan est la première des particularités présentées par le dromos d'el-Hassa. Nous savons, par l'analyse de ses fondations ainsi que de celles du kiosque, que ce dernier est contemporain de la construction du premier temple (phase 1). Or, les bases de ces statues sont suffisamment conservées pour que l'on puisse identifier 


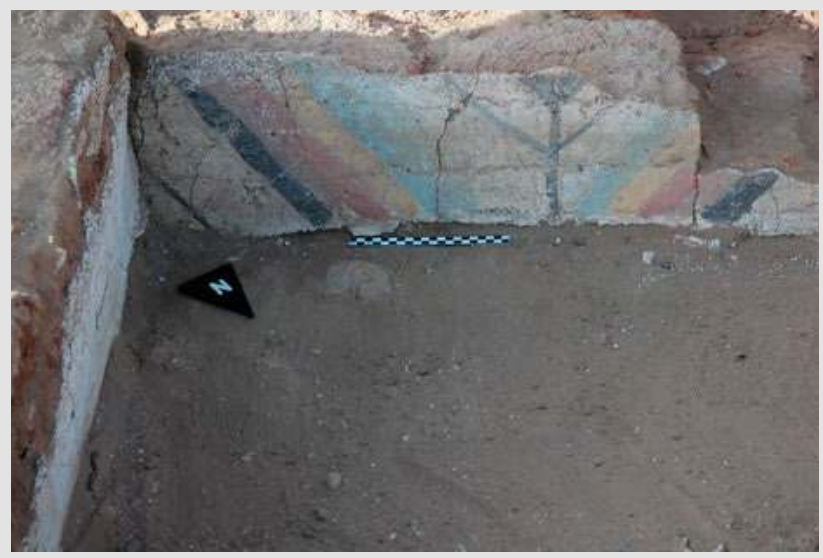

17. Palais cérémoniel. Décor géométrique polychrome sur l’un des côtés du " podium ». (C) 2009 G. Nogara, el-Hassa/Sfdas.

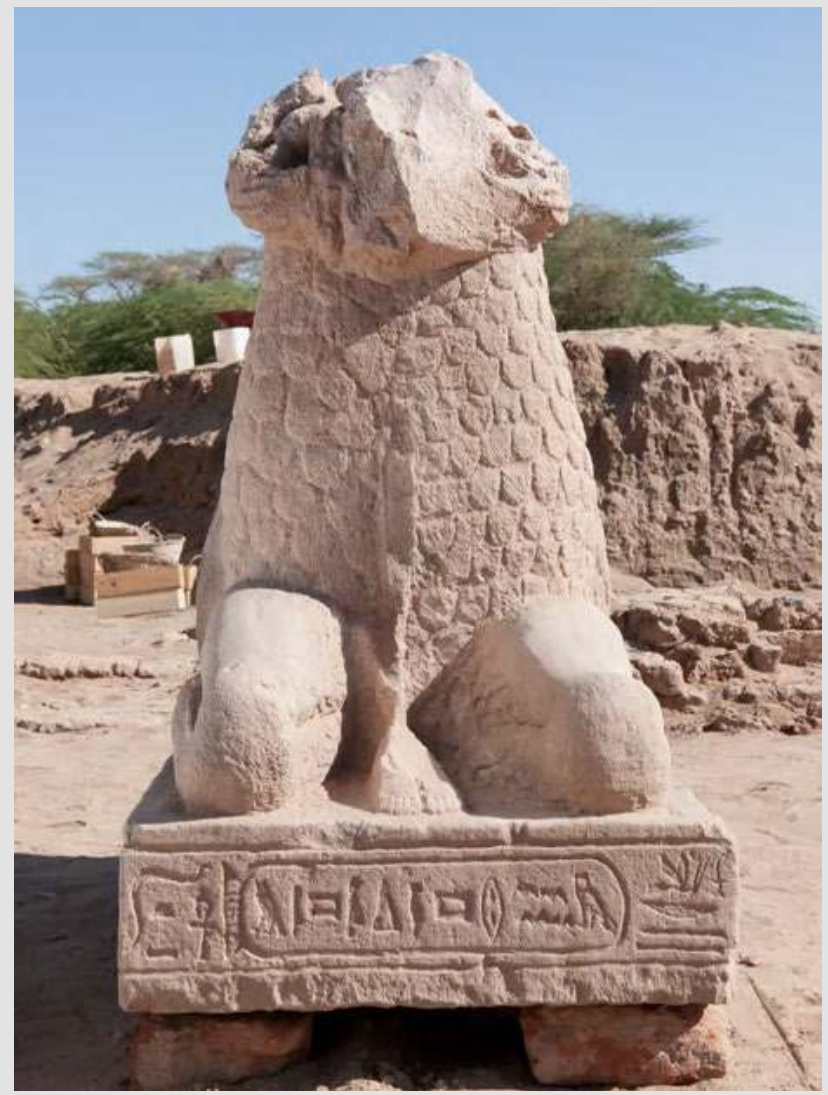

18. Dromos d'el-Hassa, bélier $2 \mathrm{~N}$. Sur la base, l'inscription mêlant titres pharaoniques et hiéroglyphes méroïtiques à l'intérieur du cartouche est à lire: «Le roi de Haute et Basse-Égypte, le Maître des Deux Terres Amanakhareqerema, vivant éternellement ». (C) 2011 J.-Fr. Gout, el-Hassa/Sfdas. 
les transformations qui leur ont été apportées: elles ont toutes été allongées dans un deuxième temps. Cela demande explication: y a-t-il eu un repentir en cours de chantier, les bases n'étaient-elles pas prévues pour ces statues de béliers à l'origine, mais pour un autre programme statuaire qui n'aurait pas été réalisé?

Au fur et à mesure des campagnes de fouille, c'est un total de six statues qui ont été retrouvées: une première, pour mémoire, découverte fortuitement en 1975, une seconde en 2002, trois autres dégagées en 2008, et enfin une dernière fouillée en 2010 . Les bases des statues de bélier sont toutes inscrites du même texte associant hiéroglyphes méroïtiques et pharaoniques (pour les titres royaux et formules de conclusion) et mentionnant le souverain Nebmaâtrê Amanakhareqerema, un qore encore peu connu il y a peu et dont le règne se trouve désormais de mieux en mieux attesté (fig. 18). Pendant longtemps, en effet, son existence n'était attestée que par trois documents: 1) la statue du bélier dit "de Soba» (Remooo1), en tous points semblable à celles d'el-Hassa, et portant sur sa base le même texte; depuis le milieu du XIX ${ }^{\mathrm{e}}$ siècle, elle était connue et décrite à Soba, capitale du royaume chrétien d'Alodia située quelques kilomètres au sud de Khartoum ; 2) les cartouches qui légendent les scènes du naos de grès en forme de hutte mis au jour en 1916 par l'archéologue américain George Reisner dans le temple à Amon du Gébel Barkal (Rem 1004, Boston

de la section

française

de la direction des Antiquités du Soudan MFA 21.3234); 3) la statue de bélier $7 \mathrm{~N}$ trouvée fortuitement à el-Hassa même lors du creusement d'un canal d'irrigation à travers le site en 1975 (REM 1151) (fig. 3).

L'intérêt pour ce souverain s'est trouvé relancé en 1998, à Naga cette fois, lorsque la mission du musée de Berlin dégagea, près du temple $\mathrm{du}$ Lion, un bloc en grès portant un court texte en cursive au nom d'Amanakhareqerema (REM 1282). Comme les écritures cursives ont une évolution beaucoup plus rapide et plus perceptible que celle des hiéroglyphes, aux formes plus figées, ce texte a permis à Claude Rilly de proposer une datation pour le règne du qore aux alentours de $80-90$ de notre ère, faisant de lui le successeur — sans doute direct — de Natakamani, ce que le temple à Amon d'el-Hassa et son palais révélés par nos travaux ne démentent pas. La découverte en 2002 d'une troisième statue de bélier à son nom, sur le site même d'el-Hassa et à son emplacement d'origine, est venue confirmer que le commanditaire de la construction du temple à Amon d'el-Hassa était Amanakhareqerema. Depuis, l'équipe du musée de Berlin et aujourd'hui de Munich a mis au jour un temple construit et décoré par ce même qore. Ainsi disposons-nous de deux temples à son nom et de nouvelles propositions pour sa place dans la chronologie des souverains méroïtiques. Ce sont 


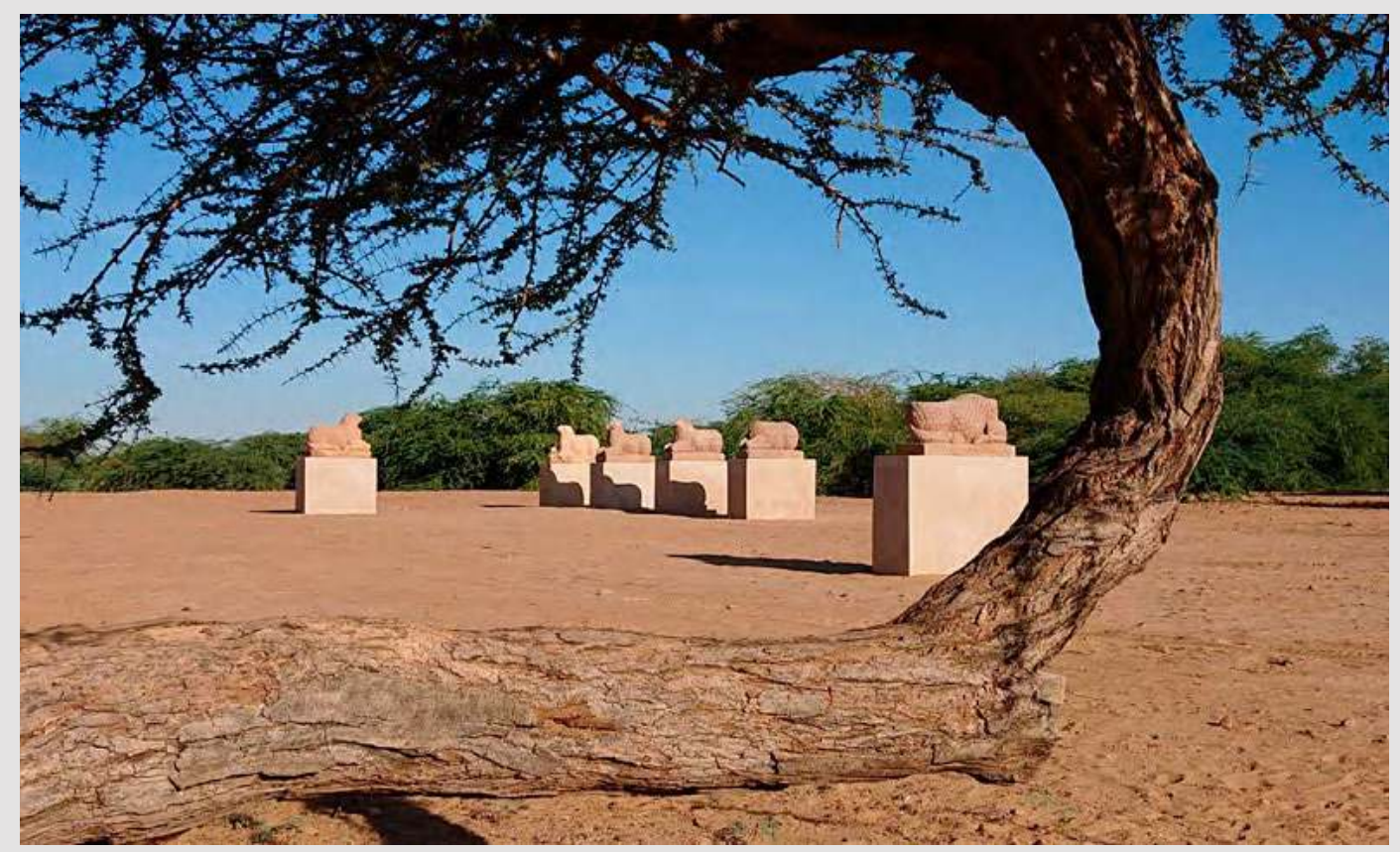

19. Présentation du site après la fouille: les statues de bélier d'el-Hassa,

avec la copie de celle du «bélier de Soba» sur leurs socles, sur les deux côtés du dromos du temple. De gauche à droite $2 \mathrm{~S},{ }_{1} \mathrm{~N}$ (Soba), ${ }_{2} \mathrm{~N},{ }_{3} \mathrm{~N},{ }_{4} \mathrm{~N}$ et $7 \mathrm{~S}$.

(C) 2019 G. Nogara, el-Hassa/Sfdas. 


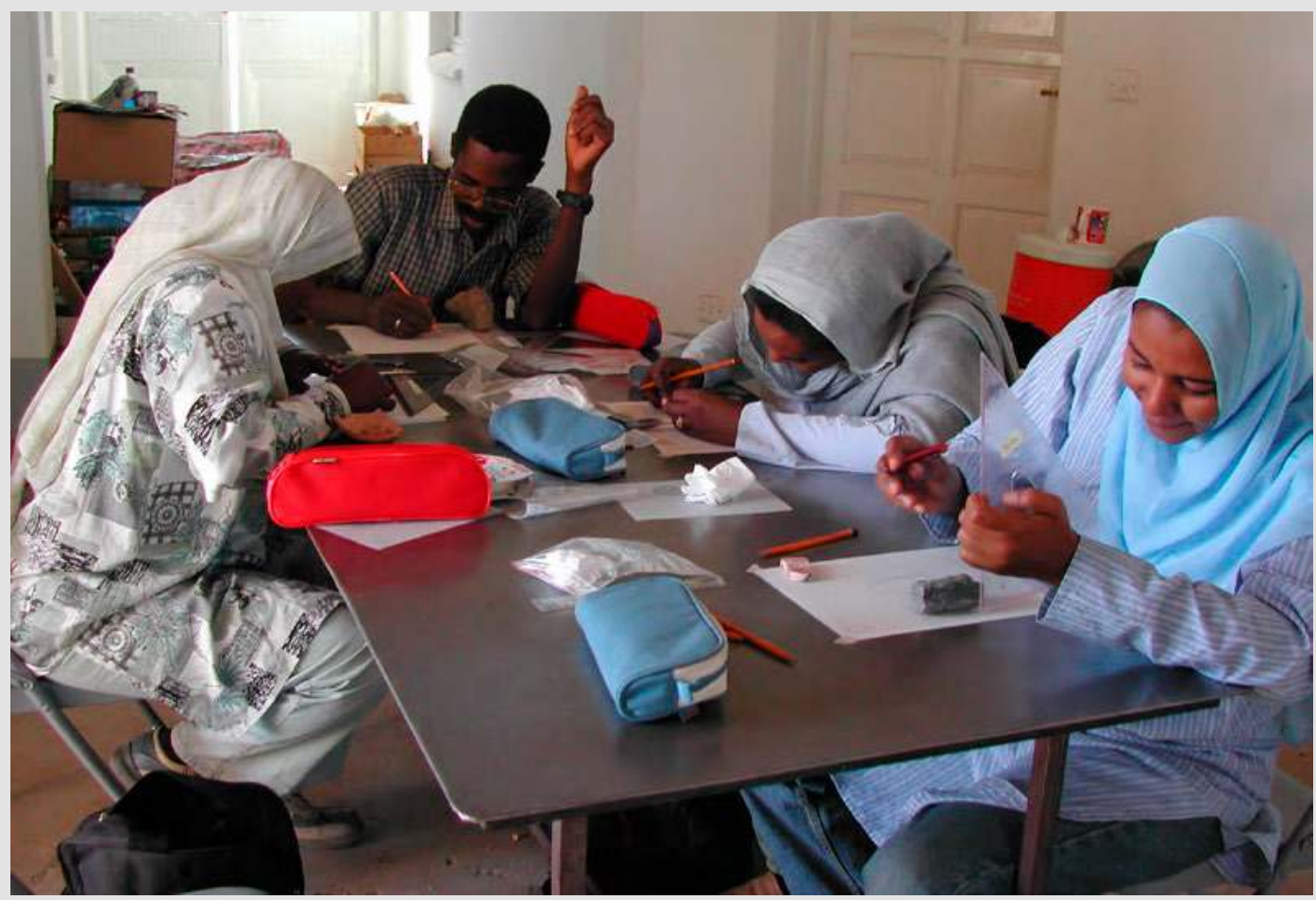

cinquantenaire

\section{8}

de la section

française

de la direction des Antiquités du Soudan
20. École de fouille d'el-Hassa, dessin d'objets archéologiques.

(C) 2006 R.-P. Dissaux, el-Hassa/Sfdas.

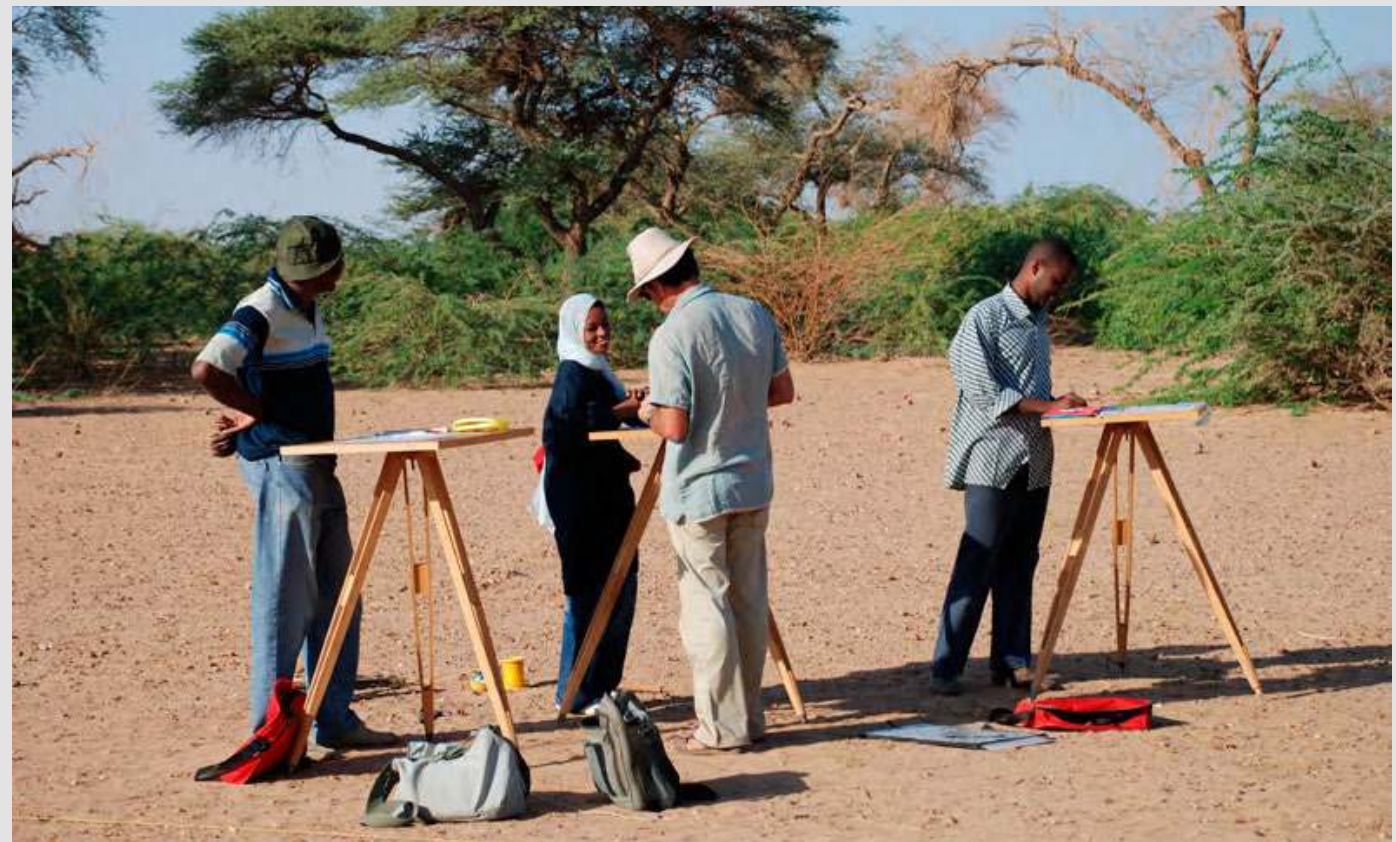

21. École de fouille d'el-Hassa, session de relevé de terrain.

(C) 2008 R.-P. Dissaux, el-Hassa/Sfdas. 
ces éléments tous récents qui ont fourni à Josefine Kuckertz la matière à son article très développé paru en 2018 dans le numéro 29 de Der Antike Sudan "Amanakhareqerema - a Meroitic King of the 1st Century AD".

Le programme soudano-qatari de financement de l'archéologie soudanaise a donné à la mission la possibilité d'une opération d'aménagement du site de façon à le rendre visitable. Les cinq statues de béliers représentent en effet un ensemble exceptionnel pour l'histoire de la sculpture monumentale du royaume méroïtique. Par ailleurs, laisser les ruines que nous avions dégagées exposées plus longtemps à la saison des pluies signifiait leur disparition inéluctable alors que nous n'avions aucune solution pour les restaurer et les rendre visitables durablement. Après enfouissement complet de la fouille du temple et du palais cérémoniel en novembre 2016, les statues ont été installées sur des bases fondées et construites en parpaings à la verticale de leur position d'origine, au milieu des arbres (fig. 19). Les hauteurs et proportions de ces bases sont inspirées de celles des statues de bélier du dromos de Naga et nous avons pensé nécessaire d'adjoindre aux cinq statues originales retrouvées par nous sur le site une copie moderne du bélier de Soba, réalisée par l'équipe de Restaurierung am Oberbaum. Pour ce faire, grâce à l'autorisation de M. Abdelrahman Ali Mohamed, ancien directeur général de la NCAM, ce bélier est revenu pendant une quinzaine de jours à el-Hassa, a été moulé et a, pour la deuxième fois, accompli le voyage qu’il avait fait il y a quelques siècles vers la ville ancienne de Soba.

\section{L'école de fouille et son programme de formation}

La nécessité, initialement ressentie par les responsables de la NCAM et des universités de Shendi et de Khartoum, de pouvoir organiser une formation de leurs personnels aux techniques d'intervention programmée fut intégrée au projet dès son début. La création d'un centre de formation sur le chantier d'el-Hassa, puis également dans les locaux de l'école de fouille, fut mise en œuvre dès 2002 et formalisée en 2006. Les stagiaires, en moyenne quatre par session, furent ainsi initiés aux différentes techniques de fouille et de documentation, graphique et écrite, aux notions de base de topographie et de photographie, ainsi qu'au dessin d'objets et de céramique (fig. 20 et 21). Les stages ont représenté dix sessions qui eurent lieu chaque année sur une période de six semaines. Les participants, trente stagiaires au total, furent intégrés à l'équipe de fouille au fur et à mesure de l'acquisition de leurs compétences. Ont ainsi bénéficié de l'enseignement dispensé dans le cadre de ce qui fut communément appelé «l'école de fouille»: 1. NCAM, Antiquities Officers/conservateurs du Musée national du Soudan, Khartoum: M. Yassine Mohamed, M. Ali el-Merghani, $\mathrm{M}^{\text {He }}$ Habab Idriss, $\mathrm{M}^{\text {He }}$ Rihab Khider, $\mathrm{M}^{\text {He }}$ Ina’am Abdel Rahman, M. Et-Taher 
Adam En-Nour, $M^{\text {He }}$ Nayla Abdine, $M^{\text {lle }}$ Na'ma Kamal Adam Sabel, $M^{\text {He }}$ Naïma Ali Abdel Razzaq, M"lle Shadia Abdel Rabou Abdel Wahab, M. Ayman Et-Tayeb, M ${ }^{\text {lle }}$ Regina Dak, M ${ }^{\text {lle }}$ Belcem Abdel Hamid, M. Moustafa Ahmed Esh-Sherif; 2. NCaM, Antiquities Officers, Antenne de Shendi: M. Mohamed Farouk Abdel Rahman, M. Ahmed el-Amin Ahmed, M Me Maha Abbas Mohammed, M. Abdelrahman Fadl Mohamed, M. Emad Tag Essir Osman, M. Osman Soleiman Mohamed, M. Soleiman Awad Soleiman; 3. Université de Shendi, Teaching Assistants: M. Abdel Moneim Ahmed Abdallah, M"le Amira Abdel Rahim Aly, $\mathrm{M}^{\text {lle }}$ Nada Babiker Mohamed, $\mathrm{M}^{\text {\|le }}$ Nouha Abd el-Hafiz, M. Mohammed el-Fatih Haiath, M. Ahmed Hamid Nasr; 4. Université de Khartoum, Teaching Assistants: M. Ahmed Hussein Abdel Rahman; Université de Bahri, Teaching Assistant: $\mathrm{M}^{\text {te }}$ Hana Abdel Hafez; 5.Gedaref, General Administration for Tourism and Antiquity: M. Fakhry Ahmed.

Au terme de ce programme de près de vingt années, nous tenons à remercier Hassan Hussein Idriss et Abdelrahman Ali, directeurs généraux de la NCAM, pour leur confiance et leur soutien

cinquantenaire bibliographie chronologique

\section{0}

de la section

française

de la direction

des Antiquités

du Soudan
Lenoble P., Rondot V. 2003 - "À la redécouverte d'el-Hassa. Temple à Amon, palais royal et ville de l'empire méroïtique", Cahiers de Recherche de l'Institut de Papyrologie et d'Égyptologie de Lille, 23, p. 101-115.

Rondot V. 2006 - «Le qore Amanakhareqerem et son temple à Amon d'el-Hassa", dans V. Rondot, N. Dextreit (éd.), Kerma et Méroé. Cinq conférences d'archéologie soudanaise, Khartoum, p. 41-47.

Letourneux J.-P., Feneuille S. 2010 — «Chemical and physical analyses of facing mortars collected from various Meroitic sites", dans Between the Cataracts, Proceedings of the 11th International Conference on Meroitic Studies, PAM supplement series 2.2, Warsaw University Press, p. 577-582.

Rondot V., Török L. 2010 — «La maison du dieu: le temple», dans M. Baud (dir.), Méroé, un empire sur le Nil, Paris, p. 227-233.

Rondot V. 2010 - "Le matériel cultuel du temple à Amon d'el-Hassa", dans M. Baud (dir.), Méroé, un empire sur le Nil, Paris, p. 236-239.

Bouchar M. 2010 - «Petrographic study of Meroitic mortars from an Amun temple (el-Hassa)», dans J. Valek, C. Groot, J.J. Hughes (éd.), Proceedings of the second Historic Mortars Conference and RILEM TC 203-RHм Final Workshop, Rilem Publications, Bagneux, p. 55-64. 
Rondot V. 2011 - «De la fonction des statues-cubes comme caleporte", Revue d'égyptologie 62, p. 141-157.

Evina M., David R. 2011 — «Patrice Lenoble à el-Hassa. Étude de la céramique du temple à Amon 2000-2005", dans V. Rondot, F. Alpi et F. Villeneuve (éd.), La pioche et la plume, Hommages archéologiques à Patrice Lenoble, Paris, p. 303-315.

Letourneux J.-P., Feneuille S. 2012 — «Mineralogical and microstructural analysis of mortars from Kushite archaeological sites", dans J. Vàlek, J.J. Hughes and C.J.W.P. Groot (éd.), Historic Mortars, Springer London, p. 37-47.

Yellin J. W. 2012 - "Al-Hassa», dans M. M. Fisher et al. (éd.), Ancient Nubia. African Kingdoms on the Nile, Le Caire, Université américaine, p. 253-254.

Rondot V. 2013 — «El-Hassa: un temple à Amon dans l'île de Méroé au $\mathrm{I}^{\mathrm{er}}$ siècle de notre ère", Comptes-rendus de l'Académie des inscriptions et belles lettres, 2012-I, p. 167-182.

Feneuille S., Letourneux J.-P., Bouchar M. 2014 - «Archaeological information extracted from a comparative study of samples of mortar collected on various ancient monuments in the Nile Valley between the Third and the Sixth Cataracts", dans J. Anderson, D. Welsby (éd.), The Fourth Cataract and Beyond, Proceedings of the 12th International Conference for Nubian Studies, BMPES 1, p. 827-832. 2016 - Protocoles d'étude des mortiers anciens à l'usage des archéologues, éditions Mergoil, Autun, p. 53-58.

Rilly Cl. 2017 — "De l'ombre à la lumière: le roi Amanakharéqérem", dans Histoire et civilisations du Soudan de la Préhistoire à nos jours, Études d'égyptologie 15, p. 286-291.

Rondot V., Claustre D. 2018 — «Nos premières sources sur le bélier de Soba Rem ooo1: le Bourguignon Pierre Trémaux, Johannes Dümichen et le Vénitien Giovanni Miani», dans M. Honegger (éd.), Nubian Archaeology in the XXIst Century. Proceedings of the Thirteenth International Conference for Nubian Studies, Neuchatel, 1st-6th September 2014, Ola 273, p. 457-472.

Kuckertz J. 2018 — «Amanakhareqerema- a Meroitic King of the 1st Century AD», AntSud 29, p. 119-144.

Rondot V., Nogara G. 2019 - «El-Hassa 2018 : en 100 apr. J.-C., un nouveau temple à Amon dans l'île de Méroé. Les acquis et les questions ", Bulletin de la société française d'égyptologie 201, p. 79-103. 



\section{un siècle de fouilles \\ archéologiques \\ au Soudan}

Marc Maillot 
Cette brève historiographie, qui s'appuie entre autres sur les travaux de S.el-Din M.Ahmed ${ }^{1}$, D. Welsby ${ }^{2}$ et D. N.Edwards ${ }^{3}$, nous permettra d'apprécier l'évolution des problématiques de recherches en archéologie soudanaise $\mathrm{du} \mathrm{XIX}^{\mathrm{e}}$ siècle à nos jours, et de réinsérer la politique scientifique française et internationale au sein d'une fresque historique compréhensible.

\section{Les récits des grands voyageurs}

cinquantenaire

\section{4}

de la section

française

de la direction

des Antiquités

du Soudan

Il faut attendre la fin du XVIII ${ }^{e}$ et surtout le XIX ${ }^{e}$ siècle pour que des voyageurs européens partent à la découverte de Méroé, avec pour but, souvent premier, l'exploration des sources du Nil ${ }^{4}$. Ces missions, essentiellement fondées sur la lecture des sources classiques, représentent des témoignages précieux des premières observations de sites archéologiques, nous permettant avec le recul de percevoir l'évolution des missions d'exploration autorisant les pillages vers des missions de recherche archéologique ${ }^{5}$.

Le précurseur, James Bruce (1730-1794), entreprit à partir de 1769 une mission de recherche des sources du Nil qu'il situait en Abyssinie $^{6}$. Après avoir effectué un voyage le menant de Massaouah, sur la rive de la mer Rouge, à Gondar, capitale de l'Éthiopie, puis le long du Nil Bleu jusqu'au lac Tana, sa source, il entreprit un voyage de retour vers l'Égypte. C'est lors de ce trajet, accompagné d'un dessinateur italien nommé Belaguni, qu'il observa le 21 octobre 1772 les premières ruines depuis Axoum, près du village de Begrawiya. Le récit de son exploration, Voyage aux sources du Nil, en Nubie et en Abyssinie, pendant les années 17681773, premier ouvrage à associer les vestiges découverts à l'antique capitale de Méroé, fut publié en 1790.

Ce n'est qu'au début du XIx siècle que cet ensemble de ruines est à nouveau repéré par Johan-Ludwig Burckhardt (1784-1817), envoyé par l'African Society de Londres pour une mission d'exploration de l'Afrique. Se rendant à Shendi, il observa en avril 1814 des fondations de briques rouges, "plus grossières que celles utilisées en Égypte», et quelques constructions en pierre sur une surface assez étendue ${ }^{7}$.

Le Nantais Frédéric Cailliaud (1787-1869) se joignit à l'expédition militaire menée, à partir de 1820, par Ismaël Pacha, troisième fils du vice-roi d'Égypte Méhémet Ali, dans l'objectif de découvrir la cité antique de Méroé ${ }^{8}$. Remontant le Nil, il repéra et étudia différents sites nubiens d'importance, tels que la nécropole de Sedeinga, le temple de Soleb (fig. 1), Kerma, la nécropole de Nouri et le Gébel Barkal ${ }^{9}$. Précédant l'armée en direction de Shendi avec son compagnon de voyage Pierre-Constant Letorzec, il aperçut les pyramides de Begrawiya le 25 avril 1821, puis découvrit la ville 


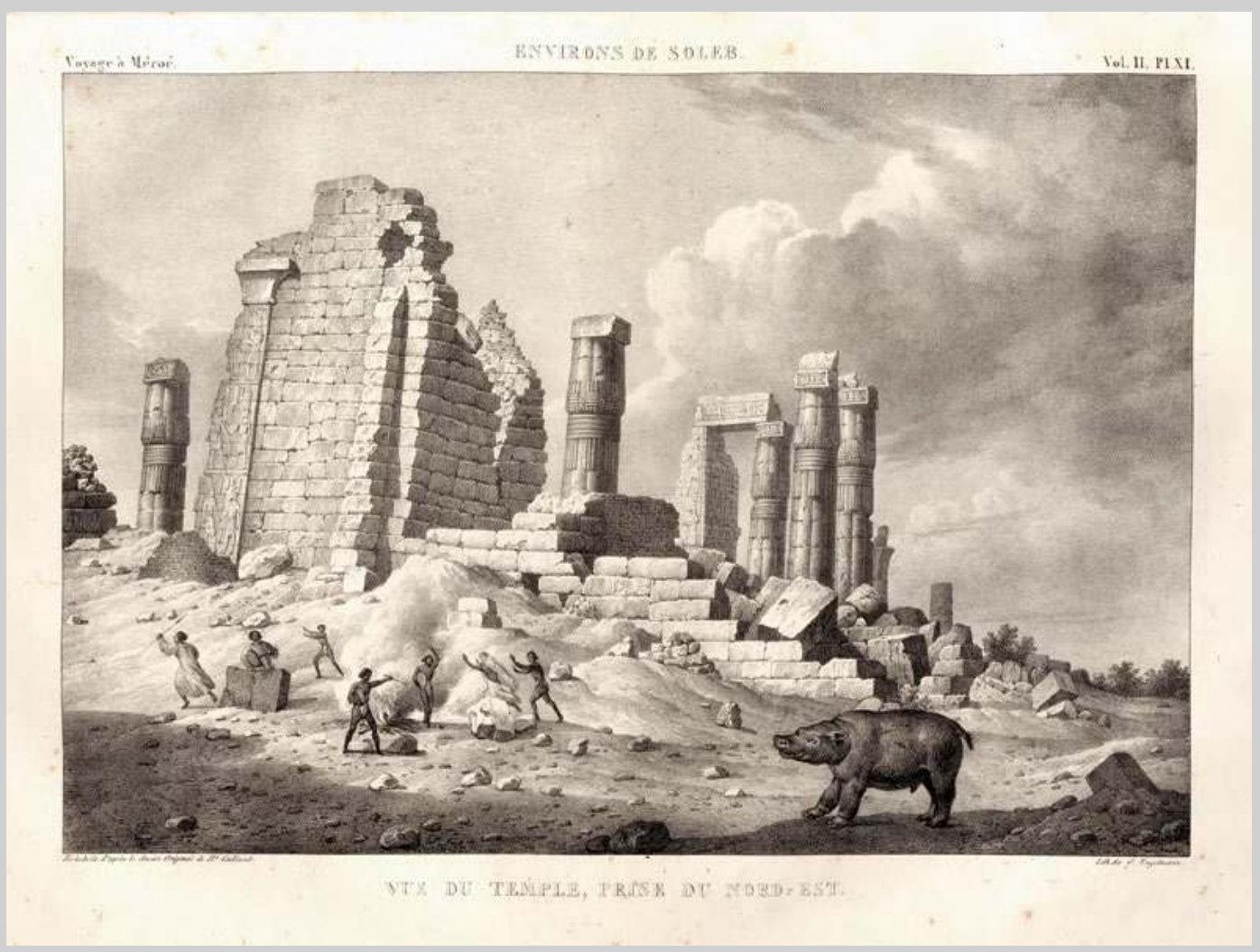

1. Temple de Soleb, vue du nord-est (d'après Cailliaud 1826, vol. II, pl. xı).

\section{5}

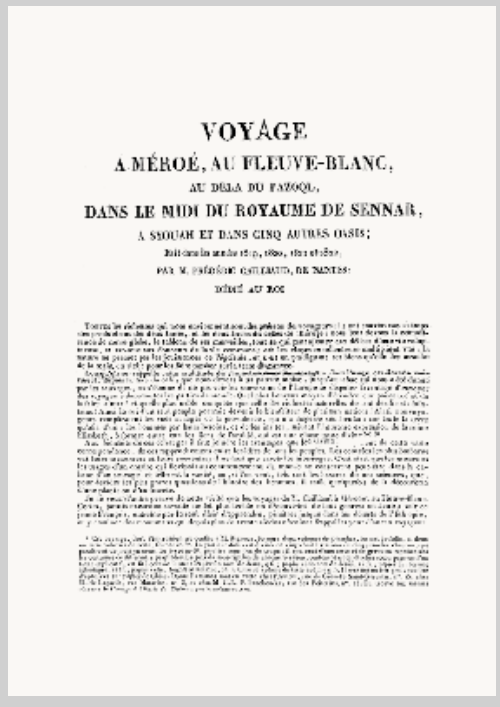

2. Première page du Voyage à Méroé et au Fleuve Blanc au-delà du Fâzoql (d'après Cailliaud 1826).

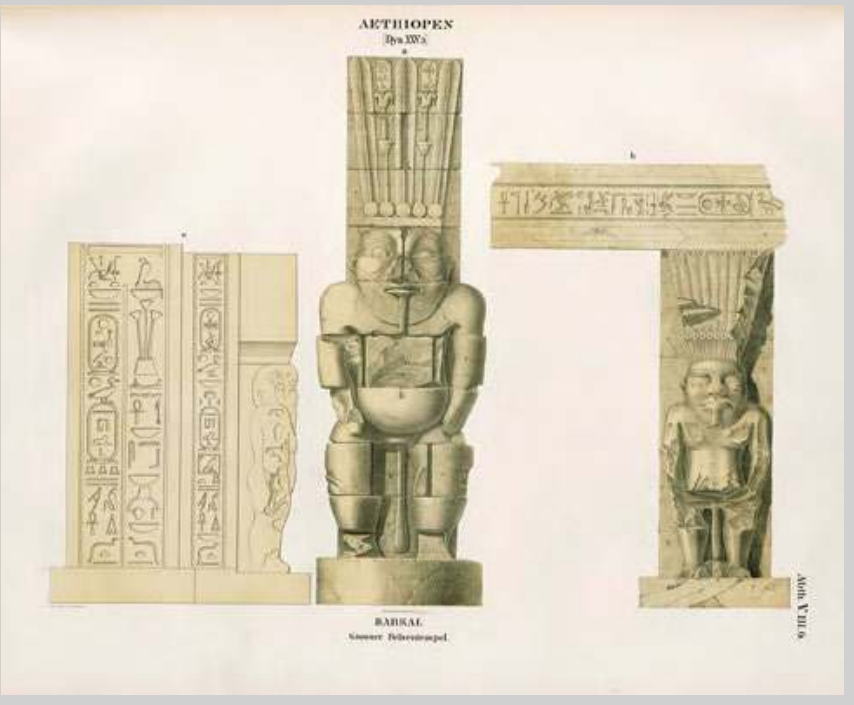

3. Barkal Felsentempel, Denkmäler aus Aegypten und Aethiopien, Tafel Werke, Band X, Aethiopien, Abth V. B1.6. (d'après http://edocz.bibliothek.uni-halle.de/lepsius/tafelwa5. html) (c) ULB Halle/Lepsius-Projekt. un siècle de fouilles archéologiques 
de Méroé. Ainsi, son ouvrage Voyage à Méroé et au Fleuve Blanc au-delà du Fâzoql, publié en 1826, représente la première étude archéologique du site, richement illustrée de ses dessins (fig. 2) ${ }^{10}$. Quelques mois seulement après la visite des sites par Cailliaud, Linant de Bellefonds (1799-1883), mandaté par William Bankes pour explorer la Nubie et voyageant dans la région de Shendi afin de se rendre à Sennar, passa à proximité du site en novembre 1821, sans s'y arrêter. Il retourna en revanche étudier les pyramides de Méroé en avril 1822, un an après Cailliaud, après avoir découvert pour la première fois les ruines de Naga et Musawwarat es-Sofra ${ }^{11}$.

La publication des découvertes de ces voyageurs, notamment celle des pyramides de Méroé, éveilla rapidement l'intérêt de "voyageurs-pilleurs" tels que Giuseppe Ferlini (1800-1870) 12. Ayant démantelé plusieurs pyramides en 1834, il fit exploser l'imposante pyramide Beg. N6, mettant ainsi au jour le trésor de la candace Amanishakheto qu'il vendit au musée de Munich en 1839 et au musée de Berlin en 1844. Ce n'est qu'avec l'expédition prussienne de Carl Richard Lepsius (1810-1884), entre 1842 et 1845 , que l'objectif d'une étude archéologique poussée se développe ${ }^{13}$. Ainsi les Denkmäler aus Aegypten und Aethiopien (fig. 3) représentent la première référence bibliographique dans le relevé et l'étude des sites archéologiques nubiens, tels que la nécropole de Méroé et les sites de Musawwarat es-Sofra et Naga, mettant en valeur l'importance archéologique de la civilisation méroïtique ${ }^{14}$.

\section{6}

de la section

française

de la direction des Antiquités du Soudan

Insistons sur le rôle joué par C. R. Lepsius en 1842, lorsque ce dernier parcourt la vallée du Nil en Égypte, puis va remonter le fleuve jusqu'au cœur du Soudan. J.-F. Champollion était pourtant venu vingt ans auparavant avec une expédition envoyée par le roi de France mais s'était arrêté à la deuxième cataracte. Lepsius descend alors jusqu’à Méroé, en collectant les artefacts qui jalonnent son passage, expliquant ainsi pourquoi le musée de Berlin est le plus riche d'Europe en antiquités soudanaises. En 1845, ces artefacts parviennent à Hambourg. La publication des Denkmäler aus Aegypten und Aethiopien, "Monuments d'Égypte et de Nubie», va permettre de redécouvrir la région et de présenter de nombreux textes, dessins et fac-similés. Lepsius, contrairement à Cailliaud, est égyptologue de formation: ces Denkmäler constituent une somme remarquable d'informations doublée d'un traitement scientifique de grande qualité. 


\section{Prémices de l'archéologie méroïtique \\ fin du XIXe siècle-premier quart du XXe siècle}

\section{La région de Méroé}

Les premières interventions archéologiques sur des sites en territoire soudanais ont été menées par W. Budge suite à la conquête britannique du Soudan en 1898. Son programme de fouille des sites de Méroé et du Gébel Barkal a majoritairement consisté en la récolte du matériel archéologique ${ }^{\mathbf{1 5}}$. Une prospection archéologique des sites méroïtiques de l'île de Méroé, dans le Boutana, fut conduite par J. W. Crowfoot en 1906. Premier à réaliser un travail archéologique novateur, à la fois analytique et synthétique, il entreprend notamment une étude des ressources économiques et une typologie des sites archéologiques de la région ${ }^{16}$. Deux ans plus tard, une description des vestiges de Naga et Musawwarat es-Sofra fut réalisée en 1908 par P. D. Scott-Moncrief ${ }^{17}$.

Le premier programme de fouille de la ville de Méroé, menée par la mission de l'université de Liverpool, fut dirigé par J. Garstang de 1909 à $1914^{18}$. Les fouilles furent vouées à l'étude de la "cité royale», de grands monuments adjacents et des nécropoles populaires orientales. Les travaux de J. Garstang sont précurseurs dans la tentative de reconstitution de l'histoire architecturale de la ville, fondée sur la diversité des matériaux de construction, ainsi que dans l'établissement d'une première typologie de la céramique usuelle.

\section{La Basse-Nubie}

Les premières opérations archéologiques d'envergure en Nubie résultent de la décision d'agrandissement du premier barrage d'Assouan par l'Égypte de 1908 à 1910. Ainsi, la First Archaeological Survey of Nubia, première prospection en Nubie égyptienne, fut destinée à sauver les sites menacés d'immersion. Se déroulant durant quatre saisons, de 1907 à 1911, elle couvrit $152 \mathrm{~km}$ de la vallée du Nil au sud de la première cataracte, entre Shellal et Ouadi es-Seboua.

Dirigée d'abord par G.A. Reisner, puis par Cecil Mallaby Firth, elle représente la fouille de 151 cimetières, soit 8 ooo tombes individuelles, et de seulement six sites d'habitat superficiellement explorés ${ }^{19}$. Parmi le groupe w, correspondant aux vestiges gréco-romains et méroïtiques, l'on ne recensa que des tombes, mises au jour dans la partie méridionale de la Basse-Nubie. Ce survey, dont le travail s'est centré sur la distinction des différentes cultures «nubiennes» et leurs contacts avec l'Égypte prédynastique et pharaonique, a été rapidement complété par d'autres expéditions aux abords de la frontière entre l'Égypte et la Basse-Nubie. 
En Nubie soudanaise, L. Woolley et R. D. MacIver furent les premiers à entreprendre un programme de fouille d'une ville méroïtique ${ }^{20}$ et de son cimetière associé ${ }^{21}$ sur le site de Karanóg (fig. 4). Cette fouille de la mission de l'université de Pennsylvanie, en 1909, a permis de documenter l'architecture civile méroïtique dans une région encore non étudiée et de décrire un matériel archéologique qui se distingue de celui provenant des sites de la région du Boutana.

De 1910 à 1912, les fouilles de la ville de Faras, dirigées par F.Ll.Griffith ${ }^{22}$, de l'université d'Oxford, ont mis au jour une structure d'importance considérée comme un exemple d'architecture civile méroïtique: le "palais occidental» (fig.5). Dans le domaine funéraire, le vaste cimetière associé à la ville contenait un matériel archéologique remarquable.

\section{Les marges méridionales du royaume}

Durant la même période, la mission de la Wellcome Foundation fouilla en 1914, sous la direction d'O. G. S. Crawford, le village d'Abou Geili ${ }^{23}$ situé sur le Nil Bleu à une latitude très légèrement supérieure à celle de Kosti, ainsi que, de 1909 à 1914, sous la direction de Fr. Addison, le cimetière du Gébel Moya ${ }^{24}$ situé dans les terres, entre Abou Geili et Kosti. Leur position très au sud par rapport au royaume de Méroé et la particularité du matériel mis au jour rendent ardue l'association de ces sites à la période et aux cultures kouchites.

de la section

française

de la direction des Antiquités du Soudan

\section{L'entre-deux-guerres}

\section{Les nécropoles royales et les grands centres urbains de Napata et Méroé}

Les missions d'envergure de l'université de Harvard et du musée des BeauxArts de Boston aux nécropoles royales d'el-Kourrou et Nouri, ainsi que dans les centres urbains de Napata (1916-1919) et Méroé (1922-1925), sont une étape majeure dans la connaissance historique et chronologique de l'époque koushite.

Les deux nécropoles d'el-Kourrou et Nouri, à proximité du Gébel Barkal, fouillées par l'expédition Harvard-Boston sous la direction de G.A.Reisner, ont révélé les tombes des souverains de la $\mathrm{xxv}^{\mathrm{e}}$ dynastie, de leurs prédécesseurs et de leurs successeurs napatéens, et leur abondant matériel associé ${ }^{25}$. Au Gébel Barkal, ce sont les temples et palais pharaoniques et kouchites de Napata qui sont fouillés ${ }^{26}$, ainsi que les deux groupes de pyramides situées à l'arrière nord-ouest du Gébel, pouvant être datés du Méroïtique ancien ${ }^{27}$. À Méroé, le travail consista en la fouille des trois nécropoles à pyramides, les cimetières nord, ouest et sud 


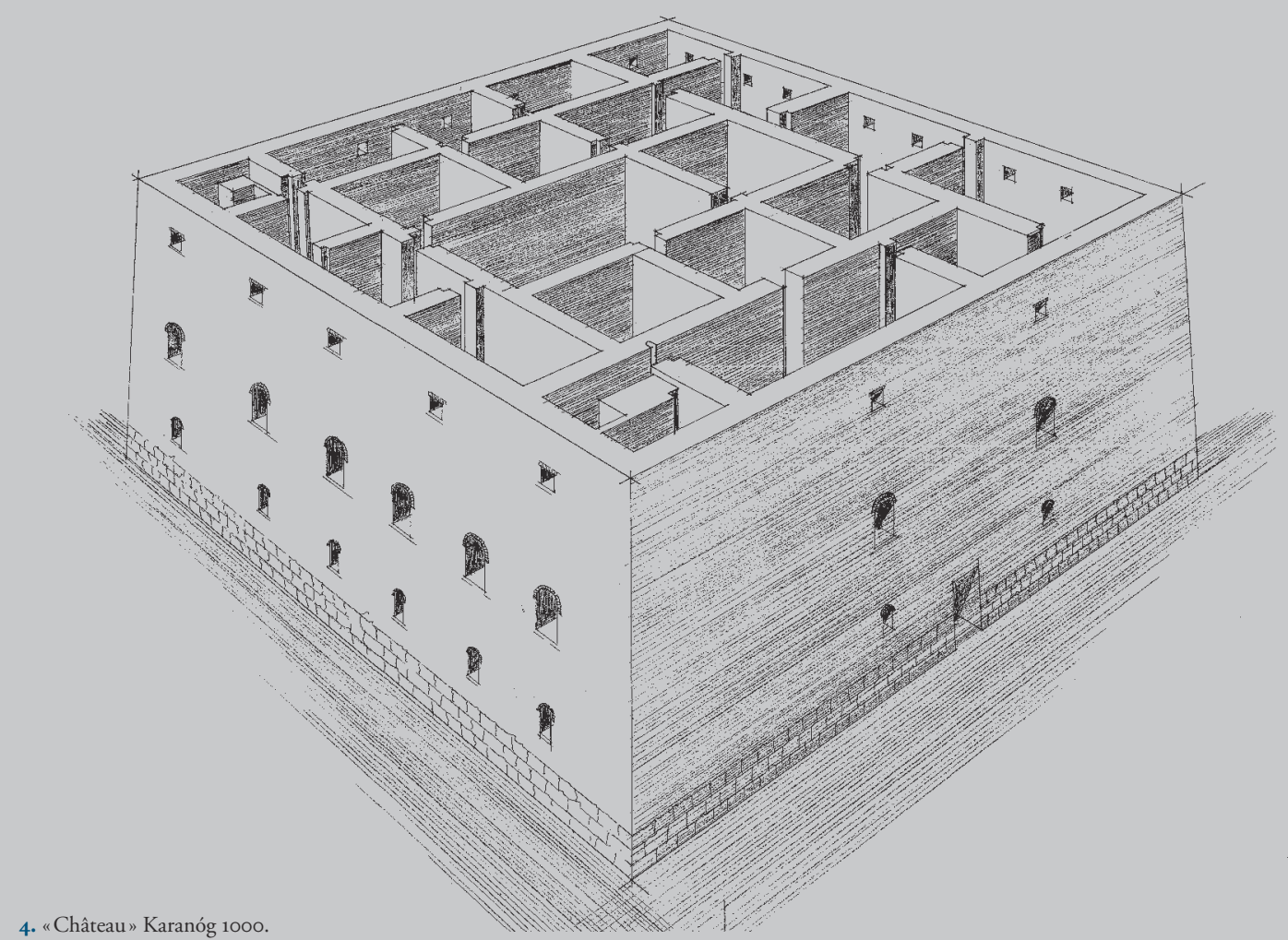

4. "Château» Karanóg 1000.

\section{9}

un siècle

de fouilles

archéologiques 
de Méroé ${ }^{28}$. L'ensemble de ces fouilles, fondées sur l'étude sérielle des tombes royales napato-méroïtiques et de leurs inscriptions, a permis à G. A. Reisner d'établir la première chronologie de la succession royale kouchite ${ }^{29}$.

\section{La Basse-Nubie}

En parallèle à ces missions, la couverture des sites méroïtiques du Boutana, dont Naga, Musawwarat es-Sofra, Basa ou le Gébel Geili et de leurs nombreux vestiges monumentaux a été assurée par J. W. Crowfoot, F. A. Addison, D. Dunham et G.O. Whitehead ${ }^{30}$. Ce travail a permis de confirmer l'importance de l' «île de Méroé» mentionnée par les auteurs anciens.

Suite à une extension du premier barrage d'Assouan, une nouvelle montée des eaux fut à l'origine de la mise en œuvre du Second Archaeological Survey of Nubia de 1929 à 1934, sous la direction de W. B. Emery ${ }^{31}$. La prospection, s'étendant au sud jusqu'à la frontière soudanaise, confirma la rareté des vestiges méroïtiques en Basse-Nubie. Les vestiges d'habitat au Wadi el-Arab comprennent plusieurs maisons et une presse à vin, dont l'ensemble peut être daté à partir du III $^{\mathrm{e}}$ siècle apr. J.-C. ${ }^{32}$

Enfin, durant la même période, la mission de l'université d'Oxford, sous la direction de M. F. L. Macadam, fouilla le centre urbain de Kawa, se concentrant sur l'architecture du temple et l'étude de ses inscriptions, mais mettant également au jour plusieurs habitations napatéennes et méroïtiques associées aux sanctuaires ${ }^{33}$.

de la section

française

de la direction des Antiquités du Soudan

\section{Les années 1950 à 1970}

\section{sauvetage en Nubie et retour à Méroé}

\section{Le Boutana occidental}

Durant les années 1950, deux prospections de faible ampleur ont été menées dans le Boutana par H.S. Smith et A. Adam ${ }^{34}$, ainsi que par H. G. BalfourPaul ${ }^{35}$. Le premier survey a révélé quatre sites probablement méroïtiques ou antérieurs, dont le Gébel Sirefāt, son hafir et son ensemble de bâtiments de maçonnerie similaire à celle de Musawwarat es-Sofra.

Dans le Kéraba, la partie nord-ouest de l'«île de Méroé», l'université Humboldt réalisa une prospection en 1957-1958, dirigée par Fr. Hintze ${ }^{36}$. Ce survey a consisté en un relevé des coordonnées des sites archéologiques, dont Naga, Moutmir, Basa ou Awalib, le ramassage du matériel de surface et le relevé d'inscriptions. Parallèlement, Musawwarat es-Sofra a fait l'objet d'opérations de fouille massives sous la direction de Fr. Hintze, tendant à distinguer les différentes composantes du Grand Enclos, afin de pouvoir établir une chronologie relative du site, à partir de sondages ${ }^{37}$. 
Dans la vallée, J. Vercoutter et Thabit Hassan Thabit, à la demande du service des Antiquités du Soudan, entreprirent de 1958 à 1960 des fouilles dans le centre urbain d'Ouad Ben Naga ${ }^{38}$. Celles-ci comprirent notamment la fouille partielle d'un palais daté du $\mathrm{I}^{\mathrm{er}}$ siècle av. J.-C., ainsi que le sondage ou la fouille partielle de deux petits temples, dont un dédié à Isis, et de plusieurs bâtiments administratifs ou religieux.

Les fouilles de la ville de Méroé sont reprises au milieu des années soixante par l'université de Calgary, sous la direction de P. L. Shinnie ${ }^{39}$. Le but de ces travaux d'envergure est alors d'effectuer des fouilles stratigraphiques destinées à réaliser une séquence chronologique complète de la ville, dont les premières occupations dans la zone d'habitat nord peuvent être datées du $\mathrm{x}^{\mathrm{e}}$ siècle av. J.-C. Ces recherches englobent non seulement l'architecture religieuse monumentale (temple d'Amon et chapelles de la voie sacrée) mais aussi les occupations domestiques. Une étude sur la métallurgie du fer, la production céramique et les conditions écologiques du site permettent de compléter la connaissance des différentes phases culturelles du site.

\section{La Basse-Nubie et la campagne de l'Unesco}

De la construction du haut barrage d'Assouan a résulté, de 1959 à 1969, la "campagne de sauvegarde des monuments de Nubie» dirigée par l'Unesco. Outre le déplacement des grands temples de Nubie du côté égyptien (Abou Simbel et Philae) (fig.6), cette campagne a consisté en une vaste opération internationale de prospection systématique et de fouille s'étendant jusqu'à l'extrémité sud de la région du Batn el-Haggar, entre les seconde et troisième cataractes. Cette fouille a permis entre autres le repérage de mille sites archéologiques sur $160 \mathrm{~km}$ de la vallée du Nil. Bien que l'ensemble des résultats n'ait pas été publié, les nombreux rapports de fouilles, révélant de multiples sites méroïtiques, ont offert une meilleure compréhension de l'archéologie et de l'histoire culturelle de cette région ${ }^{40}$.

En Nubie égyptienne, les sites de Qasr Ibrim ${ }^{41}$, Tômas ${ }^{42}$, Gébel Adda $^{43}$ et Ash-Shaukan ${ }^{44}$ ont livré une riche documentation sur l'organisation de l'occupation méroïtique à l'extrême nord du royaume. Des vestiges de la même période ont également été mis au jour à Arminna-Ouest par l'université de Pennsylvanie ${ }^{45}$ et à Gézira Dabarosa par l'université du Colorado ${ }^{46}$. La mission du service des Antiquités du Soudan, quant à elle, a mis au jour des sites d'habitat à Faras ${ }^{47}$ et sur les îles de Meinarti ${ }^{48}$, de Gaminarti et de Meili ${ }^{49}$.

L'ensemble de ces travaux, plus détaillés que ceux réalisés en Nubie égyptienne, et la mise en eau de l'ensemble de cette région sous le Lac Nubia, ont mené les chercheurs à la rédaction de synthèses généralistes sur l'état 
des recherches après cette campagne de prospection, comme les ouvrages Egypt in Nubia de W. B. Emery, publié en 1965, et Nubia under the Pharaobs de Br. Trigger, publié en $1976^{50}$. Enfin, l'important Nubia, Corridor to Africa de W.Y.Adams, publié en 1977, fournit une synthèse des résultats de l'ensemble des campagnes de prospections de la Nubie, s'intéressant aux relations particulières entre la Basse-Nubie et l'Égypte mais faisant également le point sur les connaissances archéologiques du reste du Nil Moyen ${ }^{51}$.

Plus au sud, sur l'île d'Argo, Tabo a été fouillé par la mission de la fondation H.M. Blackmer et l'université de Genève, sous la direction de Ch. Maystre ${ }^{52}$, révélant un temple construit à la xxv dynastie, utilisé et remanié jusqu’à l'époque méroïtique.

\section{Les fouilles récentes}

\section{vers un renouveau des problématiques?}

cinquantenaire

\section{2}

de la section

française

de la direction

des Antiquités

du Soudan

Suite à la disparition de la région de la Basse-Nubie, la recherche archéologique s'est trouvée contrainte de se tourner vers les territoires méridionaux. L'intérêt pour les grands établissements urbains de l'«île de Méroé» a perduré, se reflétant notamment dans l'ouvrage The Kingdom of Kush de D. A. Welsby, publié en 1996, synthèse des grandes avancées sur la connaissance de l'archéologie et l'histoire de la période koushite, ou encore dans la synthèse de L.Török, The Kingdom of Kush: Handbook of the NapatanMeroitic Civilization, publié en $1997^{53}$.

\section{Continuité des prospections}

Durant les années 1990 se développe la conscience de la nécessité de continuer les prospections de terrain en prévision des destructions consécutives à la construction d'un réseau viaire ${ }^{54}$ ou de barrages hydrauliques ${ }^{55}$ d'une part, mais également du développement urbain d'autre part ${ }^{56}$. Et l'on débute avec la prospection d'aires géographiques encore méconnues comme le Nil Blanc ou les régions désertiques ${ }^{57}$. De telles enquêtes mettent en exergue le potentiel d'études plus ambitieuses orientées sur la relation entre les établissements humains et leur environnement.

Ainsi, lors de la prospection le long de la route reliant Begrawiya et Atbara, une vaste nécropole a été découverte à Gabati. Le tracé de la route ne pouvant être déplacé, le site a été fouillé en urgence durant l'hiver 1994-1995, révélant une occupation funéraire allant de la période méroïtique à l'époque médiévale ${ }^{58}$.

Entre 2001 et 2009, le Merowe Dam Archaeological Salvage Project - MDASP, prospection d'envergure internationale, a été monté afin de mettre au jour et étudier les vestiges menacés par la construction 
du barrage hydroélectrique de Merowe, implanté à une quarantaine de kilomètres en amont du Gébel Barkal. La prospection de la zone inondable a été répartie entre de nombreuses missions archéologiques et a permis de mettre en évidence le rôle important de la région dans l'administration koushite de la quatrième cataracte ${ }^{59}$. Les sites majeurs comprennent des nécropoles méroïtiques au riche matériel funéraire ${ }^{60}$, ainsi que l'île d'Oumm Mouri, un vaste domaine habitable à vocation agricole constitué d'une succession de huttes et de maisons de briques crues ou cuites ou en pierre, datables du méroïtique tardif à la période médiévale ${ }^{61}$.

\section{Fouilles programmées}

Aujourd'hui, d'importants vestiges méroïtiques sont en cours de fouilles sur une dizaine de sites d'occupation méroïtique allant de la région de la Moyenne-Nubie au Nil Blanc. Entre les troisième et quatrième cataractes, l'important site urbain de Doukki Gel, d'une étendue de 8 ha, comprenant un temple et des palais, est fouillé sous la direction de Ch. Bonnet (université de Genève) ${ }^{62}$, tandis que la ville de Kawa est fouillée depuis 1997 sous la direction de D. Welsby (Sudan Archaeological Research Society) ${ }^{63}$. Enfin, au Gébel Barkal, deux missions se partagent les fouilles des nombreux monuments royaux et administratifs: la mission d'E. Ciampini (université de Rome) s'intéresse majoritairement au palais B 1500 ainsi qu’à deux autres bâtiments, в 2200 et в $2400^{64}$, et la mission de T. Kendall et el-Hassan Ahmed Mohamed (musée de Boston) étudie pour sa part les nombreux temples du site ${ }^{65}$.

Les sites du Soudan central situés le long de la vallée du Nil sont nombreux à faire l'objet d'un programme de fouille. Près d'Atbara, la NCAM a créé en 2000 le Berber-Abidya Archaeological Project, en collaboration avec le British Museum, qui comprend à ce jour deux chantiers de fouille. Ainsi, à Dangeil, grand centre urbain koushite, le temple d'Amon, construit à l'époque napatéenne et en activité jusqu'à la fin de l'époque méroïtique, est fouillé depuis 2000 sous la codirection de Salah Mohamed Ahmed et J. Anderson (Ncam et British Museum) ${ }^{66}$.

La ville royale de Méroé fait l'objet de deux programmes de fouille, le premier depuis 1999, sous la direction de Kr.Grzymski et Ali Osman Mohamed Saleh (Ontario Royal Museum et université de Khartoum). La politique de fouille est généraliste (prospections pédestres et magnétométriques) et s'intéresse principalement aux structures administratives et à la restauration du grand temple d'Amon de la ville ${ }^{67}$, tandis que la mission dirigée par S. Wolf (German Archaeological Institute) se concentre depuis 1999 sur la fouille des «bains royaux» et de leur système hydraulique ${ }^{68}$. 


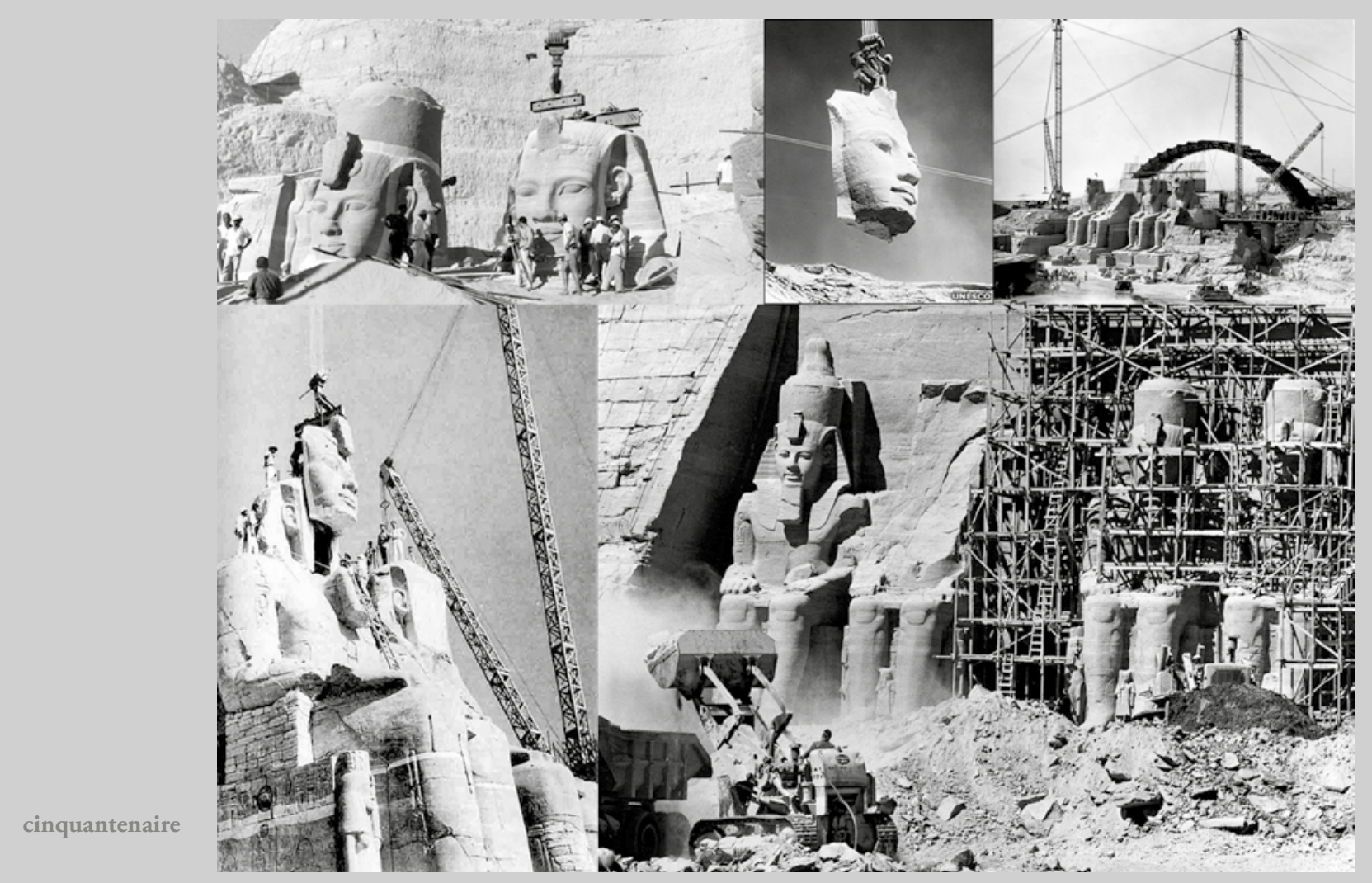

\section{4}

de la section

française

de la direction des Antiquités

du Soudan

6. Déplacement des temples de Nubie, campagne de l'Unesco.

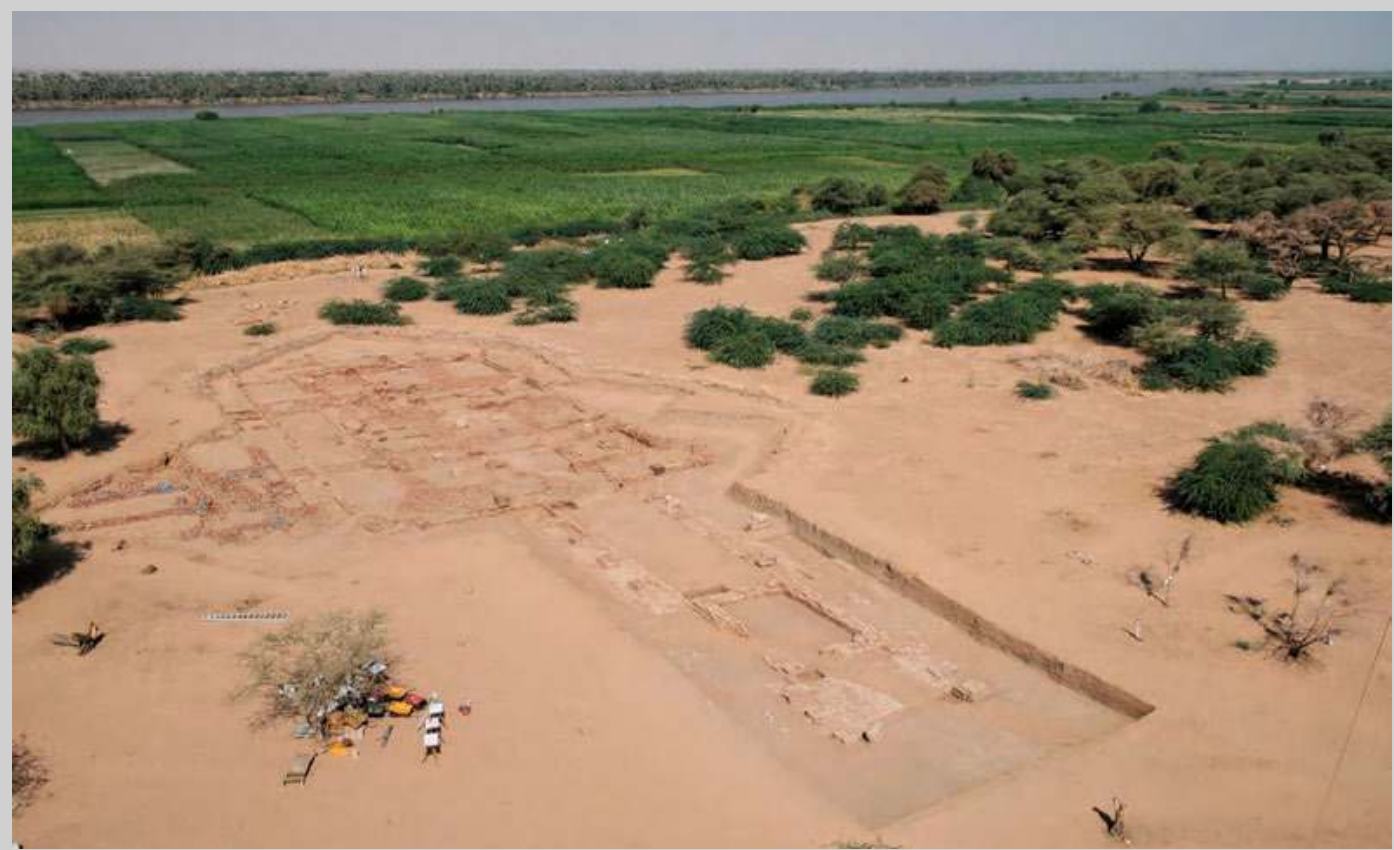

7. Vue aérienne du temple d'Amon d'el-Hassa. 
Le site urbain d'Hamadab est fouillé depuis 2001 sous la direction de P. Wolf (German Archaeological Institute, université de Shendi), dans un programme alliant magnétométrie et fouille de secteurs (habitats, fours céramiques, enceinte) ${ }^{69}$.

Le site d'Awalib, découvert lors du survey du tracé de la route Begrawyia-Shendi en 1995, est fouillé depuis 2001 sous la direction de H. Paner (musée de Gdańsk, Pologne). Il présente 5 kôms, dont un petit temple et des bâtiments administratifs ${ }^{70}$.

Le site d'el-Hassa (fig.7), prospecté en 2002 et étudié sous la direction de V. Rondot (Sfdas, France) depuis 2004, est une ville méroïtique dont seul le complexe du temple d'Amon a été fouillé de manière approfondie. Le site a également fait l'objet d'une exploration par magnétométrie et de prospections de surface ayant permis d'obtenir une vision d'ensemble de la trame urbaine de la ville ${ }^{71}$. Notons la présence proche du site de Damboya, prospecté mais non fouillé, qui comprend un palais royal et probablement un autre bâtiment de nature indéfinie.

Enfin, le site de Mouweis, fouillé sous la direction de M. Baud puis de M. Millet (musée du Louvre) depuis 2007, adopte une méthodologie plurielle, alliant magnétométrie et prospections pédestres, carottages et sondages, ainsi que la fouille poussée de certains monuments ou de secteurs artisanaux ${ }^{72}$.

Dans le Boutana, les sites majeurs de Musawwarat es-Sofra et Naga continuent à faire l'objet d'études poussées, sous les directions respectives de Cl. Näser (université de Humboldt) depuis 2005 ${ }^{73}$, de D. Wildung (directeur administratif, Musée égyptien de Berlin) et K. Kröper (directeur du chantier de fouilles) depuis $1995^{74}$, consacrées sur le premier site à l'étude des premières phases de construction et d'occupations (napatéennes et méroïtiques anciennes) et à l'étude des temples sur le second site.

Il semble au regard des fouilles actuelles que, tandis que certaines missions s'attachent à fouiller des nécropoles élitaires méroïtiques au fort potentiel pour la compréhension historique et matérielle de l'Empire de Méroé (Saï, Sedeinga ou Berber ${ }^{75}$ ), la majorité des programmes de recherche en cours se concentre autour de la question de l'urbanisme méroïtique.

Plusieurs problématiques peuvent découler de l'étude de sites dits «urbains». Certaines missions tentent de comprendre l'organisation générale et le fonctionnement d'un établissement urbain à l'époque méroïtique (Mouweis, Awalib, Hamadab, Kawa et Doukki Gel). Leur méthodologie est multiple, alliant prospections pédestres et magnétométrie afin d'obtenir un plan général de la sectorisation des sites, carottages et petits sondages servant à évaluer la durée d'occupation des sites, et fouille 


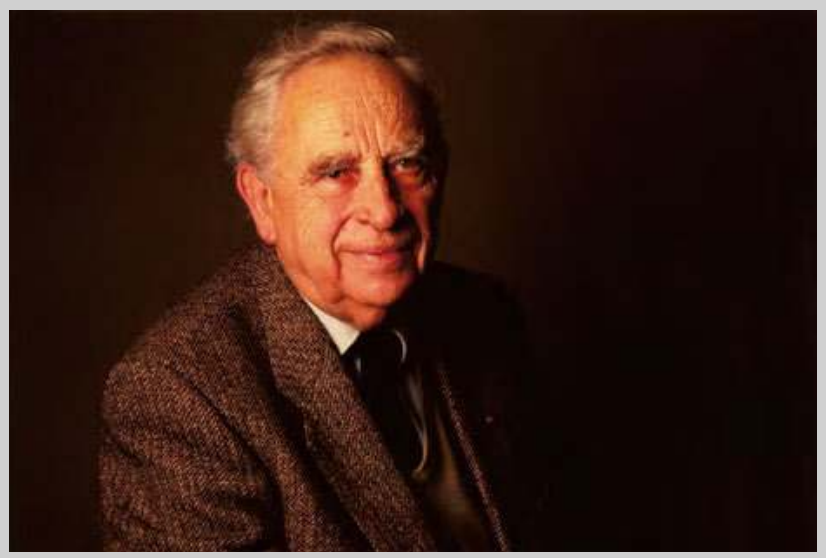

8. Jean Vercoutter.

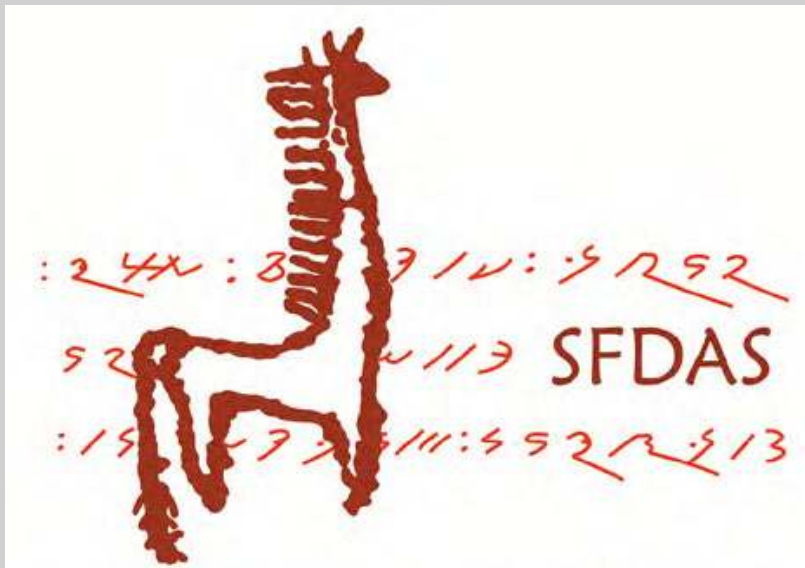

Section française de la direction des antiquités du Soudan

9. Section française de la direction des Antiquités du Soudan (Sfdas).

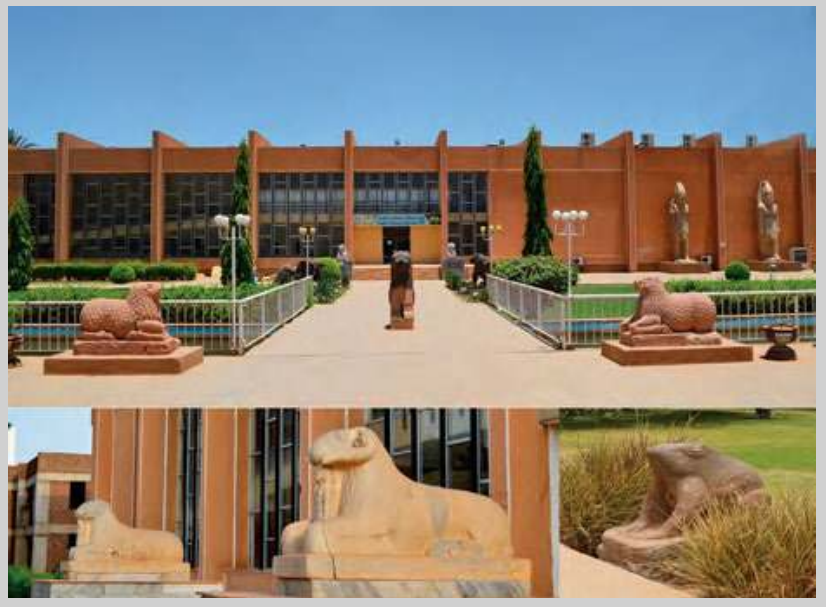

10. Musée national du Soudan, entrée principale. 
plus précise des secteurs ou de bâtiments choisis afin de réaliser des études de cas: palais (Mouweis) et bâtiments administratifs (Awalib, Doukki Gel), petits temples (Mouweis), aires d'habitat-artisanat ou encore zones d'artisanats du feu avec fours (Kawa, Hamadab, Mouweis).

D'autres missions concentrent leurs recherches autour d'un monument, en étudiant à la fois ses caractéristiques architecturales, son évolution chronologique et ses caractéristiques fonctionnelles. Les questions liées à la royauté, à la religion et à l'administration méroïtique sont au premier plan. Il en va ainsi en majorité de la fouille de temples d'Amon (Naga, el-Hassa et Dangeil). D'autres missions s'intéressent notamment à l'étude des palais (Gébel Barkal) ou encore de structures associées à la royauté (les «bains royaux» de Méroé, ou les complexes в 2200 et в 2400 de Napata).

Ce rapide résumé présente ainsi un changement important dans les problématiques de fouilles, longtemps concentrées dans la partie septentrionale de l'Empire et plus particulièrement dans le domaine funéraire. Depuis les années 1970, et notamment depuis 1990 avec les fouilles entreprises dans l'île de Méroé, la découverte progressive d'un réseau urbain au maillage dense et complexe nous permet d'entreprendre une étude synthétique centrée sur les composants urbains majeurs.

\section{La Sfdas et I'archéologie française au Soudan}

Après Lepsius et Ferlini, pendant la Turkiyya, période de l'occupation turcoégyptienne, l'administration coloniale est soutenue par les Occidentaux. Les taxes écrasantes et l'occidentalisation croissante des Turcs entraînent une réaction soudanaise, une révolte contre le pouvoir et l'établissement, pendant une douzaine d'années, d'un pouvoir islamique établi à Omdurman: la Mahdiyya. Le Mahdi meurt en 1885 et son bras droit Abdullahi le remplace. Durant toute cette période, l'archéologie subit un coup d'arrêt.

Placées sous la direction du général Kitchener entre 1896 et 1898 , les troupes anglaises parachèvent leur conquête du Soudan lors de la bataille d'Omdourman. Kitchener instaure un nouveau pouvoir colonial, le «condominium anglo-égyptien». Les archéologues reviennent: ils sont essentiellement britanniques, puis allemands. Les Français, absorbés par l'Égypte à la suite des découvertes de Champollion et en lutte avec les Anglais pour la constitution d'un Empire colonial, attendront plus longtemps. Entre 1898 et 1956, l'administration britannique est la première à développer la gestion du patrimoine archéologique soudanais. En 1939, un poste spécifique est créé, celui de Commissioner for Archaeology, assuré en premier lieu par A. J. Arkell ${ }^{76}$. Les Britanniques mettent également en œuvre, en 1905, la première législation sur les antiquités, à la base de la loi actuelle. 
cinquantenaire

\section{8}

de la section

française

de la direction

des Antiquités

du Soudan
Peu après la proclamation de l'indépendance, le 19 décembre 1955, les autorités soudanaises confient à un Français, Jean Vercoutter (fig. 8), la direction de la gestion des antiquités. C'est lui qui assurera la transition menant à la création d'un service soudanais spécialisé. Homme d'expérience au Soudan, il fouille dès 1953 la ville fortifiée du Moyen Empire à Kor, en Basse Nubie, et lance en 1954 les premiers travaux sur l'île de Saï. J. Vercoutter est également très impliqué dans le sauvetage des antiquités menacées par le barrage d'Assouan ${ }^{77}$. Il supervise plusieurs missions de prospection des zones en danger, la couverture photographique associée, et fait appel à la communauté internationale pour intégrer le Soudan à la grande campagne Unesco. Nommé professeur à l'université Charles-de-Gaulle-Lille 3 en 1961, il engage l'institution dans la campagne de sauvetage des monuments de la Nubie. À l'époque, cette implication fera de l'université le centre névralgique de la recherche française en archéologie soudanaise ${ }^{78}$, via l'association d'une unité Cnrs à l'institution et le lancement de deux fouilles archéologiques sur les sites d'Akcha et de Mirgissa ${ }^{79}$. En 1969, la fin de la campagne de Nubie permet à J. Vercoutter de concentrer ses travaux à Saï, mission qu'il dirigera jusqu'en 1981.

Dans le même temps, la section française de la direction des Antiquités du Soudan (Sfdas) ${ }^{80}$ est fondée en 1967, toujours à l'initiative de Vercoutter (fig. 9). Régie par "l'Accord de coopération culturelle et technique entre le gouvernement de la République démocratique du Soudan et le gouvernement de la République française», signé à Khartoum le 22 décembre 1969, elle assure la coopération avec la direction des Antiquités du Soudan, tant dans le domaine des fouilles que dans celui de leur publication. La muséographie, la conservation du patrimoine et l'élaboration de rapports d'activité font également partie de ses missions.

La Sfdas est intégrée au service des Antiquités du Soudan (National Corporation for Antiquities and Museums, NCAM) au sein du musée national du Soudan (fig. 10). Cette position privilégiée lui permet d'apporter un soutien aux missions françaises travaillant au Soudan et de développer des partenariats scientifique et muséologique. La Sfdas étant l'unique institut archéologique permanent au Soudan, elle occupe une position de fer de lance de la recherche scientifique française dans le pays. Au partenariat naturel avec la NCAM s'ajoutent des coopérations variées avec les établissements scientifiques français et les universités tant soudanaises qu'européennes. Avec l'appui de l'ambassade de France à Khartoum, elle permet à la diplomatie française d'entretenir durablement ses relations avec le Soudan.

La Sfdas a été dirigée successivement par André Vila (1969-1975), Francis Geus (1975-1984), Jacques Reinold (1984-2000), Francis Geus (2000-2004), Vincent Rondot (2005-2009), Claude Rilly (2009-2014), 
Vincent Francigny (2014-2019) et, depuis 2019, par Marc Maillot. Chargée de coopérer avec la direction des Antiquités du Soudan dans ses activités de terrain (fouilles et prospections), elle a d'abord participé aux dernières opérations de sauvetage de la Campagne de Nubie qui précéda la mise en eau du lac de retenue du haut barrage d'Assouan. Elle fut ensuite chargée de poursuivre le recensement systématique des sites de la vallée du Nil au sud de ce lac. Elle a par ailleurs effectué plusieurs fouilles programmées, notamment sur les sites de Missiminia (nécropole napatéenne, méroïtique, «groupe $\mathrm{x}$ » et chrétienne), el-Kadada (nécropole néolithique, méroïtique et post-méroïtique), Kadrouka (tertre funéraire néolithique) et el-Hobagi (tumuli post-méroïtiques).

\section{Prospections}

Pendant quatre ans, la Sfdas a participé, aux côtés de la Ncam, à un programme de prospections archéologiques et de fouilles de sauvetage lié à la construction d'un autre barrage dans la région de la quatrième cataracte du Nil.

Ce programme a débuté en novembre 2001 et s'est achevé en 2005. La Sfdas a été chargée par la Ncam de mener quatre interventions dans les zones de repeuplement choisies pour l'installation des populations Chaggyia et Manassir qui habitent actuellement la quatrième cataracte. Ces régions se situent près de Debba, de Korti, d'Atbara et d'Abou Hamed. La première phase du programme, qui s'est terminée en décembre 2002, a concerné la région d'el-Multaga, à l'est de Debba. La prospection a permis l'identification de cent quarante-sept localités présentant un intérêt archéologique. Son apport concerne essentiellement la préhistoire, plus précisément des sites de débitage du Paléolithique moyen, des sites d'habitats contemporains du «Mésolithique» et du Néolithique de Khartoum, et des tertres funéraires datés de la seconde moitié du cinquième millénaire avant notre ère (fig. 11).

Une seconde campagne de sauvetage s'est déroulée sur la rive droite du Wadi Muqaddam, de novembre 2003 à avril 2004. Cent quatrevingt-neuf sites ont été recensés. Le matériel le plus ancien recueilli à la surface témoigne d'occupations à la période acheuléenne et aux toutes premières phases du Paléolithique moyen. Comme ceux de Multaga, les sites néolithiques sont des habitats du «Mésolithique» de Khartoum et du Néolithique de Khartoum. La fouille de quatre cimetières post-méroïtiques de faible extension souligne l'installation de petites communautés en bordure des oueds et dans l'arrière-pays. Les sites chrétiens, les plus nombreux, sont en majorité des tombes isolées, parfois organisées en groupes de quelques unités. 
cinquantenaire

\section{0}

de la section

française

de la direction

des Antiquités

du Soudan
La troisième région, au sud d'ed-Damer, a été prospectée d'octobre à décembre 2004. Sur une zone de $240 \mathrm{~km}^{2}$ (sud d'ed-Damer, site de Mukabrab), trente-cinq sites ont été inventoriés, la plupart sur d'anciennes terrasses du Nil situées à quelques kilomètres à l'est du cours actuel du fleuve. Le site le plus ancien est un habitat néolithique contemporain du «Mésolithique de Khartoum» et du "Néolithique de Khartoum». La découverte sur le site de tessons comparables à la céramique du Kerma ancien est une première dans cette région du Nil Moyen. Un petit cimetière de tombes méroïtiques et post-méroïtiques sans matériel a fait l'objet d'une fouille de sauvetage, et quelques tombes tumulaires isolées d'époque chrétienne ont été étudiées.

La dernière opération, intitulée Kehaila East Archaeological Salvage Project, s'est déroulée en juin 2005 et a concerné la zone de Keheila entre Abou Hamed en aval et le village de Meheisa en amont. Cette zone désertique se caractérise principalement par des plaines à gravier traversées de petits ouadis, dont le plus important est le ouadi el-Go'oud. Les sites identifiés sont majoritairement néolithiques. Il faut également mentionner des sites «Kerma», "post-méroïtiques» et chrétiens.

\section{Fouilles archéologiques}

El-Hobagi ${ }^{81}$. Le site d'el-Hobagi, situé en rive gauche du Nil à $70 \mathrm{~km}$ en amont de Méroé, a été fouillé de 1985 à 1990 par une mission francosoudanaise (Sfdas-NCAM) menée par Patrice Lenoble. Rien ne permettait de distinguer ces tumuli princiers d'époque post-méroïtique des centaines d'autres de la région. Sept sépultures ont été identifiées et deux fouillées. Un abondant matériel a été mis au jour (fig. 12), similaire à celui découvert dans les pyramides les plus tardives de Méroé: vaisselle funéraire, armement, insignes de la royauté méroïtique (arcs, flèches, lances, anneaux d'archer, épées) et une abondante vaisselle en bronze gravée comportant nombre d'éléments iconographiques méroïtique: uraë̈, grenouilles, fleurs de lotus..

L'examen de ces sépultures comparées à l'iconographie des tombes (chapelles des pyramides) ou d'autres monuments royaux méroïtiques (temples, palais) nous donne d'importantes informations sur la caractérisation des rites royaux. Ainsi, l'abondance des armes retrouvées dans ces deux sépultures est à mettre en parallèle avec les scènes de l'iconographie royale méroïtique: massacres des prisonniers, scène de la soumission des Neuf Arcs (les pays soumis au pouvoir royal). La découverte du site d'el-Hobagi est capitale car elle démontre que cette région n'avait pas sombré, comme on l'avait longtemps présumé, après une hypothétique chute de Méroé. Une culture riche, imprégnée d'influences méroïtiques, a perduré pendant plusieurs siècles. 


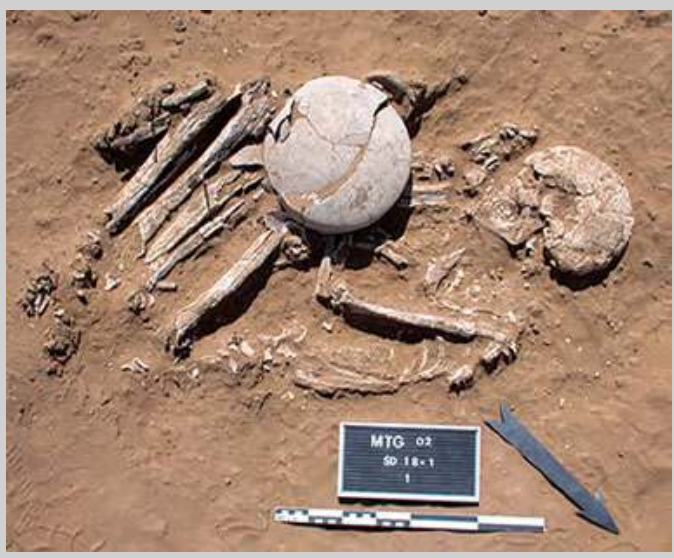

11. Sépulture d'el-Multaga.

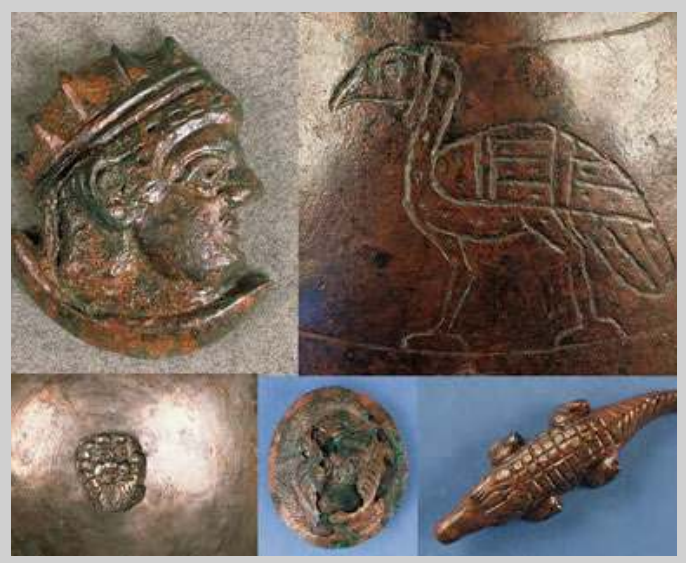

12. Collection royale d'el-Hobagi.
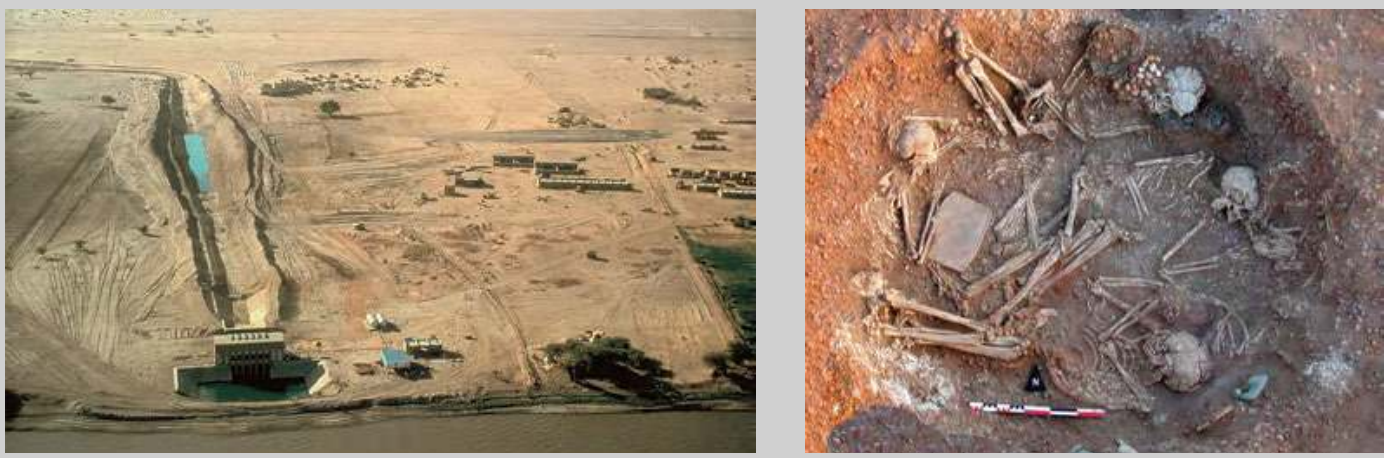

13. Site d'el-Kadada.

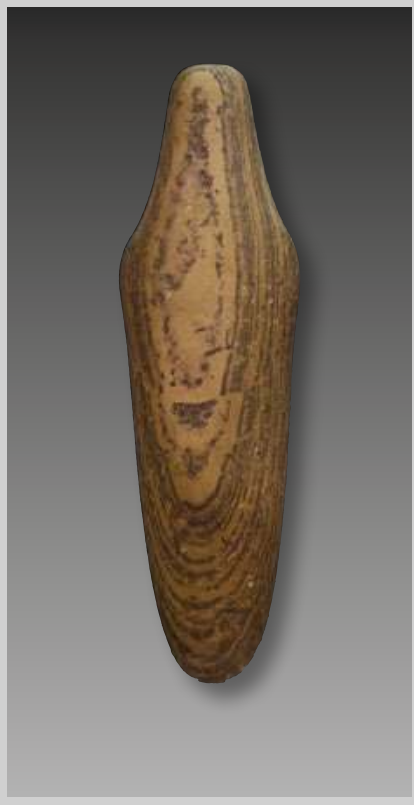

14. Sépulture néolithique d'el-Kadada KDD 86-141-144a.

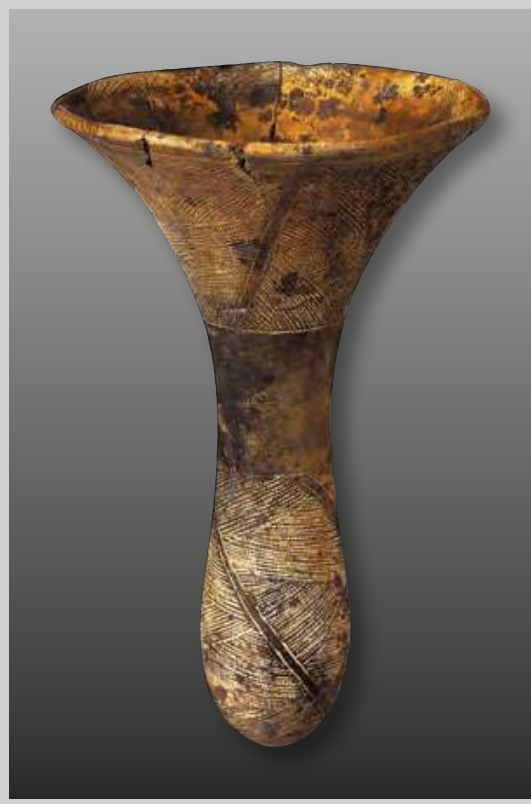

171

un siècle de fouilles archéologiques

15. Figurines féminines $S_{N M} 26861$ (KDK 1/131/8) et 28731 (KDK 21/200/1) et vase caliciforme SNM 26883 (KDK 1/12/1) de Kadrouka. 
de la section

française

de la direction

des Antiquités

du Soudan
El-Kadada ${ }^{82}$. Découvert en 1976, el-Kadada est l'un des rares sites néolithiques connus dans la région de Shendi (fig.13). Les plus anciennes traces d'occupation sont des tessons de vase céramique dont le décor indique un peuplement au "Mésolithique de Khartoum", bien qu'aucun site de cette période n'ait été découvert. La période de transition suivante est attestée par des tessons identifiés sur un petit habitat, au lieu-dit elKudra, situé à moins de $200 \mathrm{~m}$. En revanche, aucune trace d'occupation à l'époque du «Néolithique de Khartoum", daté du cinquième millénaire avant notre ère, n’a été recensée. Il semble que les installations préhistoriques de cette période se soient déplacées vers le site d'el-Ghaba, $700 \mathrm{~m}$ plus au sud.

Le décor du matériel céramique trouvé dans les tombes d'elGhaba est comparable à celui des vases d'esh-Shaheinab, site éponyme du Néolithique de Khartoum. La découverte des tombes néolithiques d'el-Kadada est venue confirmer la suggestion de l'archéologue anglais A. J.Arkell, l'inventeur du Mésolithique et du Néolithique de Khartoum, d'un épisode préhistorique tardif. Les populations néolithiques d'el-Kadada ont développé à partir du quatrième millénaire une culture complexe qui se traduit dans le raffinement des décors céramiques et la nouveauté des formes, la finesse de l'outillage lithique et la grande richesse des dépôts funéraires.

El-Kadada recèle également un grand nombre de cimetières historiques, depuis la période napatéenne jusqu'au post-méroïtique, du huitième siècle avant notre ère jusqu'au sixième siècle après. Le matériel funéraire et le rituel des tombes pré-chrétiennes révèlent que la religion funéraire méroïtique ne s'achève pas avec la «fin de Méroé» mais avec le début de la christianisation, au $\mathrm{VI}^{\mathrm{e}}$ siècle de notre ère.

Kadrouka $^{83}$. Le ouadi el-Khowi, qui correspond à d'anciens bras du Nil, se situe en rive est du fleuve, au sud de la troisième cataracte. Il est occupé par une grande densité de sites funéraires et d'habitats, parmi lesquels ceux du Néolithique tiennent une place importante. L'érosion éolienne a considérablement arasé les sites d'habitat qui ne se signalent plus aujourd'hui que par des épandages de matériel en surface. Les cimetières, en revanche, installés sur des buttes, ont bien résisté, et leur fouille est aujourd'hui le moyen privilégié pour comprendre les sociétés habitant la région entre les $\mathrm{VI}^{\mathrm{e}}$ et $\mathrm{IV}^{\mathrm{e}}$ millénaires (fig. 14).

Les interventions de sauvetages menées par la Sfdas — la région est en effet depuis plusieurs années touchée par des programmes de développement agricole — ont identifié une cinquantaine de ces sites néolithiques, funéraires ou d'habitat. Sur la vingtaine de cimetières connus, six ont été 
fouillés exhaustivement ou partiellement par la Sfdas. À l'exception de deux tertres funéraires qui doivent dépasser le millier de tombes, les autres renferment un peu plus d'une centaine d'inhumations. Près de 700 sépultures, dont les dates sont incluses entre 4800 et 4000 avant notre ère, ont pu être enregistrées. Les constantes et les variantes observées dans les domaines de la culture matérielle et des coutumes funéraires paraissent traduire à la fois l'homogénéité de ces populations et une évolution rapide de leur tissu social. Ces cimetières témoignent d'une organisation où la hiérarchisation se fait de plus en plus forte. Au cours du Néolithique, des chefferies se mettent en place avec l'émergence d'un personnage dominant. Ces sociétés vont constituer les bases des premiers états protohistoriques, préludant ainsi à l'apparition des premiers royaumes.

Autres fouilles françaises. Parmi les autres fouilles françaises en activité au Soudan, citons celle de Sedeinga ${ }^{84}$ située entre la seconde et la troisième cataracte, sur la rive gauche du Nil. Le site se trouve à une trentaine de kilomètres au sud de l'île de Saï. Il a d'abord été connu pour les vestiges du temple de la reine Tiyi, la grande épouse d'Amenhotep III. Cette ruine, avec son unique colonne encore debout, est trop fragile pour que des fouilles puissent y être effectuées sans une restauration des blocs de grès pulvérulents qui la composent. Entre le temple et le désert s'étend, sur près de 40 ha, une immense nécropole napatéenne et méroïtique, la plus vaste actuellement connue et préservée en Nubie.

À quelques kilomètres au sud de la cataracte de Dal et du lac de Nubie qui recouvre désormais la Basse Nubie, l'île de Saï ${ }^{85}$ est un véritable conservatoire archéologique naturellement protégé du développement humain gagnant les berges de la vallée nubienne. Comptant parmi les plus grandes îles jalonnant le Nil, elle héberge des vestiges qui s'étendent du paléolithique jusqu'aux époques modernes, et fait l'objet de campagnes de fouilles régulières. Enjeu territorial majeur entre les royaumes nubiens et l'Empire égyptien, elle a notamment conservé les traces d'une ville pharaonique enfouie pour un tiers sous les murs d'une forteresse d'époque ottomane. Recouverte dans sa partie nord par d'immenses champs tumulaires post-méroïtiques, l'île possède également des nécropoles appartenant au Nouvel Empire ainsi qu’aux époques «Kerma», napatéenne, méroïtique et chrétienne.

Grâce aux activités menées sur l'ensemble des sites mentionnés, et aux recherches conduites par l'archéologie française et internationale pendant près de soixante ans, le patrimoine soudanais a pu obtenir la reconnaissance internationale qu'il mérite. La variété des approches listées, combinée aux collaborations internationales toujours plus nombreuses, 
permet de valoriser et d'enrichir cette discipline, certes encore jeune, qu'est la nubiologie. À un moment où l'archéologie de terrain tient une part très importante, et où la formation des chercheurs spécialisés dans le domaine est prolifique, le rôle de la Sfdas dépasse aujourd'hui largement ses prérogatives initiales. Insistons ici sur le rôle fondamental qu' elle joue grâce à la formation des archéologues français et soudanais dans la protection et la valorisation du patrimoine soudanais.

Grâce aux deux expositions qui se sont tenues en 1997 à l'institut du Monde arabe ("Soudan, royaumes sur le Nil» ${ }^{86}$ ) puis en 2010 au musée du Louvre ( Méroé, un empire sur le $\mathrm{Nil} »{ }^{87}$ ), le grand public est aujourd'hui plus au fait de la réalité de la recherche scientifique au Soudan et fait montre d'un appétit grandissant pour ce pays et son histoire. Cependant, des territoires scientifiques entiers sont encore méconnus et demeurent à "conquérir»: la région du Kordofan, si importante pour comprendre les relations entretenues avec l'Afrique centrale, ou encore la zone située au sud de la ville de Khartoum sont de bons exemples. Pourtant, qu'il s'agisse de fouilles programmées ou de prospections, les résultats obtenus en un peu plus d'un demi-siècle sont considérables. La découverte à Doukki Gel, près de l'ancienne capitale Kerma, d'une cache contenant les statues brisées des souverains de Napata, ou encore, dans le domaine néolithique, la mise au jour d'une tombe à sacrifice humain (ou mort d'accompagnement) à el-Kadada sont, de ce point de vue, révélatrices (fig. 15)

de la section

française

de la direction

des Antiquités

du Soudan 
notes

1 Ahmed 2010, 29-34.

2 Welsby 1996.

3 Edwards 2004.

4 Mainterot 2010b, 22-27; 2011.

5 Shinnie 1967, 24-27; Török 1997, 7-20.

6 Mainterot 2010a, 19-21.

7 Burckhardt 1813, 275. Notons qu'il n'identifia pas le site à la ville de Méroé.

8 Chauvet 1989; Dewachter 1994.

9 Leclant 1967, 6-15; Chauvet 1989.

10 Caillaud 1826.

11 Shinnie 1958, 75, 138-150.

12 Ferlini 1837.

13 Freier et Reinecke 1984; Freier et Grunert 1996.

14 Lepsius 1849-1859.

15 Budge 1907.

16 Griffith 1911c et 1912; Crowfoot 1920, 85-92.

17 Scott-Moncrief 1908, 192-203.

18 Garstang 1911; Garstang 1914, 9-23; Garstang 1916, 1-27.

19 Reisner 1910; Firth 1912, 1915, 1927.

20 Woolley 1911.

21 Woolley et MacIver 1910.

22 Griffith 1924, 141-180; Griffith 1925, 57-172.

23 Crawford et Addison 1951.

24 Addison 1949; Addison 1956, 4-18.

25 Dunham 1950, 1955.

26 Dunham 1970.

27 Dunham 1957.

28 Dunham 1963.

29 Reisner 1923, 34-77.

30 Crowfoot 1920, 85-92; Addison 1926, 56-58; Addison et Dunham 1922, 39-46; Whitehead 1928, 59-67.

31 Emery et Kirwan 1935.

32 Emery et Kirwan 1935, 108.

33 Kirwan 1936, 200-211; Macadam 1949, 1955.
34 Smith et Adam 1950, 301-306.

35 Balfourpaul 1952, 202-215.

36 Hintze 1959, 171-196.

37 Hintze 1962, 170-202; Hintze 1963, 217-226; Hintze 1968, 667-684.

38 Vercoutter 1962, 263-299.

39 Shinnie 1970.17-19; Shinnie 1984, 498-504; Shinnie et Bradley 1980.

40 Smith 1962; Adams et Nordström, 1963, 10-46; Klasens 1967, 79-86.

41 Caminos 1968.

42 Leclant 1962, 197-222; Leclant 1963, 17-25.

43 Millet 1963, 147-165, pl.xlv-xlvii; Millet 1964, 7-14, pl. i-viii; Millet 1967, 123-126; Millet 1968.

44 Jacquet 1971, 121-131.

45 Trigger 1967.

46 Verwers 1962, 19-33; Hewes 1964, 174-187.

47 Verwers 1962, 19-33.

48 Adams 1965, 148-176.

49 Adams et Nordström 1963, 10-46.

50 Emery 1965; Trigger 1976.

51 Adams 1977.

52 Maystre 1973, 193-199; Jacquet-Gordon, Bonnet, Jacquet 1969; Jacquet-Gordon, Bonnet 1999.

53 Welsby 1996; Török 1997b.

54 Mallinson 1996

55 Paner 1997, 137-155.

56 Zurawski 2002, 73-85.

57 Eisa 1999; Welsby 2001a; Welsby 2003.

58 Edwards 1998.

59 Les différents instituts ayant participé au projet comprennent: l'université de Cologne et son projet Acacia (survey de l'île de Boni), le musée archéologique de Gdańsk et son projet Game (Gdańsk Archaeological Museum Expedition), la Polish Academy of Sciences, la Humboldt University of Berlin et son projet Hune (Humboldt University Nubian Expedition), l'IsiAo (Italian Institute for Africa and the Orient), l'Ucl Institute of Archaeology, la Sars (Sudan Archaeological Research
175

un siècle

de fouilles 
Society) et son projet Amri to Kirbekan

Survey 1999-2007 (nombreuses attestations d'occupations du Méroïtique tardif et Post-Méroïtique), la Hungarian Meroe Foundation, l'Ucsb (University of California at Santa Barbara) et l'Asu (Arizona State University) et leur projet commun (Ucsb-Asu Fourth Cataract

Archaeological Expedition) ayant pour nom The Ucsb West Bank Archaeological Survey from el Kab to Mograt, (aucun site méroïtique recensé) et l'Oriental Institute Museum of the University of Chicago et son projet The Oriental Institute Nubian Expédition (aucun site méroïtique recensé).

60 Pour une revue exhaustive de la bibliographie du survey, voir la page internet http ://www. nubiansociety.org/mdasp_articles.html.

61 Welsby 2003, 5-7; Payne 2007, p. 9-13; Ginns 2006, 18 et Thomas 2008, 64-66.

62 Bonnet et Ahmed 1999, 251-256; Bonnet et Valbelle 2004b, 109-112, Bonnet et Valbelle 2010, 43-50.

cinquantenaire

\section{6}

de la section

française

de la direction

des Antiquités

du Soudan
63 Welsby 2000, 5-10; Welsby 2001b, 64-70; Welsby 2002, 26-39; Welsby 2004b, 148-157; Welsby 2009, 72-77; Welsby 2010, 48-55.

64 Donadoni 1993, 101-115; Donadoni 1994, 54-59; Roccati 1997, 12-18; Roccati et Bergamini 1999, 633-642; Roccati 2003, 59-64; Roccati 2004b, 384-388; Roccati 2008, 249-261.

65 Kendall 1991, 302-313; Kendall 1994, 139-144; Kendall 1997a, 161-228; Kendall 1997b, 320-354; Kendall et Wolf 2007, 82-88; Kendall et Wolf 2011, 237-260.

66 Ahmed et Anderson 2000, 17-37, Ahmed et Anderson 2005, 10-27; Ahmed et Anderson 2006, 2-3; Ahmed et Anderson 2008, 40-46; Ahmed et Anderson 2010, 50-55.

67 Grzymski 2006, 227-238; Grzymski 2008, 47-51.

68 Wolf, Hof, Onasch 2003, 71-87 et 2008, 101-116; Wolf S., Wolf P., Onasch, Hof et Nowotnick 2008, 157-230 et 2009, 215-262.
69 Wolf P. 2002, 92-111; 2004c, 83-97; 2006, 257-264.

70 Paner 2005, 54-55; El-Tayeb et Kolosowska 2005, 145-158.

71 Lenoble et Rondot 2003, 101-115; Rondot 2005, 399-401; Rondot 2006, 41-47.

72 Lenoble et Sokari 2005, 59-61; Baud 2008, 52-53; Baud 2010d, 218-224; Baud 2011, 339-357.

73 Wolf 1997, 20-29; Wolf 1998, 10-12; Wenig et Wolf 1998-2000; Wolf 2001a et b; Wolf 2004a, 436-445; Wolf 2004d, 47-101; Näser 2011, 317-338.

74 Wildung 1998, 183-190; Wildung 1999; Wildung et Kroeper 2006 et 2011 ; Kroeper 2006, 287-296.

75 Ahmed et Anderson 2003, 25-34.

76 Gradel 2009, 387.

77 Vercoutter et Adam 1961.

78 Pour une rétrospective dédiée à l'action menée par l'université Charles-deGaulle-Lille 3 au Soudan, on consultera Gradel 2009, 383-400.

79 Gradel 2009, 389-390.

80 La Sfdas est l'un des 27 instituts français de recherches à l'étranger (IFRE), financés par le ministère des Affaires étrangères et du Développement international: www.sfdas.com; http://www.ambafrance-sd.org/ SCAC-service-de-cooperation-et-d-293).

81 Lenoble 1997, 289-308; Lenoble 1999, 157-197; Lenoble 2004, 193-195.

82 Reinold 1986, 159-169; Reinold 1994, 51-66; Reinold 2008; Lenoble 1987, 89-119.

83 Reinold, 1991, 16-29; Reinold 1998, 19-40; Reinold 2000.

84 Rilly et Francigny 2010, 62-68; Rilly et Francigny 2011, 72-79.

85 Francigny 2010a, 62-67; 2010b, 56-61; 2015, 201-212.

86 Wildung 1997.

87 Baud 2010a. 


\section{bibliographie}

Adams W.Y. 1965 — «Sudan Antiquities Service Excavations at Meinarti (1963-1964)», Kush 13, p.148-176. 1977 - Nubia: Corridor to Africa, Princeton.

Adams W.Y., Nordström H.A.

1963 - "The Archaeological Survey on the West Bank of the Nile: Third Season (1961-1962)», Kush 11, p. 10-46.

Addison F. 1926 - "Ancient Sites near Nagaa», $S_{N R}$ 9, p. 56-58. 1949 - Jebel Moya, The Wellcome Excavations in the Sudan, vol. 2, Oxford.

1956 - «Second thoughts on Jebel Moya», Kush 4, p. 4-18.

Addison F., Dunham D. 1922 - "Alem, a Meroitic Site», $S_{N R}$ 5, p.39-46.

Ahmed S. El-Din M.

2010 - «Un siècle d'archéologie méroïtique», dans Baud M. (dir.), Méroé, un empire sur le Nil, musée du Louvre éditions, Officina Libraria, Paris-Milan.

Ahmed S. El-Din M., Anderson J.

2000 - «Prospections archéologiques et fouilles de sauvetage dans le voisinage du site de Dangeil (1997-1999)», Cripel 21, p. $17-37$.

2005 — «Le temple d'Amon à Dangeil (Soudan)», BSFE 162, p. 10-27. 2006 - «Painted Plaster: A Glimpse into the Decorative Program Used in the Amun Temple at Dangeil, Sudan ", JSSEA 33 (Studies Millet II), 2006, p. 2-3.

2007 - "The "Throne Room" and Dais in the Amun Temple at Dangeil, Nile State Sudan», dans B. Gratien (éd.), Mélanges offerts à Francis Geus, Cahiers de recherche de l'institut de papyrologie et d'égyptologie de Lille 26, p. 31-32.

2008 - "The Kushite Kiosk of Dangeil and Other Recent Discoveries", SudNub 12, p. 40-46.

2010 - «Dangeil, à la découverte d'un nouveau temple d'Amon", dans Méroé, un empire sur le Nil aux confins de multiples cultures, Dossiers d'Archéologie hors-série $\mathrm{n}^{\circ}{ }^{18}$, p. 50-55.

Balfour-Paul H.G. 1952 - "Early Cultures on the Northern Blue Nile», $S_{N R} 33$, p. 202-215.

Baud M. 2008 — "The Meroitic Royal City of Muweis: first steps into an urban settlement of riverine Upper Nubia", SudNub 12, Londres, p. 52-63. 
cinquantenaire

\section{8}

de la section

française

de la direction

des Antiquités

du Soudan
2010 a - (dir.) Méroé, un empire sur le Nil, musée du Louvre éditions, Officina Libraria, Paris-Milan.

2010 b — «Les trois Méroé: la ville, la région, l'empire», in Méroé, un empire sur le Nil, musée du Louvre éditions, Officina Libraria, Paris-Milan, p. 52-64.

$2010 \mathrm{c}$ — «La force du modèle égyptien: l'exemple des reposoirs de barque sacrée ", dans Méroé, un empire sur le Nil, musée du Louvre éditions, Officina Libraria, Paris-Milan, p. 93-94. $2010 \mathrm{~d}$ - "Méroé, un monde urbain ", dans Méroé, un empire sur le Nil, musée du Louvre éditions, Officina Libraria, Paris-Milan, p. 211-224. 2011 - «Premières données sur le palais royal de Mouweis» dans V. Rondot, F. Alpi, F. and F. Villeneuve, (éds) Hommages Lenoble, Puf, Sfdas \& Ifpo, p. 339-357.

\section{Bonnet C., Ahmed S. El-Din M.}

1999 - «Excavations at Dokki Gel», dans D. A. Welsby (éd.) Recent research in Kushite History and Archaeology. Proceeding of the $8^{\text {th }}$ international conference for Meroitic studies, BMOP 131, Londres, p. 251-256.

Bonnet C., Valbelle D.

2004 b — «Kerma, Dokki Gel», dans D. Welsby and J. Anderson (éds), Sudan Ancient Treasures. Londres, 109-112.

2010 - "Les antécédents: les royaumes de Kerma et de Napata», dans Baud M. (dir.), Méroé, un empire sur le Nil, musée du Louvre éditions, Officina Libraria, Paris-Milan, p. 43-50.

Budge E. A. W. 1907 - The Egyptian Sudan: its History and Monuments, 2 vols, Londres.

Burckhardt J. L. $\mathbf{1 8 1 3}$ - Travels in Nubia, Londres.

Caminos R. A. 1968 - The Shrines and Rock Inscriptions of Ibrim, Londres.

Chauvet M. 1989 - Frédéric Cailliaud. Les aventures d'un naturaliste en Égypte et au Soudan (1818-1822), Paris.

Crawford O. G.S., Addison F. 1951 - Abu Geili and Saqadi \& Dar el Mek, The Wellcome Excavations in the Sudan, vol. 3, Oxford.

Crowfoot J. W.1920 - «Old Sites in the Butana», SNRec 3, p. 85-93.

Dewachter M. 1994 - «Les Voyageurs Français et la Nubie», dans B. Gratien, F. Le Saout (éds.) Nubie, Les cultures antiques $d u$ Soudan, Lille, p. 35-43.

Donadoni S. 1993 — «Excavation of University of Rome at Natakamani Palace (Jebel Barkal)», Kush 16, p.101-115. 
1994 - «Le palais de Natakamani au Gébel Barkal», La Nubie.

Dossiers d'Archéologie 196, p. 54-59.

Dunham D. 1950 - El Kurru, RCK 1, Boston.

1955 - Nuri, RCK 2, Boston.

1957 - Royal Tombs at Meroe and Barkal, RCK 4, Boston.

1963 - The West and South Cemeteries at Meroe, RCK 5, Boston.

Edwards D. N.1998 - Gabati. À Meroitic, post-Meroitic and Medieval Cemetery in Central Sudan, vol. 1, Londres.

2004 - The Nubian Past. An Archaeology of the Sudan, Londres.

Eisa K.A. 1999 - "The White Nile Archaeological Survey", dans D. A. Welsby (éd.) Recent research in Kushite History and Archaeology. Proceeding of the $8^{\text {th }}$ international conference for Meroitic studies, BMOP 131, Londres, p. 267-268.

El-Tayeb M., Kołosowska E.

2005 - «The Awlib Temple Complex: Kom B and its Pottery Assemblage", Gamar 3, p. 145-158.

Emery W. B. 1965 - Egypt and Nubia, Londres.

Emery W. B., Kirwan L. P.

1935 - The Excavations and Survey between Wadi Es-Sebua and Adindan, 1929-1931, 2 vols, Le Caire.

Ferlini G. $\quad 1837$ - Nell'interno dell'Africa, Bologne.

Firth C.M. 1912 - The Archaeological Survey of Nubia. Report for 1908-1909, 2 vols, Le Caire.

1915 - The Archaeological Survey of Nubia. Report for 1909-1910, Le Caire.

1927 - The Archaeological Survey of Nubia. Report for 1910-1911, Le Caire.

Francigny V. 2010a — "L'île de Saï méroïtique», Dossiers d'archéologie, Hors-Série 18, p. 62-67.

$2010 \mathrm{~b}$ - «The Meroitic Necropolises of Sai Island. Second Season at the Cemetery 8-B-5.A», Sudnub 14, p. 56-61.

2015 - "The Meroitic Temple at Sai Island » in The Kushite World, Proceedings of the $11^{\text {th }}$ International Conference for Meroitic Studies, Vienne, 201-212.

Freier E., Grunert S.

1996 - Reise durch Ägypten. Nach Zeichnungen der Lepsius Expedition 1842-1845, Berlin.

Freier E., Reinecke W. $\quad 1984$ - Karl Richard Lepsius (1810-1884). Akten der Tagung anlässlich seines 100. Todestages, 10.-12.7.1984, Berlin.

Garstang J. 1911 - Meroe. The City of the Ethiopians, Oxford. 
de la section

française

de la direction

des Antiquités

du Soudan
1914 - «Fourth Interim Report on the Excavations at Meroe dans Ethiopia", AaAliv 6, p.1-21.

1916 - J. Garstang, A. H. Sayce \& W. J. Phytian-Adams, "Fifth Interim Report on the Excavations at Meroe in Ethiopia», AaALiv 7, p. 1-24.

Ginns A. $\quad 2007$ - "Preliminary Report on the Second Season of Excavations Conducted on Mis Island (AKSC) ", SudNub 11, p. $20-25$.

Gradel C. 2009 - "L'université de Lille 3 au Soudan: une archéologie créatrice de patrimoine?» dans O. Aboukorah et J.-G. Leturcq (dirs.), Pratiques du patrimoine en Égypte et au Soudan, Égypte, Monde Arabe n ${ }^{\circ}$ /6, p.381-400.

Griffith F.LL. 1911 - Meroitic Inscriptions. Part. I, Sôba to Dangêl, AsEg 19, Londres. 1912 - Meroitic Inscriptions. Part. II, Napata to Philae and Miscellaneous, AsEg 20, Londres. 1924 - "Oxford Excavations in Nubia», AAALiv 11, p. 141-180. 1925 - "Oxford Excavations in Nubia», AAALiv 12, p. 57-172.

Grzymski K. 2006 — "Recent research at the palaces and temples of Meroe", in Between the Cataracts. Proceedings of the $11^{\text {th }}$ Conference for Nubian Studies, Warsaw University, 27 August-2 September 2006, PAM Supplement Series 2/1, Varsovie, p. 227-238. 2008 - «Excavations in Palace M 750 s at Meroe», SudNub 12, Londres, p. 47-51.

Hewes G. W. 1964 - "Gezira Dabarosa: Report of the University of Colorado Nubian Expedition (1962-63 Season) ", Kush 12, p. 174-187.

Hintze F. $\quad 1959$ - «Preliminary Report of the Butana Expédition 1958", Kush 7, p.170-196.

1962 - «Preliminary Report on the Excavations at Mousawwarat es Sofra 1960-1961", Kush 10, 170-202.

1963 - Die Inschriften des Löwentempels von Musawwarat es Sufra (Abhandlungen der Deutschen Akademie der Wissenschaften zu Berlin, Klasse für Sprachen, Literatur und Kunst 1), Berlin, Akademie Verlag.

1968 - «Musawwarat es-Sufra: Vorbericht über Ausgrabungen des Instituts für Ägyptologie der Humbold-Universität zu Berlin, 1963 bis 1966 (vierte bis sechste kampagne), WZHU 5, p. 667-684.

Jacquet J. $\quad 1971$ — «Remarques sur l'architecture domestique à l'époque méroïtique: documents recueillis sur les fouilles d'Ash-Shaukan ", В̈̈BA 12, p.121-131. 
Jacquet-Gordon H., Bonnet Ch.

1999 - "Excavations at Tabo, Northern Province, Sudan", dans D. A. Welsby (éd.) Recent research in Kushite History and Archaeology. Proceeding of the $8^{\text {th }}$ international conference for Meroitic studies, BMOP 131, Londres, p. 257-63.

Jacquet-Gordon H., Bonnet Ch., Jacquet J. 1969 - «Pnubs and the Temple of Tabo on Argo Island», JEA 55, p. 103-112.

Kendall T. 1991 - «The Napatan Palace at Gebel Barkal, a first look at в 100 ", dans W.V. Davies, éd., Egypt and Africa: Nubia from Prehistory to Islam, Londres, p. 302-313. 1994 - «A New Map of the Gebel Barkal Temples», Etnub II, p.139-144. 1997 a — «Les souverains de la montagne sacrée. Napata et la dynastie des Kouchites", Soudan. Royaumes sur le Nil, p.161-228.

1997 b — «Excavations at Gebel Barkal», Kush 17, p. 320-354.

Kendall T., Wolf P. 2007 - «Excavations in the Palace of Aspelta at Jebel Barkal, March 2007", SudNub 11, p. 82-88. 2011 - «B6oo: A Temple of Thutmose IV at Jebel Barkal» dans V. Rondot, F. Alpi, F. Villeneuve (éds), Hommages Lenoble, Puf, Sfdas \& Ifpo, p. 237-260.

Kirwan L.P. $\quad 1936$ - «Preliminary Report of the Oxford University Excavations at Kawa, 1935-1936", JEA 22, p. 199-212.

Klasens A. 1967 — «Dutch Archaeological Mission to Nubia.

The Excavations at Abu Simbel North 1962-1964", Campagne internationale de l'Unesco pour la sauvegarde des monuments de la Nubie. Fouilles en Nubie (1961-1963), Le Caire, p. 79-86.

Lacovara P. 2009 - "The Development of the New Kingdom Royal Palace» dans R. Gundlach R., J. H. Taylor (éds) Egyptian Royal Residence, $4^{\text {th }}$ Symposium on Egyptian Royal Ideology, Harrassowitz Verlag, Wiesbaden, p. 83-11o.

Leclant J. $\quad 1962$ - «Fouilles et Travaux en Égypte et au Soudan 1960-1961", Orientalia 31. 1963 - «Rapport préliminaire sur la mission de l'université de Strasbourg à Tomâs (1961)", Campagne internationale de l'Unesco pour la sauvegarde des monuments de la Nubie. Fouilles en Nubie (1959-1961), Le Caire, p. 17-25.

1967 — «Les Études méroïtiques: état des questions», BSFE 50, p. 6-15. 
Lenoble P. $\quad 1987$ — «Trois tombes de la région de Méroé: la clôture des fouilles historiques d'el-Kadada en 1985 et 1986 ", Archéologie du Nil moyen 2, p. 89-119.

1997 - «From pyramids at Meroë to tumulus at el Hobagi: Imperial graves of the Late Meroitic culture (Franco-Sudanese surveys and excavations between 1983 and 1990)", Kush 17, p. 289-308.

1999 - "The division of the Meroitic Empire and the end of the pyramid building in the $4^{\text {th }}$ C. A.D.:

an introduction to further excavations of imperial mounds in the Sudan", dans D. Welsby (éd.) Recent research in Kushite History and Archaeology. Proceedings of the $8^{\text {th }}$ International Conference for Meroitic Studies, British Museum Occasional Paper n ${ }^{\circ}$ 131, Londres, p.157-197.

2004 — «El-Hobagi», dans D. Welsby \& J. Anderson (éds), Sudan Ancient Treasures, An Exhibition of Recent Discoveries from the Sudan National Museum, The British Museum Press, Londres, p. 193-195.

de la section

française

de la direction des Antiquités du Soudan 2003 - «À la redécouverte d'El-Hassa. Temple à Amon, palais royal et ville de l'empire méroïtique», Cripel 23, Lille, p.101-115.

Lenoble P., Sokari A. 2005 - «A Forgotten Meroitic Agglomeration in the Region of Meroe (Ne-36-O/8-H-2)», SudNub 9, p. 59-61.

Lepsius C. R. 1849-1859 - Denkmäler aus Aegypten und Aethiopien, 5 vol. textes et 12 vol. planches, Berlin.

Macadam M. F. L. $\quad 1949$ - The Temples of Kawa. I. The Inscriptions, Oxford, Oxford University Press.

Mainterot P. 2010 a - «Les Éthiopiens et leur cité fabuleuse dans les récits classiques", dans Baud M. (dir.), Méroé, un empire sur le Nil, musée du Louvre éditions, Officina Libraria, ParisMilan, p.19-21.

$2010 \mathrm{~b}$ - «De l'exploration des sources du Nil au voyage à Méroé», dans Baud M. (dir.), Méroé, un empire sur le Nil, Musée du Louvre éditions, Officina Libraria, Paris-Milan, p. 22-27. 2011 - Aux origines de l'Égyptologie, Voyages et collections de Frédéric Cailliaud (1787-1869), Pur, Rennes.

Maystre C. 1973 - «Excavations at Tabo, Argo Island 1965-1968. Preliminary Report ", Kush 15, p. 193-199.

Millet N. B. 1963 - «Gébel Adda. Preliminary Report for 1963", Jarce 2, p. 147-165. 
1964 - "Gébel Adda Expedition Preliminary Report », Jarce 3,

p. 7-14.

1967 - "Gébel Adda. Progress Report of the Nubian Expedition

of the American Research Center in Egypt Inc. (1963)", Campagne

Internationale de l'Unesco pour la sauvegarde des monuments

de la Nubie. Fouilles en Nubie (1961-1963), Le Caire, p.123-126.

1968 - Meroitic Nubia. Thèse de doctorat non publiée,

Ann Arbor University Microfilms.

Paner H. 1997 - «Khartoum-Atbara Rescue Project, Shendi-

Begrawiya Section Field Project», Kush 17, p.137-155.

2005 - "The Awlib Temple Complex: Report on the 2001

and 2003 Excavation Seasons", Gamar 3, p. 54-55.

Payne J. $\quad 2007$ - «Excavation of the Late Kushite and Medieval settlement on Umm Muri», SudNub 9, p. 9-13.

Reinold J. $\quad 1986$ — «La nécropole néolithique d'el-Kadada au Soudan central, quelques cas de sacrifices humains", dans M. Krause (éd.), Nubische Studien, , Mayence, p. 159-169.

1991 — "Néolithique soudanais: les coutumes funéraires", dans W.V. Davies (éd.), Egypt and Africa. Nubia from Prehistory to Islam, Londres, p. 16-29.

1994 - «Les fouilles françaises et franco-soudanaises: el-Kadada», dans B. Gratien et F. Le Saout (éds), Nubie. Les cultures antiques du Soudan, Lille, p. 51-66.

1998 - «Le Néolithique de Haute Nubie. Traditions funéraires et structures sociales", BSFE $\mathrm{n}^{\circ}$ 143, Paris, p. 19-40.

2000 - Archéologie au Soudan. Les civilisations de la Nubie, éditions Errance, Paris.

2008 - La nécropole néolithique d'el-Kadada au Soudan central, Erc, Paris.

Reisner G.A. 1910 - The Archaeological Survey of Nubia. Report for 19071908, 2 vols., Le Caire.

1917 - "The Barkal Temples in 1916», JEA 4, p. 213-227.

1923 - "The Meroitic Kingdom of Ethiopia. Archaeological Outline», JEA 9, p. 34-77.

Rilly C., Francigny V.

2010 - «Excavations in Sedeinga. A New Start», SudNub 14, p. 62-68.

2011 — "The Late Meroitic Cemetery at Sedeinga.

Campaign 2010 ", SudNub 15, p. 72-79.

Roccati A. 1997 - «Excavating the Palace of Natakamani at Napata: the Entrances.»Kush 17, p.12-18. 
de la section

française

de la direction

des Antiquités

du Soudan
2003 - "Napata, the destroyed city. A method for plundering", dans M. Liverani (éd.), Arid Lands in Roman Times, Rome,

p. 59-64.

2004 - «Hellenism at Napata», dans T. Kendall (éd.) Nubian

Studies 1998, Boston, p.384-388.

2008 - "The Italian Archaeological Expédition to Jebel Barkal/

Napata", dans Between the Cataracts. Proceedings of the $11^{\text {th }}$

Conference for Nubian Studies, Warsaw University, 27 August-2

September 2006, PAM Supplement Series 2/1, Varsovie

p. 249-261.

Roccati A., Bergamini G.

1999 - «Scavi a Napata», dans St. Wenig (éd.), Studien

zum antiken Sudan, Meroitica 15, 633-642.

Rondot V. 2005 - «El-Hassa au cœur de l'empire mérö̈tique», dans L'Archéologie, la France et le monde. Vingt ans de recherches soutenues par le ministère des Affaires étrangères, ADpF/MaisonNeuve et Larose, p. 399-401.

2006 - «Le qore Amanakhareqerem et son temple à Amon d'el-Hassa", dans Kerma et Méroé, Cinq conférences d'archéologie soudanaise, Sfdas, Khartoum, p. 41-47.

\section{Scott-Moncrief P. D.}

1908 - "The ruined sites of Masawwarat es-Sufra and Naga", Proceedings of the Society of biblical Archaeology $x x x$, Londres.

Shinnie M. 1958 - Linant de Bellefonds. Journal d'un voyage à Méroé dans les années 1821 et 1822, Khartoum.

1967 - Meroe. A civilization of the Sudan, Londres.

1970 - «Excavations at Meroe», MNL 5, p. 17-19.

1984 - «Excavations at Meroe (1974-1976)», Meroitica 7,

p. 498-504.

Shinnie P. L., Bradley R.

1980 - The capital of Kush, I. Meroe excavations 1965-1972,

Meroitica 4, Berlin.

Smith H.S. 1962 - Preliminary Reports of the Egypt Exploration Society's Nubian Survey, Le Caire.

Smith H.S., Adam A. 1950 - "Four Ancient Sites in the Island of Meroe", $S_{N R}$ 31, p. 301-306.

Thomas R. $\quad 2008$ - "The Origin and Use of Ceramics on the Islands of Mis and Umm Muri, in the Late Meroitic to Christian Periods", SudNub 12, p. 64-73.

Török L. 1997 a - Meroe City, an Ancient African Capital. John Garstang's excavations in the Sudan, 2 vol., Londres. 
1997 b - The Kingdom of Kush: Handbook of the Napatan-Meroitic Civilization, La Haye.

Trigger B. G. 1967 - The Late Nubian Settlement at Arminna West., New Haven, Peabody Museum.

1976 - Nubia under the Pharaohs, New Haven.

Vercoutter J. 1962 — "Un palais des "candaces" contemporain d'Auguste. Fouilles à Wad ben Naqa (1958-1960)", Syria 39, p. 263-299.

Vercoutter J., Adams W.Y., 1961 - Why excavate in Sudanese Nubia, Sudan Antiquities Service.

Verwers G. J. 1962 - "The Survey from Faras to Gezira Dabarosa», Kush 10, p. 19-33.

Welsby D.A. 1996 - The Kingdom of Kush. The Napatan and Meroitic Empires, Londres. 2000 - "The Kawa Excavation Project», SudNub 4, p. 5-10. 2001 a - Life on the Desert Edge. Seven Thousand Years of Settlement in the Northern Dongola Reach, 2 vol., Londres. 2001 b - «Excavations within the Pharaonic and Kushite Site at Kawa and its Hinterland, 2000-2001", SudNub 5, p. 64-70. 2002 - "Kushite buildings at Kawa», BMSAES 1, 26-39. 2003 - Survey above the Fourth Nile Cataract, Londres. 2004 - «Kawa», dans D. A. Welsby et J. R. Anderson (éds.) Sudan Ancient Treasures, Londres, p. 148-157. 2009 - "Houses and Pyramids at Kawa, excavations 2008-9", SudNub 13, p. $72-77$. 2010 - «Excavations at Kawa, 2009-10», SudNub 14, p. 48-55.

Wenig S., Wolf P. $\quad 1998$ a — «Feldarbeiten des Seminars für SudanArchäologie und ägyptologie der Humboldt-Universität in Musawwarat es Sufra. Erste Hauptkampagne (1995-1996)", MittSag 8, p. 24-37.

$1998 \mathrm{~b}$ — «Feldarbeiten des Seminars für Sudan-Archäologie und ägyptologie der Humboldt-Universität in Musawwarat es Sufra. Zweite Hauptkampagne (1996)», MittSag 8, p.38-49. 1999 - «Feldarbeiten des Seminars für Sudan-Archäologie und ägyptologie der Humboldt-Universität in Musawwarat es Sufra. Dritte Hauptkampagne (1997)", MittSag 9, p. 24-43. 2000 — «Feldarbeiten des Seminars für Sudan-Archäologie und ägyptologie der Humboldt-Universität in Musawwarat es Sufra. Vierte Hauptkampagne (1998)", MittSag 10, p. 28-48.

Whitehead G.O. 1928 — «Nagaa and Musawwarat», $S_{N R} 9$, p. 59-67. 
Wildung D. 1997 - (dir.) Soudan. Royaumes sur le Nil, institut du Monde arabe, Paris.

1998 — «Naga Project (Sudan)_Egyptian Museum

Berlin Preliminary Report 1995-1996, Seasons 1 and 2", ANM 8, p. 183-19o.

1999 - Naga, die Stadt in der Steppe. Grabungen Des Ägyptischen Museums im Sudan, Berlin.

Wildung D., Kroeper K. 2006 - Naga. Royal City of Ancient Sudan, Berlin. 2011 - Königsstadt Naga: Grabungen in der Wüste des Sudan = Naga-Royal City: excavations in the desert of the Sudan, Sonderausstellung München, Staatliches Museum Ägyptischer Kunst, Berlin, Munich.

Wolf P. 1997 - "Recent Fieldwork at Musawwarat es-Sufra ", SudNub 1, p. 20-29.

1998 — «Bericht über die Konservatorischen Arbeiten in Musawwarat es Sufra. Zweite Hauptkampagne, 1.2.-1.4.1996", MittSag 8, p. 10-12.

$2001 \mathrm{a}$ - «Die Untersuchungen zur Baugeschichte

\section{6}

de la section

française

de la direction

des Antiquités

du Soudan an der Nordseite der Zentralterrasse", MittSag 11, p. 16-23. 2001 b — «Die Höhle des Löwen. Zur Deutung der Großen Anlage von Musawwarat es Sufra ", dans Arnst, C.-B., Hafemann, I. \& Lohwasser A. (éds.), Begegnungen, Antike Kulturen im Niltal, Festgabe für Erika Endesfelder, Karl-Heinz Priese, Walter Friedrich Reineke, Steffen Wenig, Leipzig, p. 473-508. 2002 - «Ausgrabungen in Hamadab bei Meroe», MittSag 13, p. 92-111. 2004a - «Steps Toward the Interpretation of the Great Enclosure of Musawwarat es-Sufra», dans T. Kendall (éd.) Nubian Studies 1998, Boston, p. 436-445.

2004 b - "The Sars Anglo-German Expédition at the Fourth Cataract of the Nile: the 2003/04 Season", SudNub 8, p. 17-26.

2004 c — «Hamadab—das Hauptquartier des Akinidad?", MittSag 15, Berlin, p. 83-97.

2004 d — "Fieldwork of the Humboldt University of Berlin at Musawwarat es Sufra 1993-2000", Meroitica 21, p. 47-101.

2006 - «Hamadab — Fouille d'un site urbain méroïtique, campagnes 2001-2003", ANM 10, p. 257-264. 
Wolf S., Hof C., Onasch H.-U.

2003 - «Investigations in the so-called Royal Baths at Meroë in 1999. A Preliminary Report ", Kush 18, p. 71-87.

2008 - «Investigations in the so-called Royal Baths at Meroë in 2000, 2004 and 2005", Kush 19, p. 101-116.

Wolf S., Wolf P., Onasch H.-U., Hof C., Nowotnick U. 2008 - «Meroë und Hamadab-Zwei Städte im Mittleren Niltal in den Jahrhunderten um die Zeitenwende. Bericht über die Arbeiten zwischen 1999 und 2007", Archäologischer Anzeiger 2008/2, Berlin, p. 157-230.

2009 - «Meroë und Hamadab-Stadtstrukturen und Lebensformen im afrikanischen Reich von Kusch. Die Arbeiten der Saison 2008 und 2009 ", Archäologischer Anzeiger 2009/2, Berlin, p. 215-262.

Woolley, C. L. 1911 - Karanog. The Town, Eckley B. Coxe Junior Expedition to Nubia, vol. 5, Philadelphie.

Woolley C. L., Randall-Maciver D.

1910 - Karanog. The Romano-Nubian Cemetery. Eckley B. Coxe Junior Expedition to Nubia, vol. 3 et 4, Philadelphie.

Zurawski B. 2002 - «Survey and Excavations Between Old Dongola and ez-Zuma», SudNub 6, p. 73-85. 



\section{Gereif Est \\ et le Méroïtique \\ méridional}

Romain David

Elsa Jadot

Manon Routhiau

Joanna Then-Obłuska 
La nécropole méroïtique et postméroïtique de Gereif Est fait partie des nombreux sites soudanais que la Section française de la direction des Antiquités du Soudan (Sfdas), en cinquante années d'existence, a eu l'opportunité de fouiller pour le compte de la National Corporation for Antiquities and Museum. Découvert lors d'une mission d'inspection en 1981 sur la rive droite du Nil Bleu, à $11 \mathrm{~km}$ de la confluence avec le Nil Blanc, le site a fait l'objet de deux campagnes de fouilles conduites par Patrice Lenoble entre décembre 1981 et mai 1983 pour en évaluer le potentiel archéologique et ouvrer à sa protection ${ }^{1}$. Quelques contributions ${ }^{2}$ sont venues témoigner du caractère exceptionnel de la découverte, de son intérêt scientifique majeur, et de la menace qui pesait sur la zone du fait de son exploitation comme carrière. Les fouilleurs n'ont jamais eu l'occasion de poursuivre leurs investigations, ni de finaliser l'étude du mobilier. L'essentiel du matériel découvert a été entreposé dans les magasins de la Sfdas, et les archives de la mission ont été déposées à l'université Lille 3 après le décès de Patrice Lenoble en $2007^{3}$.

cinquantenaire

\section{0}

de la section

française

de la direction

des Antiquités

du Soudan

1 Pour la première campagne, l'équipe se composait de Patrice Lenoble, Rida el-Din Mukhtar, Abd el-Hadi Mohammed Fadul, Abdallah Mohamed Abdallah el-Nazir et quelques ouvriers dont Awadallah Ali el-Basha. Pour la seconde campagne, seuls P. Lenoble et $\mathrm{D}$. Piponnier sont mentionnés dans Geus 1984a, p. 6. Toutefois, F. Geus, J. Reinold, Y. Lecointe, J. Bialais, R.-P. Disseaux sont venus sur le site et ont parfois participé à la fouille comme à la documentation des vestiges.

2 Une recension est réalisée dans SaKamoto 2016, p. 82. Nous citons ici les articles le plus pertinents selon nous: Geus 1982a; Geus, LenOble 1983a; Geus, Lenoble 1983b; Geus 1984a. Voir aussi les rapports de la Sfdas: Geus 1983; Geus 1984b.

3 Nous tenons à remercier chaleureusement Didier Devauchelle et Sylvie Vérité pour leur accueil et les facilités qu'ils ont pu nous accorder pour accéder à ces archives conservées dans les locaux de l'UmR 8164 HALMA (CNRsuniversité de Lille $6 \mathrm{MCC}$ ). Les archives contenaient en outre les carnets de fouilles de Patrice Lenoble (cités en référence comme Carnets 1982 ou Carnets 1983), les originaux des relevés de la plupart des tombes fouillées réalisés lors de la seconde campagne par Patrice Lenoble, un lot de diapositives dont l'auteur n'est pas précisé, et les dessins réalisés et encrés par Jean Bialais, René-Pierre Disseaux et P. Vandeplanque de quelques-unes des céramiques découvertes: R.-P. Disseaux, correspondance du 19 avril 2020. Nous avons conservé certains de leurs traits lors de la vectorisation informatique des céramiques issues des inhumations suivantes: GRF 1,

GrF 2, GrF 3, GrF 6, GrF 48, GrF 54 et GrF 75.

Le reste du mobilier a été dessiné, photographié et vectorisé par Elsa Jadot et Romain David. Joanna Then-Obłuska s'est chargée du traitement informatique et de la mise en page des planches consacrées aux perles et aux pendentifs. 


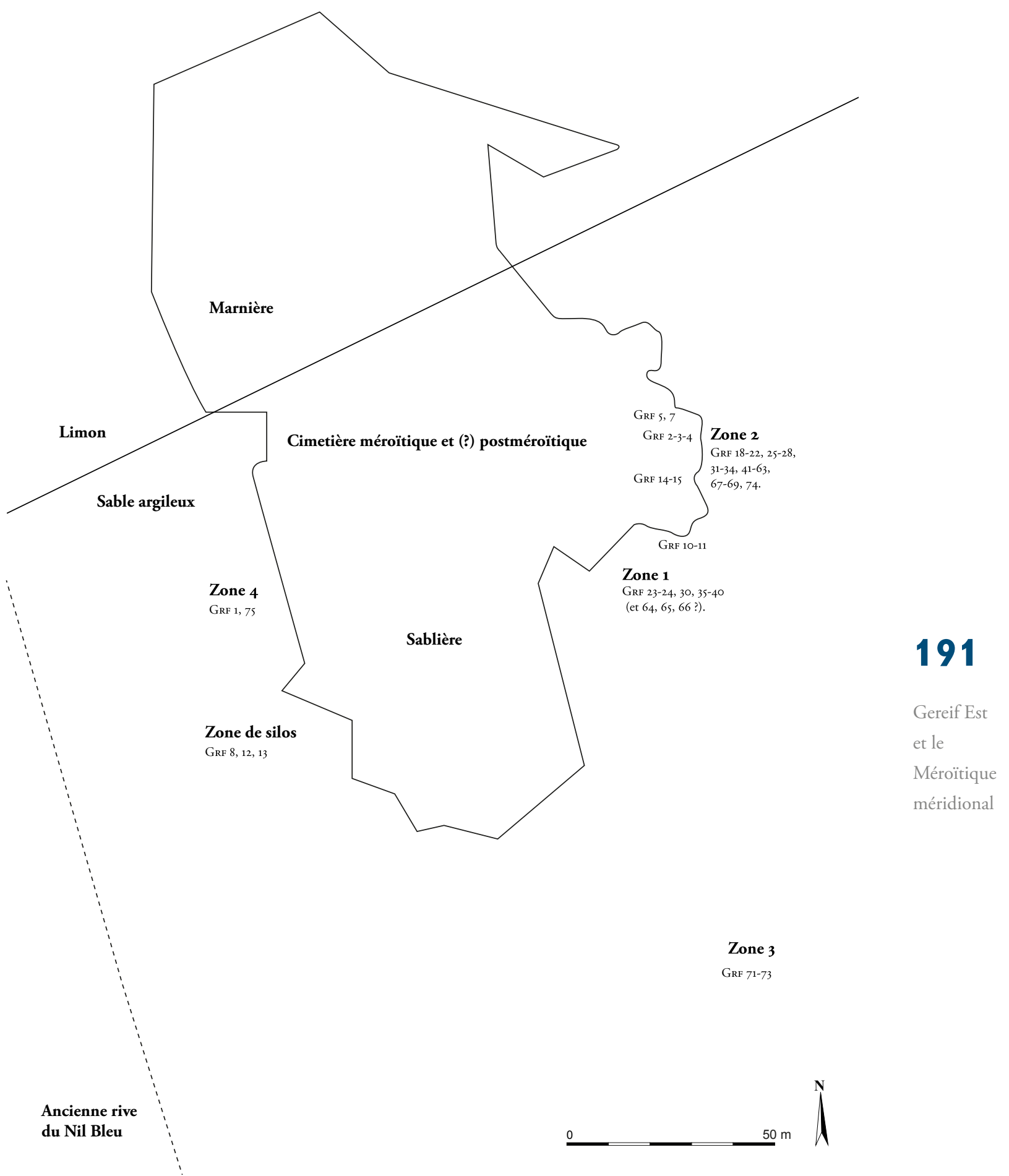

1. Vue générale de la zone explorée (d'après Geus, LeNOBLE 1983a;

Geus, Lenoble 1983b, Carnets 1982 et Carnets 1983). 

et aux archéologues qui ont fait de la Sfdas ce qu'elle est aujourd'hui, de se saisir de ce dossier pour en livrer toute la matière et poursuivre l'étude entreprise il y a près de quarante ans. Mais, il nous manquera ici l'œil de Patrice Lenoble qui nous a transmis ses observations par des notes, des schémas de la disposition des tombes entre elles, ainsi que des relevés minutieux de la plupart des inhumations. Le temps passé sur le terrain ne se remplace pas lorsqu'il s'agit d'apporter son expérience à l'examen scientifique du mobilier qui seul, pour nous, permet de restituer la fouille de Gereif. Nous avons fait le choix de livrer de manière ordonnée le plus de documentation exploitable possible: tous les relevés produits par les fouilleurs ont été repris et disposés selon les croquis tirés des carnets de notes de Patrice Lenoble. Aucun plan général indiquant la position des tombes n'a été retrouvé mais les comptes rendus de l'archéologue sont le plus souvent suffisants pour au moins reproduire une vue d'ensemble schématique. Ses commentaires sont les seuls auxquels nous nous référons lorsqu'il s'agit d'observations anthropologiques ou le parallèle fait entre deux tombes. Le mobilier encore conservé dans les locaux de la Sfdas a fait l'objet d'une attention particulière. La céramique en premier chef, parce qu' elle situe chronologiquement l'inhumation et illustre par-dessus tout un faciès rare, faisant le lien entre la région de Méroé et les périphéries les plus méridionales où son influence est constatée. Les nombreuses parures apportent également des informations essentielles, comme le bronze et les autres petits objets, qui contribuent à replacer les produc-

de la section française de la direction des Antiquités du Soudan tions découvertes à Gereif Est dans un contexte régional.

\section{La nécropole de Gereif Est}

Au terme de deux campagnes de fouille, quatre zones ont été explorées sur des segments plus ou moins importants ${ }^{1}$. Les indications figurant dans les rapports et les publications ainsi que les croquis des carnets de fouilles de Patrice Lenoble ont permis de restituer pour, la plupart des inhumations, la zone dans laquelle elles ont été découvertes ainsi que la disposition des tombes entre elles (fig. 1-2 et 4).

La zone 1 rassemble 11 tombes de formes diverses isolées sur une bande de $17 \mathrm{~m}$ de long. Une dernière (GRF 17) n'est pas localisée mais se situe sans doute à proximité. Elle signalerait la réutilisation de cet espace au cours de la période médiévale. Chacune des fosses de la zone 1 abrite l'inhumation unique d'un adulte, sans cas de réutilisation manifeste de la sépulture (fig. 2). Il s'agit dans la plupart des cas de fosses simples,

1 Geus, Lenoble 1983b; Geus 1984b. 

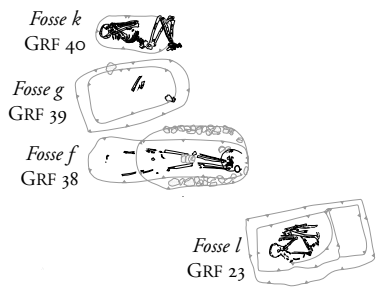
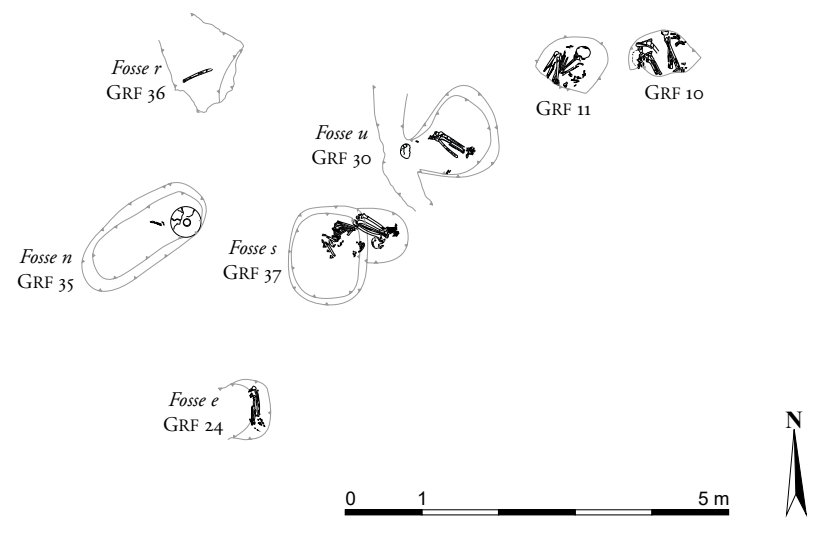

2. Plan schématique des tombes de la zone 1 (d'après les relevés

au $1 / 5^{\mathrm{e}}$ de Patrice Lenoble et Carnets 1983).

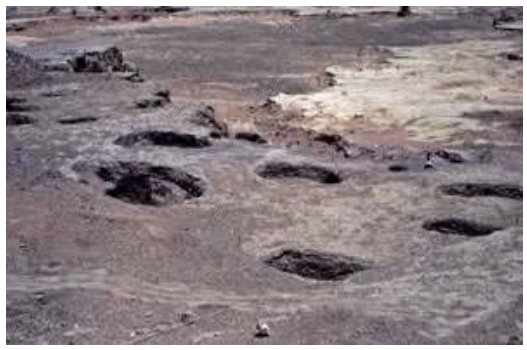

Vue de la zone 1 de Gereif Est

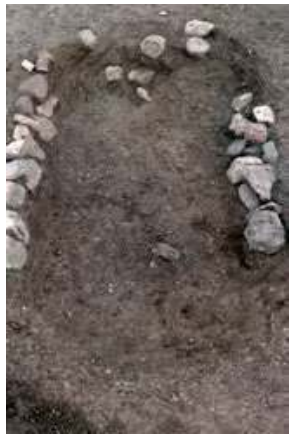

GRF 38

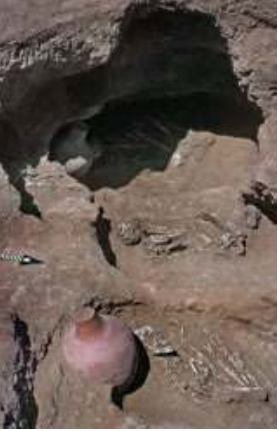

GRF 21, 22, 25 et 28

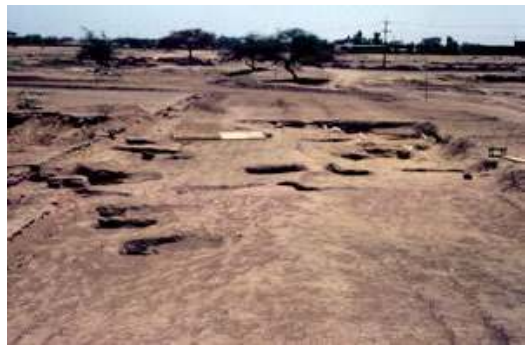

Vue de la zone 2 de Gereif Est

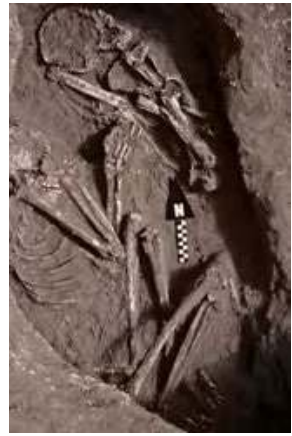

GRF 18 et GRF 69

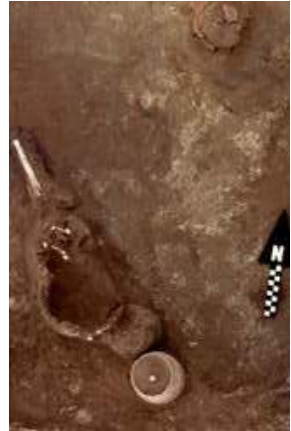

GRF 29
193

Gereif Est

et le

Méroïtique méridional 

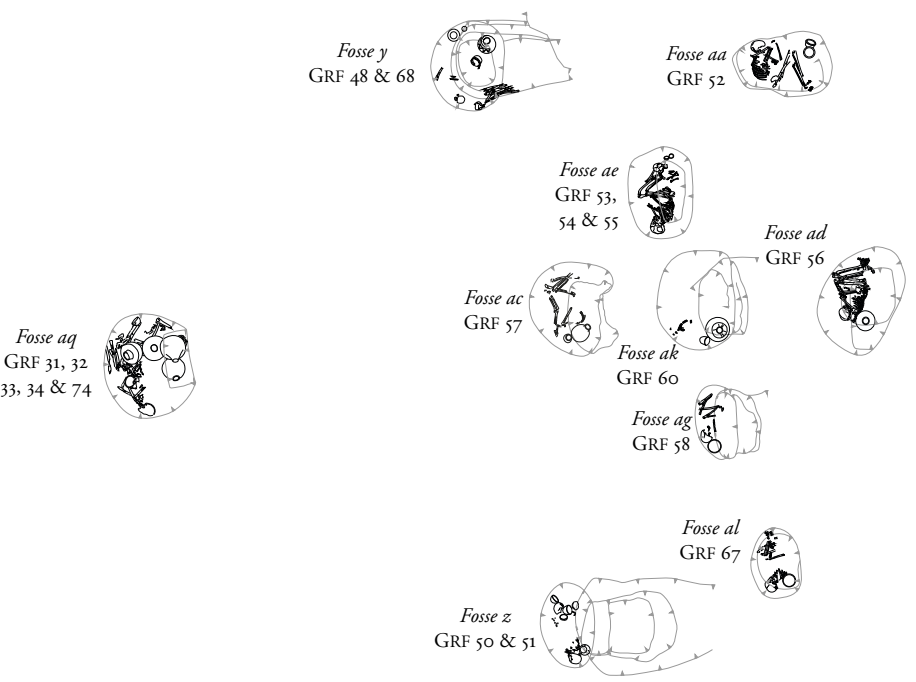

cinquantenaire

\section{4}

de la section

française

de la direction

des Antiquités

du Soudan
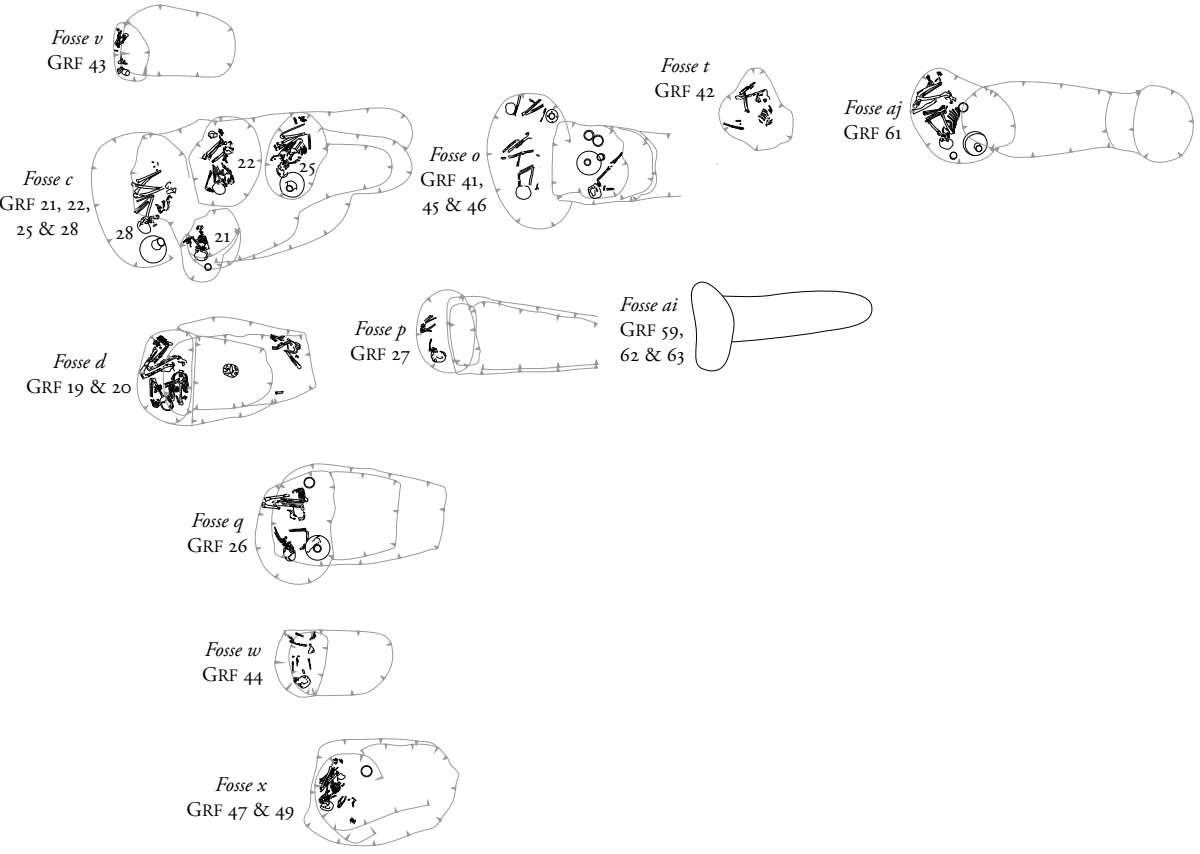

1

4. Plan schématique des tombes de la zone 2

(d'après les relevés au 1/5e de Patrice Lenoble et Carnets 1983). 
de forme ellipsoïdale. Un exemple de fosse rectangulaire est noté (fosse l, GRF 2319) de même qu'une tombe marquée par un pourtour de petites pierres à sa surface (fosse f, GRF 38). Cette particularité, notée par les fouilleurs ${ }^{2}$, n'appartient pas comme il a pu être suggéré, aux vestiges d'une superstructure tumulaire dont le cœur est formé d'un amas de pierre $^{3}$. Il s'agirait plutôt d'une délimitation de la fosse, d'une enceinte suivant rigoureusement le contour de la tombe et l'isolant des autres (fig.3). En revanche, d'autres concentrations de pierres éparses notées en fosse d (GrF 19-20), fosse x (GrF 47 et 49), ainsi qu'en fosse z (GrF 50) pourraient effectivement appartenir à un tumulus (cf. Annexe 1).

L'orientation des substructures suit la plupart du temps un axe est-ouest mais la fosse n (GRF 35) contrevient quelque peu à ce schéma avec un axe nord-est-sud-ouest. Les inhumations GRF 10 et GRF 11, en marge de cet ensemble, sont coupées par la carrière. Nous n'avons qu'une vue partielle des fosses les accueillant mais leur orientation pourrait aussi différer. Le décubitus latéral, en position contractée, tête à l'ouest regardant le nord est une position récurrente dans le secteur. Toutefois, là encore, l'individu GRF 38 fait exception avec une position étendue en décubitus dorsal, tête à l'ouest. Les inhumés GrF 10 et GrF 11 sont en position contractée mais l'orientation du squelette est cette fois-ci nordsud, tête au nord en GrF 11 et tête au sud en GrF 10. Toutefois, la tête de GrF 10 est, comme GrF 7 (infra), tournée vers l'est si l'on en croit la position des jambes. Enfin, parmi les squelettes trouvés en surface, celui de GRF 66 ne respecterait pas l'orientation commune ${ }^{4}$. Le mobilier, rare dans ces tombes parfois perturbées par de sévères pillages, consiste principalement en des restes de parures en perles, quelques céramiques et un lot exceptionnel de vaisselle de bronze (infra).

L'exploration de la zone 2, sur une bande de $65 \mathrm{~m}$ dont une trentaine seulement a été effectivement fouillée au nord-est de la zone 1, a livré 22 tombes pour 39 individus (fig. 4). Seule la fosse a contenant les individus GRF 18 et GRF 69 se situe au nord de la bande et ne peut donc figurer sur le plan (cf. fig. 3). Les fouilleurs signalent que les squelettes dont l'âge a pu être défini appartenaient tous, sans exception, à des immatures, des enfants ou des adolescents. Les multiples pillages ont rendu la lecture des fosses parfois difficiles, mais la plupart sont dotées d'une descenderie

1 Notons que pour la seconde campagne, les fouilleurs ont adopté une nomenclature distinguant les individus (GRF + chiffre), des structures (fosse + lettres) dans lesquelles ils ont été mis au jour.

2 Geus, Lenoble 1983b.

3 Sакамото 2016, p. 88.

4 Geus 1984. 
ouverte à l'est débouchant sur une cavité transversale de forme ellipsoïdale. Contrairement à ce qui a été observé dans la zone 1, quelques cas de niches juxtaposées - par exemple: fosse c, GrF 21, 22, 25 et 28 (fig. 3 et 4) et des réinhumations avec réduction du précédent occupant (notamment fosse d, GrF 19, 20 et fosse a, GrF 18, 69, cf. fig.3) ont été notés. Mis à part un individu (fosse aa, GrF 52), tous les sujets dont la position a pu être identifiée sont en décubitus latéral, en position contractée sur le côté gauche et suivent une orientation nord-sud, tête au sud regardant l'ouest. Le mobilier y est plus fréquent avec de nombreuses associations de céramiques aidant à la proposition de datation.

Les fouilles conduites durant la première campagne se situent en partie à l'ouest de la bande délimitant la zone 2 (fig. 1). Si la documentation à laquelle nous avons eu accès ne permet pas de les situer précisément sur un plan, nous disposons des relevés de chaque tombe (fig. 5). Deux fosses juxtaposées abritant les individus GrF 2, 3 et 4 illustrent un cas d'inhumation multiple où tous les individus ont été déposés conformément à la position privilégiée dans la zone 2 , contractés et tête au sud. Il s'agirait de deux adolescents au moins (GRF 2 et 3), le dernier (GRF 4) étant tour à tour identifié comme un adolescent ${ }^{1}$ puis comme un adulte. Le mobilier associé à chacun semble avoir été préservé des remaniements. Une fosse simple prise dans la coupe de la sablière accueille deux individus: le premier, un enfant (GRF 5), est en réduction contre la paroi nord et le second (GRF 7) est en position contractée, tête au sud mais regardant l'est à la différence

de la section

française

de la direction des Antiquités du Soudan des autres individus de la zone 2. Deux autres tombes (GRF 14 et 15) signalées un peu plus au sud de cette même coupe possèdent un profil comparable à celles du secteur 2 , les inhumés étant en position contractée et tête au sud. Enfin, une découverte fortuite "dans la carrière» ajoute une autre fosse et un individu (GRF 29, fig.3) possédant les mêmes caractéristiques générales que les inhumés de la zone 2.

Dans la zone 3, trois tombes ont pu être fouillées sur une tranchée longue de $10 \mathrm{~m}$, large de $1 \mathrm{~m}$ et profonde de $2 \mathrm{~m}$ taillée dans une formation naturelle nommée le "grand kôm» par les fouilleurs. Située au sudest de la carrière, cette zone abriterait une multitude de fosses. En dehors de l'attribution des fosses et des individus (GRF 71, 72, 73), nous ne possédons aucune information de contexte, ni relevé, ni matériel mis à part un lot de perles associé à GrF 72 (infra Annexe 1).

La zone 4, quant à elle, se situe à l'ouest de la carrière. Très peu explorée, elle a livré une tombe la première saison (GRF 1), et une autre (GrF 75) au cours de la seconde campagne. Toutes sont datables, par leur 
mobilier, de la période Postméroïtique. Nous ne possédons pas de relevé pour la tombe de GrF 1 dont le squelette n'est pas paru à la fouille. Seuls les objets associés à GRF 75 figurent sur le plan, le squelette étant matérialisé par d'infimes fragments non dessinés (fig. 5). Le riche mobilier de ces tombes contraste avec les dépôts plus modestes dans les zones 1 et 2.

Des sondages pratiqués au sud de GRF 1 ont permis la découverte de fosses vides avec, toutefois, des fragments résiduels d'ossements humains et un mobilier très fragmenté. Elles sont donc enregistrées comme des tombes ( $\mathrm{GRF} 8,12$ et 13) sans être pour autant clairement définies. Une interprétation comme silo (fig. 5), dont les rares témoins funéraires proviendraient de la nécropole adjacente, est privilégiée par les fouilleurs sur le plan général livré au terme de la première campagne'.

La présence de tombes postméroïtiques à l'ouest de la carrière pourrait suggérer un développement d'est en ouest de la nécropole qui s'étendrait sur une surface de $60 \mathrm{~m}$ par $100 \mathrm{~m}^{2}$. Les deux zones les mieux connues illustreraient une dynamique de répartition des individus en fonction de leur classe d'âge. Si l'on se fie aux observations des fouilleurs, les adultes seraient inhumés dans la zone 1 et les plus jeunes dans la zone 2. Ce phénomène est régulièrement observé dans le royaume de Méroé3. La spécificité de Gereif Est réside dans le fait que cette distinction est également traduite dans la forme de la structure funéraire - fosses d'un côté, et tombes à descenderie puis cavité transversale de l'autre - ainsi que dans l'orientation préférentielle des défunts, tête à l'ouest pour les adultes et tête au sud pour les enfants et les adolescents. La coexistence de formes de structures et d'orientations variées au sein d'une même nécropole n'a rien de surprenant pour la période qui nous intéresse4. C'est plutôt son association presque systématique à une classe d'âge et à une répartition spatiale qui illustre, sans doute pour la première fois aussi clairement, un usage suivi de manière plus aléatoire dans le royaume méroïtique. On ne peut que regretter que les fouilleurs n'aient pu poursuivre leurs investigations sur l'espace de transition entre les zones 1 et 2.

1 Geus, Lenoble 1983a, fig. 1.

2 Geus, Lenoble 1983a, p. 10.

3 Francigny 2016, p. 150.

4 Francigny 2016, p. 73; Usai et al. 2014. 


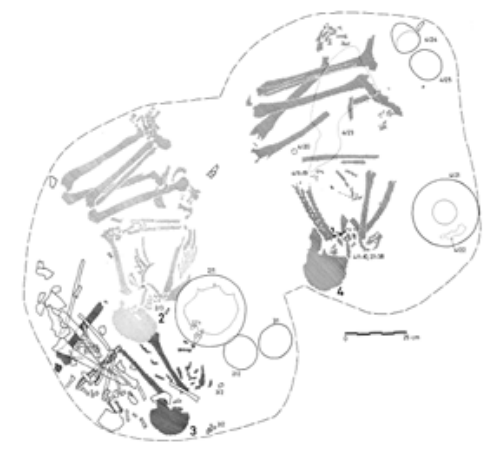

GRF 2-3-4

cinquantenaire

\section{8}

de la section

française

de la direction

des Antiquités du Soudan

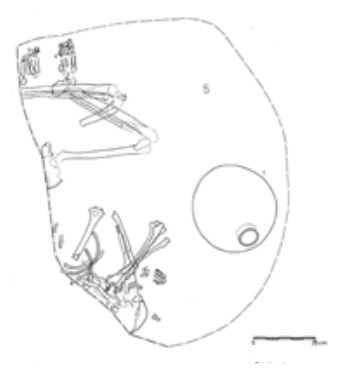

GRF 7

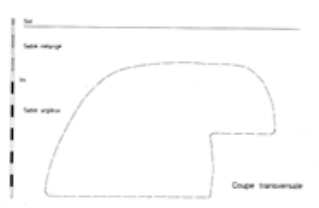

GRF 8

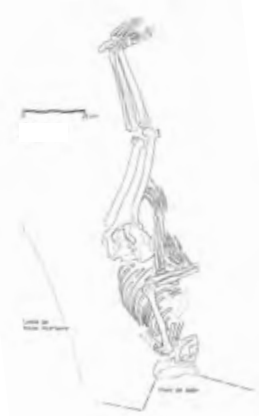

GRF 17

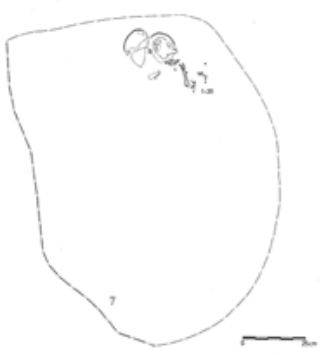

GRF 5

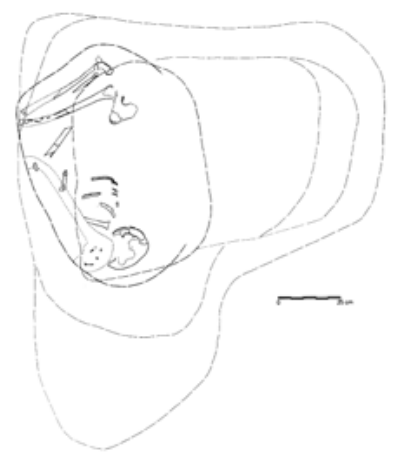

GRF 14

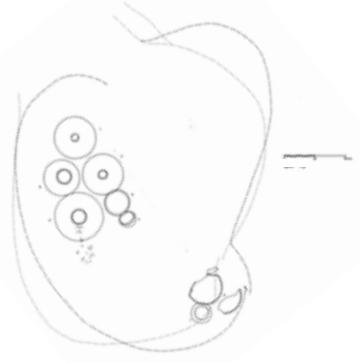

GRF 75 


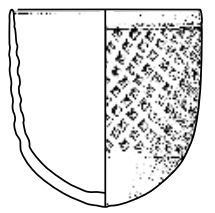

GRF $48 / 3$

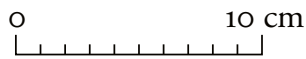

6. Céramique classée en W1.

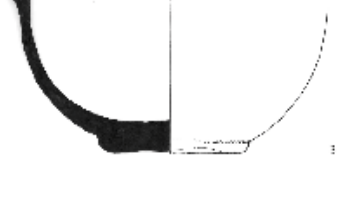

GRF $6 / 3$

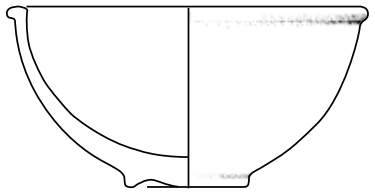

GRF 48/5

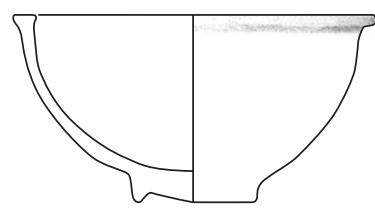

GRF 3/1

\section{9}

Gereif Est

et le

Méroïtique méridional

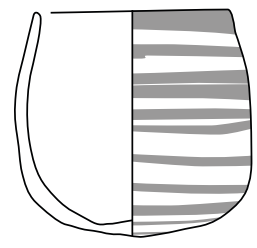

GRF 29/2

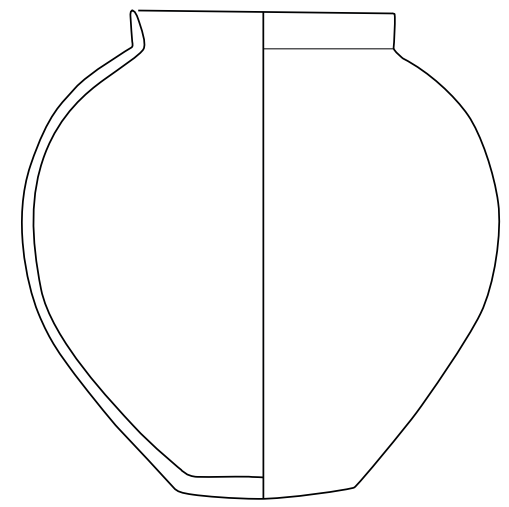

GRF 48/4

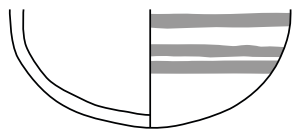

GRF $6 / 2$

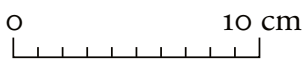

7. Céramiques classées en $W_{3}$. 


\section{Le mobilier céramique}

cinquantenaire

\section{0}

de la section

française

de la direction

des Antiquités

du Soudan

Le mobilier céramique est présent de manière irrégulière dans les zones fouillées. Rare dans la zone 1, il est plus fréquent dans la zone 2 et courant dans les deux tombes postméroïtiques de la zone 4. Les pillages, la chronologie, mais aussi le statut des défunts peuvent expliquer de telles disparités. Le choix a été fait de présenter le matériel suivant la classification en cours de définition sur plusieurs sites de la région de Méroé1. Elle s’adapte assez bien au faciès de Gereif et tend même à combler des lacunes documentaires pour des catégories sous-représentées dans les assemblages traités jusqu’à présent sur les sites d'habitat de Mouweis, el-Hassa et Damboya.

La classification établie débute avec la céramique fine tournée réalisée à base d'argile de type kaolinitique (W1). La fine ware, dans son appellation courante, n'est que très peu représentée. Les fouilleurs en mentionnent à l'état de tesson sur le site ${ }^{2}$, mais une seule coupe associée à l'individu GRF 48 (fig. 6) illustre cette catégorie. De forme hémisphérique à lèvre amincie et possédant un décor de losanges estampés sur sa face externe, elle rappelle des productions diffusées jusqu'en Nubie dans la seconde moitié $\mathrm{du} \mathrm{I}^{\mathrm{er}}$ et au $\mathrm{II}^{\mathrm{e}}$ siècle de notre ère ${ }^{3}$.

Les céramiques fines tournées en pâte alluviale $\left(\mathrm{W}_{3}\right.$, fig. 7$)$ sont plus fréquentes et consistent surtout en des coupes à lèvre étirée et base plate (GRF 6/3) ou annulaire (GRF 3/1, GRF 48/5). L'évolution morphologique de ces types a déjà été discutée ${ }^{4}$ : si ces formes perdurent dans les tombes méroïtiques entre le $\mathrm{I}^{\mathrm{er}}$ et le $\mathrm{III}^{\mathrm{e}}$ siècle de notre ère, les coupes à base annulaire apparaîtraient les premières pour être ensuite déclinées dans des types de facture plus simple et moins soignée allant dans le sens d'une productivité accrue. Deux gobelets à profil très légèrement rentrant et fond bombé (GRF 29/2, GrF 6/2) permettent de faire le lien entre deux tombes, dont une n'est malheureusement pas localisée (GRF 6). L'aplat de bandes de peinture dans les tons rouge-violacé sur la face externe intègre une mode répandue dès le Méroïtique Ancien sous l'influence des productions hellénistiques et qui perdure jusqu'au $\mathrm{II}^{\mathrm{e}}$ siècle de notre ère ${ }^{5}$. Le dernier représentant de cette catégorie est une petite jarre à col court, à panse

1 DAVID et al., à paraître.

2 Geus 1983, p. 26.

3 Par exemple TöröK 1997, fig. 103, nº 900-13; VILA 1978, p. 53 , fig. 15; Garcia Guinea, Texidor 1965, fig. 3.2; plus généralement DAVID, EVINA 2015.

4 Edwards 1999, fig. 6; Bashir, David 2011, p. 122.

5 Voir notamment TöröK 2011, p. 252-269. 
à profil globulaire et à fond plat $(\mathrm{GRF} 48 / 4)$. Le type n'est pas commun mais sa facture, à engobe rouge soigneusement bruni, intègre les faciès du Méroïtique Classique et Récent ( $\mathrm{I}^{\mathrm{er}}-\mathrm{III}^{\mathrm{e}} \mathrm{s}$.).

Les céramiques communes tournées en pâte alluviale $\left(\mathrm{W}_{4}\right)$, façonnées à l'aide de colombins montés au tour, sont illustrées par quelques jarres revêtues d'un engobe rouge à la typologie assez commune (fig. 8). Une jarre à bord en bourrelet, col moyen et panse globulaire (GRF 31/4) rejoint les modèles développés au cours des $\mathrm{I}^{\mathrm{er}}$ et $\mathrm{II}^{\mathrm{e}}$ siècles de notre ère'. Une jarre (GRF 38/1) inspirée du répertoire des céramiques non tournées est issue d'une tradition plus ancienne apparaissant vraisemblablement au cours du $\mathrm{II}^{\mathrm{e}}$ siècle avant notre ère ${ }^{2}$. Son décor peint d'une bande ondulée est apparenté à une iconographie dont on suit l'évolution depuis les jarres d'Emir Abdallah du i ${ }^{\text {er }}$ siècle avant notre ère et jusqu'à celles de Gabati de la première moitié du $\mathrm{I}^{\mathrm{er}}$ siècle de notre ère ${ }^{3}$. Les quatre jarres à col moyen de hauteur variable et profil ovoïde (GRF 25/1, GRF 28/1, GRF 61/1, GRF 4/21) sont assez répandues au cours des $\mathrm{I}^{\mathrm{er}}$ siècle avant et $\mathrm{I}^{\mathrm{er}}$ siècle de notre ère et semblent être remplacées par des modèles au col plus court par la suite comme l'indiquent les attestations des nécropoles de Méroé4. Les contextes de Gereif sont insuffisants pour aborder l'évolution morphologique de ces types mais on notera la rupture de plus en plus marquée entre le col et l'épaule des exemplaires présentés qui va de pair avec une augmentation de la hauteur du col. Le motif gravé sur la jarre GRF 4/21 a déjà été discuté par les fouilleurs, il s'agirait d'un symbole interprété comme une pyramide par Charles Bonnet, qui retranscrit visuellement la nouvelle fonction funéraire de l'objet $^{5}$. La dernière jarre (GRF 6/1), à col court et profil cylindrique

1 Edwards 1998, fig. 2.9, 2.11; Dunham 1963, fig. F43 pour des modules inférieurs.

2 Fernández 1984, fig. 7, 165-2 (Génération 7).

3 FernándeZ 1984, fig. 6, 118-1 (Génération 11); Edwards 1998, fig. 6.3. Voir aussi TöroK 1987, p. 80. L’auteur recense quelques exemples supplémentaires mais propose une datation plus haute que nous avons des difficultés à suivre compte tenu des données apportées par la nécropole de Gabati.

4 Dunham 1957, fig. 55, no 22-1-123, fig. 84, nº 21-12-65b. Pour une datation des tombes de Téritéqas et du prince Arikankharor, voir Rilly 2017, p. 121-122; Dunham 1963, fig. Do7 et I13.

Voir également EDWARDS 1999, fig. 6.8 pour une jarre comparable de la tombe 37 datée de la première moitié du $\mathrm{I}^{\mathrm{er}}$ siècle de notre ère par analyse au radiocarbone.

5 Geus, Lenoble 1983a, p. 12. 


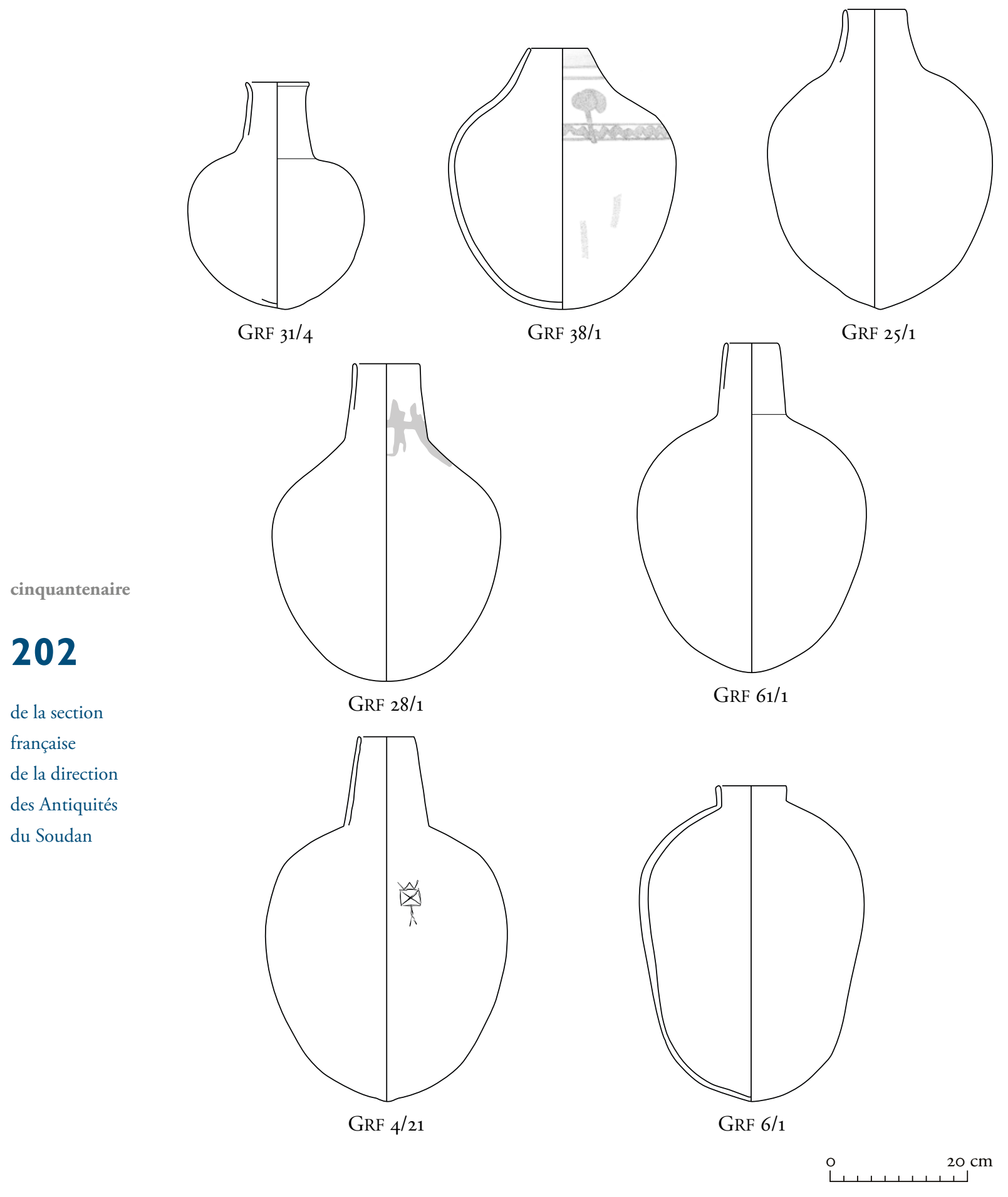

8. Céramiques classées en $\mathrm{W}_{4}$. 


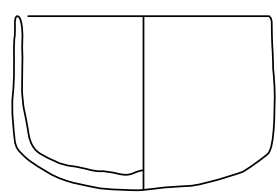

GRF 29/1

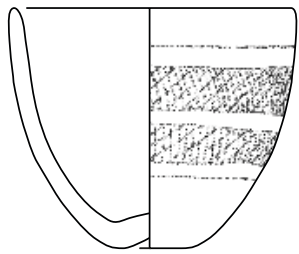

GRF 4/24

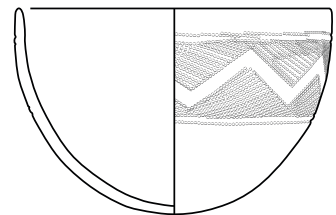

GRF 50/2

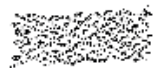

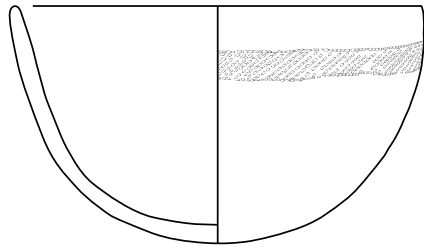

GRF 67/1
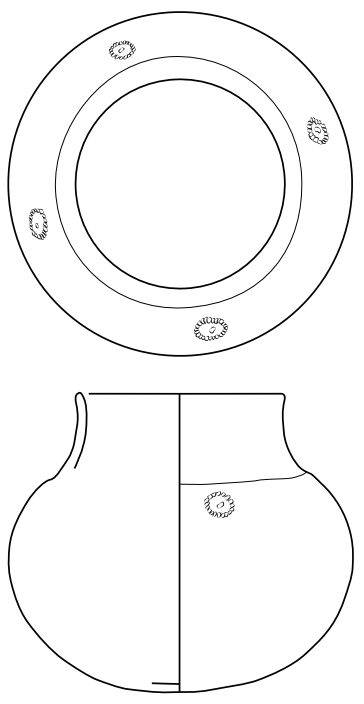

GRF 5O/1

9. Céramiques classées en W6.

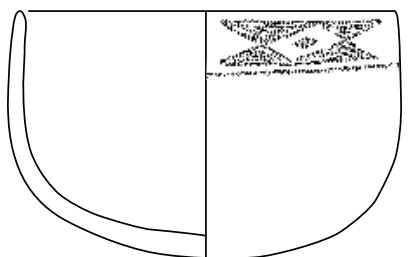

GRF 48/2

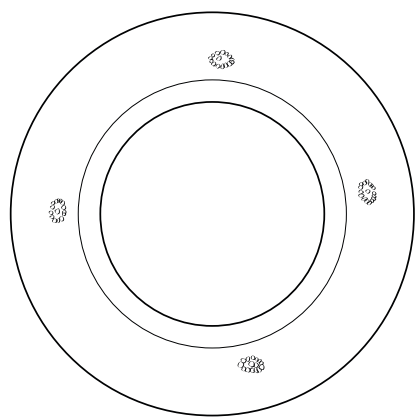

203

Gereif Est

et le

Méroïtique méridional

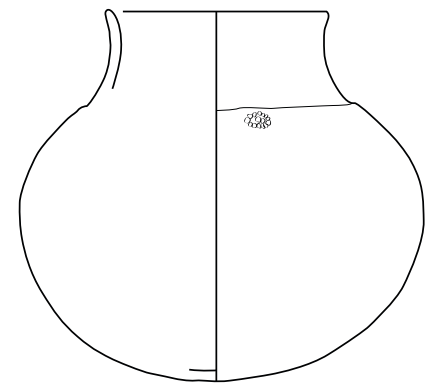

GRF 45/1

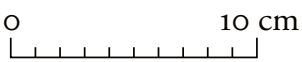


cinquantenaire

\section{4}

de la section

française

de la direction

des Antiquités

du Soudan s'insère plutôt dans un faciès du Méroïtique Récent et Final ( $\mathrm{II}^{\mathrm{e}}-\mathrm{IV}^{\mathrm{e}}$ siècles de notre ère). Son faible module est atypique au regard des nombreuses jarres de forme comparable mises au jour dans la région de Méroé1.

Différentes catégories de céramiques non tournées isolent des variations de techniques de façonnage (colombin, martelage, modelage) et de finition (présence d'engobe ou non, brunissage ou lissage, atmosphère de cuisson, etc.) ${ }^{2}$. Les céramiques non tournées noires (W6) sont montées aux colombins, brunies, et cuites en atmosphère réductrice ce qui confère à leur surface un aspect noir et lustré. Plusieurs formes de la nécropole de Gereif intègrent cette catégorie (fig. 9). Un gobelet à fond caréné (GRF 29/1) reprend le répertoire de la fine ware et pourrait donc correspondre à une mode développée au plus tôt dans les premières décennies du I ${ }^{\text {er }}$ siècle de notre ère. Les coupes de formes variées (GRF 4/24, GrF 50/2, GRF 67/1, GRF 48/2) possèdent de nombreux parallèles disséminés le long de la vallée $\mathrm{du}$ Nil, sans que l'on puisse à ce jour identifier une évolution morphologique aidant à leur sériation chronologique. Les nécropoles du Soudan central et de Nubie font état d'une réduction progressive de la part des productions non tournées jusqu'à leur limitation à de rares formes bien ancrées culturellement à partir du Méroïtique Récent ${ }^{3}$. La documentation des cimetières méridionaux est cependant trop lacunaire pour vérifier si un tel phénomène est aussi perceptible à ces latitudes. On peut toutefois observer des différences de traitement des décors: des bandes simples sur un ou plusieurs registres (GRF 4/24, GRF 67/1), une bande en réserve (GRF 50/2) ou un motif isolé (GRF 48/2). Ces éléments pourraient correspondre à des modes associées à des groupes de potiers distincts et/ou à des phases chronologiques différentes qui restent à circonscrire. Les deux jarres à ouverture large, petit col légèrement concave et panse globulaire (GRF 5O/1, GRF 45/1) sont, quant à elles, bien mieux connues. La similarité de leur décor, en plus de l'argument typologique, indiquerait la contemporanéité des deux inhumations. Le type est répandu dans l'ensemble de la vallée du Nil, de Qasr Ibrim jusqu'à Sennar ${ }^{4}$ avec, en Nubie, une présence marquée dans des contextes datés des $\mathrm{II}^{\mathrm{e}}$ et $\mathrm{I}^{\mathrm{er}}$ siècles avant notre ère ${ }^{5}$.

Les céramiques communes non tournées classées en W11 sont façonnées aux colombins mais leur surface est laissée irrégulière, sans traitement si ce n'est un lissage partiel. Cette catégorie est plutôt liée aux céramiques

1 Dunham 1963, fig. Ko5 et Lo8.

2 Voir David, Evina 2016; David et al., à paraître.

3 DaVid 2019, p. 881-882; LeNOBLE 1995.

4 Rose 1996, fig. 4.1; DiXon 1963, pl. L.a.

5 Williams 1985, fig. 4a-b; FernáNDEZ 1984, fig. 2, no 135.2; Randall-Maciver, WoOlley 1911, pl. 69, nº 10472. 
culinaires dans les secteurs d'habitat comme à Mouweis. Les jarres de forme assez commune trouvées dans deux tombes de Gereif (GRF 7/1, GRF 41/1) permettent d'étendre l'éventail des productions répertoriées (fig. 10). La connaissance de ces types est trop limitée pour en établir la chronologie.

Les céramiques classées en $\mathrm{W}_{13}$ se distinguent par le recours à une argile dans laquelle les inclusions minérales sont majoritaires, ce qui est rare à l'époque méroïtique où les argiles alluviales à dégraissant végétal dominent largement. Les formes seraient partiellement ou totalement montées aux colombins, l'hypothèse d'un moulage de la partie basse ayant aussi été suggérée 6 . Sa pâte, si particulière, a été repérée sur des sites allant du Gébel Moya, au sud, jusqu’à Qasr Ibrim, au nord, et a servi à mettre en lumière l'importance des ateliers produisant ces céramiques et leur rôle dans les échanges économiques régionaux au tournant de notre ère ${ }^{2}$. Une jarre (GRF 35/1, fig. 11) et un biberon (GRF 43/1, infra, fig. 15) permettent d'illustrer cette production à Gereif.

Les céramiques non tournées à engobe rouge bruni (W14) sont le pendant des pots classés en W6 avec qui elles partagent une bonne partie du répertoire typologique, notamment les formes ouvertes. Dans la région de Méroé, cette catégorie intervient dans les assemblages plutôt tardifs au point que leur rôle de marqueur chronologique des ensembles postérieurs au II ${ }^{\mathrm{e}}$ siècle est en cours de définition ${ }^{3}$. Toutefois, les exemplaires de Gereif s'éloignent quelque peu des faciès reconnus plus au nord (fig. 12). Les trois coupes hémisphériques (GRF 21/1, GRF 60/1, GRF 49/1) se distinguent surtout par le traitement décoratif des deux premiers exemplaires (fig. 13). L'excision de matière pour réaliser le motif de bandes ondulées de la coupe GRF 21/1 n'est pas commune. Si elle ne possède de parallèles que parmi la céramique fine dans la région de Méroé4, elle est en revanche bien développée parmi les productions non tournées de sites plus méridionaux comme à Abu Geili ${ }^{5}$. Il en est de même du décor de GrF 6o/1 alternant incisions et poinçonnage. La coupe à pied GRF 4/25 imite sans doute une forme tournée mais porte un décor incisé rappelant un motif observé à Sedeinga et à Émir Abdallah ${ }^{6}$. Les fouilleurs observent une coupe exactement semblable associée à l'inhumation de GrF 31 mais que nous n'avons pu étudier.

6 DAVID, Evina 2016, p. 109-110. Pour une actualisation voir DAVID et al., à paraître.

2 Edwards 2014; DAVID 2018, p. 485-486.

3 DAvid et al., à paraître. Voir également pour la Basse-Nubie: ADAMs 1986, p. 418, Ware H9.

4 Dunham 1963, fig. 23; David, Evina 2015, fig. 4.

5 Crawford, AdDison 1951, pl. xxxvi.B.

6 Fernández 1986, fig. 2, nº 195-2. 


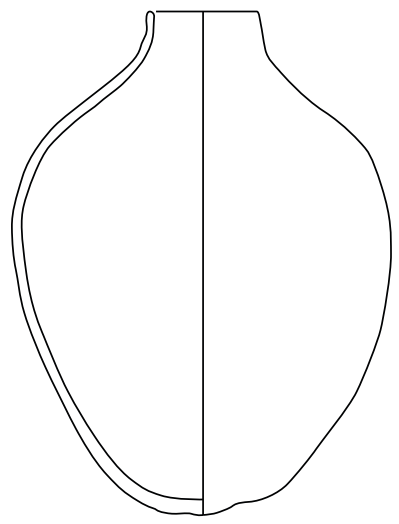

GRF 7/1

10. Céramiques classées en W11.

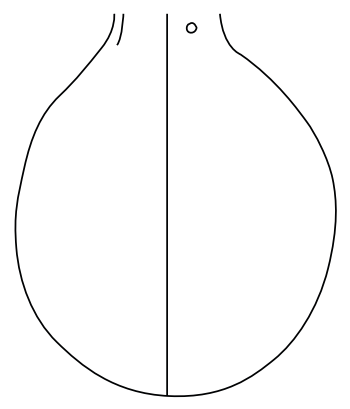

GRF $41 / 1$

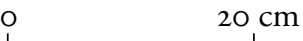

$+1$

cinquantenaire

\section{6}

de la section

française

de la direction

des Antiquités

du Soudan

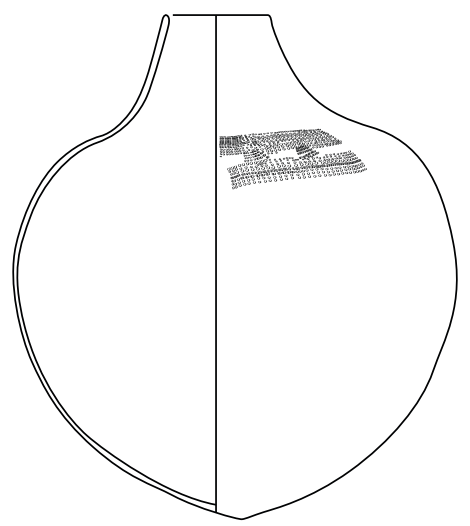

GRF 35/1 $20 \mathrm{~cm}$

11. Céramique classée en $W_{13}$. 


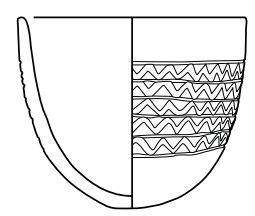

GRF 21/1

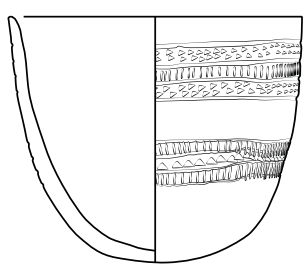

GRF 6o/1

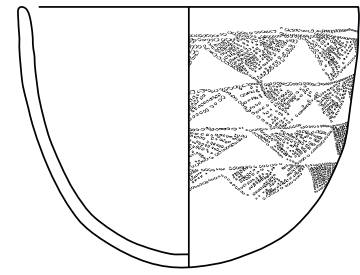

GRF 49/1
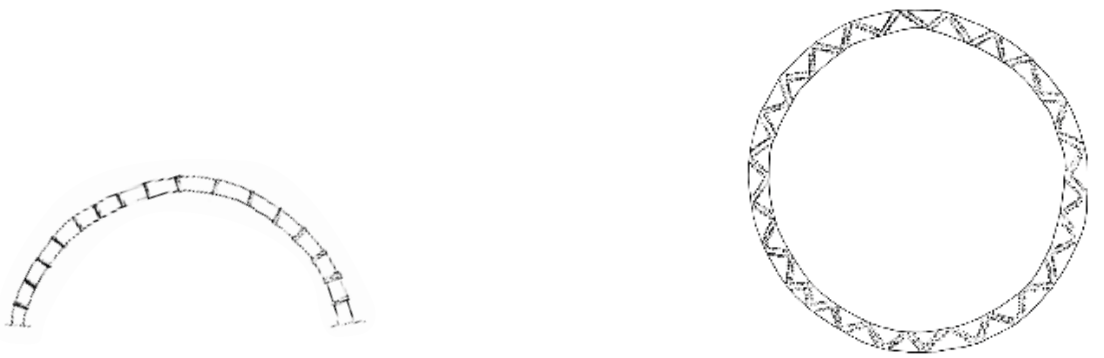

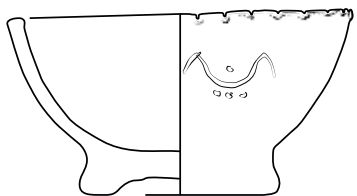

GRF 4/25

12. Céramiques classées en $\mathrm{W}_{14}$.

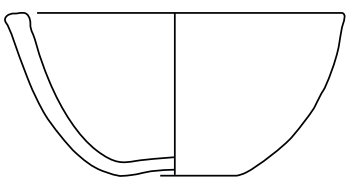

GRF 2/2 $10 \mathrm{~cm}$

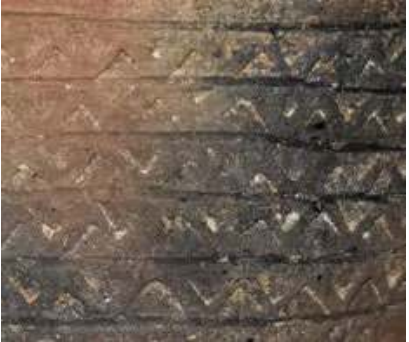

GRF 21/1

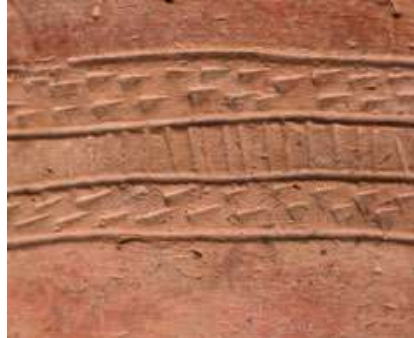

GRF 6o/1

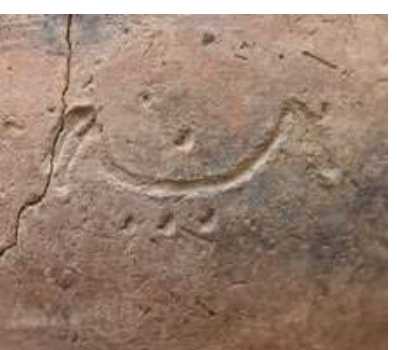

GRF 4/25
Gereif Est

et le

Méroïtique méridional

13. Détail des décors des céramiques classées en W14. 


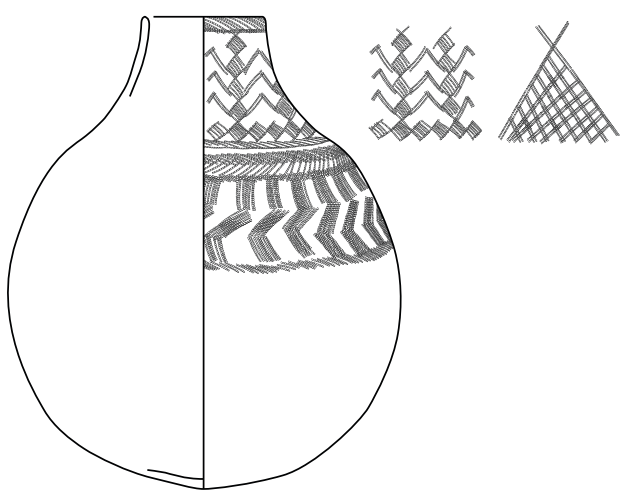

GRF 26/1

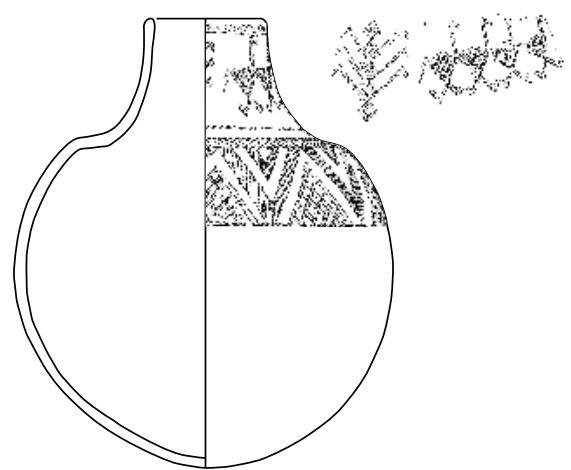

GRF 48/1 cinquantenaire

208

de la section française de la direction des Antiquités du Soudan

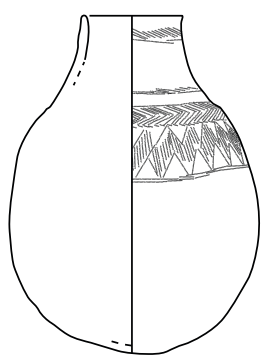

GRF 57/1

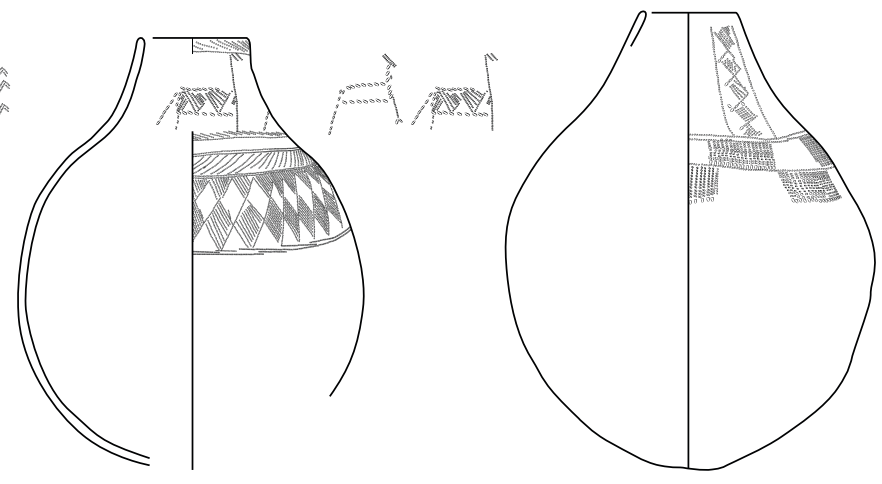

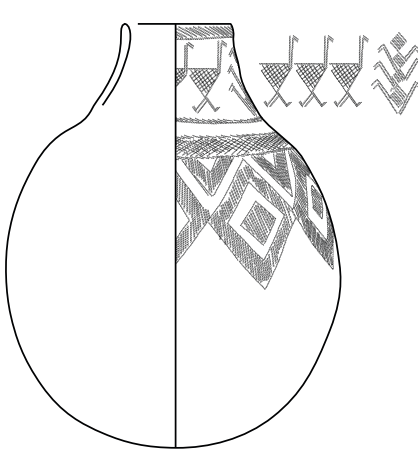

GRF 56/1
GRF 31/5

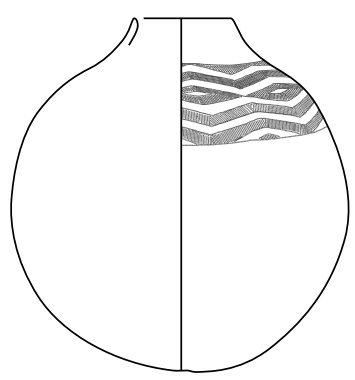

GRF 52/1

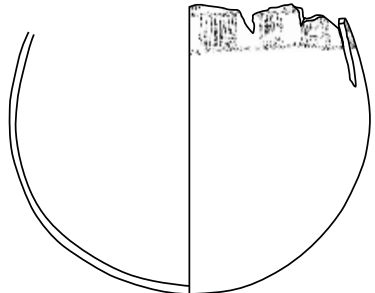

GRF 2/1

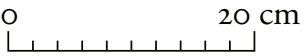




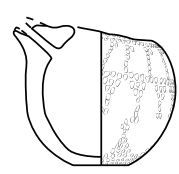

GRF 43/1

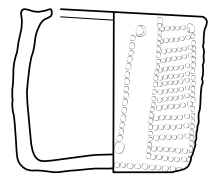

GRF 43/2

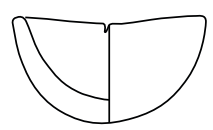

GRF 54/1
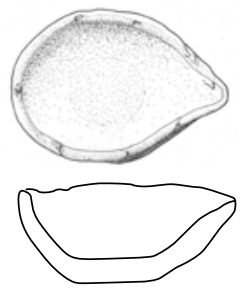

GRF 54/2

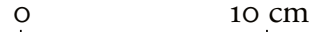

$\begin{array}{lllllllll}1 & 1 & 1 & 1 & 1 & 1 & 1 & 1 & 1\end{array}$

15. Céramiques classées en W18.

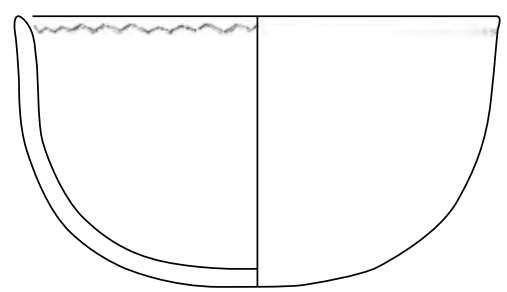

GRF $1 / 3$

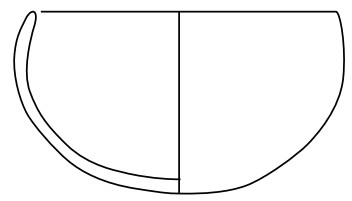

GRF 75/4

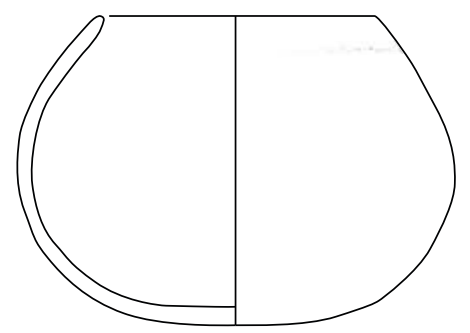

GRF 1/4

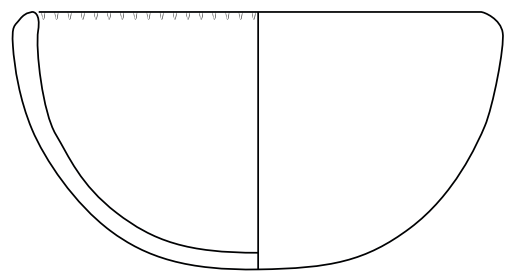

GRF 75/3

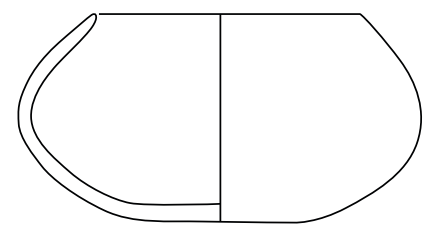

GRF 75/7

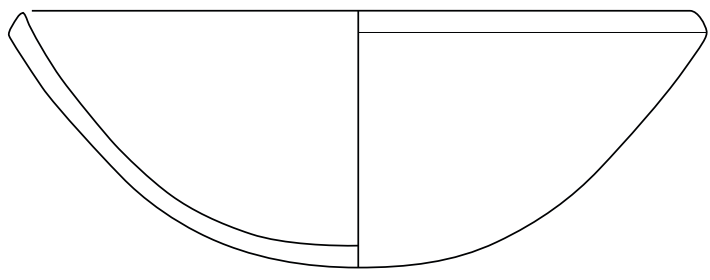

GRF 75/8
209

Gereif Est

et le

Méroïtique méridional

16. Céramiques postméroïtiques. Les formes ouvertes. 
cinquantenaire

\section{0}

de la section

française

de la direction

des Antiquités

du Soudan
La dernière coupe (GRF 2/2), avec son fond légèrement concave, est d'un type peu commun même si son décor au peigne réalisé sur la lèvre est tout à fait courant.

Les céramiques non tournées à surface lissée, sans doute façonnées par percussion sur forme concave en ce qui concerne la partie basse - le col étant réalisé par superposition de colombins d'argile (W16) - forment un groupe remarquablement homogène. Des jarres à panse globulaire ou ovoïde - épaule plus ou moins marquée et col court à moyen, rentrant à surface décorée d'impressions au peigne - renvoient à un corpus largement diffusé au Soudan central au tournant de notre ère (fig. 14) ${ }^{1}$. L'iconographie qui s'y développe est assez homogène et contient des motifs imprimés au peigne bien répertoriés. En premier lieu, un symbole (GRF 26/1, 48/1, 56/1) récemment interprété comme un épi de sorgho ${ }^{2}$ possède des déclinaisons dispersées du sud au nord du Soudan, toujours sur des jarres et en position centrale ou bien visible sur le $\mathrm{col}^{3}$. Parmi les jarres de Gereif, ce motif est associé à une frise de trois ou quatre volatiles vus comme des autruches, ou un motif en forme de hutte. Une autre jarre (GRF 31/1) possède deux animaux imprimés au traitement différent: le plus visible possède un corps rempli de triangles et un long cou permettant de l'interpréter comme une girafe ${ }^{4}$; le second, suivant la girafe, a la tête marquée de deux traits se poursuivant pour dessiner ce qui pourrait être des cornes. $\mathrm{Y}$ voir une antilope ne nous paraît pas dénué de sens dans une iconographie où le recours à l'imagerie d'une faune de savane prévaut ${ }^{5}$. Outre la récurrence de ces motifs ${ }^{6}$ appartenant à une iconographie bien établie, même si son sens nous échappe, la fréquence des attestations au Soudan central en fait un potentiel marqueur culturel méridional. Une jarre globulaire à col court (GRF 52/1), par son style mêlant bandes finement

1 Par exemple Geus 1982b, p. 186, fig. 9; Caneva 1988, p. 199, fig. 2931 ; Edwards 1998, p. 165, fabric G5, fig. 6.19-6.24; BASHIR, David 2011, p. 123, fabric B7; voir aussi BASHIR, DAvid 2015, p. 101, fig. 2. On observe aussi l'application de peinture rouge après l'impression dans le cas de GrF 56/1.

2 EDWARds, EISA 2016, p. 89.

3 Voir des listes non exhaustives dans Sakamoto 2016, p. 84; Fernández 1983, p. 389, motif P.49. Enfin, voir Rose 1996, fig. 4.1 et 4.11 pour un proche parallèle au nord.

4 Les impressions très peu profondes ont ainsi été interprétées de manière erronée dans SAKAмото 2016, fig. 2, $\mathrm{n}^{\circ} 3$.

5 Voir aussi Lenoble 2018, p. 184-185, fig. 93; AdDison 1949, pl. CII, A.4.

6 Voir par exemple Edwards 1998, fig. 6.19 à 6.25. 
imprimées et espaces en réserve, illustre un autre type de traitement iconographique que l'on rapproche des productions observées à Abu Geili ou au Gébel Moya'.

La dernière catégorie comprend les formes obtenues par modelage (W18). Il s'agit pour la plupart de coupelles et de biberons (fig. 15). Tous ces éléments ont été découverts dans des tombes accueillant une inhumation d'enfant. Le premier spécimen (GRF 43/1) est atypique à plusieurs titres: sa pâte le classerait parmi les productions en $W_{13}$ et sa forme le renvoie à des exemplaires de biberons à bec verseur plutôt connus dans les sites méridionaux ${ }^{2}$. Un pot miniature de forme cylindrique à décor imprimé (GRF 43/2) ne possède pas de parallèles à notre connaissance. À l'inverse, la coupelle (GRF 54/1) et le biberon (GRF 54/2) sont largement répandus dans le royaume méroïtique ${ }^{3}$.

Les deux tombes de l'ouest de la carrière ont livré chacune plusieurs céramiques à la typologie comparable signifiant la probable contemporanéité des inhumations. Les formes ouvertes (fig. 16), dont seuls deux exemplaires ont pu être étudiés, intégreraient sans doute le groupe W6 dans la classification mise en place pour la période méroïtique. Les jarres, quant à elles, correspondraient au groupe W11 (fig. 17). Tous ces éléments illustrent un faciès bien décrit des contextes postméroïtiques au Soudan central et au sud de Khartoum ${ }^{4}$. Toutefois, Gereif Est se situe en dehors de la zone où les jarres dites "de transition", à surface montrant des impressions de nattes, sont généralement découvertes ${ }^{5}$. La région de Khartoum se distinguant sur ce point de celle de Méroé pour ce qui est des marqueurs chronologiques du Postméroïtique, nous manquons d'éléments issus de contextes méridionaux bien circonscrits pour préciser la datation des tombes de Gereif. La proximité de son mobilier avec des ensembles mis au jour le long du Nil Bleu nous orienterait cependant vers les $\mathrm{v}^{\mathrm{e}}$ et $\mathrm{vI}^{\mathrm{e}}$ siècles de notre ère ${ }^{6}$.

1 CraWford, AdDison 1951, pl. XXVIII-XXix;

AdDison 1949, pl. c. B.

2 Addison 1949, pl. xCII; ; voir Geus 1984a, p. 75 pour un bref commentaire.

3 Par exemple EDWARDS 1998, fig. 6.25. Pour une discussion sur les biberons, voir DAvid, Evina 2016, p. 113-114.

4 Voir notamment EDWARDS 1998, p. 178-193; Garstang 1911, p. 29-47; Geus, Lenoble 1985; Edwards 1991; Marshall, Adam 1954; El-Tayeb 1999; Bashir 2007. Voir enfin LENOBLE 2018 et particulièrement p. 265-268.

5 LeNOBLE 1992 ; LeNOBLE 2018 p. 268-275.

6 EDWARDS 1991, p. 52-53. 


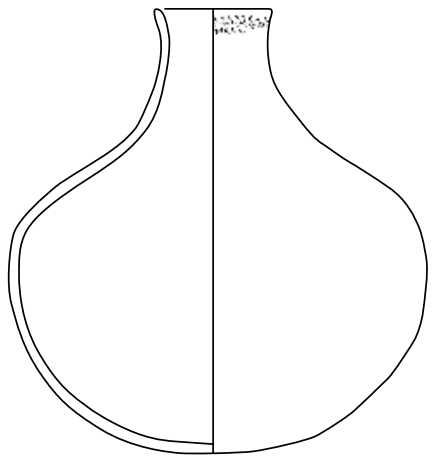

GRF 1/1

cinquantenaire

212

de la section

française

de la direction

des Antiquités

du Soudan

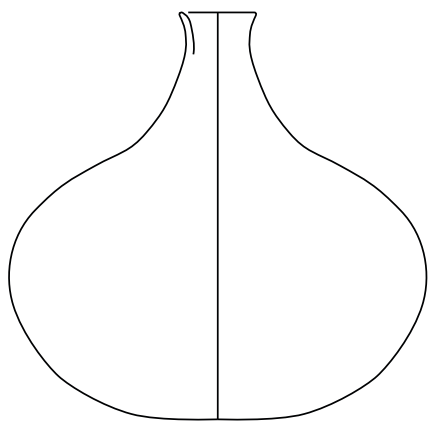

GRF 75/2

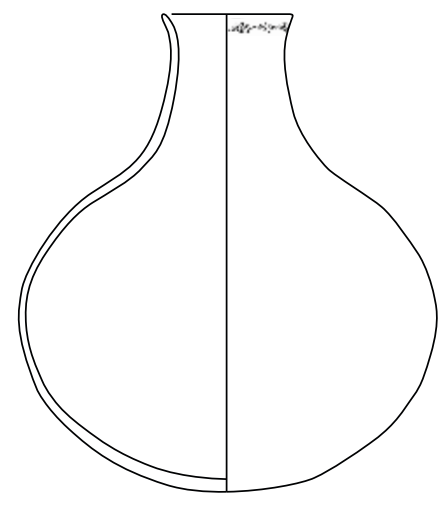

GRF $1 / 2$

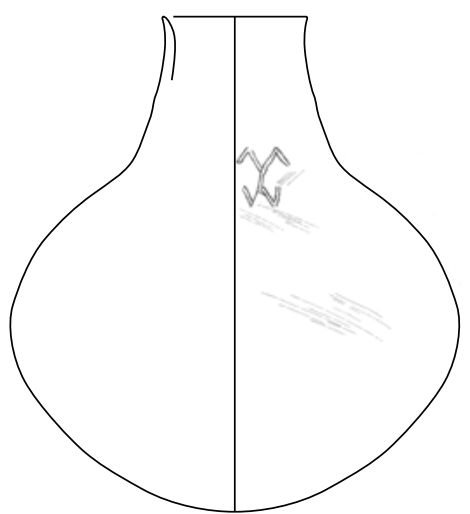

GRF 75/5

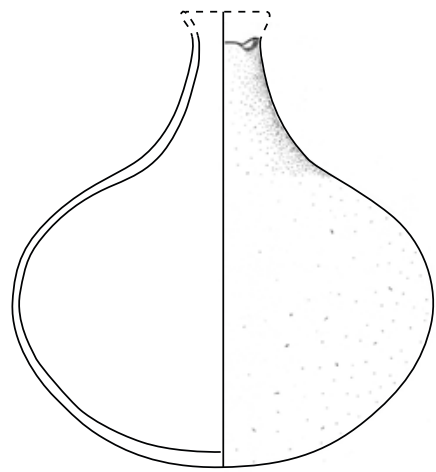

GRF 75/1

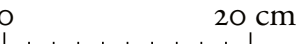




\section{Les perles et les pendentifs}

Environ 670 perles (objets à perforation centrale) et pendentifs (objets à perforation décentrée), ainsi que leurs fragments, ont été enregistrés dans de nombreuses inhumations ${ }^{1}$, et aussi dans une fosse (h) de la nécropole de Gereif Est. La majorité des perles a été trouvée dans les tombes mérö̈tiques, datées entre le $\mathrm{I}^{\mathrm{er}}$ siècle avant et le $\mathrm{III}^{\mathrm{e}}$ siècle de notre ère (infra). Les tombes 35 et 52 ont été datées du tournant de notre ère. Quelques perles associées à GrF 10 forment un ensemble datable de la fin de la période méroïtique voire du Postméroïtique. Dans un seul cas (GRF 52), toutes les perles trouvées ont pu être associées à des parties données du corps, ce qui a permis de reconstituer les différentes parures: un bracelet au bras droit (fig. 21.5), un bracelet au bras gauche (fig. 21.2), et un collier (fig. 21.4). Les perles et les pendentifs sont en matériaux organiques (coquille d'œuf d'autruche, coquille de mollusque) et inorganiques (pierre, faïence, verre). Ils sont décrits et présentés dans cet ordre dans les figures 18 à 22. Les perles sont souvent mal préservées. Les perles en faïence, qui représentent environ $61 \%$ de la collection, ont pour la plupart perdu leur revêtement, et les perles en verre et celles en verre incrusté de métal, qui représentent environ $20 \%$ de la collection, sont si altérées que cela a limité l'identification de leur type (fig. 18.10). La description de la longueur et de la forme des perles (par exemple sphériques, aplaties, en forme de tonneau, cylindriques, biconiques) suit la classification d'Horace Beck ${ }^{2}$.

Deux perles en coquille de mollusque sont très érodées et leur perforation pourrait avoir été accidentelle (fig. 18.2). Bien que l'utilisation de coquilles de mollusques dans la production des perles méroïtiques ne soit pas une tendance répandue, quelques exemples de coquilles fluviales et marines ont été enregistrés ${ }^{3}$.

$1 \mathrm{GRF} 2,4,5,10,11,12,19,24,25,26,35,43,48,50-51,52,57$, $60,66,67$ et 72 .

2 BЕСK 1928. Le rapport de longueur indique la relation entre la longueur et le diamètre de la perle. La longueur d'une perle est définie comme suit: discoïde (moins d'un tiers du diamètre), courte (plus d'un tiers et moins de neuf dixièmes du diamètre), standard (égale ou presque égale au diamètre), longue (plus d'un et un dixième du diamètre et moins de deux fois le diamètre) et très longue (plus de deux fois le diamètre). Ainsi, par exemple, un "cylindre discoïde» est un cylindre dont la longueur est inférieure à un tiers du diamètre.

3 Par exemple, Then-ObŁuska 2015. 
cinquantenaire

\section{4}

de la section

française

de la direction

des Antiquités

du Soudan
La présence de nombreuses perles en coquille d'œuf d'autruche en forme de disque et de cylindre court dans la nécropole de Gereif serait une caractéristique régionale (fig. 18.4; 20.1; 21.1; 22.1-3, 7). Les perles en coquille d'œuf d'autruche sont presque absentes des tombes méroïtiques de BasseNubie et de Begrawiya. Toutefois, certaines d'entre elles sont enregistrées dans les tombes méroïtiques de Haute-Nubie ${ }^{1}$ et dans les tombes méroïtiques tardives de la région de la quatrième cataracte ${ }^{2}$.

De minuscules perles de cornaline, d'environ $5 \mathrm{~mm}$ ou moins de diamètre, sont de forme globulaire, aplatie ou en tonneau (fig. 18.5, 12; 19.5, 10-11). Ces perles alternaient généralement avec d'autres types de perles méroïtiques ${ }^{3}$. Une grosse perle en forme de tonneau court, d'environ $12 \mathrm{~mm}$ de diamètre, a une perforation en forme de sablier (fig. 19.2) et ressemble donc plus vraisemblablement à un ensemble néolithique ou Kerma plutôt qu'à des perles méroïtiques ou plus tardives.

Le quartzite blanc et la cornaline ont été utilisés pour façonner des pendentifs en forme de goutte à base globulaire (fig. 20.5-6) ou des pendentifs en forme de goutte aplatie à base arrondie (fig. 22.4, 10). La cornaline et le cristal de roche étaient aussi utilisés dans la production de pendentifs lenticulaires avec un sommet et une base en pointe (fig. 19.4; 22.5, 8-9, 18). Les pendentifs en minéral en forme de goutte sont bien connus dans les répertoires méroïtiques de toute la Nubie 4 .

La présence de minuscules perles de faïence mesurant environ $2 \mathrm{~mm}$ de diamètre est exceptionnelle (fig. 19.13; 20.4). Leur glaçure est presque entièrement effacée, révélant le noyau blanc des perles. D’autres perles sont de forme cylindrique et globulaire (fig. 18.3; 21.7). Des perles de plus grande taille en forme de petit cylindre discoïde ou en cylindre court (fig. 18.1, 13; 19.12-13; 20.1, 9, 15; 21.2-3, 5-6; 22.14, 17) portent des traces de glaçure bleue ou bleu-vert que l'on trouve fréquemment dans les tombes méroïtiques de toute la Nubie.

Des perles beaucoup plus grandes, comme les longues perles tubulaires (fig. 18.19; 20.8), sont plus souvent trouvées dans des contextes tardifs et postméroïtiques ${ }^{5}$. Les pendentifs plats sont très probablement des noyaux de faïence érodés (fig. 20.7).

Certaines perles sont faites de verre enroulé ou plié. Elles sont généralement décorées d' "yeux ", c'est-à-dire de sections de cannes en mosäque avec un motif concentrique qui donne un effet d'œil (fig. 18.7-8;19.8).

1 Voir Then-Obeuska 2016.

2 Notamment Then-ObŁusKa 2014.

3 Then-Obeuska 2015; Then-Obeuska 2016.

4 Then-ObŁuska 2015; Then-Obeuska 2016; Then-Obeuska 2018.

5 Then-Obeuska 2014; Bashir 2007. 
GRF 2

$\mathrm{SNM} 40200$

$$
\begin{aligned}
& 000 \\
& 000
\end{aligned}
$$

GRF 4

SNM 40201
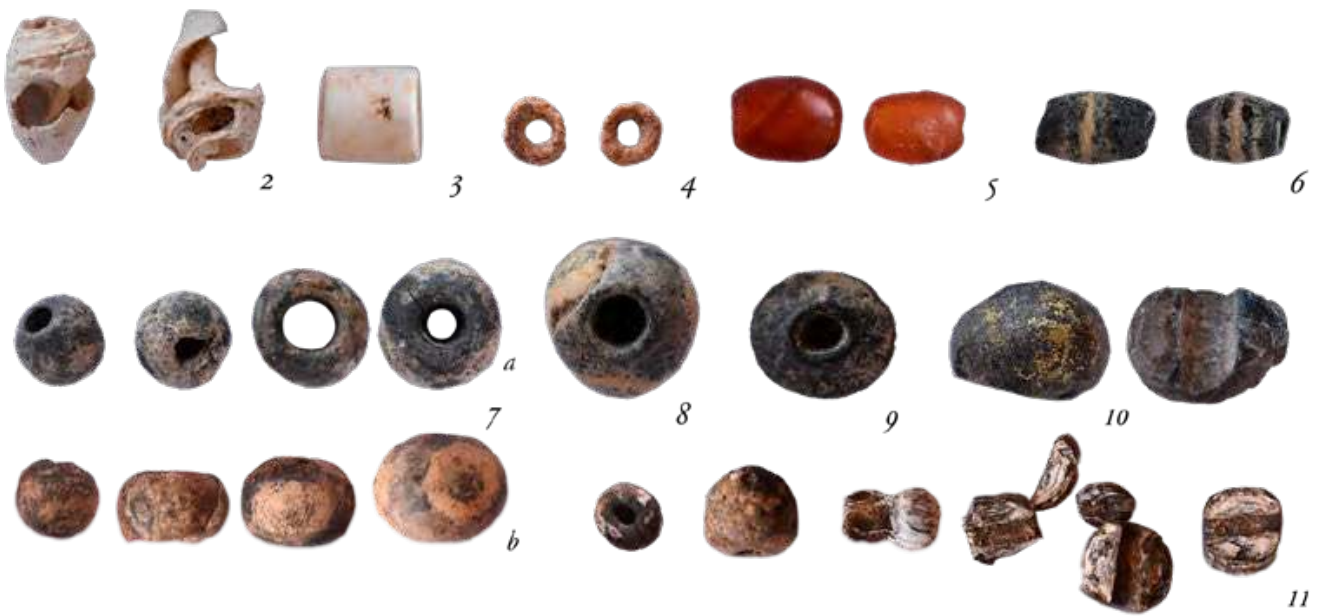

GRF 5

$\mathrm{SNM}_{402 \mathrm{O}}$

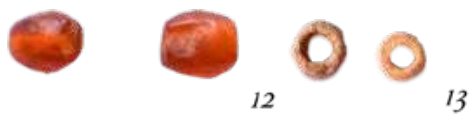

GRF 10

SNM 40203

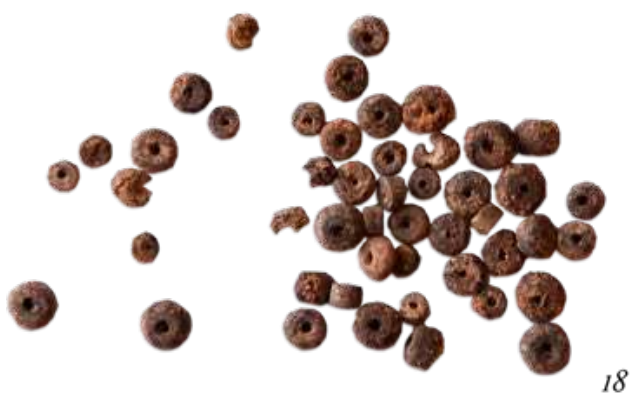

\section{GRF 10}

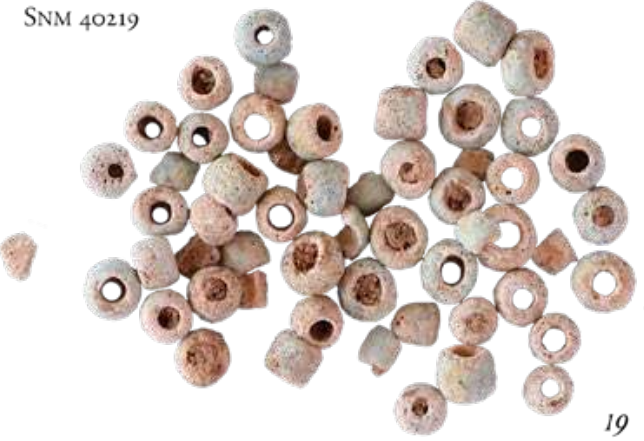

215

Gereif Est

et le

Méroïtique méridional 
GRF 11

SNM 40204
GRF 12

$\mathrm{SNM}_{4020}$

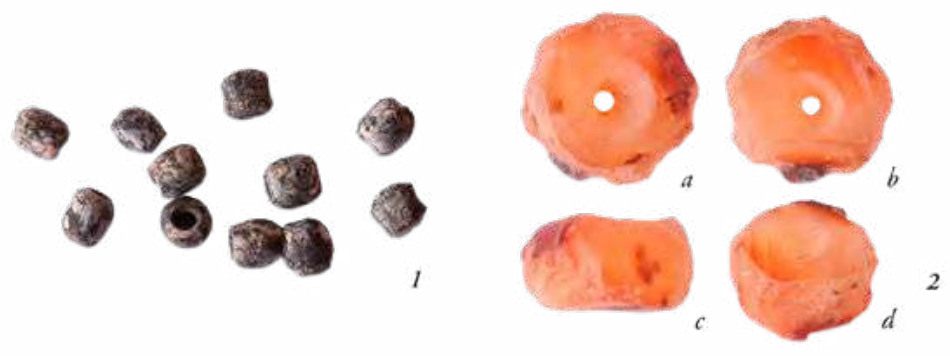

GRF 19

SNM $_{40206}$

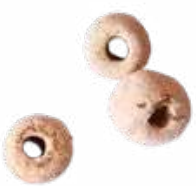

GRF 24

SNM 40207

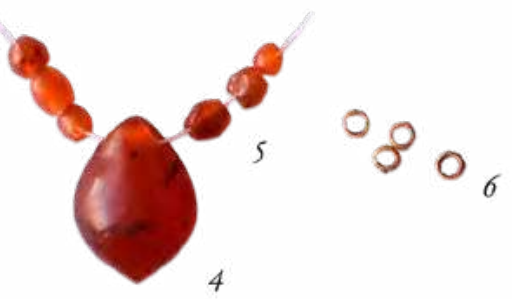

cinquantenaire

\section{6}

de la section

française

de la direction
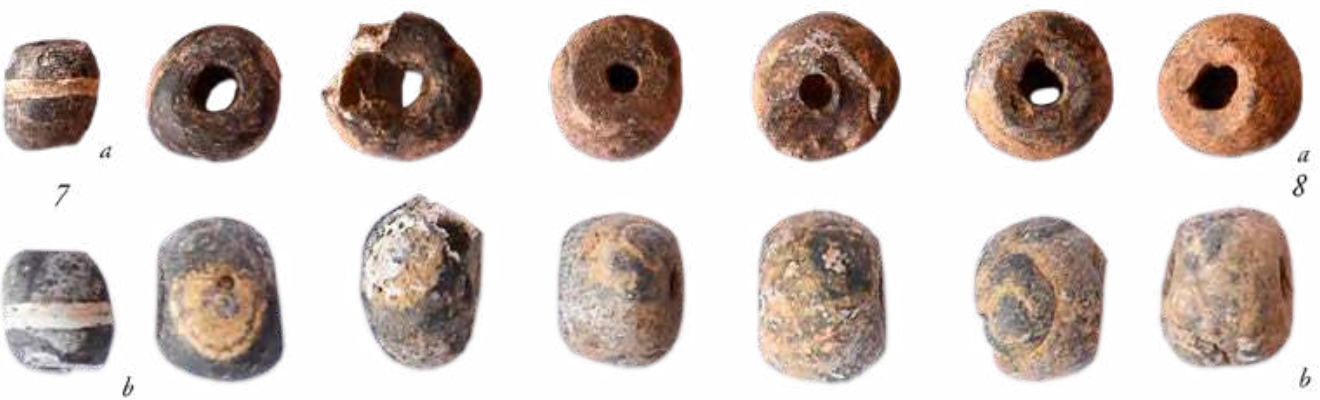

des Antiquités du Soudan

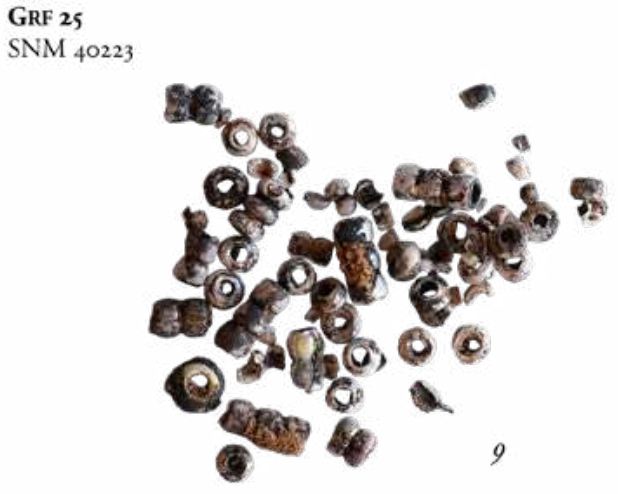

GRF 26

$\mathrm{SNM}_{40224}$

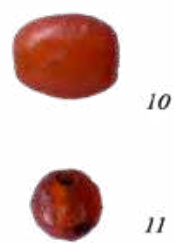

(3) 012
GRF 26

$\mathrm{SNM}_{40208}$

(c) 0013 
GRF 35

SNM 40209
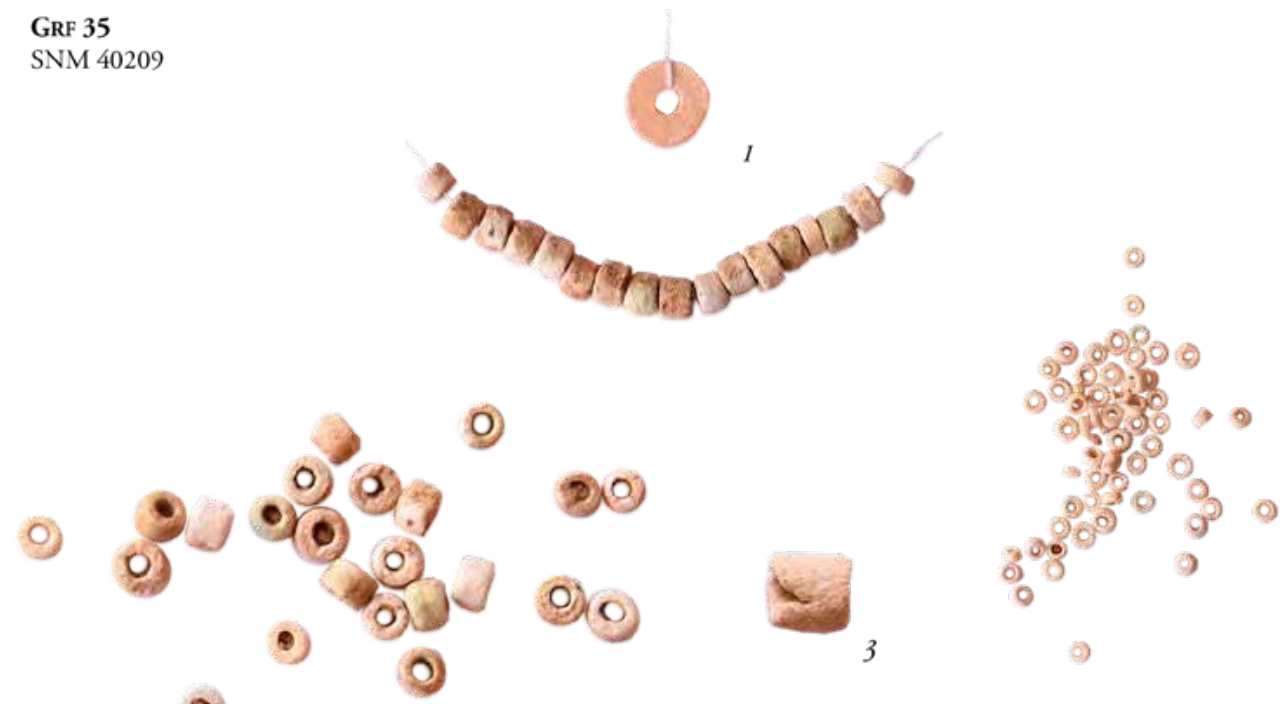

2
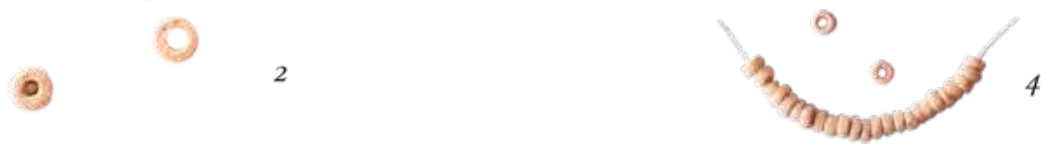

GRF 43

SNM 40210
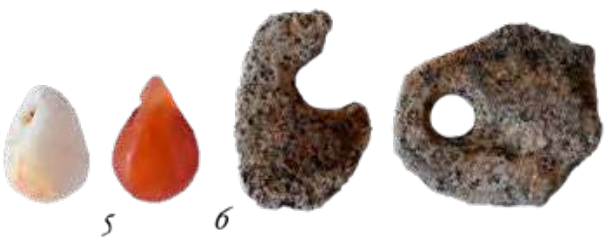

GRF 48

SNM 40222

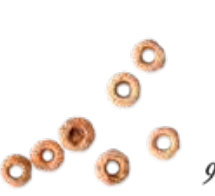

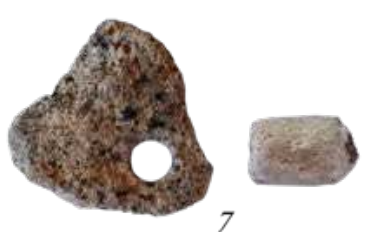
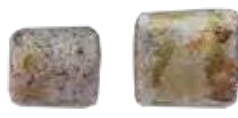

GrF 50

SNM 40212

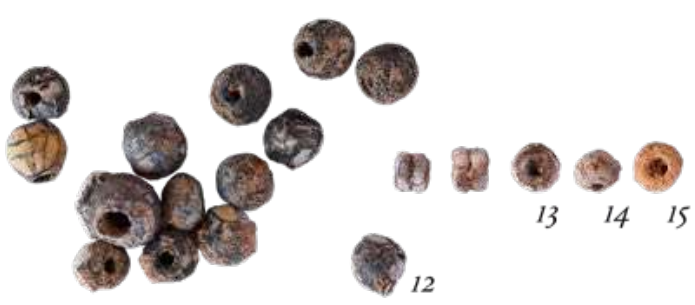

217

Gereif Est

et le

Méroïtique méridional 
GRF 52

$\mathrm{SNM}_{40213}$
GRF 52

SNM 40213

bras gauche
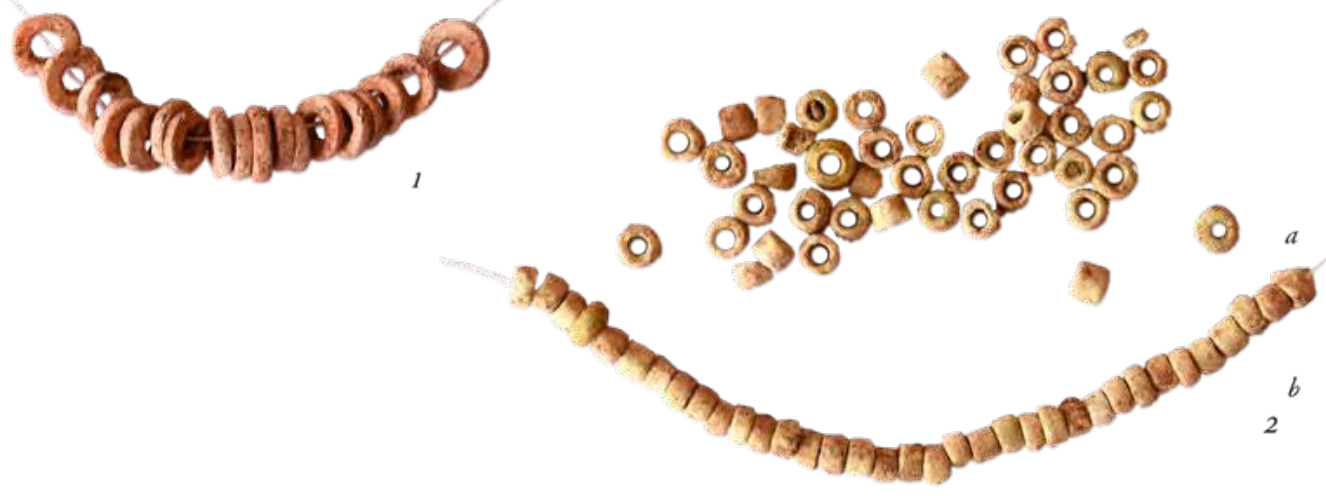

cinquantenaire

\section{8 \\ de la section \\ française \\ de la direction \\ des Antiquités \\ du Soudan}

GRF 52

$\mathrm{SNM}_{40213}$

collier
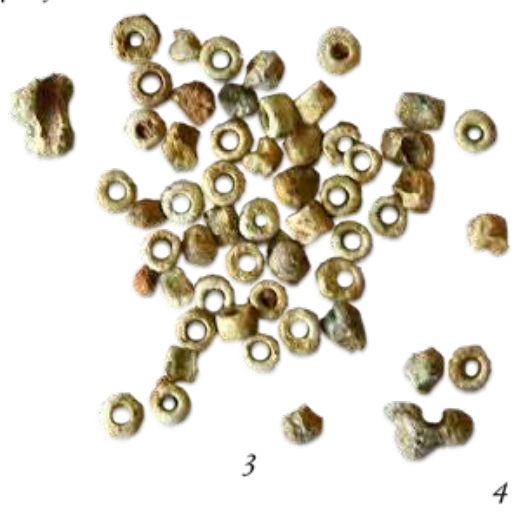

GRF 52

SNM 40213

bras droit

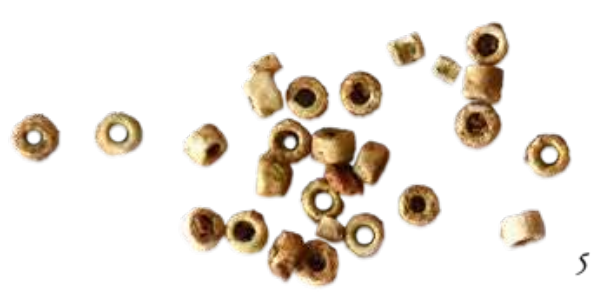

GRF 52

$\mathrm{SNM}_{40220}$

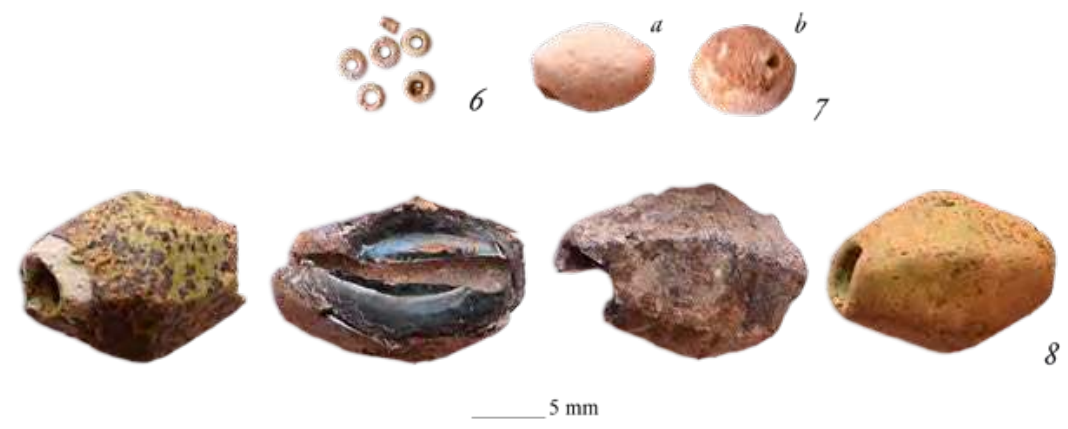


GRF 57

$\mathrm{SNM}_{40214}$
GRF 57

$\mathrm{SNM}_{40225}$
GRF 57

$\mathrm{SNM}_{40214}$

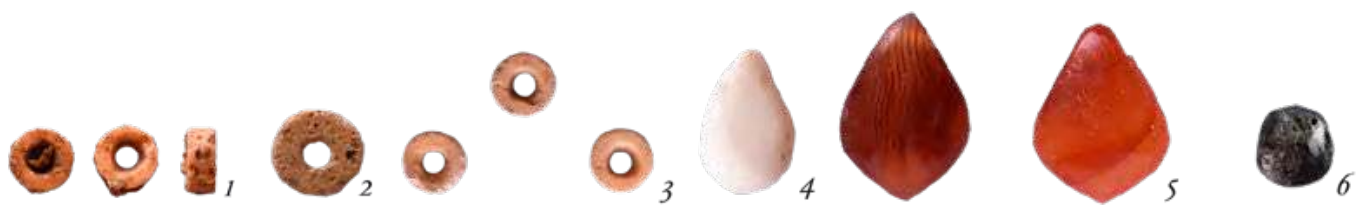

\section{GRF 60}

$\mathrm{SNM}_{40215}$
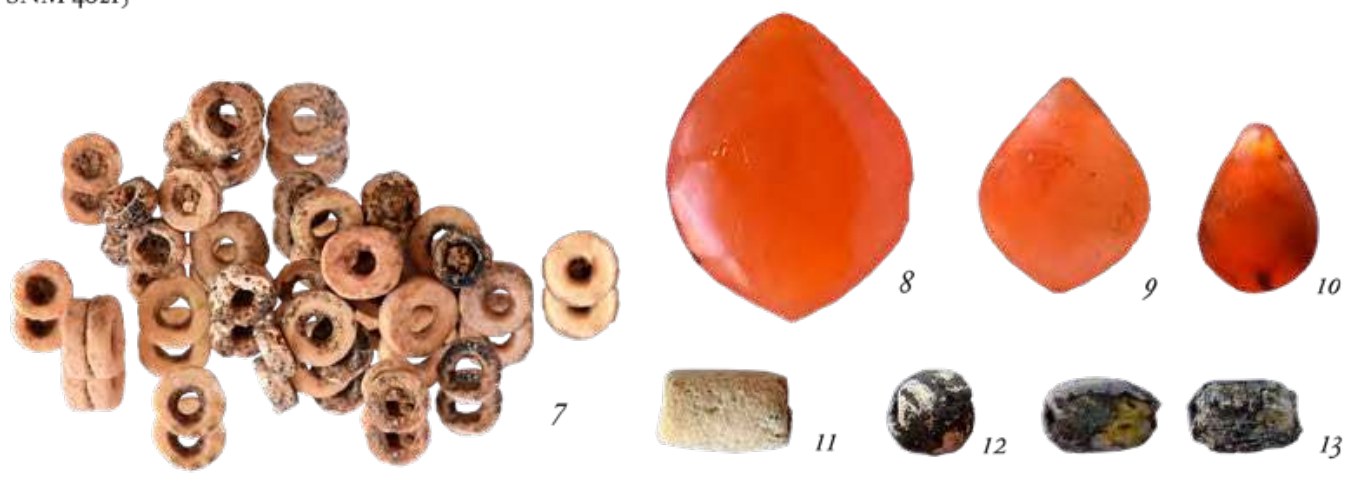

GRF 66

SNM 40216

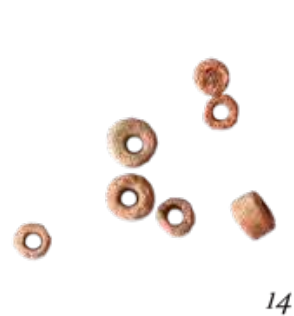

GRF 67

SNM 40217
GRF 72

SNM $_{40218}$

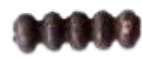

Gereif Est

et le

Méroïtique méridional
GRF -

$\mathrm{SNM}_{40221}$

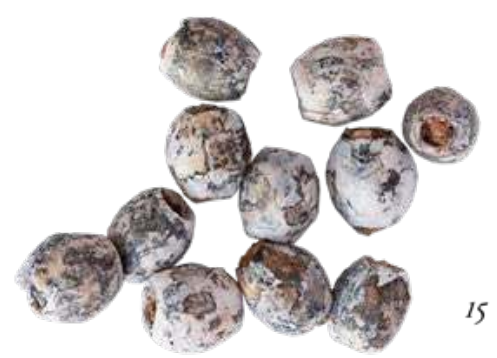

GRF -

$\mathrm{SNM}_{38941}$
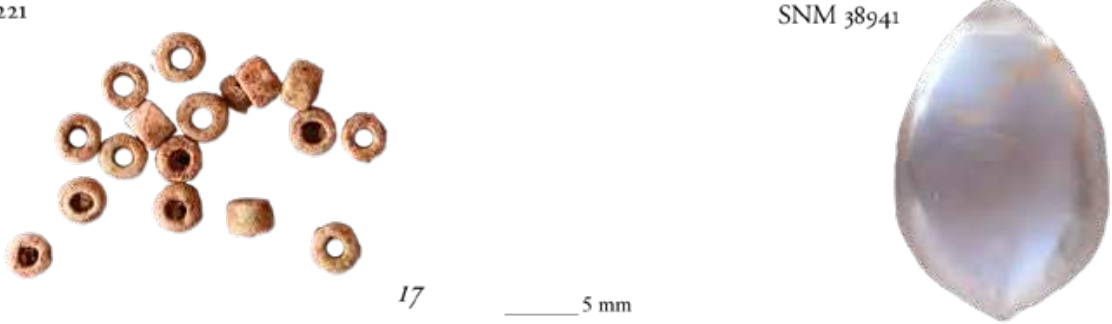
cinquantenaire

\section{0}

de la section

française

de la direction

des Antiquités

du Soudan

Alors que le corps des perles est érodé et recouvert d'une patine noirâtre, les yeux appliqués sont conservés en blanc et très probablement en bleu foncé. Des perles standards et longues de verre plié, probablement noires, sont décorées d'une bande centrale blanche (fig. 18.6, 17; 19.7). Les perles biconiques facettées, exceptionnellement grandes, mesurent environ $17 \mathrm{~mm}$ de long et sont fortement altérées (fig. 21.8).

De nombreuses perles trouvées à Gereif ont un aspect noirâtre $\mathrm{du}$ fait des conditions de conservation. Elles sont faites de verre étiré et segmenté (fig. 18.14, 18; 22.16) et de verre incrusté ou couvert de métal (fig. 18.10-11; 19.1, 9; 20.12-13; 22.13, 15). Les premières étaient fabriquées en étirant un tube de verre qui était ensuite segmenté sur un moule rainuré et brisé, ou coupé en segments simples ou multiples. D'autres pouvaient être fabriquées en pinçant un morceau du tube. D'autres tubes sont constitués de deux couches de verre entre lesquelles se trouve une couche de métal (argent ou or), et pouvaient être segmentés en perles. Le verre étiré et segmenté et les perles de verre incrusté de métal sont bien connus en Nubie méroïtique. De longs chapelets de petites perles de verre de couleur uniforme (fig. 18.18) font partie des objets de parure courants au Méroïtique Final et au Postméroïtique'.

Quatre petits anneaux, d'environ $2 \mathrm{~mm}$ de diamètre, étaient très probablement en or (fig. 19.6).

À quelques exceptions près, les assemblages de perles et de pendentifs de la nécropole méroïtique de Gereif sont conformes aux autres répertoires de perles contemporains d'autres régions de Nubie. Comme d'autres collections méroïtiques ${ }^{2}$, les assemblages de Gereif sont dominés par des perles en faïence, ensuite par des perles en verre et en verre incrusté de métal, puis par des perles en minéraux, principalement en cornaline, et des perles organiques. La présence de perles en coquille d'œuf d'autruche rend la collection de Gereif différente de la plupart de celles de Haute et de Basse-Nubie du Mérö̈tique Classique. Alors que les perles en faïence ont été enregistrées en de nombreuses couleurs en Basse et Haute-Nubie ${ }^{3}$, les perles de Berber (entre la cinquième et la sixième cataracte du Nil) et de Gereif ne conservent que des traces de glaçure bleue ou bleu-vert ${ }^{4}$. Des exemplaires de plus gros module en faïence, généralement connus dans les cimetières tardifs et postméroïtiques de Nubie, ont été trouvés à Gereif

1 Then-ObŁuska, Wagner 2019.

2 Then-ObŁuska 2015; Then-ObŁuska 2016; Then-Obeuska 2018.

3 Then-ObŁuska 2015; Then-ObŁuska 2016.

4 Then-Obeuska 2018. 
dans une tombe postméroïtique. La présence de perles décorées d' "yeux» et de perles en verre doré fait de Gereif le cimetière méroïtique connu le plus au sud où ces types ont été enregistrés jusqu’à présent au Soudan.

\section{Le mobilier métallique}

Parmi les quelques tombes ayant livré de la vaisselle métallique en alliage cuivreux possiblement importée, seuls quelques éléments ont pu être documentés. Le mobilier était en effet le plus souvent dans un état très dégradé et fragmenté (cf. Annexe 1 pour un inventaire complet). Deux tombes livrent des formes relativement communes (fig. 23). Deux coupes (GRF 24/1 et GRF 38/2), la première aux parois évasées et la seconde parfaitement hémisphérique, intègrent le répertoire étendu des formes ouvertes enregistrées dans la plupart des nécropoles méroïtiques'. Le pichet (GRF 38/3) possède quelques parallèles dont certains aident à la proposition d'une datation. Les fouilleurs, dès la découverte de l'objet, ont remarqué la similarité de l'exemplaire avec un bronze mis au jour à Sennar ${ }^{2}$. David M. Dixon lui-même, avait noté la proximité du pichet de Sennar avec celui de la tombe 115 de $\mathrm{Gemai}^{3}$. Cette tombe, dont la chronologie reste à affiner, serait à dater des environs du $\mathrm{I}^{\mathrm{er}}$ siècle avant notre ère ${ }^{4}$.

Plusieurs défunts possédaient à leurs doigts des anneaux simples ou des bagues-cachets (fig. 24). C'est un type de bijou répandu mais encore très peu étudié, sauf pour l'iconographie qu'il véhicule. Les exemplaires de Gereif sont malheureusement trop peu préservés pour en tirer une quelconque information dans l'état actuel de nos connaissances.

1 Voir par exemple Dunham 1957, fig. N; Bates, Dunham 1927, pl. LXV; Caneva 1988, p. 199, fig. 24b-c. Pour une brève synthèse, voir Francigny 2016, p. 132-133.

2 Geus, Lenoble 1983b, p. 26. Voir Dixon 1963, p. 231, pl. xlix, A21637.

3 Bates, Dunham 1927, pl. xxxi, pl. LXvi, fig. 2.

4 Cette tombe a livré deux inscriptions méroïtiques (REM 1013 et 1014) dont la paléographie indiquerait une datation comprise entre la seconde moitié du $\mathrm{II}^{\mathrm{e}}$ s. et le $\mathrm{I}^{\mathrm{er}}$ s. avant notre ère: Cl. Rilly, correspondance du 12 avril 2020. Cela conviendrait à la chronologie supposée des bronzes répertoriés selon TöRöK 1989, p. 127, $\mathrm{n}^{\circ} 53$ mais s'éloignerait des données recueillies dans HofmanN 1978, p. 214, 220 qui les date plus tardivement. La jarre inscrite (Rem 1013) est d'une forme et d'un style iconographique comparable à des jarres de Gabati datées aux environs du milieu du $\mathrm{I}^{\text {er }}$ siècle de notre ère: EDWARDS 1998, fig. 6.3, nos 2901 et 2902 et p. 247 pour la datation au radiocarbone de la tombe 29 .

5 FrancignY 2016, p. 124-125. 
La tombe de GrF 8 contenait trois pointes de flèche dont une asymétrique et triangulaire à barbelure unique (fig. 24) ${ }^{1}$. Si ce type spécifique est connu à la période méroïtique, il est prépondérant au Postméroïtique². Cette dernière datation correspondrait à la position de GRF 8 à l'ouest de la carrière.

\section{Le petit mobilier}

cinquantenaire

\section{2}

de la section

française

de la direction des Antiquités du Soudan
Outre le mobilier en métal, quelques autres objets figurent dans l'inventaire des découvertes de Gereif. Une pointe de flèche taillée (fig. 24), que nous supposons en cornaline ou en calcédoine, est associée à une sépulture de surface (GRF 64). Sa datation méroïtique est sujette à caution mais elle n'est pas exempte de parallèles parmi les sites du Soudan central et en Nubie ${ }^{3}$. Des boucles d'oreilles (fig. 24) en minéral blanc poli (quartz?) ont par deux fois été découvertes au niveau de la tête du défunt (GRF 26 et GrF 56). L'objet est d'une forme assez peu commune et apparaît en contexte napatéen et méroïtique à Méroé et au Gébel Moya ${ }^{4}$. Aussi, deux scarabées en faïence rappellent l'influence d'une coutume d'origine égyptienne très largement diffusée jusqu'aux confins méridionaux du royaume méroïtique ${ }^{5}$. Enfin, les fouilleurs observent à plusieurs reprises (GRF 4, GRF 1O, GRF 19, GRF 20) des «traces rouges " qu'ils interprètent comme les vestiges d'habits en cuir, éléments tout à fait répandus dans le royaume méroïtique ${ }^{6}$.

\section{Discussion}

L'examen du mobilier archéologique autorise en premier lieu un commentaire sur la chronologie de la nécropole. La zone 1 a fourni très peu de mobilier dont la datation est assurée. Aussi, parmi les quelques tombes dont le matériel nous est parvenu, GRF 38 est sans doute l'une des plus anciennes: la jarre (GRF 38/1) et les bronzes découverts à l'intérieur pourraient placer l'inhumation entre la seconde moitié du $\mathrm{II}^{\mathrm{e}}$ et la fin de $\mathrm{I}^{\mathrm{er}}$ siècle avant notre ère. Une datation plus large des $\mathrm{I}^{\mathrm{er}}$ siècle avant et $\mathrm{I}^{\mathrm{er}}$ siècle de notre ère pourrait être proposée pour le mobilier associé aux individus GRF 24 et GRF 35 . Parmi les tombes fouillées lors de la première campagne dans un secteur

1 Nous remercions Faïza Drici pour son éclairage sur ce type de mobilier.

2 Voir Lenoble 1997; Lenoble 1999; Lenoble 2006.

3 Dunham 1957, p. 69, fig. 42, pl. LXv; Dunham 1963, p. 265 , fig. 170.4; WeLsBY 2004, p. 153.

4 Dunham 1957, p. 35, fig. 23.O; Addison 1949, pl. LiI, Liv.B.

5 Francigny 2016, p. 123.

6 En dernier lieu Yvanez 2018. 


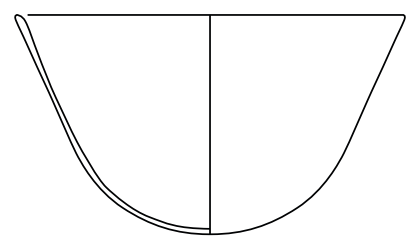

GRF 24/1

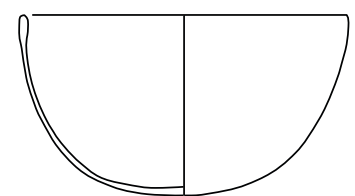

GRF 38/2

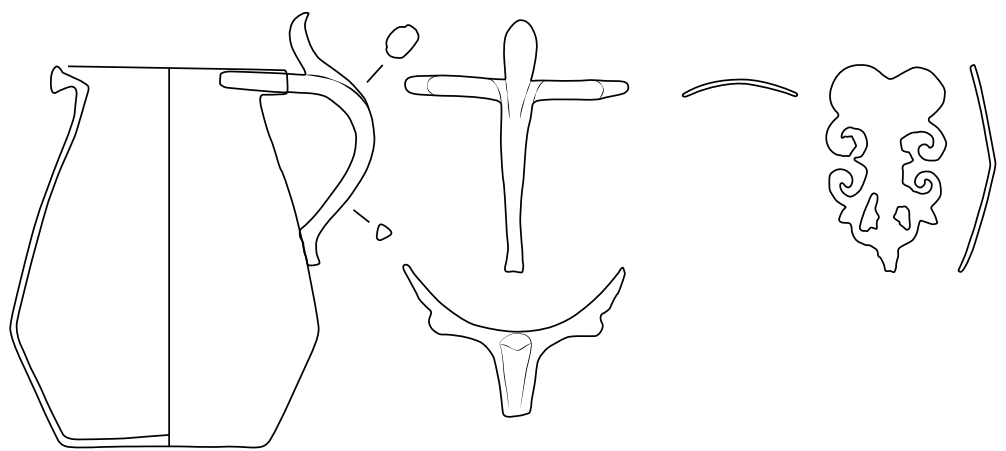

GRF 38/3
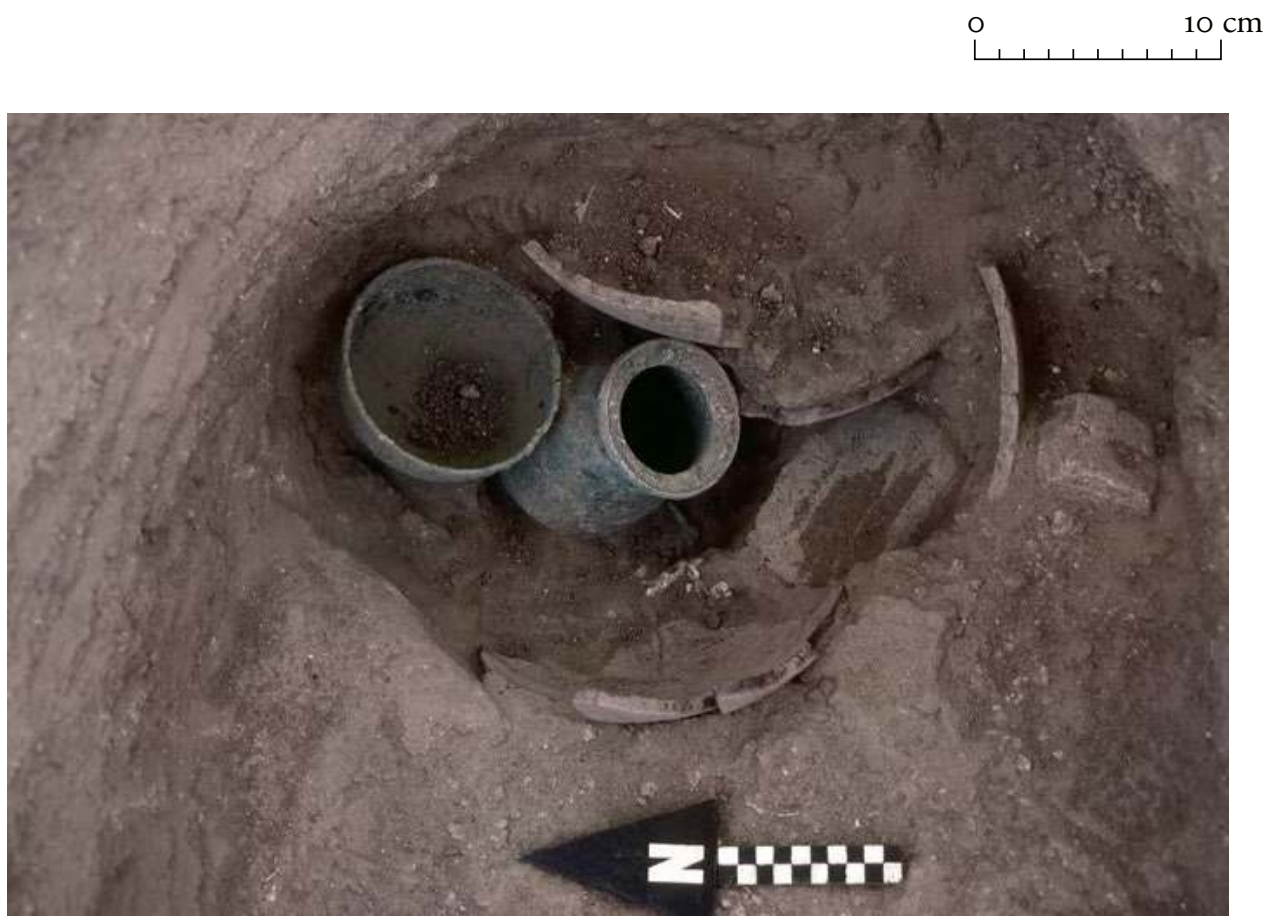

Gereif Est et le

Méroïtique méridional

\section{GRF 38}

23. Vaisselle métallique en alliage cuivreux. 


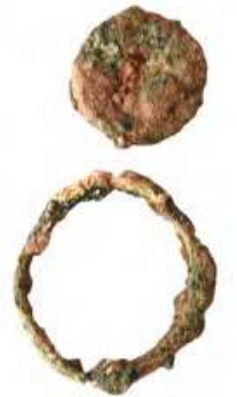

GRF 52/2
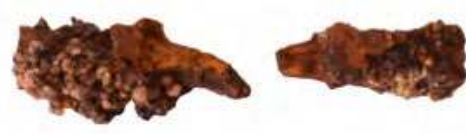

cinquantenaire

\section{4}

de la section

française

de la direction

des Antiquités

du Soudan

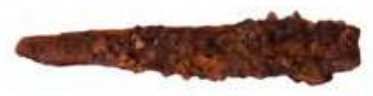

GRF 8/1

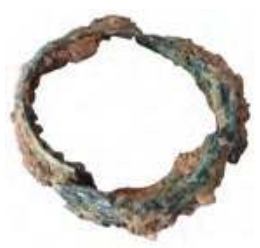

GRF 57/2

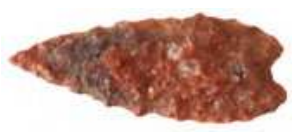

GRF 64/1
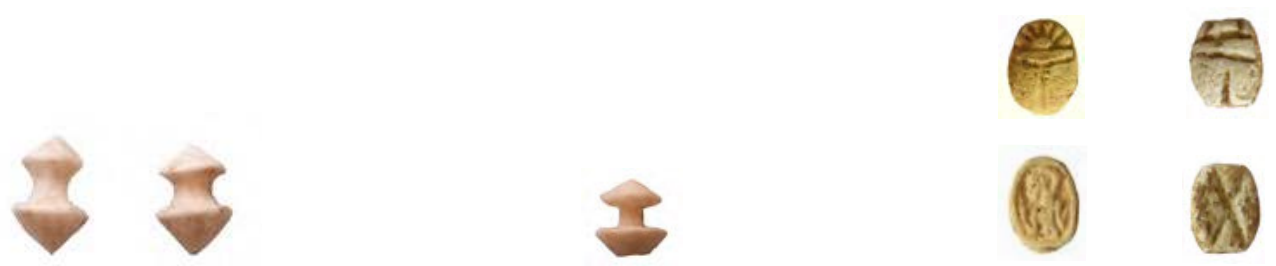

GRF 26/2
GRF 56/2
GRF $60 / 3$

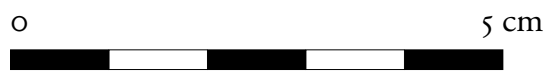


adjacent à la zone 1, les perles mises au jour dans la fosse abritant GRF 10 seraient, en toute vraisemblance de datation tardive, du Méroïtique Final voire du Postméroïtique. Comme nous l'avions signalé en introduction, la zone 2 est plus riche d'enseignement. Les deux jarres semblables associées aux individus GrF 45 et GrF 50 (fig. 9) dateraient les inhumations les plus anciennes du secteur dans une chronologie comprise entre le II $^{\mathrm{e}}$ et le $\mathrm{I}^{\mathrm{er}}$ siècle avant notre ère. Dans une fourchette un peu plus récente correspondant au Méroïtique Classique figurerait le groupe formé par les individus GRF 21, 22, 25 et 28 trouvés dans des niches juxtaposées, ainsi que GrF 26, GrF 52, GrF 56, GrF 57 et GrF 60 sur la base de la datation supposée des jarres en W16 (supra). S'y ajouterait également le mobilier des inhumations de GRF 43, GRF 49 et GrF 67 sans que l'on puisse pour autant l'assurer tant notre connaissance de l'évolution des productions non tournées fait défaut. La séquence formée par les inhumations de GRF 2, GRF 3 et GRF 4 - cette dernière possédant un parallèle exact en GRF 31 (infra, Annexe 1) - serait à placer au cours du $\mathrm{I}^{\mathrm{er}}$ siècle de notre ère. GRF 48 présente un assemblage que nous situerions dans une phase réduite à la seconde moitié du $\mathrm{I}^{\mathrm{er}}$ et au II ${ }^{\mathrm{e}}$ siècle de notre ère. Le mobilier de GRF 6 et celui de GRF 29, dont la proximité entre les coupes peintes a été notée (supra, fig.7), intégreaient un faciès des II $^{\mathrm{e}}$ et III ${ }^{\mathrm{e}}$ siècles de notre ère. Enfin, à l'ouest de la carrière, les inhumations de GrF 1 et GrF 75 interviendraient dans une phase avancée du Postméroïtique, voire à la transition avec la période chrétienne. Ces données signalent que les zones fouillées de la nécropole méroïtique ont atteint des secteurs relativement anciens, majoritairement datables du Méroïtique Classique, alors que les tombes tardives sont peu présentes. Notre perception reste insuffisante pour saisir un développement ordonné de la nécropole, si ce n'est cette répartition est-ouest entre les tombes méroïtiques et postméroïtiques.

L'imprécision des datations, avec ces fourchettes chronologiques larges, reflète l'état de notre connaissance de l'évolution des productions céramiques comme du reste du mobilier. On peut néanmoins caractériser de manière générale le faciès de Gereif. Ses inventeurs notaient déjà l'intérêt de sa position intermédiaire entre la région de Méroé et la zone du Nil Bleu des confins méridionaux ${ }^{1}$. Le corpus des céramiques de Gereif répond parfaitement à ces attentes tant on perçoit d'un côté l'intégration du site dans les circuits économiques méroïtiques - dont les formes tournées (classées en $\mathrm{W}_{1}, \mathrm{~W}_{3}$ et $\mathrm{W}_{4}$ ) se font le principal écho - et, de l'autre, l'apport de productions dont les références sont à chercher parmi les rares sites plus méridionaux connus comme Gébel Moya ou Abu Geili. Nous avons

1 Geus, Lenoble 1983b. 
cinquantenaire

\section{6}

de la section

française

de la direction

des Antiquités

du Soudan déjà discuté des styles de décorations des céramiques non tournées rouges (W14, supra) mais il semblerait que la production elle-même, au moins au Méroïtique Classique, soit associée à des pratiques des régions du Nil Bleu plutôt qu'à la région de Méroé. Seuls les niveaux postérieurs au II siècle de notre ère en attestent à Mouweis comme à el-Hassa, alors qu'elle apparaît fréquemment au Gébel Moya au point d'être qualifiée de «locale "'. Il en est de même concernant quelques céramiques non tournées noires (W6) dont le style décoratif (e.g. GRF 50/2, GRF 52/1) possède plus de parallèles avec les sites du Nil Bleu qu'avec le reste du royaume méroïtique.

Les céramiques classées en $\mathrm{W}_{16} 6$ sont en revanche bien diffusées au Soudan central et comptent quelques exemplaires en Nubie. La concentration de ces productions à Gereif peut trouver une explication d'ordre chronologique - les datations proposées du tournant de notre ère sont en effet peu fréquentes dans les nécropoles méroïtiques étudiées jusqu'à présent - comme indiquer la proximité d'un centre de production. Le recours à une iconographie singulière, tout à fait identifiée, tels que ces motifs vus comme la schématisation d'un épi de sorgho (GRF 26/1, GrF 48/1, GrF 56/1), et la récurrence des attestations dans la partie centrale et méridionale du royaume méroïtique sont autant d'éléments permettant de circonscrire une production majeure du Méroïtique Classique témoignant des échanges entre la région de Méroé et sa périphérie méridionale. Elle peut être amenée à devenir, comme d'autres l'ont été avant elle ${ }^{2}$, un instrument pertinent d'illustration de pratiques potières bien ancrées régionalement. Aussi pouvons-nous signaler une distribution comparable des céramiques issues des tombes postméroïtiques que ce soient les formes ouvertes ou les jarres (infra) qui contribuent, à leur tour, à circonscrire une zone d'influence de ce qui deviendra, à l'époque chrétienne, le royaume d'Alodia ${ }^{3}$.

D’un point de vue plus général, les données funéraires recueillies à Gereif Est intègrent, comme les fouilleurs l'avaient dès le début suggéré, des pratiques reliées à ce que nous connaissons du Méroïtique méridional. La forme des tombes, la position du défunt et le mobilier qui lui est associé favorisent une approche régionale que Gereif contribue à illustrer ${ }^{4}$. Depuis la découverte de cette nécropole, plusieurs prospections et de rares

\footnotetext{
1 ADDISON 1949, p. 210: «If one kind of pottery more than another can be called distinctively "Jebel Moya pottery" it is this ware with scratched pattern, and particularly the red-polished ware». GIBBs 2018, fig. 9 , c-d pour quelques exemples,

2 LeNoble 1995.

3 LENOBLE 2018, p. 261-276.

4 FranCignY 2016; Edwards 2004, p. 175.
} 
fouilles ont permis une meilleure compréhension de la place particulière que tiennent les sites de la Gezira dans l'approvisionnement de la capitale'. Les liens économiques - et peut-être politiques — unissant Méroé et sa périphérie méridionale ne sauraient masquer une influence autre, culturellement dissociée du Soudan central, que la reprise des investigations au Gébel Moya ${ }^{2}$ et la poursuite des prospections le long des rives du Nil Blanc et du Nil Bleu ne cessent de mettre en lumière ${ }^{3}$.

C'est là l'un des débouchés de l'étude prometteuse souhaitée par Francis Geus et Patrice Lenoble, dont la conclusion à l'article publié dans les Meroitic Newsletter demeure plus que jamais d'actualité: « Cette fouille est cependant l'occasion propice de reprendre l'ensemble des données éparses, souvent impubliées, déjà acquises dans la région de Khartoum et de les ordonner à l'aide d'une investigation ponctuelle et systématique, en sériant les points faibles de notre connaissance et en dirigeant la problématique vers les questions de la densité d'occupation, de l'identification anthropologique, des échanges économiques et de la chronologie céramique. L'urgence de ce travail n'est pas moins grande car la ville moderne se développe à un rythme impressionnant dans la région du confluent. Plusieurs campagnes de fouille, une attention soutenue de la Direction des Antiquités et une coopération avec les autres missions archéologiques présentes aux alentours de Khartoum devraient permettre d'y pourvoir. $\boldsymbol{m}$ 


\section{annexe I : listing des tombes fouillées et mobilier associé 1}
individu
fosse
zone
description de la tombe

GRF 1

4

GRF 2

Deux fosses contiguës dont la descenderie commune a disparu.

Les trois squelettes adoptent une position identique, avec une séquence chronologique 4-3-2 et un démontage partiel du squelette 3 [GRF 3] (Geus, Lenoble 1982, p. 13). GrF 2 et 3 seraient adolescents, GrF 4, un adulte. Une grande trace rouge (empreinte de cuir?) est observée entre les jambes de GrF 4 (Cahiers 1982, du 23/12/1981 au 11/o1/1982).

GRF 3

GRF 4
Crâne d'enfant, en réduction en bordure N-E de la fosse abritant GrF 7. (Cahiers 1982, 23/12/1981).

Tombe ouverte dans la coupe de la sablière. Aucun plan ni schéma. Ossements résiduels ne permettant pas d'observer la position originale de l'individu. Tombe entièrement détruite par des pilleurs (Cahiers 1982, du 14/12 au 16/12/1981).

GRF 7

Tombe ouverte dans la coupe de la sablière. Fosse partiellement préservée (Cahiers 1982, du 15/12/1981 au 05/01/1982).

GRF 8 sud de GrF 1

Terre noire très remarquable dans un sable peu dur. La stratigraphie coupe la tombe dans le sens de la largeur et une descenderie se dégage vers l'O ou le N-O. On trouve autour quelques tessons d'un même vase éparpillé par les creusements de terre, 2 dents bien usées. Tombe-silo supposée (Cahiers 1982, du 19/12 au 20/12/1981).

1 Nous nous référons aux notes des carnets de fouilles pour compléter nos observations. Les citations in extenso des carnets sont signalées en italique. Les datations sont précisées quand le matériel nous y autorise. On en trouvera la justification supra. 
GRF 1/1: céramique (fig. 17)

GRF 1/2 : céramique (fig. 17)

GRF $1 / 3$ : céramique (fig. 16)

GRF 1/4: céramique (fig. 16)
Postméroïtique

$\mathrm{V}^{\mathrm{e}}-\mathrm{VI}^{\mathrm{e}} \mathrm{s}$. de notre ère

\section{Mérö̈tique}

GRF 2/2 : céramique (fig. 12)

Lot de perles (fig. 18)

$\mathrm{I}^{\mathrm{er}} \mathrm{s}$. de notre ère

Méroïtique

${ }^{\mathrm{er}}$ s. de notre ère

GRF 4/21: céramique (fig. 8)

Méroïtique

tête au S, regardant l'O.

GRF 4/24: céramique (fig. 9)

GRF 4/25: céramique (fig. 12)

$\mathrm{I}^{\mathrm{er}} \mathrm{s}$. de notre ère

Lot de perles (fig. 18)

Lot de perles (fig. 18)

Méroïtique

\section{Méroïtique}

GRF 6/2: céramique (fig. 7)

GRF 6/3: céramique (fig. 7)

$\mathrm{II}^{\mathrm{e}}-\mathrm{III}^{\mathrm{e}} \mathrm{s}$. de notre ère
Décubitus latéral, position contractée, N-S, tête au S, regardant l'E.
GRF 7/1: céramique (fig. 10)

GRF 8/1: 3 pointes de flèche (fig. 24)
2 dents d'adultes.

Postméroïtique? 
individu

fosse

GRF 9

GRF 10

1

1

$\begin{array}{ll}\text { GrF } 12 & \text { sud de GrF } 1 \\ \text { GrF } 13 & \text { sud de GrF } 1\end{array}$

description de la tombe

Structure vide, pillée lors de la fouille, matérialisée par quelques os seulement (Cahiers 1982, 20/12/1981).

Tombe ouverte dans la coupe de la sablière. Fosse individuelle dans laquelle seuls les os des jambes sont conservés, dans un état particulièrement altéré. "Traces rouges» interprétées comme des résidus de cuir sur la partie du fémur proche de la hanche (Cahiers 1982, du 19/12/1981 au 17/01/1982).

Tombe ouverte dans la coupe de la sablière. Fosse individuelle au contenu extrêmement compact et limoneux. Seule la partie supérieure d'un individu est dégagée (Cahiers 1982, du 19/12/1981 au 17/01/1982).

Fosse vide mais contenant beaucoup de mobilier néolithique (Cahiers 1982, du 21/12/1981 au 15/01/1982).

Simple extrémité de fosse relativement profonde et vide (Cahiers 1982, du 21/12/1981 au 15/01/1982).

GrF $14 \quad 2$ Tombe ouverte dans la coupe de la sablière. Fosse ellipsoïdale N-S, à descenderie, au fond de fond pentu et prononcé vers l'O. Squelette détérioré et partiellement détruit par un terrier. Aucun matériel (Cahiers 1982, du 09/01 au 17/01/1982).

cinquantenaire

GRF 15

2

Tombe ouverte dans la coupe de la sablière. Fosse ellipsoïdale N-S dont la descenderie manque (Cahiers 1982, du 09/01 au 17/01/1982).

GRF 16

Tombe matérialisée par quelques ossements, sans contour de fosse clairement défini (Cahiers 1982, du 15/01 au 16/01/1982).

de la section

française

GRF $17 \quad$ aw

Tombe ouverte dans la coupe de la sablière. Aucune information sur la substructure.

GrF $18 \quad 2$ (?) Tombe à situer une dizaine de mètres au $\mathrm{N}$ de la zone 2. Fosse réutilisée pour installer GRF 69, conduisant à la réduction partielle de GRF 18. Aucun objet associé découvert (Cahiers 1983, du 14/03 au 02/05/1983).

GRF 19

$\mathrm{d}$

2
Fosse à inhumations multiples, descenderie unique. GRF 19 est en réduction dans la descenderie. GrF 20 est complet, dans la fosse. Les deux corps montrent des «traces rouges» au niveau du bassin interprété comme les restes d'un pagne en cuir (Cahiers 1983, du 12/03 au 16/04/1983).

GRF $20 \quad$ d 2


Quelques ossements

Décubitus latéral, position contractée, N-S, tête au S., regardant l'E d'après la position des jambes.
Lot de perles (fig. 18)

Méroïtique
Décubitus latéral, position contractée, N-S, tête au N, regardant l'O.
Lot de perles (fig. 19)

Méroïtique
1 perle (fig. 19) Néolithique?

Décubitus latéral, position contractée, N-S, tête au S, regardant l'O.

Décubitus latéral, position contractée, N-S, tête au $S$, regardant l'O.
- Méroïtique

Médiéval?

Méroïtique

Décubitus latéral, position contractée, N-S, $-$ tête au N, regardant l'E.

Squelette réduit dans la descenderie, partiellement Lot de perles (fig. 19)

Méroïtique préservé.
Gereif Est

et le

Méroïtique méridional
Décubitus latéral, position contractée, N-S, tête au S, regardant l'O.
7 fgts. de dalettes

Méroïtique

27 fgts. de grès signalant peut-être les vestiges d'une structure en pierre signalant la tombe

35 fgts. de meules et de molettes 


\begin{tabular}{|c|c|c|c|}
\hline individu & fosse & zone & description de la tombe \\
\hline GRF 21 & c & 2 & $\begin{array}{l}\text { Fosse large avec un remplissage limoneux à } 4 \text { «niches» contenant } \\
\text { chacune un individu (GRF 21, 22, } 25 \text { et } 28 \text { ). L'hypothèse d'une tombe } \\
\text { collective est contrariée par l'existence de plusieurs descenderies } \\
\text { se recoupant. La succession des inhumations observée par les fouilleurs } \\
\text { s'organise de la manière suivante: GRF 21, puis recoupement partiel } \\
\text { par GRF 22; installation de GRF } 25 \text { et enfin GRF } 28 \text { (Cahiers } 1983 \text {, } \\
\text { du 12/O3 au 25/O4/1983). }\end{array}$ \\
\hline GRF 23 & 1 & 1 & Fosse rectangulaire, sans mobilier (Cahiers 1983, du 17/03 au 29/03/1983). \\
\hline GRF 24 & e & 1 & $\begin{array}{l}\text { Fosse ellipsoïdale à descenderie située à l'O. Tombe pillée dont seuls } \\
\text { les os des jambes sont en place, deux bracelets de chevilles sont identifiés } \\
\text { (Cahiers } 1983 \text {, du 17/03 au 05/04/1983). }\end{array}$ \\
\hline GRF 25 & c & 2 & $\begin{array}{l}\text { Fosse large avec un remplissage limoneux à } 4 \text { "niches» contenant } \\
\text { chacune un individu (GRF 21, 22, } 25 \text { et 28). L'hypothèse d'une tombe } \\
\text { collective est contrariée par l'existence de plusieurs descenderies } \\
\text { se recoupant. La succession des inhumations observée par les fouilleurs } \\
\text { s'organise de la manière suivante: GRF 21, puis recoupement partiel } \\
\text { par GRF } 22 \text {; installation de GRF } 25 \text { et enfin GRF } 28 \text { (Cahiers } 1983 \text {, } \\
\text { du 12/O3 au 25/O4/1983). }\end{array}$ \\
\hline GRF 26 & q & 2 & $\begin{array}{l}\text { Fosse ellipsoïdale, creusée partiellement à travers le sable à gros } \\
\text { grains ronds, au débouché d'une descenderie ouverte à l'E. } \\
\text { Pillage de la cavité mais mobilier partiellement in situ (Cahiers } 1983 \text {, } \\
\text { du 17/03 au 05/04/1983). }\end{array}$ \\
\hline GRF 27 & $\mathrm{p}$ & 2 & $\begin{array}{l}\text { Fosse signalée par un mélange sableux bien jaune. Tombe pillée, } \\
\text { sans matériel inventorié (Cahiers 1983, du 17/03 au 26/03/1983). }\end{array}$ \\
\hline GRF 28 & c & 2 & $\begin{array}{l}\text { Fosse large avec un remplissage limoneux à } 4 \text { "niches» contenant } \\
\text { chacune un individu (GRF 21, 22, } 25 \text { et } 28 \text { ). L'hypothèse d'une tombe } \\
\text { collective est contrariée par l'existence de plusieurs descenderies } \\
\text { se recoupant. La succession des inhumations observée par les fouilleurs } \\
\text { s'organise de la manière suivante: GRF 21, puis recoupement partiel } \\
\text { par GRF } 22 \text {; installation de GRF } 25 \text { et enfin GRF } 28 \text { (Cahiers } 1983 \text {, } \\
\text { du 12/O3 au 25/O4/1983). }\end{array}$ \\
\hline
\end{tabular}


Décubitus latéral, position contractée, N-S, tête au $S$, regardant l'O. Partie inférieure manquante.

$\mathrm{I}^{\mathrm{er}} \mathrm{s}$. av. notre ère-

$\mathrm{I}^{\mathrm{er}} \mathrm{s}$. de notre ère

Décubitus latéral, position contractée, N-S, tête au S, regardant l'O.

Méroïtique
$\mathrm{I}^{\mathrm{er}} \mathrm{s}$. av. notre ère-

$\mathrm{I}^{\mathrm{er}} \mathrm{s}$. de notre ère

Mérö̈tique

tête à l'O, regardant le N.

Décubitus latéral, position contractée, O-E, tête à l'O.

Décubitus latéral, position contractée, N-S, tête au S, regardant l'O.
GRF 24/1 : bol en bronze (fig. 23)

Lot de perles formant au moins deux bracelets de cheville et un collier (fig. 19)

GRF 25/1: céramique (fig. 8)

Lot de perles (fig. 19)
Méroïtique

$\mathrm{I}^{\text {er }} \mathrm{s}$. av. notre ère-

$\mathrm{I}^{\mathrm{er}}$ s. de notre ère

Méroïtique

$\mathrm{I}^{\mathrm{er}} s$. av. notre ère-

$\mathrm{I}^{\mathrm{er}} \mathrm{s}$. de notre ère

Décubitus latéral, position contractée, N-S, tête au S, regardant l'O.

GRF 26/1 : céramique (fig. 14)

Méroïtique

GRF 26/2: 2 boucles d'oreilles (fig. 24)

Lot de perles en faïence formant un bracelet

$\mathrm{I}^{\mathrm{er}} \mathrm{S}$. av. notre èreporté à mi-bras (fig. 19)

$\mathrm{I}^{\mathrm{er}} \mathrm{s}$. de notre ère

Perles en cornaline (fig. 19)

Éléments de boîte en bronze (non illustré)

Décubitus latéral, position contractée, N-S, tête au S, regardant l'O.

Décubitus latéral, position contractée, N-S, tête au S, regardant l'O.

GRF 28/1 : céramique (fig. 8)

\section{Méroïtique}

$\mathrm{I}^{\text {er }} S$. av. notre ère-

$\mathrm{I}^{\mathrm{er}} \mathrm{s}$. de notre ère
Gereif Est

et le

Méroïtique méridional 

individu

GRF 29 ar Carrière? Découverte fortuite d'une fosse dans la "carrière». Conservation du squelette très altérée mais le mobilier est préservé in situ (Cahiers 1983, du 24/03 au 27/03/1983).

\begin{tabular}{|c|c|c|c|}
\hline GRF 30 & $\mathrm{u}$ & 1 & $\begin{array}{l}\text { Large fosse présentant une orientation différente des autres. Le squelette } \\
\text { contracté est retrouvé dans un espace beaucoup plus réduit. Partiellement } \\
\text { perturbé par une racine. Aucun matériel (Cahiers 1983, } 26 \text { et 27/03/1983). }\end{array}$ \\
\hline GRF 31 & $\mathrm{aq}$ & 2 & $\begin{array}{l}\text { Fosse large orientée E-O dont une excavation de forme rectangulaire } \\
\text { permet l'accès par une marche à une cavité ellipsoïdale. Un mobilier } \\
\text { nombreux accompagne une série d'inhumations dont la succession } \\
\text { n'est pas compréhensible tant les os sont épars et mal préservés. } \\
5 \text { individus (GRF } 31,32,33,34 \text { et } 74 \text { ) dont un seul en position primaire, } \\
\text { les autres étant parfois identifiables par un seul os (Cahiers } 1983 \text {, } \\
\text { du } 26 / 03 \text { au } 04 / 04 / 1983 \text { ). }\end{array}$ \\
\hline
\end{tabular}

GRF 33

cinquantenaire

\section{4}

de la section

GRF 34

française

de la direction

des Antiquités

du Soudan

\begin{tabular}{|c|c|c|c|}
\hline GRF 35 & $\mathrm{n}$ & 1 & $\begin{array}{l}\text { Fosse ellipsoïdale dont les contours sont perturbés par un trou } \\
\text { de pillage. } 1 \text { seul individu signalé par un os long, position primaire } \\
\text { non identifiée (Cahiers } 1983 \text {, du 26/03 au 05/04/1983). }\end{array}$ \\
\hline GrF 36 & $r$ & 1 & $\begin{array}{l}\text { Au bord du front de taille de la sablière, tombe pillée, } \\
\text { envahie par les racines, aucun matériel associé (Cahiers } 1983 \text {, } \\
\text { du } 05 / 04 \text { au } 07 / 04 / 1983 \text { ). }\end{array}$ \\
\hline GRF 37 & s & 1 & $\begin{array}{l}\text { Fosse perturbée par un trou de pillage. Le squelette est assez bien } \\
\text { préservé des pieds jusqu'au bassin, ce qui permet d'indiquer l'orientation } \\
\text { de l'individu. Aucun matériel associé (Cahiers 1983, du 31/03 au 17/04/1983). }\end{array}$ \\
\hline
\end{tabular}


Décubitus latéral, position N-S, tête au S.

GRF 29/1: céramique (fig. 9)

Méroïtique

GRF 29/2: céramique (fig. 7)

$\mathrm{II}^{\mathrm{e}}-\mathrm{III}^{\mathrm{e}} s$. de notre ère

Décubitus latéral, position contractée, O-E,

Méroïtique

tête à l'O, regardant le $\mathrm{N}$.

Décubitus latéral, position contractée, N-S, tête au S, regardant l'O.

La position primaire des autres individus n'est pas reconstituée.
GRF 31/1: bouteille noire, entièrement décorée de motifs variés sur le col et l'épaule, d'une résille sur la panse. (non retrouvée).

GRF 31/2: gobelet de terre rouge (?) à parois fine, sert de bouchon à 3 mais en position droite (non retrouvé)

GrF 31/3: bouteille rouge, elle aussi décorée, elle aussi faite main (non retrouvée)

GRF 31/4: céramique (fig. 8)

GRF 31/5: céramique (fig. 14)

GrF 31/6: gobelet semblable à GrF 4/25, noir la même marque s'y lit, sur un côté (non retrouvé)

GRF 31/7: coupe retournée, à pied et large bord (non retrouvé).

Élément de boîte en bronze (non retrouvé).

1 bague en bronze (non illustrée)

Lot de perles (non retrouvé)

GRF 35/1: céramique (fig. 11)

Lot de perles (fig. 20)

\section{Méroïtique}

$\left(\mathrm{I}^{\mathrm{er}}\right.$ s. de notre ère)
235

Gereif Est

et le

Méroïtique méridional
Décubitus latéral, position contractée, O-E, tête à l'O.
$\mathrm{I}^{\mathrm{er}} \mathrm{s}$. av. notre ère-

$\mathrm{I}^{\mathrm{er}} \mathrm{s}$. de notre ère

Décubitus latéral, position contractée, O-E, tête à l'O.

Mérö̈tique

Méroïtique
Méroïtique 


\begin{tabular}{|c|c|c|c|}
\hline individu & fosse & zone & description de la tombe \\
\hline GRF 38 & $\mathrm{f}$ & 1 & $\begin{array}{l}\text { Fosse ellipsoïdale presque rectangulaire, irrégulière, entourée de petits } \\
\text { cailloux choisis en surface (Cahiers 1983, du 14/03 au 21/04/1983). }\end{array}$ \\
\hline GRF 39 & $\mathrm{~g}$ & 1 & $\begin{array}{l}\text { Fosse ellipsoïdale se démarquant par son sédiment noir. Tombe pillée, } \\
\text { au remplissage de cailloux et d'os mêlés au sédiment, sans matériel } \\
\text { (Cahiers } 1983 \text {, du 14/03 au 05/04/1983). }\end{array}$ \\
\hline GRF 40 & $\mathrm{k}$ & 1 & $\begin{array}{l}\text { Fosse ellipsoïdale, assez restreinte autour du squelette en position } \\
\text { initiale malgré le pillage (Cahiers 1983, du 05/04 au 11/04/1983). }\end{array}$ \\
\hline GRF 41 & o & 2 & $\begin{array}{l}\text { Descenderie ouverte à l'E débouche sur une cavité ellipsoïdale. } \\
3 \text { individus sont identifiés: GRF } 41 \text { apparaît dans la descenderie, } \\
\text { très partiellement préservé; GRF } 45 \text { est dispersé mais quelques } \\
\text { os sont en position primaire alors que GRF } 46 \text { est en réduction } \\
\text { contre la paroi N la cavité (Cahiers 1983, du 17/o3 au 26/04/1983). }\end{array}$ \\
\hline GRF 42 & $\mathrm{t}$ & 2 & $\begin{array}{l}\text { Dans le prolongement de la descenderie abritant GRF 41, fosse } \\
\text { aux contours difficiles à cerner (Cahiers } 1983 \text {, du } 05 / 04 / 1983 \text { ). }\end{array}$ \\
\hline GRF 43 & $\mathrm{v}$ & 2 & $\begin{array}{l}\text { Descenderie ouverte à l'E. débouchant sur une cavité ellipsoïdale } \\
\text { abritant un enfant dont seuls les membres inférieurs sont bien préservés. } \\
\text { Un pillage a affecté la partie supérieure du corps (Cahiers 1983, } \\
\text { du } 06 / 04 \text { au 18/04/1983). }\end{array}$ \\
\hline GRF 44 & $\mathrm{w}$ & 2 & $\begin{array}{l}\text { Descenderie ouverte à l'E donnant sur une cavité ellipsoïdale. } \\
\text { Tombe d'enfant dont le pillage a occasionné la dispersion d'une partie } \\
\text { du squelette (Cahiers 1983, du 10/04 au 12/04/1983). }\end{array}$ \\
\hline GRF 45 & o & 2 & $\begin{array}{l}\text { Descenderie ouverte à l'E débouche sur une cavité ellipsoïdale. } \\
3 \text { individus sont identifiés: GRF } 41 \text { apparaît dans la descenderie, } \\
\text { très partiellement préservé; GRF } 45 \text { est dispersé mais quelques } \\
\text { os sont en position primaire alors que GRF } 46 \text { est en réduction } \\
\text { contre la paroi N de la cavité (Cahiers } 1983 \text {, du 17/o3 au 26/o4/1983). }\end{array}$ \\
\hline \multicolumn{4}{|l|}{ GRF 46} \\
\hline GRF 47 & $\mathrm{x}$ & 2 & $\begin{array}{l}\text { Fosse signalée par une petite concentration de pierre en surface, } \\
\text { extrêmement irrégulière. Un enfant en position primaire } \\
\text { (GRF 49) et un autre signalé par de rares fragments de crâne et de hanche } \\
\text { contre la paroi S (GRF 47) (Cahiers 1983, du 10/04 au 21/04/1983). }\end{array}$ \\
\hline
\end{tabular}


Décubitus dorsal, position allongée, O-E, tête à l'ouest.
GRF 38/1: céramique (fig. 8)

Méroïtique

GRF 38/2: bol en bronze (fig. 23)

GRF 38/3: pichet en bronze (fig. 23) $2^{\text {nde }}$ moitié $\mathrm{II}^{\mathrm{e}}-$

$\mathrm{I}^{\mathrm{er}} s$. av. notre ère

Mérö̈tique
Décubitus latéral, position contractée, O-E, tête à l'O, regardant le $\mathrm{N}$.

Tête au S.
Perles uniques, longues, tubulaires (non retrouvées)

GRF 41/1: céramique (fig. 10)

2 coupes rouges, type habituel, dont

l'une avec les 2 cercles externes de GrF 29.

1 gobelet
Décubitus latéral, position contractée, N-S, tête au S.

Décubitus latéral, position contractée, N-S, tête au S.
GRF 43/1: céramique (fig. 15)

GrF 43/2: céramique (fig. 15)

Lot de perles (fig. 20)
$\mathrm{I}^{\mathrm{er}} \mathrm{s}$. av. notre ère-

$\mathrm{I}^{\mathrm{er}} \mathrm{S}$. de notre ère?
- $\quad$ Méroïtique tête au S, regardant l'O.
t'ócubitus latéral, position

Décubitus latéral, position contractée, N-S, tête au $S$.
GRF 45/1: céramique (fig. 9)

2 bracelets de chevilles en perles en verre (non illustrés)

\section{Méroïtique}

$\mathrm{II}^{\mathrm{e}}-\mathrm{I}^{\mathrm{er}} \mathrm{S}$. av. notre ère

Méroïtique? 

individu

GRF $48 \quad y \quad 2$

Descenderie ouverte à l'E conduisant à une cavité ellipsoïdale. Tombe fortement pillée, des ossements étant signalés dans la descenderie et aucun en position primaire. Deux inhumations successives (GRF 68 puis GrF 48) identifiés à partir de leur crâne. Le nombre inhabituel de vases découverts pourrait signaler une réinhumation avec conservation du mobilier.

\begin{tabular}{lll}
\hline GrF 49 & $\mathrm{x}$ & 2 \\
\hline & \\
\hline GRF 50 & $\mathrm{z}$ & 2 \\
\hline
\end{tabular}

Fosse signalée par une petite concentration de pierre en surface, extrêmement irrégulière. Un enfant en position primaire (GRF 49) et un autre signalé par de rares fragments de crâne et de hanche contre la paroi S (GRF 47) (Cahiers 1983, du 10/04 au 21/04/1983).

\section{8}

de la section

française

de la direction des Antiquités du Soudan

\section{GRF 51}

GRF $52 \quad$ aa 2

2

Sous un tas de pierre dispersé, une descenderie ouverte à l'E conduit à une cavité axiale ellipsoïdale. 2 individus, deux enfants, sont identifiés. GrF 50 est le plus récent, GRF 51 a été réduit contre la paroi $\mathrm{N}$ pour l'installer (Cahiers 1983, du 12/04 au 26/04/1983).

GRF $53 \quad$ ae 2

GRF 54

GRF 55

GRF $56 \quad$ ad $\quad 2$

Fosse abritant un adulte en position très contractée et dont la partie supérieure du squelette est perturbée par un pillage (Cahiers 1983, du 14/04 au 02/05/1983).
Fosse dont la cavité s'est effondrée. Inhumation collective où GRF 53 et GRF 54 ont été réduits contre la paroi N pour installer GRF 55, le seul individu en position primaire. Le biberon et la coupelle sont interprétés comme appartenant à GRF 54 (Cahiers 1983, du 20/04 au 02/05/1983). 
GRF 48/2: céramique (fig. 9)

GrF 48/3: céramique (fig. 6)

$2^{\text {nde }}$ moitié $\mathrm{I}^{\text {er }}$ -

GrF 48/4: céramique (fig. 7)

$\mathrm{II}^{\mathrm{e}} \mathrm{s}$. de notre ère

GRF 48/5: céramique (fig. 7)

Lot de perles (fig. 20)

Décubitus latéral, position contractée, N-S, tête au S, regardant l'O.

Décubitus latéral, position contractée, N-S, tête au $\mathrm{S}$, regardant l'O.

En réduction contre la paroi $\mathrm{N}$

Décubitus latéral, position contractée, N-S, tête au $\mathrm{N}$, regardant l'E.
GrF 5o/1: céramique (fig. 9)

GrF 50/2: céramique (fig. 9)

1 bol en céramique (non retrouvé)

$\mathrm{II}^{\mathrm{e}}-\mathrm{I}^{\mathrm{er}} S$. av. notre ère

Lot de perles provenant de plusieurs colliers ((fig. 20)

$-$

GRF 52/1: céramique (fig. 14)

Méroïtique

Méroïtique

GRF 52/2: bague en bronze (fig. 24)

Lot de perles formant plusieurs colliers

et bracelets (fig. 21)

$\mathrm{I}^{\mathrm{er}} s$. av. notre ère-

$\mathrm{I}^{\mathrm{er}} \mathrm{s}$. de notre ère

2 bols près des pieds, 2 bols classiques 1 noir et 1 rouge (non retrouvés)

\section{Méroïtique}

En réduction contre la paroi $\mathrm{N}$

En réduction contre la paroi $\mathrm{N}$

Décubitus latéral, position contractée, N-S, tête au S, regardant l'O.

Décubitus latéral, position contractée, N-S, tête au $\mathrm{S}$, regardant l'O.
GRF 54/1: céramique (fig. 15)

GrF 54/2: céramique (fig. 15)
GrF 56/2 : 1 boucle d'oreille (fig. 24)

1 perle d'agate en forme de goutte (non retrouvée)

\section{Méroïtique}

\section{Méroïtique}

Méroïtique

Méroïtique

$\mathrm{I}^{\text {er }} S$. av. notre ère-

$\mathrm{I}^{\mathrm{er}} \mathrm{s}$. de notre ère 
individu

fosse

GRF 57

ac

description de la tombe

La succession des fosses ac (GRF 57) et ak (GRF 60) laisse croire à une très longue descenderie. Le squelette apparaît presque entier, la tête est cependant partiellement préservée à la suite d'un pillage (Cahiers 1983, du 19/04 au 02/05/1983).

$\begin{array}{ll}\text { GRF } 58 & \text { ag } \\ \text { GRF } 59 & \text { ai }\end{array}$

cinquantenaire

\section{0}

de la section

française

de la direction

des Antiquités

du Soudan

GRF 6o ak 2

GRF 59 ai 2

GRF $60 \quad$ ak 2

GRF $61 \quad$ aj 2

GRF $61 \quad$ aj
Descenderie ouverte à l'E donnant sur une cavité ellipsoïdale. Les fouilleurs signalent le corps d'un enfant, tête au $S$, avec un grand bol hémisphérique (Cahiers 1983, du 21/04 au 28/04/1983).

Tombe dont le plan n'a pas été retrouvé. Longue descenderie ouverte l'E, révélant des fragments de crâne (GRF 59). Deux autres individus (GrF 62 et 63) se situent dans la cavité, tête au S. Les corps de la cavité sont perturbés (Cahiers 1983, du 24/04 au 30/04/1983).

Dans la continuité de la descenderie de GrF 57, fosse ellipsoïdale, ne contenant aucun squelette mais du mobilier assez bien préservé (Cahiers 1983, du 26/04 au 02/05/1983).
Longue descenderie menant à une cavité irrégulière. Le squelette semble intact, accompagné de trois céramiques.

GrF $62 \quad$ ai 2

GRF 64

am

$1 ?$

GRF 65

an

1 ?

GRF 66

ao

$1 ?$

GRF 67

al
Tombe dont le plan n'a pas été retrouvé. Longue descenderie ouverte l'E, révélant des fragments de crâne (GRF 59). Deux autres individus (GRF 62 et 63) se situent dans la cavité, tête au S. Les corps de la cavité sont perturbés (Cahiers 1983, du 24/04 au 30/04/1983).

3 morts de surface. Les 2 premiers sont à la limite Nord de la bande des 3 mètres. Le $3^{\mathrm{e}}$ immédiatement au Sud-Ouest, passé partiellement sous l'aplanisseuse. GRF 64 a une pointe de flèche en roche jaune. GRF 64 et 65 sont tête à l'ouest, sur côté gauche. Les os sont très mal conservés (Cahiers 1983, du 30/04 au 02/o5/1983).

GRF 67 al 2

Fosse ellipsoïdale abritant le squelette d'un enfant possédant un collier de perles en verre et un grand bol en céramique (Cahiers 1983, 30/04/1983). 
Décubitus latéral, position contractée, N-S, tête au $\mathrm{S}$, regardant l'O.

Décubitus latéral, position contractée, N-S, tête au S.

En fragments dans la descenderie
GRF 57/1: céramique (fig. 14)

Méroïtique

GRF 57/2: anneau en bronze (fig. 24)

Lot de perles (fig. 22)

Un plus petit vase (gobelet?) décoré à la main (non retrouvé)

Un bol hémisphérique (non retrouvé)

Mérö̈tique

$\mathrm{I}^{\mathrm{er}} \mathrm{s}$. de notre ère

Méroïtique

GRF 6o/1 : céramique (fig. 12)

Meroïtique

GRF 6o/2 : céramique (fig. 14)

GRF 6o/3: Scarabée en faïence (fig. 24)

$\mathrm{I}^{\text {er }} S$. av. notre ère-

Lot de perles (fig. 22)

$\mathrm{I}^{\mathrm{er}} \mathrm{s}$. de notre ère

GRF 61/1: céramique (fig. 8)

Mérö̈tique

Décubitus latéral, position contractée, N-S,

2 gobelets en céramique (non retrouvés)

tête au S, regardant l'O.

Méroïtique

Position N-S, tête au S.

$-$

Position N-S, tête au S.

$-$

Méroïtique

Position O-E, tête à l'O.

GRF 64/1 : 1 pointe de flèche (fig. 24)

Mérö̈tique

1 bague en bronze

Mérö̈tique

Lot de perles (fig. 22)

Méroïtique

Décubitus latéral, position contractée, N-S,

GRF 67/1: céramique (fig. 9)

Méroïtique

tête au S, regardant l'O.

Lot de perles (fig. 22)

$\mathrm{I}^{\mathrm{er}} \mathrm{s}$. av. notre ère-

$\mathrm{I}^{\mathrm{er}}$ s. de notre ère? 

individu
fosse
zone
description de la tombe

GRF $68 \quad$ y 2

Descenderie ouverte à l'E conduisant à une cavité ellipsoïdale. Tombe fortement pillée, des ossements étant signalés dans la descenderie et aucun en position primaire. Deux inhumations successives (GRF 68 puis GRF 48) identifiés à partir de leur crâne. Le nombre inhabituel de vases découverts pourrait signaler une réinhumation avec conservation du mobilier.

$\begin{array}{llll}\text { GRF 69 } & \text { a } & 2(?) & \begin{array}{l}\text { Tombe à situer une dizaine de mètres au N } \\ \text { pour installer GrF 69, conduisant à la réduction } \\ \text { Aucun objet associé découvert (Cahiers 1983, }\end{array} \\ \text { GRF 70 } & \text { as } & \text { Tombe partiellement fouillée, sans information de plan } \\ \text { GRF 71 } & \text { at } & 3 & \text { Aucune information de contexte ni de plan } \\ \text { GRF 72 } & \text { au } & 3 & \text { Aucune information de contexte ni de plan }\end{array}$

GRF $74 \quad$ aq 2

cinquantenaire

\section{2}

GRF 75 ap $\quad 4$

de la section

française

de la direction

des Antiquités

du Soudan

4 Aucune information de contexte. Le plan ne fait figurer que les objets, rassemblés au $\mathrm{N}$ et à l'O de la cavité.

Fosse large orientée E-O dont une excavation de forme rectangulaire permet l'accès par une marche à une cavité ellipsoïdale. Un mobilier nombreux accompagne une série d'inhumations dont la succession n'est pas compréhensible tant les os sont épars et mal préservés. 5 individus (GRF 31, 32, 33, 34 et 74) dont un seul en position primaire, les autres étant parfois identifiables par un seul os (Cahiers 1983, du 26/03 au 04/04/1983). 
Décubitus latéral, position contractée, N-S, tête au N, regardant l'E.

\section{Méroïtique}

$-$

-

Lot de perles (fig. 22)

Méroïtique

$-$

75/1: céramique (fig. 17)

Postméroütique

75/2: céramique (fig. 17)

75/3: céramique (fig. 16)

$\mathrm{V}^{\mathrm{e}}-\mathrm{VI}^{\mathrm{e}} s$. de notre ère

75/4: céramique (fig. 16)

75/5: céramique (fig. 17)

75/6 : céramique (fig. 17)

75/7 : céramique (fig. 16)

75/8: céramique (fig. 16)
Gereif Est

et le

Méroïtique méridional 


\section{annexe 2 : objets rendus au musée de Khartoum}

\begin{tabular}{|c|c|c|c|c|}
\hline & individu & $\mathrm{n}^{\circ}$ objet & type & $\mathrm{n}^{\circ} \mathrm{Snm}$ \\
\hline & GRF 1 & GRF $1 / 1$ & Céramique & - \\
\hline & & GRF $1 / 2$ & Céramique & - \\
\hline & & GRF $1 / 3$ & Céramique & SNM 38972 \\
\hline & & GRF $1 / 4$ & Céramique & - \\
\hline & GRF 2 & GRF $2 / 1$ & Céramique & - \\
\hline & & GRF $2 / 2$ & Céramique & SNM 38959 \\
\hline & & & Perles & $S_{N M} 40200$ \\
\hline & GRF 3 & GRF $3 / 1$ & Céramique & - \\
\hline & GRF 4 & GRF $4 / 21$ & Céramique & SNM 38987 \\
\hline & & GRF $4 / 24$ & Céramique & SNM 38964 \\
\hline & & GRF $4 / 25$ & Céramique & SNM 38955 \\
\hline cinquantenaure & & & Perles & SNM 40201 \\
\hline 244 & GrF 5 & & Perles & $\mathrm{S}_{\mathrm{NM}} 4 \mathrm{O} 2 \mathrm{O2}$ \\
\hline de la section & GRF 6 & GRF $6 / 1$ & Céramique & SNM 38988 \\
\hline française & & GRF $6 / 2$ & Céramique & - \\
\hline $\begin{array}{l}\text { de la direction } \\
\text { des Antiquités }\end{array}$ & & GRF $6 / 3$ & Céramique & SNM 38957 \\
\hline du Soudan & GRF 7 & GRF 7/1 & Céramique & SNM 38985 \\
\hline & GRF 8 & GRF $8 / 1$ & Pointes de flèche & SNM 38938 \\
\hline & GRF 10 & & Perles & $\mathrm{S}_{\mathrm{NM}} 40203$ \\
\hline & GrF 11 & & Perles & $\mathrm{S}_{\mathrm{NM}} 402 \mathrm{O} 4$ \\
\hline & GRF 12 & & Perles & $S_{N M} 40205$ \\
\hline & GRF 19 & & Perles & $S_{N M} 40206$ \\
\hline & GRF 21 & GRF 21/1 & Céramique & $S_{\text {NM }} 38963$ \\
\hline & GRF 24 & GRF 24/1 & Bronze & SNM 38998 \\
\hline & & & Perles & $\mathrm{S}_{\mathrm{NM}} 40207$ \\
\hline
\end{tabular}




\begin{tabular}{|c|c|c|c|}
\hline individu & $\mathrm{n}^{\circ}$ objet & type & $\mathrm{n}^{\circ} \mathrm{Snm}$ \\
\hline \multirow[t]{2}{*}{ GRF 25} & GRF 25/1 & Céramique & SNM 38974 \\
\hline & & Perles & $\mathrm{S}_{N M} 4 \mathrm{O} 223$ \\
\hline \multirow[t]{5}{*}{ GRF 26} & GRF 26/1 & Céramique & SNM 38981 \\
\hline & & Élément en bronze & SNM 38935 \\
\hline & GrF 26/2 & Boucles d'oreilles & SNM 38936 \\
\hline & & Perles & $\mathrm{S}_{\mathrm{NM}} 4 \mathrm{O} 224$ \\
\hline & & Perles & SNM 40208 \\
\hline GRF 28 & GrF 28/1 & Céramique & $\mathrm{S}_{\mathrm{NM}} 38986$ \\
\hline \multirow[t]{2}{*}{ GRF 29} & GRF 29/1 & Céramique & SNM 38962 \\
\hline & GrF 29/2 & Céramique & SNM 38951 \\
\hline \multirow[t]{4}{*}{ GRF 31} & GRF 31/4 & Céramique & SNM 38992 \\
\hline & GrF 31/5 & Céramique & SNM 38991 \\
\hline & & Élément en bronze & SNM 38935 \\
\hline & & Bague en bronze & $\mathrm{S}_{\mathrm{NM}} 38935 \mathrm{~b}$ \\
\hline \multirow[t]{2}{*}{ GRF 35} & GRF $35 / 1$ & Céramique & $\mathrm{S}_{\mathrm{NM}} 38979+\mathrm{S}_{\mathrm{NM}} 38995$ \\
\hline & & Perles & $\mathrm{S}_{\mathrm{NM}} 40209$ \\
\hline \multirow[t]{3}{*}{ GRF 38} & GRF $38 / 1$ & Céramique & $\mathrm{S}_{N M} 38983$ \\
\hline & GRF $38 / 2$ & Bol en bronze & $S_{\text {NM }} 38997$ \\
\hline & GRF $38 / 3$ & Pichet en bronze & $\mathrm{S}_{\mathrm{NM}} 38996$ \\
\hline GRF 41 & GRF $41 / 1$ & Céramique & $\mathrm{S}_{\mathrm{NM}} 38990$ \\
\hline \multirow[t]{3}{*}{ GRF 43} & GRF $43 / 1$ & Céramique & $\mathrm{S}_{\mathrm{NM}} 38965$ \\
\hline & GRF $43 / 2$ & Céramique & $\mathrm{S}_{\mathrm{NM}} 38961$ \\
\hline & & Perles & $S_{N M} 40210$ \\
\hline \multirow[t]{2}{*}{ GRF $45-46$} & GrF $45 / 1$ & Céramique & $\mathrm{S}_{N M} 38945$ \\
\hline & & Perles & $\mathrm{S}_{\mathrm{NM}} 4 \mathrm{O} 211$ \\
\hline
\end{tabular}

\section{5}

Gereif Est et le Méroïtique méridional 


\begin{tabular}{|c|c|c|c|}
\hline individu & $\mathrm{n}^{\circ}$ objet & type & $\mathrm{n}^{\circ} \mathrm{Snm}$ \\
\hline \multirow[t]{6}{*}{ GrF 48} & GRF 48/1 & Céramique & SNM 38982 \\
\hline & GRF 48/2 & Céramique & SNM 38967 \\
\hline & GRF $48 / 3$ & Céramique & SNM 38960 \\
\hline & GRF $48 / 4$ & Céramique & SNM 38971 \\
\hline & GRF $48 / 5$ & Céramique & - \\
\hline & & Perles & SNM 40222 \\
\hline GRF 49 & GRF $49 / 1$ & Céramique & SNM 38953 \\
\hline \multirow[t]{3}{*}{ GRF 50} & GrF 50/1 & Céramique & SNM 38944 \\
\hline & GRF 5O/2 & Céramique & $S_{N M} 38956$ \\
\hline & & Perles & $\mathrm{S}_{\mathrm{NM}} 4 \mathrm{O} 212$ \\
\hline \multirow[t]{4}{*}{ GRF 52} & GRF $52 / 1$ & Céramique & $S_{\text {NM }} 38978$ \\
\hline & GrF $52 / 2$ & Bague en bronze & $\mathrm{S}_{\mathrm{NM}} 38935 \mathrm{a}$ \\
\hline & & Perles & SNM 40220 \\
\hline & & Perles & $\mathrm{S}_{\mathrm{NM}} 40213$ \\
\hline \multirow[t]{2}{*}{ GRF 54} & GrF $54 / 1$ & Céramique & SNM 38949 \\
\hline & GRF $54 / 2$ & Céramique & SNM 38950 \\
\hline \multirow[t]{2}{*}{ GRF 56} & GrF $56 / 1$ & Céramique & SNM 38977 \\
\hline & GRF $56 / 2$ & Perle & $S_{\text {NM }} 38937$ \\
\hline \multirow[t]{4}{*}{ GRF 57} & GrF $57 / 1$ & Céramique & SNM 38973 \\
\hline & GRF $57 / 2$ & Bague en bronze & SNM 38935 \\
\hline & & Perles & SNM 40225 \\
\hline & & Perles & SNM 40214 \\
\hline \multirow[t]{4}{*}{ GrF 60 } & GrF $60 / 1$ & Céramique & SNM 38952 \\
\hline & GrF $60 / 2$ & Céramique & $\mathrm{S}_{\mathrm{NM}} 38980$ \\
\hline & GrF $60 / 3$ & Scarabées en faïence & $S_{\text {NM }} 38939$ \\
\hline & & Perles & $\mathrm{S}_{\mathrm{NM}} 40215$ \\
\hline GRF 61 & GRF $61 / 1$ & Céramique & SNM 38984 \\
\hline
\end{tabular}




\begin{tabular}{|c|c|c|c|}
\hline individu & $\mathrm{n}^{\circ}$ objet & type & $\mathrm{n}^{\circ}$ Snm \\
\hline GRF 64 & GRF 64/1 & Pointe de flèche en pierre & $S_{N M} 38940$ \\
\hline GRF 65 & & Bague en bronze & SNM 38935 \\
\hline GRF 66 & & Perles & $\mathrm{S}_{\mathrm{NM}} 40216$ \\
\hline \multirow[t]{2}{*}{ GRF 67} & & Céramique & $\mathrm{S}_{\mathrm{NM}} 38966$ \\
\hline & & Perles & $\mathrm{S}_{\mathrm{NM}} 4 \mathrm{O} 217$ \\
\hline GRF 72 & & Perles & $\mathrm{S}_{\mathrm{NM}} 4 \mathrm{O} 218$ \\
\hline \multirow[t]{8}{*}{ GRF 75} & GRF 75/1 & Céramique & SNM 38976 \\
\hline & GrF $75 / 2$ & Céramique & SNM 38989 \\
\hline & GRF $75 / 3$ & Céramique & SNM 38968 \\
\hline & GRF $75 / 4$ & Céramique & SNM 38954 \\
\hline & GRF $75 / 5$ & Céramique & SNM 38993 \\
\hline & GRF 75/6 & Céramique & SNM 38970 \\
\hline & GRF $75 / 7$ & Céramique & - \\
\hline & GRF 75/8 & Céramique & - \\
\hline Fosse $\mathrm{H}$ & & Perles & $\mathrm{S}_{\mathrm{NM}} 4 \mathrm{O} 221$ \\
\hline \multirow[t]{8}{*}{ Sans contexte connu } & & Perles & $S_{N M} 40219$ \\
\hline & & Perles & $\mathrm{S}_{\mathrm{NM}} 38941$ \\
\hline & & Céramique & $\mathrm{S}_{\mathrm{NM}} 38946$ \\
\hline & & Céramique & $\mathrm{S}_{\mathrm{NM}} 38947$ \\
\hline & & Céramique & $\mathrm{SNM}_{\mathrm{NM}} 38948$ \\
\hline & & Céramique & $\mathrm{S}_{\mathrm{NM}} 38958$ \\
\hline & & Céramique & $S_{N M} 38975$ \\
\hline & & Céramique & SNM 38994 \\
\hline
\end{tabular}

\section{7}

Gereif Est et le

Méroïtique méridional 


\section{bibliographie}

Addison Fr. 1949 - Jebel Moya, Londres.

Adams W.Y. 1986 - Ceramic Industries of Medieval Nubia, Lexington.

Bashir M.S. $\quad 2007$ - "Rescue Excavation of a Late-Meroitic Tomb at Botri, south of Khartoum. Preliminary Report», Sudan \& Nubia 11, p. 94-98.

Bashir M.S., David R. 2011 - «Meroitic Pottery from Excavations of the Cemetery at Berber", Der Antike Sudan, MittSAG 22, p. 121-128. 2015 - "The Meroitic Cemetery at Berber. Recent Fieldwork and Discussion on Internal Chronology", Sudan \& Nubia 19, p. 97-105.

Bates O., Dunham D. 1927 — «Excavation at Gammai », HaS VIII, Cambridge, p. 1-121.

Beck H. 1928 - "Classification and Nomenclature of Beads and Pendants", Archaeologia 77, p. 1-76.

Brass M. 2015 - «Interactions and Pastoralism along the Southern and Southeastern Frontiers of the Meroitic State, Sudan ", Journal of World Prehistory 28, p. 255-288.

Brass M., Fuller D.Q., MacDonald K., Stevens C., Adam A., KozieradzkaOgunmakin I., Abdallah R., Alawad O., Abdalla A., Vella Gregory I., Wellings J., Hassan F., Abdelrahman A. 2019 - «New findings on the significance of Jebel Moya in the eastern Sahel", Azania 54:4,

de la section française de la direction des Antiquités du Soudan p. $425-444$.

Caneva I. 1988 - El Geili. The History of Middle Nile Environment, 7000 B.P-A.D.1500, BAR-IS 424, Oxford.

Crawford O.G.S., Addison Fr. 1951 - Abu Geili and Sagadi \& Dar el Mek, The Wellcome Excavations in the Sudan III, Londres.

David R. 2018 - "Funerary ceramics and Meroitic economy: a first insight», dans M. Honneger (éd.), Nubian Archaeology in the XXIt Century. Proceedings of the Thirteenth International Conference for Nubian Studies, Neuchâtel, 1-6 September 2014, OLA 273, p. 481-488.

2019 - "Ceramic Industries of Meroitic Sudan», dans D. Raue (éd.), Handbook of Ancient Nubia, Berlin-Boston, p. 877-897.

David R., Evina M. 2015 - «La fine ware méroïtique, marqueur d'une civilisation", Égypte, Afrique et Orient 78, p. 49-56. 2016 - «Introduction à l'évolution des chaînes opératoires des céramiques mérö̈tiques", Dotawo 3, p. 83-126.

David R., Benoist A., Buechner S., Jadot E., «Discussing the Classification of the Meroitic Ceramics in the Meroe Region", à paraitre.

Dixon D.M. 1963 - "A Meroitic Cemetery at Sennar (Makwar)», Kush XI, p. $227-234$. 
Dunham D. 1957 — «Royal tombs at Barkal and Meroe», RCK IV, Boston. 1963 - "The West and South Cemeteries at Meroe», $R_{C K} \mathrm{~V}$, Boston.

Edwards D.N. 1991 — "Three cemetery sites on the Blue Nile», ANM 5, p. 41-64. 1998 - Gabati. A Meroitic, Post-meroitic and Medieval Cemetery in Central Sudan, Oxford.

1999 - «Meroitic ceramic Chronology: Exploring the Meroe West Cemeteries ", Azania 34, p. 25-43.

2004 - The Nubian Past. An Archaeology of the Sudan, Londres.

2014 - "Early Meroitic Pottery and the Creation of an Early Imperial Culture?», dans A. Lohwasser, P. Wolf (éd.), Ein Forscherleben zwischen den Welten. Zum 8o. geburtstag von Steffen Wenig, MittSAG Sonderhaft. Berlin, p. 51-63.

Edwards D.N., Eisa K.A. 2016 - "Appendix: Jar found at Kawa-Hillat Said-Bir Ajab", Sudan \& Nubia 20, p. 89.

El Tayeb M. 1999 - "Rescue Excavation at El Sabeil (Soba West)», dans S. Wenig (éd.), Studien zum antiken Sudan. Akten Der 7. Internationalen Tagung Fur Meroitische Forschungen Vom 14. Bis 19. September 1992, Meroitica 15, p. 604-614.

Fernández V.M. 1983 - La Cultura Alto-Meroitica del Norte de Nubia, Madrid (en ligne: http://eprints.ucm.es/13283/1/T12423.pdf).

Fernández V.M. $\quad 1984$ - "Early Meroitic in Northern Sudan: the Assessment of a Nubian Archaeological Culture», Aula Orientalis 2, p. 43-84. 1986 — «Early Meroitic in Northern Nubia», dans M. Krause (éd.), Nubische Studien, Mayence, p. 59-65.

Francigny V. 2016 — Les coutumes funéraires dans le royaume de Méroé. Les enterrements privés, Orient \& Méditerranée Archéologie $n^{\circ} 22$, Paris.

Garcia Guinea M.A., Texidor J. 1965 - La necrópolis Meroitica de Nelluah (Argin Sur), Comite español de la UNESCO para Nubia, Memorias de la mision arqueologica VI, Madrid.

Garstang J. 1911 - Meroë, the City of the Ethiopians, Oxford.

Geus Fr., 1982a, "Franco-Sudanese Excavations in the Sudan (1981-1982)», Nyame Akuma 21, p. 33-34. 1982b — «La nécropole méroïtique d'El Kadada», Meroitica 6, p. 178-187. 1983 - Rapport annuel d'activité 1980-1982, Khartoum. 1984a - Rescuing Sudan Ancient Cultures, Khartoum. 1984b - Rapport annuel d'activité 1983, Khartoum.

Geus Fr., Lenoble P. $\quad$ 1983a - «Fouilles à Gereif Est près de Khartoum (ND-36-B/11-Q-4)», Meroitic Newsletter 22, p. 9-20. 1983b - "Excavations at Gereif East. Second Campaign ", Nyame Akuma 23, p. 26. 
de la section

française

de la direction

des Antiquités

du Soudan
1985 — «Evolution du cimetière méroïtique d'El Kadada: la transition vers le postméroïtique en milieu rural méridional», dans Fr. Geus, F. Thill (éd.), Mélanges offerts à Jean Vercoutter, Paris, p. 67-92.

Gibbs K. 2018 - «The Pottery from J. Desmond Clark's 1973 Excavations at Jebel Moya», Sudan \& Nubia 22, p. 29-37.

Hofmann I. 1978 - Beiträge zur meroitischen chronologie, Studia Instituti Anthropos 31, StAugustin.

Lenoble P. 1992 - «Documentation tumulaire et céramique entre les $5^{\mathrm{e}}$ et $6^{\mathrm{e}}$ cataractes. Un exemple de "prospection orientée» visant à renseigner la «Fin de Méroé» dans la région de Méroé», dans Ch. Bonnet (éd.), Études nubiennes I, Genève, p. 79-97.

1995 - "La petite bouteille noire, un récipient méroéen de la libation funéraire», ANM 7, p. 143-162.

1997 — «Enterrer les flèches, enterrer l'Empire: I. Carquois et flèches des tombes impériales à el-Hobagi ", CRIPEL 17/2, p. 137-152.

1999 - «Enterrer les flèches, enterrer l'Empire, II : Les archers d'El-Kadada et l'administration de l'imperium méroïtique", CRIPEL 2O, p. 125-144.

2006 - «Aux armes souverains! L'arsenal funéraire des empereurs méroïtiques», dans V. Rondot, N. Dextreit (dir.), Kerma et Méroé. Cinq conférences d'archéologie soudanaise, Khartoum, p. 17-26.

2018 - El-Hobagi. Une nécropole de rang impérial au Soudan Central. Deux tumulus sur sept, FIFAO 79, Le Caire.

Marshall K., Adam A.-R, 1951., "Excavation of a Mound Grave at Ushara ", Kush 1, p. $40-46$.

Randall-MacIver D., Woolley C.L. 1911 - Buhen, VII \& VIII, Philadelphie.

Rilly Cl. 2007 - La langue du royaume de Méroé, Paris.

2017 - "Histoire du Soudan. Des origines à la chute du sultanat Fung», dans O. Cabon et al., Histoire et civilisations du Soudan, Paris, p. 26-439.

Rose P. 1996 - Qasr Ibrim. The Hinterland Survey, Londres.

Sakamoto T. 2016 — "The Meroitic Cemetery of Gereif East. A Glance into the Regional Characteristics of Khartoum Province», Sudan \& Nubia 20, p. 82-89.

Then-Obłuska J. 2014 — "The code of the hidden beads — from the Kerma to the Islamic period according to the 4 th Cataract material from the Gdańsk Archaeological Museum collection ", dans Anderson J.R., D. Welsby (éd.) The Fourth Cataract and Beyond. Proceedings of the 12th International Conference for Nubian Studies, BMPES 1, Leuven-Paris-Walpole, p. 1069-1090.

2015 - "Beads and pendants from Sedeinga, Nubia", BEADS: Journal of the Society of Bead Researches 27, 29-45. 
2016 — «Meroitic Beadwork: an Overview Based on Finds from Saï in Ancient Nubia», PAM 25, p. 691-724.

2018 - «Beyond the Nubian Gold: Meroitic Beads between the Fifth and the Sixth Nile Cataracts", BEADS : Journal of the Society of Bead Researchers 30, p. 31-43.

Then-Obłuska J., Wagner B. 2019 - Glass Bead Trade in Northeast Africa. The Evidence from Meroitic and post-Meroitic Nubia, PAM Monograph Series 10, Varsovie.

Török L. 1987 — "The Historical Background: Meroe, North and South», dans T. Hägg (éd.), Nubian Culture Past and Present, Uppsala, p. 139-229. 1989 - "Kush and the External World", dans S. Donadoni, St. Wenig, Studia Meroitica 1984, Meroitica 10, p. 147-148. 1997 - Meroe City, an Ancient African Capital. John Garstang's Excavations in the Sudan, Londres.

2011 - Hellenizing Art in Ancient Nubia 300 BC-AD 250 and its Egyptian Models, Leyde-Boston.

Usai D. 2014 - Salvatori S., Jakob T., David R., "The Al Khiday Cemetery in Central Sudan and its "Classic/Late Meroitic" Period Graves», Journal of African Archeology 12/2, p. 183-204.

Vila A. 1978 - L'île d'Arnyatta. Le district d'Abri (Est et Ouest). Le district de Tabaj (Est et Ouest), PAVN 9, Paris.

Welsby D. 2004 - "Kawa», dans D.A. Welsby, J.R. Anderson (éd.), Sudan. Ancient Treasures. An Exhibition of Recent Discoveries from the Sudan National Museum, Londres, p. 148-157.

Williams Br.B. $\quad 1985$ - "A Chronology of Meroitic Occupation below the Fourth Cataract», JARCE XXII, p. 149-195.

Wolf P., Nowotnick U., Edwards D.N. 2019 - "Settlement in the Meroitic Kingdom», dans D. Raue (éd.), Handbook of Ancient Nubia, Berlin-Boston, p. 713-782.

Yvanez E. 2018 - "Clothing the elite? Patterns of textile production and consumption in ancient Sudan and Nubia», dans A. Ulanowska, M. Siennicka, and M. Grupa (éd.), Dynamics and Organisation of Textile Production in Past Societies in Europe and the Mediterranean, Fasciculi Archaeologiae Historicae 31, p. 81-92. 

dans les ruines

nubiennes du

désert argentique

Gilles Tiberghien

Claude Iverné 
«Ensuite, il faudra débarquer et remonter à pied la vallée pendant quarante jours, car le Nil est semé d'écueils pointus et de récifs à fleur d'eau qui interdisent toute navigation. Après ces quarante jours de marche, on s'embarquera de nouveau, on naviguera pendant douze jours et l'on attendra une ville importante qui s'appelle Méroé. C'est, dit-on, la capitale des autres Éthiopiens.»

Hérodote, Enquêtes, Livre II, 29

Aux Occidentaux, le Soudan n'évoque pas grand-chose

aujourd'hui si ce n'est lorsque I'on parle du Darfour, limitrophe de la Libye et du Tchad, une région victime de terribles sécheresses et en proie depuis 2003 à une nouvelle guerre civile entrainnant une catastrophe humanitaire qui l'a rendue tristement célèbre. Or le nord du Soudan, situé juste sous l’Égypte, correspond à l'ancienne Nubie. Là fut d'abord l'antique royaume de Kouch au XXVe siècle avant notre ère puis, plus tard, ceux de Napata et de Méroé, de 800 ans avant Jésus Christ à 350 ans après Jésus Christ. Ces puissants royaumes ont jouxté ainsi la terre des pharaons qui les ont combattus et envahis: ils sont quasi inconnus du grand public alors qu'ils furent respectés et redoutés par leurs voisins bien plus célèbres. D'ailleurs, les rois de Nubie se nommaient également Pharaons, certains ayant régné jusqu'à Alexandrie.

L'archéologie s'y est intéressée depuis un peu plus d'un siècle, dégageant des ruines impressionnantes qui élèvent leurs silhouettes mélancoliques dans le gris subtil des images de Claude Iverné. Depuis plus de vingt ans, il en a comme intériorisé les paysages au rythme de ses voyages parfois auprès des différentes missions archéologiques françaises venues travailler au Soudan et dont ce livre célèbre le cinquantenaire. Au centre de cet ensemble de vingthuit images, on trouve la nécropole de Méroé qui semble disparaître dans le vent du désert, comme si, à la faveur d'un pli particulier du temps, le photographe avait placé sa chambre en amont de l'histoire qui s'est écoulée jusqu'à nous, au moment où les sables ont envahi toute cette région.

Ici on retrouve toutes les strates de cette histoire, du temple érodé de l'antique cité de Kerma, capitale de Kouch, jusqu'aux statues de ceux que l'on appellera les "pharaons noirs" dont l'image est visible en vis-à-vis sur la même page. Ces souverains, adorateurs du dieu Amon de Napata, 
ont pris alors le pouvoir en Égypte au point d'être considérée comme une dynastie à part entière, la XXVe, qui a régné de 775 avant J.-C. à 650 environ. C'est à ces derniers, écrivait Élisée Reclus dans L'Homme et la terre, que «les envahisseurs assyriens disputèrent l'Égypte, devenue simple proie de guerre, sans force et sans volonté. "Ces Éthiopiens, comme les appelle Hérodote et le monde antique pour parler des habitants de l'Afrique - la couleur de leur peau sombre justifiant cette appellation puisque ce nom signifie "brûlé par le soleil» - ont ainsi renversé l'ordre des choses et de vassaux sont devenus suzerains.

On trouve ici des pyramides comme en Égypte mais plus petites, et mesurant jusqu'à une trentaine de mètres de haut. Les Nubiens adoptèrent cette tradition en les construisant localement d'après un modèle égyptien conçu pour les hauts fonctionnaires. Sur le site de Gébel Barkal dominé par une montagne dont semble se détacher la figure géante d'un serpent cobra, on aperçoit, au pied du massif rocheux, l'ouverture d'un temple encadré de quelques colonnes encore debout. Il faut bien regarder pour le comprendre et celui qui va trop vite ne saisira pas le rapport entre cette image et celle, tout à côté, du tambour de pierre sur lequel on aperçoit trois personnages. Sur ce détail de la photographie précédente sont représentés deux soldats encadrant un captif nubien réduit en esclavage. Il s'agit d'un piédestal dont on voit la partie arrière arrondie. Un trône était posé dessus et des marches sont taillées à l'avant. Sur ces marches on trouve aussi la représentation de prisonniers ennemis, que le roi foulait du pied à chaque passage. Cette information n'est pas essentielle mais elle enrichit sans aucun doute ce qui pourtant ne se veut nullement un document mais plutôt un témoignage.

Claude Iverné ne se soucie pas en effet de nous renseigner sur l'échelle de ces édifices en faisant poser à côté d'eux, comme sur les photographies du XIXe siècle, des personnages qui nous permettraient d'en estimer la taille. De même, ses légendes sont réduites au minimum et ne parlent qu'aux spécialistes. Est-ce important de savoir ce qu'est le kiosque de Naga ou de comprendre ce que signifie "Boucherie» à côté de Kerma? Oui et non, car ces images ont une force propre et tissent entre elles une géographie argentique et mystérieuse que les données fournies par la cartographie et de la toponymie classique ne peuvent éclairer à elles seules. Mais le voyageur photographe nous donne aussi envie d'en savoir plus, en tout cas d'en rêver davantage, laissant à notre imagination le soin d'explorer ces royaumes oubliés. 
737. Pyramides / Gébel Barkal / Dar Cheiguir / Nubie / janvier 2004. 

739. Pyramide / Gébel Barkal / Dar Cheiguir / Nubie / janvier 2004. 


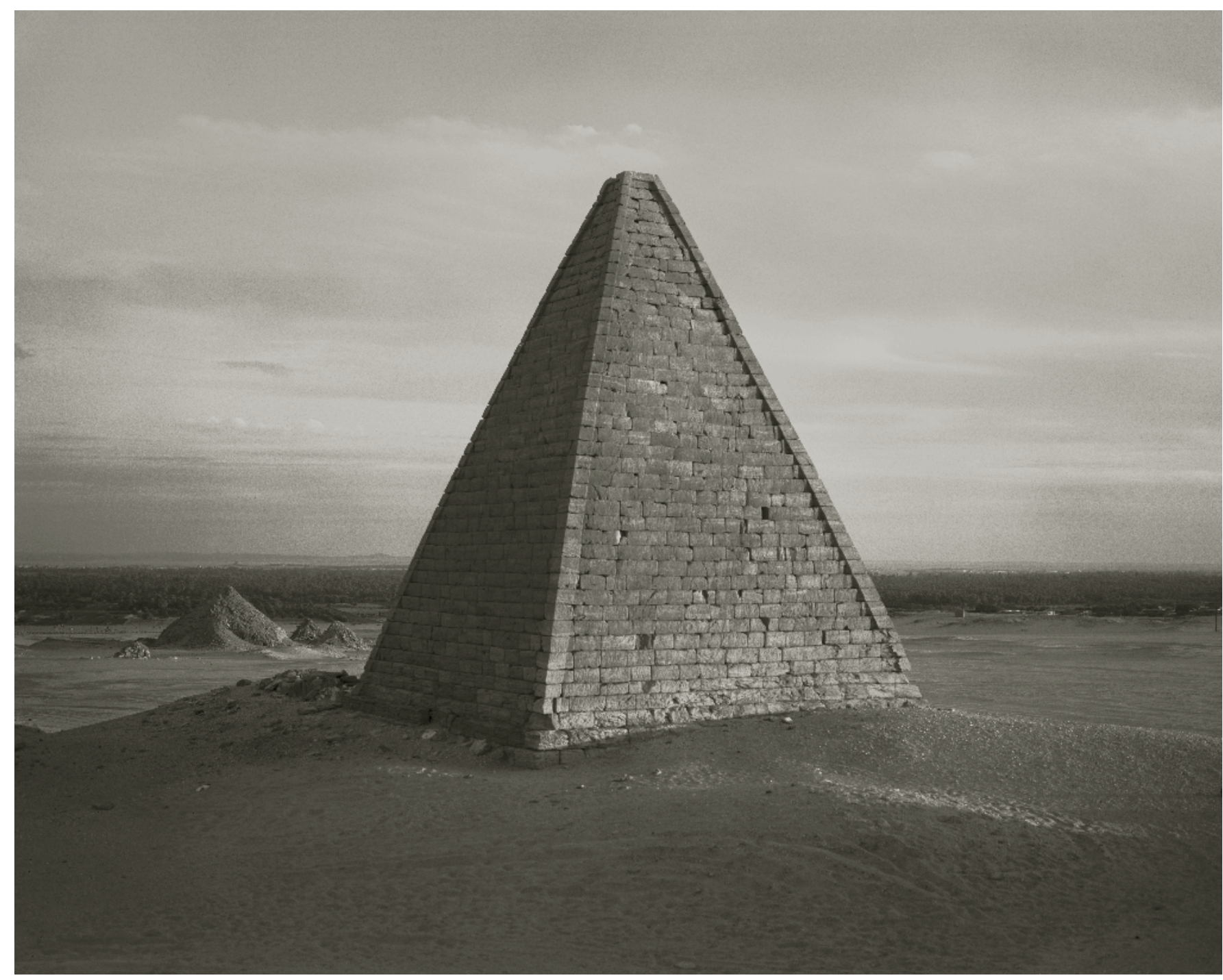


732. Temple d'Amenhotep III / Soleb / Dar Mahass / Nubie / décembre 2003. 


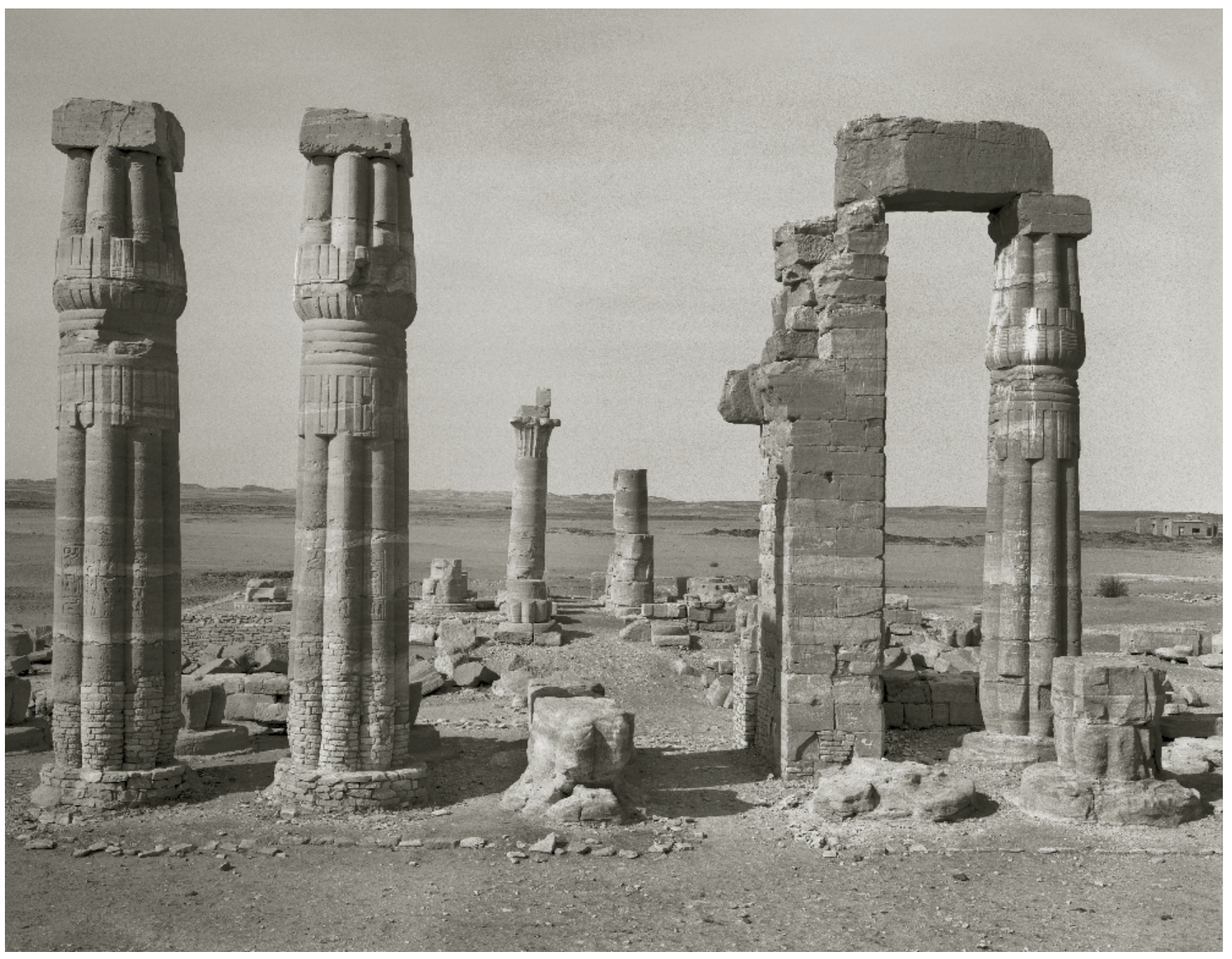




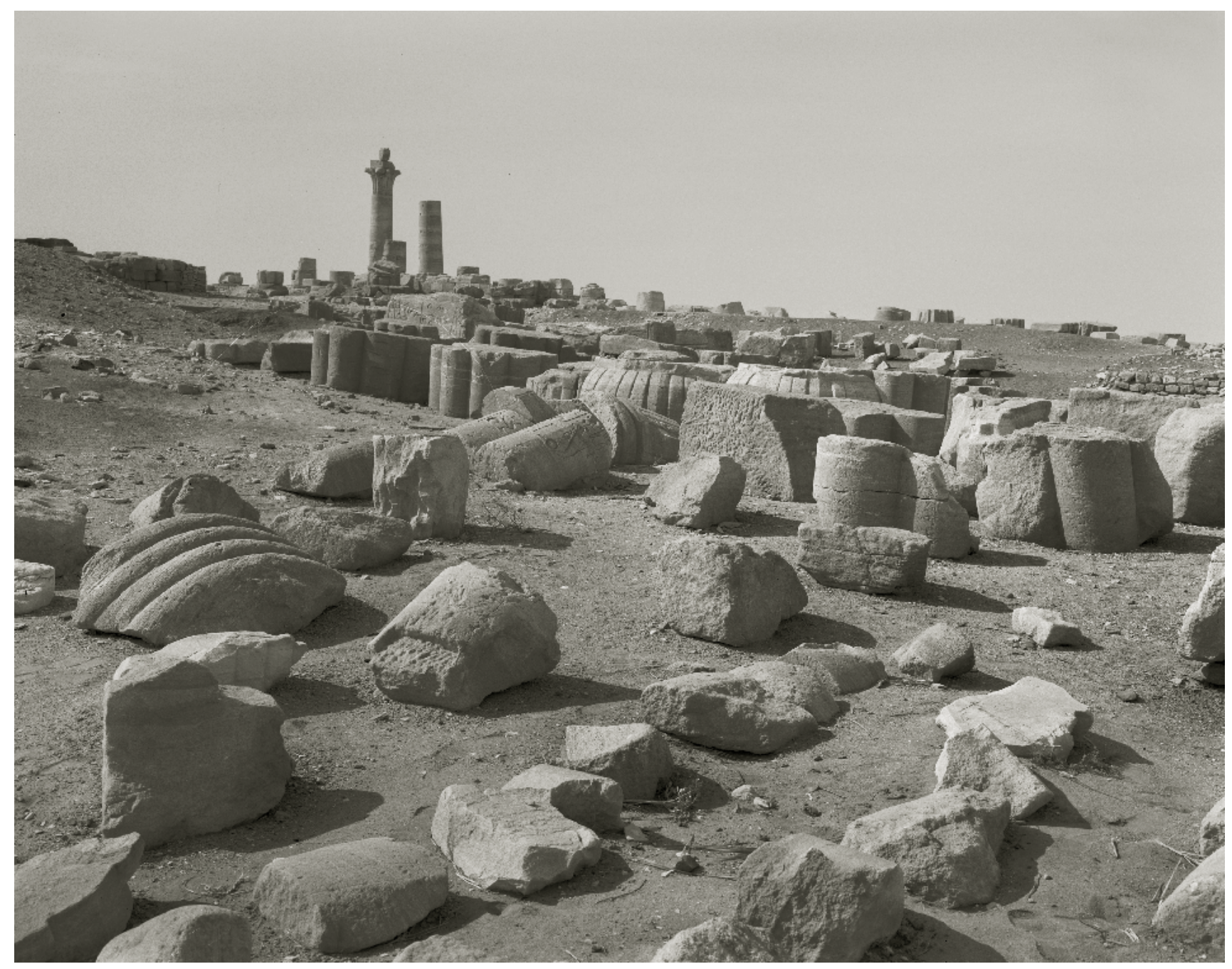

733. Temple d'Amenhotep III / Soleb / Dar Mahass / Nubie / janvier 2004. 

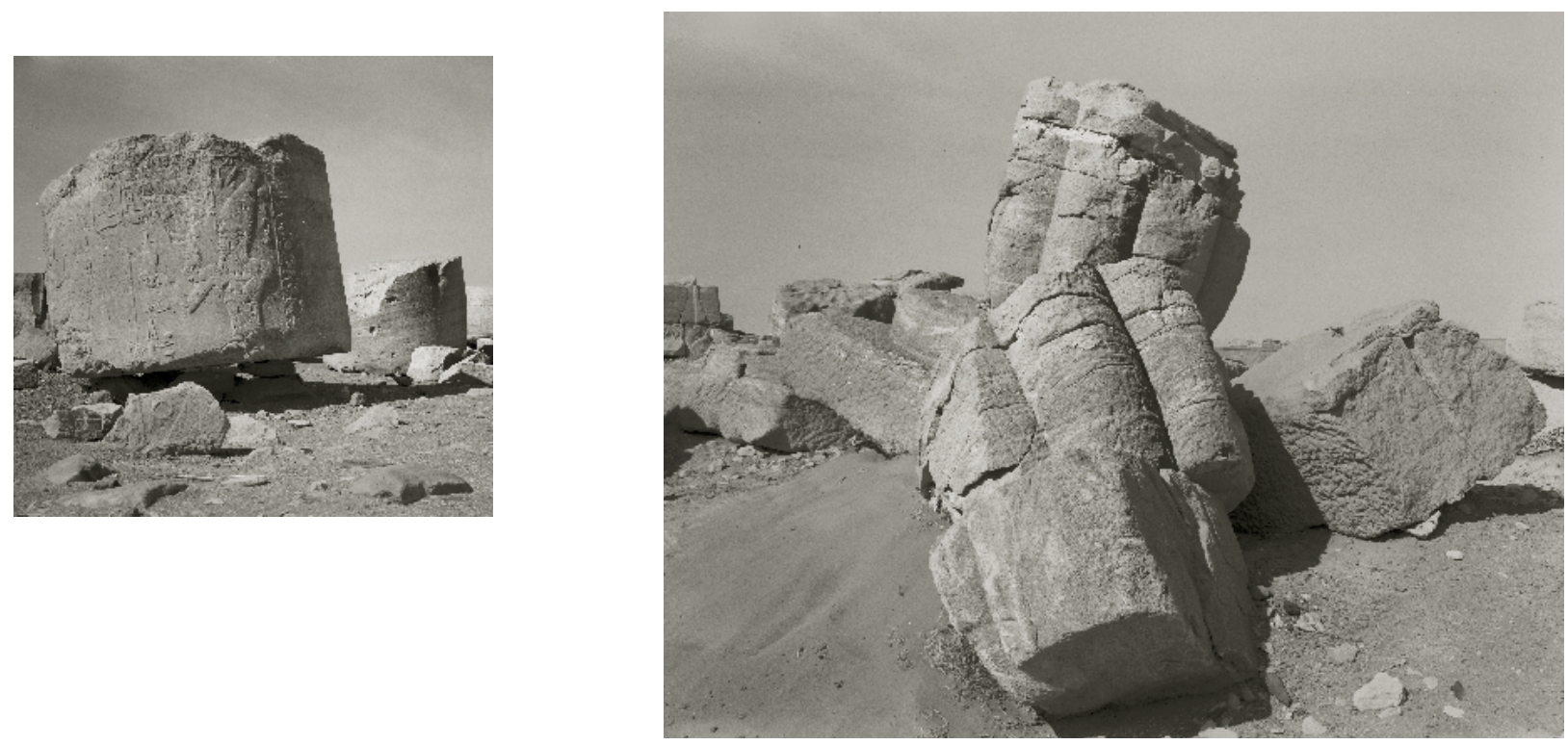

725. \& 728. Temple d'Amenhotep III / Soleb / Dar Mahass / Nubie / janvier 2004. 


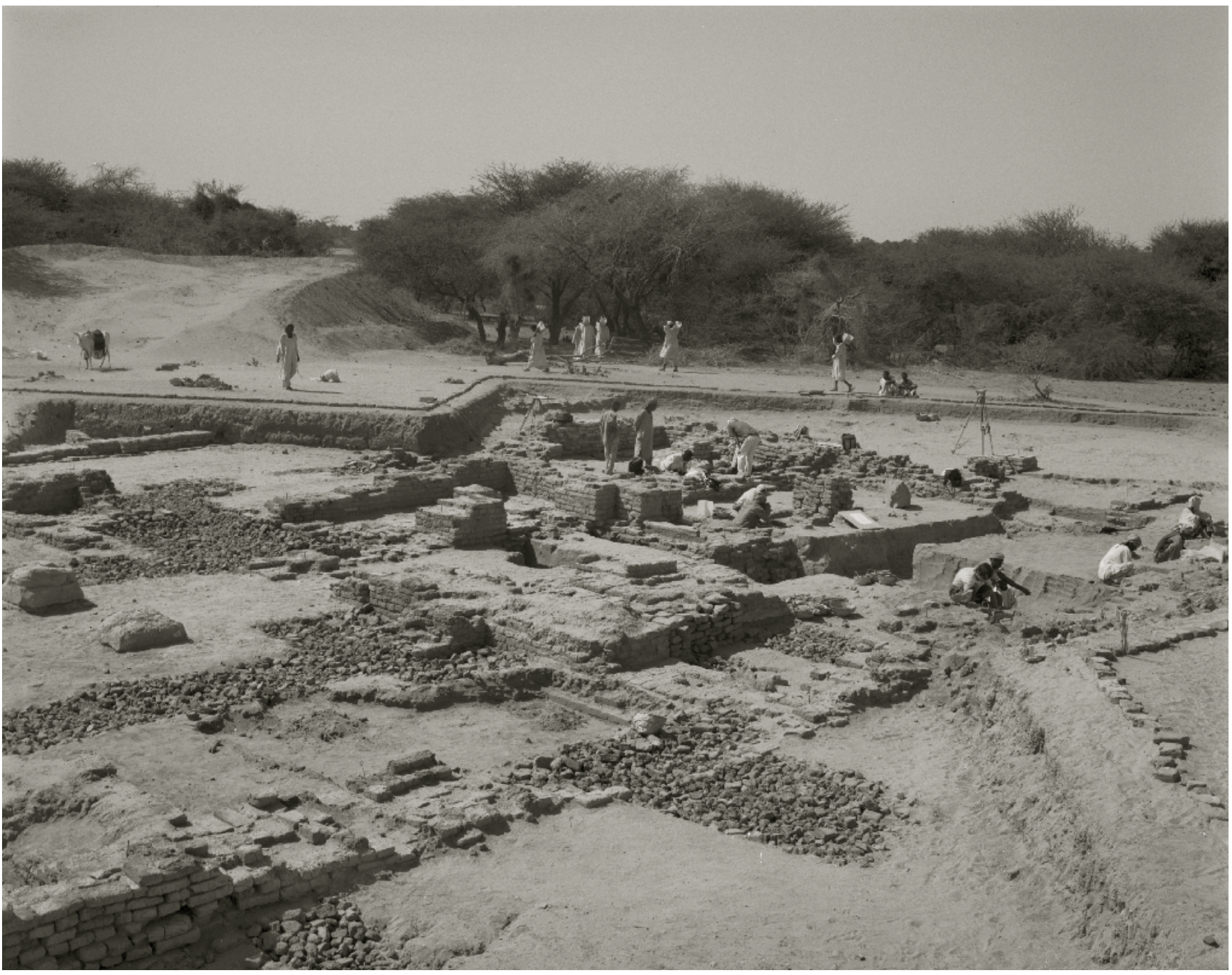

813. Fouilles d'el-Hassa / Dar Jaalinn / décembre 2006.

1352-50. Main d'un relief de Candace / el-Hassa / Dar Jaalinn / décembre 2006. 


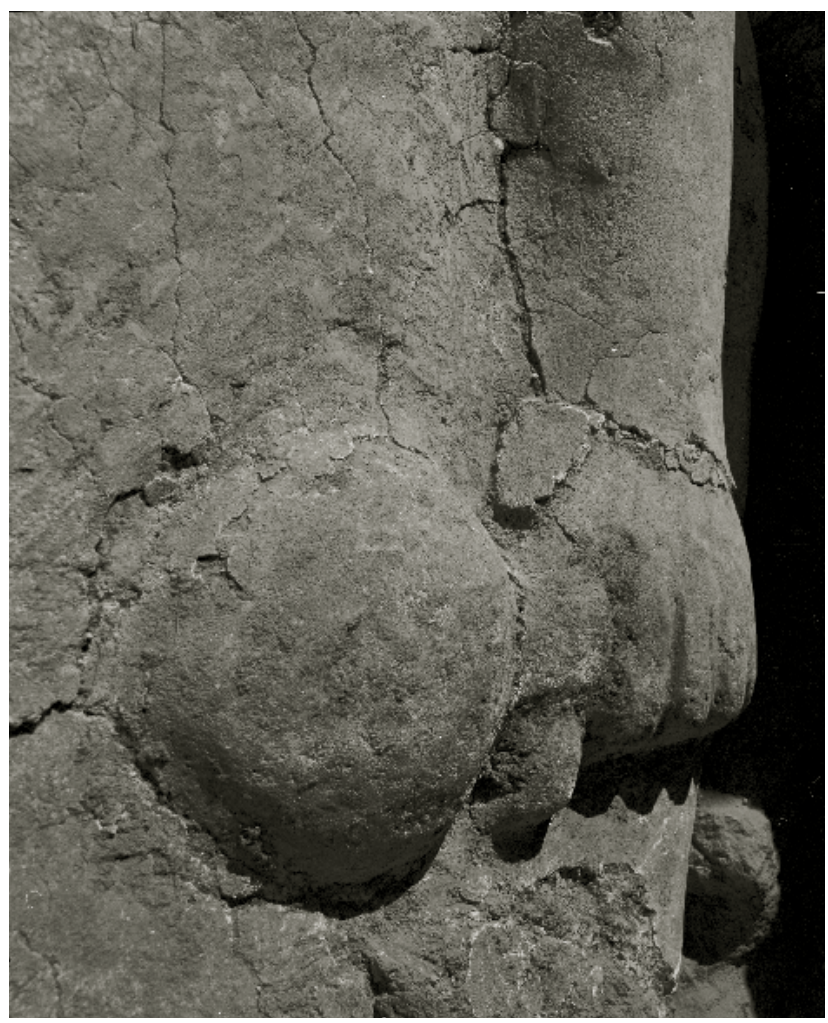




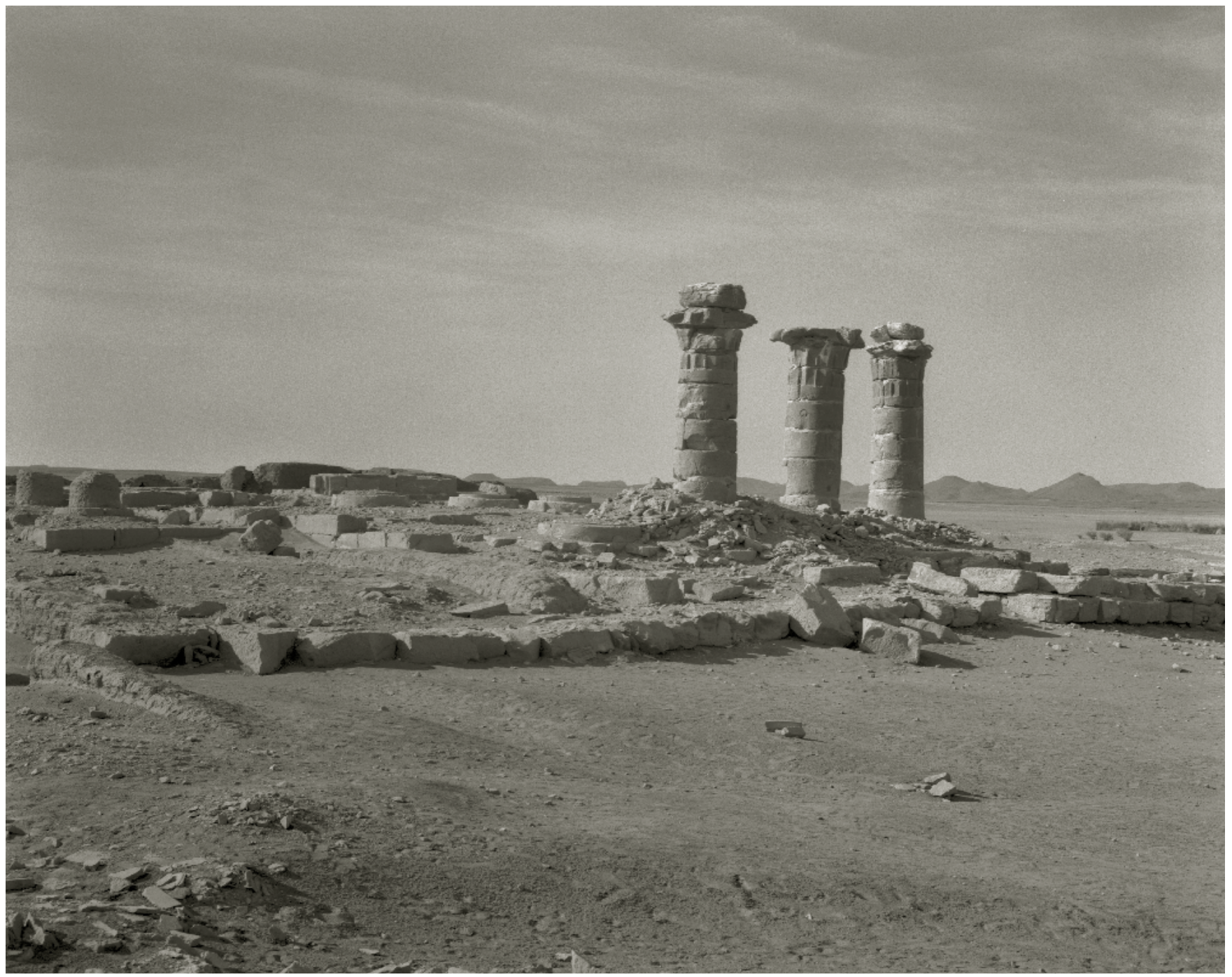

723. Temple d'Akhenaton / Sessebi / Dar Cheiguir / Nubie / janvier 2004. 


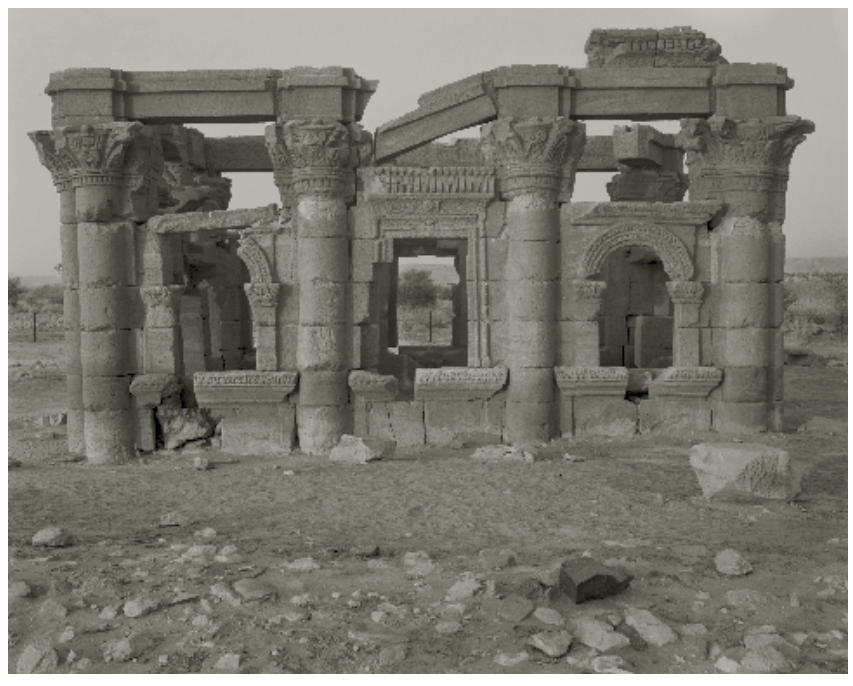

738. Kiosque romain / Naga / Dar Djaalin / décembre 2004. 


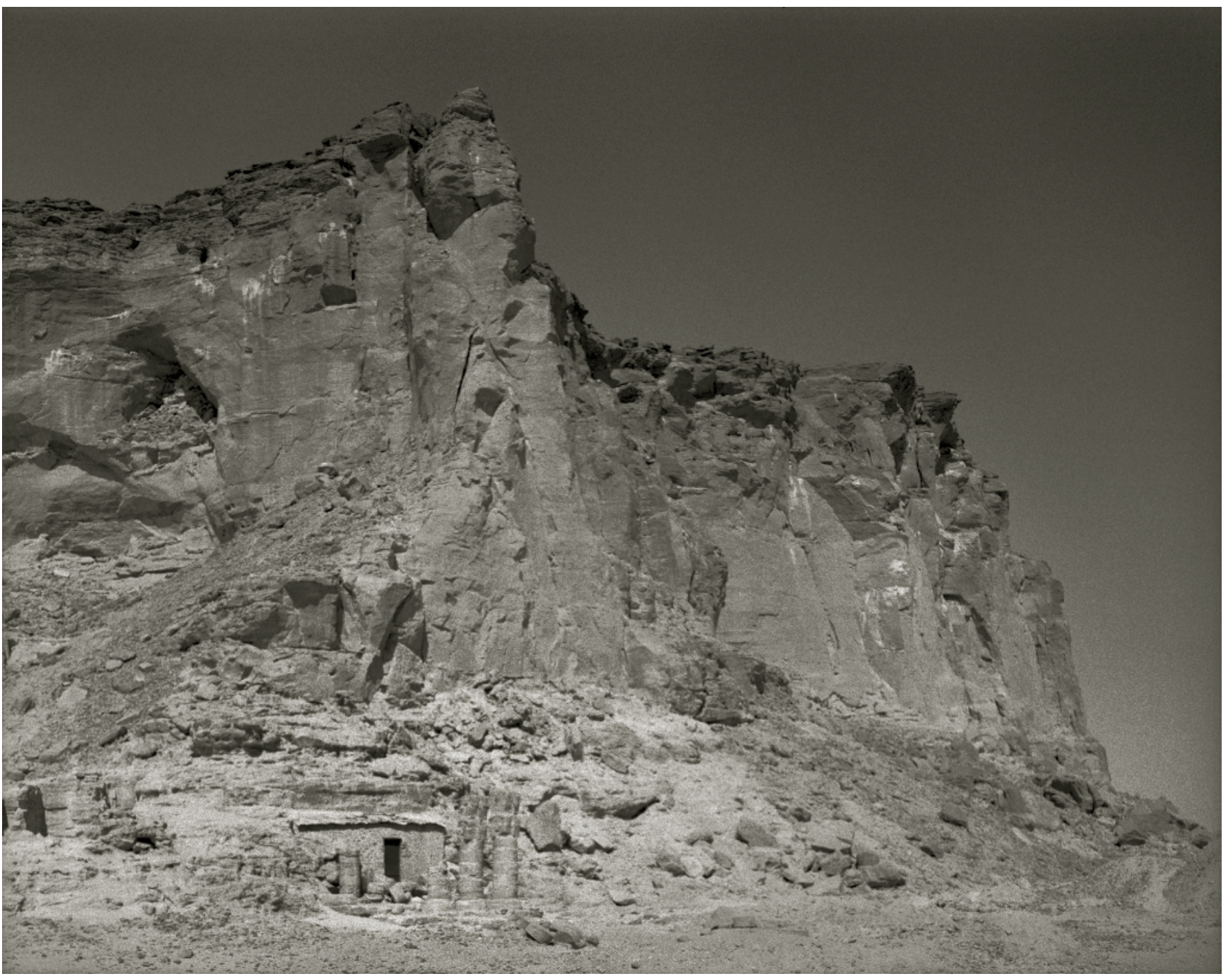

434-43. Gébel Barkal / Dar Cheiguir / Nubie / janvier 2004.

434-41. Piédestal / temple d’Amon / Gébel Barkal / Dar Cheiguir / Nubie / janvier 2004.

794. Figurine d'un Nubien recouvert de textes d'exécration / Moyen Empire / Mirgissa / musée des Beaux-Arts de Lille / 2006. 

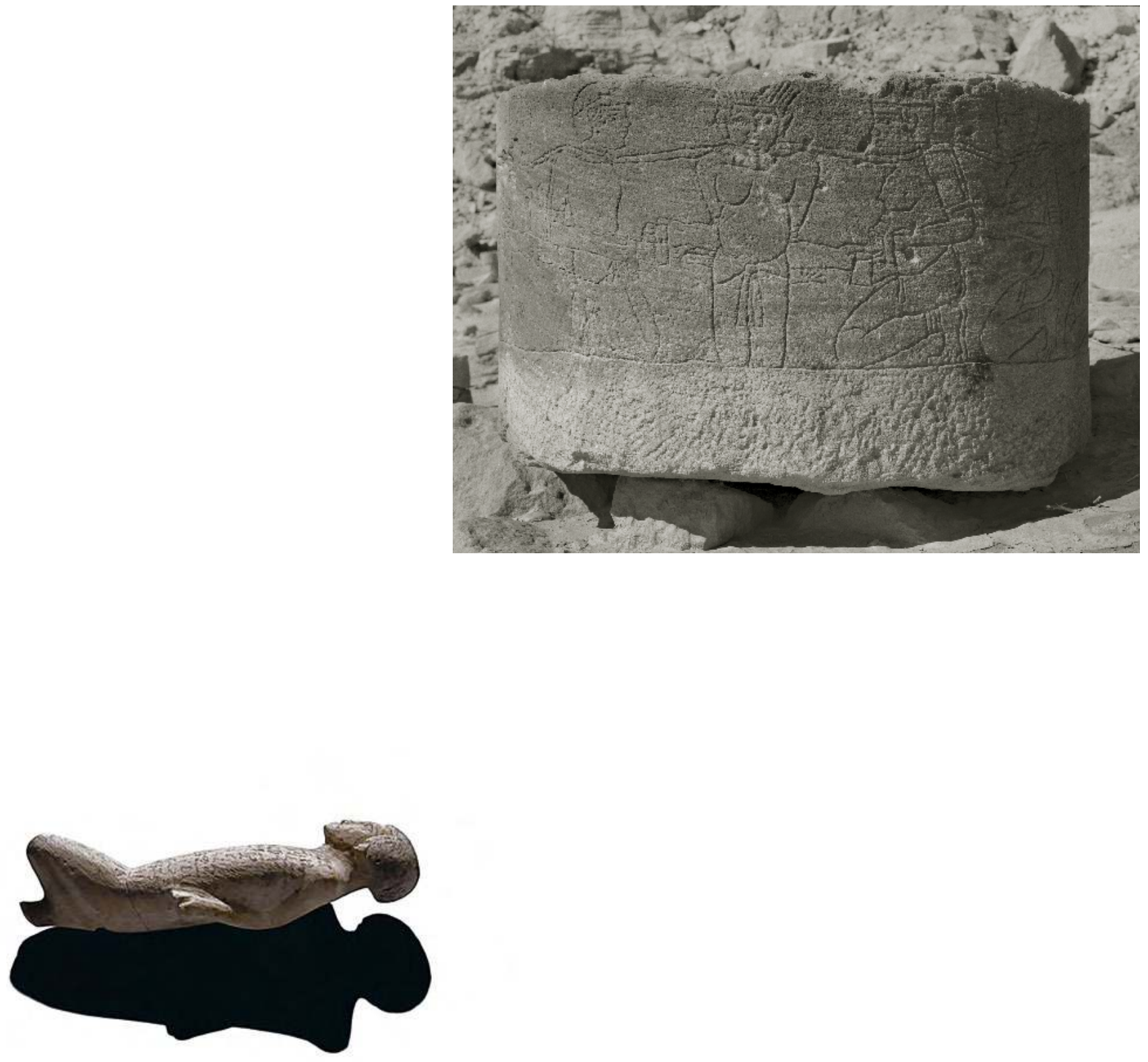


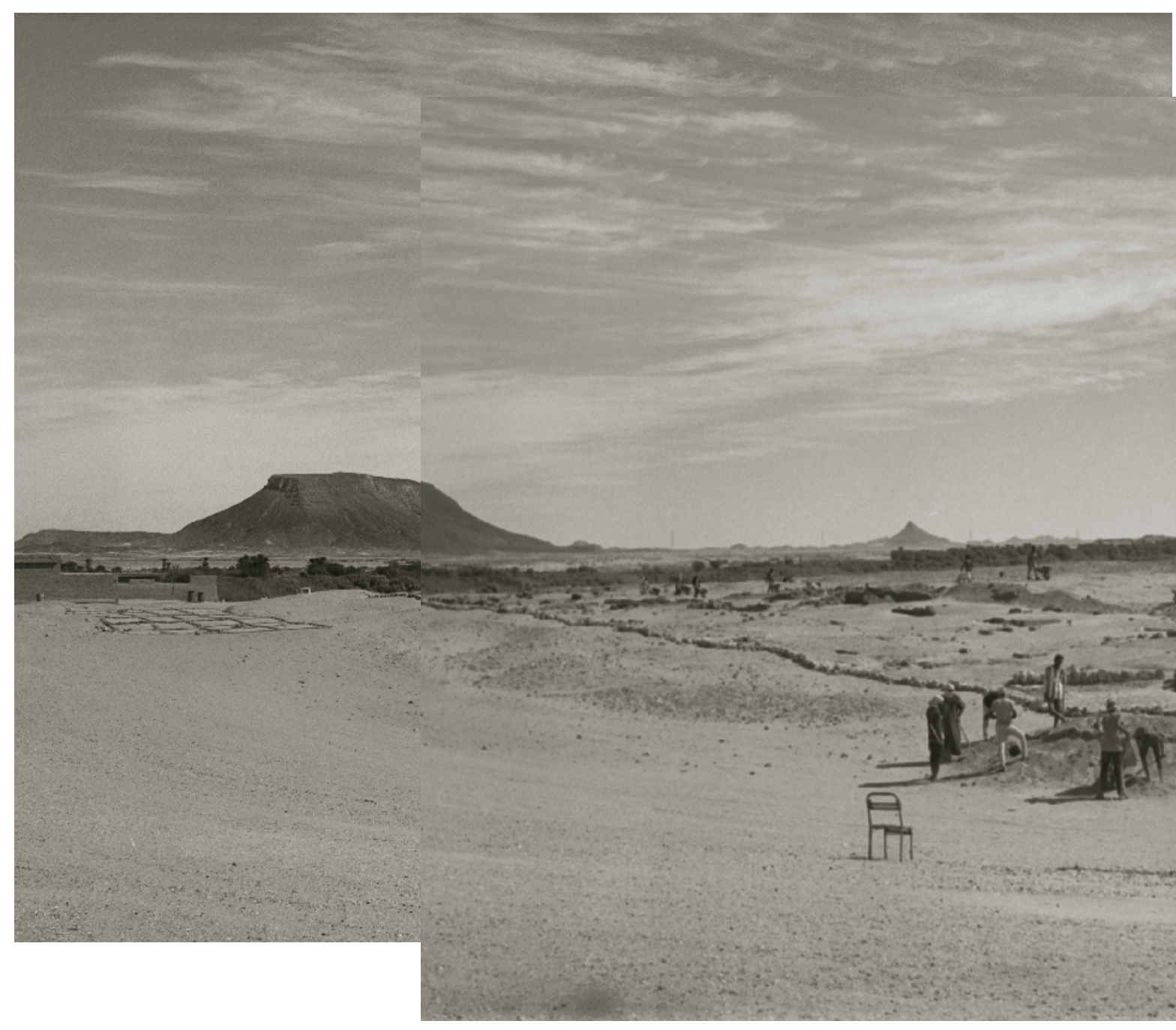

3294-44. 3297-33-36. Fouilles / île de Saï / Dar Sukkot / Nubie / octobre 2018. 


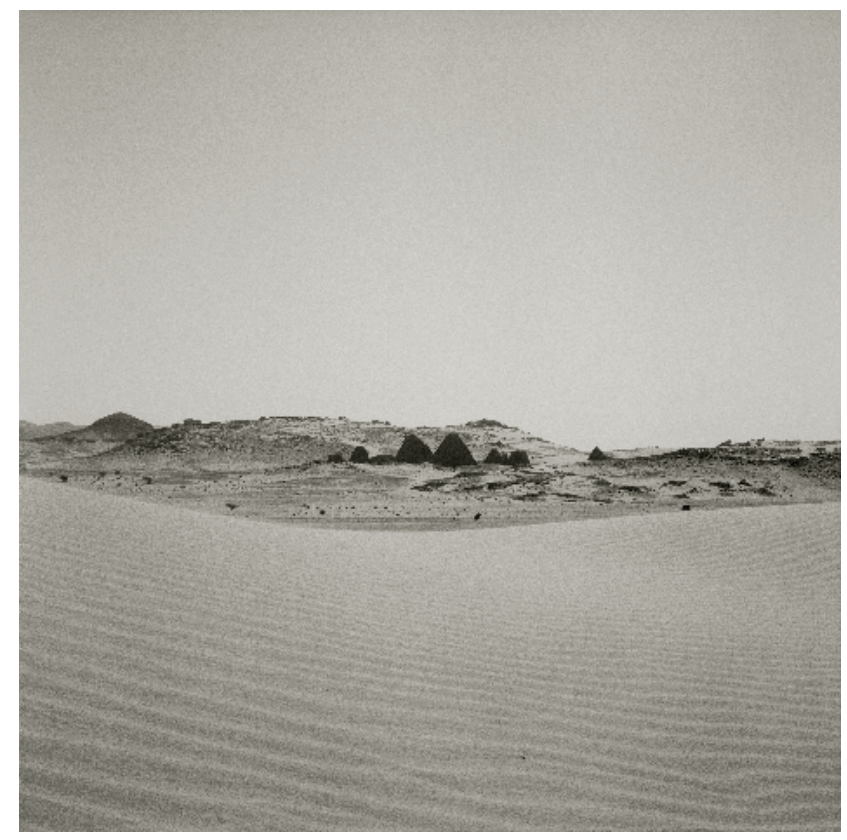

411-52. Nécropole de Méroé / cimetière Sud / Dar Jaajin / Keraba / décembre 2006. 


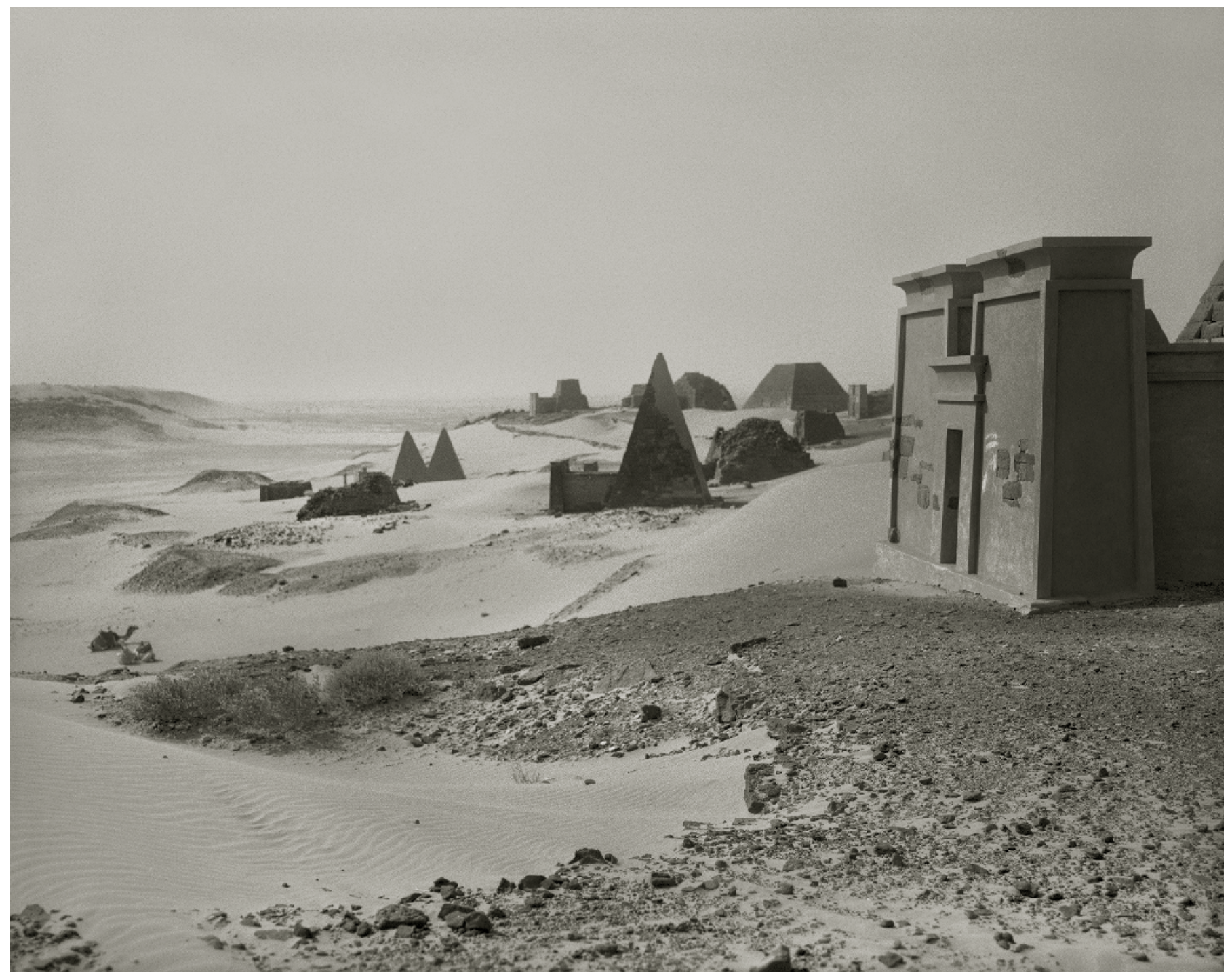

429-41. Nécropole de Méroé / cimetière Nord / Dar Jaajin / Keraba / décembre 2006. 
1010-53. Arbres silicifiés / Wadi el-Gab / désert Libyque / Soudan / février 2006. 


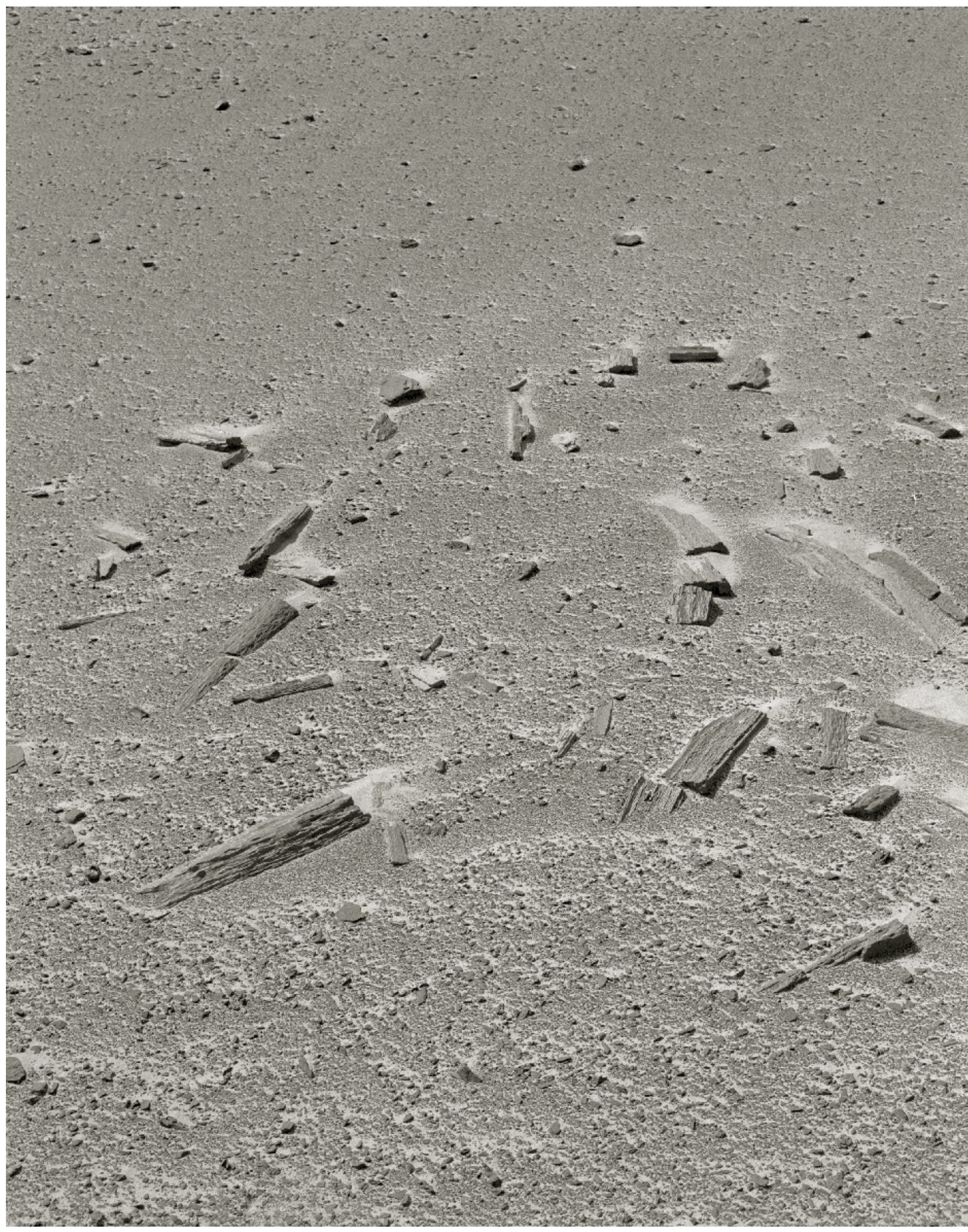




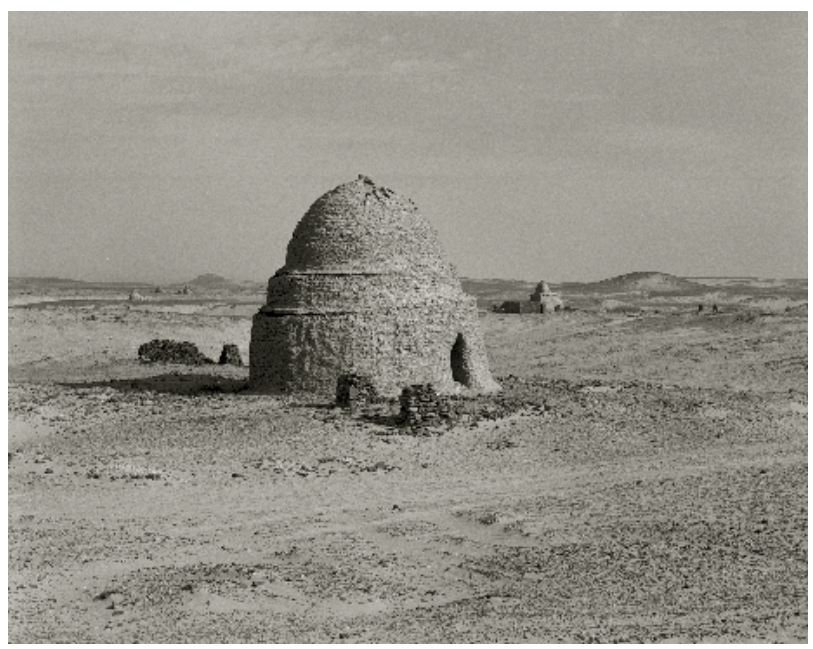

427-11. Qubba / Debba Est / Dar Danagla / Nubie / janvier 2004. 


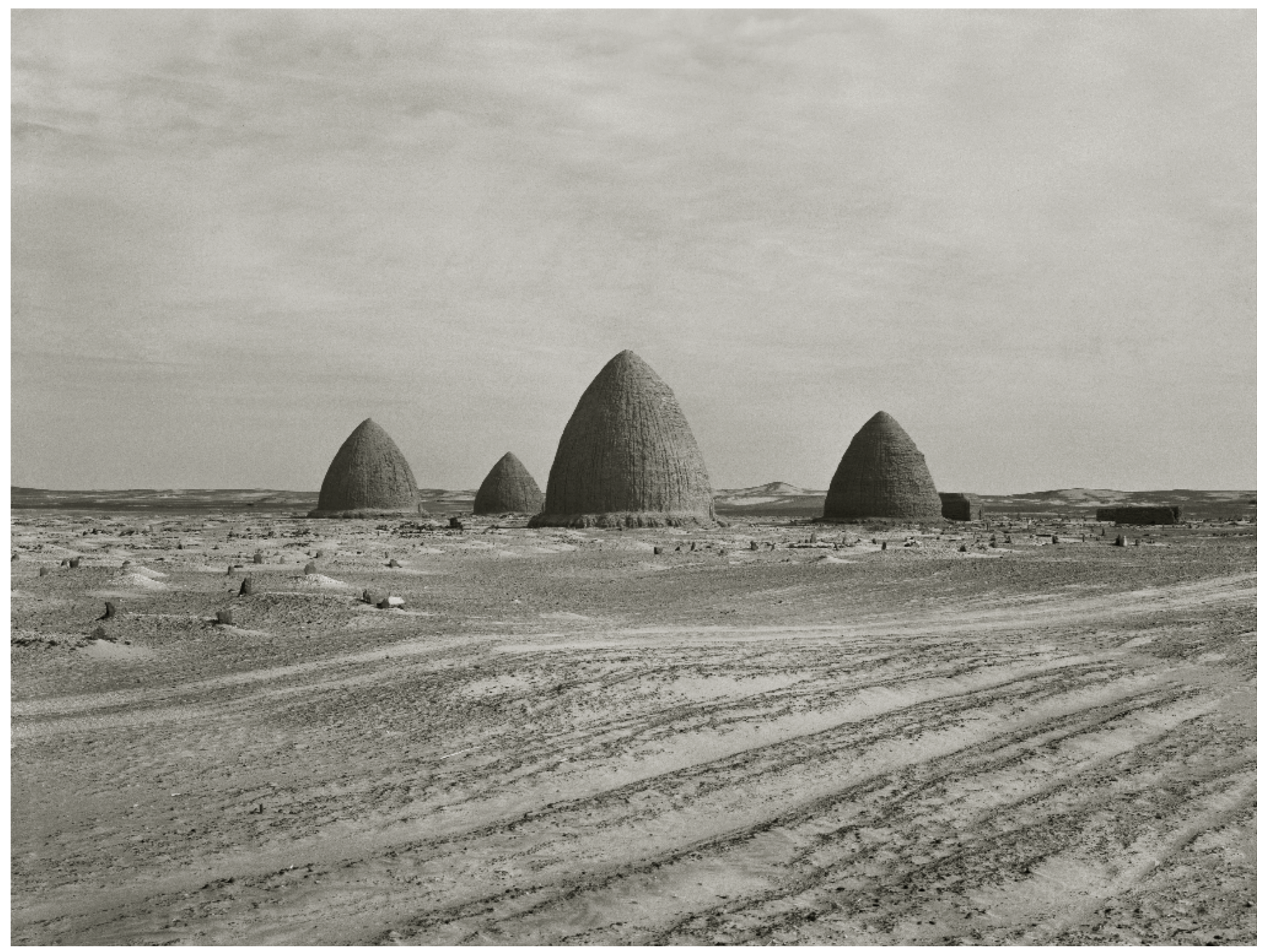

720. Qubbas de Dignitaires musulmans / Dongola el-Adjiouz / Dar Danagla / Nubie / janvier 2004. 



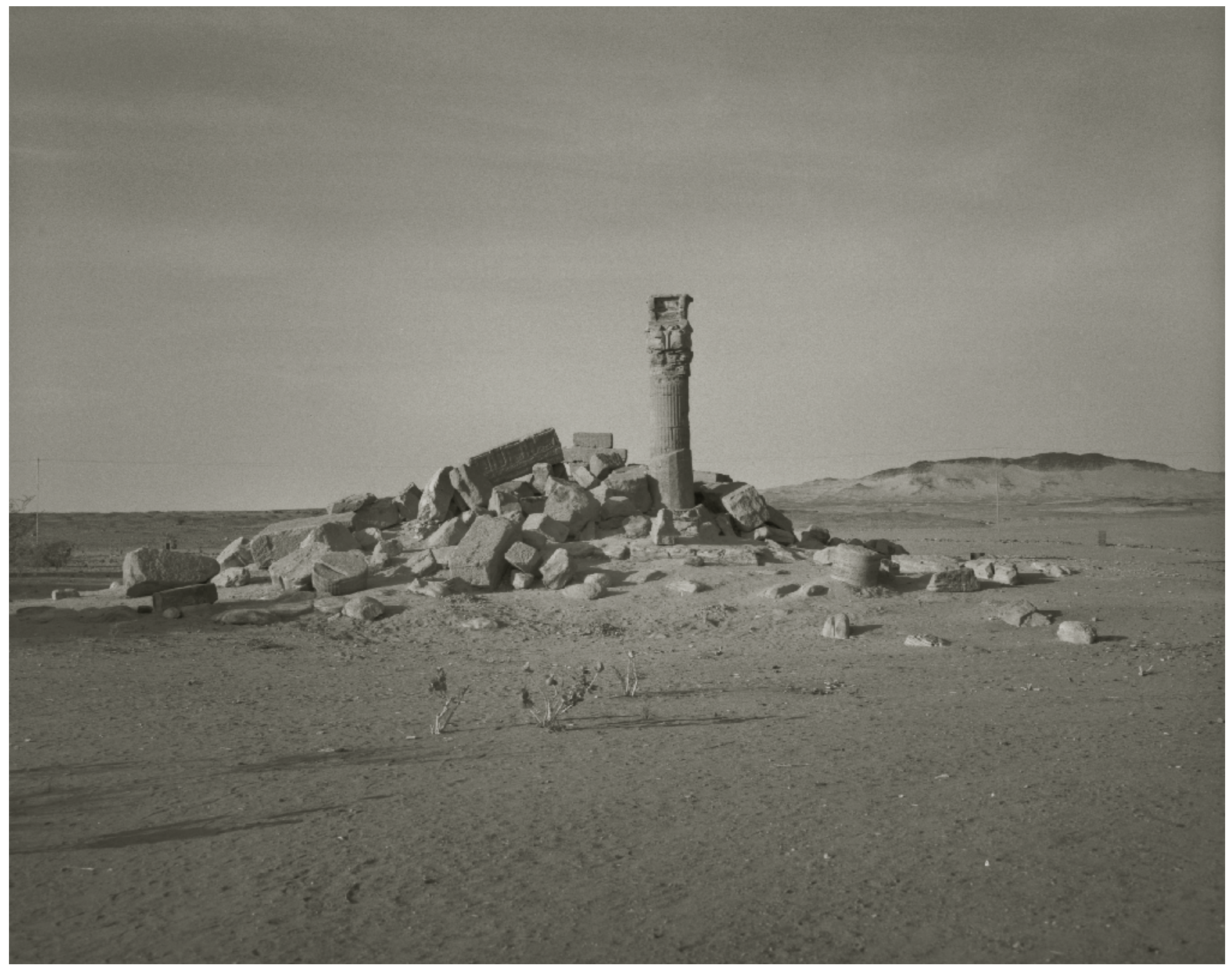




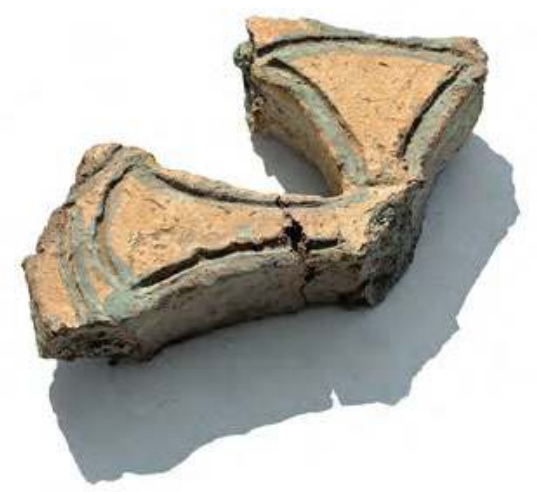

1350-12. Fragment d'une fenêtre / $11^{\mathrm{e}} \mathrm{S}$. EC / monastère de la Sainte-Trinité / Dongola el-Adjiouz / Dar Danagla / Nubie / décembre 2006.

846. Archange Michel assisté de la Sainte Trinité / monastère de la SainteTrinité / Dongola el-Adjiouz / Dar Danagla / Nubie / décembre 2006. 


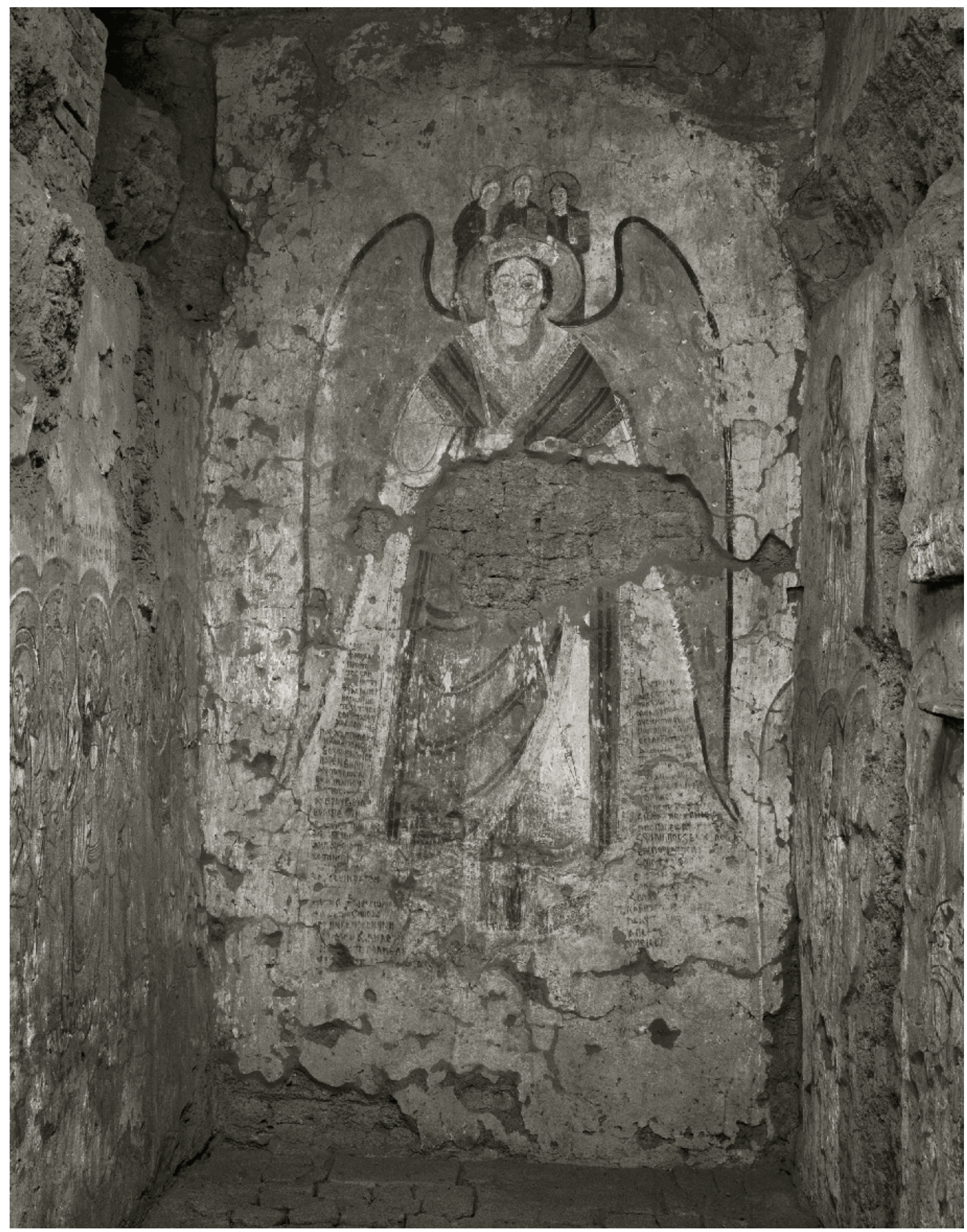




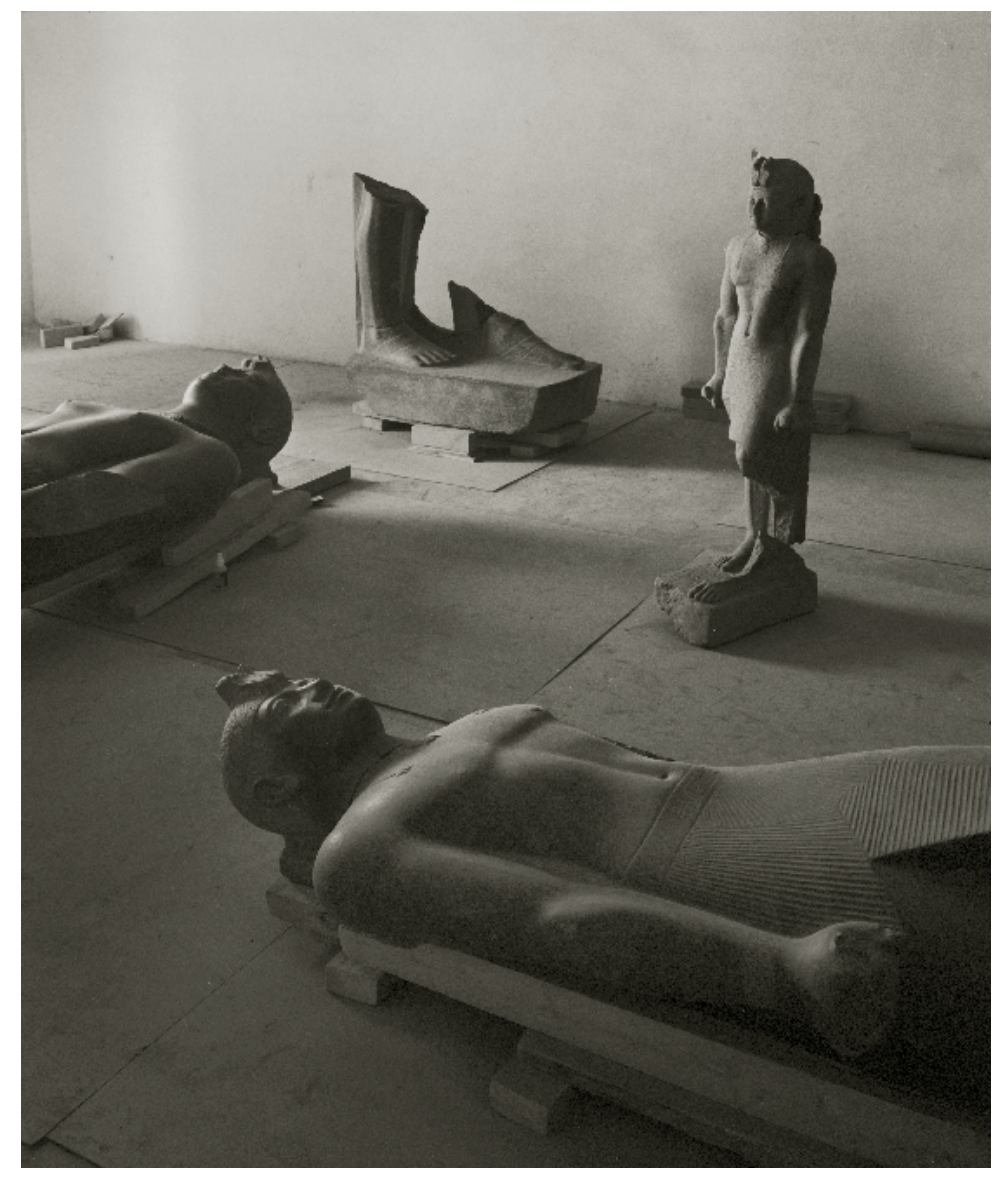




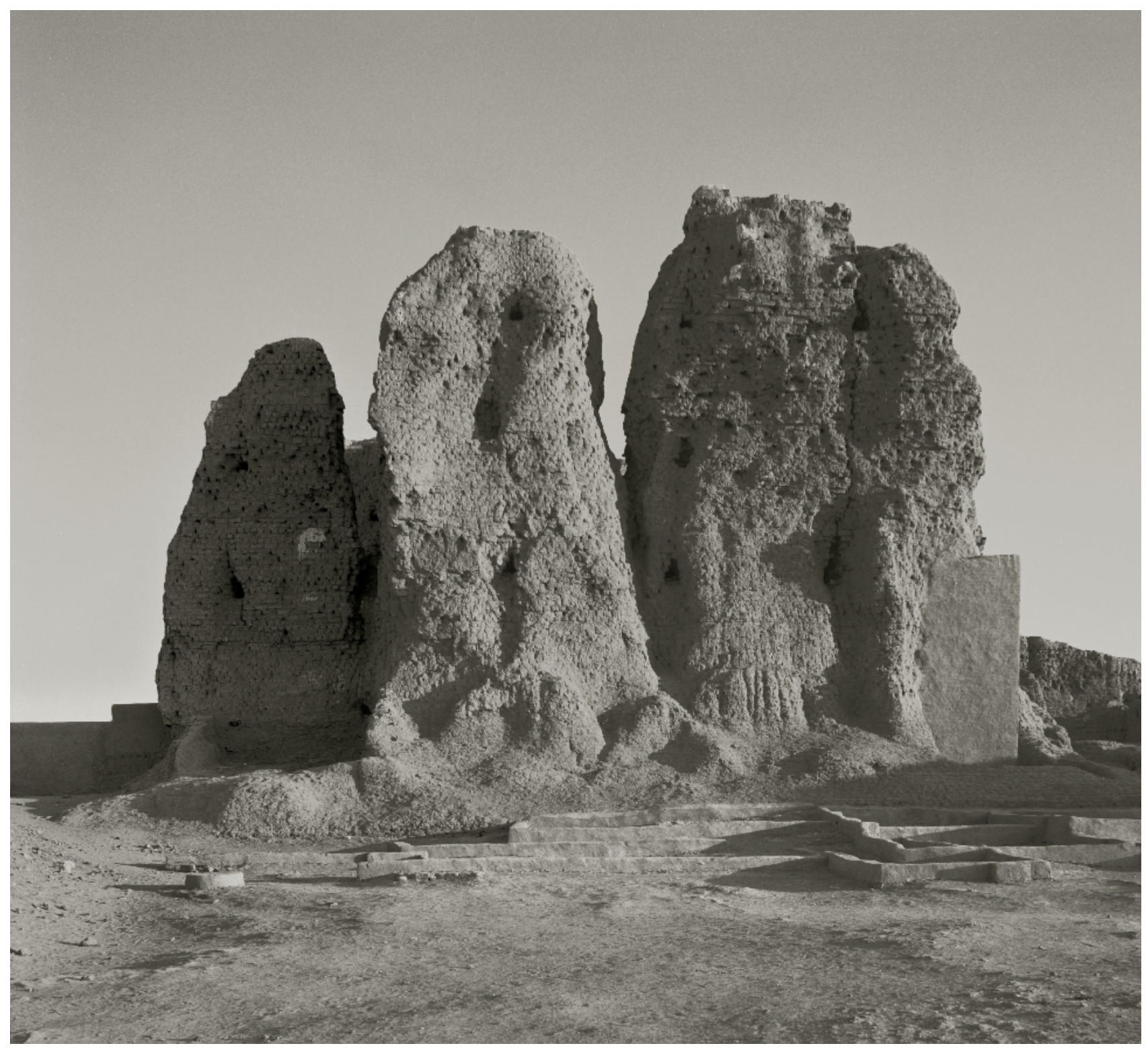

1364-44. Deffufa occidentale / temple principal de l'antique cité de Kerma / Dar Mahass / Nubie / février 2006.

1364-52. Statues royales kouchites en restauration / Kerma / Dar Mahass / Nubie / décembre 2006. 


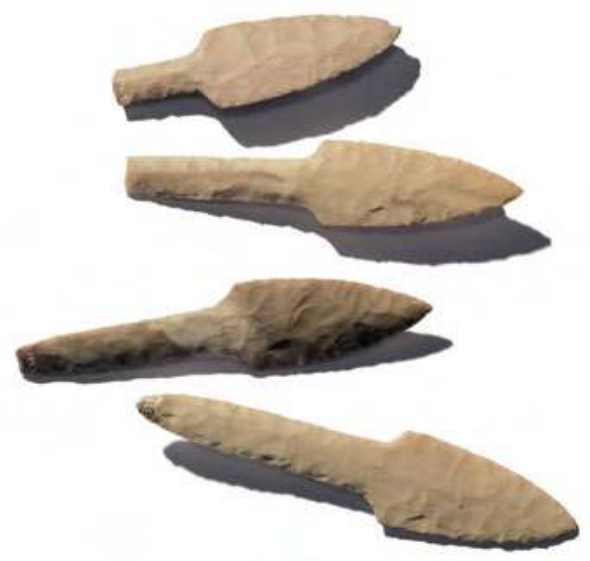

801. Pointes de lances en silex / Moyen Empire / Mirgissa musée des Beaux-Arts de Lille / 2006. 


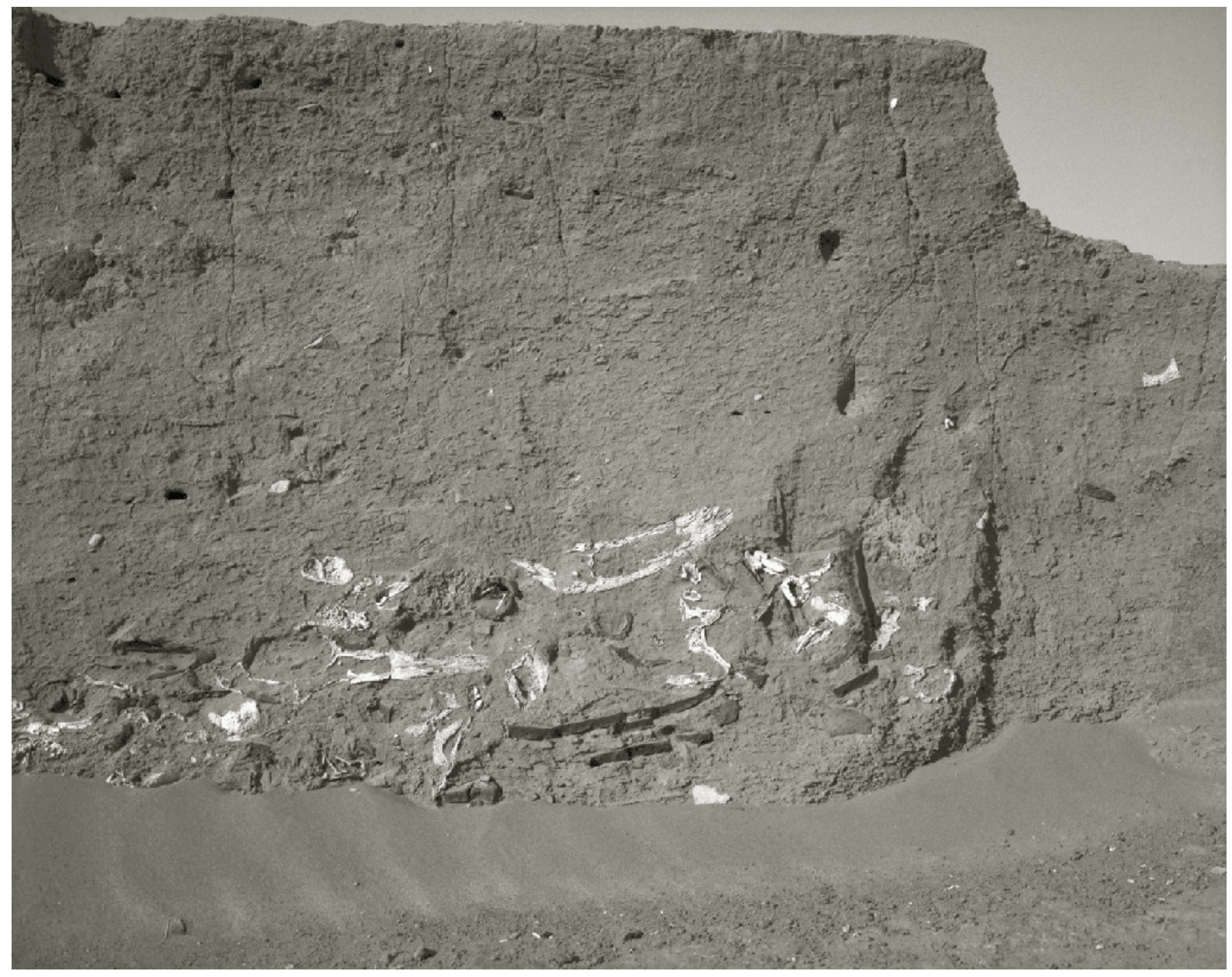

824. Restes de boucherie / Kerma / Dar Mahass / Nubie / décembre 2006. 
On tourne autour des objets, on se rapproche, puis on prend un peu de recul on explore un nouveau point de vue et l'on voit ce que ça donne. À l'instar des archéologues qui fouillent le sol sur l'île de Saï pour retrouver les restes d'une cité enfouie et dont on aperçoit ici le chantier dans un panoramique composite, le photographe remodèle un monde avec des restes visuels qui prennent dans la gélatine l'allure de pierres angulaires pour dessiner l'enceinte d'une vision.

C'est du haut du Gébel Barkal à $400 \mathrm{~km}$ au sud de Saï, que les images des pyramides ouvrant le portfolio ont été prises.

On pourrait, à première vue, penser à une photographie aérienne ou à une maquette, comme les artistes, Anne et Patrick Poirier, ont pu en réaliser inspirés par les ruines romaines. Mais le regard, s'il s'attarde un peu, comprend très vite que la nature quasi onirique de cette vision n'a rien d'artificiel et que, même suspendu entre rêve et réalité, ce qui s'étend devant appartient à une terre habitée à hauteur d'homme. Tout d'ailleurs est très humain dans ces images et l'on ne peut se défendre de l'impression que ces ruines ont posé pour le photographe, qu'il y a en tout cas, entre elles et lui, une sorte de complicité qui leur donne une grâce et une délicatesse témoignant d'une forme de confiance dans son regard.

Peut-être ce sentiment est-il renforcé par la présence visible sur les chantiers de fouille des ouvriers au travail et par le système des détails ponctuant l'ensemble et nous permettant de s'approcher de tel ou tel motif comme si nous regardions à travers les yeux de ceux qui les ont dégagés des sables du désert. Ainsi cette sorte de calebasse tenue par le manche contre le corps, appartientelle, nous informe la légende, à la sculpture représentant une des reines mères de Koush, connue sous le nom générique de "Candace». En fait c'est un épi de sorgho symbole de fécondité garantissant les récoltes et donc la survie du royaume. Ce détail, cet objet serré dans une main, ce pourrait aussi être un miroir qui nous renvoie désormais l'image pétrifiée d'un temps immémorial où les hommes se reconnaissaient encore dans l'image reflétée des dieux.

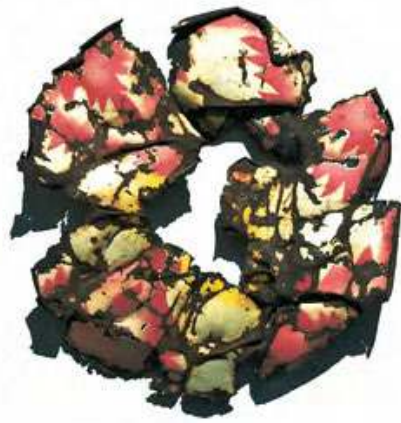




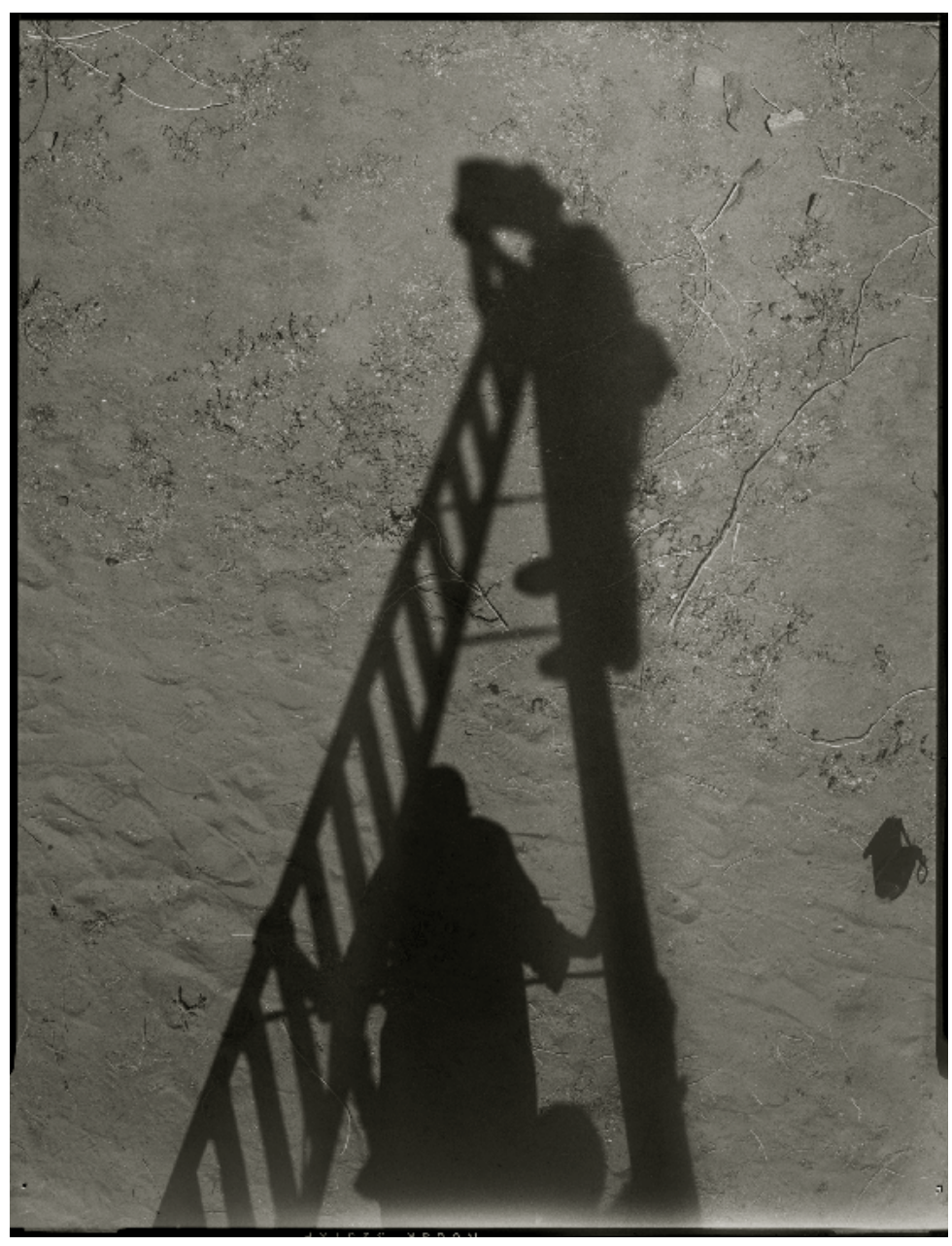

812. Autoportrait / el-Hassa / Dar Jaalinn / février 2006.

805. Bol / 20 S. EC / piste de Dongola / Dar Cheiguir / Nubie / février 2006. 
direction éditoriale

Marc Maillot

conception graphique

et réalisation

Olivier Cabon

assisté d'Izold Guégan

coédition Soleb-Bleu autour

études d'égyptologie 22

IsBN 978-2-918157-46-5

(Soleb, version

numérique gratuite)

- 978-2-918157-45-8

(Soleb, version imprimée)

- 978-2-35848-184-7

(Bleu autour,

version imprimée)

www.soleb.com

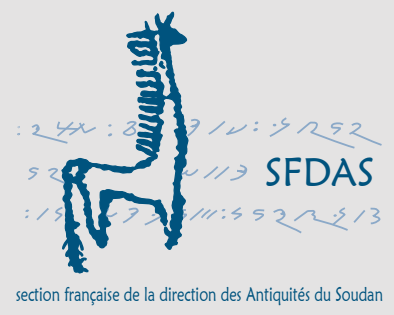




$N$ 